MANUAL OF AGRICULTURAL CHEMISTRY

\author{
HERBERT INGLE, B.SG (LEEDS)
}




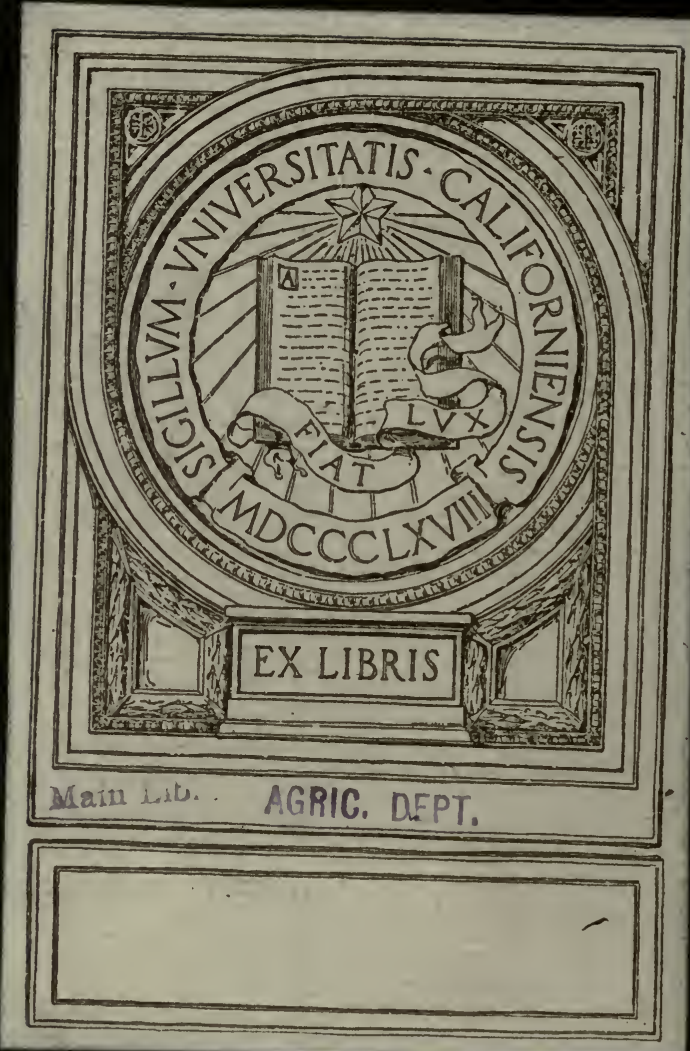


Digitized by the Internet Archive in 2007 with funding from Microsoft Corporation 


\section{A MANUAL OF}

\section{AGRICULTURAL CHEMISTRY}

BY

HERBERT INGLE, B.Sc. (LEEDS)

FELLOW OF THE ROYAL SOCIETY OF SOUTH AFRICA, OF THE INSTITUTE OF CHEMISTRY AND OF THE CHEMICAL SOCIETY, MEMBER OF THE BRITISH AND SOUTH AFRICAN ASSOCIATIONS FOR THE ADVANCEMENT OF SCIENCE AND OF THE SOCIETY OF CHEMICAL INDUSTRY; LATE CHIEF CHEMIST TO THE TRANSVAAL DEPARTMENT OF AGRICULTURE, FORMERLY LECTURER ON AGRICULTURAL CHEMISTRY AT THE LEEDS UNIVERSITY

WITH I6 ILLUSTRATIONS.

THIKD (REVISED AND LARGELY REWRITTEN) EDITION.

\section{LONDON}

SCOTT, GREEN WOOD \& SON

8 BROADWAY, LUDGATE, E.C.

IgI3

[All Rights Reserved]

D. VAN NOSTRAND COMPANT

NEW YORK 


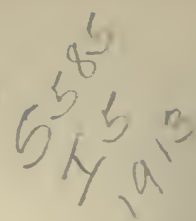

First Edition

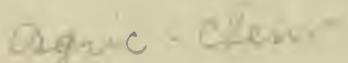

Reprinted

Second Edition (with additional matter) .

Third Edition (revised and largely rewritten)

Maln I.ii).

Irric, lept. 


\section{PREFACE TO THE THIRD EDITION.}

THE rapid exhaustion of the second (1908) edition has given the author an opportunity of fully revising the work and of rewriting certain portions which the advance of knowledge had rendered necessary.

A few omissions from the former issues have been rectified, andmuch new matter has been added. The book has, in consequence, grown considerably in length, but, by an alteration in the type-setting, it has been possible to avoid an increase in the number of its pages.

Originally, the work dealt with the chemistry and physics of subjects relating, exclusively, to English agriculture, but, in the present edition, some reference has been made to the chemistry of crops of tropical and subtropical countries as well as to questions of stock-feeding in other lands.

Such inclusions, it is hoped, will not render the book less interesting to the English reader, and may be of service to the actual or intending colonist.

The arrangement of subjects adopted in the first edition has, with very little change, been followed in the present issue, and the author trusts that the favourable reception accorded to the earlier issues may be extended to this third edition, and that the book may deserve and retain its position as a textbook for those students of agriculture who already possess a fair knowledge of general chemistry.

The author gratefully acknowledges the valuable help he has received, in the preparation of this edition, from his assistant, Mr. James Hill, M.Sc., who has contributed the drawings for several of the illustrations, has greatly helped in the correction of the proof-sheets, and is responsible for the index to this new edition.

Scarborouge, January, 1913. 


\section{PREFACE TO THE FIRST EDITION.}

THE present volume is based upon lectures delivered annually for several years past, by the author, to classes of agricultural students, many of whom had already acquired some knowledge of general chemistry. There has always been difficulty in finding a text-book suited to the requirements of such students. An attempt has therefore been made in this work to present to the reader some, at least, of the many problems of agriculture on which chemistry and physics may throw light. In all cases, the writer has endeavoured to avoid empiric statements, and to give, as far as possible, an explanation of the facts or phenomena described.

Current literature has been freely consulted, and whenever possible, reference to the source of the information has been given. In some few instances, perhaps, this may not have been done, for in the preparation of lecture notes it often happens that matter is incorporated without a record of its origin being made. In most cases, the original paper is named and, if foreign, the abstract in the Journal of the Chemical Society, or in the Journal of the Society of Chemical Industry has, if possible, also been quoted.

Much originality is not expected in a manual, except, perhaps, in the arrangement and order of the subject matter; but the author ventures to hope that not only is the book novel in scope and style, but that certain views therein expressed are original and may prove of service. Thus, in the introductory chapter, the account of the distribution and relative abundance of the elements contains some ideas, not, so far as he is aware, to be found elsewhere. Chapters IV., X., ${ }^{1}$ and XIV., ${ }^{2}$ too, will be found to contain matter not generally available.

Osmosis and diffusion appear to be commonly regarded by botanists as synonymous terms, and much confusion seems to exist as to the parts which osmotic pressure and diffusion play in the processes of plant life.

${ }^{1} \mathrm{XI}$. in the third edition.

${ }^{2} \mathrm{XV}$. in the third edition. 
In the tenth chapter, ${ }^{1}$ an attempt has been made to explain the essential difference between true diffusion through a porous membrane and the setting up of osmotic pressure when solutions of different concentrations are separated by a semi-permeable membrane, and to point out the application of the knowledge of these phenomena to the particular case of a plant's roots.

In the description of Brown and Escombe's valuable researches on the manner in which carbon dioxide is assimilated by plants, through the stomata of the leaves, the author has ventured to explain the results by a method which he devised in 1890 , and which is based on the generally accepted kinetic theory of gases.

The book does not profess to be a laboratory manual, but in several instances accounts of various analytical processes, applicable to agricultural products, are given with a view of enabling the reader to understand and appreciate the results of analyses. Many of these processes are such as the author himself uses, and certain little modifications which he has found useful are described.

The diagrams are of simple character, intended to show, as clearly as possible, the particular points desired.

The author wishes here to express his indebtedness to many friends for assistance in various ways: particularly would he acknowledge the help of one of his students-Mr. Herbert Hunter-who has kindly prepared the index.

LEEDS, March, 1902.

${ }^{1}$ Now eleventh. 


\section{ABBREVIATIONS USED IN THE REFERENCES.}

Amer. Chem. Jour. Amer. Jour. Sci. Ann.

Ann. agron.

Ann. Chim. Phys. .

Ber.

Ber. deut. bot. Gesell.

Bied. Zentr.

Bot.-Zeit.

Brit. Assoc. Rep.

Bull. Soc. chim.

Bull. Soc. chim. Belg.

Chem.-Zeit.

Compt. rend.

Expt. Stat. Rec.

Gazz. chim. ital.

Jahres. Agrik.-Chem.

Jour. Agri. Sci.

Jour. Amer. Chem. Soc.

Jour. Chem. Soc.

Jour. Landwirt.

Jour. Roy. Agric. Soc.

Jour. Soc. Chem. Ind.

Landwirt. Vers.-Stat.

Monats.

Phil. Trans.

Proc. Roy. Soc.

Rep. Storr's Expt. Stat.

U.S. Dept. of Agric.

Zeitsch. anal. Chem.

Zeitsch. angew. Chem.

Zeitsch. physiol. Chem. .

Zeitsch. Untersuch. Nahr. Genuss.

Zentr. Agrik.-Chem.

Zentr. Bakt. Par.
American Chemical Journal.

American Journal of Science.

Ciebig's Annalen der Chemie.

Annales agronomiques.

Annales de Chimie et de Physique.

Berichte der deutschen chemischen Gesellschaft.

Berichte der deutschen botanischen Gesell. schaft.

Biedermann's Zentralblatt für AgrikulturChemie.

Botaniker-Zeitung.

- Reports of the British Association for the Advancement of Science.

Bulletin de la Société chimique de France.

Bulletin de la Sociétê chimique de Belgique.

Chemiker-Zeitung.

Comptes rendus hebdomadaires des Séances de l'Académie des Sciences.

Experiment Station Record.

Gazzetta chimica italiana.

Jahresbericht über der Agrikultur-Chemie.

Journal of Agricultural Science.

Journal of the American Chemical Society. Journal of the Chemical Society.

Journal für Landwirtschaft.

Journal of the Royal Agricultural Society.

Journal of the Society of Chemical Industry.

Die landwirtschaftlichen Versuchs-Stationen.

Monatsheften für Chemie und verwandte Theile anderer Wissenschaften.

Philosophical Transactions of the Royal Society.

Proceedings of the Royal Society.

Report of the Storr's Experiment Station.

United States Department of Agriculture.

Fresenius' Zeitschrift für analytische Chemie.

Zeitschrift für angewandte Chemie.

Hoppe-Seyler's Zeitschrift für physiologische Chemie.

Zeitschrift für Untersuchung der Nahrungsund Genussmittel.

Zentralblatt für Agrikultur-Chemie.

Zentralblatt für Bakteriologie, Parasitenkunde und Infektionskrankheiten. 


\section{CONTEN'TS.}

CHAPTER

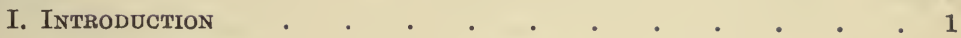

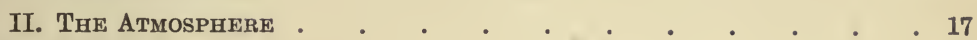

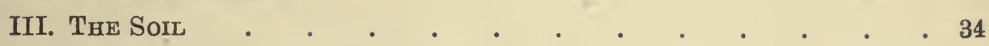

IV. The Reactions occurring in Solls . . . . . . . 51

V. The Analysis and Composition of Solls . • • • • . 82

VI. Mandring and General Manures . . . . . . . . . 103

VII. Special Manures . . . . . . . . . . . . . 132

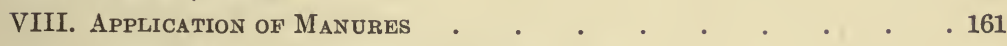

IX. The Analysis and Valuation of Manures . . . . . . 170

X. The Chemical Constituents of Plants . . . . . . . 179

XI. The Plant . . . . . . . . . . . . . . . 219

XII. CROPS . . . . . . . . . . . . . . 234

XIII. The Animal . $. \quad . \quad . \quad . \quad . \quad . \quad . \quad . \quad . \quad .264$

XIV. Foods AND FeEding . . . . . . . . . . . . . 281

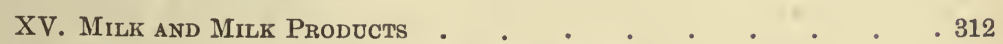

XVI. The Analysis of Milk and Milk Proddcts. . . . . . 348

XVII. Miscellaneous Products used in Agriculture 359

APPENDIX . . . . . . . . . . . . . 375

INDEX . . . . . . . . . . . . . . . . . . . . . . 



\section{A MANUAL OF AGRICULTURAL CHEMISTRY.}

\section{CHAPTER I.}

\section{INTRODUCTION.}

Chemistry has an intimate connection with the processes of life, both animal and vegetable. The processes involved in vital phenomena, those occurring in the soil and indeed, in most natural operations, are attended by slow chemical changes, often so complex in character that they are difficult to unravel. The ordinary chemical student acquires in his training a familiarity with reactions, which, as a rule, proceed quickly to a definite and well-marked termination. This, indeed, is the case with the vast majority of chemical changes occurring in the industries, and, for the most part, such reactions are thoroughly understood and can be satisfactorily explained.

But with the changes taking place in animals and plants or even in the soil, the reactions are much more involved, partly because of the complexity of the substances concerned, partly on account of the conditions under which they occur, and partly because of the numerous changes which may proceed simultaneously. Chemical reactions occur between substances in solution, and the final condition of equilibrium between two reacting substances is determined by the relative concentration of the solvent in the various dissolved substances. In nature, the solutions are usually very dilute, and the effect of the relative masses of the reacting substances influences the final result to a far greater extent than is the case in ordinary laboratory reactions.

Agricultural chemistry has often to deal with changes of this complex character, and in all attempts to explain such changes it is necessary to take into careful consideration the conditions under which they occur.

The border line between chemistry and physics, as, indeed, between any two conventional divisions of natural science, is not clearly defined, and, among the factors affecting chemical changes of the kind under discussion, physical conditions, e.g., temperature and pressure, are often of much importance. Other purely physical phenomena, among which may be mentioned diffusion, osmosis and surface pressure, play an important part in vital processes and are often closely interwoven with chemical changes.

In the present volume reference will have to be made to many phenomena which are not purely chemical, and it will be necessary to give some account of subjects which, perhaps, may be regarded as belonging to physics, geology, or biology rather than to chemistry. 
Such digressions are inevitable, if clear and adequate explanations of many natural processes are to be attempted.

In the application of chemistry to agriculture cases often arise in which the truth of the old adage, "A little knowledge is a dangerous thing," becomes strikingly apparent, and the conclusions arrived at from the consideration of a particular problem from the standpoint of ordinary elementary chemistry, are quite opposite to the results of actual practice. Such contradictions arise, not from any inaccuracies in general principles, but through leaving out of consideration the effects produced by some apparently insignificant circumstances or conditions.

It is evident, therefore, that although there is no distinct agricultural chemistry, yet the problems which arise in agriculture demand a knowledge of chemistry in which due attention is given to the peculiar circumstances under which the reactions take place.

In this work it will be assumed that the reader possesses an acquaintance with general elementary chemistry and is familiar with the properties of the more commonly occurring elements and their chief compounds.

The student of agricultural chemistry soon finds that of the eighty odd elements which are known, only a comparatively small number, some twelve or fourteen, are concerned in most of the changes which are brought before his notice. It may perhaps be advisable to very briefly remind the reader of the properties of these important elements, the mode of their occurrence, and the characteristics of some of their compounds. The elements which are most important to living organisms are-hydrogen, oxygen, nitrogen, carbon, sulphur, phosphorus, potassium, sodium, calcium, magnesium, iron, silicon, aluminium, chlorine and fluorine.

Hydrogen.-This substance, as its name implies, is a constituent of water. Its most important chemical properties are its strong tendency to combine with oxygen, the act of union being accompanied by the evolution of a large amount of heat, and its power of uniting in a vast number of different proportions with carbon, to form that very numerous and important group of bodies known as the hydrocarbons. It also enters into the composition of almost all compounds existing in the bodies of plants and animals, i.e., into nearly all forms of organic matter. Its atomic weight is the smallest of all the elements and was formerly taken as unity, but now it is more usual to take oxygen $=16$ as the basis of atomic weights, that of hydrogen on this scale being about 1.008. Consequently, though the proportion by weight of hydrogen in the substances comprising the crust of the earth is small, yet the number of atoms of hydrogen actually existent and taking part in the changes going on, must be very large compared with those of other elements apparently (and by weight) much more abundant. Take water for example-here the hydrogen by weight constitutes only $\frac{1}{9}$ of the total and the oxygen $\frac{8}{9}$, yet there really are twice as many atoms of hydrogen as of oxygen, as indicated by the formula $\mathrm{H}_{2} \mathrm{O}$. In reality, the relative amounts of elements present in any system, so far as their chemical activity is concerned, ought to be 
measured by the respective numbers of atoms present, not by their respective weights. Regarded in this way, hydrogen is of relatively far greater importance and abundance than is usually estimated (vide p. 16).

Oxygen is perhaps the most important element known. It is by far the most abundant, and takes part in a greater number of the chemical changes occurring in nature than any other element. It is, indeed, chiefly remarkable for its activity and its power of uniting with almost all other elements.

Its method of preparation and chief properties are well known to all students of chemistry, being appropriately chosen for consideration early in their course of study.

Its union with other bodies is usually attended with the evolution of much heat and often light. Present in the free state in air, it plays an important part in the chemical actions attendant upon the processes of respiration, combustion, decay and almost all the forms of "weathering" which occur around us.

Oxidation, i.e., union with oxygen, is a process of great importance. The life of animals especially, may be said almost to consist of oxidation. So, too, the changes occurring in the soil, the "fermenting " of hay, ensilage, etc., the putrefaction and decay of animal matter, and many other processes are largely dependent upon combination with oxygen. Union with oxygen is almost invariably accompanied by the evolution of heat; in fact, to union with oxygen most artificial and many natural sources of heat (and hence of energy) owe their efficiency. The rapid combination of substances with oxygen is generally accompanied by the attainment of a high temperature and is instanced by most processes of combustion or burning. In such cases, the heat evolved is rendered evident, but in others, the slow combination of substances with oxygen evolves the heat so gradually that conduction and radiation are able to carry it away almost as fast as it is produced, consequently no distinct rise of temperature may be perceptible. A very important fact, and one which should always be kept in mind, is that, in all cases, the union of a given weight of a substance with oxygen evolves the same quantity of heat, however slowly or quickly the process of oxidation may take place; provided, of course, that the final product be the same.

It is thus possible to determine experimentally the actual quantity of heat (and thus of energy) evolved by the union of any fixed weight of various combustibles with oxygen, and the numbers so obtained will apply to all cases of burning in which these combustibles take part.

Heat is measured by the quantity of water which it can raise through $1^{\circ} \mathrm{C}$. (or in some cases $1^{\circ} \mathrm{F}$.). The number of units of mass (e.g., pounds or grammes) of water which can be raised through $1^{\circ} \mathrm{C}$. by the union of the unit of mass (i.e., $1 \mathrm{lb}$. or 1 gramme) of the combustible with oxygen, is called the heat of combustion or the calorific power of the substance.

The following table gives the calorific power of a number of substances :- 
Substance.
Grammes of water raised $1^{\circ} \mathrm{C}$. in temperature by the combustion of 1 gramme of the substance.

\begin{tabular}{|c|c|c|c|c|c|c|c|c|}
\hline Charcoal . & . & - & . & - & - & - & . & 8080 \\
\hline Hydrogen . & • & - & . & . & . & . & . & 34460 \\
\hline Air-dried wood & . & • & . & • & $\cdot$ & & . & 2800 \\
\hline Charred wood & . & . & . & . & • & . & . & 3600 \\
\hline Average coal & . & • & . & . & • & - & . & 7500 \\
\hline Good coke. & . & . & . & • & • & & . & 7050 \\
\hline Albumin (serum & & . & . & . & & 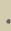 & . & 5918 \\
\hline Casein & . & . & . & . & . & . & . & 5860 \\
\hline Albumin (egg) & . & . & . & . & • & & . & 5735 \\
\hline Muscle & . & . & . & . & & . & . & 5660 \\
\hline Peptone & . & . & . & . & . & . & . & 5300 \\
\hline Asparagine & . & . & 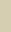 & . & . & . & . & 3514 \\
\hline Urea. & . & . & s & . & . & . & . & 2542 \\
\hline Fat of pig. & . & . & . & . & • & . & . & 9477 \\
\hline,, , ox . & . & . & . & . & . & . & . & 9486 \\
\hline ", , sheep & . & . & . & . & • & . & . & 9494 \\
\hline ,, ,, butter & . & . & . & . & & . & . & 9216 \\
\hline Olive oil & . & . & . & . & • & 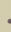 & - & 9400 \\
\hline Rape-seed oil & . & . & . & . & • & . & . & 9500 \\
\hline Arabinose . & . & . & . & . & & & . & 3730 \\
\hline Glucose & . & . & . & . & - & . & . & 3740 \\
\hline Galactose . & . & . & . & • & • & & . & 3720 \\
\hline Fructose. & . & . & . & . & . & . & . & 3755 \\
\hline Cane sugar & & . & . & . & . & . & . & 3955 \\
\hline Milk sugar (crys & & ${ }^{\circ}$ & . & - & - & & . & 3736 \\
\hline$, \quad, \quad$ (anh & ayd.) & . & & • & • & & & 3952 \\
\hline Maltose (cryst.) & & . & & • & . & & • & 3722 \\
\hline ," (anhyd. & & & & $\cdot$ & & & $\cdot$ & 3949 \\
\hline Cellulose & . & . & . & . & . & & • & 4185 \\
\hline Starch & . & . & & . & • & & . & 418 \\
\hline
\end{tabular}

As has been stated, the heat of combustion of a substance is constant, whatever be the manner in which union with oxygen occurs, provided only that the same final products be obtained. The temperature attained, however, varies greatly with the conditions under which combination takes place. For example, the temperatures reached when substances are burnt in pure oxygen are much higher than when they burn in air, though the same products are formed and, as is seen from the above statements, the same quantities of heat are evolved in both cases. It will be easily seen why such different temperatures are produced,- - the combustion in pure oxygen takes place more rapidly, in a smaller space (generally with a smaller flame) and the process is carried on without a large amount of cool, indifferent gas (nitrogen) which would abstract heat and keep the temperature down, while in air, the conditions are just the opposite.

A still more extreme case is furnished by the many processes of slow oxidation or combustion which occur so frequently in nature. Under ordinary circumstances, these processes generate heat only at about the same rate as it is carried away by contact with surrounding objects, consequently little or no elevation of temperature occurs, but occasionally, the rate of loss of heat may be greatly diminished, when a decided and, in some cases, a destructive rise of temperature ensues. 
Under particularly favourable circumstances the loss of heat may be so small that the actual ignition point (that is, the temperature at which rapid union with oxygen, accompanied by flame, occurs) is reached and the mass takes fire. Such cases of "spontaneous combustion" occur fairly frequently. Common causes are-

1. Slow oxidation of drying oils, as in greasy waste in mills ;

2. Fermentative changes produced by bacteria, e.g., in haystacks, in the manufacture of tobacco;

3. Slow oxidation of certain minerals, e.g., iron pyrites in coal ; and several others. Those of interest in agriculture will be discussed later.

Another instance of slow combustion producing only a very slight elevation of temperature is afforded by the respiratory processes of animals. Here the digested food acts as the combustible and the process of union with oxygen takes place in the tissues by means of the blood, which absorbs the oxygen from the air in the lungs, the chief product of combustion, carbon dioxide, being carried by the blood to the lungs and thence returned to the atmosphere. In this case, as in all others, the amount of heat produced is doubtless exactly proportional to the amount of the food materials oxidised, though its measurement is complicated by many other processes, involving heat changes, going on in the body.

Nitrogen is present in large proportion in the air, where it exists in the free state. In combination, nitrogen occurs but rarely, save in substances which owe their origin to animal or vegetable life. Indeed, of purely mineral substances containing it we know very few, if any. The deposits of nitrates, e.g., of sodium and potassium nitrates, which are found in certain hot climates and which are largely used as sources of combined nitrogen, have almost certainly been formed by the same agencies which produce nitrates in all fertile soils-bacteria-and probably from the same sources-organic nitrogenous bodies. Unlike other elements, nitrogen appears to occur only on the outermost parts of our globe, i.e., either in the atmosphere or, if underground, within a very short distance of the surface of the earth, the only noteworthy exception to this being the occurrence of coal and carboniferous shale, which usually contain about 1 per cent of combined nitrogen. It must be remembered, however, that these deposits are of vegetable origin and were formed at the surface. The properties of free nitrogen are well known; it is a colourless, odourless gas, possessing little chemical activity, taking part in very few of the changes occurring in the atmosphere. Indeed its most remarkable characteristic is its general chemical inertness. It accompanies oxygen in all the multitudinous processes in which the latter takes such an active part and, in most instances, escapes unchanged. Only by very extreme means can it be caused to combine with other substances and usually heat is absorbed by the act of union.

The compounds of nitrogen, unlike the element itself, are extremely active chemically and many of them are of great importance.

All organisms, whether plant or animal, require nitrogenous com- 
pounds to build up their tissues. Compounds containing nitrogen therefore are essential ingredients in the food supply of both plants and animals. Many powerful medicines and poisons contain nitrogen, e.g., prussic acid $(\mathrm{HCN})$ and all the alkaloids, of which strychnine $\left(\mathrm{C}_{21} \mathrm{H}_{22} \mathrm{~N}_{2} \mathrm{O}_{2}\right)$, quinine $\left(\mathrm{C}_{20} \mathrm{H}_{24} \mathrm{~N}_{2} \mathrm{O}_{2}\right)$, and morphine $\left(\mathrm{C}_{17} \mathrm{H}_{19} \mathrm{NO}_{3}\right)$ may be given as types. Many nitrogen compounds are extremely unstable and readily split up into simpler bodies, the nitrogen being generally set free; they are often violently explosive, e.g., nitroglycerine, $\mathrm{C}_{3} \mathrm{H}_{5}\left(\mathrm{NO}_{3}\right)_{3}$, and gun cotton, $\mathrm{C}_{6} \mathrm{H}_{7} \mathrm{O}_{2}\left(\mathrm{NO}_{3}\right)_{3}$.

We thus see that while free nitrogen is of comparatively little value, its compounds are of the utmost importance to all living beings. Consequently, the means of utilising nitrogenous compounds and of preventing their waste, often leading to the liberation of the comparatively useless free nitrogen, are matters of intense interest and great importance. By some chemists it is thought that supplies of nitrogen compounds will fail us long before the want of phosphates, potash, or other fertilising substances becomes felt. ${ }^{1}$

It is to be hoped that by means of the nitrogen-fixing bacteria which grow in nodules upon the root hairs of certain leguminous plants, or in some other way, it may be found possible to abstract from the atmosphere sufficient nitrogen to supply the wants of both plants and animals for many centuries. Nevertheless, the rapid exhaustion of our deposits of nitrates and the enormous quantities of valuable nitrogenous materials which are allowed to run to waste in the sewage of our large cities are serious matters for consideration as affecting the future supplies of this indispensable combined nitrogen.

Carbon is, perhaps, more than any of the other elements, associated with the processes of life. It constitutes a large proportion by weight of the solid portions of all animals and plants. In the mineral kingdom it is also abundant, occurring in immense quantities in carbonates, e.g., those of calcium, magnesium, iron, zinc, lead and copper. It also occurs in the air in the form of carbon dioxide, the amount of which, though small relatively to the other constituents of air, is, absolutely, considerable and is constantly being renewed.

The properties of the three allotropic forms of carbon are fully described in any general textbook of chemistry. They are not of any particular importance from our present standpoint. Much more important are the numerous compounds which carbon forms, especially with hydrogen and oxygen, and with hydrogen, oxygen and nitrogen. Indeed, it is with these compounds of carbon that almost all the chemistry of the nutrition of animals and plants is concerned, other substances taking part in vital processes (though quite essential) being small in amount.

But although animal life and plant life are both concerned with the chemical changes of carbon compounds, yet they stand towards carbon in an essentially different aspect, for while the life of an animal

${ }^{1}$ Sir W. Crookes, President's address, British Association for Advancement of Science, 1898. 
eventually leads to the more or less complete oxidation of the carbon in the food consumed and the consequent production of carbon dioxide, the characteristics of a plant's vital processes are the separation of carbon from carbon dioxide and the formation of less oxidised carbon compounds.

The former process is attended by the liberation of energy in the form of heat and mechanical work, the latter by an absorption and storing up of energy received in the form of light.

Carbon is remarkable for its power of uniting in a vast number of proportions with hydrogen and with hydrogen and oxygen. This power is pictured by the chemist as being due to the atoms of carbon possessing a tendency to link themselves together.

To take a simple case, there are several series of hydrocarbons known, of which the following may be taken as representatives :-

The Paraftin Series.<smiles>COC</smiles><smiles>CCOCC</smiles><smiles>CCCCCCCCC</smiles>

eqc.
The Olefine Series.<smiles>C=CCOCC</smiles><smiles>C=CCC</smiles><smiles>C=CCCCCCCCCCCCCCCCCCCCCCCC</smiles>

In each of these two series it will be observed that every member differs from the one preceding it by $\mathrm{CH}_{2}$ and its graphical formula is written by simply adding a carbon atom attached to two hydrogen atoms between the terminal groups in the chain. A similar power of linking together is shown by the carbon atoms in other carbon compounds. It will be noted, from the examples given, that the linkage of two carbon atoms together may be by one or by two of their combining affinities.

The presence of one pair of doubly linked carbon atoms is the characteristic of the olefine series. In another, the acetylene series, trebly linked carbon atoms occur, e.g., $\mathrm{HC} \equiv \mathrm{CH}$, acetylene itself. It is to this power of the carbon atoms of linking themselves together that the possibility of the existence of such an immense number of carbon compounds is due. No other element shows the same power, unless it 
be silicon, a few compounds of which of the above type have been prepared.

In consequence of this unique property of carbon it is now customary to place the study of carbon compounds in a separate division of chemistry. To this branch of knowledge the name of organic chemistry has been given, and although it is of comparatively recent growth it has already attained vast dimensions.

A very large number of the compounds present in the bodies of plants and animals is made up of compounds of the four elements just described. Among these compounds the following are important:-

1. Carbohydrates, e.g., starch and cellulose, $\mathrm{C}_{6} \mathrm{H}_{10} \mathrm{O}_{5}$, grape sugar, $\mathrm{C}_{6} \mathrm{H}_{12} \mathrm{O}_{6}$, cane sugar, $\mathrm{C}_{12} \mathrm{H}_{22} \mathrm{O}_{11}$.

2. Organic acids, e.g., acetic acid, $\mathrm{CH}_{3} \cdot \mathrm{COOH}$, oxalic acid, $\mathrm{C}_{2} \mathrm{H}_{2} \mathrm{O}_{4}$.

3. Fats, essentially salts of glyceryl, $\mathrm{C}_{3} \mathrm{H}_{5}$, combined with a fatty acid, e.g., stearic acid, $\mathrm{HC}_{18} \mathrm{H}_{35} \mathrm{O}_{2}$, oleic acid, $\mathrm{HC}_{18} \mathrm{H}_{33} \mathrm{O}_{2}$. These glyceryl salts, or glycerides as they are sometimes called, are possessed of a constitution similar to the following, which represents glyceryl stearate (glyceride of stearic acid, or "stearine").

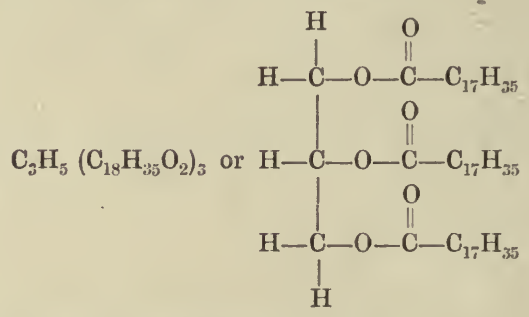

4. Hydrocarbons, e.g., turpentine, $\mathrm{C}_{10} \mathrm{H}_{16}$.

5. Albuminoids, containing all four of the elements in question, associated with small quantities of sulphur and phosphorus. The constitution of these substances is not well known. They always contain about 16 per cent of nitrogen.

6. Amides.-These also are compounds of carbon, hydrogen, oxygen and nitrogen, but their structure is much less complex than that of the albuminoids. A large number have been prepared, the characteristic feature being that they contain the group $\mathrm{NH}_{2}$ united with an oxygen-containing compound of carbon.

Amides may be regarded as organic acids in which the $\mathrm{OH}$ groups have been replaced by $\mathrm{NH}_{2}$. Thus acetamide, $\mathrm{C}_{2} \mathrm{H}_{3} \mathrm{O} \cdot \mathrm{NH}_{2}$, is derived from acetic acid, $\mathrm{C}_{2} \mathrm{H}_{3} \mathrm{O} . \mathrm{OH}-$<smiles>CC(=O)O</smiles>

Acetic acid.<smiles>[H][Y15]([H])([H])C([1H])=O</smiles>

Acetamide.

7. Amino-compounds, containing one or more $\mathrm{NH}_{2}$ groups replacing hydrogen but not $\mathrm{OH}$. 
Glycine or glycocoll is amino-acetic acid and has the constitution-<smiles>[H][Y15]([H])([H])C(=O)O</smiles>

These compounds will be discussed at greater length hereafter.

Sulphur.-The occurrence and properties of this element are well known and need not be discussed here. In the nutrition of plants and animals it plays a small part, but still it is essential.

It occurs in small quantity in albuminoids and, in certain plants, in the form of sulphides and sulphocyanides of organic bases. In animals, it is particularly abundant in the hair or wool.

Plants probably obtain the sulphur they require from the sulphates present in the soil, and in most cases from calcium sulphate. It is to be noted that soluble metallic sulphides are violent plant poisons, as are many other unoxidised sulphur compounds (e.g., sulphocyanides, sometimes present in commercial sulphate of ammonia). Yet it is found that certain plants actually secrete sulphides and sulphocyanides of organic bases and owe their characteristic odour or flavour to the presence of these compounds. Such is the case with mustard, garlic and many other plants.

Phosphorus. - The properties of this element are very remarkable and are well known to all students of chemistry. In agriculture its compounds, the various salts of phosphoric acid, are of the utmost importance.

Phosphorus is extremely widely distributed, though generally in small quantities. It is present in almost every mineral and rock, though the average amount present in the soils and rocks of the earth's crust probably does not exceed one or two parts in 10,000. From the soil, plants obtain their phosphates; these in turn pass into the bodies of animals, where they often accumulate in large quantities, so that the bones or shells of animals always contain relatively large amounts of phosphate of lime.

Some minerals, too, consist mainly of phosphates, e.g., apatite consists of $3 \mathrm{Ca}_{3} \mathrm{P}_{2} \mathrm{O}_{5} \cdot \mathrm{CaCl}_{2}$ or $3 \mathrm{Ca}_{3} \mathrm{P}_{2} \mathrm{O}_{8} \cdot \mathrm{CaF}_{2}$; vivianite is essentially $\mathrm{Fe}_{3} \mathrm{P}_{2} \mathrm{O}_{8} \cdot 8 \mathrm{H}_{2} \mathrm{O}$. More abundant are deposits of impure phosphate of lime in the various forms of phosphorite, osteolite, coprolites, etc. These are often used as fertilisers.

Potassium occurs in many silicates: some contain a relatively small quantity, while in others, e.g., orthoclase or potash felspar, $\mathrm{Al}_{2} \mathrm{O}_{3} \cdot \mathrm{K}_{2} \mathrm{O} \cdot 6 \mathrm{SiO}_{2}$, the proportion of this element is considerable. It also occurs largely in sea-water, from which seaweeds often accumulate large quantities of potassium compounds. Another very important source of potassium is the huge saline deposit at Stassfurt; this is supposed to be the result of the evaporation of a large inland sea, and 
consists mainly of sulphates and chlorides of magnesium, potassium, sodium and calcium. This deposit has been extensively worked for some years, largely for supplies of potash salts for agricultural purposes. The element itself is of little interest from an agricultural standpoint, as its great affinity for oxygen and other electro-negative elements renders its preparation and preservation difficult. Its compounds, however, are of the utmost importance, indeed potash seems very intimately connected with the processes of plant growth and is always most abundant in the growing portions, the young shoots or twigs. The maintenance of a supply of its compounds is essential to a plant's welfare. In the plant it is combined with various acids-nitric, sulphuric, hydrochloric, and very often with organic acids-oxalic, malic, citric, or tartaric. In the ashes of plants it is usually found as carbonate, this being formed by the destruction of the organic potassium salts by heat. The ashes of the twigs and leaves of trees, indeed, formerly furnished almost the whole of the potash used in the arts. The earlier chemists distinguished potash by calling it the "vegetable alkali" in contradistinction to the "mineral alkali," by which they meant soda, and the "volatile alkali" or ammonia.

Potash compounds are remarkable in the property which they possess of being retained by clay, and especially by the mixture of clay and organic matter found in nearly all fertile soils. In this respect potash differs greatly from soda, for whose compounds soil possesses little or no retentive power. This retention of potash by soil probably explains the fact that in sea-water there is so much more of sodium compounds than of potassium ones, notwithstanding the fact that the primary rocks of the earth's crust contain about equal amounts of these substances. Denudation carries off to the sea, large quantities of soluble sodium compounds, but comparatively little potassium salts, owing to the retention of the latter by the clay, simultaneously formed by the decay of the felspar, mica, ctc.

Sodium occurs in many silicates, replacing potash. It is extremely widely diffused throughout nature, and, in the form of common salt, plays an important part in animal nutrition. It is asserted by many authorities to be a merely accidental constituent of plants, and in most instances it is found that the exclusion of sodium from a plant's food produces no ill effects; on the other hand, many marine plants and plants growing near the coast contain large quantities of sodium compounds and a due supply appears essential to their welfare. Although sodium is chemically very like potassium, forming compounds whose properties are very similar to those of that element, its compounds are not retained by the clay or organic matter of a soil, and if applied to the land, soon find their way into the drains and thence by streams and rivers to the sea.

Certain sodium salts are used in agriculture, e.g., sodium nitrate and sodium borate, but in most cases it is the acid constituent which is of most value, and rarely that the sodium itself plays any important part, unless it be in rendering more available the potash or other valuable constituents of the soil. 
Calcium is an extremely abundant element, always occurring in combination. The carbonate, constituting the main ingredient in limestone, chalk and marble, and the sulphate, which is found as gypsum or selenite, $\mathrm{CaSO}_{4} \cdot 2 \mathrm{H}_{2} \mathrm{O}$, and also as anhydrite, $\mathrm{CaSO}_{4}$, are very abundant. Calcium is also found in union with phosphoric acid in the various deposits of apatite, $3\left[\mathrm{Ca}_{3} \mathrm{P}_{2} \mathrm{O}_{8}\right] \mathrm{CaCl}_{2}$ (or $\mathrm{CaF}_{2}$ ). Calcium carbonate, which is extremely abundant, dissolves in water containing carbonic acid and is therefore found in all natural waters, from which it is extracted by shell-fish, of whose hard parts it forms the chief constituent. It is essential as a plant food, but its agricultural importance arises rather from its effect in altering the texture of soils and in modifying the chemical changes attending the fermentation and decay of their organic matter. For example, calcium carbonate, lime, and other calcium compounds have a remarkable action upon clay, rendering it much less tenacious and plastic. The presence of calcium carbonate or some other substance capable of acting as a weak base, is essential to the important process of nitrification. Into plants, calcium is probably absorbed in the form of nitrate, phosphate, sulphate, or carbonate, and is found in all parts of the organism. In animals the calcium compounds are usually concentrated largely in the hard parts, the bones or shells.

Owing to its abundance, calcium is rarely used as a manure in the strict sense of the. word, i.e., as a plant food, but it is largely employed in agriculture either as free lime for the sake of the improvements it produces in the texture of the soil or, in combination with other ingredients of manurial value, e.g., phosphoric acid, as basic slag, superphosphates, etc.

Magnesium also occurs only in a state of combination, often associated with calcium. Limestone and other forms of carbonate of lime invariably contain some carbonate of magnesium, which in some, e.g., magnesian limestone, is present in considerable proportion.

Magnesium is also found in many silicates, e.g., meerschaum, steatite, talc and serpentine. It is also present in sea-water and in many mineral springs, to which it imparts a bitter taste.

Large quantities of magnesium compounds are found associated with potassium compounds in the Stassfurt deposits.

Magnesium is always present in plants, but as a rule there is far more present in a soil than is necessary for the crops' requirements. Consequently it is not of much importance as a fertiliser.

Iron is very abundant in nature, generally in the state of combination. Native metallic iron is occasionally found, but in insignificant amount. As oxides $\left(\mathrm{Fe}_{2} \mathrm{O}_{3}\right.$ and $\left.\mathrm{Fe}_{3} \mathrm{O}_{4}\right)$ and carbonate $\left(\mathrm{FeCO}_{3}\right)$ immense quantities occur in the minerals known respectively as hrematite, magnetite and spathic iron ore. These compounds form the most valuable ores of iron. In combination with other substances iron is also abundant. It is the main cause of the red or yellow colour of soils. Two series of compounds are known, ferrous salts, in which 
iron is divalent, and ferric compounds, in which it is trivalent; only the latter are suited to the requirements of plants.

Iron is essential as a plant food, but a very small quantity suffices. It is rarely advisable, therefore, to use iron compounds as manures.

Silicon always occurs in combination, either with oxygen as silica, $\mathrm{SiO}_{2}$, which is found as quartz, flint, sand, etc., or with oxygen and metals as the very numerous and abundant silicates, e.g., felspar, mica.

Sand, which consists of little fragments of quartz, is very permanent and is little affected by water or carbon dioxide.

Sand forms the largest portion of most soils and, if pure quartz, is devoid of plant food. It greatly affects the porosity and general texture of the soil. The silica which many plants contain is not believed to be essential to their growth; it probably is taken in by the roots of the plant in the form of soluble silicates or of soluble silica formed, not from the sand itself, but by the decomposition of silicates.

Silica, while not necessarily an essential constituent of plant food, has been shown by Hall and Morrison to have an important influence upon plant nutrition when applied as sodium silisate. In its presence, barley is apparently able to obtain from a soil a larger proportion of phosphoric acid and thus to give an increased yield.

Aluminium is never found in the free state in nature. It is extremely abundant and is one of the most important constituents of most mineral silicates. In the form of felspar and mica, it enters largely into the composition of many igneous rocks. By the action of water and carbon dioxide upon felspar $\left(\mathrm{K}_{2} \mathrm{O}_{2} \cdot \mathrm{Al}_{2} \mathrm{O}_{3} \cdot 6 \mathrm{SiO}_{2}\right)$ the potash is to a great extent removed and a residue of kaolin or china clay, $\mathrm{Al}_{2} \mathrm{O}_{3} \cdot 2 \mathrm{SiO}_{2} \cdot 2 \mathrm{H}_{2} \mathrm{O}$, is eventually obtained. Ordinary clay consists of a mixture of kaolin with some incompletely decomposed felspar and therefore is rich in potash. Clay constitutes an important ingredient of soils, to which it imparts valuable properties, especially as regards retentive powers for water and other substances.

Aluminium is apparently not a plant food, though the ashes of some few plants contain it in small quantities. This is notably the case with certain fungi, lycopodium in particular.

Very small dressings of aluminium salts or of alumina or kaolin are also said to have a beneficial effect upon wheat, barley and flax, according to experiments in Belgium and Japan.

Chlorine is an element possessed of remarkable and well-known properties. It rarely occurs in the free state in nature, but in the form of metallic chlorides is very abundant. This is particularly true of sodium chloride, $\mathrm{NaCl}$, which is found in sea and most spring water and as rock-salt. Chlorine is an essential constituent of plants, and in some crops, e.g., mangolds, it occurs in large quantity.

It is also absolutely necessary as a constituent of the food of animals and is often required in larger quantities than the ordinary diet of the animal can supply. 
Fluorine occurs mainly as calcium fluoride, $\mathrm{CaF}_{2}$, in the mineral known as fluor-spar. It is also present in almost all naturally occurring forms of calcium phosphate, and doubtless, in quantities too small to be readily detected, in many other minerals. The element itself is difficult to prepare owing to its great chemical activity.

It is found in combination in the bones, blood and urine of animals. Bone-ash contains about 4 per cent of calcium fluoride, while many mineral phosphates contain as much as 7 or 8 per cent. According to Lorenz, the evolution of hydrofluoric acid by a phosphate on treatment with sulphuric acid may be taken as a proof that a mineral phosphate is present. This test is not entirely satisfactory, since many mineral phosphates do not give it, indeed they are known to contain practically no fluoride, but chloride. Thus, there are two. varieties of apatite corresponding to the formulæ $3 \mathrm{Ca}_{3} \mathrm{P}_{2} \mathrm{O}_{8} \cdot \mathrm{CaF}_{2}$ and $3 \mathrm{Ca}_{3} \mathrm{P}_{2} \mathrm{O}_{8} \cdot \mathrm{CaCl}_{2}$, and many specimens have a composition intermediate between those expressed by the above formulæ. Of course the chloride variety is preferable for the manufacture of superphosphate.

Applications of calcium fluoride to the soil have been found, by a Japanese investigator, ${ }^{1}$ to have a beneficial effect upon some crops.

\section{Elements of Minor Importance.}

Boron always occurs in combination as boric acid $\left(\mathrm{HBO}_{2}\right.$ or $\mathrm{H}_{3} \mathrm{BO}_{3}$ ) or borates. It is not a very.abundant element except in a few localities, e.g., in Tuscany and in California, but of recent years its presence in a number of plants and products from plants, particularly in wines and the leaves, stalks, etc., of the vine, has been detected by various observers, leading to the conclusion that boric acid must be present in many soils, which probably derive it from igneous rocks.

There is no evidence that it is essential to plant life. Boric acid or boracic acid is possessed of considerable anti-putrefactive properties and is often used for preserving milk and other food products.

Iodine.-This element is comparatively rare in nature, being found in extremely small quantities in sea-water and in certain mineral waters. It also occurs in caliche-the crude nitrate of soda of Peru and Chili-in the form of sodium iodate, $\mathrm{NaIO}_{3}$. In the organic kingdom it occurs in the thyroid gland of man and many animals and in certain seaweeds, especially in Laminaria digitata and L. stenophylla, where it amounts to nearly 0.5 per cent of the plant. Its presence in terrestrial plants is rarely observed, but Uchiyama ${ }^{2}$ found that from the application of small quantities of potassium iodide-124 grammes per hectare-an increased yield of certain crops was obtained. This may have some bearing on the use of seaweed as a manure.

Manganese resembles iron in most of its properties. It is always found in union with other elements, often with oxygen, e.g., as pyrolusite, $\mathrm{MnO}_{2}$, psilomelane, $\mathrm{BaO} .2 \mathrm{MnO}_{2}$. It is apparently not essential

${ }^{1}$ Bull. Coll. Agr., Tokyo, 1906, 7, 85.

${ }^{2}$ Bull. Imp. Centr. Agric. Exp. Stat., Japan, 1906, 1, 35. 
as a plant food, but is often found in the ashes of plants, notably in those of tea and of Paraguay tea or Maté.

Investigations carried out at Woburn ${ }^{1}$ and at Tokyo, in Japan, show that manganese compounds applied in small quantity to soil produce a distinctly stimulating effect upon many plants, especially leguminous ones. Increases of 50 per cent in the straw and 25 per cent in the grain were produced with peas by the addition of 015 per cent of manganous sulphate to the soil.

Confirmation of this effect has been furnished by Bertrand ${ }^{2}$ with oats, and by Sutherst, in Natal (private communication), with maize, while Nagaoko records an increase of 15 per cent in a crop of rice when using manganese sulphate at the rate of 100 kilos per hectare. An increased quantity of manganese was found in the ash of plants grown in soil to which manganese salts had been added.

The author is of opinion that the action of the manganese is to be regarded rather as medicinal than as a food, and that it acts as a "tonic" much in the same way as ferrous sulphate is usualiy believed to do. It is thought that it plays some part in aiding the action of the oxydases in the leaf.

It would seem that from 50 to 100 kilos per hectare $(=44 \cdot 6$ to $89.2 \mathrm{lb}$. per acre) is the maximum dressing to be used and that larger quantities act injuriously upon the crop. Salomone ${ }^{3}$ states that manganic compounds are more toxic than manganous salts.

Titanium, which resembles silicon in its chemical functions, is not nearly so abundant. Its presence in the plant is usually overlooked, though, according to Wait, ${ }^{4}$ it is almost invariably present in plant ash.

Zinc has been found in the ashes of plants growing in localities where zinc ores-blende, $\mathrm{ZnS}$, or calamine, $\mathrm{ZnCO}_{3}$-occur. ${ }^{5}$ A plant, Viola calaminaria, grows in certain parts of Germany and its presence is regarded as indicative of the presence of zinc deposits in the neighbourhood where it is found (Liebig). The element, however, rarely occurs in animal or plant tissues, though its presence in certain food stuffs, e.g., dried fruits-through contamination from zinc utensils -is not uncommon.

Lithium has been found in the ashes of many plants, notably in those of tobacco leaves; it does not appear to have any important functions, but rather to be an accidental constituent.

Copper appears to be an essential constituent of certain gaily coloured feathers of tropical birds and has been occasionally found in

1 Jour. Roy. Agric. Soc., 1903, 64, 348 ; 1904, 65, 306 ; 1905, 66, 206.

${ }^{2}$ Comptes Rendus, 1905, 141, 1255.

${ }^{3}$ Chem. Zentr., 1906, ii. 532 .

${ }_{4}^{4}$ Jour. Soc. Chem. Ind., 1889, 367.

${ }^{5}$ Fricke, Chem. Zentr., 1900, ii. 769 ; also Labard, Zeit. Nahr. Genussm., $1901,4,489$. 
plants. Its presence in a soil, however, in anything more than very minute traces, is injurious to plant growth.

Barium.-According to Failyer, ${ }^{1}$ most of the soils of the United States contain this element. Analyses of about 100 soils from Colorado and Kansas showed them to contain from 0.01 to 0.11 per cent of barium. The element could also be detected in various plants grown on these soils.

Arsenic.-According to Headden, ${ }^{2}$ this element is present in the virgin soils of Colorado, to the extent of from 2.5 to 5.0 parts per million, while the subsoils are generally richer, the amount of arsenic reaching from 4 to 15 parts per million.

Relative Abundance of the Elements.-F. W. Clarke, ${ }^{3}$ of the U.S.A. Geological Survey, has estimated very carefully the relative proportions of the more common elements constituting the earth's crust to a depth of ten miles from the surface. He estimates that of this-

93 per cent is composed of solid rock, etc.

7 per cent " water and air - the latter only amounting to about 03 per cent.

The following table gives the relative abundance by weight of the elements named :-

\begin{tabular}{|l|c|c|c|}
\hline & $\begin{array}{c}\text { Solid Crust } \\
93 \text { per cent. }\end{array}$ & $\begin{array}{c}\text { Ocean } \\
7 \text { per cent. }\end{array}$ & $\begin{array}{c}\text { Mean } \\
\text { including Air. }\end{array}$ \\
\cline { 2 - 3 } 1. Oxygen & $47 \cdot 29$ & $85 \cdot 79$ & $49 \cdot 98$ \\
2. Silicon & $27 \cdot 21$ & - & $25 \cdot 30$ \\
3. Aluminium & $7 \cdot 81$ & - & $7 \cdot 26$ \\
4. Iron & $5 \cdot 46$ & - & $5 \cdot 08$ \\
5. Calcium & $3 \cdot 77$ & 0.05 & $3 \cdot 51$ \\
6. Magnesium & $2 \cdot 68$ & $0 \cdot 14$ & $2 \cdot 50$ \\
7. Sodium & $2 \cdot 36$ & $1 \cdot 14$ & $2 \cdot 28$ \\
8. Potassium & $2 \cdot 40$ & $0 \cdot 04$ & $2 \cdot 23$ \\
9. Hydrogen & $0 \cdot 21$ & $10 \cdot 67$ & 0.94 \\
10. Titanium & $0 \cdot 33$ & - & $0 \cdot 30$ \\
11. Carbon & $0 \cdot 22$ & $0 \cdot 002$ & $0 \cdot 21$ \\
12. Chlorine & $0 \cdot 01$ & $2 \cdot 07$ & $0 \cdot 15$ \\
13. Phosphorus & $0 \cdot 10$ & - & 0.09 \\
14. Manganese & $0 \cdot 08$ & - & $0 \cdot 07$ \\
15. Sulphur & 0.03 & $0 \cdot 09$ & $0 \cdot 04$ \\
16. Barium & 0.03 & - & $0 \cdot 03$ \\
17. Nitrogen & - & - & $0 \cdot 02$ \\
18. Fluorine & $0 \cdot 02$ & - & $0 \cdot 02$ \\
19. Chromium & 0.01 & - & $0 \cdot 01$ \\
& & & \\
\hline
\end{tabular}

These numbers, it must be remembered, are merely estimated, and can only claim to be approximations. They have been deduced from

${ }^{1}$ Bull. 72, 1910, U.S. Dept. of Agric., Bureau Soils. ii. 890 .

2 Proc. Colorado Sci. Soc., 1910, 9, 345; Jour. Chem. Soc., 1910, Abstracts,

${ }^{3}$ Bull. Philos. Soc., Washington, xi. 227. 
many analyses of rocks, but our acquaintance with the distribution and relative abundance of these rocks must obviously be incomplete.

The above table, however, giving as it does the proportions by weight of the elements, does not really represent their relative abundance reckoned in atoms. This latter certainly appears to the author to be the more correct way of grading their importance. In order to find the relative number of atoms it is only necessary to divide the numbers in the above table by the respective atomic weights. In this way the following table has been calculated, giving the number of atoms of each element present in a total of 100,000 atoms.

Table showing the relative numbers of atoms of the elements present in the earth's crust to a depth of 10 miles, including the ocean and the atmosphere:-

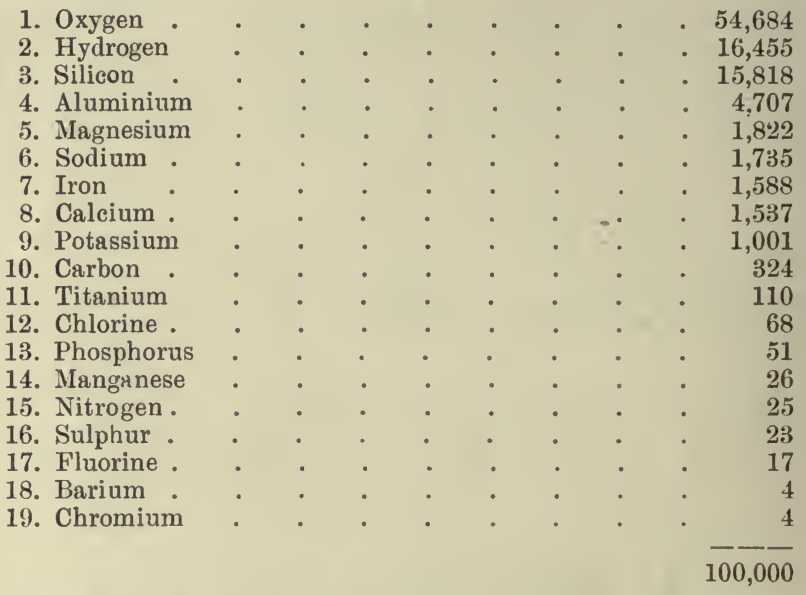

The great changes in the order of hydrogen (from 9th to 2 nd place), iron (4th to 7 th), and calcium (5th to 8 th) will be noted. The low position of nitrogen, which is usually regarded as so abundant, in both tables is also worthy of attention. It is hardly necessary to say that the other elements are very much less abundant and have been ignored in the compiling of the above tables. 


\section{CHAPTER II.}

\section{The Atmosphere.}

ALmost all the vital phenomena important from an agricultural aspect occur in contact with, and largely by the action of, the air around. Moreover, air plays an important part in the formation of soils and profoundly affects the temperature and climate of the earth. It is therefore obvious that a knowledge of the composition and properties of the atmosphere is absolutely essential in order that the chemistry of the processes involved in the life of animals and plants may be clearly understood.

The reader will already possess some acquaintance with the chemical nature of atmospheric air and with the properties of its chief constituents.

In this chapter, therefore, is given only a short summary of what is known of the extent, variations in composition, and functions of the constituents of air.

With reference to the extent, it is found that air exerts an average pressure of about $14.75 \mathrm{lb}$. per sq. in. (1033 grammes per sq. cm.) at the sea-level. This pressure is due to the earth's attraction for the air above and is, of course, a direct measure of the weight of the atmosphere. There rests, therefore, on every square foot of surface $14.75 \times 144 \mathrm{lb}$. of air; or upon an acre the total weight of air would be 41,300 tons. Allowing for the space occupied by land above the sea-level, Herschel has calculated that the mass of the atmosphere is about $\frac{1}{12 \frac{1}{0000}}$ of that of the earth.

Although it is possible, as shown above, to estimate fairly accurately the weight of the atmosphere, there is very little information available from which the height to which the atmosphere extends can be calculated.

It can easily be shown that if the atmosphere were homogeneous its height would be between 5 and 6 miles; but, as is well known, the density rapidly diminishes with the height above the sea-level. At a height of 5520 metres (i.e., about 18,110 ft.) the pressure is half what it is at the sea-level, while at 11,040 metres (or $36,220 \mathrm{ft}$.) it is reduced to one-fourth of the sea-level pressure, and so on. In the case of small elevations it may be said that, roughly, an ascent of $900 \mathrm{ft}$. lowers the barometric pressure by an inch. If $\mathrm{P}$ and $p$ be the corrected heights, in inches, of the barometers at two stations and $\mathrm{T}$ and $t$ be the respective atmospheric temperatures in ${ }^{\circ} \mathrm{C}$, then the difference in level of the two stations in feet- $\mathrm{H}$, is given by the formula-

$$
\mathrm{H}=60360(\log \mathrm{P}-\log p)\left(1+\frac{\mathrm{T}+t}{546}\right)
$$


From observations on luminous meteorites and refraction of sunlight it has been estimated that, at a height of 200 miles, air has a very small but appreciable density. It is also impossible to conceive of an actual, defined limit to a gaseous atmosphere.

The pressure of the atmosphere varies, as is well known, from day to day, and upon the variations of pressure the direction and force of the wind depend.

From a consideration of the mean pressures of many different parts of the world it has been discovered that there are two broad belts of high pressure, one north, and the other south, running roughly parallel to the equator. Near the equator itself, and also near the poles, are regions of low mean pressure.

Another fact in connection with atmospheric pressure has been clearly noticed, most distinctly in tropical districts-a diurnal variation, there being two maxima, often about $9 \mathrm{a} . \mathrm{m}$. and 9 p.m., and two minima about 3 a.m. and 3 p.m. So regular is this variation in some hot countries that, according to Humboldt, it is almost possible to tell the time of day by reading the barometer.

The consideration of the relative heights of the barometer obtaining at different places at a given time affords one of the most important criteria in forecasting weather. Though this subject to the farmer is obviously of the greatest importance, and though considerable progress has recently been made in connection with it, this is not the place in which it can suitably be discussed. The reader should consult a modern treatise on meteorology.

Dry air is almost diathermanous, i.e., transparent to heat rays. Consequently it allows the sun's heat to pass through with but little loss, becoming only very slightly warmed. It also allows a considerable, though probably much less, percentage of the heat radiated from the earth to pass through it. If, however, any appreciable amount of aqueous vapour or suspended solid matter be present, both forms of radiant heat are to a large extent absorbed. The presence of clouds confers a still greater retentive power for heat. This effect of aqueous vapour or of clouds is often very apparent at night; it is a matter of common experience that clear starlight or moonlight nights, even in summer, are often cold, because of the free radiation of heat from the earth into space, while cloudy nights are generally much warmer. Water in the air, too, has an important effect in conveying heat from one place to another. Whenever water becomes gaseous, heat is absorbed, and when the vapour condenses again (often in the upper regions of the air) heat is evolved. When air, from any cause, ascends, it cools itself by its own expansion, the rate being about $1^{\circ} \mathrm{C}$. for each rise of $340 \mathrm{ft}$. Consequently, if nearly saturated with aqueous vapour, some is deposited as cloud or mist when the air ascends.

Air itself is thus little affected by the direct heat of the sun, being heated either by contact with the hot surface of the ground, by the aid of its own aqueous vapour, or by its own contraction.

The specific heat of air is about $0 \cdot 24$, that of water being unity, i.e., to raise the temperature of a given weight of air through a given interval of temperature requires only about one-fourth as much heat as 
would raise the temperature of the same weight (or about $\frac{1}{800}$ of the volume) of water through the same interval of temperature. It is thus evident that by cooling a given volume of warm water through one degree (or any fixed interval of temperature) enough heat is extracted to raise the temperature of about 3200 volumes of air by the same amount.

Hence the potency of currents of warm water, e.g., the Gulf Stream, in affecting climate and the slowness with which water is cooled and converted into ice by cold winds, etc.

The mean temperature of the lower layers of the atmosphere varies greatly, one important factor' being the latitude, which mainly determines the amount of heat received from the sun. The temperature is also found to vary greatly along the same parallel of latitude, with the nature of the soil and particularly with the proximity or otherwise of large areas of water, places near the sea-coast always enjoying a more uniform climate than those far inland. Then, too, the height above the sea-level greatly affects the temperature of a place, there being on the average a fall of $1^{\circ} \mathrm{C}$. for about every $350 \mathrm{ft}$. above the sealevel, but the rate is very variable.

The most important discovery in recent meteorological research is that at a height of about 9 miles, the temperature of the atmosphere remains practically constant at about $-56^{\circ} \mathrm{C}$. The air above this height is probably almost motionless and takes. no part in the circulation which is so constantly in play in the lower layers. Above this isothermal layer, the composition of the atmosphere probably changes rapidly with increasing elevation, the carbon dioxide, water vapour, argon, oxygen and nitrogen in turn diminishing until, in the highest regions, probably little but hydrogen remains.

\section{Composition of the Atmosphere.}

Air is a mechanical mixture of various gases and vapours, but it invariably contains suspended solid matter, some of which consists of micro-organisms.

The main gaseous constituents are-oxygen, nitrogen, argon, carbon dioxide, water vapour, ammonia, oxides of nitrogen or nitric acid vapour, and ozone. All these are subject to variation, but to very different extents.

Nitrogen, the largest constituent, is the least variable in amount. It usually constitutes about 78 per cent by volume or 75.5 per cent by weight of dry air. Its function in the atmosphere has usually been regarded as mainly that of a diluent. Apparently very few reactions, in which nitrogen takes part, occur in the atmosphere. Recently, however, many obscure changes in which the free nitrogen of the air enters into combination with oxygen and hydrogen have been observed, some of which are of the greatest importance in agriculture. These changes occur by the agency of micro-organisms in the soil or plant (vide Chap. IV).

Very high temperatures, such as obtain in the blast furnace, will cause nitrogen to combine with carbon in the presence of alkalies, with the production of cyanides. Nitrogen may be made to combine with 
oxygen under the influence of the high temperature of the electric spark, ${ }^{1}$ and such combination is doubtless brought about in the atmosphere by lightning discharges, with the production of oxides of nitrogen and eventually of nitric acid. Similar combination between nitrogen and oxygen has been observed to occur during the combustion, in air, of certain substances which, in their burning, produce a high temperature.

The amount of free nitrogen removed from the atmosphere by these various agencies is relatively small and probably quite equalled by that yielded by processes of decay and putrefaction.

It is found that organic nitrogenous bodies during decomposition yield their nitrogen, partly as ammonia and, under certain circumstances, partly as free nitrogen. So, too, by combustion, organic substances evolve practically the whole of their nitrogen in the free state.

Oxygen, the most important constituent, since it takes part in so many of the reactions occurring in the atmosphere, is liable to considerable local variations. Its amount, on the average, is nearly 21 per cent by volume or 23.2 per cent by weight of dry air. As processes of oxidation are taking place continually it might be expected that the proportion of oxygen in air would show great variations from place to place. In consequence, however, of diffusion, air currents, and the compensating influences of vegetation, the variations which have been observed, though well marked, are not great.

The extremes noticed by various observers are-

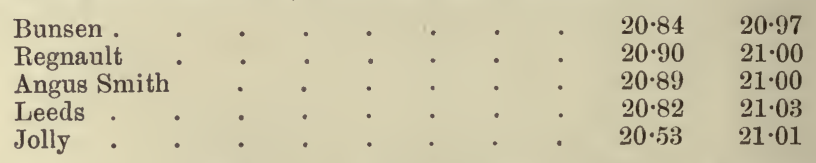

As is to be expected, the air of towns is found to contain less oxygen than that of the country or over the sea. The lower numbers given in the above table were, in all cases, observed in the air of large cities. In marshy places, too, the amount of oxygen is generally lower than elsewhere.

In 1886 a series of daily analyses of air were made simultaneously at Dresden, Bonn (Germany), Cleveland (U.S.A.), Para (Brazil) and Tromsöe (Norway), from 1 April to 16 May. The mean values for the amount of oxygen were-

\begin{tabular}{|c|c|c|c|c|c|c|c|c|}
\hline Para & - & - & - & - & . & \multicolumn{3}{|c|}{20.92 per cent, by volume } \\
\hline Bonn & & & • & . & . & $20 \cdot 92$ & ," & \\
\hline Cleveland & . & • & . & • & . & $20 \cdot 93$ & ," & ", \\
\hline Dresden. & • & • & - & . & . & $20 \cdot 93$ & ," & \\
\hline Tromsöe & 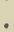 & . & . & . & . & $20 \cdot 95$ &, &, \\
\hline
\end{tabular}

The maximum was 21.0 at Tromsöe and the minimum 20.86 at Para. The mean percentage of oxygen of the whole series was $20.93 .^{2}$

${ }^{1}$ McDougal and Howles (Jour. Chem. Soc., 1900, Abstracts, ii. 651) found that, by a large electric discharge in air, as much as 303 grammes of nitric acid per 12 horse-power hours could be produced.

${ }^{2}$ Hempel, Ber., 20, 1864. 
Comparatively few experiments on the composition of air from great heights have been made, but the general result of what is known is in agreement with theory, which indicates that relatively less of the heavy constituent, oxygen, should be present in such air. ${ }^{1}$ In the Alps it has been observed that a descending current of air produces a lower proportion, while an ascending wind gives a higher proportion of oxygen. ${ }^{2}$ Differences of 0.18 per cent (by weight) were observed on two consecutive days at a height of 2060 metres. In Paris the same author gives 23.20 per cent as the mean proportion of oxygen by weight, while $23 \cdot 1$ per cent by weight is the amount he estimates as the average in London air.

Argon was discovered in 1894 by Lord Rayleigh and Prof. Ramsay. The experiments which led to its discovery were the determinations of the densities of gases, in which it was noticed that the residue left after the removal of oxygen and carbon dioxide from atmospheric air, was distinctly heavier than nitrogen prepared from chemical compounds. This fact was eventually traced to the presence, in air, of a hitherto unknown substance, which was named argon by the discoverers.

${ }^{1}$ According to Hinrichs (Compt. Rend., 1900, 131, 442), if each constituent of the air were independent of the others the composition of air at various heights would be as given in the accompanying table.

\begin{tabular}{|c|c|c|c|c|c|}
\hline Altitude in kilometres. & Carbon dioxide. & Oxygen. & Argon. & Nitrogen. & Hydrogen. \\
\hline $\begin{array}{l}0 \\
10 \\
20 \\
30 \\
40 \\
50 \\
60 \\
70 \\
80 \\
90 \\
100 \text { (=62.14 miles) }\end{array}$ & $\begin{array}{l}.03 \\
.02 \\
.01 \\
.00 \\
= \\
= \\
= \\
= \\
--\end{array}$ & $\begin{array}{c}21 \cdot 00 \\
18 \cdot 43 \\
16 \cdot 07 \\
13 \cdot 90 \\
11 \cdot 86 \\
9 \cdot 83 \\
7 \cdot 52 \\
4 \cdot 7 \\
2 \cdot 2 \\
0 \cdot 7 \\
0 \cdot 3\end{array}$ & $\begin{array}{l}1 \cdot 20 \\
0 \cdot 75 \\
0 \cdot 46 \\
0 \cdot 28 \\
0 \cdot 16 \\
0 \cdot 12 \\
0 \cdot 00 \\
= \\
= \\
=\end{array}$ & $\begin{array}{r}77 \cdot 75 \\
80 \cdot 74 \\
83 \cdot 26 \\
85 \cdot 18 \\
85 \cdot 94 \\
83 \cdot 94 \\
75 \cdot 54 \\
56 \cdot 2 \\
31 \cdot 0 \\
12 \cdot 9 \\
4 \cdot 6\end{array}$ & $\begin{array}{c}0 \cdot 02 \\
0 \cdot 06 \\
0 \cdot 20 \\
0 \cdot 64 \\
2 \cdot 04 \\
6 \cdot 11 \\
16 \cdot 94 \\
39 \cdot 1 \\
66 \cdot 8 \\
86 \cdot 4 \\
95 \cdot 1\end{array}$ \\
\hline
\end{tabular}

From the above table it is seen that the carbon dioxide becomes inappreciably small at a height of 30 kilometres (about 18.6 miles), that the proportion of nitrogen attains a maximum at about 40 kilometres (about 25 miles), that at a height of about 60 kilometres (37 miles) the oxygen and hydrogen are in the proportion in which they combine with explosion to form water. Explosion in this highly rarefied atmosphere would be impossible, especially in the presence of so large a quantity of nitrogen.

Hinrichs asks-might not the hydrogen found in meteoric iron be obtained during the passage of a meteorite through the outermost layers of our atmosphere, which, according to the table, consists of almost pure hydrogen? It may be mentioned that hydrogen is, according to Gautier (Compt. Rend., 1898, 127, 693), always to be detected in pure air, in proportion varying from 11 to 18 per 100,000 , i.e., $\cdot 01$ to $\cdot 018$ per cent by volume. Moreover, he has shown that hydrogen is to be found among the gases evolved by the action of water upon many rocks, e.g., gr ınite, at a temperature of about $280^{\circ}$ or $300^{\circ}$ (Compt. Rend., 1900, 647). In a later paper, however, doubt is expressed as to the hydrogen being actually derived from the granite.

${ }^{2}$ Le Juc, Compt. Rend., 1898, 413. 
Argon is a gas possessed apparently of no chemical properties whatever; that is, it appears to be incapable of uniting with any other substance or even with itself, for, unlike most gases, its molecule contains only one atom. Its density, when carefully purified, was found to be $19 \cdot 94$, which gives as its atomic (and molecular) weight the number $39 \cdot 88$. So far as is known, argon takes part in none of the chemical changes which occur in the atmosphere.

Associated with argon, Ramsay has found several other gases of the same inert character and monatomic molecules, but differing in density and other physical properties. These have been named helium (identical with the substance so named, which was, long ago, detected in the sun by spectroscopic analysis), density 2.0 ; neon, density, 10.0 ; krypton, density, $41 \cdot 4$; and xenon, density probably about 65 . These elements, however, are present in such extremely small quantities and their chemical inertness is so great that they are probably of no importance from our present standpoint.

The amount of argon present in the air is apparently very constant -about 0.94 per cent by volume or 1.3 per cent by weight. It constitutes about 1.19 per cent by volume of the residue left after the removal of oxygen.

Carbon Dioxide.-This constituent, though present only in small proportion (usually less than 04 per cent by volume), is of great importance with reference to vegetable life. Its amount is subject to considerable variation, since it is a constant product, in large quantity, of the combustion and putrefaction of all organic bodies.

In the free open country, air contains on the average about 033 per cent of carbon dioxide. ${ }^{1}$ In large towns or in the neighbourhood of manufactories the quantity is usually larger. In London, Angus Smith found · 044, in Glasgow · 05 , in Manchester ·045. The amount is always greater during fogs (sometimes rising to 0.1 per cent) and snow.

Air in the country shows a distinct diurnal variation, the amount of carbon dioxide being greater at night. Armstrong's ${ }^{2}$ experiments made at Grasmere in summer-time gave 0296 per cent for the day and 0330 per cent for the night, and similar results have been obtained by other observers. Müntz and Aubin give 0278 per cent as the universal average; they noticed $\cdot 0273$ as the mean in the day and .0288 in the night. ${ }^{3}$ H. T. Brown gives as a result of many determinations made in 1898-9, 0285 as the mean and 027 and $\cdot 030$ as the usual limits of variations in summer. ${ }^{4}$ Over the sea or in places far from vegetation no such difference can be detected, and the average amount is lower. Schulze, as a mean of nearly three years' daily determinations of carbon dioxide in the air at Rostock, found 0292 per cent, the maximum being $\cdot 0344$ per cent and the minimum 0225 per cent. $^{5}$

${ }^{1}$ Recent determinations have almost invariably given lower values for the mean amount in the atmosphere.

2 Pro. Roy. Soc., $1880,343$.

${ }^{3}$ Bieder. Zentral., 1883, 469.

${ }^{4}$ Brit. Assn. Report, 1899, Presidential Address, Section B.

${ }^{5}$ Versuch. Stat., 14, 366. 
Theoretically, assuming that the composition of the atmosphere is not modified by any disturbing influences, the amount of carbon dioxide should diminish with the height above the sea-level. Experimental evidence on this point is conflicting. Truchot found distinctly less at heights of 1440 (.020 per cent) and 1880 metres ( 0172 per cent) than nearer the sea-level ('0313), while recently (1899) Thiérry ${ }^{1}$ found on Mont Blanc 0262 per cent at 1080 metres and 0269 per cent at 3050 metres. Müntz and Aubin ${ }^{2}$ found in 1882 , as a mean of many analyses, 0286 volumes on the Pic du Midi (2877 metres), practically the same as in the plains. The earlier observers, too, found more on the tops of mountains than at sea-level. . It is obvious that vegetation must have a great local influence on the amount of carbon dioxide and may, in some cases, cause misleading indications.

Among the many causes tending to increase the amount of carbon dioxide in the air, the following are the most important:-

1. Emission from volcanoes, deep springs, and other subterranean sources ; immense quantities are thus sent into the atmosphere.

2. Oxidation of carbonaceous matter; this occurs in the processes of respiration of animals and plants, the decay and fermentation of animal and vegetable products, and the combustion of most fuels.

3. The dissociation of carbonates by heat; this is seen in such processes as lime-burning.

4. The decomposition of calcium bicarbonate by shell-fish, the calcium carbonate being retained in building up the shell, and the carbon dioxide evolved.

The main cause tending to diminish its quantity is the decomposition effected by the green portions of plants under the influence of light. The rapidity with which this absorption of carbon dioxide occurs is astonishing (vide Chap. XI). Other causes which remove it are the weathering of rocks, e.g., the conversion of felspar into kaolin-

$$
\begin{aligned}
& \mathrm{Al}_{2} \mathrm{O}_{3} \mathrm{~K}_{2} \mathrm{O} \cdot 6 \mathrm{SiO}_{2}+\mathrm{CO}_{2}+10 \mathrm{H}_{2} \mathrm{O}=\mathrm{Al}_{2} \mathrm{O}_{3} \cdot 2 \mathrm{SiO}_{2} \cdot 2 \mathrm{H}_{2} \mathrm{O}+\mathrm{K}_{2} \mathrm{CO}_{3} \\
& +4 \mathrm{H}_{4} \mathrm{SiO}_{4} \text {. }
\end{aligned}
$$

-and the conversion of normal into acid carbonates. Indeed, to this last-mentioned action and its reverse, in the case of calcium carbonate in sea-water, Schloesing attributes the maintenance of the constancy of composition of the atmosphere above the ocean. If, from any cause, the quantity of carbon dioxide in the air above the ocean increases, an increased amount goes into solution as calcium bicarbonate, whereas, if the quantity in the air diminishes, a portion of the dissolved bicarbonate dissociates, thus liberating some of the gas.

Ammonia is a small but important constituent. It exists, prob. ably, as carbonate, nitrite and nitrate in the air. Its amount is very variable and is always greater in town than in country air.

Truchot in 1874 found 0.93 to 2.79 milligrams of ammonia in 1 cubic metre of air collected in Auvergne at a height of 395 metres above the sea, on the Puy de Dome (1446 metres) he found 3.18 milligrams, and on the Pic du Saucy (1884 metres) 5.5 milligrams per cubic metre. He concludes that the amount of ammonia increases with

${ }^{1}$ Compt. Rend., 129, 315.

2 Ibid., 93, 797. 
the elevation and is greater in cloudy than in clear weather. ${ }^{1}$ These amounts are much greater than have been found by other observers, and his conclusions as to distribution of the ammonia are not generally accepted. Levy at Montsouris ${ }^{2}$. found as a mean 1.68 and 2.06 milligrams per 100 cubic metres in summer. The maximum observed was 9 milligrams per 100 cubic metres, while on several occasions no ammonia was present. According to Heinrich ${ }^{3}$ air contains the greatest amount of ammonia in June, the least in February. $\mathrm{He}$ found three times as much in the summer months as in the winter, while spring and autumn gave intermediate values.

Ammonia, in common with nitric acid and suspended matter, is found in rain-water.

According to Levy, rain (unlike air) in summer contains least and in winter most ammonia. This may be due to the solubility of ammonia being greater in cold than in hot water. At Montsouris ${ }^{4}$ the following were the mean amounts of ammonia per litre, rainfall (in $\mathrm{mm}$.), and quantity of nitrogen (ammoniacal) falling upon each square metre in each of the following years:-

\begin{tabular}{|c|c|c|c|}
\hline & Rainfall. & Ammonia. & Nitrogen per sq. met. \\
\hline $\begin{array}{l}1875-6 \\
1876-7 \\
1877-8 \\
1878-9\end{array}$ & $\begin{array}{l}541 \cdot 5 \mathrm{~mm} . \\
601 \cdot 7 \quad ", \\
600 \cdot 1 \quad ", \\
655 \cdot 3 \quad, "\end{array}$ & $\begin{array}{l}1.98 \mathrm{mgm} . \\
1.54 \quad, \\
1.91 \quad " \\
1.20 ",\end{array}$ & 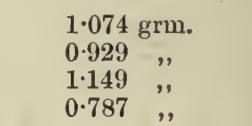 \\
\hline
\end{tabular}

-This, being practically town rain, is richer in ammonia than rain falling in country places. As the average of 16 years' observations Levy gives 2.2 parts of ammonia per million $=1.82$ parts of nitrogen per million in the rain at Montsouris. (See also analysis of rainwater, p. 25.)

Bunsen observed that at the commencement of a shower the rain contained 3.7 milligrams of ammonia per litre, while at the end only 0.64 milligrams were present. The author has also observed in the Transvaal, that the content of combined nitrogen in the rain is often roughly inversely proportioned to the amount of rainfall.

Thus, in 1904 :-

\begin{tabular}{|c|c|c|c|}
\hline Week ending. & Rainfall mm. & N. per million. & N. lb. per acre. \\
\cline { 1 - 1 } & & & \\
\cline { 1 - 2 } Nov. 19 & 97.79 & $0 \cdot 69$ & $0 \cdot 600$ \\
5 & $45 \cdot 18$ & $0 \cdot 89$ & $0 \cdot 361$ \\
Sept. 10 & $10 \cdot 00$ & $2 \cdot 90$ & $0 \cdot 259$ \\
Oct. 22 & $6 \cdot 48$ & $7 \cdot 70$ & $0 \cdot 446$ \\
", 29 & $1 \cdot 22$ & $17 \cdot 62$ & $0 \cdot 192$ \\
Aug. 27 & $1 \cdot 06$ & $47 \cdot 27$ & $0 \cdot 448$ \\
\hline
\end{tabular}

${ }^{1}$ Jour. Chem. Soc., 1874, Abstracts, 223.

${ }^{2}$ Ibid., 1877, 509; 1878, 243, and 1880, 848.

${ }^{3}$ Ibid., 1898, Abstracts, ii. 3, 114.

${ }^{4}$ Compt. Rend., 91, 94 . 
Nitric Acid, or some compound of nitrogen and oxygen, is also found in air, in which it probably exists in the form of nitrate or nitrite of ammonia, and, according to Müntz and Aubin, ${ }^{1}$ these in the state of finely-divided solid. The authors quoted state that thunderstorms (and the accompanying formation of nitrates) are confined to the lower portion of the atmosphere, below 3000 metres, and that above that height no nitrates are found in rain or snow.

The amount of nitric acid in air is so small that it can only be detected, as a rule, by examination of rain-water, in which it becomes more concentrated.

Rain-water, too, brings down ammonia and suspended matter, so that analyses of rain-water are valuable as indications of the composition of the atmosphere. Many such analyses have been published. Thus Angus Smith ${ }^{2}$ in 1872 gave the following result of a large number of analyses :-

\section{ANALYSES OF RAIN-WATER.}

Parts per Million.

\begin{tabular}{|c|c|c|c|c|c|c|c|c|}
\hline Where collected. & 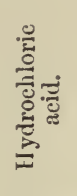 & 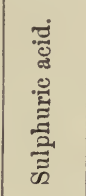 & 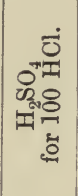 & 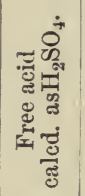 & 节 & 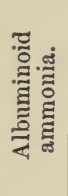 & 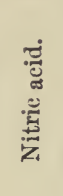 & 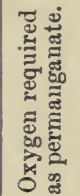 \\
\hline $\begin{array}{l}\text { Ireland, Valentia } \\
\text { Scotland, five coast c }\end{array}$ & $48 \cdot 67$ & $2 \cdot 73$ & 6 & None & $\cdot 18$ & $\cdot 03$ & $\cdot 37$ & $\cdot 05$ \\
\hline $\begin{array}{l}\text { places, west } \\
\text { eight coast country }\end{array}$ & $12 \cdot 28$ & $3 \cdot 61$ & 29 & $\cdot 14$ & $\cdot 48$ & $\cdot 11$ & $\cdot 37$ & .02 \\
\hline $\begin{array}{l}\text { places, east } \\
\text { twelve inland }\end{array}$ & $12 \cdot 91$ & $7 \cdot 66$ & 59 & $2 \cdot 44$ & .99 & $\cdot 11$ & $\cdot 47$ & $\cdot 65$ \\
\hline $\begin{array}{l}\text { country places } \\
\text { England, twelve inland }\end{array}$ & $3 \cdot 38$ & $2 \cdot 06$ & 61 & $\cdot 31$ & 53 & $\cdot 04$ & $\cdot 31$ & $\cdot 26$ \\
\hline country places & $3 \cdot 99$ & $5 \cdot 52$ & 138 & None & $1 \cdot 07$ & $\cdot 11$ & .75 & $\cdot 47$ \\
\hline Scotland, six towns . & $5 \cdot 86$ & 16.50 & 282 & $3 \cdot 16$ & $3 \cdot 82$ & $\cdot 21$ & $1 \cdot 16$ & $1 \cdot \varangle 6$ \\
\hline Germany, Darmstadt . & .97 & $29 \cdot 17$ & 2998 & $1 \cdot 74$ & - & - & - & - \\
\hline England, London . & $1 \cdot 25$ & $20 \cdot 49$ & 1645 & $3 \cdot 10$ & $3 \cdot 45$ & $\cdot 21$ & $\cdot 84$ & \\
\hline $\begin{array}{ll}" & \text { six towns } \\
\text { Manchester }\end{array}$ & $\begin{array}{l}8 \cdot 70 \\
5 \cdot 83\end{array}$ & $\begin{array}{l}34 \cdot 27 \\
44 \cdot 82\end{array}$ & $\begin{array}{l}394 \\
768\end{array}$ & $\begin{array}{r}8 \cdot 40 \\
10 \cdot 17\end{array}$ & $\begin{array}{l}4 \cdot 99 \\
5 \cdot 96\end{array}$ & $\begin{array}{l}\cdot 21 \\
\cdot 25\end{array}$ & $\begin{array}{r}\cdot 85 \\
1 \cdot 01\end{array}$ & $\begin{array}{l}2 \cdot 74 \\
3 \cdot 22\end{array}$ \\
\hline Scotland, Glasgow . & 8.97 & $70 \cdot 19$ & 782 & $15 \cdot 13$ & $9 \cdot 10$ & $\cdot 30$ & $2 \cdot 44$ & $10 \cdot 04$ \\
\hline
\end{tabular}

In these analyses it is to be noted that the chlorine is mainly due to the dried-up particles of sea-water cast into the air as spray. The amount is always greatest near the sea and smallest far inland; it is greatly influenced by the direction and force of the wind. Sulphuric acid is also partly attributable to the same cause, but if its ratio to the chlorine be more than 12:100 (the ratio in sea-water) combustion of coal or the decay of animal or vegetable matter is probably to be assigned as one of its sources.

Another extensive series of analyses of rain-water collected at

${ }^{1}$ Compt. Rend., 95, 919.

2 Jour. Chem. Soc., 1872, 33. 
Rothamsted was made by Frankland and published in 1881 and $1882^{1}$ by Lawes, Gilbert and Warington. From sixty-nine samples collected in 1869-70 the following numbers were obtained. (Parts per million) :-

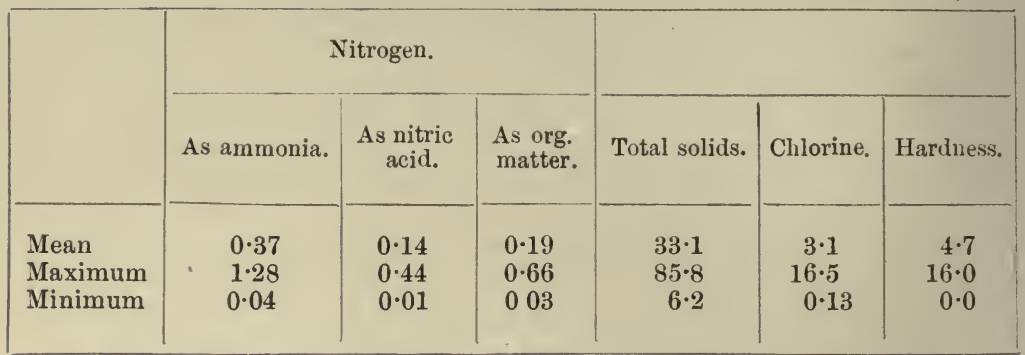

In 1888-9 a series of monthly determinations of the amounts of ammonia and nitric acid in the rainfall at Rothamsted was made by Warington. ${ }^{2}$ The results are given in the accompanying table :-

\begin{tabular}{|c|c|c|c|c|c|c|}
\hline \multirow{2}{*}{\multicolumn{2}{|c|}{. }} & \multirow{2}{*}{$\begin{array}{l}\text { Rainfall. } \\
\text { Inches. }\end{array}$} & \multicolumn{2}{|c|}{ Per million of rain. } & \multicolumn{2}{|c|}{ Per acre (in lb.). } \\
\hline & & & $\begin{array}{c}\mathrm{N} \text {. as } \\
\text { ammonia. }\end{array}$ & $\begin{array}{c}\mathrm{N} \text {. as } \\
\text { nitrates. }\end{array}$ & N. as & $\begin{array}{c}\text { N. as } \\
\text { nitrates. }\end{array}$ \\
\hline \multirow[t]{12}{*}{1888.} & May & $1 \cdot 28$ & $\cdot 256$ & $\cdot 109$ & $\cdot 074$ & $\cdot 031$ \\
\hline & June & $4 \cdot 87$ & .500 & $\cdot 167$ & $\cdot 551$ & $\cdot 184$ \\
\hline & July & $3 \cdot 86$ & $\cdot 388$ & $\cdot 104$ & $\cdot 338$ & .091 \\
\hline & Aug. & $3 \cdot 38$ & $\cdot 288$ & $\cdot 090$ & $\cdot 220$ & $\cdot 069$ \\
\hline & Sept. & 1.03 & $1 \cdot 025$ & $\cdot 253$ & $\cdot 238$ & $\cdot 059$ \\
\hline & Oct. & $1 \cdot 09$ & .525 & $\cdot 173$ & $\cdot 129$ & $\cdot 043$ \\
\hline & Nov. & $4 \cdot 46$ & $\cdot 313$ & $\cdot 096$ & $\cdot 315$ & $\cdot 097$ \\
\hline & Dec. & 1.69 & $\cdot 500$ & $\cdot 155$ & $\cdot 191$ & $\cdot 059$ \\
\hline & Jan. & $1 \cdot 29$ & .575 & $\cdot 190$ & $\cdot 168$ & $\cdot 055$ \\
\hline & Feb. & 1.95 & $\cdot 238$ & .095 & $\cdot 105$ & $\cdot 042$ \\
\hline & Mar. & 1.89 & $\cdot 400$ & $\cdot 136$ & $\cdot 171$ & $\cdot 058$ \\
\hline & April & $2 \cdot 48$ & .575 & $\cdot 230$ & .323 & $\cdot 129$ \\
\hline \multicolumn{2}{|c|}{ Whole year } & $29 \cdot 27$ & $\cdot 426$ & $\cdot 139$ & $2 \cdot 823$ & $\cdot 917$ \\
\hline
\end{tabular}

This gives a total of combined nitrogen in the rain of $3.74 \mathrm{lb}$. per acre per annum.

The mean amount from seven Continental agricultural stations between 1864 and 1872 is 0.47 parts of nitrogen as nitric acid per million, and $1 \cdot 26$ parts of ammonia per million in the rain, yielding a total fall of $10 \cdot 18 \mathrm{lb}$. of combined nitrogen per acre.

Results obtained in New Zealand and in Japan agree better with the Rothamsted results.

On the other hand, Müntz and Marcano $^{3}$ in 1883-5, as the result of over 120 analyses of rain-water in Venezuela, found as a mean 2.23 parts of nitric acid per million (equal to 0.578 parts of nitrogen), the

1 Jour. Roy. Agric. Soc., 1881 and 1882.

2 Jour. Chem. Soc., $1889,537$.

${ }^{3}$ Compt. Rend., 108, 1062 ; Jour. Chem. Soc., 1889, Abstracts, 923. 
maximum amount being $16.25(4.2$ parts of nitrogen) and the minimum 0.2 parts $(0.05$ nitrogen) per million. In the island of Réunion an average of 2.67 parts per million of nitric acid (equal to 0.69 parts of nitrogen) was found. As the rainfall, too, is much greater, it is obvious that the amount of nitric nitrogen conveyed to the soil by the rain is very much greater in the tropics than in England.

The same authors in $1890^{1}$ found a mean of 1.55 milligrams of ammonia ( $=1.28 \mathrm{mgm}$. of nitrogen) per litre in rain-water collected in the tropics. Here, too, the amount is much greater than in England.

Many analyses of rain-water in various parts of the world have been published in recent years. The following table gives some of the results :-

\begin{tabular}{|c|c|c|c|c|c|}
\hline \multirow{2}{*}{ Date. } & \multirow{2}{*}{ Place. } & \multirow{2}{*}{ Rainfall. } & \multicolumn{2}{|c|}{ Nitrogen in parts per million. } & \multirow{2}{*}{$\begin{array}{l}\text { Total N. } \\
\text { lb. per acre. }\end{array}$} \\
\hline & & & As ammonia. & $\begin{array}{l}\text { As uitrates } \\
\text { and nitrites. }\end{array}$ & \\
\hline 1904-5 & $\begin{array}{l}\text { Pretoria }{ }^{2} \\
\text { (Transvaal) }\end{array}$ & $24 \cdot 31$ & $1 \cdot 194$ & $0 \cdot 196$ & $7 \cdot 67$ \\
\hline $1905-6$ & $\begin{array}{l}\text { Dehra Dun } \\
\text { (India) }\end{array}$ & $84 \cdot 8$ & $0 \cdot 104$ & $0 \cdot 070$ & $3 \cdot 41$ \\
\hline$"$ & $\begin{array}{l}\text { Cawnpore }{ }^{3} \\
\text { (India) }\end{array}$ & $49 \cdot 36$ & $0 \cdot 221$ & $0 \cdot 068$ & $3 \cdot 25$ \\
\hline 1909 & $\begin{array}{l}\text { Flahult } \\
\text { (Sweden) }\end{array}$ & $32 \cdot 55$ & $0 \cdot 450$ & $0 \cdot 177$ & $4 \cdot 62$ \\
\hline 1908 & $\begin{array}{l}\text { Brisbane } \\
\text { (Australia) }\end{array}$ & $45 \cdot 44$ & $0 \cdot 216$ & $0 \cdot 186$ & $4 \cdot 15$ \\
\hline ", & $\begin{array}{l}\text { Roma }{ }^{5} \\
\text { (Australia) }\end{array}$ & $26 \cdot 16$ & 0.419 & $0 \cdot 207$ & $3 \cdot 71$ \\
\hline " & $\begin{array}{l}\text { Cairns }{ }^{5} \\
\text { (Australia) }\end{array}$ & $75 \cdot 12$ & $0 \cdot 080$ & $0 \cdot 104$ & $3 \cdot 13$ \\
\hline 1906-7 & $\begin{array}{l}\text { Garforth }{ }^{\prime} \\
\text { (Yorkshire) }\end{array}$ & $26 \cdot 44$ & $1 \cdot 060$ & $0 \cdot 236$ & $7 \cdot 84$ \\
\hline $1907-8$ & $\begin{array}{l}\text { Garforth }{ }^{6} \\
\text { (Yorkshire) }\end{array}$ & $29 \cdot 16$ & 0.773 & $0 \cdot 481$ & $8 \cdot 64$ \\
\hline $1907-9$ & $\begin{array}{l}\text { Canada }^{7} \\
\text { Canterbury, N.Z. }{ }^{8}\end{array}$ & $\begin{array}{l}37 \cdot 35 \\
26 \cdot 80\end{array}$ & $\begin{array}{l}0 \cdot 296 \\
0 \cdot 132\end{array}$ & $\begin{array}{l}0.134 \\
0.178\end{array}$ & $\begin{array}{l}4 \cdot 33 \\
1 \cdot 55\end{array}$ \\
\hline & vanteroury, N.Z. & 2000 & 0.102 & & 1.55 \\
\hline
\end{tabular}

The amounts of nitrogen in the rain collected in Pretoria and at Garforth were probably higher than exists in that of the neighbouring open country, being affected by the proximity of towns. This is indicated by the large amount of sulphates and free sulphuric acid present in the rain at Garforth (mean for two years, 11.67 parts total $\mathrm{SO}_{3}$ per million, equivalent to about $73 \mathrm{lb} . \mathrm{SO}_{3}$ per acre), which, being about seven miles to the east of Leeds, is doubtless affected by the products of combustion of coal carried by the prevailing westerly winds.

For a discussion and summary of results obtained by the examina-

${ }^{1}$ Compt. Rend., 114, 184.

${ }^{3}$ Ibid. 1906, Abstracts, ii. 302.

5 Ibid. 1910, Abstracts, ii. 647.

${ }^{7}$ Ibid. 1909, Abstracts, ii. 429.
2 Jour. Chem. Soc., 1906, Abstracts, ii. 302.

+ Ibid. 1910, Abstracts, ii. 444.

${ }^{6}$ Ibid. 1909, Abstracts, ii. 340.

${ }^{8}$ Ibid. 1911, Abstracts, ii. 327. 
tion of rain-water, collected in various parts of the world, the reader is referred to a paper by Miller. ${ }^{1}$

Ozone, the active form of oxygen, is present in air, but in very varying and always excessively small amount. The measurement of the absolute proportion of ozone in air is difficult, and the greater number of observations recorded merely give the relative amounts according to an arbitrary scale (Schönbein and Houzeau). Moreover it is very probable that many of the results obtained are really due, wholly or in part, to the presence of hydrogen peroxide.

Houzeau, who estimated the relative amount of ozone present in air by the colour imparted to strips of red litmus paper coated for half their length with 1 per cent solution of potassium iodide and exposed for a given time, concluded that the amount of ozone in country air was, at the most, 1 in 450,000 by weight or 1 in 700,000 by volume. $\mathrm{He}$ observed that the amount was greatest in May and June and least in December and January, and that during rain and particularly during violent thunder-storms and gales the amount was often greatly increased. Over marshes or in towns no ozone can be detected.

According to Schöne ${ }^{2}$ the indications usually ascribed to ozone are really due to hydrogen peroxide. In 1874 and 1875 he made many determinations (in Moscow) of the amount of hydrogen peroxide in rain and snow, also, by artificially producing hoar-frost, in air. $\mathrm{He}$ found the maximum amount occurred in air at 4 p.m. and the minimum between midnight and 4 a.m., and that it was most abundant in July and least abundant in December and January. ${ }^{3}$

It seems established as a fact that country and sea air contains a powerful oxidising agent in small quantity, that this substance, whether it be ozone or hydrogen peroxide, is destroyed by contact with organic putrescible substances, and that the fact of its presence in any particular sample of air is practically an indication of the purity of that air. The popular belief in the health-giving character of "ozoneladen" air is thus seen to possess a real foundation in fact, but not in the way it is generally supposed. The ozone is not of itself important, so far as is known, except as proof of the purity of the air from all readily oxidisable ingredients, and probably from germs of microorganisms. It has been shown that ozonised air quickly destroys germs in air. ${ }^{4}$

According to Bach ${ }^{5}$ hydrogen peroxide is present in the leaves of a large number of plants, being produced by the decomposition of carbon dioxide in presence of water by the chlorophyll of the plants. Peyru ${ }^{6}$ found that ozone (or hydrogen peroxide) was evolved from growing plants. He found that more ozone was in nearly all cases to be detected in the air over a field with a growing crop than over a fallow fie!d. He noticed that the amount of ozone was fairly con-

1 Jour. Agric. Sci., 1905, i. 280.

z Ber., 1880 [13], 1503.

3 Jour. Chem. Soc., 1878, Abstracts, 552.

${ }^{4}$ Chappuis, Jour. Chem. Soc., 1881, Abstracts, 632.

${ }^{5}$ Jour. Chem. Soc., 1895, Abstracts, 26 and 239.

${ }^{6}$ Compt. Rend., 1894, 1206 ; Jour. Chem. Soc., 1895, Abstracts, ii. 240. 
stant during the day in August, but that from 6 to 9 p.m. no ozone could be found in the atmosphere.

Determinations made by Thiérry ${ }^{1}$ on Mont Blanc showed $3 \cdot 5-3 \cdot 9$ milligrams of ozone in 100 cubic metres of air at Chamounix (1050 metres), while at the Grand Mulets (3020 metres) 9.4 milligrams per 100 cubic metres were present.

At Montsouris (Paris) the amount found was 1.9 to 4.0 milligrams per 100 cubic metres of air. It thus seems highly probable that the air from great altitudes contains more ozone or hydrogen peroxide than that near the surface of the earth.

A marked diminution in the average amount of ozone in the air at Montsouris (Paris), and Marseilles was noted during the outbreak of cholera epidemic in France in 1884, the proportion of ozone at Paris sinking from $2 \cdot 0$, the average of the same period of the previous year, to $0 \cdot 27$, while at Marseilles the diminution was from $2 \cdot 17$ to $0 \cdot 86$. This may have been caused by the prevailing wind bringing air, charged with sulphur dioxide from the cities, over the observatories. ${ }^{2}$

\section{Accidental Gaseous Constituents.}

In addition to the substances already mentioned, which may be regarded as essential constituents, the atmosphere near towns and in manufacturing districts contains other, accidental, constituents. Some of these are very prejudicial to the life of plants. Sulphur dioxide, which eventually becomes sulphuric acid, is the commonest of these harmful impurities. It is derived chiefly from the combustion of coal, though the decay of animal and vegetable matter yields small quantities of sulphuretted compounds.

The acid character of town rain is to be judged from the analyses on page 25. It is mainly on account of this acidity of the air and rain that there is difficulty and, in many cases, impossibility of growing plants in our large towns, young grasses being especially affected.

Bailey ${ }^{3}$ in 1892 described the results obtained by the examination of a large number of specimens of air collected in Manchester, Liverpool and London, with the especial object of determining the sulphur dioxide present. It was found that in clear, breezy weather less than 1 milligram of sulphurous acid per 100 cubic feet was present in the air of Manchester; but during fogs the amount sometimes rose to as high as 34 to 50 milligrams.

The chief causes which prevent or interfere with the growth of plants in towns are-

1. Diminished sunlight, often less than 50 per cent of the intensity of the light in the country.

2. The amount of sulphurous acid in the air. In heavy, calm weather the amount is often ten to twenty times that present in windy, clear weather. During fogs the amount is even greater.

3. The acidity of the rain. In Manchester often as much as seventy

1 Jour. Chem. Soc., 1897, Abstracts, ii. 253.

2 Jour. Soc. Chem. Ind., 1885, 462.

${ }^{3}$ British Association Report, 1892, 679 and 781. 
parts of sulphuric acid per million were found. It was noticed that the rime deposited on the leaves of plants during frost sometimes contained as much as 400 parts of sulphuric acid per million.

Organic matter of a readily putrescible nature is also present in air where respiration of men or animals or decay of organic matter (e.g. in marshy and malarious districts) takes place. To this organic matter, perhaps, rather than to the increased carbon dioxide and diminished oxygen, the bad effects of breathing the atmosphere of close and crowded rooms are to be ascribed. This organic matter is probably suspended, but is very finely divided.

In 1906 to 1910 , Crowther and Ruston ${ }^{1}$ examined the rain falling in and near the city of Leeds, with especial reference to the total suspended matter, acidity, sulphur as sulphur trioxide and in other forms (chiefly $\mathrm{H}_{2} \mathrm{~S}$ and $\mathrm{SO}_{2}$ ), chlorine and nitrogen (as ammonia, nitrates and in organic combination.) They also divided the suspended matter into ash, tarry matter soluble in ether, and soot.

Samples were collected from eleven stations, three, Nos. 1, 2 and 4, being in industrial parts ; two, 6 and 7, in city residential parts ; five, 3 , $5,8,9$ and 10, in suburban residential districts and one, 11, at Garforth, 7 miles to the east of the city.

Their results are briefly summarised in the following table in lb. per acre, per annum :-

\begin{tabular}{|c|c|c|c|c|c|c|c|c|c|c|c|}
\hline & \multicolumn{11}{|c|}{ Station. } \\
\hline & 1 & 2 & 3 & 4 & 5 & 6 & 7 & 8 & 9 & 10 & 11 \\
\hline Total suspended & & & & & & & & & & & \\
\hline matter & 1886 & 1565 & 1163 & 849 & 659 & 593 & 399 & 352 & 147 & 90 & - \\
\hline Ash $\quad$. & 1113 & 655 & 709 & 423 & 199 & 216 & 146 & 141 & 54 & 49 & - \\
\hline Tar & 110 & 69 & 149 & 78 & 43 & 34 & 32 & 28 & 26 & 14 & - \\
\hline Soot & 663 & 841 & 305 & 348 & 417 & 343 & 221 & 183 & 67 & 27 & - \\
\hline Free acid, as $\mathrm{H}_{2} \mathrm{SO}_{4}$ & 35 & 90 & 30 & 45 & 11 & 29 & 26 & 8 & 11 & 0 & 28 \\
\hline $\begin{array}{c}\text { Sulphur as } \mathrm{SO}_{3} \\
, \quad \text { in other }\end{array}$ & 123 & 185 & 269 & 149 & 118 & 110 & 85 & 77 & 82 & 53 & 65 \\
\hline forms & 43 & 30 & 67 & 48 & 40 & 46 & 49 & 70 & 16 & 20 & 26 \\
\hline Total sulphur & 169 & 215 & 336 & 197 & 158 & 156 & 134 & 147 & 98 & 73 & 91 \\
\hline Chlorine & 164 & 198 & 101 & 75 & 41 & 108 & 51 & 57 & 34 & 38 & 22 \\
\hline Nitrogen, as $\mathrm{NH}_{3}$ & $13 \cdot 0$ & $15 \cdot 5$ & $14 \cdot 4$ & $14 \cdot 4$ & $11 \cdot 1$ & $9 \cdot 9$ & $8 \cdot 4$ & $7 \cdot 7$ & $8 \cdot 3$ & $5 \cdot 8$ & $5 \cdot 0$ \\
\hline " as $\mathrm{NO}_{3}$ & none & none & 0.5 & $0 \cdot 3$ & $1 \cdot 1$ & $1 \cdot 0$ & 0.8 & $0 \cdot 2$ & $1 \cdot 1$ & 0.7 & $3 \cdot 2$ \\
\hline " matter. & $4 \cdot 7$ & $2 \cdot 9$ & $3 \cdot 5$ & $2 \cdot 2$ & 0.8 & $3 \cdot 2$ & $1 \cdot 6$ & $2 \cdot 3$ & $2 \cdot 1$ & $1 \cdot 3$ & $1 \cdot 1$ \\
\hline Total nitrogen & $17 \cdot 7$ & $18 \cdot 4$ & $18 \cdot 4$ & $16 \cdot 9$ & $13 \cdot 0$ & $14 \cdot 1$ & $10 \cdot 8$ & $10 \cdot 2$ & 11.5 & $7 \cdot 8$ & $9 \cdot 3$ \\
\hline
\end{tabular}

The high figures for chlorine found in stations 1 and 2 are accounted for by the salt glazing carried on at fireclay works in the neighbourhood.

Direct determinations of the average intensity of daylight (as measured by the amount of iodine set free from a dilute acid solution of potassium iodide) showed that the smoke pall over station 2 in the

${ }^{1}$ Jour. Agric. Sci., 1911, 4, 25. 
industrial portion of the city, intercepted at least 40 per cent of the daylight received at station 9 in the suburbs, and that there was a distinct correlation at stations $3,4,5$ and 7 between the light intercepted and the total suspended matter in the air. It was also shown that leaves of laurel from the smokier parts of the town, possessed very much lower assimilatory powers than similar leaves obtained from near the suburban station 9 , the figures ranging from 53 (station 5) to as low as $11 \frac{1}{2}$ per cent (station 4 ) of the assimilating power, per unit area, of the leaves from station 9. Further experiments showed that by simply cleaning the laurel leaves with a cloth, their assimilatory powers were considerably enhanced.

The acid character of the rain was shown to have a distinct and cumulative effect upon grasses, greatly diminishing the yield and.increasing the proportion of crude fibre in the product, while greatly diminishing the proportion of nitrogenous matter.

It was also noticed that acid rain had a considerable effect upon the soil, the nitrogen as ammonia being increased with increasing acidity while that as nitrates became very small and in the case of very acid water being employed, disappeared altogether. The bacteria content of the soil was also very seriously diminished by acid rain, the nitrogen-fixing organisms and the nitrifying bacteria being especially affected.

Solid Matter.-Air always contains large quantities of suspended solids, some of which consist of micro-organisms and their spores. The total number of micro-organisms in a given volume of air can be estimated by aspirating a known volume of air through a wide tube coated internally with sterilised nutrient gelatine. The tube is afterwards kept in an incubator for a few days and the number of colonies of micro-organisms can be counted. By this and other processes the air of various places has been examined bacteriologically. ${ }^{1}$ The number present varies enormously and is less at greater elevations. Thus at Norwich, 18 organisms in 10 litres of air were found near the ground, 9 at a height of $180 \mathrm{ft}$., and 7 at $300 \mathrm{ft}$. At S. Kensington it was found in 1886 that an average of 279 micro-organisms fell on each square foot of surface per minute, and that an average of 35 were present in 10 litres of air.

In air are to be found dust particles of every description, blown up from the surface of the ground and consisting of fragments of very diverse character.

In addition, air, even at considerable heights, contains solid particles of a more definite and uniform character-the minute particles left by the evaporation of the tiny droplets of the spray from the sea. Each drop of the spray loses its water by evaporation and leaves an excessively minute particle of dust, which remains suspended in the air until washed out by rain. These saline particles are naturally most abundant near the coast, as is evident from the analyses of rain-water ; but at places far inland, chlorine is to be found in rain-water, and sometimes in considerable quantities. 
Thus, Kinch ${ }^{1}$ at Cirencester, during a storm from the S.W. by W. (from the Bristol Channel) found as much as 44.79 parts of chlorine per million of rain-water. The average quantity of chlorine found in the rain at Cirencester for the fourteen years 1887 to 1900 was, during the winter (September to March) periods, 3.55 parts per million, during the summer (March to September) periods, 2.27 parts per million. This, if calculated to sodium chloride, with the average rainfalls of $14 \cdot 26$ in. and $12.78 \mathrm{in}$. respectively, corresponds to the deposition of $19.35 \mathrm{lb}$. common salt per acre during each winter and $10.40 \mathrm{lb}$. during each summer, or a total of $29.75 \mathrm{lb}$. per acre per annum. In Demerara, during the six years 1891 to 1895, Harrison found that the rain (average fall 111 in. per annum) contained an average of 4.69 parts of chlorine per million, corresponding to a total of $186 \mathrm{lb}$. sodium chloride per acre per annum. Ruston ${ }^{2}$ at Garforth, near Leeds, found an average of 3.60 parts of chlorine per million of rain during 1906-1908, corresponding, if calculated to sodium chloride, to $37 \cdot 3 \mathrm{lb}$. per acre per annum.

Rain-water thus supplies a considerable quantity of solid matter, some of which has manurial value, from the sea to the soil. At Valentia (Ireland) Smith found about 49 parts of chlorine per million; this would correspond to about 1.5 parts of lime and 1.0 part of potash per million, assuming that the chlorine was due entirely to the spray of sea-water. This would mean the deposition of the equivalent of about $5 \mathrm{oz}$. of lime and about $3 \frac{1}{2} \mathrm{oz}$. of potash per inch of rain on each acre of land. At inland places the quantities are, of course, much less, and the amount of manurial mineral matter conveyed to the soil by rain is usually so small as to be almost negligible.

Water for Irrigation Purposes.-In arid climates the composition of river water, used for irrigation purposes, is a matter of considerable importance. If saline matter, especially chlorides, be present, there is a danger of setting up a "brackish" or "alkali " condition of the surface soil, which may be very destructive to plants. Several of the South African rivers are distinctly alkaline from the presence of sodium carbonate, and to this fact is doubtless due their very muddy character and the slowness with which the suspended clay separates.

Moreover, several of the bore holes in the Transvaal yield water which contains small quantities of sodium carbonate, and this fact may have considerable influence when the water is used for irrigation.

Plants show very different degrees of tolerance to the presence of saline matter in the soil. As a rule sodium carbonate has the most deleterious effect, followed by sodium chloride, while sodium sulphate is much less harmful. In America, soils, which are "brackish" from the presence of chlorides and sulphates, are known as "white alkali" soils, while those containing sodium carbonate are called "black alkali" soils.

The following table (from American sources) gives the maximum

${ }^{1}$ Jour. Chem. Soc., Trans., 1900, 1271.

${ }^{2}$ Rep. No. 74, Univ. Leeds and Yorks Counc. Agric. Education, 1908. 
amount, in pounds per acre, of the three salts which may be present in the upper four feet of a soil without serious injury to the various plants :-

\begin{tabular}{|c|c|c|c|c|c|}
\hline & & & Sodium chloride. & Sodiun sulphate. & Sodium carbonate. \\
\hline Wheat & . & . & 1160 & 15120 & 1480 \\
\hline Barley & . & & 5100 & 12020 & 12170 \\
\hline Lucerne (o & & . & 5760 & 102480 & 2360 \\
\hline Lucerne (y & & . & 760 & 11120 & - \\
\hline Sugar beet & . & . & 5440 & 52640 & 4000 \\
\hline Salt bush & . & . & 20320 & 19240 & 3200 \\
\hline Oranges & . & . & 3360 & 18000 & 3840 \\
\hline Lemons & . & . & 800 & 4480 & 480 \\
\hline Pears & . & . & 1360 & 17800 & 1760 \\
\hline Apples & . & & 1240 & 14240 & 640 \\
\hline Grape vine & . & $\varphi^{\circ}$ & 9640 & 40800 & 7550 \\
\hline
\end{tabular}




\section{CHAPTER III.}

\section{The SolL.}

SoIL is the layer of more or less disintegrated rock which covers a large portion of the surface of the earth and which is fitted, under proper conditions of climate, to support the growth of plants. The thickness of this layer varies greatly, being mainly determined by the relative rates at which veathering (i.e., disintegration of the rock under climatic influences) and denudation (i.e., removal of the débris produced) go on under the local conditions.

In countries of temperate climate and moderate rainfall, with many rocks, these processes are so proportioned that the depth of débris over-lying the hard rock is a few feet, but obviously this depends largely upon the nature of the rock. In other places, denudation is restricted, either by the contour of the surface, the character of the rainfall or other circumstances and the layer of débris attains a great thickness. For example, in many districts in the Transvaal, the material available for the formation of soil is 30 or $40 \mathrm{ft}$. in depth. On the other hand, in mountainous districts with heavy rainfall, denudation keeps pace with weathering and little material is left from which soil can be formed. In such places the layer of soil may be only a few inches in thickness, and may rest upon hard, undisturbed rock. In limestone or chalk districts, too, where denudation consists largely in the removal of calcium carbonate in solution, the soil-forming material is often mainly confined to the siliceous or argillaceous matter present and is, therefore, small.

In addition to the mineral ingredients, which usually constitute the largest portion, all soils contain certain quantities of organic matter resulting from the decay of previous vegetable growths. Soils also contain living organisms and varying quantities of water and gases. The depth of the soil proper varies, but on cultivated land, is generally from 9 to 12 in. It rests upon the subsoil, which differs from it in being less oxidised, not so rich in organic matter, and often lighter in colour, the difference in the last respect being due partly to the subsoil being poorer in the dark-brown organic matter-humus-and partly to the iron being in a lower state of oxidation in the subsoil.

Since soil consists largely of disintegrated rock, it is evident that a knowledge of the composition of the rock beneath and of its constituent minerals is of considerable help in judging of the probable composition and character of a soil. An acquaintance, therefore, with geology and mineralogy is useful to the scientific agriculturist. 
Minerals.-The word mineral is used in several senses ; as an adjective it is often employed as synonymous with inorganic, e.g., the mineral constituents of soil or of food. As a noun, in popular language it is used as the name for any deposit which is obtained from the earth by mining - thus gold, silver, coal, and even sandstone are often spoken of as minerals. But in scientific language, as a noun, it has a more restricted meaning.

A mineral, in the sense in which the word is used by a geologist, is characterised chemically by possessing a perfectly definite molecular structure and yet showing great variation in composition. This is due to the power which similar isomorphous elements exhibit of replacing each other in a compound without altering its crystalline form or general characteristics. Thus in felspar, $\mathrm{K}_{2} \mathrm{O} \cdot \mathrm{Al}_{2} \mathrm{O}_{3} \cdot 6 \mathrm{SiO}_{2}$, as it is usually represented, the potash is almost always replaced to some extent by soda, and the mineral can be traced through all intermediate stages to albite, with the ideal composition, $\mathrm{Na}_{2} \mathrm{O}_{2} \mathrm{Al}_{2} \mathrm{O}_{3} \cdot 6 \mathrm{SiO} \cdot 2$ So, too, in calcite, which is theoretically $\mathrm{CaCO}_{3}$, traces of magnesium are invariably present, and the replacement of $\mathrm{Ca}$ by $\mathrm{Mg}$ may go on until the composition of the substance would be more correctly represented by $\mathrm{MgCO}_{3}$.

Minerals important in agriculture because of their abundance are :-

Quartz.-This is, practically, pure silica, $\mathrm{SiO}_{2}$, and is extremely abundant. It occurs in granite and many other igneous rocks. It is practically insoluble in water and so is little affected by weather. Usually, however, the other constituents of the rocks in which it occurs (e.g.; the felspar in granite, the cementing material-calcium carbonate, clay, or ferric oxide-in sandstone, etc.) disintegrate by weathering, and the quartz fragments become detached and are thus removed. Quartz, though the most abundant constituent in most soils, is of practically no value as a plant food.

$$
\begin{gathered}
\text { Felspar may be orthoclase, } \mathrm{K}_{2} \mathrm{O}_{2} \cdot \mathrm{Al}_{2} \mathrm{O}_{3} \cdot 6 \mathrm{SiO}_{2}, \\
\text { albite, } \mathrm{Na}_{2} \mathrm{O} \cdot \mathrm{Al}_{2} \mathrm{O}_{3} \cdot 6 \mathrm{SiO}_{2}, \\
\text { oligoclase, } 2\left(\mathrm{Na}_{2}: \mathrm{Ca}\right) \mathrm{O} \cdot 2 \mathrm{Al}_{2} \mathrm{O}_{3} \cdot 6 \mathrm{SiO}_{2}, \\
\text { or labradorite, }\left(\mathrm{Na}_{2}: \mathrm{Ca}\right) \mathrm{O} \cdot \mathrm{Al}_{2} \mathrm{O}_{3} \cdot 3 \mathrm{SiO}_{2} .
\end{gathered}
$$

Orthoclase, the most important of these, is very abundant, forming an essential ingredient in granite, gneiss, syenite and many other rocks. Though a hard substance, felspar is very easily decomposed by the influence of the weather. Water containing carbonic acid attacks it readily, removing the larger portion of the potash and a portion of the silica in a soluble form and leaving, eventually, a residue containing pure clay or kaolin, $\mathrm{Al}_{2} \mathrm{O}_{3} \cdot 2 \mathrm{H}_{2} \mathrm{O} \cdot 2 \mathrm{SiO}_{2}$. Clay, however, is usually contaminated with partially decomposed felspar containing still a portion of its potash. Felspar furnishes a considerable portion of the potash of a soil.

Mica, $3 \mathrm{Al}_{2} \mathrm{O}_{3} \cdot \mathrm{K}_{2} \mathrm{O} .4 \mathrm{SiO}_{2}$, always contains considerable quantities of ferric oxide, which partially replaces the alumina ; magnesia, soda and lime, also, are usually present. This, mineral occurs in many rocks, 
notably in granite and gneiss. It is disintegrated by atmospheric agencies, but not so easily as felspar. It furnishes plant food by virtue of the potash, lime and iron which it contains.

Calcium Carbonate.-This occurs in a great variety of different forms, constituting, when crystallised, the various modifications of calcite (rhombohedral) and arragonite (rhombic), and, when in the massive form, the rocks chalk, limestone and marble. As already stated, these substances contain magnesium in smaller or larger quantities, also iron, and often manganese, the metals magnesium, iron and manganese partially replacing calcium. Rocks containing calcium carbonate also invariably contain notable quantities of phosphates. Limestones thus furnish important constituents of plant food and are almost indispensable in many of the processes which go on in soils under the influence of bacteria (vide Chap. IV).

Silicates of Magnesia are also extremely abundant. Many different varieties exist, among the most common being talc and steatite, $6 \mathrm{MgO} .4 \mathrm{SiO}_{2} \cdot \mathrm{H}_{2} \mathrm{O}$ (usually containing ferrous oxide and alumina), hornblende, asbestos and augite (Mg:Ca:Fe:Mn)O. $\mathrm{SiO}_{2}$, chlorite, $4 \mathrm{Mg}\left(\mathrm{Fe}^{\prime \prime}\right) \mathrm{O} .2 \mathrm{SiO}_{2} \cdot \mathrm{Al}_{2} \mathrm{O}_{3} \cdot 3 \mathrm{H}_{2} \mathrm{O}$, and olivine, $2(\mathrm{Mg}: \mathrm{Fe}) \mathrm{O} . \mathrm{SiO}_{2}$. Many of these also contain silicate of alumina, ana ${ }^{*}$ both ferrous and ferric silicates.

Clay, in its pure form, occurs as kaolin, $\mathrm{Al}_{2} \mathrm{O}_{3} \cdot 2 \mathrm{SiO}_{2} \cdot 2 \mathrm{H}_{2} \mathrm{O}$. Common clay, however, always contains iron (replacing the aluminium) and generally some imperfectly decomposed felspar, so that it serves as a source of potash and iron to plants.

Rocks.-Any detailed account of rocks, their origin and characteristics would be out of place here; but a few words may fitly be said about the chemical composition and characteristics of a few typical soil-yielding rocks.

If we accept the nebular theory of the earth's origin, it is evident that all rocks must have been formed out of the original intensely heated matter which, ages ago, represented the earth. The greater portion of the rocks at present forming the crust has probably been through a succession of changes, at one time forming hard igneous rock, then broken down by weathering into débris, which in course of time was again consolidated into rock, in some cases to be again denuded. The rocks now found are classified in various ways by geologists. One convenient method is based upon the process by which they were formed. We thus get three principal clasşes :-

1. Igneous rocks, subdivided into (i) Plutonic. (ii) Volcanic.

2. Sedimentary rocks, subdivided into (i) Mechanically precipitated. (ii) Chemically precipitated.

3. Metamorphic rocks.

These terms are almost self-explanatory. Class 1 , generally hard and silicious, often crystalline, comprises those rocks which have been formed by solidification from a fused state ; class 2 , those formed from the fragments of previous rocks by deposition, generally under water; class 3 , rocks (generally of class 2) which have been altered in character, since their deposition, by high temperature and pressure. 
Another method of classification is based upon structure. Thus we have-

A. Crystalline rocks, e.g., granite.

B. Vitreous rocks, e.g., obsidian.

C. Colloidal rocks, e.g., silicious sinter, nodules.

D. Fragmentary rocks, e.g., sandstones, shales.

Rocks of classes A and B are generally igneous in origin (exception -certain limestones, rock salt, gypsum, etc., which may be classed as crystalline). Class $\mathrm{C}$ have probably been deposited from solution. Class D are sedimentary in origin.

Class 1 include the oldest rocks, from which probably the other rocks have been formed. Rocks of this class generally contain several minerals.

The oldest igneous rocks probably consisted mainly of silicates and silica; granite, syenite, basalt, diorite and trap, are types of such old rocks. Under the denuding influences of the weather, portions of their silicates are decomposed and the whole rock disintegrates and is carried away by running water to the sea, the alkalies (potash and soda), the greater part of the lime, and portions of the magnesia and silica being in solution, much of the silica and the silicate of alumina in suspension. In the sea and rivers the suspended matter speedily settles to the bottom, the heaviest and coarsest portion, consisting of large fragments of quartz and some felspar, mica, etc., first, then the more finely divided quartz, etc., and lastly, after a long time and only in deep water, the very finely divided clay. The dissolved matters, consisting of compounds of potash, soda, lime and magnesia, remain in solution until removed by the agency of living organisms, e.g., shellfish, coral polyps, or sea-plants.

In this way are formed accumulations in the bed of the ocean which, under pressure subsequently applied, will furnish grits, sandstones, shales and limestones respectively, the latter being mainly composed of the débris of marine crustacea. The dissolved silica is also removed by diatoms, whose silicious skeletons sink to the bottom and remain admixed with the calcareous materials.

Sedimentary rocks are thus divided into the three great classes-

1. Sandstones, grits and conglomerates, whose main ingredient is quartz, almost always mixed with some felspar and mica, and having their grains cemented together by either calcium carbonate (calcareous sandstone), clay (argillaceous sandstone), ferric oxide (ferruginous sandstone), or soluble silica (silicious sandstone).

2. Shales or clays. - These are mainly composed of kaolin, but also contain finely divided silica, particles of imperfectly decomposed felspar and often considerable quantities of ferric oxide.

3. Limestones, including chalk and magnesian limestones. Here the chief ingredient is calcium carbonate, but magnesium, silica, iron, aluminium, phosphoric acid and other substances are almost always present in varying proportions.

In addition to these are some few rocks formed in other ways. Thus, by precipitation from solution, either by loss of carbonic acid, 
when calcareous deposits such as tufa, travertine, sinter, result; or by evaporation, by which gypsum, rock-salt and the Stassfurt deposits were probably formed. Then, too, by the agency of animals, phosphatic deposits, e.g., guano coprolites and bone-earth, have been produced, while the remains of plants have given rise to the important rocks coal, lignite and peat.

Metamorphic rocks partake of the nature of both igneous and sedimentary rocks, many having been formed from the latter by chemical and physical changes produced by great pressure or high temperature. As a rule they tend to show a crystalline character and are often hard and very similar to true igneous rocks. Sandstones become changed by metamorphism into quartzites. Shales become slates or even gneiss. Limestones are converted. into marble.

\section{Formation of Solls.}

The inorganic portion of a soil is really the insoluble portion of the débris resulting from the weathering of the rock on which it rests. It is, in fact, the disintegrated rock which has not yet been carried away to the final resting-place of all products of denudation-the ocean.

By the decay of igneous rocks there result, as has already been described, the materials which, when separated according to the order in which they settle out from suspension and solution in water, would form grits, sandstones, shales and limestones. Soil formed by the decay of such a rock might be expected to have the composition of such a mixture, and to a great extent this is actually the case, except that the soluble products of denudation, viz., the carbonates of potash, soda, lime and magnesia, have been to a great extent carried off in the drainage water.

By the decay of sandstones there results a soil composed very largely of grains of silica, but generally containing, in addition, whatever fragments of other minerals there might have been in the rock, most commonly particles of felspar, mica, oxide of iron and clay. Such soils are usually light and friable and poor in the main inorganic constituents of plant food, with the exception of potash, which is sometimes sufficiently abundant because of the felspar or other potash-containing minerals present.

Shales, consisting essentially of the very plastic hydrated silicate of alumina, when disintegrated, tend to yield heavy clay soils, in most. cases sufficiently well provided with potash, but often deficient in phosphates and lime.

Calcareous rocks, including chalk, limestone and marble, are rapidly eroded by the combined action of water and carbon dioxide, their calcium carbonate being removed in solution, and the foreign bodies, e.g., flint, sand, clay and oxide of iron, left behind on the surface. It thus often happens that the surface soil on limestone is almost free from calcium carbonate and would be benefited by the application of lime. In the case of many limestone soils, the actual inorganic matter in the soil probably does not exceed 1 per cent of the amount of limestone which must have been denuded in order to leave it. 
Soils resting on the rocks from which they have been formed are known as sedentary or indigenous soils and depend, for their fertility, upon the stores of plant food present in those rocks.

Transported soils.-Many soils are produced from the decay of rocks other than those upon which they rest. The rich, alluvial soils of wide valleys contain inorganic materials which have been transported from a distance by the river and deposited there. The materials, in many cases, have been brought from various rock formations, and the resulting soil consequently possesses a greater fertility than would be shown by a soil formed exclusively of the débris of any one kind of rock.

Other means of effecting transportation are provided by glaciers. Large areas of land have, in many places, been covered with a thick deposit of débris brought from a distant source by moving ice. Such deposits are known as glacial drift and often consist of a finely divided clay matrix holding blocks of hard rock, which, in some cases, show the marks of ice scratches and have been brought from an immense distance.

Wind is sometimes a means of transporting matter from a distance and depositing it so as to form a soil. This occurs with sand near the sea coast or on the shores of large lakes, and also, over greater distances, with the ashes ejected from volcanoes.

The formation of soils is mainly brought about by the following agencies :-

1. Water.-This acts in various ways:-

(i) Mechanically. - The flow of water over a rock subjects it to slight abrasion; this is greatly increased by the pebbles and stony fragments, which are urged by the current over its surface: In this way, rapid-streams and rivers carry down large quantities of materials from high ground and deposit them in the low-lying plains, giving rise to alluvial deposits. This action becomes most evident after heavy rains, when the water becomes muddy and discoloured.

(ii) By alternate frost and thaw.-Ice, as is well known, occupies more space than the water from which it is formed. The increase in volume amounts to about 10 per cent, and the force exerted by water in freezing is almost irresistible. Indeed, freezing cannot take place without this expansion, and if it be prevented, the water remains liquid, though its temperature be reduced much below $0^{\circ} \mathrm{C}$. It is found that if an additional atmosphere of pressure be exerted upon water its freezing point is lowered by $\cdot 0075^{\circ} \mathrm{C}$. The bursting of water pipes in winter is a familiar consequence of this expansion in freezing.

In nature, the disintegration of rock is greatly aided by this action of water. During the warm part of a winter's day, the crannies and crevices of a rock may become filled with water. As the temperature falls, the water begins to freeze, at first on the outside, so that every crevice becomes stopped with a plug of ice, the still fluid water behind the plug continuing to lose heat and therefore tending to solidify. This it can only do if it can increase its bulk' by about 10 per cent. In order to 
do this it must either widen or lengthen the crevice which contains it. When the next thaw comes, the widened or deepened crevice again fills with water, and the next frost repeats the action described. This process, going on at hundreds of places on the surface of a rock, soon breaks it up into smaller fragments, and these in turn are subjected to the same action. The process is necessarily confined to the outermost layer and is only of much importance when frost and thaw alternate rapidly. Long-continued frost appears to protect rocks from weathering, the ice formed cementing the whole surface together.

The above is the generally accepted explanation of the disintegrating effect of the alternate freezing and thawing of wet rocks and soils. But the writer, from observations he has made in hilly districts and from facts that have come under his notice, is of opinion that there is another important factor to be. taken into account, viz., the forces exerted by the crystals of water, during freezing, in striving to maintain their original direction of growth. The writer has noticed that sandy surfaces near cliffs in mountainous districts are sometimes covered, after a frosty night, following wet weather, with a moss-like growth or efflorescence, consisting of fine filaments of ice, in apparently prismatic crystals. In some cases, this growth attains a height of several inches, and pebbles and fragments of gravel are lifted by it, two or three inches above the level of the ground.

Moreover, it has been shown ${ }^{1}$ that a disintegrating effect perfectly similar to that produced by the alternate freezing and thawing of water on porous earthenware can be produced by replacing the water by melted, crystallised sodium thiosulphate, $\mathrm{Na}_{2} \mathrm{~S}_{2} \mathrm{O}_{3} \cdot 5 \mathrm{H}_{2} \mathrm{O}$, which is fluid at about $50^{\circ} \mathrm{C}$. and which is denser in the solid than in the liquid state, and which therefore, unlike water, contracts very slightly in solidifying. The disintegrating effect, in this case, can only be ascribed to the forces brought into play by crystallisation. A somewhat similar effect is sometimes to be noticed with a photographic dry plate. If a gelatine plate be removed from the fixing bath and, without washing, set aside to dry, the residual sodium thiosulphate crystallises out on drying and often tears holes in the gelatine film. The expansive effect of solidification of water is probably the more potent factor in bringing about the disruption of large fragments of rock, but with the smaller fragments and with clods of clayey soil, the effect of the crystallising forces may be the more important.

(iii) As glaciers.-Glaciers have played a very important part, both in grinding and wearing down rocks into the finest powder and also in transporting the materials, in some cases for hundreds of miles. The water which issues from the snout of a glacier is always heavily laden with the finest mud, and huge heaps of débris, known as moraines, mark the successive positions of the termination of the glacier. The fine portions of the glacial deposits possess a composition similar to that of the rock from which they were formed, comparatively little chemical change having taken place in their production.

(iv) Chemically. - As already stated, many minerals, e.g., felspar, exposed to the action of water, undergo chemical changes leading to

${ }^{1}$ Cobb, Jour. Soc. Chem. Ind., 1907, 390. 
their disintegration. In many cases soluble compounds are produced and carried away in solution by the water. This is pre-eminently the case with calcium carbonate, which, though almost insoluble in pure water, dissolves readily in water containing carbon dioxide, probably because of the formation of calcium bicarbonate, $\mathrm{Ca}\left(\mathrm{HCO}_{3}\right)_{2}$. Hence it is found that all river and spring waters contain dissolved mineral matter, and in many cases calcium carbonate is the largest constituent. The action of water on felspar has already been described.

In these and in other ways, water, by its solvent properties, aids greatly in rock disintegration.

2. Air.-This also acts in several ways:-

(i) Mechanically.-In mountainous districts, high winds undoubtedly act destructively upon rocks, both by the actual pressure exerted on projecting portions and also by hurling pebbles and smaller fragments of rock against them. The results are sometimes seen in the production of fantastic forms in sandstone, produced by the erosion due to sand blown by the wind against the lower portion of a projecting rock, giving rise to an undercutting. This action, well shown at Brimham Rocks, in Yorkshire, is probably not a very important one.

(ii) Chemically.-Many rocks contain the lower oxides of metals, especially of iron. On exposure to air, such oxides combine with an additional quantity of oxygen, in so doing altering their volume and changing their colour. The change in volume, accompanied very often by falling to powder, aids in breaking up the rock. Air in the presence of water also oxidises metallic sulphides, e.g., iron sulphide, and so produces disintegration in rocks containing such compounds. The carbon dioxide of the air, acting with water, is necessary for many of the chemical changes described as being due to water.

3. Earthworms play an important part in the formation and modification of soil. Darwin ${ }^{1}$ has shown that they bring portions of the subsoil to the surface, render the soil more porous and pulverulent, and aid greatly in the conversion of vegetable refuse, leaves, etc., into humus. This they do partly by drawing dead leaves, etc., into their holes, and partly by actually passing the vegetable matter and the soil containing it through their bodies. This matter is ejected and deposited on the surface of the ground at the rate of about 10 tons to the acre per annum, burying all small objects, like stones, fragments of bones, etc., to a depth which increases at an average rate of about $\frac{1}{10}$ of an inch per year. The number of earthworms to the acre is estimated to average over 25,000 , so that the part played by them must be most important. According to Russell, ${ }^{2}$ however, the effect of earthworms in promoting decomposition of organic matter and formation of nitrates is very small, though their effect in loosening the soil is valuable. In tropical countries white ants probably perform much the same kind of work as that done by earthworms in temperate climates. In South

2 Jour. Agric. Sci., 1910, 3, 246. 
Africa, the veld in many districts is thickly studded with ant-heaps, ranging from a foot to three or four feet in height, some nearly hemispherical in shape, others columnar. The subterranean galleries of the nest extend to a depth of six or eight feet and have a considerable lateral extension. When such land is ploughed and cultivated, it is generally noted that the sites of the ant-heaps are decidedly more fertile than the surrounding soil.

Chemical examination shows that this is due to the material of an ant-heap being decidedly richer in plant food than the surrounding soil. For example, ant-heap material and the veld soil taken a few feet away, collected by the writer near Christiana, in the Western Transvaal, yielded the following figures on analysis :-

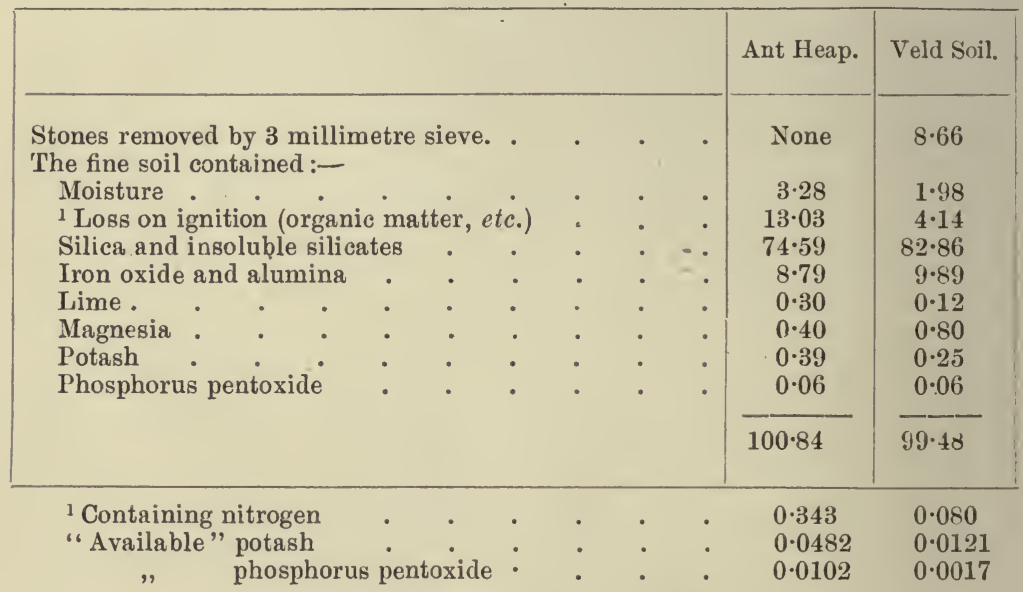

It is to be noted that the ant-heap material contains more than four times as much nitrogen, nearly four times as much "available" potash and six times as much available phosphorus pentoxide as the neighbouring soil. It is also richer in lime, magnesia and total potash.

Ant-heap material proves in practice to be very fertile, and when mixed with a little sand, or sandy soil, so as to remedy its somewhat too coherent nature, is admirable for seed beds.

4. Yegetation.-This acts in several ways :-

(i) Mechanically. - The roots of a plant penetrate the rocks or soil, rendering them porous, and so admitting air and water. Roots, indeed, are capable of exerting considerable disruptive force, as is sometimes strikingly shown by the dislocation of pavements, walls, or buildings by the growth of trees. Plants also tend to prevent the access of sunlight and air to the surface of rocks, and so favour their denudation by moisture.

(ii) Chemically. (a) During life, by the solvent action of the roots, which secrete an acid liquor capable of dissolving many constituents of rocks. (b) After death, by decaying and producing both acids of 
the type of humic acid and also carbon dioxide, which is always found in large proportion in the air of a soil. These acids have powerful solvent properties.

5. Bacteria.-As will be discussed hereafter, ordinary vegetation requires the presence of nitrogenous organic matter, "humus," in the soil, and since the main source of this organic matter is the remains of previous plants, the question naturally suggests itself-What is the first source of organic matter in the mineral débris resulting from the disintegration of rocks? According to the observations of Müntz ${ }^{1}$ the bare surfaces of the rocks, even near the summits of mountains, yield large numbers of nitrifying and other organisms which are able to withstand the lowest temperatures. Direct experiments showed that these organisms, with no other food than the mineral matter of the rocks and small quantities of ammonia and alcohol vapour in the moist atmosphere around, were able to live and produce nitrates, also to accumulate carbon. According to Winogradsky ${ }^{2}$ these organisms, by the energy liberated by the oxidation of ammonia to nitric acid, are able to obtain carbon from mineral carbonates. It is evident, if these conclusions are correct, that bacteria must play an immensely important part in initiating the formation of the indispensable humus in soils. They are equally important in carrying on the functions of a fertile soil (vide Chap. IV).

It is also to be noted that certain low forms of vegetation, e.g., lichens and algæ, are apparently able to grow.on a purely inorganic soil ; they must therefore obtain the nitrogen they require from the air, possibly by the aid of micro-organisms associated with them. Such vegetable growth furnishes humus to a soil and renders it suitable for maintaining the life of higher plants.

\section{Proximate Constituents of Soils.}

The constituents of a soil are popularly divided into four groups, an arrangement which, though perhaps not scientific, is often convenient.

These proximate constituents are :-

(i) Sand, consisting mainly of silica, but containing small fragments of felspar, mica, or even of limestone.

(ii) Clay, mainly kaolin, but also containing finely divided felspar.

(iii) Finely divided limestone.

(iv) Humus, the somewhat indefinite product resulting from the decay of organic matter in the soil.

Sand, from a chemical standpoint, is one of the least important constituents of a soil, furnishing as it does only very little of the food of plants. In fact, the essential constituents, the grains of quartz, are probably of no value whatever as plant food. The little plant food "sand" does provide is furnished by the fragments of felspar, mica, or calcium carbonate which may be present in it. From a practical point of view, however, sand is of the greatest value, because of the

${ }^{1}$ Ann. Chim. Phys. [6] 11, 136 ; Jour. Chem. Soc., 1887, Abstracts, 1135.

2 Ann. Agron. 16, 273; Jour. Chem. Sòc., 1890, Abstracts, 1180. 
effect of its presence upon the physical texture of the soil. The importance of the physical condition of a soil is apt to be overlooked by a student of chemistry, but is often even greater than that of the chemical composition. Recently much attention has been paid to a study of the physical properties of soils, and valuable information is rapidly being accumulated, especially in America and Germany. ${ }^{1}$

The terms "light" and "heavy" as applied to soils possess a meaning well known to agriculturists, referring to the ease of working and really depending upon the tenacity or cohesion and not upon relative weight. As a matter of fact, the specific gravities of "light" and "heavy" soils are just the opposite to what the terms would seem to imply, the specific gravity of quartz being 2.62 , that of clay $2 \cdot 50$, that of humus $1 \cdot 3$. However, the numbers quoted are the true specific gravities, i.e., they represent the weights of volumes of solid quartz or solid clay compared with that of an equal volume of water. The " apparent specific gravities" or the weights of given volumes of dry soil or powdered material, compared with that of the same volume ot water, are much lower, since there are air spaces between the particles of the soil or powder.

The apparent specific gravity of powdered quartz is found to be 1.449 , of clay 1.011, and of humus 0.335 while that of a good arable soil will usually be about $1 \cdot 2$, its real specific gravity being about 2.5 . Sand is thus the heaviest of the main constituents and humus the lightest.

Sand confers friability, power of draining quickly, and good conductivity for heat upon a soil ; it also has a low specific heat, consequently is soon rendered hot and cools quickly.

The specific heats of various soil constituents are given in the following table :-

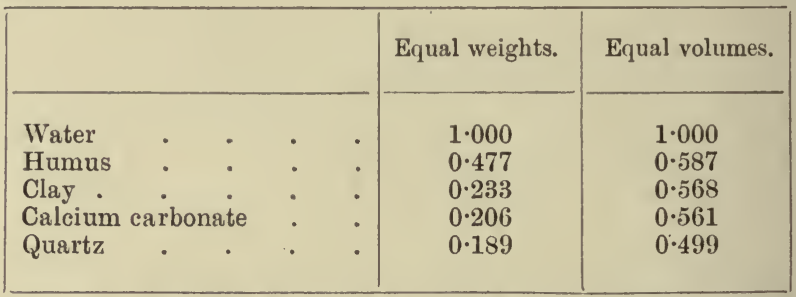

The average specific heat of a dry soil is 0.20 to 0.25 (equal weights).

The relative conductivities for heat are as follows:-

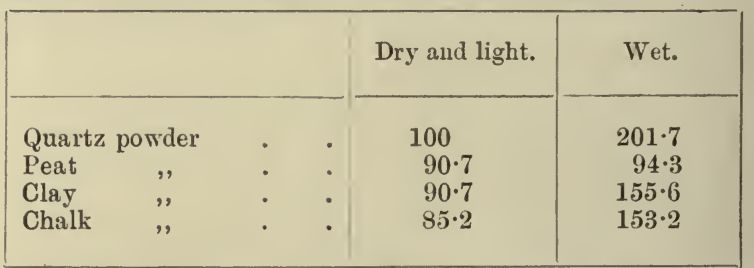

1 Vide Warington, "The Physical Properties of Soils"; Wiley, "Agricultural Analysis," Vol. I ; and King, "The Soil". 
The conductivity, however, becomes greater with an increase in the coarseness and compactness of the material, as well as with an increasing amount of moisture, since the bad conductivity of all powders is due mainly to air spaces.

The amount of water held by the constituents varies greatly; thus, 100 parts by weight

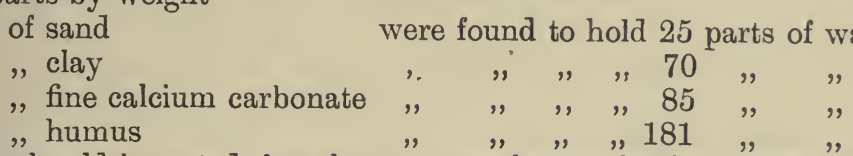

It should be noted that the amount of water held by any powdered substance varies with the fineness of its particles; very fine sand, for example, will hold more than twice as much water as a coarser sand.

It is thus apparent that sand, which in most soils constitutes by far the largest ingreaient, profoundly affects their relations to water and heat and thus their fertility.

Clay.-This term is loosely used. Sometimes, and by the agriculturist generally, it is employed to denote any earthy deposit which is free from granular matter and which possesses plasticity. In the mechanical analysis of soils, it is usually given to the smallest particles present, all with a diameter less than 002 millimetre being considered as clay, without reference to their chemical nature. Chemically, "clay," if it is given a definite meaning, refers to hydrated aluminium silicate, $\mathrm{Al}_{2} \mathrm{O}_{3} \cdot 2 \mathrm{SiO}_{2} \cdot 2 \mathrm{H}_{2} \mathrm{O}$.

Clay has characteristic physical properties which greatly affect any soil in which it forms a large constituent. As has been already stated, clay usually contains undecomposed or partially decomposed silicates, e.g., felspar, containing potash, iron and lime. It thus serves as a source of plant food. When carefully examined, it is found to consist of exceedingly fine particles, which in typical clay are kaolin $\left(\mathrm{Al}_{2} \mathrm{O}_{3}\right.$. $2 \mathrm{SiO}_{2} \cdot 2 \mathrm{H}_{2} \mathrm{O}$ ), but in common clays often partly quartz, felspar, or even (as in marls) calcium carbonate, cemented together with a colloidal form of kaolin, whose particles are so small as to escape detection even under the microscope. This colloidal or jelly-like form of clay only constitutes about $1 \frac{1}{2}$ per cent of the whole, even in stiff clays, and it is probably more hydrated than the rest of the kaolin (Schloesing). It is upon the condition of this colloidal constituent that the peculiar properties of clay mainly depend. If it be in a fully swollen condition, the clay is sticky and impervious, whereas, if it be coagulated and shrunken, the clay loses its stickiness and becomes quite workable.

If pure clay be mixed with a large quantity of distilled water a muddy liquid is obtained which shows practically no sign of depositing its suspended matter. By the addition of a small quantity of a mineral acid, of many salts, or of lime-water, coagulation of the colloidal clay occurs with complete separation as a flocculent precipitate. Salts of calcium are as good as lime-water in causing this coagulation, while 
alkaline solutions tend to favour the diffusion of the colloidal clay and will even destroy the flocculation produced by acids or salts. ${ }^{1}$

It is this action of lime or salts upon colloidal clay which causes the improvement in the texture of clay soils which is brought about by liming, also the quick settling of the clay particles when a muddy river flows into the sea, with the consequent production of deltas and bars. The waters of rivers remain muddy for a long time if deficient in lime compounds, while rivers containing very hard water soon clarify. The persistent muddiness of the waters of some rivers, even in the lower reaches, where the flow is very slow, is probably due to the presence of alkaline carbonates. Frost also produces, to some extent, the shrinkage and coagulation of colloidal clay.

Clay possesses strong retentive powers both for water and for certain soluble substances (vide Chap. IV).

It is to be noted that the characteristic properties of clay, especially its plasticity, are dependent upon its being in the hydrated condition. If the two molecules of water of hydration which it contains, be expelled by exposure to a high temperature, the clay is greatly altered in properties and does not, afterwards, take up water again. Such a permanent change is familiar to everyone in the production of bricks, tiles and earthenware of all kinds. Advantage was formerly taken of this fact in the improvement of very heavy clay soils. Large quantities of the clay were dried by exposure to air and sun, then mixed with fuel-brushwood or faggots-piled into heaps and the fuel ignited. The clay was, by this treatment, rendered anhydrous and any ferrous oxide present was converted into red ferric oxide. The resulting mass spread over the land and ploughed in, was found to exert a good influence on the physical properties of the soil. To be of much effect, however, very large dressings of burnt clay were necessary-50 to 100 tons per acre were sometimes used. The practice, because of the large amount of labour and expense involved, is now rarely adopted.

Limestone.-This term in connection with the constituents of a soil, must be taken to mean the finely divided particles of calcium carbonate, which are present, acting, perhaps, in some cases, partly as a cementing material to the quartz grains. As already stated, it furnishes plant food by virtue of the calcium, magnesium and phosphoric acid which are always present in it. Its action in the soil, however, is more important than as a mere source of plant food. It acts upon the colloidal clay in a manner already deseribed as characteristic of lime and other salts and thus modifies the physical texture of the soil. Perhaps its most important function, however, is to act as a weak base, with which acid products, formed by decomposition of the organic matter in the soil, can readily unite and by which their harmful acidity is destroyed. If such basic material be absent, the soil becomes "sour," as it is called, and unfitted for the growth of most crops. This sourness is generally due to the production of free organic acids of the humic acid type and is possessed by many peaty soils

${ }^{1}$ For a study of the comparative flocculating effects of various salts, acids, and alkalies upon colloidal clay, see Hall and Morrison, Jour. Agric. Sci., 1907, 2, 244. 
where the amount of organic matter is excessive. The acidity is often apparent in such soils by the bleaching effect they have upon the sand and gravel upon which they rest. In many cases all the iron, etc., to which the gravels and sands owe their colour, is found to be washed out by the acid drainage from the peaty soil. ${ }^{1}$ Then still more important is the part played by calcium carbonate in the process of nitrification (vide Chap. IV). Some basic material is essential for the continuance of this process, and the base is most generally found in the easily decomposable carbonate of lime or magnesia.

Calcium carbonate, owing to its ready solubility in water containing dissolved carbon dioxide and to its tendency to react with other substances produced in, or added to soils, is liable to suffer many losses or to undergo many movements and changes in soils.

It is active in the changes which accompany the application of many manures to the soil, notably so in the case of sulphate of ammonia.

Humus, the organic matter of the soil, is of great importance on account of both its physical and chemical properties.

As has already been stated, it is a light, bulky substance, having a high specific heat, great capacity for holding water, and a dark colour. This last property is of considerable importance as affecting the absorption of the sun's heat; dark soils are found to become heated much more readily by the sun than light-coloured ones, while their radjating powers, by which they are cooled at night, are practically the same, the radiation being of obscure heat, while the absorption was of the intense radiant heat.

Schloesing ${ }^{2}$ has shown that humus, or rather calcium humate, is a colloidal body possessing greater cementing power than clay in the proportion of about 11 to 1 . It is thus highly important in sandy soils as a cementing material, as well as on account of its power of retaining water. On the other hand, it has been shown that in clay, humus materially lessens the plasticity and coherence.

The chemical nature of humus is still very imperfectly known. According to Mulder, ${ }^{3}$ from 2.5 to 4.0 per cent of nitrogen is present. Many experimenters have obtained from the dark brown substance known as humus, several distinct bodies, amongst others humic acid, humin, ulmic acid, ulmin, crenic acid and apocrenic acid; but little definite knowledge is possessed of the character and composition of these acids.

Humic acid was obtained by Detmer ${ }^{4}$ by treating peat with a solution of potassium carbonate and precipitating with hydrochloric acid. After repeated purifications, an amorphous substance corres-

${ }^{1}$ Another possible explanation of this bleaching action is that the organic matter draining from the peat reduces the ferric oxide to ferrous oxide, which is converted first into carbonate and then into the soluble bicarbonate by the carbon dioxide also abundant in the drainage water.

${ }^{2}$ Compt. Rend., 74, 1408; Jour. Chem. Soc., 1872, 839.

${ }^{3}$ Annalen, 36, 243.

${ }^{4}$ Landw. Versuchs. Stat., 14, 248 ; Jour. Chem. Soc., 1872, 521. 
ponding in composition to the formula $\mathrm{C}_{20} \mathrm{H}_{18} \mathrm{O}_{9}$ was obtained; it still, however, contained 0.179 per cent of nitrogen. It is described as being soluble in 8300 parts of cold or 625 parts of boiling water, it reddens litmus, and expels carbon dioxide from carbonates, forming humates which are all insoluble with the exception of those of the alkalies.

The ammonium compound, $\mathrm{C}_{60} \mathrm{H}_{48}\left(\mathrm{NH}_{4}\right)_{6} \mathrm{O}_{27}$, is very soluble in water. With calcium chloride a compound, $\mathrm{C}_{60} \mathrm{H}_{46} \mathrm{Ca}_{3}\left(\mathrm{NH}_{4}\right)_{2} \mathrm{O}_{27}$, is precipitated. Ulmic acid is stated by Detmer to be identical with humic acid. Crenic and apocrenic acids are produced by oxidation of humic acid. The former is said to be found in moist soils, the latter in dry, loose ones. Crenic acid is said to have the composition $\mathrm{C}_{24} \mathrm{H}_{24} \mathrm{O}_{16}+3 \mathrm{H}_{2} \mathrm{O}$, apocrenic acid, $\mathrm{C}_{24} \mathrm{H}_{12} \mathrm{O}_{12}+\mathrm{H}_{2} \mathrm{O} .{ }^{1}$ The free acids are soluble in water.

In 1889, a study of the black soils of Russia was published by Kostytcheff, ${ }^{2}$ in which he found that the humus contained from 4.0 to 6.65 per cent of nitrogen, a quantity greatly in excess of that in the original vegetable matter from which it was produced (1.6 to 2 per cent). $\mathrm{He}$ found that when wet vegetable matter (hay) was allowed to decay under a bell jar, air being injected daily, the dry matter considerably diminished, but that no loss of nitrogen occurred, so that the percentage of nitrogen increased from $1 \cdot 27$ to $2 \cdot 04$. He concludes that the nitrogen in humus exists mainly as proteid bodies, very little being as amide; that both bacteria and moulds aid in the conversion of vegetable matter into humus; that if decay occurs beneath water, the vegetable structure is retained and peat results, if in air, all trace of structure is destroyed by the leaves being passed through the bodies of worms, caterpillars, etc. He states that fungi aid greatly in disseminating humus (say from a dead root) through the soil. In black earth the humic acid is almost exclusively in combination with lime.

Humic acid and the soluble humates are colloidal bodies. According to Grandeau, humic acid and the humates combine with phosphoric acid, lime, potash, oxide of iron, or silicic acid to form double compounds, which, though soluble in ammonia, do not give the reactions characteristic of their constituents. When solutions of these double compounds are submitted to dialysis, decomposition occurs and the ash ingredients pass through the membrane entirely free from the organic matter. This has, to some extent, been confirmed by Simon. ${ }^{3}$ These absorptive properties of humus for substances in solution, as well as those of clay, are of great importance in agriculture and will be considered hereafter. The alleged power of humus to absorb nitrogen from the air and convert it into ammonia, described by Simon and others, is denied by Prévost. ${ }^{4}$

Much work on the chemical nature of the organic matter of soils has been published recently, but a detailed account of these investigations cannot be given here.

\footnotetext{
${ }^{1}$ Mulder, Ann., 361, 243.

2 Jour. Chem. Soc., 1891, Abstracts, 611.

${ }^{3}$ Landw. Versuchs. Stat., 18, 452 ; Jour. Chem. Soe., 1876, 731.

${ }^{4}$ Jour. Chem. Soc., 1881, Abstracts, 371.
} 
It appears to have been demonstrated that the organic matter of soils, usually termed "humus," is highly complex in constitution, that it is closely associated or combined with certain mineral constituents of the soil, especially with portions of the potash, lime, phosphoric acid, sulphur and iron; that nitrogenous compounds are invariably present, mainly in the form of protein-like substances, ${ }^{1}$ and that it, or a nortion of it, is possessed of acid properties and can form compounds, known as humates, with bases.

A number of substances obtained from soils have been identified recently, by American investigators, especially Schreiner and Shorey, to some of which, e.g., dihydroxystearic acid and picoline carboxylic acid, powerful toxic effects upon plants are ascribed (vide Chap. IV.). But whether these substances were actually present in what may be regarded as normal "humus" or were derived from the unchanged or little changed residues from the crops recently growing in the soil, appears to the writer to be doubtful. The same remark also applies to several other substances isolated by American investigators from soils, e.g., agroceric acid, paraffinic acid, lignoceric acid, agrosterol, pentosans, xanthine, fatty glycerides and resin acids. Probably, in a soil which had just borne a crop of mustard, a careful examination would disclose the presence of allyl isothiocyanate, derived from the plant débris.

In fact, "humus" can only be regarded as a complex mixture of various decomposition products formed in the various stages of the complicated chain of reactions attending the ultimate conversion in the soil, of all the organic compounds of vegetable (and animal) tissues into the simple compounds, carbon dioxide, water and nitrates. It has thus no permanent or definite chemical composition or constitution. The more knowledge we can obtain as to the composition and functions of its various transition compounds, the better, but it is evident that at any point in the process of decay, the composition of the substance will be highly complex and must depend largely upon the nature of the original organic material from which it has been derived.

\section{Classification of Soils.}

Soils are usually divided by practical agriculturists into-

Sandy soils, containing less than 10 per cent clay and less than 3 per cent calcium carbonate.

Loams, containing from 40 per cent to 70 per cent clay and less than 3 per cent calcium carbonate.

Clay soils, containing from 70 per cent to 95 per cent clay and less than 3 per cent calcium carbonate.

Marls, containing from 5 per cent to 20 per cent calcium carbonate, the rest mainly clay.

${ }^{1}$ Suzuki (Bull. Coll. Agric., Tokio, 1907, 7, 513 ; Jour. Chem. Soc., 1908, ii. Abstracts, 127) obtained, by the action of strong hydrochloric acid on humus, various amino-acids, characteristic of the products of hydrolysis of proteids, e.g., alanine, leucine, amino-valeric acid, aspartic acid, histidine and tyrosine. Schreiner and Shorey (Jour. Biol. Chem., 1910, 8, 381) also separated various cleavage products of protein from soils. 
Calcareous soils, containing more than 20 per cent calcium carbonate.

Peaty or humic soils, containing more than 20 per cent of humus.

The terms "sand" and "clay" are here to be understood in their usual practical sense, i.e., sand refers to granular fragments, consisting chiefly of silica, but also including some felspar, mica and other silicates; clay refers to the plastic material, consisting mainly of hydrated aluminium silicate, but including also finely divided felspar, mica and even silica. Soils, intermediate in character to those mentioned above, are known by names which are self-explanatory, e.g., sandy loam, clay loam, calcareous sand.

The Colour of a Soil depends mainly upon the amount of humus and of oxide of iron which it contains and upon the quantity of moisture present. Organic matter tends to produce a black colour when moist and a grey when dry. Oxide of iron gives a yellow or reddish tint, which, however, varies with the state of hydration; if a soil is poor in organic matter and very porous, as is the case with sandy soils, although a large amount of iron may be present, the colour will not be a rich red but yellow, the iron being probably present in the state of limonite, $2 \mathrm{Fe}_{2} \mathrm{O}_{3} \cdot 3 \mathrm{H}_{2} \mathrm{O}$. The rich red,-usually taken as a sign of fertility, is produced when both oxide of iron and a considerable quantity of organic matter, and consequently moisture, are present. The oxide of iron, present as hematite, $\mathrm{Fe}_{2} \mathrm{O}_{3}$, in such cases, probably acts as a carrier of oxygen from the air to the humus and so favours its decay, even in the presence of an amount of moisture which would interfere with direct oxidation by the air.

The Odour of Soil.-When soil is moistened a peculiar odour is evolved. The cause of this was investigated by Berthelot and André in 1891. They found it to be due to a volatile substance which they were not able to isolate, but obtained in aqueous solution by distillation with water. It possesses the peculiar odour of moistened soil, is not an acid nor alkali, does not reduce ammoniacal silver nitrate, and therefore is not an aldehyde; with potassium carbonate it gives a precipitate, and with potash and iodine it yields iodoform. Its amount is extremely small. According to Berthelot and André ${ }^{2}$ clay soils kept in a moist state slowly lose nitrogen by the evolution of volatile nitrogen compounds; they also state that soils contain two classes of nitrogenous organic compounds, distinguished by their different rate of decomposition with cold potash solution.

${ }^{1}$ Compt. Rend., 112, 598; Jour. Chem. Soc., 1891, Abstracts, 858.

${ }^{2}$ Compt. Rend., 112, 195; Jour. Chem. Soc., 1891, Abstracts, 611. 


\section{CHAPTER IV.}

\section{The Reactions Occurring in Soils.}

THE chemical changes occurring in a soil are numerous and complex. To acquire a general knowledge of their nature and direction is difficult, especially as they are greatly influenced by circumstances, e.g., temperature, strength of the solution with which the soil is moistened, free or difficult access of air, and a number of other constantly varying conditions. It is therefore only possible to indicate some of the actions which take place and to describe, to some extent, the effect thereon of variations in conditions.

CHANGES IN THE INORGANIC MATTER.-The inorganic portion of the soil is subjected to the same actions of the air and water as gave rise to its formation from the original rock and which have been already considered. It is to be noted, however, that the changes probably proceed at an accelerated rate because of the larger quantity of carbon dioxide provided by the decomposing organic matter of the soil. Fragments of felspar, mica and other minerals are thus exposed to the action of air and of water rich in carbonic acid. Their disintegration and the solution of the potash, lime and magnesia which they contain thus proceed rapidly.

The reactions which occur are probably of a type which may be thus represented:-

$$
\begin{aligned}
& \mathrm{Al}_{2} \mathrm{O}_{3} \cdot \mathrm{K}_{2} \mathrm{O} \cdot 6 \mathrm{SiO}_{2}+\mathrm{CO}_{2}+10 \mathrm{H}_{2} \mathrm{O} \\
& =\underset{\text { Kaolin. }}{\mathrm{Al}_{2} \mathrm{O}_{3} \cdot 2 \mathrm{SiO}_{2} \cdot 2 \mathrm{H}_{2} \mathrm{O}} \underset{\text { Potassium carbunate. }}{+} \underset{\text { Silicic acid. }}{\mathrm{K}_{2} \mathrm{CO}_{3}+\underset{\mathrm{H}_{4}}{\mathrm{SiO}_{4}}}
\end{aligned}
$$

Also-

$$
\begin{gathered}
\mathrm{Ca}\left(\mathrm{HCO}_{3}\right)_{2}+\mathrm{Al}_{2} \mathrm{O}_{3} \cdot \mathrm{K}_{2} \mathrm{O} \cdot 6 \mathrm{SiO}_{2}+9 \mathrm{H}_{2} \mathrm{O} \\
=\mathrm{Al}_{2} \mathrm{O}_{3} \cdot 2 \mathrm{SiO}_{2} \cdot 2 \mathrm{H}_{2} \mathrm{O}+\mathrm{CaCO}_{3}+\mathrm{K}_{2} \mathrm{CO}_{3}+4 \mathrm{H}_{4} \mathrm{SiO}_{4},
\end{gathered}
$$

-the $\mathrm{CaCO}_{3}$ acting as a carrier of $\mathrm{CO}_{2}$; or if lime or magnesia be present, as in anorthite, proportionately more carbon dioxide is required :-

$$
\begin{aligned}
\mathrm{Al}_{2} \mathrm{O}_{3} \cdot(\mathrm{CaO}: \mathrm{MgO}) 2 \mathrm{SiO}_{2}+2 \mathrm{CO}_{2}+3 \mathrm{H}_{2} \mathrm{O} \\
\quad \mathrm{Anorthite} . \\
=(\mathrm{Ca}: \mathrm{Mg})\left(\mathrm{HCO}_{3}\right)_{2}+\mathrm{Al}_{2} \mathrm{O}_{3} \cdot 2 \mathrm{SiO}_{2} \cdot 2 \mathrm{H}_{2} \mathrm{O} \\
\text { Bicarbonate of lime or magnesia. Kaolin. }
\end{aligned}
$$

The calcium carbonate present in the soil also becomes soluble-

$$
\mathrm{CaCO}_{3}+\mathrm{H}_{2} \mathrm{O}+\mathrm{CO}_{2}=\mathrm{Ca}\left(\mathrm{HCO}_{3}\right)_{2}
$$

-and is either absorbed by the plant or carried away in the drainage water. 
Exactly how the phosphoric acid exists in the rocks and minerals forming a soil, it is difficult to determine. A portion probably occur's as calcium phosphate, $\mathrm{Ca}_{3} \mathrm{P}_{2} \mathrm{O}_{8}$, and undergoes a change thus :-

$$
\left.\mathrm{Ca}_{3} \mathrm{P}_{2} \mathrm{O}_{8}+2 \mathrm{CO}_{2}+2 \mathrm{H}_{2} \mathrm{O}=\begin{array}{l}
\mathrm{Ca}_{2} \mathrm{H}_{2} \mathrm{P}_{2} \mathrm{O}_{8} \\
\text { or } 2 \mathrm{CaHPO}_{4}
\end{array}\right\}+\mathrm{Ca}\left(\mathrm{HCO}_{3}\right)_{2} \text {. }
$$

The monohydrogen calcium phosphate, $\mathrm{CaHPO}_{4}$, being slightly soluble in water, is available to plants. ${ }^{1}$ It is possible, too, that the solution of calcium bicarbonate thus formed, together with that furnished by the calcium carbonate in the soil, may react upon such silicates as orthoclase and liberate their potash as carbonate, the lime uniting with the other constituents of the mineral :-

$$
\mathrm{Al}_{2} \mathrm{O}_{3} \cdot \mathrm{K}_{2} \mathrm{O} \cdot 6 \mathrm{SiO}_{2}+\mathrm{Ca}\left(\mathrm{HCO}_{3}\right)_{2}=\mathrm{Al}_{2} \mathrm{O}_{3} \cdot \mathrm{CaO} \cdot 6 \mathrm{SiO}_{2}+2 \mathrm{KHCO}_{3} \text {. }
$$

The soluble potassium salt is then either absorbed by the roots of the crop growing on the soil or held in a weak state of combination by the hydrated silicates present.

The substances which become soluble owing to the action of water, carbon dioxide and other reagents in a soil are not necessarily washed out of the soil by the drainage. The chlorides, sulphates, carbonates, and, perhaps, to a less extent the silicates, especially of lime and soda, are in great measure thus removed, the only action interfering with their complete removal being apparently the surface attraction exerted by the particles of the soil, an action similar to that exerted by charcoal towards salts in solution.

Absorption and Retention by Soils.-With the potassium and ammonium salts and with phosphoric acid, however, the case is very different. In addition to the physical absorption or adhesion alluded to (adsorption), there is a chemical retention exerted by certain constituents of soils for these substances. It can be shown by direct experiment that dilute solutions of potassium or ammonium salts or of phosphates, if filtered through a sufficiently thick layer of soil, are robbed of some of their constituents. In most cases the acids of the ammonium or potassium salts are found in the filtrate in combination with calcium.

This retentive power is apparently to be attributed mainly to the presence of hydrated silicates analogous in composition to the crystalline minerals known as zeolites (so called from their frothing, due to evolution of steam, when heated on platinum wire in the blow-pipe flame). It is, however, extremely unlikely that fragments of such minerals should exist in the soil, as they are, as a rule, easily decomposable and not very abundant in rocks. It seems more probable that the retentive substances are transition bodies produced in the weathering of such silicates as felspar and mica, and consequently that they are not permanent ingredients in the soil and are present, not in a crystalline, but in an amorphous state.

The phenomenon of the retention of certain substances by soils

${ }^{1}$ In the presence of ferric hy lrate, often present in soils, the phosphoric acid of tricalcium phosphate is, by prolonged action of carbon dioxide and water, converted into ferric phosphate, the lime being removed as carbonate.-G. v. Georgievies, Jour. Soc. Chem. Ind., 1892, 254. 
was noticed by Bronner in 1836. It was investigated in 1850 by Way, ${ }^{1}$ by Peters in 1860 , by Knop in 1868 , by Armsby in $1877,{ }^{2}$ and by Van Bemmelen in $1878 .^{3}$

It is found that when salts are applied to the soil, there is a replacement of one base by another (lime or soda from the hydrated double silicate), and that the absorbed oxide is only slightly soluble in water, more soluble in water containing carbon dioxide, and easily soluble in hydrochloric acid. The absorbed oxide can be re-exchanged by treating the soil with a solution of a salt of another metal. Alkaline hydroxides, carbonates and phosphates are absorbed without any replacement. That the zeolitic silicates are the main agents in effecting this absorption is said to be proved by-

1. Soils richest in silicates soluble in hydrochloric acid, have the greatest absorptive power.

2. Soils treated with strong hydrochloric acid, which decomposes the basic zeolites, possess practically no absorptive power for salts, though they will still absorb, without exchange of metals, alkaline carbonates and hydrates.

3. Powdered natural zeolites, e.g., chabazite, a hydrated silicate of alumina, lime and potash, have been shown to possess the power of readily exchanging their lime for other bases when treated with saline solutions.

The exact nature of the reactions by which the bases are retained has not been determined, especially as the composition of the zeolitic silicates in the soil is unknown. Assuming these substances to be analogous in composition to a mineral, stilbite, the change with potassium sulphate would be thus represented :-

$$
\mathrm{Al}_{2} \mathrm{O}_{3} \cdot \mathrm{CaO} \cdot 6 \mathrm{SiO}_{2} \cdot 5 \mathrm{H}_{2} \mathrm{O}+\mathrm{K}_{2} \mathrm{SO}_{4}=\mathrm{Al}_{2} \mathrm{O}_{3} \cdot \mathrm{K}_{2} \mathrm{O} \cdot 6 \mathrm{SiO}_{2}+5 \mathrm{H}_{2} \mathrm{O}+\mathrm{CaSO}_{4} \text {. }
$$

This reaction would in no case go to completion as represented, but equilibrium would be attained when the solution contained a certain ratio of calcium sulphate to potassium sulphate. ${ }^{4}$

Hall and Gimingham ${ }^{5}$ in 1907, investigated the retention of ammonium salts by clay and humus of soils. They found, too, that the reaction was one of double decomposition and that an equivalent to the ammonium withdrawn, of calcium, magnesium, potassium, or sodium from the zeolitic double silicates of the clay, or of calcium from calcium humate, went into solution. In no case was there any evidence of the formation of free acid.

Ferric hydrate and aluminium hydrate or hydrated basic carbonates of these metals are also present in some soils and have the power of retaining potash, lime and ammonia, and, to a still greater extent, phosphoric acid (see footnote on page 52). The bases, however, are absorbed without replacement and can be removed by prolonged washing with water. The absorption may possibly be due to the weak

1 Jour. Roy. Agric. Soc., 1850, 313.

${ }^{2}$ Amer. Jour. Sci., 14, 25.

${ }^{3}$ Landw. Versuchs. Stat., 21, 135 ; Jour. Chem. Soc., 1878, Abstracts, 598.

4 See Appəndix to this chapter for further explanation of such reactions.

${ }^{5}$ Jour. Chem. Soc., 1907, Trans. 677. 
acidic properties possessed by ferric oxide and alumina, leading to the formation of salt-like compounds analogous to spinel, $\mathrm{MgO}_{2} \mathrm{Al}_{2} \mathrm{O}_{3}$.

It must be remembered that complete absorption never occurs, but that a small proportion of the substance always remains in the solution.

The humus in a soil also possesses, in a high degree, the physical retentive power of all porous, bulky substances, and in addition it acts as an acid and forms insoluble humates with lime, magnesia, etc. It possesses great absorbent powers for ammonia. Whenever a soluble salt, particularly of a strong acid, is applied to a soil, interchange of base occurs to some extent; thus, even sodium nitrate or chloride will cause the formation of potassium or calcium nitrate or chloride by interaction with the silicates of those metals present in the soil.

Phosphoric acid is mainly retained by the uppermost layers of the soil, especially if it be applied in the form of superphosphate; with dung, some of the phosphoric acid is carried into the second or even the third 9 in. With potash, although the uppermost 9 in. contains the largest quantity of the unused fertiliser, a considerable amount penetrates to, and is retained by, the second and third 9 in. ${ }^{1}$

The Distribution of Dissolyed Matters in a soil is regulated partly by diffusion, i.e., motion of the dissolved substances without that of the water as a whole, and partly by motion of the liquid itself,

1. Diffusion is the phenomenon in which a dissolved substance passes from a greater to a less concentrated portion of the solvent. It is shown in different degrees by different substances. Colloidal bodies have the slowest rate of diffusion. The diffusibility of a salt depends partly on its acid and partly on its metal. The common acids and metals stand in the following order, starting with the most diffusible :-

Acid radicals.
Chloride
Nitrate
Sulphate
Carbonate

Acid radicals.

Nitrate

Carbonate

\author{
Metals. \\ Potassium \\ Ammonium \\ Sodium \\ Calcium \\ Magnesium
}

Diffusion is, under any circumstances, a slow process and has been shown by the experiments of Müntz and Gaudechon ${ }^{2}$ to lead to very little lateral movement of soluble manures in soils. A crystal of sodium nitrate, placed on the surface of wet soil, dissolved, but diffusion did not carry the dissolved salt laterally or vertically more than 1 in. in thirty days. Even after rain, the soluble salt was confined to a steep-sided vertical cone of soil, below the crystal.

In field trials of manures on grass land, it has been noticed that repeated applications of manure, year after year, to one plot has practi-

${ }^{1}$ Dyer, Proc. Roy. Soc., 1901, 11.

${ }^{2}$ Compt. Rend., 1909, 148, 253; Jour. Chem. Soc., 1909, Abstracts, ii. 259. 
cally no influence on the herbage beyond $1 \mathrm{ft}$. over the boundary of the plot.

2. The liquid in the soil moves from two chief reasons :-

(a) Motion due to Surface Pressure.-The motion of water in a soil, due to surface pressure, may be understood from the following considerations: The particles of a liquid exert an attraction upon each other, but this attraction is exerted only through a very short distance. If a particle, A (Fig. 1) of water, well below the surface of a mass of water, be considered, it will be seen that the attractions of other particles will be exerted equally in all directions, and it is possible to conceive of the particle being surrounded by a sphere beyond which the attraction of other particles becomes negligible. But in the

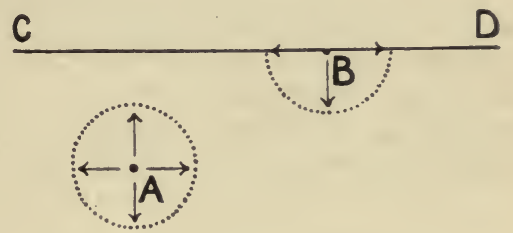

FIG. 1.-To explain surface pressure. case of a particle, $B$, on the actual surface, $C D$, of the liquid, it will be seen that there remains a resultant attraction, in a direction at right angles to the surface, pulling the particle inwards towards the mass of the liquid. Thus the surface of a liquid exerts considerable inward pressure (estimated in the case of water at ordinary temperatures to be about 1300 atmospheres). Any mass of liquid therefore tends to take up a form which hais the least surface, i.e., a sphere. But under ordinary conditions this tendency is overpowered by other forces, e.g., gravitation.

A liquid surface always assumes a form at right angles to the resultant of all the forces acting upon it. Since gravitation is usually the largest force, large masses of liquid have a truly horizontal surface. When a liquid touches a solid body, one of two things happens, either the liquid wets the solid or it does not. In the first case, e.g., with glass and water, the attraction of the solid for the liquid particles is greater than that of the liquid particles for each other; in the second, that of the liquid particles for each other than that of the solid for the liquid particles.

In the former case, the surface of the liquid near the solid is deformed and becomes concave, owing to the previously horizontal surface being pulled up the surface of the solid.

In the latter case, the liquid surface becomes convex near the solid, owing to the superior attractive force exerted by the liquid upon the particles near the solid.

In both cases, the surface remains always at right angles to the resultant of all the forces acting upon it, gravitation having added to it, near the solid, other forces, in one case directed laterally toward the solid, in the other, away from the solid.

If a tube of glass be immersed in a liquid, both the interior and exterior of the walls of the tube will be wetted and the surface of the liquid will therefore be deformed. If the tube be a narrow one, the liquid within the tube will have a concave surface, as shown in Fig. 2. 
In a concave surface the pressure exerted by the surface will be less than that exerted by a horizontal or plane surface, because each particle of liquid in the concave surface has not only the same forces acting upon it as one in a plane surface, but, in addition, the attractive forces exerted by the particles contained in the liquid surrounding it, which is above the horizontal plane passing through the particle shown in section by the black area in Fig. 2. The resultant of all these attractions will be a small upward force.

Thus while a particle, A, on a plane surface has a resultant force, which we may call $P$, acting inward upon it, a particle, $\mathrm{B}$, on a concave surface has a resultant force, $P$, of the same magnitude acting upon it inwards, but also another small force, which we may call $p$, acting outwards. The final resultant force, therefore, acting upon a particle on a concave surface is $P-p$.

As the whole free plane surface of the liquid outside the tube has

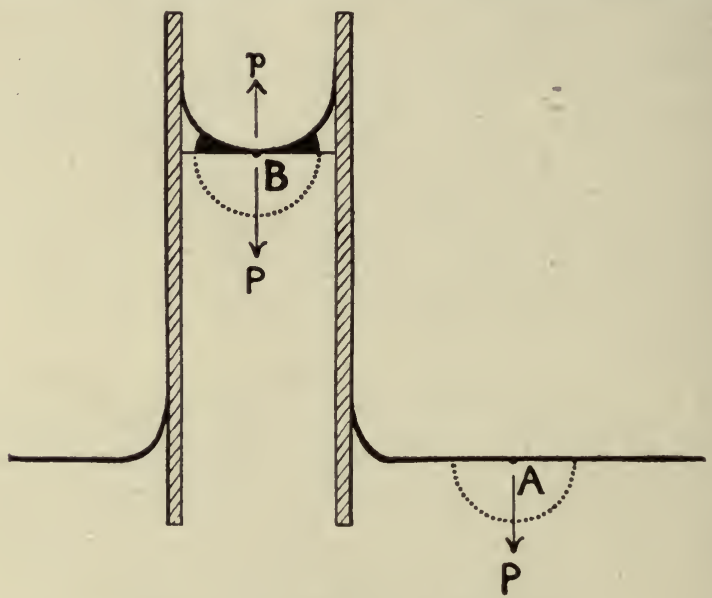

Frg. 2.-To explain true capillarity.

thus a force, $P$, acting upon each particle, it is evident that the pressure per unit area of a plane surface is greater than that of a concave surface.

OI Consequently, the water is forced up the tube until the hydrostatic pressure of the column, due to gravitation, balances $p$.

11i This is true capillarity, i.e., the phenomenon shown by hair-like tubes, and it is found that the smaller the diameter of the tube, the higher will the liquid rise within it, because then the greater is the concavity and, consequently, the greater is $p$.

By similar reasoning it can be shown that the pressure exerted by a convex surface is greater than that of a plane one.

In a soil, the movements of water, though due to similar causes (viz, surface pressure) as those which give rise to capillarity, are mainly effected in quite a different manner.

In many textbooks, it is said that the rise of water in a soil is effected by capillary tubes existing in the soil. This is, in the writer's 
opinion, erroneous, for nothing analogous to tubes filled with water exists in a fertile soil except, perhaps, in the interstices of compound particles (clods), made up of very small particles cemented together. In no case, probably, can these capillary tubes be of any great length. The particles of a soil rest upon each other, leaving interspaces, which, if the soil is to be fertile, must be filled with air. The water present in a soil exists mainly in the form of thin films surrounding the particles, but not filling the interspaces.

The rise is chiefly due to the movement of the water in these films, and is greatly facilitated and influenced by changes in the forms of the free surfaces of the water.

Let two spherical particles of soil, each coated with its thin film of liquid water, be brought into contact. At the point of contact the water films will have a concave surface, and the surface pressure will. consequently be less there than on the convex surface surrounding the particles; consequently the water will move from the films around the particles until the curvature of the concave surface becomes less, and consequently the surface pressure there becomes greater. The water will thus tend to accumulate around the points of contact of the soil particles, being held there by a surface-pressure effect similar to that which causes the rise of water in a narrow tube.

If a number of particles all wetted with water are in contact, and some of them lose water by evaporation or root absorption, the concave curvature of the surfaces of water at their points of contact will become greater, and thus the surface pressure will be locally decreased. Consequently, water will be forced from the wetter particles where the concavity of the surface is less, and where, therefore, the surface pressure is greater (see Fig. 3).

Thus water moves always towards the portion possessing the greatest concavity of surface until equilibrium is attained with gravitation or other force acting upon it.

The motion due to this cause may be upward, down-

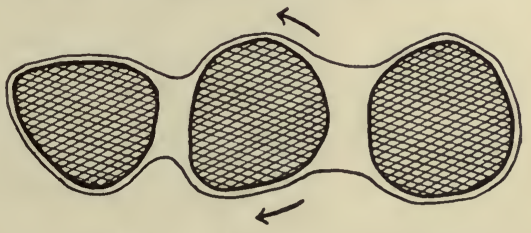

FIG. 3.-Motion of water on soil particles. ward, or lateral ; but since the greatest loss usually occurs at or near the surface, and the supply of water-the water table-is below, the upward movement is generally the most important.

In irrigation, the lateral movement is often important, and in an already moistened soil, subsequent water, e.g., rain, is carried downwards, partly by this action, though mainly, perhaps, by gravitation.

Fig. 4 represents, in a diagrammatic manner, the constitution of a soil under normal conditions. The particles of sand, etc., are represented by the shaded areas, the water present as films around the particles by black lines, the air spaces in the interstices of the soil, by white areas. Compound particles or small clods are indicated by a difference in the shading, and in these compound particles the interstices probably are sometimes completely filled with water, which, in the particle, may exhibit true capillary phenomena. The water table, i.e., the surface 
below which all the interstices of the soil are filled with water, is near the bottom of the diagram, and the thickness of the water films surrounding the soil particles gradually diminishes towards the actual surface of the soil.

The lessening of loss of water by stirring the upper layers of soil, as in "mulching," is achieved, not, as is so often stated, by "breaking the capillary tubes," which we have seen do not play an important part, but by disturbing the continuity of contact between moistened particles.

When some of the dry particles from the surface are turned under, the upward motion of the soil-water is interrupted, since, before the concave surfaces of liquid at the points of contact of the soil particles

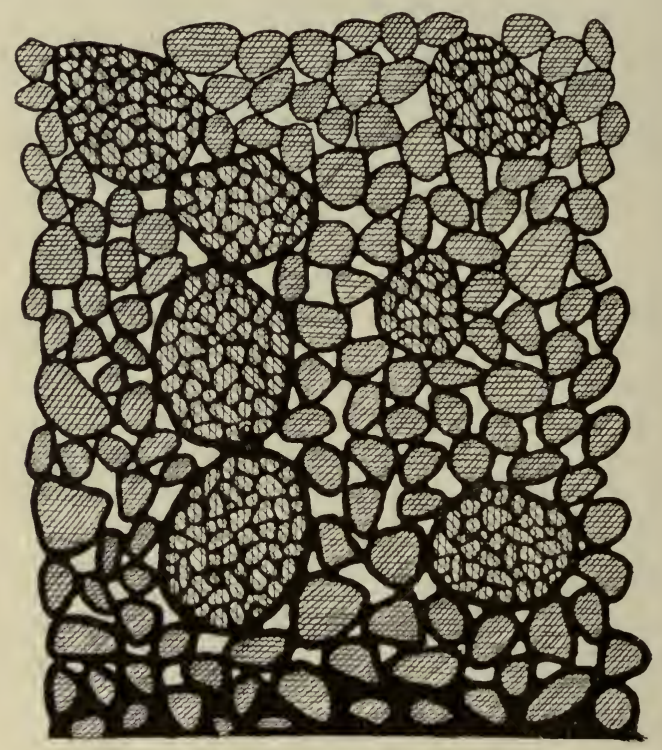

Fig. 4.-Diagrammatic section of soil.

can be established, the dry particles have to receive a liquid film. The wetting of a dry particle can only be effected by a slow, creeping movement of water, and is not aided by the effect of the concave surfaces as described.

While stirring the surface of a soil in dry weather increases for a time the rate of evaporation, the total loss of water may be greatly diminished owing to dry particles of soil impeding the upward flow of water by abolishing, for a time, the concave surfaces of the water films at the points of contact of the soil particles which are so powerful in producing the movement.

The rise of water in a soil from below is usually attended with beneficial results--the maintenance of sufficient moisture for the needs of plants in the surface soil and the concentration of the very dilute solution of plant food-but, in some cases, it produces disastrous effects. 
Where little or no drainage occurs, the continual passage downwards of rain-water and its subsequent rise and evaporation from the surface, may lead to the eventual charging of the surface soil with so much saline matter, dissolved out of the soil, that the growth of plants is prevented. We thus get "brak" or "alkali " soils.

This motion, as already stated, takes place in any direction, and may be either helped or hindered by gravitation. If, however, the interstices of a soil be completely filled with water, surface tension within the soil becomes zero and gravitation alone acts on the water.

Whitney has shown ${ }^{1}$ that nearly all dissolved mineral substances increase the surface tension, while organic bodies and ammonia diminish it.

(b) Gravitation. - This, of course, always acts in the same direction, and, as has been shown, is the only force acting on the water in a fully saturated soil. It greatly affects distribution of dissolved substances, though its tendency to cause the liquid to sink in the soil is, in many cases, overcome by the surface tension phenomenon above described.

As a rule, the motions of the water in a soil caused by the two agencies just described, overpower the diffusive tendencies of the substances in solution. Thus, in dry weather, the water from the subsoil is brought up to the soil by the surface tension effect. Evaporation and consequent concentration of the solution takes place, and the diffusive powers of the dissolved substances would tend to move them downwards to the weaker solution in the subsoil. This they undoubtedly do to some extent, but not as rapidly as the liquid moves upwards. The net result thus is, that, in dry weather, the solution of plant food in the upper layers may be more concentrated than that in the subsoil. The roots of plants are probably, therefore, often bathed in a solution of plant food much richer in dissolved matters than is the drainage water from the same soil. For description of the methods by which plants obtain their food from the soil, see Chap. XI.

Soil "Pans".-Under certain conditions the productiveness of a soil becomes seriously impaired by the formation of a hard, impervious layer, generally between the soil proper and the subsoil. Such formations are known as "pans". They are produced by mechanical or chemical processes.

A so-called "plough pan" may result from repeated ploughing to the same depth, year after year, especially on heavy land. In this case, the sliding of the base of the plough-share, together with the treading of horses and plough-men in the furrows, so consolidates the top layer of the clayey subsoil as to render it impervious.

When the subsoil is rich in calcium carbonate a "lime pan " may form, owing to solution of this compound in water containing carbon dioxide and the re-deposition, when the carbon dioxide escapes into the air, of the carbonate of lime.

Soils containing much organic matter and resting on a subsoil rich in iron compounds, sometimes form what is known as an "iron pan," some little distance below the surface. The iron compounds, being

${ }^{1}$ Weather Bureau, U.S.A., Bulletin No. 4, 13. 
reduced to the ferrous condition by the organic matter, dissolve as ferrous bicarbonate in the water of the soil; the solution on exposure to air, absorbs oxygen and deposits its iron as ferric oxide or basic ferric carbonate, forming an incrustation in the soil. Such iron pans are often very hard.

"Pans" of any kind are very objectionable and greatly diminish fertility. They interfere with drainage and with the rise of water from below, as well as proving impassable to roots. It is, therefore, necessary to break them up by subsoil ploughs or other mechanical means.

CHANGES IN THE ORGANIC MATTER.-Important as the complex and little-known changes which affect the inorganic portions of soils undoubtedly are, quite as much interest and perhaps more fruitful labour have been directed to the study of the changes undergone by the carbonaceous and nitrogenous constituents. The organic matter in a soil is continually undergoing alteration, attended by the absorption of oxygen, and the consequent evolution of heat. This heat emission becomes greater when farm-yard manure is applied to land, and in some cases has been sufficient to raise the temperature of the soil $1^{\circ}$ or $2^{\circ} \mathrm{C}$. (Wagner). The air in the interstices of a soil is always poorer in oxygen and much richer in carbon dioxide than the air above it.

It is by changes of this kind that humus is produced from vegetable fibre (vide p. 48). Other organic acids are also formed by oxidation of vegetable matter, and if the soil be deficient in basic materials these acids may exert a baneful influence (as in so-called "sour" land).

Humus itself is not a permanent substance, but is continually being oxidised and broken down in a soil, a portion of its carbon being ovolved as carbon dioxide, while its nitrogen passes eventually into the form of nitrates.

Biology of the Soil.-These chemical changes are brought about chiefly through the life processes of minute organisms existing in the soil. An ordinary soil is teeming with living beings, the majority of which belong to those lowest forms of life-bacteria, but other organisms, yeasts, moulds, algæ, larger fungi, protozoa and amœbæ are also present.

These are engaged in a perpetual struggle for existence and whenever the circumstances become favourable, are busily engaged in carrying on the chemical changes in the organic matter essential to their growth. In some cases, the processes of one set of organisms are favourable to those of others, while in others they are inimical and a fierce battle for supremacy may be going on.

It would be out of place to attempt to give here any detailed account of the micro-organisms of soil, or any reference to the methods used in investigating their nature and functions. Such matters belong to the domain of biology and bacteriology, subjects which now have extensive literatures of their own.

But the influence of the micro-organisms in a soil upon fertility is of great importance and it is advisable to consider the character of the chemical changes which are induced by their life processes and to pay some attention to the circumstances which affect their activity. 
The organisms concerned consist chiefly of protozoa and amœbæ (belonging to the animal kingdom), fungi, including moulds and yeast, bacteria and algæ.

Protozoa and amœbæ, according to Russell and Hutchinson ${ }^{1}$ are always present in soils and live on bacteria, thus keeping down the numbers of the latter. The fertility of a soil, according to this theory, depends mainly upon the number of ammonia-producing bacteria present, and this, in turn, depends upon the activity of the protozoa and amœbæ for which the bacteria serve as food. Any cause, e.g., sterilisation by heat or by antiseptics, which destroys, or diminishes the number of the protozoa, enables the bacteria to increase rapidly and thus to accelerate the production of ammonia from the nitrogenous organic matter of the soil. The investigators found that in a Rothamsted soil containing about 7,000,000 micro-organisms per gramme, heating reduced the number to about 400 per gramme, but after moistening and keeping for four days, the bacteria became as numerous as ever, and in a few more days became far more numerous than they were originally. At the same time, the rate of ammonia production in the soil enormously increased, though the conversion of ammonia into nitrites and nitrates practically ceased.

The enhanced fertility of soils induced by sterilisation is therefore due to the destruction of protozoa and amœbæ and the survival (doubtless due to spore formation) of the ammonia-producing bacteria, which, when again placed under conditions suited to active growth, increase at an enormous rate, being freed from the destructive influence of the protozoa, which in the original soil limited their number.

The fungi and yeasts act upon certain kinds of organic matter in the soil, the former using this material to build up their own structure and then, by their decay, leaving again a residue, which in many cases, appears to be more susceptible to nitrification than the original. It is to such an action of a fungus, spreading outwards from a starting point, that the existence of those richer coloured and more luxuriant circles of grass in pasture fields, known as "fairy rings," is due. ${ }^{2}$

The vital processes, too, of many of the moulds appear to be connected with important changes in nitrogenous organic matter (e.g., the formation of ammonium carbonate from proteids).

But most interesting, perhaps, are the minutest forms of life known as bacteria. These bodies are of various external forms and are often classified into some four or five groups according to their characteristic appearance. Thus there are bacilli or rod-like, spirilla or corkscrewlike, micrococci or spherical, organisms. Their size is very minute, being about $\frac{1}{1000}$ of a millimetre in diameter and rarely exceeding $\frac{4}{1000}$ of a millimetre in length. Bacteria multiply by simple fission, but many forms have the power, at intervals, of reproducing themselves in another manner, viz., by spore formation. Spores are resting states of existence and can resist treatment which would, at once, kıll the active form of the bacterium. For example, they may be dried and some even heated to $100^{\circ} \mathrm{C}$. without destroying their power of germinating under favourable conditions.

${ }^{1}$ Jour. Agric. Sci., 1909, 3, 111.

${ }^{2}$ Lawes, Gilbert and Warington, Jour. Chem. Soc., 1883, Trans., 208. 
Ordinary soils contain large numbers of different bacteria, some fulfilling useful functions in agriculture, some being destructive to plant food, and some highly injurious to animal life if they once gain admission to the proper portion of their victims (e.g., the bacterium of tetanus or lock-jaw).

Of organisms possessing the power of converting organic nitrogenous substances into ammonium compounds, a considerable number is known, some being moulds (active especially where the quantity of organic matter is large), while others are bacilli, e.g., B. mycoides and $B$. fluorescens, and micrococci, e.g., Micrococcus urea.

Nitrification.-Of organisms capable of effecting the oxidation of ammonia to nitrous acid there appears to be possibly more than one, but according to Winogradski only one is usually present in any particular soil.

The pure nitrous organism is described by Warington ${ }^{1}$ as consisting of two forms of micrococcus. One form is nearly spherical in shape and varies in diameter from the very minute up to 1 micromillimetre $(.001 \mathrm{~mm}$.). The other is oval shaped and larger, its greatest length being more than 001 millimetre.

The nitric organism isolated by Winogradski in 1890 is of very minute size, consisting of rods not more than 0005 millimetre in length and from 00017 to $\cdot 00025$ millimetres in thickness.

The conversion of nitrogen existing as organic matter or ammonium compounds into nitric acid, is a most important one and has received an immense amount of attention of late years. It is known as $n i$ trification and is effected, as indeed are probably all the changes of organic matter, through the action of micro-organisms.

The process of nitrification is an extremely important one, since in the case of the majority of plants, it is mainly in the form of nitrates that nitrogen is assimilated. The organic nitrogenous matter existing in the soil is present in various forms, which appear to differ in their susceptibility of undergoing nitrification and also in their behaviour towards alkalies and acids. ${ }^{2}$ All animal and vegetable refuse contains combined nitrogen, probably mainly in the form of proteid substances ; as these undergo putrefaction in the soil and become converted into humus, carbon dioxide is evolved, and the nitrogen is probably converted into bodies of simpler constitution, amides, ${ }^{3}$ ammonium carbonate, and in some cases free nitrogen. As has been already shown, the form in which nitrogen occurs in humus is not known. It probably exists mainly as somewhat complex compounds, possibly partly of an amide character, or as amino-acids, ${ }^{4}$ but of this little knowledge has been acquired. These organic compounds are probably broken down in the soil, yielding first, ammonium compounds, e.g. :-

${ }^{1}$ Jour. Chem. Soc., 1891, Trans., 484.

${ }^{2}$ André, Compt. Rend., 1898, 414.

${ }^{3} \mathrm{An}$ amide is a substance derived from an organic acid by the replacement of the $\mathrm{OH}$ group by $\mathrm{NH}_{2}$. Thus from acetic acid, $\left\{\begin{array}{l}\mathrm{CH}_{3} \\ \mathrm{COOH}\end{array}\right.$, is derived acetamide, $\left\{\begin{array}{l}\mathrm{CH}_{3} \\ \mathrm{CO} . \mathrm{NH}_{2} ;\end{array}\right.$ from carbonic acid, $\mathrm{CO}\left\{\begin{array}{l}\mathrm{OH} \\ \mathrm{OH}\end{array}\right.$ carbamide (urea), $\mathrm{CO}\left\{\begin{array}{l}\mathrm{NH}_{2} \\ \mathrm{NH}_{2}\end{array}\right.$.

${ }^{4}$ Sestini, Jour. Chem. Soc., 1899, Abstracts, ii. 120. 

$\mathrm{CO}\left\{\begin{array}{l}\mathrm{NH}_{2} \\ \mathrm{NH}_{2}\end{array}+\right.$
Carbamide (urea).
$\mathrm{H}_{2} \mathrm{O}$
$2 \mathrm{NH}_{3}$
$+\mathrm{CO}_{2}$
Ammonia. Carbon dioxide.

In this case, the ammonia and carbon dioxide, in the presence of water, would yield ammonium carbonate, $\left(\mathrm{NH}_{4}\right)_{2} \mathrm{CO}_{3}$. This change takes place very readily (as is shown by the smell of ammonium carbonate in stables, etc.) and is in all probability effected under the influence of a micro-organism. Indeed, according to experiments made by Müntz and Condon, and especially by Marchal, ${ }^{1}$ a large number of different bacteria and moulds are possessed of the power of converting the nitrogen of albumin into ammonia. Moulds probably do a large portion of the work in the case of manure heaps, and very peaty soils; but in ordinary arable soils, bacteria, of which Bacillus mycoides appears to be the most important, predominate. The bacterium just named is very widely distributed and constantly occurs in surface soils, in the air and in natural waters. In decomposing albumin, it produces ammonium carbonate with small quantities of formic, $\mathrm{HCOOH}$, propionic, $\mathrm{C}_{2} \mathrm{H}_{5} \mathrm{COOH}$, and butyric acids, $\mathrm{C}_{3} \mathrm{H}_{7} \mathrm{COOH}$. No hydrogen nor nitrogen is evolved in the free state. It requires the presence of oxygen, or if nitrates be present they are reduced to nitrites or even ammonia. Its action nearly ceases at $5^{\circ} \mathrm{C}$, is greatest about $30^{\circ} \mathrm{C}$, and stops at $42^{\circ} \mathrm{C}$. It acts upon other nitrogenous organic compounds, e.g., leucine, $\mathrm{CH}_{3} \cdot\left(\mathrm{CH}_{2}\right)_{3} \cdot \mathrm{CH}\left(\mathrm{NH}_{2}\right) \cdot \mathrm{COOH}$, tyrosine, $\mathrm{HO} . \mathrm{C}_{6} \mathrm{H}_{4} \cdot \mathrm{CH}_{2}$. $\mathrm{CH}\left(\mathrm{NH}_{2}\right)$. $\mathrm{COOH}$, creatine, $\mathrm{C}_{4} \mathrm{H}_{7} \mathrm{~N}_{4} \mathrm{O}_{3}$, or asparagine, $\mathrm{C}_{4} \mathrm{H}_{8} \mathrm{~N}_{2} \mathrm{O}_{3}$, but not upon urea, $\mathrm{CO}\left(\mathrm{NH}_{2}\right)_{2}$.

The ammonium salts thus formed from the nitrogenous organic matter of the soil usually quickly oxidise again under the influence of a micro-organism, with the production of nitrous acid, or rather a nitrite, and finally, by additional oxidation, a nitrate. The ultimate chemical reactions are simple :-

$$
\begin{array}{ll}
\text { (i) }\left(\mathrm{NH}_{4}\right)_{2} \mathrm{CO}_{3}+3 \mathrm{O}_{2} & =\mathrm{CO}_{2}+2 \mathrm{HNO}_{2}+3 \mathrm{H}_{2} \mathrm{O} \\
\text { (ii) } 2 \mathrm{HNO}_{2}+\mathrm{O}_{2} & =2 \mathrm{HNO}_{3}
\end{array}
$$

These changes, effected by the oxygen of the air, were shown in 1877 by Schloesing and Müntz ${ }^{2}$ to be produced only under the influence of micro-organisms. Since then the subject has been carefully studied by Winogradski, Dehérain, Warington, Frankland and many others.

The general conclusions arrived at may be stated as follows :-

1. The nitrogen of organic matter and humus is converted into nitrates by passing through the intermediate stages of ammonium compounds and nitrites, the successive steps being the work of different organisms. Karerer, ${ }^{3}$ however, states that some soils contain an organism, Bacillus nitrator, which can, in one operation, effect the conversion of ammoniacal nitrogen into nitrates. The production of ammonium compounds may be brought about by quite a number of bacteria and moulds, but the changes of nitrogen from the state of am-

${ }^{1}$ Jour. Chem. Soc., 1894, Abstracts, ii. 248.

${ }^{2}$ Compt. Rend. 84, 301 ; Jour. Chem. Soc., 1877, 215.

3 Jour. Chem. Soc., 1907, Abstracts, ii. 381. 
monia to a nitrite and from a nitrite to a nitrate are each apparently the work of only one particular organism called by Winogradski, Nitroso-monas and Nitroso-coccus, capable only of affecting the oxidation of ammonia to a nitrite, and Nitro-bacter, capable only of converting nitrites into nitrates. The simpler terms nitrous organism (of which possibly two or more species exist) and nitric organism, used by Warington, are equally distinctive.

The change from organic nitrogen to ammoniacal nitrogen is always accompanied by oxidation of carbonaceous matter and the consequent production of carbon dioxide, the formation of which probably suppl es the energy necessary for the reaction.

The other two stages of the reaction, ammoniacal nitrogen to nitrites and nitrites to nitrates, are themselves processes of oxidation and are consequently sources of energy. It is found that both the nitrous and the nitric organisms can effect their work in solutions free from organic matter and assimilate the carbon which they require for their growth from carbonates (Winogradski) or carbon dioxide ${ }^{1}$ and without the aid of sunlight. Winogradski found that on the average 35 parts of nitrogen were oxidised for each part of carbon-assimilated from carbonates. The necessary energy for this assimilation of carbon must be derived from the oxidation of the nitrogen. The oxidation of ammonia to a nitrite evolves about four times as much heat as the oxidation of the nitrite to a nitrate. Even the latter process evolves more heat than is necessary to account for the energy required in the experiments of Winogradski, 9 parts of nitrogen as nitrite oxidised to nitrate yielding sufficient energy to allow of 1 part of carbon being converted from carbon dioxide into cellulose. ${ }^{2}$

2. Nitrification can only occur under favourable conditions.

The main essentials are-

(a) Suitable food.-Certain mineral substances, particularly potash, lime, sulphates and phosphates, must be present, and carbon dioxide is also essential. Organic matter is not necessary for either the nitrous or nitric organism. Ammonium compounds appear to be most easily nitrified, but the pure nitrous organism can apparently attack certain organic nitrogenous bodies, e.g., asparagine, casein, urea.

(b) The presence of a basic material in order to combine with the nitrous and nitric acid. The medium in which the process occurs may be slightly alkaline or neutral, but acidity or much alkalinity prevents nitrification. Calcium carbonate acts very efficiently as a basic material, the carbon dioxide being easily expelled or perhaps used for the assimilation of carbon by the organisms. Sodium bicarbonate, $\mathrm{NaHCO}_{3}$, is also suitable; but sodium carbonate, $\mathrm{Na}_{2} \mathrm{CO}_{3}$, hinders or entirely prevents nitrification.

(c) Suitable temperature.-Nitrification probably ceases about the freezing point of water and it is stopped at a temperature of about $50^{\circ} \mathrm{C}$. or $55^{\circ} \mathrm{C}$. It is most active about $36^{\circ} \mathrm{C}$.

(d) Sufficient moisture.-The action is suspended if a soil be airdried.

${ }^{1}$ Godlewski, Jour. Chem. Soc., 1896, Abstracts, ii. 668.

${ }^{2}$ Warington, Jour. Chem. Soc., 1891, Trans., 521. 
(e) Absence of strong light.-Bright light, e.g., sunlight, suspends the action of and eventually destroys the organisms.

$(f)$ Presence of sufficient oxygen.-Since the process is one of oxidation it is obvious that free supplies of oxygen should be provided. Hence it cannot proceed in a waterlogged soil and is greatly increased by stirring the soil. ${ }^{1}$

(g) While the work of the nitrous organism obviously proceeds best in the presence of considerable amounts of ammonium salts, the nitric organism is rendered inactive by more than small amounts of such compounds and only produces nitrates when the ammonium compounds have, to a great extent, been destroyed by the nitrous organism. Nitrification is stopped if the amount of ammonium carbonate present exceeds 400 parts of nitrogen per million, but 1000 parts of nitrogen as ammonium chloride do not prevent the action. Warington ${ }^{2}$ found that the presence of gypsum effectively prevented the inhibitory effect of too large a quantity of ammonium carbonate by producing ammonium sulphate. The presence of gypsum would thus be advantageous in all cases where rapidly decomposing animal nitrogenous matter (e.g., urea) has to be nitrified, for it would prevent the danger of the too rapid formation of ammonium carbonate, and consequent stoppage of nitrification (or even in some cases the destruction of the nitrifying organism).

(h) The action of the nitric organism is hindered by the presence of alkalies (sodium carbonate) or by calcium chloride, but is favoured by bicarbonates and sulphates.

(i) Nitrification can be stopped by the use of certain antiseptics, e.g., chloroform or carbon disulphide vapour. It has even been suggested to employ the latter in autumn to lessen loss of nitrates by drainage from a soil. ${ }^{3}$

(k) Potash compounds added to soils rich in humus have a favouring action upon nitrification, especially if the carbonate be employed. or if calcium carbonate be simultaneously applied. ${ }^{4}$ Some of the results obtained are given below :-

$\begin{array}{lccccc}\begin{array}{c}\text { Moor soil } \\ \text { only. }\end{array} & \begin{array}{c}\text { Soil }+4.5 \\ \text { per cent } \\ \mathrm{K}_{2} \mathrm{CO}_{3} .\end{array} & \begin{array}{c}\mathrm{Soil}+2 \cdot 5 \\ \text { per cent } \\ \mathrm{CaCO}_{3}\end{array} & \begin{array}{c}\mathrm{Soil}+5 \\ \text { per cent } \\ \mathrm{K}_{2} \mathrm{SO}_{4}\end{array} & \begin{array}{c}\text { Soil }+2.5 \text { per cent } \mathrm{CaCO}_{3} \\ +5 \text { per cent } \mathrm{K}_{2} \mathrm{SO}_{4} \cdot\end{array} \\ \begin{array}{c}\text { Amount of nitric } \\ \begin{array}{c}\text { nitrogen pro- } \\ \text { duced in 20 } \\ \text { days, per mil- } \\ \text { lion. }\end{array}\end{array} & 25 & 438 & 30 & 18 \text { to } 25 & 189 \\ \end{array}$

With reference to the distribution of the nitrifying organisms, Warington found that they did not exist at greater depths than 18 inches and were most abundant within a short distance from the surface. In later experiments he found that a few nitrifying organisms were present even at a depth of several feet.

${ }^{1}$ Dehérain, Compt. Rend., 116, 1091.

2 Jour. Chem. Soc., 1885, Trans., 758.

${ }^{3}$ Dehérain, Ann. Agron., 1895, 501 ; Jour. Chem. Soc., 1896, Abstracts, ii. 329.

${ }^{4}$ Dumont and Crochotelle, Compt. Rend., 118, 604; Jour. Chem. Soc., 1894, Abstracts, ii. 248. 
Nitrogen-fixing Organisms in Soils.-Winogradski ${ }^{1}$ in 1893 obtained from soil a large bacillus which, when cultivated in a solution containing suitable mineral ingredients and pure dextrose and supplied with air purified by means of potash and sulphuric acid, caused the destruction of the dextrose $\left(\mathrm{C}_{6} \mathrm{H}_{12} \mathrm{O}_{6}\right)$, the formation of butyric acid $\left(\mathrm{C}_{3} \mathrm{H}_{7} \mathrm{COOH}\right)$, the evolution of carbon dioxide and free hydrogen, and the formation of nitric acid. The nitrogen must have been obtained from the air. Subsequent experiments of Winogradski showed that the bacillus was anærobic and if air were present could only assimilate free nitrogen by the aid of other micro-organisms which may have acted by removing the dissolved oxygen from the solution. The amount of nitrogen assimilated seems to bear some relation to the sugar consumed, but the action is greatly affected by the presence of combined nitrogen.

Cultures of an organism (known as Bacillus ellenbachensis), said to have similar properties, were made in Germany and sold under the name of "alinit". They have not been very successful in practice.

A large number of organisms, capable of effecting fixation of nitrogen from the air when supplied with mineral matter and carbohydrates, have been discovered. The most active of these appears to be Azotobacter chroococcum discovered by Beyerinck, associated with another organism known as Radiobacter. At one time the nitrogenfixation was ascribed to the simultaneous life processes of the two organisms, but it is now considered that the former alone does most of the work. ${ }^{2}$

In the presence of many carbonaceous compounds-mannitol, xylose, arabinose, dextrose, starch, sodium tartrate, calcium lactate, calcium malate, or even humus-Azotobacter can fix considerable quantities of atmospheric nitrogen, provided it be supplied with mineral nutrients and with calcium or magnesium carbonate. Ashby ${ }^{3}$ found it to be most abundant in the soil near the surface, that it withstands drying well and can be carried about as dust by wind.

It is apparently only active when the soil is well supplied with carbonaceous food, is free from acid, contains a fair supply of calcium or magnesium carbonate, and has a high temperature. Addition of sugar or starch to soil has, in some cases, been found to diminish fertility; this is attributed to the carbohydrates, in cold weather, favouring the increase of other bacteria and moulds, rather than Azotobacter. Hutchinson and Marr ${ }^{4}$ in one case noted that the application of starch and sugar increased the number of micro-organisms from 6.4 to 14.9 millions per gram of soil, and still reduced the fertility. This occurred when the carbohydrate was added in the spring, when, the temperature being low, putrefactive bacteria were more active than Azotobacter. In other experiments, when the carbohydrates were added to the warm soil, in autumn, the Azotobacter was stimulated and nitrogen fixation and consequently enhanced fertility followed.

${ }^{1}$ Compt. Rend., 116, 1385 ; Jour. Chem. Soc., 1893, Abstracts, ii. 482.

$1^{2}$ Jour. Chem. Soc., 1908, Abstracts, ii. 97 j.

3 Jour. Agric. Sci., 1907, 2, 35.

$1^{4} 7$ th Inter. Congr. App. Chem., 1909, VII, 37. 
Remy and Rösing ${ }^{1}$ have shown that the stimulative effect of humus upon the nitrogen-fixing power of Azotobacter is mainly due to the iron and silicates contained therein. They found that ferric oxide, held in solution by sugar, was very effective and that ferric silicate is also good. They attribute the beneficial effect of basic slag largely to its stimulating effect, due to this cause, upon the development of Azotobacter in the soil to which it is applied and the consequent increased fixation of nitrogen.

Another class of micro-organisms, of which various species of Clostridium afford the best type, are able, in the absence of oxygen (anærobic conditions) to effect nitrogen fixation. Such organisms are abundant in woodland soils and on the leaves of forest trees, according to Haselhoff and Bredemann. ${ }^{2}$

Keutner ${ }^{3}$ found that both Azotobacter chroococcum and Clostridium Pasteurianum were abundant in sea-water and that the former can effect nitrogen-fixation, even in the presence of an eight per cent solution of sodium chloride.

Pringsheim ${ }^{4}$ has recently found that many soils contain bacteria which are able to live at as a high temperature as $61^{\circ} \mathrm{C}$. and which can fix nitrogen in the presence of dextrose.

These nitrogen-fixing organisms elaborate from the free nitrogen of the air, nitrogenous compounds which are readily nitrified in the soil by the nitrifying organisms and thus rendered easily available to plants.

In laboratory experiments the amount of nitrogen fixed per gram of carbohydrate destroyed is small, usually not exceeding 10 milligrams, but there is evidence that in the field a much larger rate of fixation is attained. This is thought to be due to nitrification keeping pace with nitrogen-fixation in the field, thus preventing the accumulation of nitrogenous material, which, in laboratory experiments, probably limits the action of Azotobacter. Indeed, Koch and Seydell ${ }^{5}$ have shown that at first, even in laboratory experiments, the rate of nitrogen-fixation may reach as high as 50 to 60 milligrams per gram of dextrose oxidised, but that the rate soon falls off.

Henry ${ }^{6}$ proved that fallen leaves of forest trees bring about fixation of nitrogen during their decay. Hall, indeed, attributes the richness in nitrogen of virgin soil, where organic matter of the nature of carbohydrates has accumulated, largely to the activity of Azotobacter under these favourable conditions. Some remarkable examples of the great activity of Azotobacter, accompanied by nitrification, have been investigated by Headden and Sackett ${ }^{7}$ who found that in some soils in Colorado, patches of brown colour, produced by this means, were barren owing to the excessive quantities of nitrates produced.

Nitrogen-fixation through Symbiosis.-Another class of microorganisms is of great importance in agriculture, viz., those which

1 Jour. Chem. Soc., 1911, Abstracts, ii. 758.

2 Landw. Jahrb., 1906, 35, $381 . \quad{ }^{3}$ Chem. Zentr., 1905, i. 395.

${ }^{4}$ Jour. Chem. Soc., 1911, Abstracts, ii. 916.

${ }^{5}$ Centr. Bakt. Pur., 1911, ii. 31, 570. ${ }^{6}$ Bied. Zentr., 1904, 33, 795.

${ }^{7}$ Bull., 178 and 179, Agric. Exp. Stat. Colorado, 1911. 
flourish in the nodular swellings on the roots of certain leguminous plants.

The great question as to the possibility or otherwise of utilising the free nitrogen of the air has excited much attention and an enormous amount of research has been devoted to its solution. That leguminous crops apparently increased rather than diminished the amount of nitrogen in the upper part of the soil, although they contained large quantities themselves, had been observed, and use had been made of the fact in agriculture. No satisfactory explanation as to how this was effected was forthcoming until, in 1886, Hellriegel published an account of the bacteria which he found in the root nodules possessed by clover and other leguminous plants. In later papers, in conjunction with Wilfarth, ${ }^{1}$ he clearly showed that, living in these nodules were bacteria (Bacillus radicocola), which have the power of bringing about the assimilation by the parent plant of the free nitrogen of the air. From other investigations by the same chemists, and also by Nobbe and Hiltner, Schloesing and Laurent, and others, it has been proved that the various leguminosa have different bacteria, and that assimilation of free nitrogen by a plant depends upon the presence in the soil of the particular micro-organism capable of growing in symbiosis ${ }^{2}$ with it. The importance of this discovery attracted considerable attention, and pure cultures of the nodule bacteria were put on the market for application to soils which might be deficient in them. These preparations were known as nitragin and were not so successful in actual practice as had been hoped. They are, I believe, no longer commercially obtainable. This culture of Bacillus radicocola fell into disuse, but in 1903, Hiltner and Störmer ${ }^{3}$ claimed to have remedied the defects in Nobbe and Hiltner's earler preparation by supplying nourishment for the bacteria in the form of grape sugar and peptones (also milk) in the liquid to be used for cultivating the bacteria prior to the inoculation of the seed.

Moore of the U.S.A. Department of Agriculture, in 1904, also prepared these micro-organisms for distribution, and a sensational "boom" was given to the new cultures in popular magazines. He claimed that Nobbe's failure arose from the bacteria being cultivated in media too rich in nitrogen. The new preparation was sent out in the form of cotton wool, impregnated with the organisms and dried. Before use they were to be incubated for twenty-four hours in a solution containing cane sugar, magnesium sulphate and potassium phosphate, then for a further twenty-four hours with the addition of ammonium phosphate. The liquid was then used for moistening the seed and thus inoculating it. Separate cultures for various leguminous crops were prepared and largely distributed.

But the results of extended trials - under the direction of the Board of Agriculture in Great Britain and in Canada under the Canadian

${ }^{1}$ See Abstracts in Jour. Chem. Soc., 1888, 742; 1889, 640.

${ }^{2}$ By this term is meant the living together of two organisms for their mutual welfare, as distinguished from parasitism, in which one organism preys upon another to its own advantage, but to the injury of the host.

${ }^{3}$ Berichte v. Inter. Kongress for Angewandte Chemie, Berlin, 1903, 3, 799. 
Department of Agriculture-fail to show any great advantage attending the use of either the new German or the American preparation.

In South Africa, many parcels of lucerne, peas, beans, etc., have been inoculated in the Government laboratories, but, with few exceptions, very little advantage has been attained. The writer has seen many instances of leguminous plants grown without any inoculation well provided with root nodules, though where inoculated seed has been used the nodules certainly appear to be more abundant.

On the whole, the value of these preparations was not clearly marked, so that they, like their forerunner, fell into comparative obscurity.

More recently (1907) the subject was again brought into prominence by Bottomley, and for a time excited considerable popular attention, especially as it was hinted that it might be possible to cause nitrogen fixation in the roots of cereals and crops other than leguminosce, by the use of the so-called "Nitro-bacterine".

Nevertheless, Hellriegel's discovery is very important and affords a satisfactory explanation of many hitherto puzzling facts in reference to the nitrogen question. Some investigators have obtained results which show that plants other than the leguminous ones assimilate free nitrogen, but to a much less extent. ${ }^{1}$ With the exception of lupines, the author just quoted found that all the plants he tried were developed best when combined nitrogen was also supplied. In many cases the amount of free nitrogen assimilated was increased if combined nitrogen was also supplied.

Other experimenters, e.g., Lotsy, ${ }^{2}$ do not confirm the fixation of free nitrogen except in the case of leguminous crops.

According to later investigations the bacteria in the nodules of leguminous plants secrete an enzyme (i.e., a so-called unorganised or soluble ferment) and the assimilation of the atmospheric nitrogen really occurs in the leaves of the plant under the influence of the enzyme. ${ }^{3}$ That the fixation takes place in the leaves is denied by Nobbe and Hiltner, ${ }^{4}$ who found that if the nodules on the roots were kept under water, fixation of nitrogen ceased.

The symbiosis of certain moulds with the roots of heaths and some forest trees-the production of the mycorrhiza-in which the fungus prepares and hands on certain items of plant food to the host plant, is a process of a somewhat similar kind, but has not so much importance from an agricultural point of view.

Denitrification.-A chemical change involving the liberation of free nitrogen from nitrates takes place under certain circumstances in soils and in manure heaps. This process is effected by the agency of micro-organisms, several species of which appear to exist. The loss of nitrogen consequent upon this reaction is of serious importance and the subject has, of late, attracted considerable attention in France and Germany, as well as in England.

${ }^{1}$ Frank, Jour. Chem. Soc., 1892, Abstracts, 370.

${ }^{2}$ U.S. Dept. of Agric., Bull. 18, 1894.

3 Stoklasa, Jour. Chem. Soc., 1900, Abstracts, ii. 610.

${ }^{4}$ Jour. Chem. Soc., 1900, Abstracts, ii. 234. 
Bréal in $1892^{1}$ showed that straw always contains micro-organisms which, in the absence of air, can produce free nitrogen, and to a small extent organic nitrogenous compounds, from nitrates. Wagner in $1895^{2}$ by numerous experiments showed that the application of large quantities of organic manures, e.g., farm-yard manure or cow-dung, actually diminished the crop yielded by a soil, and to a great extent interfered with the increase otherwise produced by nitrate of soda. Maercker and other experimenters found similar results attended the use of farm-yard manure when used with nitrates; the manure not only did no good, but actually interfered with the action of the nitrate. The crop was both smaller and poorer in nitrogen. These results are apparently due to denitrification produced by the addition of the farm-yard manure, thus leading to the destruction of nitrates. By the German investigators, the denitrifying organisms introduced by the manure are credited with the phenomenon, but it has been pointed out by Warington ${ }^{3}$ and others that the farm-yard manure introduces into the soil another factor of importance, viz., a large increase in easily oxidisable organic matter, and this must greatly favour denitrification, both by lessening the gaseous oxygen in the soil and by actually tending to rob the nitrates of their oxygen. Nevertheless, it can hardly be denied that the micro-organisms are essential to the process, though it is not proved that there are not abundance of these actually present in soils, only waiting for favourable circumstances to perform their destructive work. Such favourable circumstances are a diminished supply of oxygen, even by consolidation of the soil, ${ }^{4}$ and an increased quantity of oxidisable carbonaceous matter.

In 1886 Gayon and Dupetit described two micro-organisms which they named Bacterium denitrificans, $a$ and $b$, which in the absence of air, effect the oxidation of organic carbonaceous matter by reducing any nitrates which may be present, nitrogen, or in some cases nitrous oxide, being evolved. In presence of air, nitrates are not reduced, but the oxidation is effected by the oxygen of the air.

Other varieties of this Bacterium denitrificans have been discovered, some obtained from soil, some found floating in the air. ${ }^{5}$ The authors just alluded to ascribe denitrification to a reaction which they thus formulate :-

$$
\underset{\text { Sugar. }}{5 \mathrm{C}_{6} \mathrm{H}_{12} \mathrm{O}_{6}}+24 \mathrm{KNO}_{3}=24 \mathrm{KHCO}_{3}+6 \mathrm{CO}_{2}+18 \mathrm{H}_{2} \mathrm{O}+12 \mathrm{~N}_{2} \text {. }
$$

This reaction is quite possible and would be attended by the evolution of heat.

Deherain ${ }^{6}$ found that the addition of starch to a soil resulted in the almost complete destruction of nitrates, but that when straw was

${ }^{1}$ Compt. Rend., 114, 681; Jour. Chem. Soc., 1892, Abstracts, 1259. 428.

2 Jour. Agric. Prat., 1895, Aug. 26 ; also Jour. Chem. Soc., 1897, Abstracts, ii.

3 Jour. Roy. Agric. Soc., 1898.

${ }^{4}$ Bréal, Ann. Agron., 1896, 32 ; Jour. Chem. Soc., 1896, Abstracts, ii. 444.

5 Ampola \& Ulpiani, Gazzetta, 1898, i. $410 . \quad{ }^{6}$ Ann. Agron., 1898, 130. 
added, even to the extent of 1 per cent of the soil, only about one third of the nitric nitrogen was lost. He suggests that the injurious effects of large additions of farm-yard manure to a soil may be largely due to the nitrification being checked, rather than to actual destruction of nitrates.

Beyerinck and Minkman ${ }^{1}$ in 1909 , confirmed the presence in soils of the denitrifying organisms isolated by Gayon and Dupetit and also found two other organisms destructive to nitrates. One of these was able to produce large quantities of nitrous oxide from nitrates. Other organisms present in soils are able to remove oxygen from nitrous oxide, setting free nitrogen. They also found an organism which could cause the interaction of a mixture of free hydrogen and nitrous oxide and utilise the energy evolved in decomposing carbon dioxide and building up complex organic nitrogenous compounds.

This has, to a great extent, been confirmed by Suzuki $^{2}$ and Lebedeff. ${ }^{3}$

Toxic Substances in Soils. - Enough has been said to show how highly complex are the processes occurring in soils, but in addition to the factors already mentioned, there are, according to American investigators (e.g., Whitney and Cameron, Schreiner and Shorey), substances which are toxic to plants, produced in soils, either by the growth of the plants themselves or by bacteria, and upon the relative scarcity or abundance of these substances, the fertility or non-fertility of a soil mainly depends.

Fletcher ${ }^{4}$ in India, supports the view that toxic substances are produced by the growth of plants in soils, while other investigators ascribe to bacteria the production of toxins, to which the non-fertility of some soils is attributed.

Soil gases.-The interstices between the particles composing a soil are usually occupied by air except when heavy rain or other cause fills them with water. This enclosed air must not be regarded às confined, but is constantly undergoing renewal by diffusion from the air above. Inasmuch as the processes going on in a soil are accompanied by, and indeed largely consist of, oxidation, it is obvious that the air within a soil will be poorer in oxygen than that of the atmosphere above. Schloesing ${ }^{5}$ in 1890 published the results of a number of analyses of air sucked out from soil from various depths. This was always found to contain only the gases of the atmosphere, no measurable amount of marsh gas or other combustible gas being detected. The general results of these determinations were-

1. The sum of the percentage amounts of carbon dioxide and oxygen is equal to 21 .

2. The amount of carbon dioxide varies very much, from about 1 per cent to as high as 8 or 10 per cent, the oxygen from 10 to 20 per cent.

${ }^{1}$ Jour. Chem. Soc., 1909, Abstracts, ii. 1043.

2 Ibid., 1911, Abstracts, ii. 916.

${ }^{3}$ Ibid., 917.

4 Jour. Chem. Soc., 1908, Abstracts, ii. 617.

${ }^{5}$ Compt. Rend., 109, 173. 
3. In general, the amount of carbon dioxide increases with the depth (up to 50 or $60 \mathrm{~cm}$.) from which the sample is collected. This is due not to diminished production near the surface, but to more rapid diffusion there.

4. Carbon dioxide is more abundant in summer and autumn than at other periods of the year.

In addition to the gases existing in the gaseous state in the interstices of the soil, considerable quantities are present in an absorbed condition. The various constituents of a soil possess very different powers of absorbing gases and vapours from the air. The table ${ }^{1}$ below gives the maximum amount of water vapour, ammonia and carbon dioxide which can be absorbed by 100 grammes of the various soil constituents at $0^{\circ}$ and from an atmosphere containing the maximum amount of the aqueous vapour, or from the pure gas, ammonia, or carbon dioxide :-

\begin{tabular}{|c|c|c|c|c|c|c|c|}
\hline \multirow[b]{2}{*}{ - } & & \multicolumn{2}{|c|}{$\begin{array}{l}\text { Aqueous vapour from } \\
\text { saturated air. }\end{array}$} & \multicolumn{2}{|c|}{ Ammonia. } & \multicolumn{2}{|c|}{ Carbon dioxide. } \\
\hline & & Grams. & $\begin{array}{l}\text { C.C. } \\
\text { (N.T.P.). }\end{array}$ & Grams. & (N.T.P.). & Grams. & $\begin{array}{l}\text { C.C. } \\
\text { (N.'T.P.). }\end{array}$ \\
\hline Quartz & • & $0 \cdot 159$ & 199 & $0 \cdot 107$ & 145 & 0.023 & 12 \\
\hline Kaolin & . & $2 \cdot 558$ & 3172 & 0.721 & 947 & $0 \cdot 329$ & 166 \\
\hline Humus . & . & $15 \cdot 904$ & 19722 & $18 \cdot 452$ & 22228 & $2 \cdot 501$ & 1263 \\
\hline Ferric hydrate. & . & $15 \cdot 512$ & 19236 & $4 \cdot 004$ & 5275 & 6.975 & 3526 \\
\hline Calcium earbonate & . & 0.224 & 278 & 0.256 & 320 & 0.028 & 14 \\
\hline
\end{tabular}

If the soil be water-logged the decomposition of the organic matter proceeds in a different way, and marsh gas, $\mathrm{CH}_{4}$, free nitrogen and other gases are evolved. Such decomposition rarely occurs in a cultivated and properly drained soil.

The Water in a Soil.-The water in a soil is present to a great extent as a liquid film enveloping the particles composing the soil. This liquid film contains the soluble matter of the soil and of its enclosed air. It consists, therefore, of a highly dilute solution of a large number of compounds. In a fertile soil it contains all the constituents of plant food (since they can only be assimilated by the plant in the soluble form) ${ }^{2}$ and generally other substances non-essential to plants, e.g., sodium and silicic acid.

The water retains the sodium chloride and sulphate originally present in the rain; but inasmuch as considerable evaporation always takes place, these substances beeome more concentrated.

The composition of the water present in a soil can be deduced from analyses of drainage water, though doubtless the former is richer in dissolved substances.

Many analyses of drainage water have been made-at Rothamsted by Warington, ${ }^{3}$ and at Grignon by Dehérain. At Rothamsted the average rainfall and drainage through $5 \mathrm{ft}$. of bare soil were as follows :-

1 Von Dobeneck, quoted by Wiley, Agric. Analysis (1894), Vol. I, 290.

${ }^{2}$ Or in some instances perhaps after being rendered soluble by the acid liquid secreted by the roots.

${ }^{3}$ Jour. Chem. Soc., 1887, Trans., 500. 


\begin{tabular}{|c|c|c|c|c|}
\hline & & & \multicolumn{2}{|c|}{ Average of 16 years, $1871-1886}$. \\
\hline & & & $\begin{array}{l}\text { Rainfall. } \\
\text { Inches. }\end{array}$ & $\begin{array}{l}\text { Drainage. } \\
\text { Inches. }\end{array}$ \\
\hline March . & . & . & $1 \cdot 58$ & $0 \cdot 66$ \\
\hline April . & . & $\dot{.}$ & $2 \cdot 32$ & 0.75 \\
\hline May & . & . & $2 \cdot 21$ & 0.54 \\
\hline June & : & 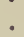 & $2 \cdot 56$ & 0.54 \\
\hline July & : & . & $2 \cdot 88$ & $0 \cdot 61$ \\
\hline August . & . & . & $2 \cdot 50$ & 0.53 \\
\hline Septembe & . & $\theta^{\circ}$ & $2 \cdot 98$ & 0.88 \\
\hline October. & . & • & $3 \cdot 39$ & $1 \cdot 71$ \\
\hline November & . & . & $3 \cdot 13$ & $2 \cdot 09$ \\
\hline December & . & . & 2.55 & 1.94 \\
\hline January. & $\dot{.}$ & • & $2 \cdot 69$ & $2 \cdot 10$ \\
\hline February & . & . & $2 \cdot 25$ & $1 \cdot 60$ \\
\hline Total, wh & year. & . & $31 \cdot 04$ & $13 \cdot 95$ \\
\hline March to & tember & 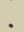 & $17 \cdot 03$ & $4 \cdot 51$ \\
\hline October to & ebruary & . & $14 \cdot 01$ & $9 \cdot 44$ \\
\hline
\end{tabular}

According to later results at Rothamsted, the average for twenty years gives-rainfall, 30 in.; drainage from uncropped land, 14 in. From a soil bearing a vigorous crop the amount of drainage is very much less (not much more than half), especially in summer, when drainage is often entirely suspended, except after very heavy rain. The composition of the drainage water will thus be altered, even if the crop does not actively exert any influence, for the dissolved matter should become more concentrated. But the plant exerts an influence in taking up and retaining much of the dissolved matter in the water, particularly the nitrates.

The average amount of chlorine in rain-water at Rothamsted is about 2.0 parts per million. In drainage water from 60 in. of bare soil (equal, as is shown in the table just given, to not quite half the rainfall) the average amount is 3.9 parts per million and is very constant. Nitrogen as nitrates in drainage water from the same soil varied from about 10 in winter to about 14 parts per million in summer, the yearly average being 107 , or a loss of about $40 \mathrm{lb}$. per acre per annum. From unmanured wheat land, the drainage water contained as the average for the whole year 6.0 parts per million of chlorine and $3 \cdot 4$ parts per million of nitrogen as nitrates, the latter varying from $4 \cdot 3$ in winter to $0 \cdot 1$ in summer.

In manured (farm-yard) wheat land the average numbers were $7 \cdot 3$ for chlorine and 5.8 for nitrogen.

From these numbers it appears that at Rothamsted the amount of chlorine in the drainage water is almost exactly equal to that supplied in the rain. From the results of a large number of analyses of drainage water and well waters, Warington concludes that 4.4 parts of nitrogen as nitrates per million is the average proportion in the drainage from cultivated land in the Rothamsted district. 
Dehérain's experiments were commenced in 1892. His method of observation was to use 20 large water-tight cases 2 metres square and 1 metre deep, each holding 4 cubic metres, or about 5 tons of soil. These were filled with soil and subsoil. Access was provided to one side by means of a sunk path, so that the drainage water could be collected from the bottom of the cases. The results obtained during the first year were probably untrustworthy because of the increased nitrification due to the trituration and aeration of the soil in filling the cases Reports as to the results are published annually in the "Annales Agronomiques". The Grignon soil is rich in organic matter and capable, if moist, of yielding large quantities of nitrates.

In the year March, 1896 to March, 1897, the results which follow were obtained. ${ }^{1}$

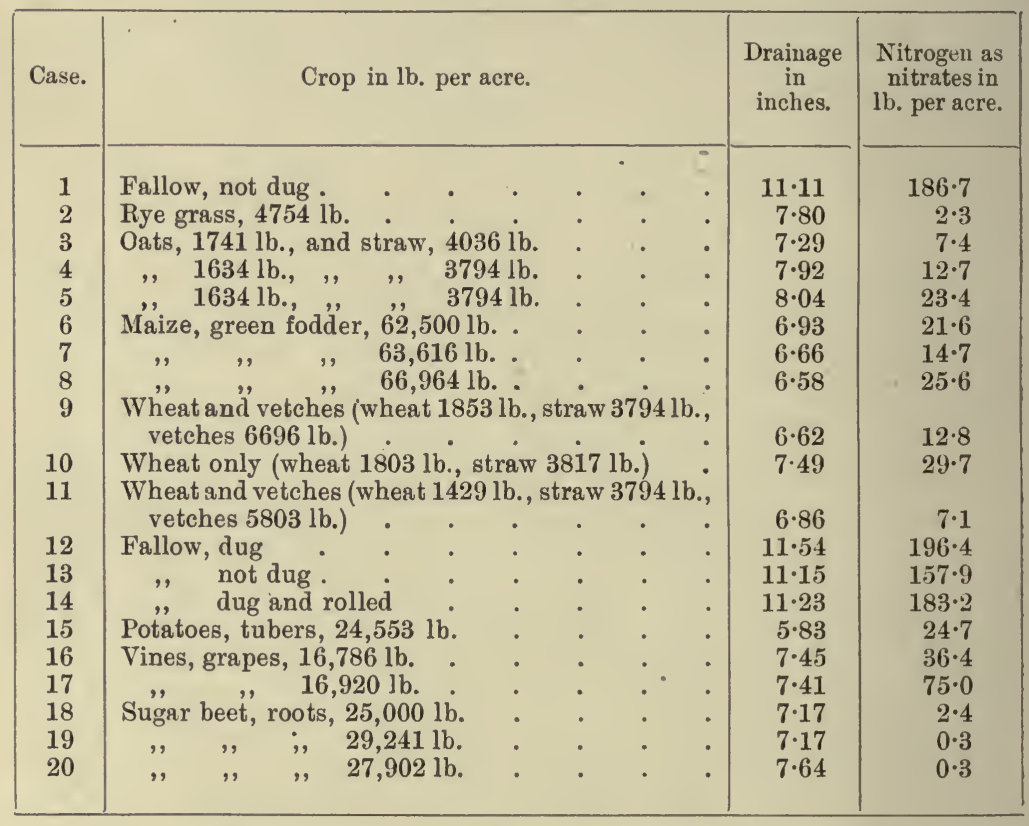

The effect of vegetation in checking the loss of nitrates is clearly evident in these results. This it does in several ways: (i) By actually absorbing the nitrates; (ii) by lessening the amount of drainage by increasing the evaporation; and (iii) in checking nitrification by rendering the soil too dry. This last effect is most marked when the period of most active growth corresponds with a dry portion of the year and is least evident when rain is abundant during that period. [Compare the results with maize (with late development)the crop of which is estimated to contain $156 \mathrm{lb}$. nitrogen per acre ; this added to $20 \mathrm{lb}$., the amount lost in drainage, gives $176 \mathrm{lb}$.

${ }^{1}$ Jour. Chem. Soc., 1897, Abstracts, ii. 591. 
nitrogen per acre (almost equivalent to that produced on fallow) with those with wheat (case 10), early growth during somewhat dry period; the crop is here estimated to contain $54.5 \mathrm{lb}$. nitrogen per acre, which, added to the amount lost in drainage, $29 \cdot 7 \mathrm{lb}$., makes a total for amount of nitrogen converted into nitrates of only $84 \cdot 2 \mathrm{lb}$.; less than half that produced on the fallow cases.]

With reference to the loss of other constituents in drainage waters, Stoklasa ${ }^{1}$ has determined the amount of calcium carbonate in drainage waters from soils derived from primitive rocks, from chalk, and from peaty soils. He estimates the yearly loss of calcium carbonate in soils from primitive rocks at over 560 kilos per hectare (500 lb. per acre) ${ }^{2}$ and at about 3000 kilos per hectare (2700 lb. per acre) in soils from chalk. Its amount is increased by the application of ammonium compounds, owing to the acid of these salts being converted into calcium salts by interaction with calcium carbonate, and also to the formation of the very soluble calcium nitrate from nitrification. He also gives the amounts of phosphoric acid found in the drainage water from (1) loam from granite and gneiss formations, (2) clay from the Permian, (3) marl, (4) humic soil. The results were as follows :-

\begin{tabular}{|c|c|c|c|c|}
\hline 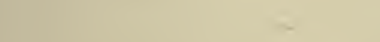 & Loamy soil. & Clay soil. & Marl. & Humic soil. \\
\hline $\begin{array}{l}\text { Total } \mathrm{P}_{2} \mathrm{O}_{5} \text { in soils } \\
\mathrm{P}_{2} \mathrm{O}_{5} \text { in drainage, per million } \\
\text { Estimated loss, lb. per acre. }\end{array}$ & $\begin{array}{c}0 \cdot 024 \\
0 \cdot 620 \\
12 \cdot 00\end{array}$ & $\begin{array}{l}0 \cdot 087 \\
0 \cdot 420 \\
8 \cdot 13\end{array}$ & $\begin{array}{c}0 \cdot 125 \\
0 \cdot 700 \\
13 \cdot 60\end{array}$ & $\begin{array}{l}0.008 \text { per cent } \\
1 \cdot 010 \\
19 \cdot 60\end{array}$ \\
\hline
\end{tabular}

This shows the enormous loss of phosphoric acid from humic soils, although they contain only very small quantities. This great loss is doubtless due to the solvent action of the large quantities of carbon dioxide contained in the drainage of such soils.

Hall ${ }^{3}$ estimates the annual loss of calcium carbonate from an arable, unmanured soil containing 1 per cent of this substance, at 800 to $1000 \mathrm{lb}$. per acre; the loss is increased by the use of ammonium salts but diminished by application of sodium nitrate.

Few determinations of the amount of potash in drainage waters have been published.

Its amount is probably always very small and the loss of potash from this cause is seldom a matter of much importance. Any potasb which becomes soluble, or is applied in a soluble form as manure, appears to be, to a great extent, held firmly in the upper layers of the soil. ${ }^{4}$

On the other hand, American investigators found as much as from 0.43 to 44.0 parts of potash $\left(\mathrm{K}_{2} \mathrm{O}\right)$ in a million of drainage water. ${ }^{5}$

${ }^{1}$ Landwirth. Versuchs. Stat., 1894, 45, 161.

2 Lawes, Gilbert and Warington (Jour. Roy. Agric. Soc., 1882, 1), estimate the loss at about half this at Rothamsted, on unmanured land.

${ }^{3}$ Brit. Ass. Report, 1905, sect. B.

${ }^{4}$ H. Liebig, Jour. Chem. Soc., $1872,318$.

5 Massachusetts State Station Report, 1883, p. 27. 
Way found from 0.3 to 3.1 parts $\mathrm{K}_{2} \mathrm{O}$ and up to 1.7 parts $\mathrm{P}_{2} \mathrm{O}_{5}$ per million of drainage water. ${ }^{1}$

Schloesing ${ }^{2}$ states that the amount of phosphoric acid in the water impregnating soils is usually about 1 milligram per litre, but sometimes is as much as 2 or 3 milligrams.

The composition of drainage water naturally varies with many circumstances, e.g., rainfall. Complete analyses have not recently been published. The average of aualyses by Way (1856), Kröcker (1853), and Zöller (1857) gave the following:-

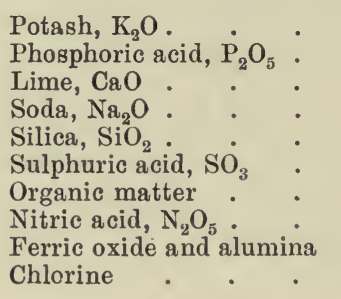

$$
\begin{aligned}
& \text { Parts per million. } \\
& \text { - } 2 \text { to } 60 \\
& \text { traces to } 2 \\
& 68 \text { to } 180 \\
& \text { - } 5 \text { to } 46 \\
& \text { - } 5 \text { to } 25 \\
& .18 \text { to } 130 \\
& \text {. } 16 \text { to } 180 \\
& \text { - } 2 \text { to } 210 \\
& 0.7 \text { to } 7 \\
& \text { - } 1 \text { to } 57 \\
& \text { Total solids (average) } 365
\end{aligned}
$$

In conclusion, it may be useful to summarise the chief sources of gain and loss of nitrogen to soils, apart from the agriculturists' efforts.

The chief sources of gain are-

(1) The ammonium compounds and nitric acid brought down in the rain (see Chap. II).

(2) Gaseous ammonia absorbed from the atmosphere by the soil constituents. This is probably a comparatively unimportant source.

(3) Compounds of nitrogen (chiefly nitric acid, probably) formed by micro-organisms existing in the soil itself, air furnishing the necessary nitrogen and oxygen.

(4) Similar compounds produced by the micro-organisms (or by the enzymes resulting from them) frequenting the tubercles or nodules on the rootlets of leguminous plants.

(5) The products of the nitrification of organic compounds already present in the soil. This is also the work of micro-organisms, and is often limited by the abundance and activity of protozoa present, which feed upon the ammonia-forming bacteria.

(6) The small quantity of nitrogenous matter (in solution or suspension) brought in occasionally by flood water, and its subsequent nitrification, if necessary.

While the losses are chiefly due to-

(1) Denitrification-the liberation of free nitrogen or of nitrous or nitric oxide from the nitrogen compounds. This is due to the action of micro-organisms in the absence of oxygen and therefore occurs most readily in soils rich in decaying carbonaceous matter, or partially water-logged.

이 (2) In the drainage water, by which nitrates and, to a much less

1 Jour. Roy. Agric. Soc., 1856, 133.

${ }^{2}$ Compt. Rend., 127, 236 ; Jour. Chem. Soc., 1899, Abstracts, ii. 119. 
extent, ammonium compounds and organic nitrogenous substances are carried away.

(3) By volatilisation of ammonia or ammonium carbonate resulting from the decomposition, under the action of organisms, of nitrogenous organic matter. Owing to the solubility of ammonia in water and the ease with which it is absorbed by humus and other ingredients, this loss is probably of. small consequence. It is, doubtless, greatest in hot weather and in dry soils.

\section{Appendix to Chapter IV.}

The chemical changes occurring in a soil take place between substances in highly dilute solution, and it is probable that considerable help might be afforded by the application of Arrhenius's electrolytic dissociation theory of solution to such problems.

It would be out of place to attempt complete exposition of this theory here, but it may perhaps be advisable to very briefly mention the chief conceptions contained in it.

When a compound capable of undergoing electrolysis in aqueous solution is dissolved in water, the mere act of solution is accompanied by its partial or complete dissociation into ions, as the metal and acid radical are called. Thus in a solution of common salt there are a number of molecules of $\mathrm{NaCl}$, but if the solution be dilute the greater portion of the salt exists as free ions of sodium and chlorine, the ions consisting of atoms (in this case) each carrying a charge of electricity, positive in the case of the metal, negative in the case of the halogen. The degree of dissociation, i.e., the proportion of the total quantity of salt which thus undergoes "ionisation," increases with the dilution.

The chemical changes which may ensue when two solutions are mixed are dependent upon the action of the ions upon each other. Thus, if to a dilute solution of $\mathrm{NaCl}$ a solution of silver nitrate be added, we get a precipitate of silver chloride, because this substance, being insoluble in water, cannot undergo ionisation. The action which occurs is to be regarded thus: Both solutions contain chiefly ions, the one $\stackrel{+}{\mathrm{Na}}$ and $\overrightarrow{\mathrm{Cl}}$, the other $\stackrel{+}{\mathrm{Ag}}$ and $\overrightarrow{\mathrm{NO}}_{3}$. On mixing the solution a precipitate of insoluble $\mathrm{AgCl}$ separates owing to the union of the $\mathrm{Ag}$ and $\mathrm{Cl}$ ions, and the solution now contains not $\mathrm{NaNO}_{3}$, as is usually taught, but really ions $\stackrel{+}{\mathrm{Na}}$ and $\overline{\mathrm{NO}}_{3}$. On evaporation these ions unite and form $\mathrm{NaNO}_{3}$, which may be obtained in crystals. All the changes which take place when aqueous solutions of salts are mixed are to be thus represented. The most difficult conception in connection with the theory is that the ions have not the usual properties of the free substances themselves (which in many cases could not exist in contact with water), but, because of their electrical charges, are utterly different. When the electrical charge is removed, as by electrolysis, the ions disappear and the material of which they are composed takes its usual properties.

Thus, to consider common salt solution, the Na ions possess none 
of the properties of sodium nor the $\mathrm{Cl}$ ions any of those of chlorine; but when a current of electricity is passed the Na ions are freed from their charge and metallic sodium is set free at one pole (cathode), and, being in contact with water, at once reacts, giving free hydrogen and caustic soda, while at the other pole (anode) the $\mathrm{Cl}$ ions lose their charge of negative electricity and are evolved as chlorine gas.

When a salt is dissolved in water, it may partially dissolve as such, that is, some molecules of the original salt dissolve; but decomposition into ions at once commences and goes on until there is a certain fixed ratio (for the particular salt and dilution) between the undecomposed salt and the product of the number of ions present. Take common salt, for example. The equilibrium will be reached when-

\section{$k$ (number of mols. of undecomposed $\mathrm{NaCl}$ ) \\ $=$ number of $\mathrm{Na}$ ions $\times$ number of $\mathrm{Cl}$ ions}

( $k$ being a constant which varies with the dilution and temperature, the numbers being those present in unit volume of the solution).

If another salt, having ions of a similar kind, be dissolved in the same solution, the equilibrium previously existent is disturbed. Suppose, for example, sodium sulphate were added to the common salt solution, The ions of the new salt are $\stackrel{+}{\mathrm{Na}}, \stackrel{+}{\mathrm{Na}}$, and $\overrightarrow{\mathrm{SO}}_{4}^{-}$, and the conditions of equilibrium are determined by the equation-

$$
k\left(\mathrm{Na}_{2} \mathrm{SO}_{4}\right)=\stackrel{+}{\mathrm{Na}} \times \stackrel{+}{\mathrm{Na}} \times \overline{\mathrm{SO}_{4}}
$$

as before, $k$, of course, having another value; but in the mixture the $\mathrm{Na}$ ions are partly furnished by the common salt, partly by the sodium sulphate. The consequence is that inasmuch as the degree of dissociation of each salt depends partly upon the number of Na ions, less dissociation is suffered by each salt than would be the case if the other were absent.

It is found that nearly all salts, but only strong acids and strong bases, suffer a large amount of dissociation in dilute solution. Weak acids and bases undergo little or no ionisation, and it is upon this fact that the weakness of the acid depends, the activity of an acid being really measured by the proportion of ionised hydrogen in its solution.

It is thus evident that when two neutral salts are mixed in dilute solution, if no insoluble or volatile product is formed by interaction of their ions, no chemical action really takes place. Thus, if sodium chloride and potassium nitrate be mixed together no evidence of chemical action is presented; indeed, none occurs, and in the mixed solution the ions $\stackrel{+}{\mathrm{K}}, \stackrel{+}{\mathrm{Na}}, \overline{\mathrm{Cl}}$, and $\overline{\mathrm{NO}}_{3}$ remain side by side.

If, however, two of the ions can unite and form a non-ionisable substance, then a decided interaction, accompanied usually by a thermal disturbance, occurs. Such a non-ionisable substance may be an insoluble body or it may be a soluble substance, e.g., water, which is practically non-dissociated. 
For example- $\quad \stackrel{+}{\mathrm{Na}}+\overline{\mathrm{Cl}}+\stackrel{+}{\mathrm{Ag}}+\overline{\mathrm{NO}}_{3}=\stackrel{+}{\mathrm{Na}}+\overline{\mathrm{NO}}_{3}+\underset{\substack{\text { Silver } \\ \text { chloride. }}}{\mathrm{AgCl}}$

Or again- $\underbrace{++\overrightarrow{\mathrm{H}}+\overrightarrow{\mathrm{Cl}}}_{\begin{array}{c}\text { Ions of hydro- } \\ \text { chloric acid. }\end{array}}+\underbrace{\stackrel{+}{\mathrm{Na}}+\overrightarrow{\mathrm{OH}}}_{\begin{array}{c}\text { Ions of caustic } \\ \text { soda. }\end{array}}=\underbrace{+\stackrel{+}{\mathrm{Na}}+\overrightarrow{\mathrm{Cl}}}_{\begin{array}{c}\text { Ions still in } \\ \text { solution. }\end{array}}+\begin{array}{c}\text { Water } \\ \text { non-ionised. }\end{array}_{\mathrm{H}_{2} \mathrm{O}}^{+}$

$$
\text { Or- } \underbrace{\stackrel{+}{\mathrm{Na}}+\mathrm{C}_{2} \overline{\mathrm{H}}_{3} \mathrm{O}_{2}}_{\begin{array}{c}
\text { Ions of sodium } \\
\text { acetate. }
\end{array}}+\underbrace{\stackrel{+}{\mathrm{H}}+\overline{\mathrm{NO}}_{3}}_{\begin{array}{c}
\text { Ions of nitric } \\
\text { acid. }
\end{array}}=\underbrace{+\stackrel{+}{\mathrm{Na}}+\overline{\mathrm{NO}}_{3}}_{\begin{array}{c}
\text { Ions still free } \\
\text { in solution. }
\end{array}}+\underbrace{\mathrm{HC}_{2} \mathrm{H}_{3} \mathrm{O}_{2}}_{\begin{array}{c}
\text { Acetic acid } \\
\text { very little ionised. }
\end{array}}
$$

In the last case in the solution there would be a very few ions $\stackrel{+}{\mathrm{H}}$ and $\mathrm{C}_{2} \overline{\mathrm{H}}_{3} \mathrm{O}_{2}$, as acetic acid is slightly dissociated. Indeed, in every case very small quantities of the ions of the assumed non-ionisable substance remain in solution, as probably no substance is absolutely non-ionisable, just as probably no substance is absolutely insoluble in water.

When a chemical reaction takes place simply between ions it is completed in an exceedingly short time, but if other changes occur, very often they do so slowly and the reaction extends over a considerable period.

Mass Action.-When two substances are brought into contact by one or both being in solution a reaction often occurs and goes on until equilibrium is attained.

This equilibrium is generally reached before the whole of a reaction as represented by an equation is completed. What actually occurs will perhaps be best understood by taking an example. If barium sulphate (insoluble) be treated with a solution of potassium carbonate a reaction begins, resulting in the formation of barium carbonate (also insoluble) and potassium sulphate, in accordance with the equation-

$$
\mathrm{K}_{2} \mathrm{CO}_{3}+\mathrm{BaSO}_{4}=\mathrm{BaCO}_{3}+\mathrm{K}_{2} \mathrm{SO}_{4} \text {. }
$$

But this reaction never goes on to completion as is represented by the equation. When equilibrium is attained, the solution is found to contain both potassium sulphate and carbonate and the precipitate both barium carbonate and sulphate. Moreover, it is found that if barium carbonate be treated with potassium sulphate solution, a similar state of equilibrium is attained and the ratio between the number of equivalents of potassium sulphate and potassium carbonate present in the solution would be the same in each case (the ratio actually found is about $1: 4$ ). The reactions really take place in both directions at the same time, and equilibrium is attained when the velocities of the two opposing reactions are equal. The reaction may therefore be better represented thus :-

$$
\mathrm{K}_{2} \mathrm{CO}_{3}+\mathrm{BaSO}_{4} \leftrightarrows \mathrm{K}_{2} \mathrm{SO}_{4}+\mathrm{BaCO}_{3}
$$


As has been shown by Guldberg and Waage in 1867, the velocity with which two substances react depends upon-

(1) The product of their active masses, i.e., the number of equivalents of each of the substances present in the unit volume.

(2) Another factor, depending upon the nature of the two substances, the temperature and other physical conditions of the reaction.

Thus, if $m$ and $m^{\prime}$ be the number of gramme equivalents of the two substances A and B present in the unit volume of the solution, the speed of the reaction would be measured by $k \times m \times m^{\prime}$ where $k$ is a constant. It is obvious that, other things being uniform, the rapidity of a reaction will depend upon the frequency of collisions between substances which are to react. If the number of equivalents $m$ of one substance be doubled, the number of collisions per unit time between the molecules of $\mathrm{A}$ with those of $\mathrm{B}$ will be doubled. So, too, if $m^{\prime}$ be also doubled, the number of collisions per unit time will be again doubled, so that the speed of the reaction will now be represented by $k \times 2 m \times 2 m^{\prime}$, i.e., four times as great as before.

If one of the substances is insoluble in water (or so little soluble that there is always some of it present in the solid state) its active mass is constant and the speed of the reaction then varies only as the active mass of the soluble substance varies.

Now when two substances react they, as a rule, form two other substances, which may react upon each other, re-forming the original two. This occurs in all so-called reversible reactions. In such cases equilibrium is attained when the speeds of the reaction in the two directions are equal. Consider the case to which allusion has already been made and let $a$ represent the number of equivalents of $\mathrm{K}_{2} \mathrm{CO}_{3}$ per unit volume, $b$ the active mass of $\mathrm{BaSO}_{4}$ (constant because insoluble), $c$ the number of equivalents of $\mathrm{K}_{2} \mathrm{SO}_{4}$, and $d$ the active mass of $\mathrm{BaCO}_{3}$ (again constant). Then the condition for equilibrium would be-

$$
k(a-x)(b-x)=k^{\prime}(c+x)(d+x)
$$

but since $b$ and $d$ are constant they are not altered by the subtraction or addition of $x$, which represents the number of equivalents of $\mathrm{K}_{2} \mathrm{CO}_{3}$ (or $\mathrm{BaSO}_{4}$ ), which undergoes the change.

Hence the equation may be written-

$$
\begin{aligned}
k(a-x)(b) & =k^{\prime}(c+x)(d) \\
\therefore \quad \frac{k}{k^{\prime}} & =\frac{(c+x) d}{(a-x) b}
\end{aligned}
$$

or if single equivalents were taken of $\mathrm{K}_{2} \mathrm{CO}_{3}$ and $\mathrm{BaSO}_{4}$

$$
\begin{gathered}
k(1-x)(b)=k^{\prime} x d \\
i . e ., \frac{k}{k^{\prime}}=\frac{x d}{(1-x) b}
\end{gathered}
$$

and since $\frac{d}{b}$ is constant, we see that equilibrium is reached when $\frac{x}{1-x}$ attains a certain value. 
This result means that equilibrium is attained when the ratio of potassium sulphate to potassium carbonate reaches a certain fixed value.

The same is true (with different values for the ratio) with all other reactions of similar type where there are two soluble and two little soluble or insoluble substances concerned. It applies, for example, to a change which is often made use of in agricultural practice and affords an explanation of what may appear puzzling and contradictory to the student. Calcium sulphate is used as a means of lessening the loss of ammonium compounds from manure heaps; this it is said to do by undergoing double decomposition with the volatile ammonium carbonate, yielding non-volatile ammonium sulphate and calcium carbonate.

On the other hand, when ammonium sulphate is applied as a manure to a soil, calcium sulphate is found in the drainage water, and ammonium carbonate is apparently held back in the soil until nitrification occurs.

As represented in the ordinary textbook manner the reactions are-

in the case of the manure heap-

$$
\mathrm{CaSO}_{4}+\left(\mathrm{NH}_{4}\right)_{2} \mathrm{CO}_{3}=\mathrm{CaCO}_{3}+\left(\mathrm{NH}_{4}\right)_{2} \mathrm{SO}_{4}
$$

and in the case of ammonium sulphate applied to soil-

$$
\mathrm{CaCO}_{3}+\left(\mathrm{NH}_{4}\right)_{2} \mathrm{SO}_{4}=\mathrm{CaSO}_{4}+\left(\mathrm{NH}_{4}\right)_{2} \mathrm{CO}_{3} \text {. }
$$

Now, in the light of what has been said, it is obvious that neither of the equations really represents what happens in either case.

In the first place the carbonates involved in the reactions are probably not normal carbonates but acid carbonates, since excess of carbon dioxide is present both in the manure heap and in the soil.

The reaction might be represented-

$$
\mathrm{CaSO}_{4}+2 \mathrm{NH}_{4} \mathrm{HCO}_{3} \rightleftarrows \mathrm{Ca}\left(\mathrm{HCO}_{3}\right)_{2}+\left(\mathrm{NH}_{4}\right)_{2} \mathrm{SO}_{4}
$$

equilibrium being attained when the ratio of the ammonium sulphate to the ammonium carbonate attains a certain value, if the solutions are so concentrated that separation of $\mathrm{CaSO}_{4}$ and $\mathrm{Ca}\left(\mathrm{HCO}_{3}\right)_{2}$ in the solid state can occur (as perhaps may happen in a manure heap); but the conditions of equilibrium will, in dilute solution, be also affected by the quantities of calcium sulphate and calcium bicarbonate present in a dissolved state, for it must be remembered that their influence only becomes constant when they are present in such quantities that they separate partially in the solid state.

It is only fair to say, however, that the tendency for the soil to absorb and retain ammonium carbonate will also play an important part in the case of the action in the soil, that compound being withdrawn from the sphere of action as fast as it is formed, thus diminishing the speed of the reaction represented by the equation read from left to right. 


\section{CHAPTER V.}

\section{The Analysis and Composition of Solls.}

IN this chapter only a brief outline of the methods of sampling and analysing soil will be given. For full details a treatise on soil analysis should be consulted. The methods described here are such as the author himself uses, and variations may be made in them to suit special cases.

Sampling.-This is an important operation, and careful consideration should be given to it. Much depends upon the particular object for which the analysis is to be made. If it be desired to report upon the soil of a farm or field as a whole, and much difference exists in the soil from different parts of it, care must be taken that in the final sample, each different soil should be represented, as far as possible, by a quantity bearing a proportion to the total sample equal to the proportion (of the whole area) covered by that particular soil. Better knowledge of the nature of the soil, however, is obtained if samples representing notable differences be kept apart and analysed separately.

Then, too, the depth to which the samples are taken is a matter for consideration. Generally speaking, the samples should be taken down to the line of separation of the soil from the subsoil, which is often very clearly visible by a difference in colour, the soil proper being darker (because of organic matter) than the subsoil. The depth is usually from 6 to $10 \mathrm{in}$. In many cases it is also required to examine the subsoil, when, of course, separate samples must be collected.

Of the various methods of taking the samples the following may be mentioned :-

(1) Having selected the place, the vegetation growing upon it is removed and a hole is dug with a sharp spade to a depth of about 12 in., one side of the hole being trimmed so as to be quite smooth and perpendicular. A slice from this side is then cut with the spade to a suitable depth and about 3 or 4 in. in thickness. This is placed on a clean board to be mixed with the other samples obtained in a similar way from other parts of the field. Finally, these sub-samples are mixed together thoroughly with trowel or spade, the sticks, large stones and roots being removed, and a sample of 2 or 3 kilograms taken for analysis.

(2) Another, more laborious, plan is to have wooden boxes 6 in. square and 12 in. in depth to hold the samples. A large hole is then dug at the selected spot and a square prism of soil is left in the middle ; this is carefully trimmed with the spade until the box will just slip 
over it. The surface of the prism is freed from vegetation, the box is inverted over it, and by means of the spade, the box with the column of soil is removed, a label giving particulars of the sample put in, and the lid screwed on. A sample of the soil and sub-soil in situ is thus obtained which can be further treated in the laboratory. Several of such samples can be united before a final sample is taken.

(3) A quicker and in many ways a satisfactory method of sampling consists in taking specimens by means of a 2 or $2 \frac{1}{2}$ in. auger, the borings being placed on a board, a number of them (a dozen or more) from various parts of the area to be examined being mixed together and taken for analysis. A board about $2 \mathrm{ft} .6$ in. $\times 1 \mathrm{ft} .2$ in., with a hole in it just large enough to easily pass the auger, will be found convenient to stand upon and also to receive the borings.

For general purposes a chemical analysis of the soil is all that is usually done, but great importance is undoubtedly to be attached to its physical properties (e.g., specific gravity, real and apparent, specific heat, conductivity for heat, absorptive power for salts and for water, size of particles, capillarity), and in America and Germany soils are examined with a view to determining these properties and expressing them quantitatively; but for methods the student is referred to the writings of Knop, Koenig, Warington, Hall and Wiley. It is usual to submit the soil to a rough mechanical analysis before commencing the chemical analysis.

Mechanical Analysis.-The soil collected in its damp state is first air-dried. This is done by spreading it on paper and exposing to air for some days, care being taken to exclude dust, products of combustion or other foreign matters. In order to increase the rate of drying, the author has used a glass chamber provided with shelves, from which air is drawn by a fan, driven by an electric motor, the necessary supply of fresh air being admitted at the bottom, after being warmed by passing over resistance coils (used for diminishing the current supplied to the motor) and filtered through calico. In this way air at a temperature of $25^{\circ}$, to $30^{\circ} \mathrm{C}$. is drawn over the soil, and drying is completed in a short time. Before the soil is thoroughly dry it is rubbed between the hands or with a wooden or rubber-covered pestle, in order to crumble it to powder, care being taken not to crush stones or mineral fragments. When dry, a convenient quantity, 1 or 2 kilograms, is weighed out and passed through a sieve having meshes of 3 millimetres, or $\frac{1}{8}$ in. diameter (best made of metal with circular perforations). The portion failing to pass this is subjected again to hand rubbing until no aggregations of clay, etc., are left. Finally, the stones retained by the 3 millimetre sieve are removed and weighed, whilst the portion passing through is stored in a stoppered bottle for the chemical analysis and duly labelled, the percentage of stones removed being conveniently recorded on the label.

It is rarely desirable to make an analysís of the stones, though in a thorough examination of the soil their character and probable composition should be recorded.

Further mechanical analysis of the portion passing the 3 millimetre 
sieve is sometimes performed, depending upon its separation (i) by sieves of suitable mesh, and (ii) by elutriation, i.e., washing in a current of water of suitable strength and allowing the turbid liquid to settle.

By the sieve method it is not advisable to attempt any further subdivision than is given by holes 0.5 millimetre in diameter. Sieves of 3 millimetre, 1 millimetre, and 0.5 millimetre holes are sufficient for most purposes, thus dividing the soil into four parts. If further separation be desired, elutriation must be resorted to, for details of which a treatise on soil analysis should be consulted.

The usual sizes of particles into which a soil is divided in the mechanical analysis, are-

(1) Stones and gravel, above 2 millimetres in diameter.

(2) Coarse sand, between 2 and 0.2 millimetres in diameter.

(3) Fine sand, between 0.2 and 0.02 millimetre in diameter.

(4) Silt, between 0.02 and 0.002 millimetre in diameter.

(5) Clay, less than 0.002 millimetre in diameter.

Numbers 1 and 2 are usually separated by sieves [that for (2) having about 80 meshes to the inch (linear)], the others by elutriation, the times of subsidence, in a 10 centimetre column prescribed for the separation, being ${ }^{1}$ :-

\section{Particles above 02 millimetres, $7 \frac{1}{2}$ minutes. " " 002 " 8 hours.}

In some cases a microscopical examination of the various sediments is made in order to determine their mineralogical nature. For a purely chemical examination a sieve of 3 millimetre and one of 1 millimetre perforations (practically $\frac{1}{8}$ in. and $\overline{\overline{2} 5}$ in.) are all that are necessary.

- Chemical Analysis.-A full chemical analysis of a soil, including the determination of the quantities of every ingredient, is rarely required. If it be, the "fine soil " passing the 3 millimetre sieve is reduced to fine powder, the particles of which are, at least, able to pass the 1 millimetre sieve.

Determination of moisture.-About 5 grammes of the air-dried fine soil which has passed the 1 millimetre sieve are accurately weighed in a flat-bottomed platinum dish previously weighed, with a short piece of stout platinum wire to act as stirrer. The dish is heated to $100^{\circ}$ in a steam bath for 12 hours, with occasional stirring of its contents. It is then cooled in a desiccator and weighed, again heated for an hour, and re-weighed. If the difference between the two weighings does not exceed 2 milligrams, the moisture is calculated from the loss in weight. If the difference between the two weighings exceeds 2 milligrams the dish is again heated for an hour at $100^{\circ}$ and re-weighed until two successive weighings show less difference.

Determination of loss on ignition.-The residue from the moisture determination is heated to low redness, with occasional stirring, until all black particles are destroyed. This can very conveniently be done in a muffle furnace. The dish is removed, allowed to cool, the contents moistened with ammonium carbonate solution, dried, heated to

${ }^{1}$ Beam, Fourth Rep. Gordon College, Khartoum, Chem. Sect., 1911, 34. 
about $150^{\circ}$ or even to low redness for a minute or two, again cooled and weighed. The loss is equal to the organic matter and combined water. The object of the treatment ${ }^{1}$ with ammonium carbonate is to restore any calcium carbonate (which would be decomposed by the heating into carbon dioxide, which would escape, and quick-lime) back into its original form. Otherwise the loss on ignition would include the carbon dioxide thus expelled.

Care must be taken that the temperature be as low as is consistent with the oxidation of the carbon, or loss, due to volatilisation of alkaline chlorides, may occur.

Determination of nitrogen.-The nitrogen in a soil may exist.in three states of combination:-

1. As nitrates.

2. As ammonium compounds.

3. As organic compounds of complex but little known constitution, associated with the "humus".

The nitrogen existing at any given time in a soil in the state of nitric acid or ammonia is usually very small in amount and in most cases does not require separate determination.

Total nitrogen.-Several methods are in use for the determination of nitrogen in soil, but, in recent years, the well-known Kjeldahl process for the determination of nitrogen in organic substances generally, has, with various modifications in detail, been adopted in soil analysis.

Broadly speaking, the method is based upon the behaviour of strong sulphuric acid towards organic matter; by continued heating with strong acid the carbonaceous matter is oxidised into carbon dioxide and water, the nitrogen which it contains being converted into ammonia, which, in the presence of the large excess of acid, remains behind as ammonium sulphate. A large proportion of the sulphuric acid is reduced with the evolution of sulphur dioxide. It is found that the oxidation of the organic matter is facilitated by the addition of small quantities of certain metallic salts, e.g., of mercury or copper. They apparently act as carriers of oxygen from the acid to the organic matter.

The following are the details of the method which the author uses :-

10 to 15 grammes of the air-dried "fine soil" (i.e., which has been crushed and passed a 1 millimetre sieve) are introduced into a $16 \mathrm{oz}$. spherical flask and treated with 20 to 25 cc. of pure sulphuric acid, ${ }^{2}$ heated for some time over the bare flame, care being taken that the soil is completely wetted by the acid and that no dry places are left in the lower part of the flask. When the frothing has ceased (usually

${ }^{1}$ Several errors in the determination of organic matter are not adequately corrected for by this treatment; magnesia left from magnesium carbonate on ignition only very slowly takes up carbon dioxide again; so, too, lime present as calcium humate will be converted into carbonate. These errors and others inherent in the method are small and can usually be ignored.

${ }^{2}$ Which must be free from ammonia ; the re-distilled acid of commerce is usually pure enough. 
in about half an hour) 10 grammes of pure potassium sulphate are added to the flask and about half a gramme to a gramme of anhydrous copper sulphate (easily prepared by heating powdered blue vitriol in a porcelain basin until it becomes quite white); the heating is then continued in the draught place, the flask being either placed in an inclined position or a small funnel or watch glass being placed on its neck in order to prevent loss by spirting. The contents of the flask should be kept in constant ebullition, due care being taken to avoid frothing over, which may occur in the early stages of the heating. The flask is best supported upon a retort-stand ring, its neck passing through a smaller ring, and it is advisable to periodically rotate the flask so that no fragments of soil may escape the action of the acid, or rather of the acid potassium sulphate. ${ }^{1}$ When all black or brown colouration disappears (generally in about $1 \frac{1}{2}$ to 2 hours from the time of starting the heating) it is safe to assume that the reaction is completed. The flask is then allowed to cool, about $50 \mathrm{cc}$. or more of distilled water added, and a cork carrying a separating funnel, delivery tube and inlet tube for steam is inserted, the arrangement being shown in the diagram, Fig. 5. In the separating funnel is placed about 80 or 90 cc. of strong caustic potash solution, made by dissolving "stick" potash in its own weight of water and boiling the solution for some time to expel any possible ammonia. This solution can be prepared in considerable quantities and kept in a closely corked bottle.

When the apparatus is fitted up as described, a measured quantity -25 cc. - of decinormal sulphuric acid is run from a pipette into $\mathrm{F}$ through $G$, the cork being loosened to allow of the escape of air. B should be disconnected from $A$ at the rubber joint $R$ and the water in $\mathrm{B}$ heated to boiling. In the meantime the 80 or $90 \mathrm{cc}$. of potash solution in $\mathrm{C}$ are allowed to trickle slowly and with frequent shaking, or better, rotation, in to $\mathrm{A}$. The copper sulphate affords a good indication of the amount required. When the solution is alkaline the copper is precipitated as blue copper hydroxide, which, however, is usually quickly converted into black copper oxide owing to the heat evolved by the action of the potash on the sulphuric acid. Care should be exercised, lest frothing takes place during neutralisation. When an excess of potash has been added, the tap of the separating funnel is turned off and steam from $\mathrm{B}$ is admitted by connecting with the rubber tube at $R$. The lamp under A should only have a small flame, lest bumping, due to the presence of the solid matter in the flask, be produced. The flame under B should be of such a size that the pressure of the steam is sufficient to raise the water in the vertical tube some 8 or $10 \mathrm{in}$., due attention being, particularly at first, directed to the prevention of frothing in A. The flask, F, should be surrounded with cold water in order to condense the steam coming over. This method works very satisfactorily and the ammonia is entirely driven over in about half an hour, and there is little risk of bumping or sucking back.

1 The object of adding the potassium sulphate is to allow the temperature to be raised to a higher point than is possible with sulphuric acid alone. Indeed, the liquid in the flask at the end consists essentially of fused potassium hydrogen sulphate. 
When the operation is over, the rubber at $\mathrm{K}$ is disconnected; the cork is loosened from $\mathrm{F} ; \mathrm{E}$ and $\mathrm{G}$ are rinsed out by distilled water

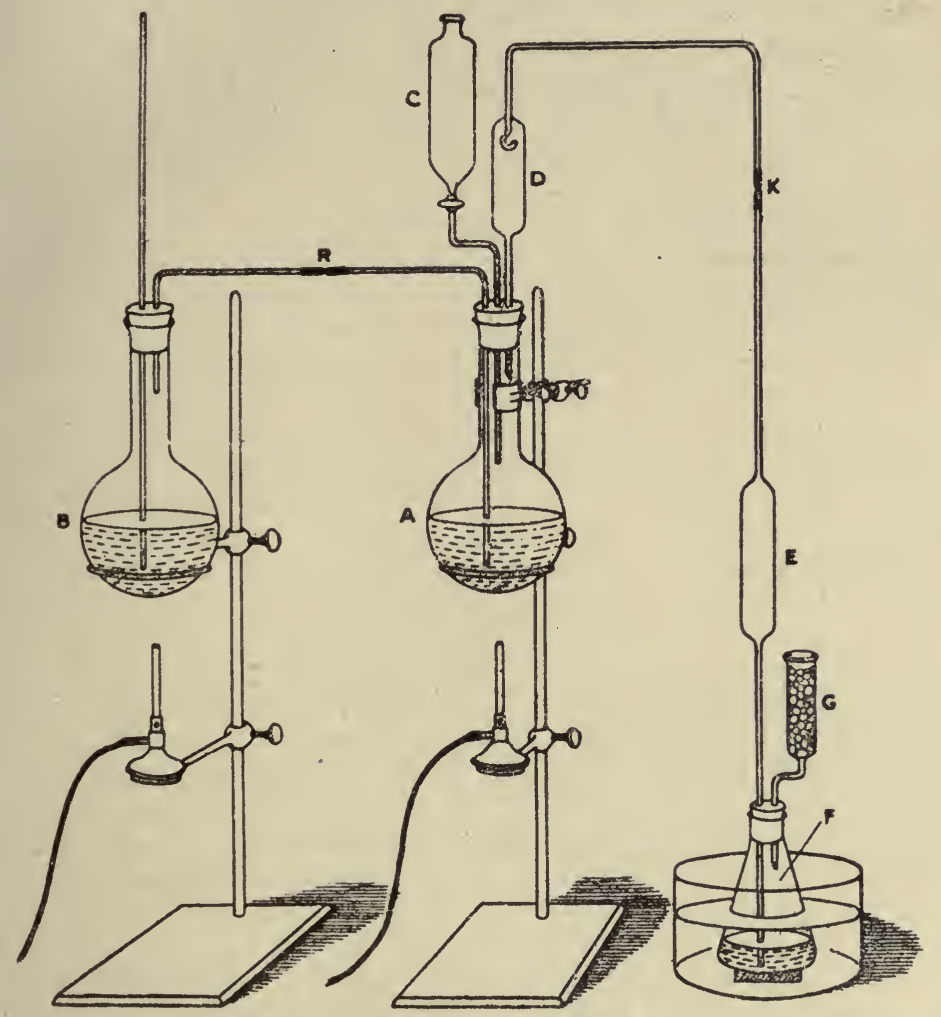

Fig. 5.-Determination of Nitrogen

A is the flask in which the soil has been beated with the sulphuric acid.

$\mathrm{B}$ is a similar flask containing water and a scrap of granulated zinc so as to ensure a steady evolution of steam. This flask is fitted with a safety tube so that the pressure in the apparatus can be determined at once (by the height of the water in this tube).

$\mathrm{C}$ is a separating funnel, bent so as to fit properly and containing the strong potash solution.

$\mathrm{D}$ is a bulb on the delivery tube, with an arrangement for preventing any particles of the solution in A from being carried over by the steam.

$\mathrm{E}$ is a 50 or $100 \mathrm{cc}$. pipette, which acts as a condenser to some extent and prevents any standard acid being drawn back if the evolution of steam be suddenly stopped.

$\mathrm{F}$ is an $8 \mathrm{oz}$. conical flask.

$\mathrm{G}$ is a tube shaped as shown and filled with glass beads through which the standard acid has been allowed to run into $\mathrm{F}$.

into $\mathrm{F}$; a little (one or two drops) methyl orange solution is added; and decinormal caustic soda solution is run in from a burette until the red colour just disappears. The amount of ammonia and hence of 
nitrogen is then easily calculated from the amount of sulphuric acid which has been neutralised by the ammonia carried over in the steam.

The method gives the nitrogen existing as organic matter and as ammonia in the soil ; it also probably gives some, at least, of that existing as nitrates, but if nitrates are likely to be present in any considerable quantity, about a gramme of salicylic acid or benzoic acid should be added with the sulphuric acid, when nitro-compounds of these acids will be formed, readily capable of reduction to amides and finally to ammonia.

An example will show the method of calculation. 10.868 grammes of soil were treated as described. On distillation into $50 \mathrm{cc}$. of decinormal sulphuric acid there were required afterwards 27.0 cc. of decinormal sodium hydrate solution. Hence $50-27 \cdot 0=23$ cc. of the acid must have been neutralised by the ammonia. $1 \mathrm{cc}$. of decinormal sulphuric acid contains 0049 gramme of real $\mathrm{H}_{2} \mathrm{SO}_{4}$, capable of neutralising 0017 gramme of ammonia, corresponding to 0014 gramme of nitrogen. Hence the $23 \mathrm{cc}$. of sulphuric acid correspond to $23 \times \cdot 0014$ gramme of nitrogen, and this was present in 10.868 grammes of soil.

The percentage of nitrogen is therefore-

$$
\frac{23 \times \cdot 0014 \times 100}{10 \cdot 868}=0.270 \text {. }
$$

Direct estimation of humus.-A method originally proposed by Grandeau ${ }^{1}$ is based upon the solubility of humus in ammonia. About 10 grammes of the soil are treated with dilute hydrochloric acid (containing about 1 per cent pure acid) until all lime and magnesia are removed. Then the acid is washed out by water and the soil residue is treated with about $15 \mathrm{cc}$. of ammonia (strong ammonia diluted with about its own volume of water) for three or four hours; the whole is then filtered and the residue washed once or twice with dilute ammonia. The dark-coloured solution is then evaporated in a weighed platinum dish, dried at $100^{\circ}$ and weighed. The contents of the dish are then ignited and the organic matter thus oxidised. The loss of weight on ignition is the amount of humus. The phosphoric acid in the residue may be determined in the usual way, and, according to Grandeau, affords a good measure of the available phosphoric acid of the soil.

Determination of the silica, alumina, ferric oxide and total potast. -3 or 4 grammes of the finely divided soil are weighed out accurately into a conical flask, $20 \mathrm{cc}$. of strong hydrochloric acid are added, and the whole boiled on a sand tray for ten minutes, a watch glass being placed on the neck of the flask to prevent loss by spirting; the flask is then placed on the steam bath and digested at $100^{\circ} \mathrm{C}$. for forty-eight hours. The liquid is then diluted and filtered, the residue washed with hot water, dried, ignited and weighed.

This is reported as silica, though in many cases it doubtless still contains some refractory silicates. The filtrate and washings are evaporated to complete dryness in a platinum or porcelain basin on the water bath, the residue heated over a flame until thoroughly dry and

${ }^{1}$ Vide Analyse des Matières Agricoles, 1897, Vol. I, 141. 
the organic matter charred or burnt, cooled, moistened with strong hydrochloric acid, taken up with water, and filtered; the residue is ignited and weighed, its weight, "soluble silica," being added to the other " silica," already separated.

The filtrate and washings are made up to $100 \mathrm{cc}$. (or 250 if more convenient). $25 \mathrm{cc}$. (or 50 if from $250 \mathrm{cc}$.) are then taken, boiled with a few.drops of nitric acid, in order to oxidise the iron, and mixed with just sufficient ammonia to neutralise the free acids present. A slight excess of ammonia is then added and the whole boiled until the free ammonia is nearly all expelled. The precipitate is filtered off, washed, thoroughly dried, ignited and weighed. The weight is equal to the ferric oxide, alumina and phosphoric acid present. The aggregate weight of ferric oxide and alumina is then obtained by deducting the weight of phosphoric acid, calculated from the results of its direct determination (vide p. 90).

Another portion of the filtrate from the silica is taken for the determination of the total potash. This can be done conveniently and accurately by Tatlock's method.

25 cc. (or. $50 \mathrm{cc}$.) of the hydrochloric acid solution are placed in a porcelain dish, and platinum tetrachloride in sufficient quantity to convert all the potash, soda and magnesia into double chlorides is added (in general, about 0.3 gramme will be sufficient), and the liquid slowly evaporated on the water bath. The residue is washed, first with a little platinum chloride solution, which dissolves and removes sulphates, phosphates, etc., also the double chlorides of platinum with calcium, sodium, magnesium, etc., and then by decantation, in the dish, with alcohol (96 per cent, not methylated), the washings being passed through a small filter. When the washings are colourless, the precipitate, which should consist of bright orange crystals, is washed with alcohol into a weighed porcelain crucible, and the alcohol poured off as completely as possible through the filter. The crucible is then placed in a warm place for a short time, heated in a steam bath for two hours, and then weighed. The small filter, which should only contain traces of precipitate, is then burnt in platinum wire, its ash added to the crucible, and the whole again weighed. The last increase is taken as being due to $2 \mathrm{KCl}+\mathrm{Pt}$. It is calculated to $\mathrm{K}_{2} \mathrm{PtCl}_{6}$ and added to the weight of the main quantity of the precipitate. From the sum of these weights the amount of potash in the soil can be calculated, knowing that 94 of potash $\left(\mathrm{K}_{2} \mathrm{O}\right)$ correspond to every 485 of the double chloride.

This method works very well and is a great saving in time and labour over the old method requiring the preliminary removal of the iron, aluminium, lime and magnesium. Unfortunately it prevents the simultaneous determination of the sodium.

The so-called "total potash" obtained in this way is not necessarily the whole quantity of potash which the soil contains, for hydrochloric acid does not remove all the potash from silicates.

If the real total potash be required, it is necessary to analyse the residue insoluble in hydrochloric acid, exactly as is done with a mineral silicate. However, the potash in a soil, insoluble in hydro- 
chloric acid, is probably unavailable to plants for many years to come, so that its determination is not often of importance.

Determination of "total" phosphoric acid.-This can conveniently be done in the portion of the soil taken for determination of loss on ignition. The residue in the platinum dish is treated with strong hydrochloric acid, digested for some time, evaporated to dryness, and heated to render the silica insoluble, moistened with strong hydrochloric acid, taken up with water, filtered and evaporated with strong nitric acid. It is again diluted and mixed with excess of ammonium molybdate solution and allowed to stand in a warm place for eighteen or twenty-four hours. It is then filtered, washed by decantation with dilute nitric acid and once with water, then dissolved in dilute ammonia (filtered.if necessary), mixed with "magnesia mixture," 1 and allowed to stand twelve hours. The ammonium magnesium phosphate, $\mathrm{NH}_{4} \mathrm{MgPO}_{4}$, is then filtered off, washed with ammonia, dried, ignited slowly and carefully, and weighed as $\mathrm{Mg}_{2} \mathrm{P}_{2} \mathrm{O}_{7}$. Phosphoric acid may also be determined in a portion of the hydrochloric extract of the soil.

Determination of the lime and magnesia.-Except in some few cases, the amount of these constituents is so small that they cannot be accurately determined in the 3 or 4 grammes of soil taken for the previous determinations, especially as at least half of the solution will have been used for determinations of iron and alumina and total potash.

It is usually advisable, therefore, to take 6 or 8 grammes of soil, treat and digest with hydrochloric acid as before, remove the silica, ferric oxide, alumina and phosphoric acid as before from the whole solution, then to the filtrate from ferric oxide, etc., to add ammonium oxalate, allow to stand twelve hours, filter, wash, dry, ignite in platinum crucible to constant weight and weigh as calcium oxide.

The filtrate from the calcium oxalate is freed from ammonium salts by evaporation with nitric acid in the usual manner and the magnesium precipitate 3 as ammonium magnesium phosphate and weighed as magnesium pyrophosphate.

Determination of the amount of calcium carbonate.-A direct determination of the amount of carbon dioxide evolved on treatment with dilute hydrochloric acid is sometimes advisable, since for many purposes the lime existing as carbonate is of more importance (as regards nitrification, for example) than the total lime, some of which may be as silicate. This can be done by any of the usual methods, either by receiving the evolved gas in weighed potash bulbs; or, if its amount be large, by determining the loss in weight of an apparatus in which it is generated and from which it can be wholly removed by a current of air. Details of these methods will be found in any manual of quantitative analysis.

Limitations of Chemical Analysis.-A complete chemical analysis, though of service as giving the limits of the plant food which a soil can provide, is often of disappointingly little use and frequently affords no information of value as to fertility or manurial requirements.

${ }^{1}$ A solution containing magnesium chloride, ammonium chloride and ammonia. 
A good example of such failure is seen in the following analyses of two soils from pasture land at the Experimental Farm at Garforth, made by the author in June, 1900 :-

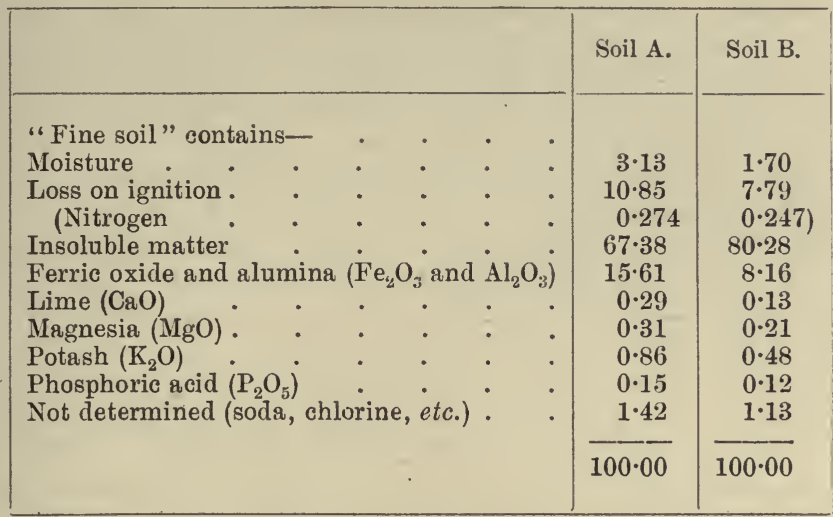

From these figures it would appear that soil A is better provided with lime, potassium and phosphoric acid than soil B, and inasmuch as there is also more nitrogen present one would conclude that soil $\mathrm{B}$ would receive much more help from phosphatic and lime manures than soil A.

Actual practice shows exactly the opposite, for it is found that basic slag produces a large increase and great improvement in the crop on the field from which seil A was taken, while the field from which soil $\mathrm{B}$ was derived does not respond to applications of basic slag.

From such disagreements between the results of chemical analysis and actual farming experience, which are often met with, it is evident that to know what a soil contains is not sufficient to enable one to form a judgment as to its fertility; one must know, in addition, something about the state of existence of the important items of plant foodmust know, in fact, the amounts of these which are directly available to the plant.

Many methods of extracting soil so as to obtain some measure of the phosphoric acid and potash particularly, which are in an assimilable form, have been suggested. One of the most successful is that of Dyer. ${ }^{1}$ This method is based upon the extraction of the soil with a 1 per cent solution of citric acid, which Dyer found to be about the average acidity of the juices of the roots and root hairs of a large number of plants examined by him.

The method is thus carried out: 200 grammes of the air-dried soil which has passed the 3 millimetre sieve are, without further treatment, placed in a flask or bottle, and treated with $2000 \mathrm{cc}$. of water containing 20 grammes of pure crystallised citric acid. The two are left in contact, with frequent stirring or shaking, for

1 Jour. Chem. Soc., 1894, Trans., 141. 
seven days at the ordinary temperature of the laboratory. The liquid is then filtered, best through a Buchner's "nutschen " or porcelain funnel with parallel sides and perforated base, by the aid of a filter pump. $500 \mathrm{cc}$. of the filtrate are taken for the determination of the available potash and a like quantity for the available phosphoric acid.

These two portions are evaporated to dryness and gently ignited to destroy organic matters. The potash and phosphoric acid are then determined exactly as already described.

That this method of determining the available potash and phosphoric acid affords valuable help in judging of probable fertility is shown by its application to the two soils whose analyses have been given.

The results were as follows :-

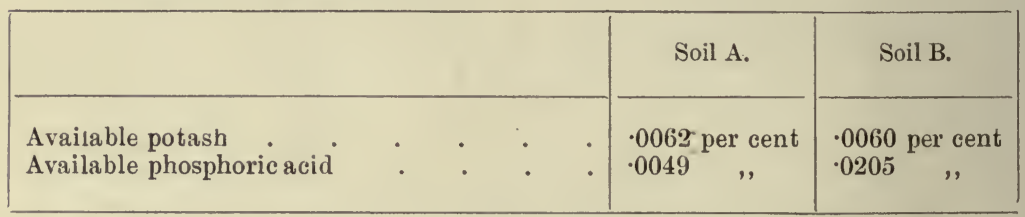

It is thus evident that, so far as potash is concerned, the two soils are almost alike, but that soil $\mathrm{A}$, though containing more total phosphoric acid than $\mathrm{B}$, contains less than one-fourth as much in an available form. The beneficial effect of basic slag on soil A is thus easily understood, soil B containing an abundance of available phosphates.

Dyer points out that less than 01 per cent of available phosphoric acid in a soil indicates that it stands in immediate need of phosphatic manures. With reference to the limit for the available potash, Dyer thinks, though he expresses more doubt in this case than with the phosphoric acid, that soils containing much less than 005 per cent available potash require application of potash manures. ${ }^{1}$

"Available" plant food in soils as determined by Dyer's method is undoubtedly a valuable method of gauging the relative fertility of soils which exist under similar climatic conditions, so far as their power of supplying potash and phosphoric acid is concerned, but the writer's experience has led him to conclude that there is another factor which greatly influences fertility, and that is the rate at which the "available" matter is renewed by the processes of weathering which occur in soils.

This occurs with considerable rapidity even in England, for it was found that a soil, which had been deprived of the potash and phosphoric acid soluble in 1 per cent solution of citric acid, exactly as in Dyer's method, after a few months, again contained quite a large proportion

${ }^{1}$ In a subsequent paper (Proc. Roy. Soc., 1901, 11) Dyer states that for cereals the limit denoting deficiency in phosphoric acid is between 0.01 and 0.03 per cent soluble in 1 per cent citric acid solution. In root crops, especially turnips, the limit would probably be higher. He also states that soils containing 0.01 per cent of potassium soluble in 1 per cent citric acid probably require no further application of potash manures. 
of the same materials extractable by 1 per cent citric acid solution. ${ }^{1}$ Plants sown in such soil grew very slowly at first, but later on, probably because of the gradual production of "available" plant food, they grew much better.

In warmer climates, the rate at which potash and phosphoric acid become available is probably greater than in England, and this is probably why soils of such apparent poverty (on analysis) are able to produce fair crops. This is very noticeable in South Africa and also in India.

Many other methods of determining the available plant food in soils have been proposed, in which weak solutions of hydrochloric acid, carbonic acid and other substances are used as solvent, but careful investigations have shown that all these methods, like that of Dyer, yield empiric results.

At present, therefore, it cannot be claimed that any method has been designed which will determine directly the amount of plant food which a given soil is capable of yielding to plants. Nevertheless, Dyer's method and perhaps some of those in which aqueous solutions of carbon dioxide are used as solvent, afford useful indications of the relative powers of soils to supply the mineral requirements of crops under similar conditions of temperature and humidity. The results obtained by the application of such methods are, in most cases, much more in accordance with the indications of actual field trials, than the figures obtained by a "complete" analysis of the same soil.

Determinations occasionally made.-A few other constituents may require determination for special purposes :-

Determination of sulphuric acid.-Sulphur is found in a soil as sulphates (most frequently calcium sulphate), in organic compounds, and occasionally also as sulphides (e.g., iron pyrites). The sulphuric acid, existing as such, may be determined by digestion of the soil with dilute hydrochloric acid, filtration, and precipitation of the solution with barium chloride, in the usual way employed for sulphuric acid determinations. The total sulphur may be sufficiently well determined by digestion with concentrated nitric acid for six hours, diluting with water, filtering, and precipitating the filtrate with barium chloride.

Determination of nitrates. - The amount of nitrate present in a soil at any given time is usually very small.

If a determination be required, it is important that the soil be airdried as soon after its collection as possible, otherwise the process of nitrification may continue and increase the amount of nitrates. It is advisable to accelerate the process of drying by heating the soil to $30^{\circ}$ or $40^{\circ} \mathrm{C}$. and drawing a current of warm air over it. An arrangement which the author finds very convenient for drying soils before analysis is described on p. 83. With this apparatus the operation can be rapidly completed without the possibility of contamination by dust or products of combustion, and with little opportunity for nitrification to appreciably increase the quantities of nitrates in the soil. 
From the air-dried soil the nitrates are extracted by washing with water. Many methods may be used:-

(1) 1000 grammes are treated with 2 litres of pure water and allowed to stand for forty-eight hours, with occasional shaking. 1 litre of the liquid is then filtered, mixed with a little pure sodium carbonate, and evaporated to small volume on the water-bath, any precipitate which may form being removed by filtration.

(2) A cylindrical funnel is made by removing the bottom from a "Winchester quart" bottle, placing a disc of copper gauze on the shoulder, and covering this with two filter papers. The bottle is then connected by means of a cork and tube to a filtering flask and from 200 to 500 grammes of dried soil are placed in it, resting on the papercovered wire gauze. Water is then poured in until the whole of the soil is moistened, small quantities of water are added from time to time, and the filter pump started gently. When $100 \mathrm{cc}$. have percolated it may be assumed that all the nitrates are removed (Warington).

In the extract obtained, the amount of nitric nitrogen may be determined by one of the following methods :-

(1) The reduction of the nitric acid to nitric oxide and the measurement of the volume of this gas.

This can be effected either by-

Schloesing's method, in which the nitrate is treated with ferrous chloride and strong hydrochloric acid-

$$
6 \mathrm{FeCl}_{2}+2 \mathrm{KNO}_{3}+8 \mathrm{HCl}=6 \mathrm{FeCl}_{3}+2 \mathrm{KCl}+4 \mathrm{H}_{2} \mathrm{O}+2 \mathrm{NO} .
$$

or Crum-Frankland's method, in which by the action of metallic mercury and sulphuric acid the nitrate yields its nitrogen as nitric oxide-

$$
6 \mathrm{Hg}+4 \mathrm{H}_{2} \mathrm{SO}_{4}+2 \mathrm{KNO}_{3}=3 \mathrm{Hg}_{2} \mathrm{SO}_{4}+\mathrm{K}_{2} \mathrm{SO}_{4}+4 \mathrm{H}_{2} \mathrm{O}+2 \mathrm{NO} \text {. }
$$

This latter method is vitiated if any appreciable quantity of organic matter be present. The former method gives good results, even in the presence of organic matter. The Crum-Frankland method can be conveniently carried out in Lunge's nitrometer, for a description of which any treatise on quantitative analysis may be consulted.

(2) The reduction of the nitrates to ammonia and the subsequent determination of the amount of ammonia so formed.

This reduction is brought about by the action of nascent hydrogen, which may be generated by-

(a) An oxidisable metal in presence of an alkali.

(b) Action of a metal on an acid.

(c) Electrolysis of water.

In all cases the main chemical reaction is the same-

$$
\mathrm{HNO}_{3}+4 \mathrm{H}_{2}=\mathrm{NH}_{3}+3 \mathrm{H}_{2} \mathrm{O}
$$

-one molecule of ammonia being formed from one molecule of nitric acid.

The ammonia formed is then estimated by distillation with an alkali and reception in a measured quantity of standard acid, the amount of acid neutralised being afterwards determined by titration 
with standard sodium hydrate exactly as in the Kjeldahl process for total nitrogen.

In some cases, where the quantity of nitrate present is small, the amount of ammonia formed is estimated by the well-known Nessler's method, as used in water analysis.

(3) The production of a colour with certain organic substances in presence of sulphuric acid and the comparison of the depth of colour produced with that formed by a known amount of pure potassium nitrate under like conditions. - Several substances give characteristic colours with nitrates and may be used for the determination, the most generally used being carbazole or diphenylimide, $\left(\mathrm{C}_{6} \mathrm{H}_{4}\right)_{2} \mathrm{NH}$, which in acetic acid solution, gives a deep-green colouration with a nitrate; phenyl-sulphuric acid, $\mathrm{C}_{6} \mathrm{H}_{5} \mathrm{HSO}_{4}$, which yields picric acid $\mathrm{C}_{6} \mathrm{H}_{2}\left(\mathrm{NO}_{2}\right)_{3} \mathrm{OH}$ with a nitrate and, on the subsequent addition of ammonia, gives an intense yellow colouration; and brucine, $\mathrm{C}_{23} \mathrm{H}_{26} \mathrm{~N}_{2} \mathrm{O}_{4} \cdot 4 \mathrm{H}_{2} \mathrm{O}$, which with strong sulphuric acid and a nitrate yields a characteristic intense red colouration.

Determination of ammonia.-If a determination of ammonium salts in a soil be desired, distillation of a weighed quantity of the soil with pure water and magnesia is performed, the ammonia evolved being received in standard sulphuric acid. Magnesia is employed instead of soda or potash because it has not, like these alkalies, the power of setting free a portion of the nitrogen (as ammonia) from organic nitrogenous compounds.

Determination of nitrites.-Nitrites are, as has been shown in Chapter IV, an intermediate stage in the conversion of organic or ammoniacal nitrogen into nitrates. Their presence in a soil may sometimes be detected, but only minute quantities are usually present unless the activity of the nitric organism is not so great as that of the nitrous organism.

Many delicate reactions, mainly colourimetric ones, can be used for their detection and estimation. Metaphenylene diamine, $\mathrm{C}_{6} \mathrm{H}_{4}\left(\mathrm{NH}_{2}\right)_{2}$, gives with nitrous acid an intense yellow colouration, and this colouration, developed by heating, is compared with that obtained by the use of a known quantity of a nitrite.

A more delicate test, not so readily interfered with by the yellow colour which the soil extract may possess, is the addition of a mixture of sulphanilic acid and naphthylamine in acetic acid. ${ }^{1}$ This gives with minute traces of nitrites, when warmed to $70^{\circ}$ or $80^{\circ}$, a red colouration.

The reaction is due to the following changes:-

$$
\begin{aligned}
& \underset{\text { p-amino benzene sulphonic acid }}{\mathrm{C}_{6} \mathrm{H}_{4} \mathrm{NH}_{2} \mathrm{HSO}_{3}}+\underset{\mathrm{HNO}_{2}}{\mathrm{HNO}_{4}}=\mathrm{C}_{4}\left\{\begin{array}{c}
\mathrm{N}: \mathrm{N} \\
\mathrm{SO}_{3}
\end{array}\right\}+2 \mathrm{H}_{2} \mathrm{O} \\
& \text { or sulphanilic acid. } \\
& p \text {-diazo benzene } \\
& \text { sulphonic acid. } \\
& \mathrm{C}_{6} \mathrm{H}_{4} \mathrm{~N}_{2} \mathrm{SO}_{3}+\underset{a \text {-naphthylamine (or }}{\mathrm{C}_{10} \mathrm{H}_{7} \mathrm{NH}_{3} \mathrm{C}_{2} \mathrm{H}_{3} \mathrm{O}_{2}} \\
& \text { naphthylammonium) acetate. }
\end{aligned}
$$

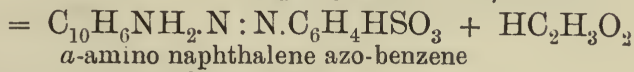

$$
\begin{aligned}
& p \text {-sulphonic acid. }
\end{aligned}
$$


This complex compound has intense tinctorial power and is the cause of the red colouration.

Another reaction for nitrites, of considerable delicacy, though liable to interference by the presence of organic matter, is the liberation of iodine from hydriodic acid and its detection by the formation of the blue colour with starch.

Another good reaction for nitrites is the formation of a blue colour with a solution in strong sulphuric acid of diphenylamine, $\left(\mathrm{C}_{6} \mathrm{H}_{5}\right)_{2} \mathrm{NH}$.

Chemical Methods for Measuring Bacterial Activity.-It has been seen how dependent upon the activity of micro-organisms is the rate at which the organic matter of a soil becomes available to plants. It is thus obvious that the fertility of a soil, containing a good supply of nitrogenous organic matter, will be largely influenced by its bacteriological condition. To investigate, at any length, the number, character and activity of the micro-organisms in a soil is a difficult task and belongs to the domain of the bacteriologist rather than to that of the chemist.

Certain direct chemical methods of attacking the problem, however, have been devised and are capable of yielding useful information. Russell ${ }^{1}$ has proposed to measure the total bacterial activity of a soil by determining the rate at which oxygen is absorbed from a known volume of air confined in contact with a known weight of the soil at a definite temperature.

Ashby ${ }^{2}$ has described a method of estimating the comparative nitrifying power of soils. Briefly it consists in "seeding" with 0.2 gramme of the soil, $100 \mathrm{cc}$. of a culture solution containing per litre-

Potassium dihydrogen phosphate.

Magnesium sulphate

Ammonium sulphate.

Ferrous sulphate.

Sodium chloride .

$\begin{array}{lc}0.25 & \text { gramme } \\ 0.125 & \quad, \\ 0.5 & , \\ 0.1 & , \\ 0.5 & ,\end{array}$

This can be most conveniently kept in a solution four times as strong and diluted as required. $100 \mathrm{cc}$. of this sterilised solution are placed in a clean flask, 0.2 gramme of the soil and 0.2 gramme of sterilised precipitated calcium carbonate added, the flask closed by a plug of cotton wool and incubated at $29^{\circ}$ to $30^{\circ} \mathrm{C}$.

Periodically, a few drops of the liquid are taken from the flasks and tested for nitrites by means of diphenylamine and strong sulphuric acid, or starch paste, potassium iodide and dilute sulphuric acid. When most of the flasks show a distinct nitrite reaction or after, say, thirty days' incubation, the amounts of nitrogen present in an aliquot portion of the liquid as (1) nitrite, (2) nitrate, and (3) ammonia are determined. In this way, the relative nitrifying powers of a series of soils may be determined. Ashby states that he never found, in his experiments with Rothamsted soils, any trace of nitrite or nitrate pro-

1 Jour. Agric. Sci., 1905, 261.

2 Jour. Chem. Soc., Trans., 1904, 85, 1158, and Jour. Agric. Sci., 1907, 2, 52. 
duced during the first fourteen days' incubation and rarely before the end of twenty-one days. With Transvaal soils, however, experiments made under the writer's direction, in Pretoria, showed, under conditions parallel to those in Ashby's experiments, formation of nitrites in five or six days. As a rule, the nitrifying power of a soil is greater, the larger the amount of nitrogenous organic matter present, but in some of the vlei soils of the Transvaal, very rich in organic matter, the nitrifying organisms are apparently absent, for after addition of calcium carbonate, no nitrification of ammonium sulphate occurred, even after sixty days' incubation at $30^{\circ} \mathrm{C}$.

The writer is of opinion that in soils of temperate climates the progress of nitrification is generally limited by the temperature being too low, while in hot countries it is rather the absence of basic material (lime or magnesia) and perhaps, often of moisture, that limits the rapidity of nitrification.

For another method of determining the nitrifying efficiency of soils vide Stevens \& Withers, U.S. Dept. of Agric., Bull. 132, 1910.1

Interpretation of the Results of Analyses of Soils.- The results of an analysis of a soil are usually expressed in the following manner :-

1. Stones retained by 3 millimetre sieve The air-dry "fine-soil" contains :-

2. Moisture expelled at $100^{\circ} \mathrm{C}$.

3. * Loss on ignition

4. Insoluble matter

5. Iron oxide and alumina

6. Lime

7. Magnesia ..

8. Potash

9. Phosphorus pentoxide

10. Total

11.* Containing nitrogen

12. "Available" potash .

13. " phosphorus pentoxide

The meaning of these terms has already been explained as well as the methods of which their amounts are determined. A few words may, however, be said as to the deductions which may be made from the results expressed in this manner.

1. Stones retained by 3 millimetre sieve.-This item is subject to enormous variation. Except in tenacious, heavy soils, as a rule, the smaller the percentages of stones present in a soil the better, though their presence in certain cases is useful in rendering the soil more porous and open. In the Transvaal the soils are, as a rule, remarkably free from stones. In some gravelly soils, on the other hand, stones may be very numerous. As sources of plant food they are practically useless.

2. Moisture.-This, determined on the air-dried sample, varies greatly. With sandy soils it is usually small, while the presence of large amounts of humus or clay tends to eause it to be higher. As a

${ }^{1}$ Abstract in Jour. Soc. Chem. Ind., 1910, 1262. 
rule, a high content of moisture is accompanied by a high percentage of organic matter and of total nitrogen.

3. Loss on ignition.- This includes the organic matter and combined water present. Consequently it is high in soils containing much humus or in those rich in hydrated silicates (chiefly clay).

4. Insoluble matter. - This - the mineral matter which resists the action of boiling strong hydrochloric acid for forty-eight hours-may be taken as sand. It usually contains some difficultly decomposable silicates, but they must be of such a refractory character that they are useless as sources of potash or lime to plants. In sandy soils the quantity is high, sometimes amounting to 90,95 , or even 97 per cent of the total, while in clayey soils it usually ranges from 55 to 75 per cent.

5. Iron oxide and alumina.-This item is of no great importance as affecting the power of a soil to supply plant food, but sometimes, since it depends upon the clay present, affords useful information as to the physical properties.

If separate determinations of the oxide of iron and alumina be desired, recourse must be had to any of the usual methods of separation described in manuals of analytical chemistry. A high figure may result from the presence of much ferric oxide in the soil, or in other cases it may be due to a large proportion of clay. If to the latter cause, the soil is generally also found to be well supplied with potash.

6. Lime.-The quantity given in an analysis conducted as described includes all the lime present as carbonate, phosphate and humate and a large proportion of that occurring as silicate. Its amount is of great importance, affording valuable information as to the probable fertility and manurial needs of a soil. If its amount be below 0.2 per cent, it may be assumed in most cases, that liming the soil would be advisable; but much depends upon the relative proportions of the other constituents present. Thus, in a very sandy soil, containing say 95 or 96 per cent of insoluble matter, 0.2 per cent of lime would be a relatively large amount, while in a peaty or clayey soil the same percentage of lime would be comparatively small.

In some cases, a determination of the lime existing as carbonate is useful. For methods of making such a determination, a manual on chemical analysis should be consulted.

7. Magnesia.-This constituent, though essential to plants, is usually sufficiently abundant in soils, occurring as carbonate associated with limestone and also in many silicates. Much work has recently been done in determining the most suitable ratio between the amounts of lime and magnesia in soils. This depends upon various circumstances, but, generally speaking, it is found desirable that the percentage of lime should exceed that of magnesia.

8. Potash.-This is usually the total amount of potash which can be extracted by prolonged treatment of the powdered soil with strong hydrochloric acid, and may safely be taken as a measure of the total quantity which the soil can yield to crops for many years to come. No doubt some potash in the form of refractory silicates remains in the "insoluble matter" and may be determined by the methods used for estimating potash in silicates, but such potash has probably no agricul- 
tural importance. Sandy soils are sometimes deficient in potash, as are also calcareous soils, whilst clays and loams are often well supplied.

9. Phosphoric acid.-This, the total amount of phosphorus pentoxide extracted from the ignited soil by strong hydrochloric acid, though perhaps not all that is actually present in the soil, certainly includes all that plants are likely to obtain from it. Much of the phosphoric acid of soils is doubtless present in the forms of aluminium and ferric phosphates, which are only slightly assimilable by plants. This is especially the case in soils poor in lime. The phosphorus pentoxide of a soil is often one of the most important constituents in determining its potential fertility. Its amount is generally small, rarely exceeding 0.18 per cent, while in some sandy soils it may fall as low as 0.02 per cent. Most of the soils of S. Africa are notably deficient in this constituent.

10. Total.- If the analysis of a soil were complete and perfectly accurate, this would, of course, amount to 100 per cent. In actual practice it rarely does so, and this is easily understood. In the first place, certain constituents, e.g., soda, chlorine, sulphuric acid, carbonic acid, manganese and a few others, may be present and are not always estimated, thus tending to make the "total" of those determined less than 100. Then no estimation is absolutely accurate-in all experimental determinations, errors necessarily occur, and though these errors in the various items may to some extent counteract each other, they do not often exactly do so. Consequently we find that the total of all the various constituents is rarely, and then only by coincidence, exactly 100. At the same time the approximation to this figure is a confirmation of the accuracy of the analysis, and an indication that no important amounts of any constituents have been overlooked.

11. Nitrogen.-This is the total amount of nitrogen, whether existing as nitrates (always small), ammonia, or complex organic compounds. It is in the last form that most of the nitrogen is stored in soils, and from these compounds, a gradual supply of nitrates for the plant should be maintained by the action of the nitrifying organisms.

12 and 13. "Available" potash and phosphoric acid.-As already stated, no accurate method of actually determining the amounts of potash and phosphoric acid which plants can obtain from a soil is known. Dyer's method, although it is admitted that it gives only empiric results, is believed to furnish the best measure of these amounts, and has been employed in many analyses.

Many attempts have been made to express the fertility of a soil by some figure, generally derived by giving arbitrary values to each of the important plant food constituents and adding these together. But these attempts have not been successful and have never met with much acceptance. Indeed it is difficult to see how any numerical expression of fertility could be arrived at, even if only the chemical composition of the soil be considered. Practical fertility, depending as it does upon so many circumstances, would be still harder to express. The physical and mechanical properties of the soil are difficult to measure, and when the size of particles, water retentive power, etc., are measured, it is still almost impossible to interpret them. Much 
attention has been and is being given to a study of the mechanical composition of soils, especially in America, but, so far, it is not exactly clear how the results are to be co-ordinated with fertility.

Summary.-In considering the results of a chemical analysis of a soil, the most important data are:-

1. The nitrogen and organic matter.

2. The total phosphoric acid, lime and potash.

3. The "available" phosphoric acid and potash.

4. The presence or absence of injurious ingredients ("alkali " ferrous compounds, etc.).

The first two afford the best means of gauging the potential fertility, i.e., the actual amounts of plant food which the soil can supply, and which therefore determine the limit of the number of crops which the soil can carry without manure. The third affords the best criteria as to a soil's requirements with respect to phosphatic and potash manures, or gives the best means of estimating the actual present fertility of the soil. In this connection, the limits to be taken as indicating need of manuring are somewhat uncertain, and the best and most reliable method would be to compare the figures for the soil in question with those obtained from the analysis of similar soils of known fertility.

In all cases it is well to keep in mind Liebig's "law of minimum," viz., that the limits of fertility are fixed by the amount of the particular constituent of plant food which is most deficient in the soil under consideration. For example, if a soil be lacking in phosphates, applications of potash or nitrogenous manures will not enable it to give a full crop.

Examples of Actual Analyses. - This chapter may conclude with a few examples of analyses of soils, in order to illustrate the points discussed. The following table gives the figures derived from analyses, made in most cases by the writer, of a few typical English and Transvaal soils, and will serve to show some of the main points of difference between soils of various classes and particularly between those of tropical and temperate countries:-

A is a good English pasture soil, a sandy loam, from the coal measures.

$\mathrm{B}$ is an arable sandy loam also from the coal measures.

C is a sandy soil, poor in plant food.

$D$ gives the median values from analysis of 100 soils of the county of Dorset. ${ }^{1}$

$\mathrm{E}$ is a "black turf"- a peaty clay soil of the Transvaal.

$\mathrm{F}$ is a red clay soil of the Transvaal.

$\mathrm{G}$ is a chocolate-coloured clay soil of the Transvaal.

$\mathrm{H}$ is a chocolate loam.

I is typical of red and brown loams.

$J$ is typical of red sandy soils.

$\mathrm{K}$ is a brown sandy soil.

$\mathrm{L}$ is a representative of grey and yellow sandy soils.

The most noticeable feature in the above table is the comparative

${ }^{1}$ The Soils of Dorset, Dr. Luxmoore, Aug., 1907. 


\begin{tabular}{|c|c|c|c|c|}
\hline$\mapsto$ & $\stackrel{\infty}{\infty}$ & 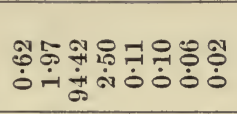 & $\begin{array}{l}\mathscr{D} \\
\stackrel{\mathscr{D}}{\mathscr{S}}\end{array}$ & 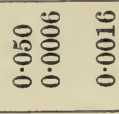 \\
\hline$\approx$ & $\stackrel{\oplus}{\dot{0}}$ & 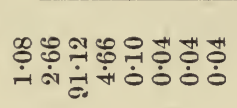 & $\stackrel{\mathbb{2}}{\stackrel{\mathscr{S}}{8}}$ & 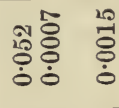 \\
\hline$r$ & ๓ึ & 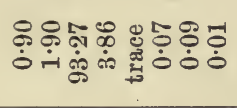 & $\stackrel{9}{\dot{8}}$ & 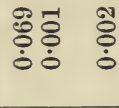 \\
\hline$\mapsto$ & के & 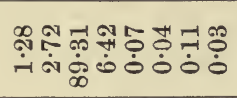 & $\begin{array}{l}\infty \\
\stackrel{\leftrightarrow}{\circ} \\
\dot{\mathscr{S}}\end{array}$ & $\begin{array}{ll}0 & 0 \\
0 & 0 \\
0 & 0 \\
0 & 0 \\
0 & 0\end{array}$ \\
\hline II & $\stackrel{20}{\stackrel{20}{0}}$ & 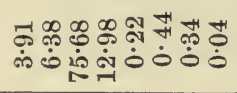 & $\begin{array}{l}\stackrel{\dot{\sigma}}{\dot{S}} \\
\dot{\sigma}\end{array}$ & $\begin{array}{ll}20 & 0 \\
\text { Nै } & 0 \\
\dot{0} & 0 \\
0 & \dot{0}\end{array}$ \\
\hline ש & $\ddot{9}$ & 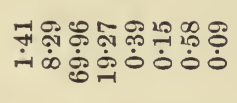 & $\underset{\mathscr{\delta}}{\dot{\delta}}$ & 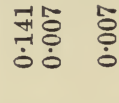 \\
\hline Ex & ழ̊ & 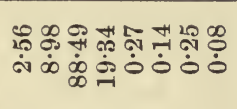 & $\underset{-1}{\stackrel{20}{8}}$ & 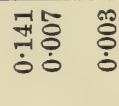 \\
\hline$\Leftrightarrow$ & 1 & 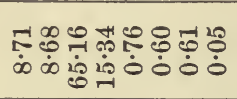 & क्் & 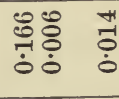 \\
\hline A & $\stackrel{\varphi}{\dot{\infty}}$ & 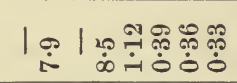 & 1 & $\begin{array}{ll}\text { ๓๐ } & 0 \\
\text { ஸे } & 0 \\
\dot{0} & \dot{0}\end{array}$ \\
\hline ס & I & 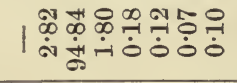 & 1 & $\stackrel{+}{+} 1$ \\
\hline$\infty$ & 蚛 & 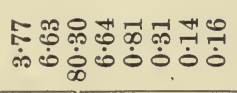 & $\stackrel{\mathscr{2}}{\mathscr{\infty}}$ & 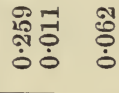 \\
\hline 4 & 1 & 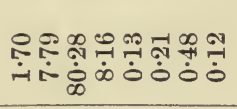 & 1 & 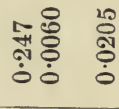 \\
\hline & 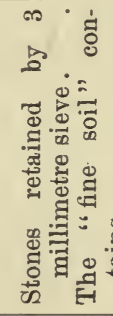 & 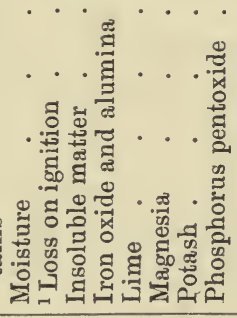 & 胥 & 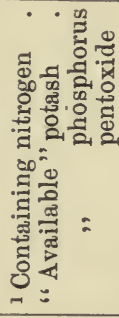 \\
\hline
\end{tabular}

poverty of Transvaal soils in nitrogen, phosphorus pentoxide and lime. English soils contain, as a rule, from 0.15 to 0.30 per cent of nitrogen, and from 0.1 to 0.25 per cent of phosphorus pentoxide, while, in most eases, Transvaal soils contain less than 0.15 and often less than 0.08 
per cent of nitrogen and rarely as much as $0 \cdot 1$ per cent of phosphorus pentoxide, and generally much less.

On the other hand, Transvaal soils are usually well supplied with potash. In spite of their apparent poverty, however, soils of tropical countries are often capable of yielding good crops. It is evident, therefore, that in judging soils from analytical results, consideration must be given to other circumstances than actual composition. Doubtless, important factors are the rates at which nitrification and other chemical changes occur, the porosity and friability of the soil, as affecting root development and the favouring influences of high temperature, abundant moisture and sunlight upon plant growth.

It is clearly difficult to establish any standard of composition as indicating relative fertility and in any case, comparisons of the compositions of two soils can only be expected to afford indications of their relative fertility when the soils are in the same locality or exposed to the same climatic conditions. 


\section{CHAPTER VI.}

\section{Manuring and General Manures.}

From what has been said in Chapters III, IV and V, it is evident that the fertility of a soil depends upon a number of circumstances; among others, upon the existence of suitable relationships between its properties regarded from-

(1) Mechanical,

(2) Chemical,

(3) Biological,

points of view.

(1) The possession of the proper fineness of subdivision, porosity, water-holding power, and other physical properties is essential to permit of the ready growth of a plant's roots, to afford the necessary mechanical support and access of air to the roots, and to provide them with a due supply of moisture. If these properties are lacking, no matter how rich the soil may be, it cannot possess, in the highest degree, true fertility.

(2) So, too, from a chemical standpoint, the possession of a suitable store of plant food in an available condition is obviously necessary. If the plant food, or any part of it, be present in insufficient amount, or in a completely insoluble or unavailable form, the soil, however suitable in mechanical structure, must be incapable of yielding the best results.

(3) The conversion of one of the most important constituents of plant food, nitrogen, from a state of combination in the insoluble, highly complex organic substances associated with humus into the directly assimilable nitrates, is, as already described (Chap. IV), accomplished by the action of micro-organisms, so that it is evident that the realisation of one of the above conditions-as to availability of plant food in the soil-can only be effected if the necessary micro-organisms or their spores are present. Even more dependent upon the presence of suitable micro-organisms is the utilisation of the free atmospheric nitrogen by the leguminosa. Fungi, yeasts and other low forms of vegetable life, as well as worms, caterpillars and larvæ, also play an important part in altering both the physical and chemical properties of soil. Unfortunately, in the case of the latter organisms, their influence on the plant itself often exceeds in importance their effect on the soil.

Improvements in the soil are naturally the aim of the agriculturist. As regards its physical condition, much can be done by tillage operations-ploughing, harrowing, draining, etc.-also by the introduction of materials which affect the mechanical properties of its constituents, e.g., lime, and bulky vegetable refuse.

With reference to the actual plant food in a soil, improvements can be effected in two ways- 
(1) The addition of substances containing plant food.

(2) The addition of substances which may act upon the insoluble compounds present in the soil and render available the plant food they contain.

As to improvement in its biological qualities, little has hitherto been done, but probably in the future, this may be a direction from which considerable help may be derived.

The destruction of insect pests, and the eradication of organisms producing diseases in crops or in animals feeding upon the land, are problems which have already been studied with some success. A certain amount of progress, too, has been made in devising means for inoculating the soil or seed with desirable micro-organisms, as witness the commercial production of "alinit" and "nitragin". 1 Proposals to regulate nitrification by the application of antiseptics, so as to lessen the autumnal loss of nitrates in the drainage, have been made ${ }^{2}$; but, so far as the author is aware, these methods have not sufficiently commended themselves to the practical farmer to be adopted to any extent on the large scale.

It is with the improvements in the chemical state of the soil that this chapter has mainly to deal.

These are effected by the application of Manures. The word manure has apparently a connection with the Latin manus-a handand was probably used because of an old belief that the main function of a manure was, by its fermentation in the soil, to aid in the work of pulverisation usually brought about by hand labour, i.e., tillage.

This aspect of the matter was strongly held by Jethro Tull, who, about the middle of the eighteenth century, wrote a book entitled, "Horse-hoeing Husbandry," in which he attempted to prove that by sufficiently tilling the ground, manures might be rendered unnecessary.

"Manure" is no longer used in this sense, but it is now the name given to any material which is intended, by its application to the soil, to restore those constituents which have been removed by cropping and thus to render it possible for the soil to supply another crop with a sufficiency of plant food.

The constituents of a soil which are most liable to be deficient in amount, and which it is therefore advisable to replenish by manuring, are combined nitrogen, phosphates and potash compounds.

Manures, therefore, are usually valued according to their richness in these three constituents, though in the case of many so-called natural manures, e.g., farm-yard manure, many other constituents which may serve as useful items of plant food are also present.

Manures are variously classified; sometimes in a somewhat loose manner, into-

1. Natural Manures.

2. Artificial Manures.

By natural manures are usually meant those produced on the farm itself ; they consist mainly of the remains of plants and animals.

${ }^{1}$ See pp. 65 and 68.

${ }^{2}$ Dehérain, vide p. 65. 
By artificial manures are indicated products either derived from mineral deposits or manufactured in the arts, though the term is often extended to substances of animal or vegetable origin, which are not produced on the farm. In this sense, guano, sea-weed, oil-cakes and other substances are sometimes classed as artificial manures.

Another, perhaps more satisfactory classification, is into-

1. General Manures.

2. Special Manures.

A general manure is one which contains all the necessary constituents of plant food and thus imparts, to the soil to which it is applied, a complete store of the nutriment required for fertility. Examples of such manures are afforded by farm-yard manure, guano and most plant and animal remains.

A special manure contains only one or two constituents of plant food, and cannot therefore supply all the requirements of plants. Nitrate of soda, sulphate of ammonia, potash manures and phosphates are good examples of this class.

General manures are the safest to employ in practice, especially when the manurial requirements of the soil are not well known, for though, by their use, the soil may be receiving additions of certain constituents which it does not require, such additions do no harm and a better crop results from the increased supply of the other constitnents in which the soil may be lacking.

Special manures, however, if intelligently employed, possess great advantages and are often more economical. By their aid, the farmer, if sufficiently well informed, is enabled to supply the soil with just those constituents which it most needs, without the waste of labour and expense entailed by using materials which are not necessary.

To regard manures with reference to their chemical composition only and to value them exclusively by the amounts of plant food which they contain, is, however, distinctly erroneous. All manures have some influence upon the texture and physical properties of the soil, while some also exert a powerful effect upon the activity and development of the micro-organisms of the soil, and in these ways produce effects upon its fertility, apart altogether from their power of supplying one or more items of plant food.

But to ascribe the beneficial effect of the application of manures to soil, solely to their physical action in altering its mechanical properties, as seems to have been done recently by certain American writers, is contrary to the experience of many years and to the results of thousands of field trials, and cannot be seriously considered. It is true that the mechanical effects of bulky organic manures, e.g., farm-yard manure, upon light, sandy soils is often very great and sometimes, perhaps, as important as their power of supplying plant food. Even with concentrated "artificial" manures, marked effects upon the texture of the soil are often produced and doubtless greatly affect its fertility. Examples are seen in the beneficial action of manures containing free lime upon heavy, clay soils, while repeated applications of nitrate of soda to such soils, render them more plastic and tenacious and 
generally less suited for the development of roots in them. But to believe that such manures as nitrate of soda, sulphate of ammonia, potash salts, or superphosphates owe their efficiency solely to their physical action on the soil, seems absurd. If it were so, it is difficult to see why other saline compounds, not containing the essential elements of plant food-nitrogen, potassium, or phosphoric acid-should not produce the same effect, for it is highly probable that precisely similar physical action upon the soil would be produced by other salts.

Nor does the more recent attitude assumed by the supporters of this American theory, viz., that the beneficial effect of manures is to be attributed to their destructive action on the toxic substances produced in the soils, either by the growth of the plants themselves or by bacterial action, seem, as yet, to be supported by sufficiently strong evidence to justify its general adoption.

It is, however, evident that the effects of the application of a manure to soil are complicated and cannot be adequately explained by merely considering its influence in increasing the store of plant food. This last influence, nevertheless, must be of importance, and if the store of available plant food, rather than that of total plant food be considered, it is probably the greatest factor involved.

The special manures, on account of their more definite character and simpler chemical constitution might, perhaps, with advantage, be considered first, but the more extended use and greater importance in farming practice, of the more complex, general manures justify their being given the preference. In this chapter, therefore, an account of the more important general manures will be given, to be followed, in the next chapter, by a description of the special manures.

\section{GENERAL MANURES.}

Farm-yard Manure.-This has long been the most popular manure used on the farm. It would seem that, inasmuch as it contains the remains of the vegetable substances used as food and litter on the farm, it should be a most suitable means of restoring to the land the ingredients removed from it in the crops. A little thought, however, will show that it cannot completely restore such losses. Some of the crops are sold; often these are particularly rich in nitroger, potash and phosphates, and of those eaten by the animals of the farm, only a portion is voided as excrement-the animal has to build up its body out of the materials supplied in its food. This consumes large quantities of plant food, particularly of nitrogen and phosphates. Then, too, the production and sale of milk removes large quantities of manurial ingredients from the soil, and though butter contains little other than carbonaceous material, cheese is highly nitrogenous.

It will be advisable to consider briefly the chemical nature of the raw materials which go to form the average farm-yard manure. The ingredients of this substance may be first divided into two groups :-

1.- Animal excrements, both solid and liquid.

2.- Litter and waste food materials.

The excreta of animals consist of the undigested parts of the food consumed by them, together with excretions consisting of effete matters 
resulting from waste of their tissue and the water drunk by them which they have not exhaled as vapour from their lungs or skin.

The chemical nature and the total quantity of the excreta depend very largely upon the character and quantity of the food supplied. This is especially true of the solid portion, which consists mainly of the undigested matter of the food, but contains also certain products derived from the digestive fluids, e.g., the bile and the pancreatic juice.

The liquid portion of the excreta, on the other hand, consists mainly of water, holding in solution substances produced by the wear and tear of the muscles, etc., of the animal, these waste products being separated from the blood stream of the animal by appropriate organs. Of course these matters originally came from the food, but they are not the immediate products, as are most of the constituents of the solid excreta.

Both the liquid and solid portions of the excreta contain large quantities of substances of little or no value as fertilisers directly; but, inasmuch as they readily undergo putrefactive changes resulting in the liberation of carbon dioxide and other gases, and the production of bulky carbonaceous substances akin to humus in their nature, these ingredients are of considerable importance in determining the effect of farm-yard manure on land.

The chemical character of the excreta produced on the farm, depends upon a number of conditions-the food, the breed of animals kept, their age, whether fattening, working, or milking, and other circumstances.

Obviously, if an animal is growing in size, or is yielding milk, its food must contain much more of the important flesh-forming constituents than its excreta; while in the case of an animal not increasing in size nor providing milk, one might expect that the excreta would contain practically all the matters contained in its food, with the exception of those consumed in respiration. Remembering these facts, it is not surprising to find, among published analyses of the excrements of animals, considerable discrepancies.

The following table gives the percentage amounts of the most important manurial constituents of the excrements of the common animals ${ }^{1}:-$

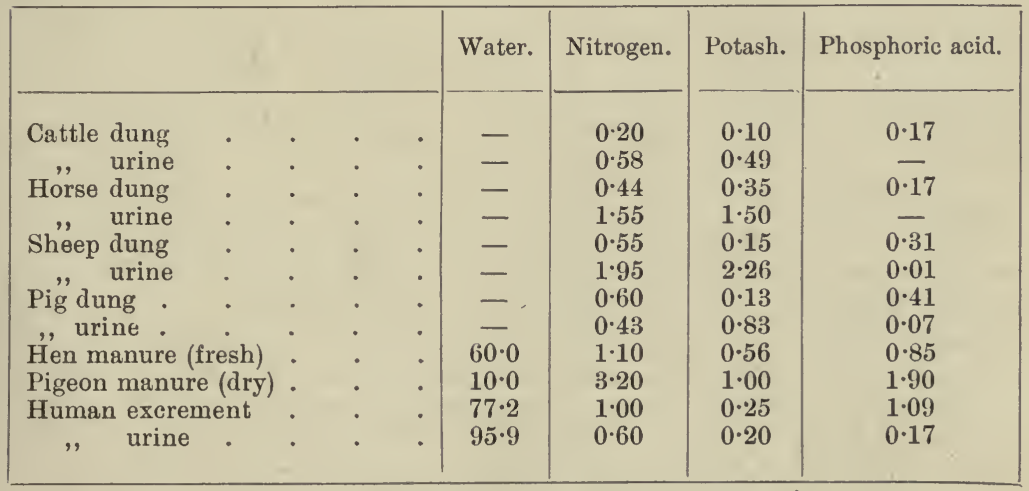

${ }^{1}$ U.S. Dept. of Agriculture, Bulletin 15, 1893. 
The following table gives analyses of the excrements of the common farm animals and of man. The figures are quoted by Storer ${ }^{1}$ from analyses by Stoeckhardt and Way:-

\section{PERCENTAGE COMPOSITION OF ANIMAL EXCREMENTS.}

\begin{tabular}{|c|c|c|c|c|c|c|c|c|c|c|}
\hline & \multicolumn{5}{|c|}{ Solid excrement. } & \multicolumn{5}{|c|}{ Liquid excrement. } \\
\hline & Sheep. & Pigs. & Horses. & Cows. & Men. & Sheep. & Pigs. & Horses. & Cows. & Men. \\
\hline Water & 58 & 80 & 76 & 84 & 75 & $86 \cdot 5$ & $97 \cdot 5$ & $89 \cdot 0$ & $92 \cdot 0$ & $97 \cdot 0$ \\
\hline Solid matter & 42 & 20 & 24 & 16 & 25 & $13 \cdot 5$ & $2 \cdot 5$ & $11 \cdot 0$ & $8 \cdot 0$ & $3 \cdot 0$ \\
\hline Ash . & 6 & 3 & 3 & $2 \cdot 4$ & $2 \cdot 9$ & $3 \cdot 6$ & $1 \cdot 0$ & $3 \cdot 0$ & $2 \cdot 0$ & $1 \cdot 0$ \\
\hline Organic matter & 36 & 17 & 21 & $13 \cdot 6$ & $22 \cdot 1$ & $9 \cdot 9$ & $1 \cdot 5$ & $8 \cdot 0$ & $6 \cdot 0$ & $2 \cdot 0$ \\
\hline Nitrogen . & 0.75 & $0 \cdot 6$ & 0.5 & $0 \cdot 3$ & 1.5 & $1 \cdot 4$ & $0 \cdot 3$ & $1 \cdot 2$ & $0 \cdot 8$ & 0.6 \\
\hline $\begin{array}{c}\text { Phosphorus pent- } \\
\text { oxide }\end{array}$ & 0.6 & 0.45 & 0.35 & $0 \cdot 25$ & $1 \cdot 1$ & 0.05 & 5.12 & - & - & 0.05 \\
\hline Alkalies . & $0 \cdot 3$ & 0.5 & $0 \cdot 3$ & $0 \cdot 1$ & $0 \cdot 4$ & $2 \cdot 0$ & 0.2 & 1.5 & $1 \cdot 4$ & $0 \cdot 15$ \\
\hline Lime and magnesia & $1 \cdot 5$ & $0 \cdot 3$ & $0 \cdot 3$ & $0 \cdot 4$ & 0.8 & 0.6 & 0.05 & 0.8 & $0 \cdot 15$ & 0.03 \\
\hline Sulphur trioxide. & 0.15 & 0.05 & $0 \cdot 05$ & 0.05 & 0.05 & 0.4 & 0.05 & $0 \cdot 15$ & $0 \cdot 15$ & 0.01 \\
\hline Common salt & 0.025 & 0.05 & trace & 0.005 & 0.05 & $0 \cdot 25$ & 0.5 & 0.2 & $0 \cdot 1$ & 0.6 \\
\hline Silica . . & $3 \cdot 2$ & $1 \cdot 6$ & 20 & $1 \cdot 6$ & $0 \cdot 4$ & trace & trace & $0 \cdot 025$ & 0.01 & - \\
\hline
\end{tabular}

From the preceding tables, it will be seen that the excrements of the sheep are less watery than those of the other animals, while the solid excrement of the cow and the urine of pigs are richest in water.

Other analyses of the excrements of horses and cows have been published by Boussingault and by Audoynaud and Zacharewicz. ${ }^{2}$ The results, expressed in percentages, were as follows :-

\begin{tabular}{|c|c|c|c|c|c|c|}
\hline \multirow[t]{2}{*}{$\cdot$} & \multicolumn{3}{|c|}{ Boussingault. } & \multicolumn{3}{|c|}{ Audoynaud and Zacharewicz. } \\
\hline & Nitrogen. & Potash. & $\begin{array}{l}\text { Phosphorus } \\
\text { pentoxide. }\end{array}$ & Nitrogen. & Potash. & $\begin{array}{l}\text { Phosphorus } \\
\text { pentoxide. }\end{array}$ \\
\hline $\begin{array}{l}\text { Cow urine } \\
\text {,, dung. } \\
\text { Horse urine } \\
\text {,, dung }\end{array}$ & $\begin{array}{l}1 \cdot 12 \\
0 \cdot 44 \\
1 \cdot 56 \\
0 \cdot 57\end{array}$ & $\begin{array}{l}1 \cdot 39 \\
0 \cdot 04 \\
1 \cdot 06 \\
0 \cdot 15\end{array}$ & $\begin{array}{l}\overline{0.14} \\
\text { trace } \\
0 \cdot 40\end{array}$ & $\begin{array}{l}0 \cdot 97 \\
0 \cdot 42 \\
1 \cdot 48 \\
0.55\end{array}$ & $\begin{array}{c}1 \cdot 32 \\
\text { trace } \\
0 \cdot 80 \\
\text { trace }\end{array}$ & $\begin{array}{l}\text { trace } \\
0 \cdot 10 \\
\text { trace } \\
0 \cdot 30\end{array}$ \\
\hline
\end{tabular}

In the paper referred to, the authors estimate the annual yield per cow at 31.5 kilograms of nitrogen and 40.8 kilograms of potash in the urine and 42 kilograms of nitrogen, $4 \cdot 2$ of potash, and 12 of phosphorus pentoxide in the dung; while in the total excreta of one horse per annum will be 37.8 kilograms of nitrogen, 13.1 of potash, and $14 \cdot 4$ of phosphorus pentoxide. They think that the potash in dung is that existing in the food as inorganic salts, while that in the

${ }^{1}$ Agriculture in some of its Relations to Chemistry, Vol. I, p. 489.

2 vide Abstract in Jour. Soc. Chem. Ind., 1886, 541. 
urine existed in the food in combination with organic acids. They found a deficiency of potash in the excreta, even after allowance for that removed in the milk of the cows and the growth of the bodies of the animals. They account for this by attributing it to loss through the skin. The dust removed from the skin by currycomb and brush, contained from 2 to 2.2 per cent of potash in the rase of cows and from $7 \cdot 4$ to $9 \cdot 7$ per cent in that of horses. ${ }^{1}$ A much larger amount of potash is exuded from the skin of sheep.

The "kraal manure" of S. Africa consists of the excrement of animals kept (generally only during the nights) in enclosures, mixed with a little soil, but with little or no litter. Analyses of air-dried deposits from sheep kraals were made by Croghan ${ }^{2}$ in 1905 , who found, in twenty-five samples, figures ranging as follows :-

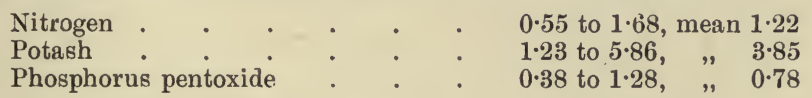

The composition of the excreta of animals is liable to such enormous variations in composition, according to the nature of the food and other conditions, that it is almost impossible to give any average figures.

As showing how variable the utilisation of the ingredients of food may be, in the case of animals living under different conditions, the following table may be quoted from Warington ${ }^{3}$ as giving the destination of the nitrogen supplied in the food. For every $100 \mathrm{lb}$. of nitrogen consumed-

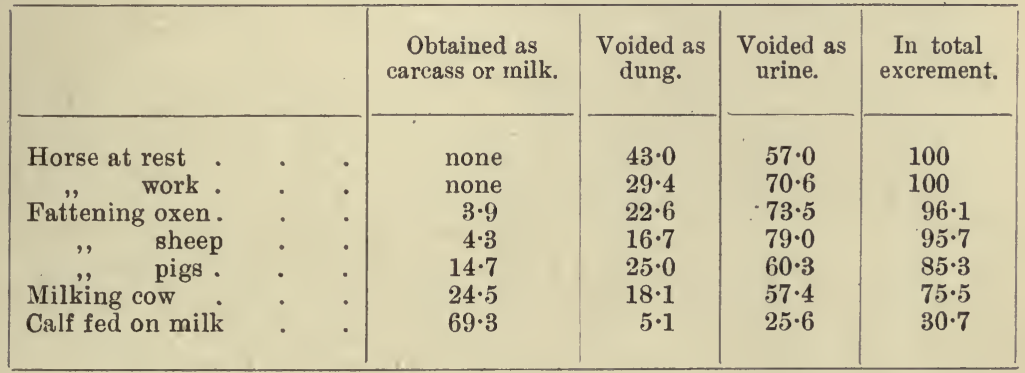

As has already been stated, the dung consists mainly of the undigested portion of the food mixed with a certain amount of the residue from the bile and other digestive fluids. It is therefore to be expected

${ }^{1}$ An analysis of the perspiration of a horse was published by Smith (Journal of Physiology, 11, 497; also Jour. Chem. Soc., 1891, Abstracts, 349) :-

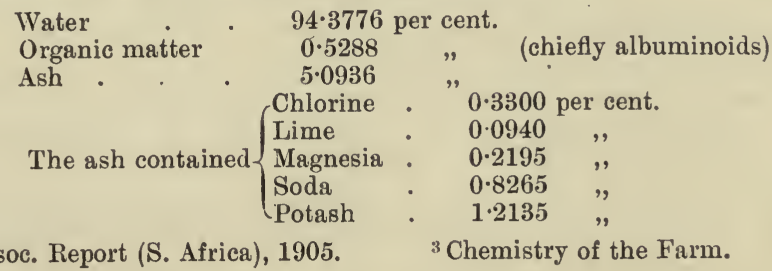

${ }^{2}$ Brit. Assoc. Report (S. Africa), 1905.

${ }^{3}$ Chemistry of the Farm. 
that the amount of plant food, say nitrogen, in the solid excrement, will be greater, the less digestible the food consumed.

The composition of the excreta of animals depends greatly upon that of their food. This is well known, and as will be discussed in a later chapter, is the basis upon which manurial residues of foods are based. In a paper on "The distribution of manure values of foods between dung and urine," ${ }^{1}$ Crowther emphasises the very high proportion of the total manurial value which is contained in the urine of farm animals. After considering, in detail, the cases of fattening oxen, horses, milch cows and young growing animals, he arrives at the conclusion that the total liquid excreta, as they leave the animals, possess from three to four times the manurial value of the total solid excrements, so far as these manurial values are determined by the chemical composition of the fresh excreta. Owing, however, to the ready decomposition of the nitrogenous constituents of urine, the ratio tends to diminish rapidly when the excreta are kept, unless special precautions against loss of nitrogen are taken. He considers that 40 per cent of the nitrogen of the urine is probably the average loss, during storage, of farm-yard manure. Even after suffering this loss, the manurial value of the urine produced by an animal greatly exceeds that of the solid excrement.

In the estimation of the money values employed in the calculations, the following values were ascribed to the manurial ingredients:-

Digestible nitrogen (that in urine) .

Indigestible nitrogen (that in dung)

Phosphorus pentoxide

Potash

$$
\begin{aligned}
& \text { d. } \frac{1}{2} \text { per lb. }=12 \frac{\text { s. }}{1} \text { per unit. } \\
& 2 \frac{1}{4}, \quad=42 \text {, , } \\
& 1 \frac{1}{2}, "=29 \frac{1}{2}, \\
& \text {, = } 39^{2},
\end{aligned}
$$

The urine is assumed to contain all the nitrogen in the digestible protein of the food, except that retained by the animal in the form of increase of weight, or in milk production, and 85 per cent of the total potash, while the dung is assumed to contain all the nitrogen in the indigestible protein, all the phosphoric acid of the food, except that in the increase or milk, and 15 per cent of the total potash of the food.

The litter and waste food.-Litter serves several useful purposes. Besides the obvious advantages attending its use from the point of view of cleanliness and comfort for the animal, it also fulfils several other functions. It greatly increases the bulk of the manure, rendering it more porous and therefore better able to retain the valuable liquid portion of the excreta, it provides a large amount of carbonaceous matter which will eventually be converted into humus, and it adds its quota of plant food, small though it be. It has a considerable effect upon the various fermentative changes which the excreta of animals so readily undergo, both by its influence on the porosity and consequent admission of air and also by the micro-organisms with which it is said to be often abundantly supplied.

Various substances are used as litter in different districts. The following are the chief :-

${ }^{1}$ Trans. High. and Agric. Soc. Scotland, 1910, 125. 

1. Straw.
4. Dried leaves.
2. Peat or peat moss.
5. Sawdust.
3. Dried bracken.
6. Tanners' refuse.

Straw is the material most largely used as litter on the farm. Its composition varies considerably, but it always consists mainly of woody fibre, cellulose, etc., which have practically no manurial value; its nitrogen, phosphoric acid and potash are always small in quantity. The average proportion of manurial constituents in the straw of different plants is seen in the following table:-

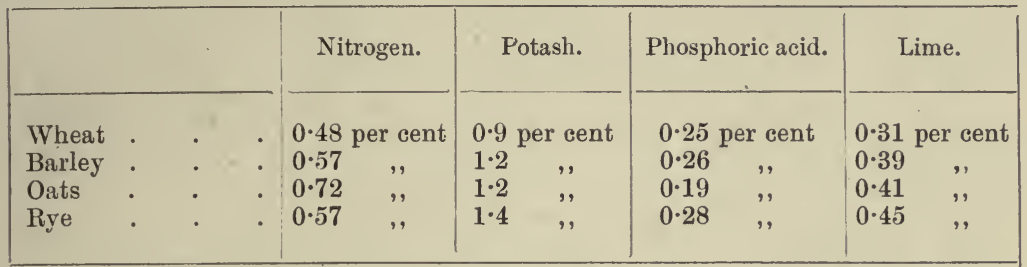

A point which has recently attracted great attention is the general occurrence of denitrifying organisms on the outsides of the stems of wheat and other straws (see Chap. IV).

Mingled with the litter, there are generally considerable quantities of the wasted fodder supplied to the cattle or horses, consisting often of hay or straw. The manurial value of such material is similar to that of the straw used as litter.

Peat, or better, peat moss, is largely used as litter in Germany, and, to some extent, in town stables in England. It possesses great porosity and absorptive powers for liquids, and in itself often contains a considerable quantity of nitrogenous matters, varying in different samples from 0.3 to as high as 2.0 per cent. It also has strong absolptive powers for gases, e.g., ammonia, and acts as an antiseptic in preventing the too rapid putrefaction of the organic matter of the excreta and the injury to the health of the animals resulting from such putrefaction. The manure produced is richer, especially in nitrogen, than that produced by straw.

The chief manurial constituents of peat, according to American analyses, ${ }^{1}$ are as follows :-

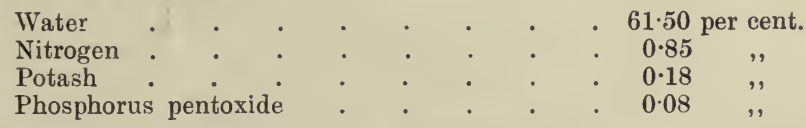

Dyer found in peat moss and wheat straw-

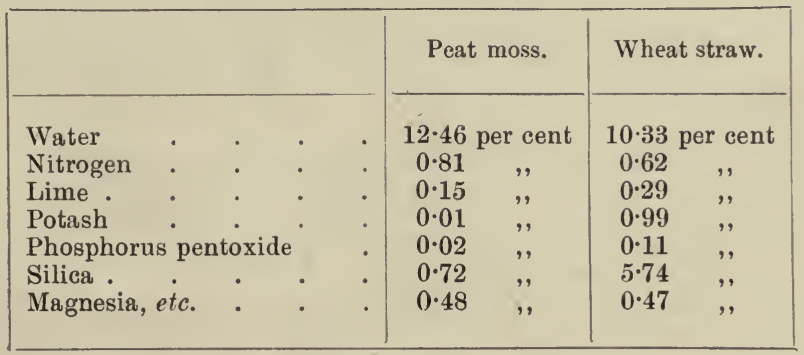

${ }^{1}$ U.S. Dept. of Agric., Bulletin 15, 1893. 
Analyses of fibres extracted from peat obtained in Würtemburg and Silesia and of moss litter from North Germany, were made by Fleischer ${ }^{1}$ in 1883 :-

\begin{tabular}{|c|c|c|c|c|}
\hline & & $\begin{array}{l}\text { Wirtemburg } \\
\text { fibre. }\end{array}$ & $\begin{array}{l}\text { Silesian } \\
\text { fibre. }\end{array}$ & $\begin{array}{l}\text { German } \\
\text { peat moss. }\end{array}$ \\
\hline $\begin{array}{l}\text { Nitrogen } \\
\text { Phosphorus pentoxide } \\
\text { Lime }\end{array}$ & $\begin{array}{l}\dot{5} \\
\dot{ }\end{array}$ & $\begin{array}{l}2 \cdot 20 \text { per cent } \\
0 \cdot 06 \text {, ", } \\
1 \cdot 72 \text {, }\end{array}$ & $\begin{array}{l}2 \cdot 90 \text { per cent } \\
0 \cdot 06 \quad, \quad, \\
3 \cdot 10 \quad,\end{array}$ & $\begin{array}{l}0.90 \text { per cent } \\
0.04 \quad, \\
0.20 \quad ",\end{array}$ \\
\hline
\end{tabular}

Peat sometimes contains iron pyrites, and in some cases, arsenic is present in the pyrites. The manure made with such peat may be destructive to plant life.

Dried bracken is often used as litter in mountainous and thickly wooded districts, e.g., in the English Lake district and the New Forest, in Scotland and Ireland, and in certain parts of Germany.

It is not so absorbent as other litters, but is of value on account of its composition. This varies with the age at which it is cut and with other circumstances. A dried sample examined by Homberger ${ }^{2}$ contained 0.706 per cent nitrogen, 0.13 per cent potash, and 0.12 per cent phosphorus pentoxide, while two samples examined by J. Hughes contained in one case (young plants) 2.42 per cent nitrogen, $1 \cdot 15$ per cent potash, and 0.6 per cent phosphorus pentoxide, while in the other (old plants) there were only 0.90 per cent nitrogen, 0.10 potash, and 0.30 of phosphorus pentoxide.

Dried leaves.-These are only rarely used and are not of much value. According to numbers obtained from American investigations, ${ }^{3}$ autumn leaves contain about-

$0 \cdot 75$ per cent nitrogen,

$0 \cdot 10$ to $0 \cdot 50$ per cent potash,

$0.06,0.30 \quad, \quad$ phosphorus pentoxide.

Sawdust is used in stables in large towns. It has good absorptive powers, and, according to Storer (just quoted), contains about-

1.0 per cent nitrogen,
$0.10 \quad " \quad$ potash,
$0.05 \quad " \quad$ phosphorus pentoxide.

It renders horse manure very open and porous and therefore favours. rapid oxidation and fermentation, sometimes to a harmful extent. It would be less objectionable as a litter for cows. The turpentine found in pitch-pine sawdust may seriously retard its decomposition in the soil.

Tanners' refuse.-This is sometimes used as a litter, but is of comparatively little value. Storer gives as its average composition-

1 Jour. Chem. Soc., 1884, Abstracts, 105.

2 Ibid., 1886, Abstracts, 485.

${ }^{\Im}$ Quoted by Storer, Agriculture, etc., Vol. I, p. 446. 


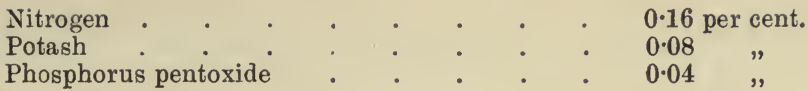

Farm-yard manure consists usually of the mixed excrements of the animals of the farm, together with the litter used for their bedding. To it are added any waste organic matters occurring near the farmstead, including animal offal of various kinds, vegetable refuse, and, too often, the waste matter from the thrashing machine, which often contains the seeds of weeds.

According to German authorities, the average amount of manure yielded per day per head by the various animals of the farm, may be taken as the following:-

\begin{tabular}{|c|c|c|c|c|c|c|}
\hline & & $\sigma_{0}$ & & Total excrement. & Straw required. & Nitrogen in whole. \\
\hline $\begin{array}{l}\text { Horse } \\
\text { Cow } \\
\text { Pig } \\
\text { Sheep }\end{array}$ & $\dot{.}$ & $\begin{array}{l}\dot{5} \\
\dot{5}\end{array}$ & $\dot{.}$ & $\begin{array}{cc}28 & \text { lb. } \\
73 & , \\
8 \cdot 3 & ", \\
3 \cdot 8 & ,\end{array}$ & $\begin{array}{ll}5 & \text { lb. } \\
8 & , \\
4 & , \\
0.6 & ,,\end{array}$ & $\begin{array}{l}0.19 \mathrm{lb} . \\
0.28 \quad, \\
0.07, " \\
0.04,\end{array}$ \\
\hline
\end{tabular}

American ${ }^{1}$ estimates are much higher :-

\begin{tabular}{|c|c|c|c|c|c|}
\hline \multirow{2}{*}{ Animal. } & \multirow{2}{*}{ Food. } & \multirow{2}{*}{$\begin{array}{l}\text { Manure } \\
\text { per day. }\end{array}$} & \multicolumn{3}{|c|}{ Composition of manure. } \\
\hline & & & Nitrogen. & Potash. & $\begin{array}{l}\text { Phosphorus } \\
\text { pentoxide. }\end{array}$ \\
\hline Cow & $\begin{array}{l}\text { Hay, silage, bran, cot- } \\
\text { ton-seed meal, etc. }\end{array}$ & $81.5 \mathrm{lb}$. & 0.50 per cent & 0.29 per cent & 0.45 per ce \\
\hline Horse $^{2}$ & Hay and oats & $52 \cdot 5$, & $0.47^{2}$, & $0.94 \quad$, & $0.39 \quad$, \\
\hline Sheep & Grain, beets and hay & $7 \cdot 2$, & $1 \cdot 00$ & $1 \cdot 21$ & 0.08 \\
\hline Pig & Maize meal & $3 \cdot 5$, & $0 \cdot 83$ & 0.61 & $0 \cdot 04$ \\
\hline
\end{tabular}

The composition of the manure produced on a farm must vary considerably owing to a great number of varying conditions. It is obvious, therefore, that any particular analysis is of little value as a means of judging of the nature of manure produced in other cases. Large numbers of analyses have been published, some showing, in great detail, the substances present. An often quoted series of analyses of farm-yard manure was made by Voelcker many years ago.

A summary of his results, as quoted by Storer, ${ }^{3}$ is here given :-

${ }^{1}$ Bull. 27 of the New York Cornell Station.

2 The horses were working. The quantities are estimated on the assumption that three-fifths of the manure was collected.

${ }^{3}$ Agriculture, etc., Vol. I, p. 521. 


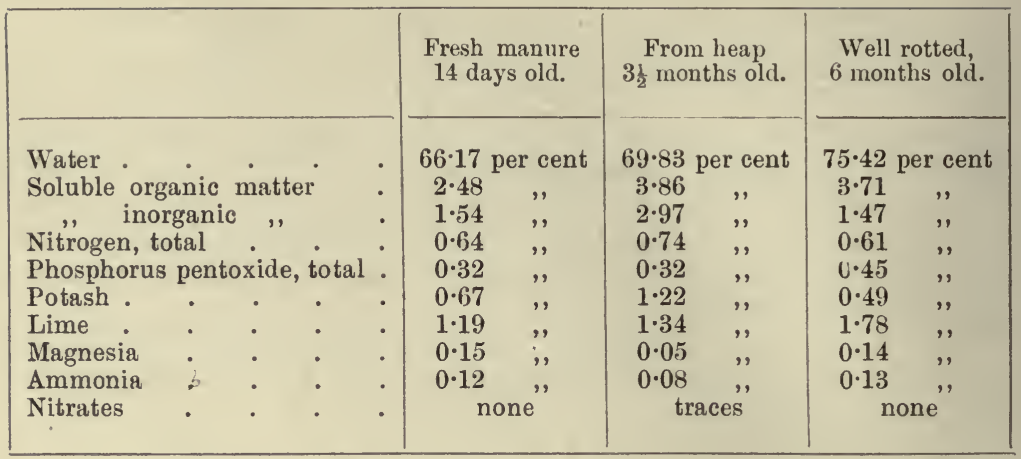

Fermentation of Farm-yard Manure.-Fresh manure soon begins to ferment and to change its character. This is due to the effect of the micro-organisms which find a suitable breeding ground in the complex organic substances present in the manure. An account of the bacteria of stable manure and their action was given in a paper by Herzfeld. ${ }^{1}$

According to this paper, the fermentations which manure undergoes, partly in the stables etc., but mainly in the heap and finally on the land, may be divided into-

(a) Fermentations of the fatty acids.

(b) Fermentations of the amino-compounds.

(c) Putrefactive fermentation.

(d) Ammoniacal or urea fermentation.

(e) Sulphuretted hydrogen fermentation.

(f) Cellulose or methane fermentation.

(g) Fermentations of the carbohydrates.

(a) Many of the fatty acids, or rather their salts (best the calcium salts), are capable of undergoing changes under the action of various bacilli, micrococci and other bacteria, generally giving rise to the formation of other simpler organic acids, often carbon dioxide and, sometimes, hydrogen and alcohol.

(b) Amino-acids and other amino-compounds, i.e., compounds containing $\left(\mathrm{NH}_{2}\right)$, are formed by the putrefaction of albumin. Tyrosine, $\mathrm{OH} \cdot \mathrm{C}_{6} \mathrm{H}_{4} \cdot \mathrm{CH}_{2} \cdot \mathrm{CH}\left(\mathrm{NH}_{2}\right) \cdot \mathrm{COOH}$, para-hydroxyphenyl a-amino-propionic acid, leucine, $\mathrm{CH}_{3} \cdot\left(\mathrm{CH}_{2}\right)_{3} \cdot \mathrm{CH}\left(\mathrm{NH}_{2}\right) \cdot \mathrm{COOH}$, a-amino-caproic acid, asparagine, $\mathrm{COOH} \cdot \mathrm{CH}_{2} \cdot \mathrm{CH}\left(\mathrm{NH}_{2}\right) \cdot \mathrm{CONH}_{2}$, amino-succinamic acid, and glycocoll, $\mathrm{CH}_{2} \cdot\left(\mathrm{NH}_{2}\right) \cdot \mathrm{COOH}$, amino-acetic acid, are among such products.

Tyrosine is converted by fermentation, if air be excluded, into indol, $\mathrm{C}_{6} \mathrm{H}_{4}\left\langle{ }_{\mathrm{CH}}^{\mathrm{NH}} \backslash \mathrm{CH}\right.$, carbon dioxide, and hydrogen; in the presence of air, other substances, like phenol, $\mathrm{C}_{6} \mathrm{H}_{5} \mathrm{OH}$, are formed and the

${ }^{1}$ Zentralblatt für Bacteriologie, 1895, and Jour. Soc. Chem. Ind., 1895, 449. 
nitrogen is converted into ammonia. Leucine by its fermentation forms valerianic acid, $\mathrm{C}_{4} \mathrm{H}_{9} \cdot \mathrm{COOH}$, ammonia, carbon dioxide and hydrogen.

(c) Putrefactive fermentation is the rapid decomposition of albuminoid substances, attended by the evolution of evil-smelling gases and produced by the agency of various species of bacteria. Generally, the first step is the conversion of the insoluble or colloidal albuminoids into soluble and diffusible peptones; these next split up, yielding amino-acids, e.g., leucine. These in turn are decomposed into fatty acids and ammonia and the fatty acids then ferment as described under $(a)$.

However, the kind of change produced is determined to a great extent by the admission or exclusion of air from the fermenting substances. Indeed, the presence or absence of air from the decomposing mass determines the species of bacteria which can flourish in it. Bacteria are sometimes classed into two great groups :-

Aerobic bacteria, which require the presence of oxygen, and

Anaerobic bacteria, which only perform their functions in the absence of oxygen.

The distinction is not altogether satisfactory, as under conditions of air exclusion, certain aerobic organisms can carry on their work if nitrates be present. In the case of the aerobic bacteria the compounds formed by their vital processes are usually of a simple character, e.g., water, carbon dioxide and ammonia. Such fermentation is sometimes called mouldering or decay and is not attended by the evolution of foul-smelling gases.

The anaerobic organisms, on the other hand, tend to produce unoxidised products, some of which are highly complex, and the gases evolved consist of methane, hydrogen, sulphuretted hydrogen, etc. Many of these products are possessed of disagreeable smells and the changes leading to their production are considered as true putrefaction. These putrefactive changes can be brought about by a great number of different organisms and the albuminoid substances are the chief raw material for their activity. Many of the bad-smelling gases evolved have not been identified. Among other products, amines, e.g., trimethylamine, $\mathrm{N}\left(\mathrm{CH}_{3}\right)_{3}$, volatile acids, e.g., butyric acid, $\mathrm{C}_{3} \mathrm{H}_{7} . \mathrm{COOH}$, and caproic acid, $\mathrm{C}_{5} \mathrm{H}_{11} . \mathrm{COOH}$, and mercaptans, e.g., $\mathrm{C}_{2} \mathrm{H}_{5} . \mathrm{SH}$, have been detected.

In a manure heap, both aerobic and anaerobic organisms perform their functions, the former chiefly at first, and until the air in the interstices of the manure has been exhausted, producing mainly carbon dioxide, water and ammonia. Then the anaerobic bacteria begin to operate and evil-smelling gases come off. The evolution of heat, which is often considerable during the life of the aerobic organisms, diminishes.

(d) Ammoniacal or urea fermentation. This has already been briefly referred to (vide p. 63). The main reaction is there given as-

$$
\mathrm{CO}\left(\mathrm{NH}_{2}\right)_{2}+2 \mathrm{H}_{2} \mathrm{O}=\left(\mathrm{NH}_{4}\right)_{2} \mathrm{CO}_{3} \text {, }
$$

thus giving ammonium carbonate; in addition a reaction expressed by the following equation:- 


$$
\mathrm{CO}\left(\mathrm{NH}_{2}\right)_{2}+\mathrm{H}_{2} \mathrm{O}=\underset{\text { Urea. }}{\mathrm{NH}_{4} \cdot \mathrm{O} . \mathrm{CO} \cdot \mathrm{NH}_{2}}
$$

-resulting in the formation of ammonium carbamate, has been detected. At least five or six different bacteria, some micrococci, some bacilli, and even some moulds have been shown to have the power of bringing about this change.

(e) Sulphuretted hydrogen fermentation. A large number of different bacteria have been shown to have the power, under certain conditions which are not exactly known, of producing sulphuretted hydrogen by their action upon albumin.

(f) Cellulose fermentation. Cellulose, which forms the larger portion of the tissues of straw and other vegetable matter is, under the influences of an organism known as Bacillus amylobacter and other bacteria, converted eventually into carbon dioxide, $\mathrm{CO}_{2}$, and methane, $\mathrm{CH}_{4}$, though many intermediate products, e.g., acetic acid, $\mathrm{CH}_{3} . \mathrm{COOH}$, free hydrogen and perhaps, butyric acid, $\mathrm{C}_{3} \mathrm{H}_{7} \cdot \mathrm{COOH}$, have been detected. The process is anaerobic and the bacteria producing it have been detected in the intestines of cattle.

(g) Other carbohydrates, chiefly starch, various sugars and gums, occur in dung and readily undergo change by the influence of many bacteria, some aerobic, some anaerobic. Carbon dioxide, water, lactic acid, $\mathrm{CH}_{3}$. CH.OH.COOH, butyric acid, $\mathrm{CH}_{3} \cdot \mathrm{CH}_{2} \cdot \mathrm{CH}_{2} \cdot \mathrm{COOH}$, and sometimes free hydrogen are formed.

A study of the gases evolved during fermentation of manure was made by Schloesing in 1892. ${ }^{1}$ He found that, in presence of air, the temperature of a manure heap is raised by the action of aerobic organisms until purely chemical oxidation sets in and this may go on until the temperature is so high that destruction of the organisms is effected. No combustible gases are produced. By allowing the fermentation to proceed in a current of nitrogen or other indifferent gas, the anaerobic bacteria only are active and carbon dioxide and marsh gas are chiefly produced.

The details of one experiment may be of interest. $124 \cdot 4$ grammes of fresh manure were allowed to ferment in an atmosphere of carbon dioxide for two months; in this period, nearly 9 litres of gas were evolved, the maximum rate of evolution being $16 \cdot 3$. cc. per hour (on the sixth day). The gas contained $15.8 \mathrm{cc}$. of hydrogen, $4217.5 \mathrm{cc}$. of carbon dioxide, and $4577.4 \mathrm{cc}$. of marsh gas (equal to 4.72 grammes of carbon, 6.033 grammes of oxygen, and 0.819 gramme of hydrogen).

The loss suffered by the manure is shown by the following table, which gives the amounts, in grammes, of the various constituents in the dried manure, before and after the experiment:-

\begin{tabular}{|c|c|c|c|c|c|c|}
\hline & & Carbon. & Hydrogen. & Oxygen. & Nitrogen. & Ash. \\
\hline Before & & $12 \cdot 67$ & $1 \cdot 653$ & $10 \cdot 70$ & 0.453 & $3 \cdot 69$ \\
\hline After & . & $7 \cdot 92$ & 1.125 & 7.08 & 0.392 & $3 \cdot 79$ \\
\hline Loss & . & $4 \cdot 75$ & 0.528 & $3 \cdot 70$ & $0 \cdot 061$ & $-0 \cdot 10$ (gain) \\
\hline
\end{tabular}

${ }^{1}$ Ann. Agron. 18, 5 ; Jour. Chem. Soc., 1892, Abstracts, 1123. 
No free nitrogen was found in the gases, the loss of nitrogen being due to its liberation as ammonia, which would be lost in drying. The oxygen and hydrogen in the gases evolved, including the hydrogen lost as ammonia, exceed by 2.333 grammes and 0.305 gramme respectively that lost by the manure, showing that water enters into the reactions by which these gases are produced.

Preservation of Farm-yard Manure.-The best means of using farm-yard manure, whether fresh or rotted, and the most advantageous manner of treating it so as to minimise the loss of fertilising ingredients, are matters which have received much consideration and about which the greatest diversity of opinion, especially among farmers, exists.

Such obvious precautions as the prevention of loss of soluble matter by drainage hardly need mention here, unless it be to show how rich in fertilising materials such drainage often is. In fresh manure, the liquid portion consists mainly of urine, which has been shown to be rich in nitrogen and potash.

The dark-brown drainage from old manure heaps is often rich in manurial matters; a sample analysed by Voelcker contained nearly 2 per cent of solid matter, including 0.04 per cent nitrogen, 0.52 per cent of carbonate and chloride of potassium, and a considerable quantity of phosphoric acid. It is obviously desirable that such drainings should be preserved, either by the use of sufficient litter-best, peat or peat moss-to absorb it, or by collecting it in a tank.

Of more importance from the chemical aspect is the loss of nitrogen and other substances which occurs during fermentation. A great amount of attention has lately been directed to this matter, more especially with reference to the methods of minimising the loss. The loss of nitrogen occurs chiefly in two ways, by volatilisation of ammonia from ammonium carbonate and by the liberation of free nitrogen.

According to Berthelot and André, ammonium carbonate dissociates when it volatilises, yielding ammonia, carbon dioxide and water :-

$$
\left(\mathrm{NH}_{4}\right)_{2} \mathrm{CO}_{3} \rightleftarrows 2 \mathrm{NH}_{3}+\mathrm{CO}_{2}+\mathrm{H}_{2} \mathrm{O} .^{1}
$$

In accordance with the law of dissociation, the equilibrium represented above is attained when the product of the square of the number of molecules of ammonia into the number of molecules of carbon dioxide present in unit volume, reaches a certain value. Now this product may be reached by an increase of both or of only one of the two factors ; if either be increased the other factor will diminish if the product is to remain the same. It is obvious, therefore, if the amount of carbon dioxide in the surrounding air be increased, the amount of ammonia set free by dissociation will be diminished. Hence, if the production of carbon dioxide by the fermentation of merely carbonaceous matters in a manure heap can be encouraged, the dissociation of ammonium carbonate will be diminished and the loss of ammonia 
hindered. ${ }^{1}$ Another important consideration affecting this source of loss of nitrogen as ammonia is the renewal of the gas in the interstices of the manure by diffusion. If the gaseous carbon dioxide and ammonia are removed by, say, a current of air, the dissociation of the ammonium carbonate will proceed more rapidly.

A method of preventing, or rather of lessening, the loss of ammonia from manure heaps which has been recommended and used for many years, is the strewing of powdered gypsum $\left(\mathrm{CaSO}_{4} \cdot 2 \mathrm{H}_{2} \mathrm{O}\right)$ over the heap or in the stall. This was supposed to act by producing calcium carbonate and ammonium sulphate. This reaction could, even in solution, only go on to a limited extent, in accordance with the mass-action law (see p. 80), and according to many recent experiments gypsum is quite useless as a preservative. ${ }^{2}$ These investigations show that kainite and superphosphate or free phosphoric acid are very effective in preventing loss of ammonia.

As the result of a series of experiments, Kreuz and Gelach ${ }^{3}$ arrived at the following conclusions. Conversion of urea into ammonium carbonate takes place rapidly, either in the presence or absence of air and without any liberation of free nitrogen. The ammonium carbonate dissociates if the dung dries and is easily volatile except in an atmosphere of carbon dioxide; the loss is greater if a stream of air pass through the dung. The nitrogen of the ammonium carbonate which remains in the dung is gradually, in presence of air, converted into nitric acid, again with no liberation of free nitrogen. The nitric acid so formed, however, is, by the denitrifying bacteria, decomposed with evolution of free nitrogen. This decomposition proceeds either in presence or absence of air, provided the bacteria are furnished with suitable food materials, such as straw, grape sugar, glycerine, sodium lactate or citrate, or the green parts of plants. The whole of the nitrogen of the nitrates decomposed is not evolved as free nitrogen, but about 10 per cent of it is converted into highly complex organic substances resembling albumin.

The loss of nitrogen which animal refuse undergoes during storage, results from the liberation of ammonia and of free nitrogen. If the manure be kept in a loose, porous condition, the volatilisation of ammonia is favoured; if compact, so as to exclude air, much free nitrogen escapes, but the ammonia formed is retained. The loss of nitrogen, which is mainly suffered by the liquid portion of the manure, is shared to a small extent by the solid dung and the straw, the nitrogenous compounds of which, by the action of the bacteria, are converted into amino-compounds, which suffer the same fate as the urea. If the manure has to be kept long, it is desirable to cover the heap, with soil, preferably with peaty soil.

${ }^{1}$ Dehérain recommends (Compt. Rend., 1898, 1305) that the soiled litter be removed to the manure heap as often as possible and the stable or cow-shed gutters be rinsed with water to carry the liquid excreta into the liquid manure tank and that the dung heap be well heaped up and watered with the liquid from the tank. In this way a constant production of carbon dioxide by fermentation is produced and loss of ammonia hindered.

${ }^{2}$ Burri, Herfeldt and Stutzer, Jour. Land., 1895, 1.

${ }^{3}$ Jahr. Agric. Chem., 1899, 98. 
Maercker and Schneidewind ${ }^{1}$ found that in a deep stall, the loss of nitrogen from dung, analysed immediately after the fattening animals were removed, was small, amounting to about 13.25 per cent of the original amount, and was about the same in summer as in winter. If, however, the manure was left for four weeks in the stall after the animals had been removed, the loss in warm weather amounted to 34.8 per cent of the whole. In open dung heaps, the loss of nitrogen observed was $37 \cdot 4$ per cent of the total, while in a parallel experiment in a covered heap, 36.9 per cent of the total nitrogen was lost; but the covered heap held manure containing 70 per cent of water, while the open one contained 78 per cent. The large loss of nitrogen from the covered heap is due to the higher temperature and drier state of the dung, favouring the volatilisation of ammonia. An addition of 30 per cent of marl to the manure reduced the loss of nitrogen from 22.6 per cent, to 9.9 per cent, and a mixture of 30 per cent marl and 2 per cent of turf litter reduced it to $6 \cdot 1$ per cent. The best result was obtained by the addition of 6 per cent of sodium hydrogen sulphate, $\mathrm{NaHSO}_{4}$, (containing 1.5 per cent of free acid), when the loss was diminished to 1.3 per cent of the nitrogen originally present.

The action of free sulphuric acid in preventing loss of nitrogen is partly attributable to its combining with the ammonia and partly to its preventing the growth of denitrifying bacteria.

The application of fresh manure to the soil probably leads to a greater conservation of its nitrogen, but there is considerable risk of excessive denitrification being set up in the soil, both by the large amount of oxidisable carbonaceous matter and the numerous denitrifying organisms which are present in straw and the fæces of most animals, and this denitrification may extend to the nitrates already present or being produced in the soil. Well-rotted manure, on the other hand, though it may have lost some of its nitrogen, will be much less likely to bring about denitrification. It would seem, therefore, best to favour the fermentations which destroy carbonaceous matter, while attempting to retain, by absorption in peat moss or other porous material, the ammonia which volatilises. In this way, the denitrifying organisms will be quickly deprived of their favourable environment, and their destructive effects, both in the manure heap and subsequently in the soil, will be weakened.

The addition of kainite, or better, of acid substances, e.g., free sulphuric acid or superphosphate, has been highly recommended as a means of preserving nitrogen. Heiden ${ }^{2}$ states that by strewing the stalls in which cattle are kept, three times a day with superphosphate at the rate of $2 \mathrm{lb}$. for every $1000 \mathrm{lb}$. live weight, a great economy is effected in the manure, and this is true whether the stalls are cleaned out frequently or the dung and litter be left under the cattle for six weeks.

From extensive experiments made by Holdefleiss, ${ }^{3}$ the effect of

' Jahr. Agric. Chem., 1899, 100.

${ }^{2}$ Bieder. Zentr., 17, 154; Jour. Soc. Chem. Ind., 1888, 332.

3 Jahr. über Agric. Chem., 1900, 117. 
covering the manure with earth was shown to greatly preserve the nitrogen, while allowing of the fermentation and consequent loss of the carbonaceous matter; superphosphate and kainite, which also prevent loss of nitrogen, when applied at the rate of about 2 per cent of the manure, interfere with other fermentative changes and allow the straw to remain practically intact. Hence they act as antiseptics rather than absorbents.

Other Organic Manures.-A number of other refuse matters of vegetable or, more frequently, animal origin are used as manures, the chief being-

Guano.

Pigeon and fowl dung.

Fish refuse or fish guano.

Sea-weed.

Dried blood.

Meat meal or meat guano.

Bones.

Woollen refuse, shoddy manure.

Soot.

Oil-cakes and oil-seed refuse.

These can only be briefly dealt with here.

Guano is the dried dung of sea-birds, together with portions of their feathers, bones, and the refuse of their food; the older deposits also contain the remains of seals, walruses, etc. Guano accumulates on islands or near the coasts in tropical climates, the chief deposits being found in North and South America, Africa, Australia, the West Indies, and islands in the Pacific. The original Peruvian guano, the deposits of which are now exhausted, was a very valuable and concentrated manure, containing nearly half its weight of ammonium salts-urate, $\mathrm{C}_{5} \mathrm{H}_{3}\left(\mathrm{NH}_{4}\right) \mathrm{N}_{4} \mathrm{O}_{3}$, oxalate, $\left(\mathrm{NH}_{4}\right)_{2} \mathrm{C}_{2} \mathrm{O}_{4}$, and phosphate, $\left(\mathrm{NH}_{4}\right)_{3} \mathrm{PO}_{4}$, together with calcium phosphate and potash compounds.

It contained from 11 to 16 per cent of nitrogen and from 10 to 12 per cent of phosphorus pentoxide.

The guano now obtainable contains much less nitrogen (about half or a little more), though often much more phosphates.

Two varieties of guano are now imported:-

(1) Nitrogenous and phosphatic. These have accumulated in practically rainless districts and the excreta which formed them have been desiccated before much fermentation was possible. True Peruvian guano from the Chincha Islands, and Ichaboe guano, a recent deposit, are examples of such guanos, the latter usually containing from 7 to 11 per cent nitrogen and 5 per cent phosphorus pentoxide.

(2) Phosphatic. These are the remains left after the weathering by rain, etc., of the dung of sea-birds. Uwing to the moist state in which it has been kept, the nitrogenous matter has been lost, by solution or volatilisation, and only the mineral (phosphatic) portion left.

Considerable deposits of guano were discovered some years ago on islands lying off Damaraland, on the West Coast of Africa, and are being extensively worked. 
An analysis of Damaraland guano ${ }^{1}$ gave the following numbers :-

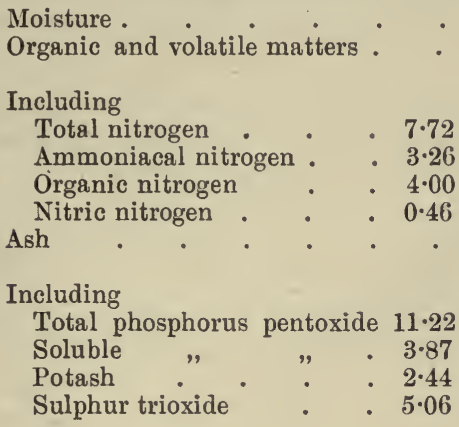

$100 \cdot 00$

In some samples, the phosphorus pentoxide and potash are higher in quantity.

As types of the less valuable products, Baker Island, Mexillones and Lacepede guanos may be quoted. In these, the nitrogen varies from 0.5 to 2.0 per cent, while the phosphorus pentoxide may reach as high as 34 per: cent and is usually above 23 per cent.

The nitrogenous guanos are particularly valuable from the fact that a large portion of their phosphates is soluble and the nitrogen which they contain is in a readily available form, being present as ammonium salts or in such easily decomposable substances as uric acid, $\mathrm{C}_{5} \mathrm{H}_{4} \mathrm{~N}_{4} \mathrm{O}_{3}$, or guanine, $\mathrm{C}_{5} \mathrm{H}_{5} \mathrm{~N}_{5} \mathrm{O}$, a body first obtained from guano.

Uric acid and guanine are interesting from their close relationships to xanthine, $\mathrm{C}_{5} \mathrm{H}_{4} \mathrm{~N}_{4} \mathrm{O}_{2}$, found in meat extracts; to theobromine, $\mathrm{C}_{7} \mathrm{H}_{8} \mathrm{~N}_{4} \mathrm{O}_{2}$ (dimethyl xanthine), the characteristic ingredient in cocoa ; and to caffeine or theine, $\mathrm{C}_{8} \mathrm{H}_{10} \mathrm{~N}_{4} \mathrm{O}_{2}$ (trimethyl xanthine), the main valuable constituent of coffee and tea (vide Chap $\mathrm{X}$ ).

In the phosphatic guanos, the phosphoric acid is mainly present as tricalcium phosphate, and therefore not easily available to plants. Such guanos are often used for conversion into superphosphate.

The chemical nature of guano is highly complex, as is indicated by what has already been said. It is almost impossible to say how the various acids and bases present in such a mixture are distributed, but attempts to do so have been made.

Wagner ${ }^{2}$ gives the table on the following page as the composition of three samples of Peruvian guano.

Pigeon and fowl dung.- These substances, according to Storer, ${ }^{3}$ were formerly much prized as manures, and played an important part in Roman, Persian and Egyptian husbandry. In France, too, large dovecotes formerly constituted an almost necessary adjunct to farmsteads. Their importance has diminished since the introduction of nitrate of soda, kainite and other artificial manures.

${ }^{1}$ Barth, Jahr. über Agric. Chem., 1900, 118.

${ }^{2}$ Chemical Technology, 1892, p. 424.

${ }^{3}$ Agriculture, Vol. I, 368. 


\begin{tabular}{|c|c|c|c|c|c|c|c|}
\hline & & & & & I. & II. & III. \\
\hline Ammonium chloride & . & . & . & . & $2 \cdot 25$ & $6 \cdot 50$ & $4 \cdot 2$ \\
\hline urate . & . & . & . & . & $12 \cdot 20$ & $3 \cdot 24$ & $9 \cdot 0$ \\
\hline oxalate & . & . & . & . & $17 \cdot 73$ & $13 \cdot 35$ & $10 \cdot 6$ \\
\hline phosphate & - & . & . & . & $6 \cdot 90$ & $6 \cdot 25$ & $6 \cdot 0$ \\
\hline carbonate & . & . & . & . & $0 \cdot 80$ & - & - \\
\hline bromate & & & . & . & $1 \cdot 06$ & - & - \\
\hline magnesium & phe & sphate & & . & $11 \cdot 63$ & $4 \cdot 20$ & $2 \cdot 6$ \\
\hline Sodium phosphate & . & . $\quad$. & . & . & - & $5 \cdot 29$ & - \\
\hline ,, chloride. & . & . & . & • & $0 \cdot 40$ & $0 \cdot 10$ & - \\
\hline ", sulphate . & . & . & . & . & $4 \cdot 92$ & $1 \cdot 12$ & $3 \cdot 8$ \\
\hline Potassium sulphate & . & . & . & . & $4 \cdot 00$ & $4 \cdot 23$ & $5 \cdot 5$ \\
\hline Calcium phosphate & . & . & . & . & $20 \cdot 16$ & $9 \cdot 94$ & $14 \cdot 3$ \\
\hline , oxalate. & . & . & . & . & $1 \cdot 30$ & $16 \cdot 36$ & $7 \cdot 0$ \\
\hline carbonate & . & . & . & . & $1 \cdot 65$ & - & - \\
\hline Sand and clay & . & . & . & . & $1 \cdot 68$ & $5 \cdot 90$ & $4 \cdot 7$ \\
\hline \multirow{2}{*}{\multicolumn{2}{|c|}{ Water and organic matte }} & . & . & . & $13 \cdot 32$ & $23 \cdot 32$ & $32 \cdot 3$ \\
\hline & & & & & $100 \cdot 00$ & $99 \cdot 80$ & $100 \cdot 0$ \\
\hline
\end{tabular}

Storer gives as the percentage composition of the fresh excreta of the common domestic birds-

\begin{tabular}{|c|c|c|c|c|c|c|c|c|c|}
\hline & & & & & & Fowls. & Pigeons. & Ducks. & Geese. \\
\hline Water. & 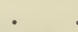 & . & . & . & . & $56 \cdot 0$ & $52 \cdot 0$ & $56 \cdot 6$ & $77 \cdot 1$ \\
\hline Organic ma & atter & . & . & . & . & $25 \cdot 5$ & $31 \cdot 0$ & $26 \cdot 2$ & $13 \cdot 4$ \\
\hline Nitrogen & . & . & . & . & . & $1 \cdot 6$ & $1 \cdot 8$ & $1 \cdot 0$ & $0 \cdot 6$ \\
\hline Phosphorus & pento & oxide & & . & . & 1.7 & $1 \cdot 7$ & $1 \cdot 4$ & $0 \cdot 5$ \\
\hline Potash & . & . & . & . & . & 0.8 & $1 \cdot 1$ & 0.6 & $1 \cdot 0$ \\
\hline Lime & . & . & . & . & . & $2 \cdot 2$ & $1 \cdot 7$ & $1 \cdot 7$ & $0 \cdot 8$ \\
\hline Magnesia & . & . & . & . & . & 0.8 & 0.5 & $0 \cdot 4$ & $0 \cdot 2$ \\
\hline
\end{tabular}

He gives as an estimate of the quantities produced by each bird per year-pigeon, $6 \mathrm{lb}$; hen, 12 lb.; duck, 18 lb. ; goose or turkey, $25 \mathrm{lb}$.

Ulrich ${ }^{1}$ gives the following as the average percentage composition of the dung of poultry-

\begin{tabular}{|c|c|c|c|c|c|c|c|}
\hline & & & Pigeons. & Fowls. & Ducks. & Geese. \\
\hline Water & . & . & . & 62 & 65 & 53 & 82 \\
\hline Organic matt & tter & . & . & $31-32$ & $21-26$ & 40 & 14 \\
\hline Nitrogen & . & . & . & $1 \cdot 2-2 \cdot 4$ & $0.7-1.9$ & 0.8 & $0 \cdot 6$ \\
\hline Phosphorus $\mathrm{p}$ & pentoxide & . & . & $3 \cdot 0-4 \cdot 2$ & $5 \cdot 0$ & $3 \cdot 5$ & $0 \cdot 9$ \\
\hline Alkaline salts & ts & . & . & $2 \cdot 0-2 \cdot 2$ & $1 \cdot 2-1 \cdot 6$ & $0 \cdot 4$ & $3 \cdot 1$ \\
\hline Ash & . & . & . & $6-7$ & $9-14$ & 7 & 4 \\
\hline
\end{tabular}

He estimates the annual production at-

${ }^{1}$ Biedr. Zentr., 1900, 3 ; Jour. Chem. Soc., 1900, Abstracts, ii, 308. 


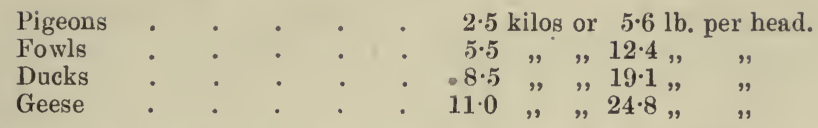

and recommends that the manure be mixed with water containing sulphuric acid ( $30 \mathrm{lb}$. of acid to $1 \mathrm{cwt}$. of manure), in order to prevent loss by volatilisation of ammonia.

The excreta of wild animals and birds are sometimes found in sufficiently large accumulations to be of importance. Those of carnivorous birds are particularly rich in nitrogen (largely due to their high content of uric acid, which itself contains 33 per cent of nitrogen).

A sample of the excrement of the S. Airican vulture collected in the Orange River Colony, was examined by the author and found to contain-

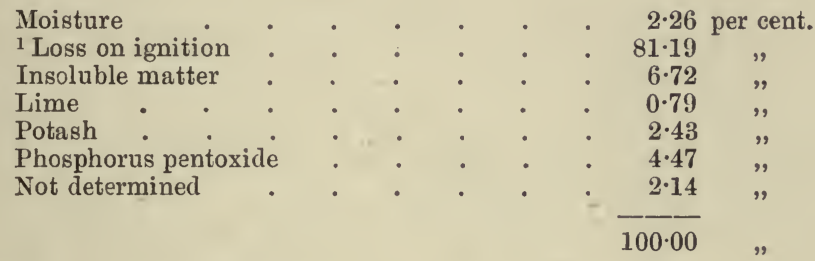

Such products are extremely valuable as manure, for their nitrogen is probably readily available.

Deposits of the dung of sea-birds occur at places on the coast, sometimes in sufficient quantities to be important. The material is rich in nitrogen and phosphoric acid, though in ordinary climates somewhat too heavily charged with water to be very valuable, except locally. A deposit of this character from the coast of Ireland, examined by the author, contained, in the damp sample, $47 \cdot 5$ per cent water, 1.25 per cent nitrogen and 8.5 per cent phosphoric acid.

Bats' guano.-Deposits of this substance are found in caves in tropical climates, occasionally in sufficient quantities to be useful as manure. Its composition varies considerably. A sample from Eboli, Salerno, analysed by Paris, ${ }^{2}$ contained-

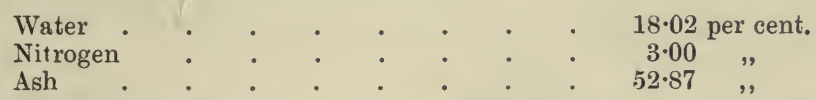

The ash contained, in each 100 parts, 2 of potash, 13.8 of lime, 20.7 of phosphorus pentoxide, and a small quantity of copper. The nitrogen was almost all as nitrates. An American analysis ${ }^{3}$ gives as the composition of bats' guano-

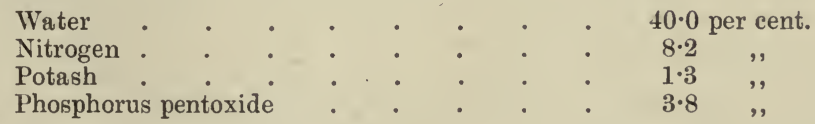


In many limestone caves in South Africa, immense deposits occur. These consist of silt, bats' excreta, bones of various animals, and often of the excrement of wolves, jackals, etc.

The deposits are of very variable composition, as is shown by many analyses made by the writer. The following may be quoted as examples of the valuable manurial ingredients found in various samples :-

\begin{tabular}{|c|c|c|c|c|c|c|c|c|c|c|c|}
\hline & & & & & & I. & II. & III. & IV. & V. & VI. \\
\hline Phosphorus & pentoxide & & . & . & . & $3 \cdot 81$ & $2 \cdot 82$ & $1 \cdot 71$ & $26 \cdot 55$ & $2 \cdot 26$ & $7 \cdot 4$ \\
\hline Potash & . & . & : & . & . & $1 \cdot 29$ & 0.78 & 0.21 & 0.05 & 0.19 & - \\
\hline Nitrogen & . & . & . & . & .. & $9 \cdot 70$ & $1 \cdot 50$ & $0 \cdot 19$ & $0 \cdot 32$ & $2 \cdot 52$ & $6 \cdot 2$ \\
\hline Lime. & . & . & . & : & . & - & - & $0 \cdot 37$ & $33 \cdot 14$ & $7 \cdot 28$ & 0.8 \\
\hline
\end{tabular}

I. was a fresh bulky deposit consisting entirely of the excrement of bats from the Zoutpansberg.

II. consisted of bats' dung and silt from caves near Potchefstroom.

III. consisted of bats' guano and silt from a large cavern at Wonderfontein, near Potchefstroom.

IV. was believed to consist mainly of wolves' dung, and was from a considerable depth -8 or $10 \mathrm{ft}$. - in a deposit in a cave near Wonderfontein.

V. contained many bones, from a cave at Wonderfontein.

VI. was a recent deposit, consisting largely of the excrement of bats, from a cave at Elandsfontein, near Pretoria.

Many of these deposits contained a considerable proportion of their nitrogen in the form of nitrates, and some of them contained appreciable quantities of manganese dioxide.

Fish Manure or Fish Guano.-The bodies of fish are highly nitrogenous and their bones, in particular, contain large quantities of phosphates. They therefore form a valuable manure and are often used whenever, through an unusual glut in the market, the price falls sufficiently. Then, too, the refuse of fish-their heads, bones and other offal-is now manufactured into manure, especially in Norway. In America the refuse from the manufacture of Menhaden oil is an important manure. The flesh of whales is also used as manure. In general the most objectionable ingredient in fish guano is the oil, which prevents or hinders the fermentation and decay of the manure by repelling water. The following table shows the average amount of fertilising material in various kinds of fish manure :-

\begin{tabular}{|c|c|c|c|c|}
\hline & $\begin{array}{l}\text { Norwegian } \\
\text { fish guano. }\end{array}$ & $\begin{array}{l}\text { Raw fish } \\
\text { refuse. }\end{array}$ & $\begin{array}{c}\text { Cod } \\
\text { guano. }\end{array}$ & $\begin{array}{l}\text { Anerican } \\
\text { dried fish. }\end{array}$ \\
\hline $\begin{array}{l}\text { Water. } \\
\text { Nitrogen : } \\
\text { Calcium phosphate } \\
\text { Oil }\end{array}$ & $\begin{array}{r}8 \cdot 0 \text { per cent } \\
9 \cdot 0 \quad,, \\
2 \cdot 2 \cdot 0 \quad \text {, }\end{array}$ & $\begin{aligned} 50 \cdot 0 \text { per cent } \\
3 \cdot 0 \quad,, \\
3 \cdot 8 \quad, \\
\text { up to } 15.0 \quad,,\end{aligned}$ & $\begin{array}{r}6 \cdot 2 \text { per cent } \\
9 \cdot 0 \quad, \\
26 \cdot 0 \quad,,\end{array}$ & $\begin{array}{r}12 \cdot 8 \text { per cent } \\
7 \cdot 3 \quad,, \\
18 \cdot 2 \quad,,\end{array}$ \\
\hline
\end{tabular}


Sea-weed, which is plentiful on some coasts, forms a cheap and valuable manure. It has one great advantage-its rapidity of decomposition, which causes it to be a quick-acting manure. Its composition may be gathered from the following analyses :-

\begin{tabular}{|c|c|c|c|c|c|c|c|c|c|c|c|}
\hline & & & & & & & I. & II. & III. & & IV. \\
\hline Water. & . & . & - & . & . & 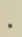 & $80 \cdot 44$ & $77 \cdot 94$ & $77 \cdot 0$ & $81 \cdot 5$ & per cent \\
\hline Organic mat & tter & . & . & . & . & . & $9 \cdot 25$ & $18 \cdot 12$ & $20 \cdot 0$ & - & \\
\hline Ash & . & . & . & . & . & . & $10 \cdot 31$ & $3 \cdot 94$ & $3 \cdot 0$ & - & \\
\hline Nitrogen & . & . & . & . & . & . & 0.45 & 0.3 & 0.38 & $0 \cdot 73$ & ," \\
\hline Potash. & . & . & . & . & . & . & 1.95 & 0.65 & $0 \cdot 30$ & $1 \cdot 50$ & , \\
\hline Phosphorus & pent & oxide & . & . & . & . & 0.47 & $0 \cdot 10$ & $0 \cdot 15$ & 0.18 & ," \\
\hline
\end{tabular}

I. Mixed weed from the Orkney Islands (Anderson).

II. Rock-weed, American (Storer).

III. Various varieties of Fucus (Marchand).

IV. Mixed weed (American).

From the above analyses it will be seen that sea-weed is comparable as a manure with farm-yard manure, being, however, slightly deficient in phosphates. It has the advantage over farm-yard manure of being more easily fermented and quite free from the seeds of weeds, which are often abundant in the latter product.

An account of sea-weed as a manure, giving analyses of many specimens of different varieties and the relative values of it and other manures, was given by Hendrick. ${ }^{1}$

The following is a brief summary of the analyses:-

\begin{tabular}{|c|c|c|c|c|}
\hline & \multicolumn{2}{|c|}{ Black wrack. } & Drift-weed. & Dulse. \\
\hline & $\begin{array}{l}\text { Collected at } \\
\text { Helensburgh. }\end{array}$ & Stonehaven. & Turnberry. & Oban. \\
\hline Water . & 70.78 per cent & 74.99 per cent & 79.00 per cent & 78.20 per cent \\
\hline Organic matter. & $23 \cdot 08$, & $19 \cdot 15$ & $14 \cdot 49$, & $17 \cdot 23$ \\
\hline Ash . & $6 \cdot 14$ & 5.86 & $6 \cdot 51$ & 4.57 \\
\hline Phosphorus pentoxide & 0.09 & 0.09, & $0 \cdot 18$, & 0.07 \\
\hline Potash . & $1 \cdot 38$ & $0.85 \quad$, & $1 \cdot 69$ & $1 \cdot 67$ \\
\hline Nitrogen : & $0.76 \quad "$, & $0.51 \quad "$ & 0.62 & 0.74 \\
\hline
\end{tabular}

In the field experiments it was found that sea-weed gave with potatoes, quite as good results as an equal weight of farm-yard manure and that the application of superphosphate further increased the crop, confirming the statement just made that sea-weed is an excellent organic general manure, though deficient in phosphates.

Dried blood from slaughter-houses is occasionally used as a manure. Sometimes the blood is simply evaporated at a steam heat, in which (1898).

${ }^{1}$ Transactions of the Highland and Agricultural Society of Scotland, Vol. $\mathrm{X}$ 
case the residue can easily be ground to powder. Sometimes the clot only of blood is employed, the clot being produced either by simple separation by a filter or settling, or by the addition of acid or iron salts to the blood.

The following table will show the fertilising value of various commercial forms :-

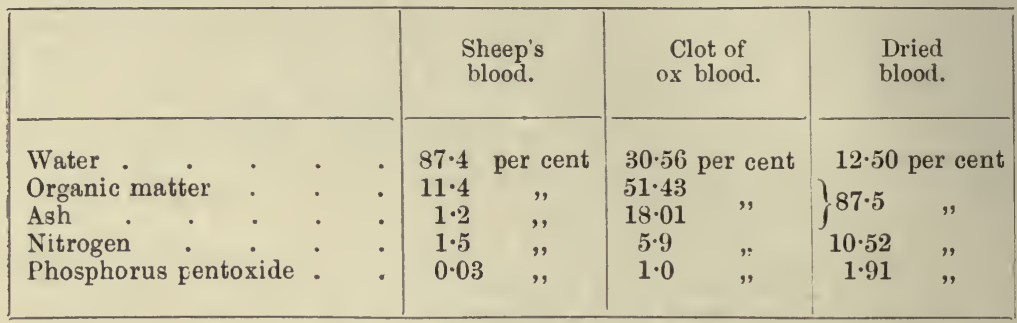

Blood easily decomposes in the soil, and its nitrogen and phosphoric acid soon become available to the plant. It gives excellent results with wheat.

Bones are an important manure and are used in many forms. They form the hard framework of the body of an animal and are largely composed of mineral matter-mainly phosphate of lime. In addition there are, in fresh or "green" bones, about 30 per cent of organic matter, containing, perhaps, 3 to 4 per cent nitrogen, and a certain amount of fat. This last ingredient is objectionable, since it hinders the decomposition of the organic matter after the bones are applied to the soil, partly mechanically and partly, perhaps, by forming a lime soap which gives an impervious crust to each fragment. Moreover, it renders the grinding or disintegration of the material more difficult. For this reason, and also in order to extract gelatine from the bones, they are often submitted to the action of steam under pressure; they are thus robbed of a large portion of their fat and some of their nitrogenous matter, and are rendered much more friable and more susceptible to processes of putrefaction and decay.

Bones, when applied to the soil in large fragments, only slowly become assimilable, remaining almost unchanged in some cases, especially on clay soils, for years. They are therefore always now reduced to small fragments before being applied, being graded according to their degrees of fineness, as " half-inch bones," "crushed bones," "bone dust," "bone meal," and "bone flour". Sometimes bones are treated with acid, when the calcium phosphate dissolves, and the organic matter, from which glue is made, is left behind. From the acid solution, by the action of lime, the calcium phosphate can be precipitated and the dried product is sometimes sold as "precipitated bone flour".

Large quantities of bones are obtained from towns and they are now imported from America and Africa. They are slow in action and their effect upon a soil often extends over several years. In order to render their action more rapid they are often converted into superphosphate or "dissolved bones," which will be described hereafter. 
Bone ash is imported from South America; it, of course, is a purely mineral manure, the organic matter having been removed. Occasionally, bones are fermented by moistening them with urine and leaving them exposed to the air.

The following analyses will show the composition of various commercial products from bones :-

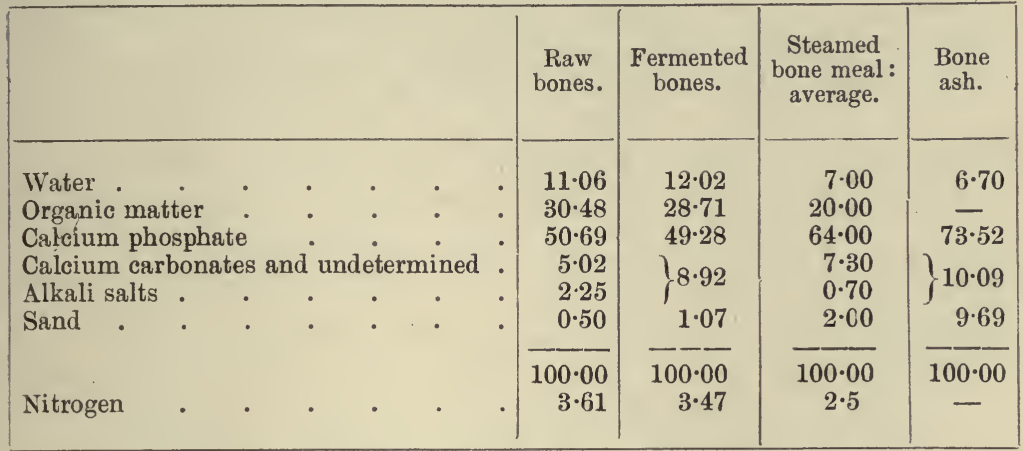

Another product from bones is bone black, used in decolourising liquids, e.g., sugar syrup ; this consists of about 10 per cent finely divided carbon, mingled with the mineral constituents of bone, often containing 75 to 80 per cent calcium phosphate. It is made by heating bones in closed retorts, and after it has become so clogged with colouring substances as to be useless for decolourising purposes it is used under the name of "spent char" as a manure, especially as it then contains a small quantity of nitrogen.

Meat meal or meat guano.-This is the dried refuse, with bones, from the manufacture of "extract of meat," etc., reduced to fine powder. A similar product is obtained by drying the offal from slaughter-houses, etc., also, in Germany particularly, by drying the carcasses of horses or cattle that have died from disease. Usually the fat and gelatine are first removed by steaming. Various other byeproducts, e.g., the refuse from the manufacture of "oleomargarine," and from the manufacture of tallow, are also used for the same purpose. These products are usually fairly free from grease and contain their fertilising materials in a readily fermentable form. The following table gives the average contents of valuable ingredients :-

\begin{tabular}{|c|c|c|c|c|}
\hline & $\begin{array}{l}\text { Meat } \\
\text { meal. }\end{array}$ & $\begin{array}{l}\text { German } \\
\text { flesh } \\
\text { meal. }\end{array}$ & $\begin{array}{l}\text { Oleomar- } \\
\text { garine } \\
\text { refuse. }\end{array}$ & $\begin{array}{l}\text { American tank- } \\
\text { age from tallow } \\
\text { refuse. }\end{array}$ \\
\hline $\begin{array}{l}\text { Water } \\
\text { Nitrogen } \\
\text { Calcium phosphate }\end{array}$ & $\begin{array}{l}10 \cdot 0 \text { per cent } \\
7 \cdot 0 \quad, \\
27 \cdot 0 \quad,\end{array}$ & $\begin{array}{r}28 \cdot 0 \text { per cent } \\
9 \cdot 7 \quad \text { ", } \\
13 \cdot 7 \quad \text { " }\end{array}$ & $\begin{array}{l}8 \cdot 5 \text { per cent } \\
12 \cdot 1 \quad ", \\
1.9 \quad ",\end{array}$ & $\begin{array}{l}10 \cdot 0 \text { per cent } \\
6.7 \quad, \\
2 \cdot 6 \quad "\end{array}$ \\
\hline
\end{tabular}

Woollen waste, shoddy manure.-After wool has been spun into yarn, woven into a fabric, and worn, the rags are torn to pieces by 
appropriate machinery and the wool fibre again converted into cloth. This process may go on several times, until finally the fibres, known as "shoddy," become so short that they will no longer hold together. They then constitute "shoddy waste," or shoddy manure, and are useful as a source of nitrogen.

Such manure is variable in composition, according to the treatment which the wool has undergone and the amount of oily substances (used in the cloth manufacture) left in it.

The following analyses have been published:-

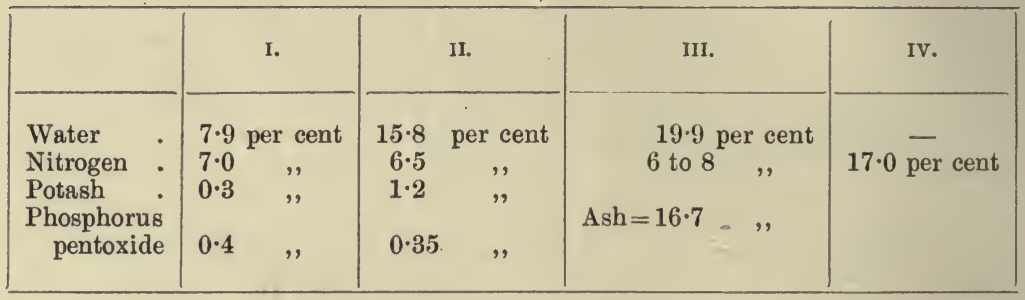

I. English commercial "ground wool".

II. American wool waste.

III. Shoddy manure of high quality.

IV. Average of pure wool.

Substances of similar composition, sometimes used as nitrogenous manures, are hair from tanneries and horn chips.

Hair contains about 10 to 14 per cent nitrogen, horn shavings about the same.

An American product-horn and hoof waste-contains on the average-

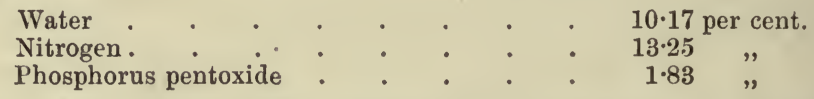

Wool, hair and horn suffer decomposition in the soil only very slowly ; consequently they are not quick in their action, but afford a slow supply of nitrogen for a long period, in some cases for five or six years. They are used in the preparation of certain " mixed manures," and especially in the cultivation of hops. Feathers, which resemble hair in composition, are also used as manure in Ireland.

In fact, any animal matter, if obtainable in quantity, would furnish valuable manurial material.

Insects (for example, locusts) might with advantage be used as manure. A sample of locusts (Pachytylus sulcicollis) killed by immersion in boiling water, dried and ground to powder, was examined by the writer and yielded the following analytical figures:-

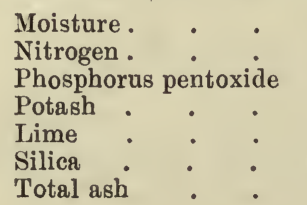

$10 \cdot 3$ per cent.

$\begin{array}{ll}9 \cdot 3 & , \\ 1.48 & \quad \\ 0.52 \quad " \\ 0.28 \quad " \\ 1.53 \quad " \\ 5.34 \quad "\end{array}$


showing the product to be rich in manurial ingredients. The nitrogenous matter-doubtless consisting largely of chitin, the horny, external skeleton of the insects-would probably be somewhat slow in decomposing in the soil, but despite this, locusts should form a valuable manure. In the Argentine, in 1899, they gave excellent results when mixed with superphosphates:

Even when the carcasses of animals are incinerated (e.g., with a view of preventing the spread of contagion during the prevalence of a disease) and the organic nitrogenous matter thus mainly destroyed, the ash left is possessed of considerable manurial value.

A product obtained from a Veterinary Bacteriological Station, where the bodies of the animals used were thus disposed of, was found by the writer to contain-

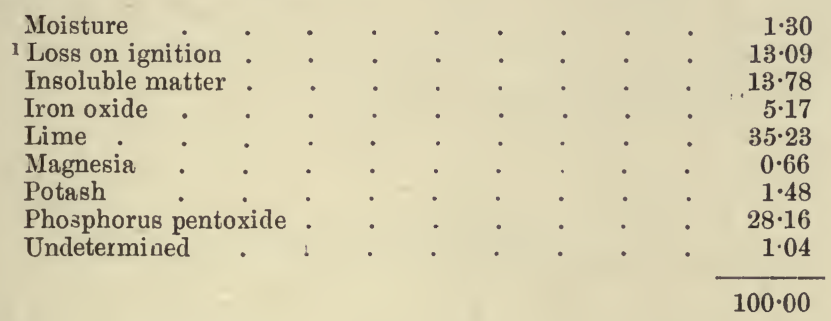

${ }^{1}$ Containing nitrogen $\quad . \quad$. $\quad . \quad$. . . $1 \cdot 27$

Evidently, from the occurrence of organic matter and nitrogen, the combustion of the bodies had not been complete. Probably the amount of iron oxide was increased in consequence of the presence of iron shoes and nails, for the carcasses employed were chiefly those of horses and mules.

Soot.-The soot collected from the imperfect combustion of coal contains a portion of the nitrogen of the coal in the form of ammonium salts and as organic nitrogenous compounds of an amine character. Its usefulness as a manure depends upon the nitrogen which it contains; this varies from very little up to 3 or 4 per cent; on an average perhaps 1.8 or 2 per cent will be present. Soot is useful as an insecticide.

It also has a value in increasing the absorptive power of the soil for the heat rays of the sun and it has been found that, in bright sunlight, a soil may rise two or three degrees in temperature from the application of a thin sprinkling of soot. It also tends to render a heavy soil more friable and porous, by virtue of the coal-ashes which are present in nearly all samples of soot. Its action as an insecticide is partly due to the ammonium salts, partly to the sulphur compounds and partly to the tarry constituents which it contains.

The composition of soot varies greatly; factors which most powerfully affect its character are-draught of flue, height in the chimney from which the sample was collected, character of fuel and manner of stoking. 
The following analyses ${ }^{1}$ will illustrate some of these points :-

\begin{tabular}{|c|c|c|c|c|c|}
\hline & \multirow{2}{*}{ Coal used. } & \multirow{2}{*}{ Domestic soot. } & \multicolumn{3}{|c|}{ Boiler soot. } \\
\hline & & & Base. & $70 \mathrm{ft}$. & Top, $110 \mathrm{ft}$. \\
\hline Carbon . & $69 \cdot 30$ & $40 \cdot 50$ & $16 \cdot 66$ & $21 \cdot 80$ & $27 \cdot 00$ \\
\hline Hydrogen & $4 \cdot 89$ & $4 \cdot 37$ & 0.86 & $1 \cdot 44$ & $1 \cdot 68$ \\
\hline Nitrogen. & $1 \cdot 39$ & 4.09 & 0.00 & $1 \cdot 18$ & $1 \cdot 21$ \\
\hline $\mathrm{Ash}$ & $8 \cdot 48$ & $18 \cdot 16$ & $75 \cdot 04$ & $60 \cdot 04$ & $61 \cdot 80$ \\
\hline Tar & - & $25 \cdot 91$ & 0.09 & 0.80 & $1 \cdot 66$ \\
\hline Sulphur. & $1 \cdot 74$ & $2 \cdot 99$ & $2 \cdot 07$ & 2.58 & $2 \cdot 84$ \\
\hline Chlorine. & $0 \cdot 27$ & $5 \cdot 19$ & $0 \cdot 11$ & $1 \cdot 46$ & $1 \cdot 60$ \\
\hline Acidity . & 0.00 & 0.37 & $1 \cdot 33$ & 0.58 & 0.56 \\
\hline
\end{tabular}

Further analyses of domestic soot gave-

\begin{tabular}{|c|c|c|c|c|c|c|c|c|}
\hline & & & & \multirow{2}{*}{ Coal used. } & \multirow{2}{*}{ Soot from kitchen. } & \multicolumn{3}{|c|}{$\begin{array}{l}\text { Soot from dining-room } \\
\text { chimney. }\end{array}$} \\
\hline & & & & & & $5 \mathrm{ft}$. & $20 \mathrm{ft}$. & $30 \mathrm{ft}$. \\
\hline Carbon. & . & . & . & $76 \cdot 8$ & $52 \cdot 3$ & $36 \cdot 5$ & $34 \cdot 1$ & $37 \cdot 2$ \\
\hline Hydrogen & . & . & . & $4 \cdot 9$ & $3 \cdot 7$ & $3 \cdot 5$ & $3 \cdot 5$ & $3 \cdot 5$ \\
\hline Nitrogen & . & . & . & $1 \cdot 72$ & $4 \cdot 11$ & $6 \cdot 89$ & $6 \cdot 04$ & $5 \cdot 05$ \\
\hline Ash & . & . & . & $1 \cdot 80$ & $17 \cdot 8$ & $5 \cdot 09$ & $4 \cdot 97$ & $4 \cdot 04$ \\
\hline Tar & . & . & . & - & $12 \cdot 5$ & $34 \cdot 0$ & $37 \cdot 2$ & $40 \cdot 4$ \\
\hline Sulphur & . & . & . & $0 \cdot 79$ & $2 \cdot 20$ & $2 \cdot 18$ & 256 & $2 \cdot 45$ \\
\hline Chlorine & . & . & . & $0 \cdot 25$ & $1 \cdot 35$ & 0.07 & $6 \cdot 41$ & $4 \cdot 96$ \\
\hline Acidity . & . & . & . & - & $0 \cdot 28$ & 0.92 & 0.55 & 0.92 \\
\hline
\end{tabular}

According to these investigations, about 96 per cent of the nitrogen in soot is present as ammonium salts, though some could be detected in the form of pyridine bases. Light, bulky soot is always richer in nitrogen than the denser varieties and therefore more valuable for manurial purposes. A good sample ought not to weigh more than $28 \mathrm{lb}$. per bushel.

Coal ash.-As a rule the ash of coal is comparatively poor in manurial ingredients, and though, on some soils, coal ash may with advantage be used, it probably acts mainly by its influence on the porosity and other physical properties of the soil rather than as a true manure. The usual proportion of phosphorus pentoxide in the ash of coal appears to be about 1 per cent and rarely exceeds 1.5 per cent, but the author found, in the ash of a coal from Witbank in the Transvaal, 5.5 per cent. Only one other similar instance has been recorded, so far as the author can ascertain, and that was in the case of the ash 
from a coal from Porthmawr in Wales, which, according to an analysis by Phillips, ${ }^{1}$ contained $6 \cdot 6$ per cent of phosphorus pentoxide.

Though in such coal ash the phosphorus is probably locked up in a somewhat insoluble form, it might furnish a useful source of plant food in districts where phosphates are difficult or expensive to procure.

Oil-cakes.-These, the residue of husks, etc., left after the oil is expressed from certain seeds, are often highly nitrogenous and generally contain considerable quantities of phosphates and potash ; indeed, of all forms of plant food. Usually they are used as food for animals; but in some cases, owing to the presence in the seed of poisonous or unpalatable substances, they are only fit for manurial purposes.

Rape, mustard, cotton and castor cakes are the principal ones used for manure, and of these, cotton cake but rarely. The percentages of the important constituents in such cakes are given in the following table :-

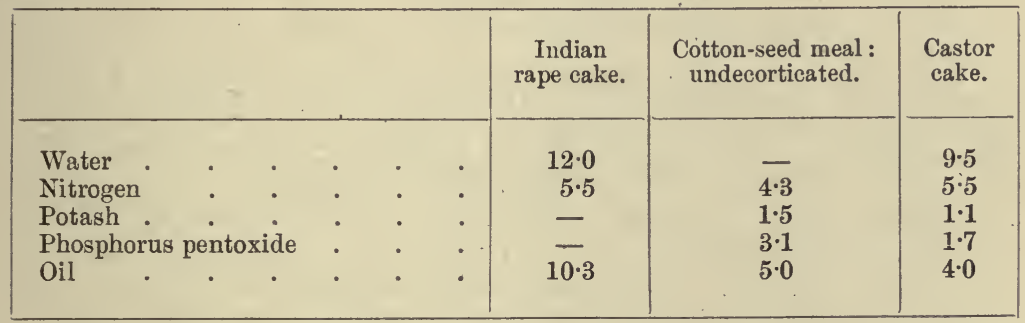

These substances decompose slowly in the soil, so that they are not quick-acting manures. They give better results as a rule on clay soils than on light sandy ones.

When the oil has been extracted by solvents the cake is of greater value as a manure, since not only is it richer in the proportion of valuable ingredients, but the absence of oily matter permits of more ready access of water and thus favours oxidation.

${ }^{1}$ Quoted in Muspratt's Dictionary of Chemistry. 


\section{CHAPTER VII.}

\section{Special Manures.}

In the previous chapter the chief organic manures have been described; it remains to consider the other substances, generally of mineral or artificial origin, which are employed as fertilisers. They may be conveniently divided into four groups :-

\section{Nitrogenous manures. \\ II. Phosphatic manures. \\ III. Potash manures. \\ IV. Miscellaneous.}

Many of the organic manures already described contain variable quantities of all the chief manurial substances, but those about to be dealt with are, as a rule, intended to supply only one important item of plant food. Their employment gives the farmer, therefore, the power of applying exactly what he thinks may be necessary, without the introduction of other plant food with which his land may already be abundantly provided. Their general introduction into farming practice has thus rendered easy a far more scientific treatment of the soil than was possible with complex manures only.

1. NITROGENOUS MANURES.-These include the two important substances, sodium nitrate and ammonium sulphate, the recently introduced calcium cyanamide and nitrate of lime, and also the less abundant and more expensive potassium nitrate.

Sodium Nitrate, "Chili Saltpetre," occurs in the enormous nitrate deposits of Peru, Chili and Bolivia. It is found in rainless districts and comparatively near the surface, covering a huge desert, devoid of both animal and vegetable life. The raw product, known as caliche, is found beneath a covering consisting of two layers, the upper one of sand and gypsum and the lower of baked clay and gravel; beneath the caliche is a soft earth known as cova. The thickness of the caliche varies from a few inches to $12 \mathrm{ft}$. It is extracted by boring through the upper layers and introducing a charge of gunpowder, which, when fired, exposes a considerable quantity of the material. It is then broken up by means of picks and carried to the refinery. ${ }^{1}$ There it is purified by crystallisation. This is done by dissolving in water by the aid of heat, allowing the solution to settle, and then run-

See Article by Aikman in Blackwood's Magazine, March, 1892, and Report on the Nitroto Trade of Chili, Jour. Soc. Chem. Ind., 1890, 664 . 
ning it into tanks, where, on cooling, crystals of sodium nitrate are deposited. The mother liquor is then run off the crystalline mass and treated with sodium sulphite and sodium bisulphite (made on the spot) in large wooden tanks lined with pitch. A precipitation of iodine then takes place by the decomposition of the sodium iodate always present in the caliche. The reaction is-

$$
2 \mathrm{NaIO}_{3}+3 \mathrm{Na}_{2} \mathrm{SO}_{3}+2 \mathrm{NaHSO}_{3}=5 \mathrm{Na}_{2} \mathrm{SO}_{4}+\mathrm{I}_{2}+\mathrm{H}_{2} \mathrm{O} \text {. }
$$

The iodine is then purified by sublimation and forms an important source of profit.

The crystals of nitrate are slightly rinsed with water, to wash out the mother liquor adhering to them, and are then dried in the sun. The average composition of the product, as it leaves the works, is said to be-

\begin{tabular}{|c|c|c|c|c|c|c|c|}
\hline um nitrate & • & & & & & \multicolumn{2}{|c|}{96.75 per cent. } \\
\hline Water & • & & • & & & $2 \cdot 10$ & \\
\hline Sodium chloride & . & • & & & $\bullet$ & $0 \cdot 75$ & ," \\
\hline Sulphates . & . & • & $\bullet$ & • & • & $0 \cdot 30$ & , \\
\hline Insoluble matter & . & . & . & . & . & $0 \cdot 10$ & $"$ \\
\hline
\end{tabular}

$96 \cdot 75$ per cent.

The proportion of iodine obtained is about 50 grammes per 100 kilogrammes of crude nitrate. ${ }^{1}$

The composition of the caliche varies greatly, and as a rule the larger the proportion of sodium nitrate present, the less iodine does it contain. It is usual to mix the various qualities so that the mixture becomes fairly constant in composition-

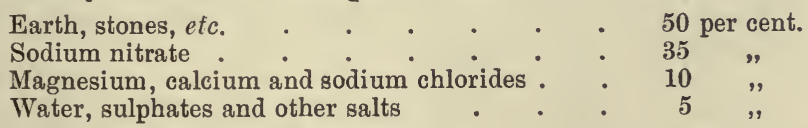

Associated with the nitrate in the caliche, a large number of different salts have been detected, including sulphates, nitrates, chlorides, iodates and borates of calcium, magnesium and sodium.. There are also traces of chromium, existing probably as calcium chromate. ${ }^{2}$

Pure sodium nitrate is a white crystalline salt containing no water of crystallisation, but generally holding a small quantity of hygroscopic moisture. Indeed, in moist air it is deliquescent. In addition to its use as a manure, it finds application in the arts as a source of nitric acid and in the manufacture of gunpowder and of potassium nitrate.

The product supplied for agricultural purposes is supposed to contain 95 per cent or over, of real sodium nitrate and thus to yield more than $15 \cdot 6$ per cent of nitrogen. Being extremely soluble and diffusible, it is at once available to plants and should only be applied when the crop is sufficiently grown to be capable of assimilating it; otherwise, since it is not retained by any constituent of the soil, considerable loss in the drainage may occur. Nitrate of soda is poisonous to animals and should not be left about in places to which cattle have access. Its saline taste induces cattle to eat it, in districts where they show great eagerness for salt, and the results are often fatal.

${ }^{1}$ Report on the Nitrate Trade of Chili, by Consul-General Walker, 1890.

${ }^{2}$ Buchanan, Jour. Soc. Chem. Ind., 1893, 128. 
In $1897^{1}$ Sjollema found that in many cases, in Holland and Belgium, rye was damaged by the application of "nitrate of soda". On investigation he found that the injury was due to the presence, in the nitrate, of perchlorates. In a number of samples examined he found from 0.14 to 6.79 per cent of perchloric acid $\left(\mathrm{ClO}_{4}\right)$. By direct experiment, he showed that potassium and sodium perchlorates retard germination and cause the leaves of plants to which they are applied to become yellow.

Other investigations have confirmed these results; e.g., Zaharia, as a result of an examination of 206 samples of Chili saltpetre at Halle, found one sample containing between 5 and 6 per cent, one 3 to 4 per cent, three 2 to 3 per cent, eleven 1.5 to 2 per cent, thirty-nine 1.0 to 1.5 per cent, while the remaining 151 contained less than 1 per cent of perchlorate. ${ }^{2}$

Maercker ${ }^{3}$ in 107 samples of Chili saltpetre found-

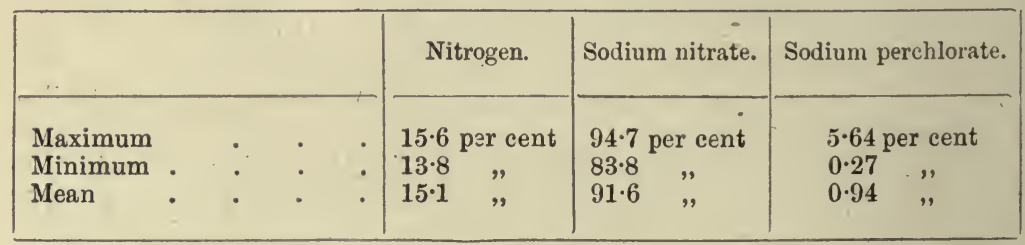

and Crispo ${ }^{4}$ gives the following analyses of specimens of Chili saltpetre from the same cargoes as those which had been observed to have a harmful effect upon plants :-

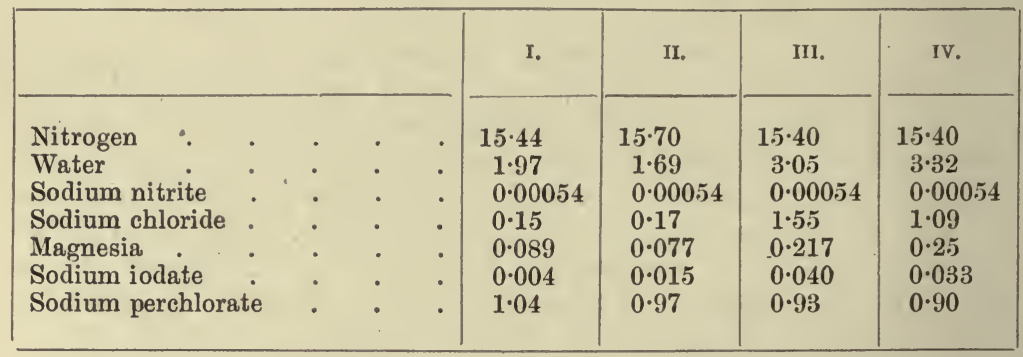

That sodium perchlorate has an injurious effect on most plants appears certain, but the quantity which is permissible in sodium nitrate, is a matter on which much diversity of opinion appears to exist.

Zaharia (just quoted) found that solutions containing less than $0 \cdot 1$ per cent of perchlorate had little or no effect upon the germination of beet, rye and wheat, though oats were affected. The seedlings, however, were injured by even much weaker solutions, oats being most affected, then rye, wheat and lastly barley; a 0.001 per cent solution had no effect on barley and wheat, but injured oats. He found that

${ }^{1}$ Ann. Agron., 1897, 328; Jour. Chem. Soc., 1897, Abstracts, ii, 585.

2 Bied. Zentr., 1899, 511; Jour. Chem. Soc., 1899, Abstracts, ii, 799.

${ }^{3}$ Jahr. über Agric. Chem., 1899, 105.

${ }^{4}$ Ann. Agron., 1898, 92. 
the application of nitrate containing 1 per cent perchlorate decreased the production of grain and straw about 4 per cent, while nitrate containing 2 per cent lessened the grain by 25 per cent and affected the straw to an even greater extent.

De Caluwe ${ }^{1}$ found that sodium perchlorate was more poisonous than the potassium salt, rye and maize being the most susceptible crops. The application of 150 grammes of sodium nitrate to the square metre gave a crop of 6.7 kilogrammes with pure nitrate, but when the nitrate contained 2.67 per cent of sodium perchlorate the yield was only 3.35 kilogrammes, while nitrate containing 4 to 5 per cent of the perchlorate proved fatal in all cases.

Sodium nitrate is the most important artificial source of nitrogen and has taken the place, to a great extent, of guano; as the supplies of the latter substance have now been almost exhausted, it naturally occurs to one that a similar fate may soon befall the supplies of nitrate. Various estimates of the total available nitrate in: the deposits of Chili, Peru and Bolivia have been made, ranging from $63 ; 000,000$ to 178,000,000 English tons. In 1895 the total export from South America reached 1,220,000 tons, while in 1910 it was $2,285,000$ tons. The following statistics, giving the estimated total world's consumption of nitrate of soda in the various years, may be of interest:-

\begin{tabular}{|c|c|c|}
\hline Year. & World's consumption, tons. & Price per cwt., on 31 Dec. \\
\hline 1831 & 100 & $28 \mathrm{~s} .0 \mathrm{~d}$. \\
1840 & 7,200 & $20 \mathrm{~s} .6 \mathrm{~d}$. \\
1860 & 50,000 & 15s. 0d. \\
1870 & 103,000 & $15 \mathrm{~s} .9 \mathrm{~d}$. \\
1880 & 228,000 & $14 \mathrm{~s} .3 \mathrm{~d}$. \\
1890 & 885,000 & $7 \mathrm{~s} .7 \frac{1}{2} \mathrm{~d}$. \\
1900 & $1,324,000$ & $8 \mathrm{~s} .6 \mathrm{~d}$. \\
1910 & $2,250,000$ & $9 \mathrm{~s} .6 \mathrm{~d}$. \\
1911 & $2,420,400$ & $9 \mathrm{~s} .9 \mathrm{~d}$. \\
\hline
\end{tabular}

During the earlier years, England consumed the greater portion of the total production. In 1875 , the amount consumed in the United Kingdom was 165,000 tons, while the European continent used only 132,000 tons. In 1879, however, the continental consumption, for the first time, exceeded that of the United Kingdom and since then has enormously increased, mainly because of the development of the sugar-beet crop, while that of this country has remained stationary or even diminished.

The table on the following page, giving the estimated consumption of nitrate, in tons, for the years mentioned, will show how greatly the use of nitrate has increased in other countries.

Ammonium Sulphate.-When organic nitrogenous bodies are submitted to destructive distillation, i.e., heated strongly without access of air, the nitrogen which they contain is, to a great extent, ex-

${ }^{1}$ Bull. Assoc. Belge des Chim., 12, 363; Jour. Soc. Chem. Ind., 1899, 114. 


\begin{tabular}{|c|c|c|c|c|c|}
\hline $\begin{array}{l}\text { Nitrate of soda } \\
\text { consumed in- }\end{array}$ & 1894. & 1898. & 1902. & 1906. & 1910. \\
\hline United Kingdom & 114,500 & 132,000 & 111,000 & 108,000 & 120,000 \\
\hline Continent of Europe. & 749,500 & 900,000 & 917,000 & $1,135,000$ & $1,531,000$ \\
\hline United States. & 100,000 & 142,000 & 214,000 & 355,000 & 510,000 \\
\hline Other countries & - & 12,000 & 17,000 & 38,000 & 89,000 \\
\hline Whole world & 964,000 & $1,186,000$ & $1,259,000$ & $1,636,000$ & $2,250,000$ \\
\hline & s. d. & s. d. . & s. d. & s d. & s. d. \\
\hline $\begin{array}{l}\text { Average price per ewt. } \\
\text { on } 31 \text { Dec. }\end{array}$ & $810 \frac{1}{2}$ & $77 \frac{1}{2}$ & $91 \frac{1}{2}$ & $111 \frac{1}{2}$ & 96 \\
\hline
\end{tabular}

pelled as ammonia, which is carried away in the vapours and gases simultaneously produced. The most important operation of this kind is the distillation of coal, and it is mainly from this source that the supplies of ammonium compounds are obtained. Ordinary coal contains a little over 1 per cent of nitrogen, and when burnt in the usual way, this nitrogen escapes into the air, mainly in the free state. When coal is distilled, however, a portion of the nitrogen is liberated as ammonia and is found in the so-called "ammoniacal liquor" which results from the cooling of the vapours evolved during the distillation. Coal is distilled for the production of coal-gas for illuminating purposes and also, in a somewhat different manner, for the manufacture of the special coke used in iron smelting. Gas works and coke ovens thus provide a large share of the "ammoniacal liquor" which forms the raw material for the manufacture of ammonium salts. A similar operation is the distillation of the bituminous shales used in the Scotch paraffin industry, while the production of pig iron is sometimes effected by the use of coal instead of coke, and, in this case, arrangements are sometimes made by which the ammonia and tarry products which are evolved during the first stages of the heating of the coal, may be collected. Another source of ammonia is the liquid condensed from the "producer gas " and "water gas," formed when a current of air or steam is forced over red-hot coal.

The product obtained in any of these processes is a complex mixture consisting of an aqueous solution of ammonium sulphide, carbonate, thiosulphate, thiocyanate and chloride.

The composition of gas liquor may be gathered from the following analyses of products obtained from the Leeds gasworks, I in $1883^{1}$ and II in January, $1901^{2}$ :-

${ }^{1}$ S. Dyson, Jour. Soc. Chem. Ind., 1883, 229 ; Jour. Chem. Soc., 1884, Abstracts, 928.

${ }^{2}$ A. W. Cooke, Jour. Soc. Chem. Ind., 1901. This sample represented the yield of three works, a total of about 6000 tons of liquor. For an account of the composition of gas liquor obtained at various stages of the distillation, etc., vide L. T. Wright, Journal of Gas Lighting, 48, 280 ; or abstract in Jour. Soc. Chem. Ind., 1886,655 . 


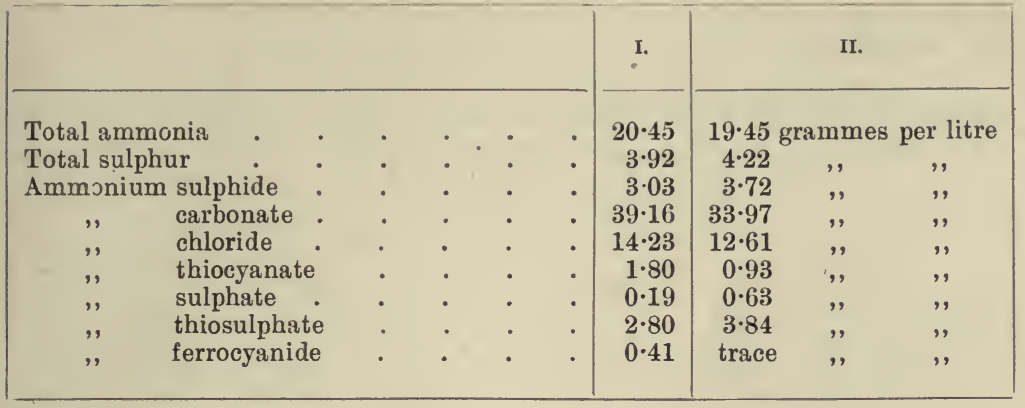

Organic bases and other substances were also present, but were not estimated.

In order to prepare a marketable commodity from this liquid, it is heated and lime is added. The ammonia volatilises, partly as carbonate and sulphide, partly as free ammonia, and is received in sulphuric acid, whereby sulphate of ammonia is formed, and carbon dioxide, sulphuretted hydrogen and other gases are evolved; these are led away and suitably disposed of. The liquid is then evaporated in leaden pans until it crystallises. Formerly the ammoniacal liquor was sometimes directly neutralised with sulphuric acid and the solution evaporated. In this case the resulting sulphate was impure and contained the highly objectionable thiocyanate, $\mathrm{NH}_{4} \mathrm{CNS}$, which is very injurious to vegetable life. Its detection in a specimen of sulphate is easy, its presence being at once indicated by the production of a blood-red colouration when the solution is mixed with a little ferric chloride solution. In the modern product, this impurity is rarely present. Another possible impurity of importance is arsenic, which may be present in the sulphuric acid; it, too, is objectionable, being highly poisonous both to animals and plants.

The sulphuric acid used in the manufacture of sulphate of ammonia ought to be either the arsenic-free acid specially prepared for the purpose from brimstone, or pyrites acid which has been freed from arsenic. Certain forms of Spanish pyrites give acid containing as much as 1 per cent or even 2 per cent of arsenious oxide and a few years ago were brought into prominence from the numerous cases of arsenic poisoning by beer, the arsenic being traced to the sulphuric acid used in the preparation of the glucose added to the wort in the brewing. Arsenic, if present in large quantities, usually imparts a yellow colour (due to $\mathrm{As}_{2} \mathrm{~S}_{3}[?]$ ) to the ammonium sulphate.

Theoretically, coal containing 1.3 per cent of nitrogen ought to yield about $149 \mathrm{lb}$. of sulphate of ammonia per ton; but in practice, the coal used in gasworks and for coke-making only gives about $20 \mathrm{lb}$. of sulphate per ton of coal, owing to a large portion of the nitrogen being retained in the coke, some being evolved as free nitrogen and some as pyridine, pyrrol and other nitrogenous tarry products.

In the manufacture of producer and water gas, especially by some of the most recent methods (e.g., by the "Mond" process), where the 
temperature is kept low, the yield of sulphate may amount to three or four times that just given.

The magnitude of the ammonium sulphate manufacture may be judged from the following table, which gives the production, in tons, in the United Kingdom during the years 1899, 1907, 1908 and $1909^{1}$ :-

\begin{tabular}{|c|c|c|c|c|c|c|c|}
\hline & & & & 1899. & 1907. & 1908. & 1909. \\
\hline From gasworks . & . & . & . & 133,000 & 165,474 & 165,218 & 164,276 \\
\hline , iron works & . & : & . & 18,700 & 21,024 & 18,131 & 20,228 \\
\hline ", shale works & • & . & . & 37,300 & 51,338 & 53,628 & 57,048 \\
\hline coke ovens & • & . & & - & 53,572 & 64,227 & 82,886 \\
\hline ", producer gas & and & carbonising & works & 13,000 & 21,873 & 24,024 & 24,705 \\
\hline Total. & . & . & . & $202, \mathrm{C} 00$ & 313,281 & 325,228 & 349,143 \\
\hline
\end{tabular}

In 1910 , the total production of this country was 367,587 tons.

In $1909,264,000$ tons of sulphate of ammonia were exported, leaving about 85,000 tons for home consumption. In 1908, the figures were 235,000 and 90,000 tons, respectively.

If a successful method of utilising the sulphur, always present in coal, in the formation of sulphuric acid, could be devised, a further cheapening of sulphate of ammonia would result. The price of sulphate of ammonia varies considerably, but is usually about $12 \mathrm{~s}$. per cwt.

Calcium Cyanamide.-This substance was prepared by Franck and Caro in 1895, by the action of nitrogen upon strongly heated calcium carbide. It was first used as a manure in 1901.

The reaction involved in its production is simple:-

$$
\mathrm{CaC}_{2}+\mathrm{N}_{2}=\mathrm{CaCN}_{2}+\mathrm{C}
$$

calcium carbide and nitrogen yielding calcium cyanamide and free carbon. The temperature required is said to be about $1000^{\circ} \mathrm{C}$. and the nitrogen is obtained from the air by removal of oxygen, either by means of heated copper, or by fractional distillation of liquid air. It is said that the addition of a small quantity of calcium chloride to the calcium carbide, enables the reaction to occur at a lower temperature (Polzeniusz).

A similar product is formed when lime or chalk is heated with coke or coal to a temperature of $2000^{\circ}$ in a current of air.

Two forms of calcium cyanamide were put on the market-one prepared by the Caro and Franck process known as "Kalk-stickstoff" or "lime nitrogen" the other by the Polzeniusz process, known as " Stickstoffkalk" or "Nitrolime " or "Nitrolim".

Many factories for its production have been erected and a considerable trade has already been established. Works in Italy, Dalmatia, France, Switzerland, Germany, Norway, Japan, and near Niagara are in operation. The commercial product is a fine, nearly black powder,

${ }^{1}$ Report of Chief Inspector of Alkali Works, 1910 ; abstract in Jour. Soc. Chem. Ind., 1910, 942. 
with an alkaline reaction and the unpleasant odour characteristic of commercial calcium carbide. It contains much impurity, indeed usually only from 48 to 58 per cent of real calcium cyanamide, the remainder consisting of lime (16 to 30 per cent), carbon (12 to 16 per cent), oxide of iron ( 2 to 4 per cent), and sand ( 4 to 7 per cent). The " nitrolime" form contains 5 or 6 per cent of calcium chloride.

Its nitrogen content is usually about 20 per cent; pure calcium cyanamide would contain 35 per cent.

When exposed to the air, it absorbs moisture and carbon dioxide, but does not become damp.

The constitution of the real calcium cyanamide is shown by the formula-<smiles>[Al]=CN=[W]</smiles>

which is to be regarded as derived from cyanamide $\mathrm{H}_{2} \mathrm{~N}-\mathrm{CN}$ by the replacement of the two atoms of hydrogen by calcium.

By exposure to air, the calcium is slowly converted into hydroxide and carbonate, and cyanamide is liberated :-

$$
\begin{aligned}
& \mathrm{Ca}: \mathrm{N} . \mathrm{CN}+2 \mathrm{H}_{2} \mathrm{O}=\mathrm{CaH}_{2} \mathrm{O}_{2}+\mathrm{H}_{2}: \mathrm{N} . \mathrm{CN} \\
& \text { and } \mathrm{Ca}: \mathrm{N} . \mathrm{CN}+\mathrm{H}_{2} \mathrm{O}+\mathrm{CO}_{2}=\mathrm{CaCO}_{3}+\mathrm{H}_{2}: \mathrm{N} \text {.CN }
\end{aligned}
$$

The cyanamide then polymerises, yielding dicyano-diamide.

$$
2 \mathrm{H}_{2}: \mathrm{N} . \mathrm{CN}=\mathrm{NH}: \mathrm{C}\left(\mathrm{NH}_{2}\right) \text { NH.CN }
$$

This substance, cyano-guanidine according to Bamberger, ${ }^{1}$ has a toxic action on plants. When calcium cyanamide is applied to soils, however, it undergoes nitrification and produces much the same effect as an equivalent amount of nitrogen applied as sulphate of ammonia. At first, however, nitrification is inhibited, especially if the dressing be a large one. Probably another portion of the cyanamide may split up, yielding ammonia and dicyanamide-

$$
2 \mathrm{H}_{2}: \mathrm{N} . \mathrm{CN}=\mathrm{NH}_{3}+\mathrm{H} . \mathrm{N}:(\mathrm{CN})_{2}
$$

According to Kappen ${ }^{2}$ the micro-organisms of soil are capable of readily bringing about the decomposition of cyanamide or of calcium cyanamide, but affect dicyanamide or dicyano-diamide very little, if at all.

Field experiments show that, as a nitrogenous manure, calcium cyanamide is nearly equal to sulphate of ammonia and that the fears expressed that if applied at the same time as the seed, it was injurious to germination (deduced from pot experiments) are not justified on the large scale provided excessive quantities of the manure are not used. ${ }^{3}$

The cost of production of calcium cyanamide is mainly determined by that of calcium carbide, which, in turn, depends chiefly upon that of electricity. Only where large sources of power are obtainable at a cheap rate (i.e., water-falls), can the process be carried out economically

${ }^{1}$ Ber., 1893, 26, 1583; Jour. Chem. Soc., 1893, Abstracts, i, 494.

2 Bied. Zentr., 1908, 37,204 ; Jour. Chem. Soc., 1908, Abstracts, ii, 414.

${ }^{3}$ Hendrick, Trans. High and Agric. Soc. Scotland, 1909, 133, and Muntz and Nottin, Compt. Rend., 1908, 147, 902 ; Jour. Chem. Soc., 1908, Abstracts, ii, 88. 
and, under the best of conditions, the cost of production probably equals that of the same amount of nitrogen as nitrate of soda or sulphate of ammonia. ${ }^{1}$

Nitrate of Lime.-The formation of nitric acid when electric sparks are passed through moist air was noticed by Cavendish in 1785. In recent years, successful attempts to practically utilise this reaction in the manufacture of a nitrogenous manure have been made. In 1905, the first factory designed for this purpose was started at Notodden in Norway, working according to a method devised by Birkeland and Eyde. Air is passed through a specially constructed electric furnace in which the arc, produced by an alternating current, is spread out into a flat flame by means of powerful electro-magnets.

The effect of the high temperature is first, to dissociate the molecules of gaseous oxygen and nitrogen into atoms :-

$$
\mathrm{N}_{2}=2 \mathrm{~N} \quad \mathrm{O}_{2}=2 \mathrm{O}
$$

and then to cause combination between the atomic oxygen and nitrogen :-

$$
\mathrm{O}+\mathrm{N}=\mathrm{NO} \text {. }
$$

This last reaction is reversible and the condition of equilibrium is determined by temperature.

According to Nernst, the following figures give the observed and calculated (on the basis of the law of mass action) percentages of nitric oxide in air after being raised to the various temperatures.

\begin{tabular}{|c|c|c|}
\hline Temperature. & Per cent by vol. of NO observed. & Calculated. \\
\hline & $0 \cdot 37$ & \\
\hline $2083^{\circ}$ & $0 \cdot 64$ & $0 \cdot 37$ \\
$2306^{\circ}$ & $0 \cdot 97$ & $0 \cdot 67$ \\
$2468^{\circ}$ & $5 \cdot 00$ & $0 \cdot 98$ \\
$3473^{\circ}$ & & $4 \cdot 40$ \\
\hline
\end{tabular}

Not only is the amount of nitric oxide greater at high temperatures, but the reaction occurs more rapidly. It is important that the cooling of the gases after the transformation be as rapid as possible, otherwise the reversed reaction leads to a great destruction of the nitric oxide first formed. When, however, the temperature has sunk to about $600^{\circ}$, the nitric oxide unites with additional oxygen to form nitrous fumes which escape reversal.

The gases obtained, in practice, only contain about one or two per cent by volume of nitric oxide as they come out of the furnace. The nitrous fumes are absorbed in water or in alkaline solutions and yield either nitric acid or nitrates or mixtures of nitrates and nitrites. Usually an excess of lime is employed and basic calcium nitrate is thus obtained, containing about 75 per cent of $\mathrm{Ca}\left(\mathrm{NO}_{3}\right)_{2}$ and some free lime.

${ }^{1}$ Vide Paper by Guye, Jour. Soc. Chem. Ind., 1906, 567. 
A very simple form of apparatus has been devised by the Badische Anilin und Soda Fabrik, ${ }^{1}$ consisting essentially of an iron tube provided at one end with an insulated concentric electrode, from which, on passing the current, an are springs to the adjacent part of the iron tube which forms the other electrode. A current of air passed tbrough the tube, carries the end of the are along, so that a column of are flame is produced, burning quietly in the axis of the tube and surrounded by the air passing through the tube. The gases which leave the tube traverse a firebrick flue surrounding the furnace, thus heating the air supply. The solution of calcium nitrate obtained at a later stage can be evaporated by the heat generated by the arc. A large factory to work this process is to be established in Norway, and is expected to use about 140,000 horse-power.

The commercial nitrate of lime is a white or yellowish substance containing about 13 per cent of nitrogen, readily soluble in water and, unfortunately, deliquescent. In field trials, it has proved quite equal to nitrate of soda, and on many soils, superior, because of its supplying lime as well as nitrogen.

Ammonium Nitrate.-This substance, $\mathrm{NH}_{4} \mathrm{NO}_{3}$, would be a very concentrated nitrogenous manure, containing, as it does, 35 per cent of nitrogen. It has not, unfortunately, been obtained at a sufficiently cheap rate to allow of its being used as a manure. Its deliquescent character would render it difficult to handle even if it could be obtained cheaply.

Potassium Nitrate.-This substance, though doubly valuable as a fertiliser, inasmuch as it supplies both potassium and nitrogen in a directly available form, is too expensive to be used as a manure except under special circumstances. Like sodium nitrate, it occurs as a deposit in rainless districts in the tropics, especially in India. It was also made by the so-called "Nitre plantations" in France and other countries. These consisted of heaps of earth, old mortar, road scrapings rich in calcium carbonate, etc., mixed with decomposing animal matter, protected from the rain by a shed, and placed on an impervious floor. The heap was watered periodically with urine, liquid manure, or other liquid rich in animal nitrogenous matter. Nitrification under these favourable conditions took place rapidly, and the liquid draining away contained large quantities of nitrates of potassium and calcium. At long intervals the heap was lixiviated with water and the solution mixed with wood ashes or potassium carbonate, when calcium carbonate was precipitated and removed and potassium nitrate was extracted from the solution by evaporation and crystallisation:-

$$
\mathrm{K}_{2} \mathrm{CO}_{3}+\mathrm{Ca}\left(\mathrm{NO}_{3}\right)_{2}=\mathrm{CaCO}_{3}+2 \mathrm{KNO}_{3} \text {. }
$$

It is probable that the saltpetre of India owes its origin to a similar action of nitrification, the potash coming from the minerals in the soil.

Potassium nitrate is now made in large quantities from sodium

${ }^{1}$ Bernthsen, Seventh Intern. Cong:. Appl. Chem., 1909; Jour. Soc. Chem. Ind., $1909,706$. 
nitrate and potassium chloride, which when mixed in solution and evaporated yield, first, sodium chloride crystals, and then, on cooling, potassium nitrate.

The properties of saltpetre are well known and need not be described here.

II. PHOSPHATIC MANURES. - Several of the manures already described are mainly valued for the phosphates they contain; this is the case with the non-nitrogenous guanos, steamed and burnt bones, etc. There are other sources of phosphoric acid of greater importance, which must now be described. Before mentioning the manures themselves, it may be advisable to briefly describe the various forms in which phosphoric acid occurs in fertilisers. These are-

(1) As tricalcium phosphate, $\mathrm{Ca}_{3}\left(\mathrm{PO}_{4}\right)_{2}$.

(2) "dicalcium phosphate, $\mathrm{Ca}_{2} \mathrm{H}_{2}\left(\mathrm{PO}_{4}\right)_{2}$ or $\mathrm{CaHPO}$.

(3) " monocalcium hydrogen phosphate, $\mathrm{CaH}_{4}\left(\mathrm{PO}_{4}\right)_{2}$.

(4) ", free phosphoric acid, $\mathrm{H}_{3} \mathrm{PO}_{4}$.

(5) ", ferric or aluminium phosphate, $\mathrm{FePO}_{4}$ or $\mathrm{AlPO}_{4}$.

(6) "tetracalcium phosphate, $\mathrm{Ca}_{4} \mathrm{P}_{2} \mathrm{O}_{9}$.

Tricalcium phosphate is a white, almost insoluble substance, which dissolves easily in acids. It is the form in which phosphoric acid occurs in bones, in most mineral phosphates, and, to a large extent, in guano. The solubility of the salt in water, free from carbon dioxide and air, is, according to Pollacci, ${ }^{1} 0.0098$ gramme per litre at $12.5^{\circ}$, or, if the phosphate be dried at $25^{\circ}$ instead of moist, 0.0181 gramme; if the water be saturated with carbon dioxide it dissolves 0.1605 at $10.5^{\circ}$. The solubility and particularly the rate of solution depend greatly upon the physical condition of the phosphate, being favoured by fineness of subdivision, porosity and an amorphous state.

The most important mineral phosphate is apatite, which has a composition corresponding to the formula $3 \mathrm{Ca}_{3} \mathrm{P}_{2} \mathrm{O}_{8} \cdot \mathrm{CaCl}_{2}$, or $3 \mathrm{Ca}_{3} \mathrm{P}_{2} \mathrm{O}_{8} \cdot \mathrm{CaF}_{2}$, the varieties being sometimes distinguished by the names-chlor-apatite and fluo-apatite; this substance occurs as hexagonal crystals, often of a green or yellow colour. Many of the mineral phosphates consist of what is practically amorphous apatite.

Dicalcium phosphate, $\mathrm{CaHPO}_{4}$, when prepared by precipitation, is a white solid containing 2 molecules of water. It is only slightly s sluble in water, but its solubility is greatly increased by the presence of many neutral salts, e.g., ammonium citrate. It probably is more readily dissolved by the acid juices of plants' roots than is tricalcium phosphate. By long boiling with water, it is said to yield a mixture of tricalcium and monocalcium phosphates.

$$
4 \mathrm{CaHPO}_{4}=\mathrm{Ca}_{3} \mathrm{P}_{2} \mathrm{O}_{8}+\mathrm{CaH}_{4} \mathrm{P}_{2} \mathrm{O}_{5} \text {. }
$$

Monocalcium phosphate, $\mathrm{CaH}_{4} \mathrm{P}_{2} \mathrm{O}_{5} \cdot \mathrm{H}_{2} \mathrm{O}$, can be obtained in thin rhombic plates. It is best prepared by dissolving dicalcium phosphate in phosphoric acid and washing the crystals obtained with alcohol and ether. ${ }^{2}$ It is not hygroscopic if free from excess of phosphoric acid.

1 Jour. Chem. Soc., 1897, Abstracts, ii, 260.

${ }^{2}$ Stoklasa, Jour. Chem. Soc., 1890, Abstracts, 695. 
When treated with a small quantity of water a portion of the salt is decomposed, with the formation of dicalcium phosphate as a precipitate and free phosphoric acid; but with larger quantities of water or in the presence of free phosphoric acid, this does not occur.

Free phosphoric acid, $\mathrm{H}_{3} \mathrm{PO}_{4}$, is a thick semi-solid mass, of specific gravity $1 \cdot 88$, formed by decomposing, say, calcium phosphate with sulphuric acid :-

$$
\mathrm{Ca}_{3} \mathrm{P}_{2} \mathrm{O}_{\mathrm{S}}+3 \mathrm{H}_{2} \mathrm{SO}_{4}=3 \mathrm{CaSO}_{4}+2 \mathrm{H}_{3} \mathrm{PO}_{4} \text {. }
$$

It is soluble to practically any extent in water.

Ferric phosphate, $\mathrm{FePO}_{4}$, and Aluminium phosphate, $\mathrm{AlPO}_{4}$, are practically insoluble in water and, unlike tricalcium phosphate and most other phosphates, are not dissolved to any appreciable extent by weak vegetable acids, e.g., acetic acid. Consequently they are not easily available to plants and possess little value as manurial ingredients.

Tetracalcium phosphate, $\mathrm{Ca}_{4} \mathrm{P}_{2} \mathrm{O}_{9}$, is found in the slag produced in the dephosphorisation of cast-iron by the Basic Bessemer or Basic Siemens process. It is practically insoluble in water, but dissolves in many saline solutions. It is therefore available as a plant food.

The chief varieties of phosphatic manures yet to be described are-

Coprolites.

Phosphorites, of which there are many varieties.

Redonda phosphate.

Mineral superphosphates.

Bone superphosphate.

Basic slag.

Coprolites are concretionary nodules found in the chalk or other deposits in the South of England and in France; they are believed to be the fossilised excrements or intestinal deposits of extinet animals which fed upon fish.

They were formerly of great importance and are still largely used. Their composition varies considerably, the chief constituents being-

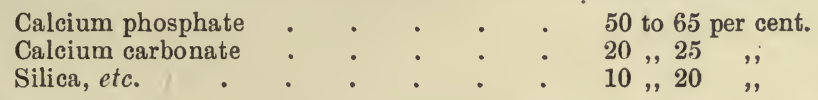

They are sometimes used raw in a finely divided state, but are more frequently converted into "superphosphate".

Of mineral phosphates or phosphorites there are many varieties, the most important being Norwegian, Canadian, Sombrero, Belgian, Carolina, Florida and Somme. These are occasionally employed in the raw state, but are mainly used in the preparation of "mineral superphosphates ". They all consist essentially of more or less impure apatite, some containing calcium chloride, others calcium fluoride, and some both compounds. In the process of manufacture of superphosphate the first variety is much preferred, for reasons which will be mentioned shortly.

Another factor of importance in gauging the value of a mineral phosphate is the proportion of iron and aluminium which it contains. 
The extent and growth of the phosphate mining industry may be seen from the following table, giving the total production, in tons, of raw phosphates in 1880 and $1890:^{1}$ -

\begin{tabular}{|c|c|c|c|c|c|c|c|c|}
\hline & & & & & & & 1880. & 1890. \\
\hline \multicolumn{3}{|c|}{ England (coprolites) } & . & . & . & . & 30,000 & 20,000 \\
\hline France & . & . & . & . & . & . & 125,000 & 370,000 \\
\hline Belgium & . & . & . & . & , & . & 15,000 & 200,000 \\
\hline Germany & . & & . & . & . & 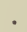 & 25,000 & 30,000 \\
\hline Norway & . & . & . & . & . & 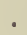 & 5,000 & 10,000 \\
\hline Canada & & . & . & . & . & 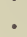 & 7,500 & 26,000 \\
\hline South Caroli & lina & . & . & . & . & . & 187,000 & 537,000 \\
\hline Florida & . & . & . & . & & 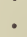 & - & 40,000 \\
\hline Spain. & . & . & 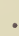 & . & . & 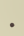 & 40,000 & - \\
\hline West Indies & & . & . & . & . & . & 35,000 & 50,000 \\
\hline Other source & & - & . & • & - & - & 30,000 & 20,000 \\
\hline Total & . & . & - & - & - & - & 499,500 & $1,303,000$ \\
\hline
\end{tabular}

Since 1890 many new sources of phosphates have been discovered and the total production has greatly increased. T The Florida deposits alone, in 1903, yielded 860,000 tons, while the total production of the United States was estimated at 1,581,000 tons. Large quantities also come from North Africa (chiefly Algeria) : in 1903 this district yielded 647,846 tons.

The following table gives the average composition of a number of mineral phosphates :-

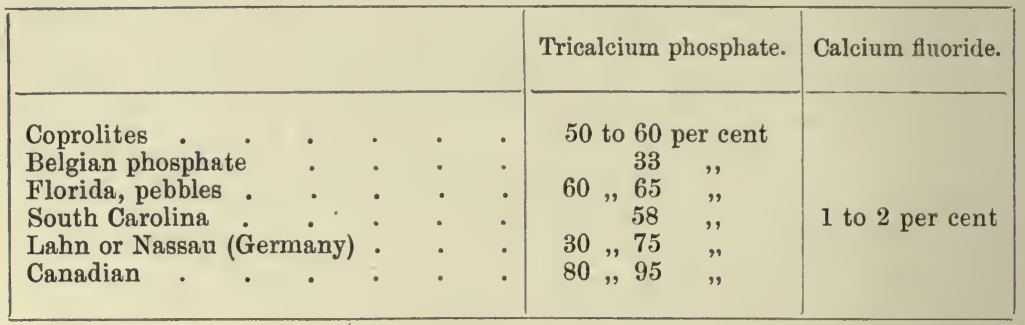

Redonda Phosphate (Leeward Islands) consists largely of aluminium phosphate and is therefore, in its raw state, not of much value. Lahn phosphate also contains a considerable quantity of ferric oxide and alumina, which lowers its value.

Mineral Superphosphates.-It is for the manufacture of these substances that the mineral phosphates are chiefly used, for in their raw state the latter are too insoluble to be of much value as fertilisers. In an extremely fine state of division, however, they become more available and are sometimes used. 
Superphosphate is made by treating the mineral with sulphuric acid, when a replacement of phosphoric acid by sulphuric acid takes place, calcium sulphate and free phosphoric acid being formed :-

$$
\mathrm{Ca}_{3} \mathrm{P}_{2} \mathrm{O}_{8}+3 \mathrm{H}_{2} \mathrm{SO}_{4}=3 \mathrm{CaSO}_{4}+2 \mathrm{H}_{3} \mathrm{PO}_{4} \text {. }
$$

The sulphuric acid also acts upon calcium carbonate, calcium chloride or fluoride, and oxides of iron and aluminium, if these be present, evolving carbon dioxide, hydrochloric or hydrofluoric acid:-

$$
\begin{aligned}
& \mathrm{CaCO}_{3}+\mathrm{H}_{2} \mathrm{SO}_{4}=\mathrm{CaSO}_{4}+\mathrm{H}_{2} \mathrm{O}+\mathrm{CO}_{2} \\
& \mathrm{CaCl}_{2}+\mathrm{H}_{2} \mathrm{SO}_{4}=\mathrm{CaSO}_{4}+2 \mathrm{HCl} \\
& \mathrm{CaF}_{2}+\mathrm{H}_{2} \mathrm{SO}_{4}=\mathrm{CaSO}_{4}+2 \mathrm{HF} \\
& \mathrm{Al}_{2} \mathrm{O}_{3}+3 \mathrm{H}_{2} \mathrm{SO}_{4}=\mathrm{Al}_{2}\left(\mathrm{SO}_{4}\right)_{3}+3 \mathrm{H}_{2} \mathrm{O} \\
& \mathrm{Fe}_{2} \mathrm{O}_{3}+3 \mathrm{H}_{2} \mathrm{SO}_{4}=\mathrm{Fe}_{2}\left(\mathrm{SO}_{4}\right)_{3}+3 \mathrm{H}_{2} \mathrm{O} .
\end{aligned}
$$

These various reactions consume a portion of the sulphuric acid and, in many cases, are completed before the action upon the calcium phosphate begins.

In general, the amount of sulphuric acid used is only sufficient to liberate phosphoric acid from a portion of the calcium phosphate, and a subsequent interaction then occurs between the phosphoric acid so liberated and the unchanged tricalcium phosphate:-

$$
\mathrm{Ca}_{3} \mathrm{P}_{2} \mathrm{O}_{8}+4 \mathrm{H}_{3} \mathrm{PO}_{4}=3 \mathrm{CaH}_{4} \mathrm{P}_{2} \mathrm{O}_{8}
$$

-thus producing monocalcium tetrahydrogen phosphate.

Superphosphates thus consist essentially of a mixture of

calcium sulphate, $\mathrm{CaSO}_{4} \cdot 2 \mathrm{H}_{2} \mathrm{Q}$,

calcium tetrahydrogen phosphate, $\mathrm{CaH}_{4} \mathrm{P}_{2} \mathrm{O}_{8}$,

and, generally, tricalcium phosphate, $\mathrm{Ca}_{3} \mathrm{P}_{2} \mathrm{O}_{8}$.

In many samples, aluminium sulphate and ferrous or ferric sulphate are also present in small proportions.

The important constituent is, of course, the monocalcium phosphate, $\mathrm{CaH}_{4} \mathrm{P}_{2} \mathrm{O}_{s}$, which is soluble in water, the tricalcium phosphate being of much less value. On keeping, many superphosphates show a reduction in the amount of phosphate soluble in water, and an increase in the insoluble phosphoric acid. This may be caused in two ways :-

(a) By the interaction of the monocalcium phosphate and the tricalcium phosphate leading to the formation of dicalcium phosphate ${ }^{1}-$

$$
\begin{array}{r}
\mathrm{CaH}_{4} \mathrm{P}_{2} \mathrm{O}_{8}+\mathrm{Ca}_{3} \mathrm{P}_{2} \mathrm{O}_{8}=4 \mathrm{CaHPO}_{4} \\
\text { (or } 2 \mathrm{Ca}_{2} \mathrm{H}_{2} \mathrm{P}_{2} \mathrm{O}_{8} \text { ). }
\end{array}
$$

(b) By the formation of ferric and aluminium phosphates by the action of the monocalcium phosphate upon the iron and aluminium sulphates :-

1 This substance is present even in fresh superphosphate, so that "reverted" phosphate is to some extent a misleading name, inasmuch as some of the substance so-called has never been present in a soluble form. The amount of phosphates of this character is determined by taking advantage of their solubility in ammonium citrate (vide Chap. IX) ; the name "citrate-soluble" phosphorus pentoxide would therefore be preferable to the names already mentioned. 


$$
\begin{aligned}
& \mathrm{Al}_{2}\left(\mathrm{SO}_{4}\right)_{3}+\mathrm{CaH}_{4} \mathrm{P}_{2} \mathrm{O}_{8}=2 \mathrm{AlPO}_{4}+\mathrm{CaSO}_{4}+2 \mathrm{H}_{2} \mathrm{SO}_{4} \\
& \mathrm{Fe}_{2}\left(\mathrm{SO}_{4}\right)_{3}+\mathrm{CaH}_{4} \mathrm{P}_{2} \mathrm{O}_{8}=2 \mathrm{FePO}_{4}+\mathrm{CaSO}_{4}+2 \mathrm{H}_{2} \mathrm{SO}_{4} .
\end{aligned}
$$

The free sulphuric acid thus formed would be used in acting upon some of the unchanged $\mathrm{Ca}_{3} \mathrm{P}_{2} \mathrm{O}_{8}$ as before.

In either case, a quantity of phosphoric acid formerly in the soluble condition as $\mathrm{CaH}_{4} \mathrm{P}_{2} \mathrm{O}_{8}$ would pass into an insoluble form. Such phosphoric acid and phosphates are often spoken of as "retrograde," "reduced," or "reverted" phosphate. They generally possess a higher manurial value than tricalcium phosphate.

In the process of manufacturing superphosphate, the ground phosphate is mixed with the suitable quantity of sulphuric acid (chamber acid of specific gravity 1.55) in "mixers" made of wood lined with lead, or of iron lined with fire-brick, and provided with stirrers rotated by gearing. The carbon dioxide, hydrofluoric or hydrochloric acid, and steam evolved by the action are led away into a "scrubber" or "condenser," in which the steam condenses and-absorbs the acids. The prevention of their escape into the atmosphere is enforced by law. When the lining of the "mixer" is fire-clay (highly silicious), phosphates containing calcium fluoride cause the production of gaseous silicon fluoride:-

$$
\begin{gathered}
\mathrm{CaF}_{2}+\mathrm{H}_{2} \mathrm{SO}_{4}=\mathrm{CaSO}_{4}+2 \mathrm{HF} \\
\mathrm{SiO}_{2}+4 \mathrm{HF}^{2}=\mathrm{SiF}_{4}+2 \mathrm{H}_{2} \mathrm{O} .
\end{gathered}
$$

The silicon fluoride escapes with the other gases and, on contact with the condensed steam, produces a gelatinous presipitate of silica and a solution of hydrofluosilicic acid, $\mathrm{H}_{2} \mathrm{SiF}_{6}$ :-

$$
3 \mathrm{SiF}_{4}+4 \mathrm{H}_{2} \mathrm{O}=\mathrm{SiO}_{4} \mathrm{H}_{4}+2 \mathrm{H}_{2} \mathrm{SiF}_{6} \text {. }
$$

The presence of fluorine in phosphates is thus attended with the production of the very corrosive hydrofluoric acid, the consequent wear and corrosion of the fire-clay lining, and the accumulation of the very bulky, gelatinous silicic acid in the condenser, tending to choke it. The bye-product, hydrofluosilicic acid, possesses antiseptic properties and can be used as a preservative of farm-yard manure. When the admixture of the acid and phosphate is complete, the contents of the "mixer" are transferred to pits or "dens" made of brick-work or masonry. The mixture at this stage is usually semi-fluid and runs easily. In the "dens" the union of the calcium sulphate with water takes place, resulting in the formation of crystals of the same composi. tion as the mineral gypsum, $\mathrm{CaSO}_{4} \cdot 2 \mathrm{H}_{2} \mathrm{O}$. This causes the product to "set" or "dry," and after this it is ground in suitable mills and screened and is ready for the market.

"Double superphosphate" is sometimes made by preparing phosphoric acid by the action of excess of acid upon one portion of the phosphate, removing the greater part of the calcium sulphate, and adding the phosphoric acid to another portion of the original phosphate thus converting the tricalcium into monocalcium phosphate:-

$$
\mathrm{Ca}_{3} \mathrm{P}_{2} \mathrm{O}_{8}+4 \mathrm{H}_{3} \mathrm{PO}_{4}=3 \mathrm{CaH}_{4} \mathrm{P}_{2} \mathrm{O}_{8} \text {. }
$$

Such a product is very concentrated and may contain as much as 40 per cent of phosphoric acid, nearly all in the soluble form. 
Manures similar to superphosphate are made by the action of sulphuric acid upon bone-ash, bones, or guano. These resemble mineral superphosphates so far as the state of existence of their phosphoric acid is concerned, but may, of course, contain nitrogenous constituents.

The following table gives the amount of the most important fertilising ingredients in various forms of manures of this class, expressed in the usual conventional way:-

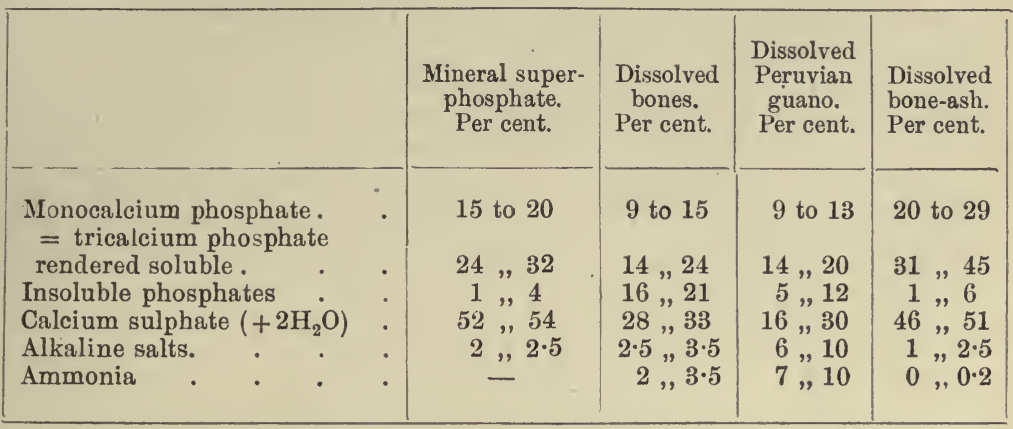

A word of explanation as to the commercial methods of expressing analytical results may be here given. It is the custom to indicate by, say, " 24 per cent soluble phosphates" that 24 is the amount of tricalcium phosphate which contains the same quantity of phosphoric acid as is present in the soluble (monocalcium) phosphates contained in 100 parts of manure.

$$
\begin{aligned}
& \text { Since } \mathrm{Ca}_{3} \mathrm{P}_{2} \mathrm{O}_{8} \quad \text { corresponds to } \mathrm{CaH}_{4} \mathrm{P}_{2} \mathrm{O}_{8} \\
& \underbrace{120+62+128 \quad}_{310} \quad " \quad 40 \underbrace{+4+62+128}_{234}
\end{aligned}
$$

the amount of real calcium tetrahydrogen phosphate corresponding to " 24 per cent soluble" would be $24 \times \frac{234}{310}=18 \cdot 1$; but even this is not what is meant, for by "monocalcium phosphate" in the trade the substance $\mathrm{CaP}_{2} \mathrm{O}_{6}$ (really calcium meta-phosphate, which is not present in manures) is understood; so that as this contains the same amount of $\mathrm{P}_{2} \mathrm{O}_{5}$ as $\mathrm{Ca}_{3} \mathrm{P}_{2} \mathrm{O}_{8}$ the connection becomes-

$$
\underbrace{40+62+96}_{198} \begin{gathered}
\mathrm{CaP}_{2} \mathrm{O}_{6} \\
\text { corresponds to }
\end{gathered} \quad \begin{gathered}
\begin{array}{c}
\mathrm{Ca}_{3} \mathrm{P}_{2} \mathrm{O}_{8} \\
20+62+128
\end{array} \\
310
\end{gathered}
$$

Consequently, in the trade, the quantity of monocalcium phosphate equivalent to " 24 per cent soluble phosphates" or to " 24 per cent bone phosphate rendered soluble," as it is sometimes more explicitly described, is given by-

$$
24 \times \frac{198}{310}=15.4 \text { per cent. }
$$

By the term "insoluble phosphates" in the above analyses is meant the amount of tricalcium phosphate present as such, together with that equivalent to the dicalcium phosphate or "reverted " phosphate. The latter is much more valuable than the former and in recent analyses the quantities of each present are given (see Chap. VIII). 
Reference may here be made to a recently patented manure to which the contradictory name of basic superphosphate has been given. This is a product obtained by adding 15 parts of slaked lime to 85 parts of good superphosphate, thoroughly mixing the two, and allowing them to stand at least twenty-four hours. A dry, bulky powder is thus produced, which, it is claimed, has many advantages over basic slag. ${ }^{1}$

The phosphoric acid of the superphosphate, is, of course, rendered insoluble in water by this treatment, though the phosphate of lime thus produced is doubtless more easily dissolved by soil solvents than that existing even in finely ground mineral phosphates.

The new manure may probably produce a better effect than superphosphate upon soils deficient in calcium carbonate or other basic material, but it would certainly seem preferable either to use basic slag on such soils, or to apply the lime and superphosphate separately and thus secure the advantage of their more uniform distribution in the soil which their solubility in water (while separate) ensures.

Basic Slag, or Thomas Phosphate, is now one of the cheapest and best sources of phosphoric acid. It results as a bye-product in the manufacture of steel from pig-iron rich in phosphorus. In order that the student may clearly understand its origin, it will perhaps be advisable to briefly review the chemistry of the processes used in the production of steel.

Until 1856 steel was made by the laborious and expensive process of first obtaining pig-iron or cast-iron, in which are numerous impurities (as is seen from the subjoined analyses), removing these impurities, including almost the whole of the carbon, by refining and puddling, and so obtaining wrought-iron, which is almost pure iron, and lastly causing this, after it had been rolled out into thin bars, to combine with the requisite quantity of carbon by the process known as cementation, in which the bars of wrought-iron are heated in a closed iron case with powdered charcoal for several days. The iron under this treatment was converted into steel. The process was so costly and tedious that steel commanded a very high price and was only used for special purposes.

Analyses of pig-iron, wrought-iron and steel :-

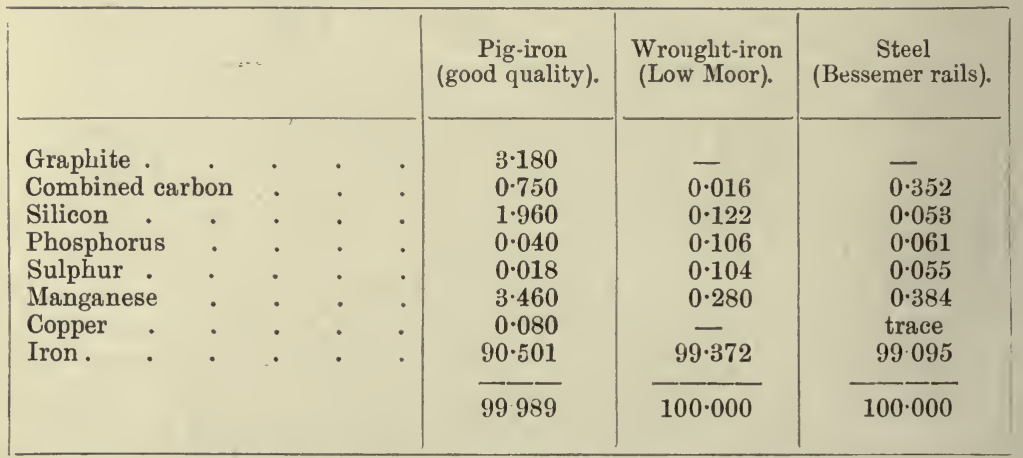

${ }^{1}$ Hughes, Jour. Soc. Chem. Ind., 1901, 325. 
In 1856, Bessemer introduced his process for making steel directly from pig-iron. This consists in running the molten pig-iron into an egg-shaped vessel mounted on trunnions and constructed of boiler plates lined with a particularly infusible fire-clay known as ganister and consisting of almost pure silica. At the bottom of this vessel, known as a converter, are holes through which air can be blown by means of a pipe passing through one of the trunnions. The blast of air passing through the molten iron oxidises the carbon, silicon, sulphur and part of the iron, producing thereby a higher temperature, so that although pure iron has a much higher melting-point than cast-iron, the contents of the converter do not solidify. The carbon, by its oxidation, produces carbon monoxide, which burns at the mouth of the converter, and the end of the operation can be detected by the sudden dying down of this flame; the contents of the converter then consist of practically molten wrought-iron. It is converted into steel by the addition of a suitable quantity of a particular variety of cast-iron known as "spiegeleisen," which contains a high percentage of carbon. The metal is then poured out of the converter.

This process quite revolutionised the iron industry, and steel became so cheap that it almost replaced iron. The Bessemer process, however, could only be applied to pig-iron fairly free from phosphorus, for the process does not remove any phosphorus, and if steel contains much of this element its properties are so altered that it becomes valueless.

The following table shows the change in the composition of the metal in the "Bessemer converter" (acid lining) :-

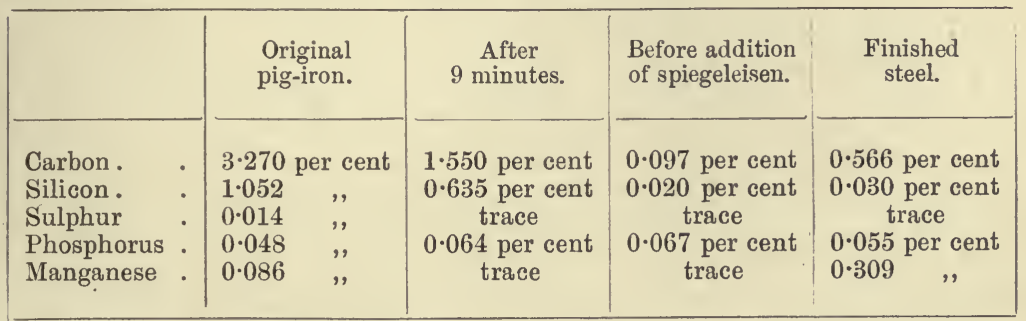

It will be noticed that there is no reduction in the amount of phosphorus, but rather an increase, while the sulphur, carbon and silicon are almost entirely removed.

About 1878-9, a modification in the method of working the Bessemer process was introduced by Thomas and Gilchrist, by which pig-iron containing high percentages of phosphorus could be successfully converted into steel of good quality. Their improvement consisted in lining the converter with lime, or a mixture of lime and magnesia, and the introduction of freshly burnt lime into the converter. They found that, under these circumstances, the phosphorus in the pig-iron (existing in combination with iron as phosphide) was oxidised by the air after the carbon had been completely removed, and the phosphoric acid so formed united with the lime and magnesia of the basic lining to form a slag which floated on the molten iron. The 
rest of the process is conducted as in the original Bessemer or "acid" process. This improvement was of great importance, especially to iron masters in districts where the iron ore contained large quantities of phosphates.

The following table gives the data in the case of the Thomas-Gilchrist or Basic-Bessemer process, the pig-iron used being so rich in phosphorus as to be quite unfit for use by the ordinary Bessemer process :-

\begin{tabular}{|c|c|c|c|c|c|}
\hline & $\begin{array}{l}\text { Original } \\
\text { pig-iron. }\end{array}$ & $\begin{array}{c}\text { After } \\
12 \mathrm{~min} .\end{array}$ & $\begin{array}{l}\text { After } 14 \mathrm{~min} \text {. } \\
\text { End of ordi- } \\
\text { nary blow. }\end{array}$ & $\begin{array}{l}\text { After } 16 \frac{1}{2} \text { min. } \\
\text { End of after } \\
\text { blow. }\end{array}$ & Steel. \\
\hline $\begin{array}{l}\text { Carbon } \\
\text { Silicon : } \\
\text { Phosphorus } \\
\text { Manganese } \\
\text { Sulphur. }\end{array}$ & $\begin{array}{l}3.57 \text { per cent } \\
1.70 \quad, \\
1.57 \quad, \\
0.71 \quad, \\
0.06 \quad,\end{array}$ & $\begin{array}{lc}0.88 & \text { per cent } \\
0.01 & ,, \\
1.42 & , \\
0.27 & ,, \\
0.05 & ,,\end{array}$ & $\begin{array}{l}0.07 \text { per cent } \\
\text { trace } \\
1.22 \text { per cent } \\
0.12 \quad,, \\
0.05 \quad,\end{array}$ & $\begin{array}{c}\text { trace } \\
\text { nil } \\
0.08 \text { per cent } \\
\text { trace } \\
0.05 \text { per cent }\end{array}$ & $\begin{array}{l}0.124 \text { per cent } \\
0.030 \quad, \\
0.220 \quad, \\
0.270 \quad, \\
0.040 \quad,\end{array}$ \\
\hline
\end{tabular}

It will be seen from the above table that the silicon is first oxidised and removed, then the carbon, and not until practically all the carbon is removed does the removal of the phosphorus begin.

The slag obtained by the basic process therefore receives its phosphate in the last few minutes of the process. This is seen from the following figures :-

\begin{tabular}{|c|c|c|c|c|c|}
\hline \multirow{2}{*}{$=$} & \multicolumn{4}{|c|}{ Time from commencement of the blow. } & \multirow{2}{*}{$\begin{array}{l}\text { Slag at the end } \\
\text { of the process. } \\
\text { Per cent. }\end{array}$} \\
\hline & $\begin{array}{l}6 \text { min. } \\
\text { Per cent. }\end{array}$ & $\begin{array}{l}12 \text { min. } \\
\text { Per cent. }\end{array}$ & $\begin{array}{l}14 \frac{1}{2} \text { min. } \\
\text { Per cent. }\end{array}$ & $\begin{array}{l}16 \frac{1}{2} \min . \\
\text { Per cent }\end{array}$ & \\
\hline Silicon & $42 \cdot 60$ & $35 \cdot 60$ & $33 \cdot 00$ & $16 \cdot 60$ & $18 \cdot 60$ \\
\hline Phosphorus pentoxide & $0 \cdot 15$ & $2 \cdot 61$ & $5 \cdot 66$ & $16 \cdot 03$ & $13 \cdot 87$ \\
\hline Iron . & $2 \cdot 00$ & $4 \cdot 80$ & $6 \cdot 15$ & $11 \cdot 35$ & $7 \cdot 10$ \\
\hline
\end{tabular}

The process resulted in a still further cheapening of steel. For some years the slag produced-though it was known to contain a considerable quantity of phosphoric acid-was regarded as simply a byeproduct of no use. It was thought that the oxide of iron present in the slag would prevent the phosphoric acid from being available to plants. Its use as a manure for soils poor in lime was suggested about $1882,{ }^{1}$ as it was found that a considerable proportion of the phosphoric acid in the slag was in such a state of combination as allowed of its easy solubility in ammonium citrate solution. This led to numerous trials of the slag, and, many of these proving highly satisfactory, its use rapidly extended and has now assumed gigantic proportions.

The composition of the slag necessarily varies somewhat, but its

${ }^{1}$ Maercker, Bied. Zentr., 1882, 490 ; Jour. Chem. Soc., 1882, Abstracts, 1229. 
main constituents are represented in the following analysis of a specimen ${ }^{2}:-$

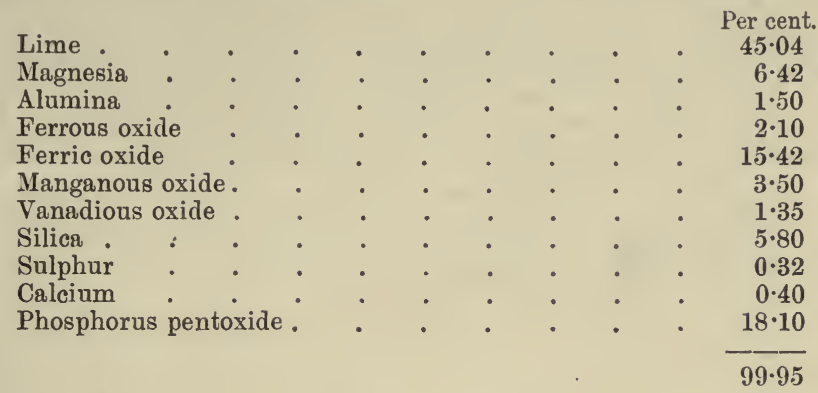

The sulphur present seems to exist as a sulphide, probably of calcium. The phosphoric acid is present as tetracalcium phosphate, $\mathrm{Ca}_{4} \mathrm{P}_{2} \mathrm{O}_{9}$, a substance which sometimes occurs nearly pure as crystals imbedded in the slag.

According to Hoyermann and Wagner ${ }^{2}$ the citrate-solubility of the phosphoric acid in basic slag is greatly increased if the slag be fused with sand. Wagner states that the citrate-solubility (by which he judges of the availability) of the basic slag of commerce varies from 100 to 40 per cent, and that a high solubility depends upon the presence of at least a certain percentage of silica. Ridsdale ${ }^{3}$ denies this, and states that the only function of the silica is the neutralising of a certain proportion of the free lime of the slag and thus preventing the action of this upon the citrate solution employed.

According to Blome, ${ }^{4}$ tetracalcium phosphate, $4 \mathrm{CaO} \cdot \mathrm{P}_{2} \mathrm{O}_{5}$, melts at $1870^{\circ} \mathrm{C}$., while a compound $-4 \mathrm{CaO} \cdot \mathrm{P}_{2} \mathrm{O}_{5}+\mathrm{SiO}_{2}$, melts at $1700^{\circ}$ and is totally soluble in 2 per cent solution of citric acid. Blue crystals having this composition have been found in basic slag by Stead and Ridsdale.

Blome also obtained evidence of the existence of

$$
4 \mathrm{CaO} \cdot \mathrm{P}_{2} \mathrm{O}_{5}+2 \mathrm{CaO} \cdot \mathrm{SiO}_{2} \text { and of } 4 \mathrm{CaO} \cdot \mathrm{P}_{2} \mathrm{O}_{5}+4\left(2 \mathrm{CaO} \cdot \mathrm{SiO}_{2}\right)
$$

the former melting at $1710^{\circ}$, the latter at $1780 .^{\circ}$ In both cases, the melted mass contained about 4 per cent of free lime. By slow cooling of the melt corresponding to $4 \mathrm{CaO} \cdot \mathrm{P}_{2} \mathrm{O}_{5}+2 \mathrm{CaO} . \mathrm{SiO}_{2}$, a large increase in the amount of free lime was observed and the resulting product was much more soluble in citric acid solution. He concludes that it is probable that a double compound of tetracalcium phosphate and calcium ortho-silicate is the combination, whose presence in Thomas' slag conditions the citrate solubility of that material.

Many attempts to improve basic slag as a manure have been made, some directed to the removal of the iron, others the sulphur, while others have attempted to render the phosphoric acid more soluble by treatment with sulphuric acid. Practically all these

${ }^{1}$ Stead and Ridsdale, Jour. Chem. Soc., 1877, Trans., 601.

2 Chem. Zeitung, 1895, $1511 . \quad 3$ Jour. Soc. Chem. Ind., 1895, 170.

* Metallurgie, 1910, 7, 659; also Jour. Soc. Chem. Ind., 1910, 1467. 
attempts have been abandoned, and the only process through which the slag is passed is that of grinding. This must be thoroughly done, for it is found that the availability of the phosphoric acid depends very largely upon the fineness of subdivision. A sample should contain at least 80 or 90 per cent of powder which passes through a sieve of 100 meshes to the linear inch, i.e., 10,000 to the square inch. Thomas' phosphate has given excellent results, especially in soils somewhat deficient in lime and rich in organic matter.

The magnitude of the trade in basic slag may be gathered from the accompanying table giving the quantity sold as a fertiliser in Europe during 1899. ${ }^{1}$

\begin{tabular}{|c|c|c|c|c|c|c|c|}
\hline & & & & & $\begin{array}{l}\text { Sold. } \\
\text { Tons. }\end{array}$ & $\begin{array}{c}\text { Used in the country. } \\
\text { Tons. }\end{array}$ & $\begin{array}{c}\text { Exported. } \\
\text { Tons. }\end{array}$ \\
\hline Germany & . & . & . & . & 786,000 & 730,000 & 56,000 \\
\hline Great Britain & . & . & . & . & 256,000 & 110,000 & 146,000 \\
\hline France. & . & . & . & . & 198,000 & 198,000 & - \\
\hline Belgium & : & . & . & . & 112,000 & 80,000 & 32,000 \\
\hline Austria Hungary & . & . & . & . & 64,000 & 90,000 & -2 \\
\hline Total & . & . & - & . & $1,416,000$ & $1,208,000$ & 234,000 \\
\hline
\end{tabular}

So successful has Thomas' phosphate proved as a manure that lately a product, known as "artificial Thomas phosphate meal," has been made in Germany by a method devised by Wolters. Raw mineral phosphates are fused with silicious materials, e.g., sand or glass, and chalk or limestone, and a product resembling basic slag is thus obtained. In another preparation potash is introduced. According to analyses of the two products by Maercker ${ }^{3}$ they contain-

\begin{tabular}{|c|c|c|c|c|c|c|c|c|c|c|c|c|}
\hline & & & & & & & & & \multicolumn{2}{|c|}{ I. } & \multicolumn{2}{|c|}{ II. } \\
\hline \multicolumn{6}{|c|}{$\begin{array}{l}\text { Total phosphorus pentoxide } \\
\text { Phosphorus pentoxide, soluble }\end{array}$} & . & . & . & \multicolumn{2}{|c|}{$15 \cdot 50$ per cent } & \multicolumn{2}{|c|}{ 16.89 per cent } \\
\hline in $\mathrm{ci}$ & rat & & & . & . & . & . & . & $14 \cdot 52$ & & $15 \cdot 38$ &, \\
\hline Lime & . & . & . & . & . & . & . & . & $41 \cdot 80$ & ," & - & \\
\hline Silica & . & . & 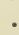 & . & . & . & . & . & $26 \cdot 83$ & ," & - & \\
\hline Potash & . & . & . & . & . & . & . & . & - & & $13 \cdot 10$ &, \\
\hline
\end{tabular}

According to Wagner ${ }^{4}$ Wolters' phosphate is now prepared by fusing a mixture of crushed phosphorite (100 parts), sodium bisulphate (70), calcium carbonate (20), sand (22), and coal (6 or 7 parts). The melt is granulated by being poured into cold water and is there finely ground. 97 per cent of the total phosphate present is soluble in weak

${ }^{1}$ Engineering and Mining Journal, 69, 648. Jour. Soc. Chem. Ind., 1900, 574.

226,000 tons were imported, chiefly from Germany.

3 Jah. Agric. Chem., 1899, 129.

${ }^{4}$ Bied. Zentr., 1904, 301; Jour. Soc. Chem. Ind., 1904, 615. 
citric acid solution. In some experiments, the Wolters' phosphate was found to be almost as quick in action as superphosphate.

Another product of somewhatsimilar character as to citrate-solubility of its phosphates is the so-called Wiborgh phosphate, another German product. It is prepared by heating the crude phosphate (mainly apatite), containing some felspar, with soda-ash, to about $1000^{\circ} \mathrm{C}$.

The reactions are said to be-

$$
\begin{gathered}
3\left(\mathrm{Ca}_{3} \mathrm{P}_{2} \mathrm{O}_{8}\right) \cdot \mathrm{CaF}_{2}+3 \mathrm{Na}_{2} \mathrm{CO}_{3} \\
=2 \mathrm{Na}_{2} \mathrm{O} \cdot 10 \mathrm{CaO} \cdot 3 \mathrm{P}_{2} \mathrm{O}_{5}+2 \mathrm{NaF}+3 \mathrm{CO}_{2} \\
\mathrm{~K}_{2} \mathrm{O} \cdot \mathrm{Al}_{2} \mathrm{O}_{3} \cdot 6 \mathrm{SiO}_{2}+2 \mathrm{Na}_{2} \mathrm{CO}_{3}=\mathrm{K}_{2} \mathrm{O} \cdot 2 \mathrm{Na}_{42} \mathrm{O} \cdot \mathrm{Al}_{2} \mathrm{O}_{3} \cdot 6 \mathrm{SiO}_{2}+2 \mathrm{CO}_{2} .
\end{gathered}
$$

The double sodium-calcium phosphate has a constitution similar to tetracalcium phosphate, and like that substance is soluble in ammonium citrate solution (up to 95 per cent of the total phosphoric acid). The triple silicate of sodium, potassium and aluminium contains its potash in a more readily available form than the original felspar. The composition of the residue, which is easily powdered, is ${ }^{1}:-$

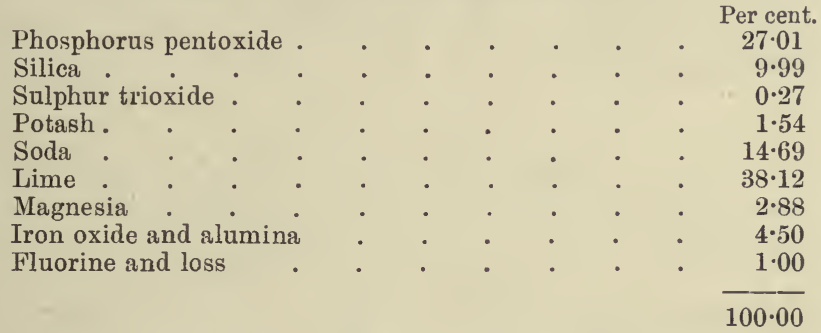

It is probable that a recently devised continuous process of dephosphorising pig-iron (Talbot's patent) may lead to an increased production of basic slag.

III. POTASH MANURES.-Potash is much more widely distributed and less frequently deficient in soils than are nitrogen and phosphoric acid. Potash manures, therefore, are less often used than those already described; although certain crops, e.g., potatoes, are greatly helped by their application. Formerly, the chief source of potash, both for manurial and other purposes, was the ash left when twigs, leaves, etc., of plants are burnt. Potash occurs in such material as carbonate, and plant ashes are still used to some extent as a manure. They contain the other mineral ingredients, phosphates, lime, etc., but they are especially rich in potash. The chief source of potash is now the immense saline deposits at Stassfurt, and other deposits of a similar kind have been discovered in Thuringia, Brunswick and Mecklenburg.

These deposits, in some cases hundreds of feet in thickness, rest upon beds of rock-salt, and it was in boring for the rock-salt that they were discovered about 1857. At first they were regarded as useless, as is indicated by the name "Abraumsalzen" (rubbish salts), by which they are still sometimes known. About five or six years later they

${ }^{1}$ Nilson, Jahr. Agric. Chem., 1899, 127. 
were worked as a source of potash compounds, and now enormous quantities are annually raised and furnish almost all the potash required in the arts as well as in agriculture.

The chief compounds are classed under the following mineralogical names :-

Sylvine, $\mathrm{KCl}$.

Sylvinite, a mixture of sylvine, rock-salt and kainite.

Carnallite, $\mathrm{MgCl}_{3} \cdot \mathrm{KCl} \cdot 6 \mathrm{H}_{2} \mathrm{O}$.

Schönite (Picromerite), $\mathrm{MgSO}_{4}, \mathrm{~K}_{2} \mathrm{SO}_{4} \cdot 6 \mathrm{H}_{2} \mathrm{O}$.

Kieserite, $\mathrm{MgSO}_{4} \cdot \mathrm{H}_{2} \mathrm{O}$ (mixed with carnallite).

Kainite, $\mathrm{MgSO}_{4} \cdot \mathrm{KCl} .3 \mathrm{H}_{2} \mathrm{O}$, or $\mathrm{MgSO}_{4} \cdot \mathrm{K}_{2} \mathrm{SO}_{4} \cdot \mathrm{MgCl}_{2} \cdot 6 \mathrm{H}_{2} \mathrm{O}$.

Polyhalite, $\mathrm{K}_{2} \mathrm{SO}_{4} \cdot 2 \mathrm{CaSO}_{4} \cdot \mathrm{MgSO}_{4} \cdot \mathrm{H}_{2} \mathrm{O}$.

The substances do not occur in the pure form indicated by these formulæ, but are more or less mixed with each other and especially with rock-salt. Carnallite is, by far, the most abundant.

The output of Stassfurt salts is now regulated by a syndicate, who limit the production and fix the prices of the various salts.

In 1898 the quantities, in tons, produced and sent out to the various countries were as follows:-

\begin{tabular}{|c|c|c|c|c|c|}
\hline & $\begin{array}{l}\text { Potassium } \\
\text { chloride, } \\
80 \text { per cent. }\end{array}$ & $\begin{array}{l}\text { Potassium } \\
\text { sulphate, } \\
90 \text { per cent. }\end{array}$ & $\begin{array}{l}\text { Calcined } \\
\text { potassium } \\
\text { and mag. } \\
\text { sulphate. }\end{array}$ & $\begin{array}{c}\text { Kainite } \\
\text { and } \\
\text { sylvinite. }\end{array}$ & $\begin{array}{c}\text { Carnallite } \\
\text { and } \\
\text { kieserite. }\end{array}$ \\
\hline Germany & 70,877 & 679 & 136 & 722,115 & 60,793 \\
\hline Austris and Switzerland & 3,844 & 20 & - & 17,302 & - \\
\hline Great Britain . & 13,481 & 1,818 & 352 & 26,311 & 229 \\
\hline France. & 14,870 & 1,957 & 108 & 12,241 & 141 \\
\hline Belgium and Holland. & 8,723 & 1,089 & 967 & 37,118 & 6,798 \\
\hline Italy . . . & 3,924 & 337 & - & 149 & - \\
\hline Sweden and Denmark . & 4,048 & 1 & - & 51,364 & 1 \\
\hline Russia. . . & 2,379 & 577 & - & 8,004 & 30 \\
\hline North America & 54,272 & 9,308 & 8,945 & 176,065 & - \\
\hline Spain and Portugal & 1,118 & 521 & - & 2,364 & - \\
\hline Other countries & 446 & 1,474 & 27 & 3,193 & - \\
\hline Total . & 177,983 & 17,781 & 10,533 & $1,056,226$ & 67,982 \\
\hline
\end{tabular}

Of the 70,877 tons of chloride used in.Germany only about 1528 tons were employed in agriculture, the rest being used as the raw material for the production of other potash salts. Of the 107,107 tons exported, however, about 64,000 tons were employed for agricultural purposes, the extra cost of this material over the raw products, kainite, etc., being compensated by the greater cheapness of its transport, owing to its high potassium content. The same is true of potassium sulphate, which in Germany is chiefly used in the preparation of alum, not more than a third of the quantity given in the table being used as a fertiliser, while of that exported more than seven-eighths of the total is employed in agriculture. ${ }^{1}$ 1900.

${ }^{1}$ Sammel-Ausstellung der Deutschen Chemischen Industrie, Paris Exhibition, 
The production of potash salts from the German mines has enormously increased. The following table ${ }^{1}$ gives, in metric tons, the totals produced in 1907 and 1908 :-

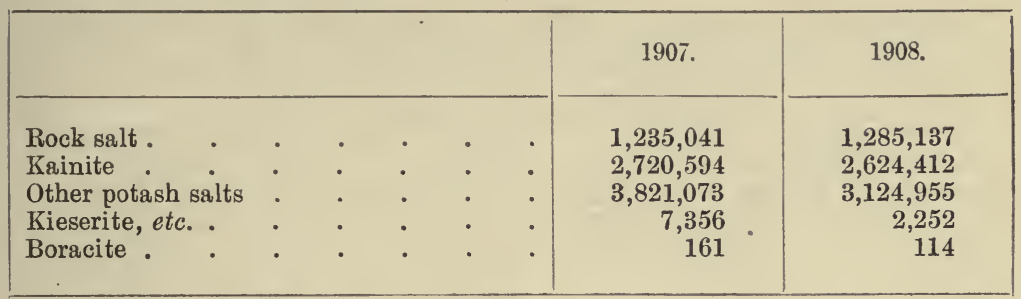

while the prepared salts marketed were as follows, also in metric tons (2205 lb.).

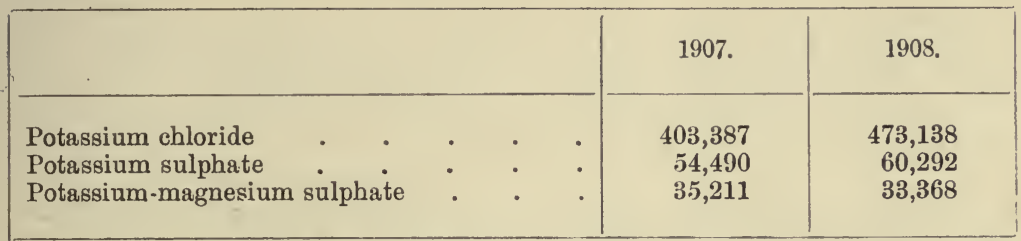

In this country, the products employed are mainly kainite, the calcined double sulphate of potash and magnesia and "muriate of potash". For special horticultural purposes, pure sulphate of potash and nitrate of potash are also employed.

The important potash manures contain their potassium either as chloride or sulphate. The chloride has the advantage in being more diffusible in the soil ; but in most other respects the sulphate is preferable. As in the case of other soluble manures, interaction between the potassium salt and the calcium and other compounds in the soil begins immediately, resulting in the formation of calcium chloride or sulphate. The former has an injurious action upon plants, while the latter is harmless or probably beneficial. Moreover, when potassium chloride is applied in large quantities, the salt as a whole seems to be absorbed by some plants, and in the case of tobacco, for example, the ash left when the dried plant is burnt contains the easily fusible potassium chloride. This acts as a fire-proofing material to some extent and prevents the proper burning of the tobacco; potassium sulphate yields a crop containing no such fusible ash constituent. In the case of clover, corn and grass, however, potassium chloride appears to have little or no harmful effect.

Potash manures are most needed on light sandy or calcareous soils and are seldom required on clay land. Potatoes, grass land and leguminous crops are particularly benefited by potash manures. When the nitrogenous manure used is sulphate of ammonia, the soil is often benefited by potash manuring, while nitrate of soda on the same land will often render it indifferent to potash manures. This is particularly 574.

${ }^{1}$ Engineering and Mining Journal, May 9, 1908 ; Jour. Soc. Chem. Ind., 1908, 
the case with mangolds. Potash manures are best applied in the autumn or winter so as to be well diffused through the soil before the plant requires them. Little loss through drainage need be feared.

Muriate of Potash is usually sold as guaranteed to contain 80 per cent $\mathrm{KCl}$ (equivalent to about 51 per cent $\mathrm{K}_{2} \mathrm{O}$ ).

The Double Sulphate of Magnesium and Potassium actually occurs crystallised with six molecules of water-as Schönite $\mathrm{MgSO}_{4} \cdot \mathrm{K}_{2} \mathrm{SO}_{4} \cdot 6 \mathrm{H}_{2} \mathrm{O}$, and then contains, theoretically, about 44 per cent of $\mathrm{K}_{2} \mathrm{SO}_{4}$ : practically, 42 per cent is about the average. The commercial product is calcined, whereby a portion of the water is expelled, and the residue then contains on the average 48 per cent $\mathrm{K}_{2} \mathrm{SO}_{4}$ (equivalent to 26 per cent $\mathrm{K}_{2} \mathrm{O}$ ). It usually contains about 2 per cent of lime and $2 \frac{1}{2}$ per cent of chlorine.

Sylvinite contains varying quantities of common salt, water, etc., and is not often used as a manure in England, though it is imported into America. Its average content of potassium is said to correspond to 16 or 17 per cent $\mathrm{K}_{2} \mathrm{O}$.

Sulphate of Potash is usually of from 90 to 95 per cent purity ( 49 to 51 per cent $\mathrm{K}_{2} \mathrm{O}$ ), and is too high priced to be often employed in agriculture.

Kainite is the most widely used potash manure. This substance, the exact constitution of which has not yet been determined, is the mineral itself, crushed or ground. Its composition varies, doubtless owing to its admixture with other minerals, especially carnallite and rock-salt, occurring in association with it.

The proportion of potash varies from 12 to 20 per cent, being usually near the lower figure. The sodium chloride varies from 25 to 45 per cent. It also contains lime, magnesia and sulphates. The presence of much magnesium chloride is objectionable, since this compound is deliquescent.

The table on the following page gives the average composition of the various commercial preparations. ${ }^{1}$

IY. MISCELLANEOUS MANURES.-Under this heading may be classed substances which contain none of the three chief manurial ingredients, potash, phosphoric acid and nitrogen, but convey to the soil some other constituent of plant food, or effect by their action upon the soil the liberation of some necessary plant food from the insoluble and unavailable condition. Among the most important are the following :-

Common salt.

Gypsum.

Lime and chalk.

Ferrous sulphate.

Gas lime.

${ }^{1}$ Lierke, Agricultural Chemist to the Verkaufs-Syndicat der Kaliwerke, Leopoldshall-Stassfurt. 


\begin{tabular}{|c|c|c|c|}
\hline 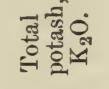 & 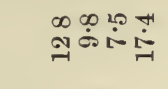 & 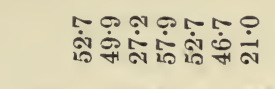 & $\dot{\dot{m}}$ \\
\hline 这 & 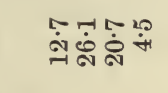 & 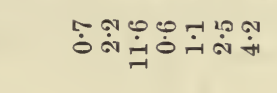 & $\overrightarrow{10}$ \\
\hline 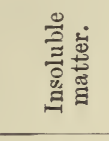 & من & ن் & $\dot{\leftrightarrow}$ \\
\hline 昙弯 & 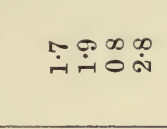 & $\dot{0} \dot{0} \dot{0} \mid$ | & $\stackrel{\text { ஸे }}{\text { ஸे }}$ \\
\hline 芯氖 & फ़ं & . & ڤั) \\
\hline 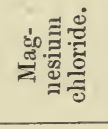 & 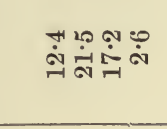 & $\dot{0}$ & $\stackrel{\infty}{\dot{\pi}}$ \\
\hline 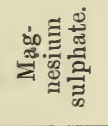 & 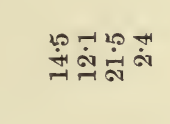 & ஸ́ ஸ் & $\stackrel{+1}{\dot{\sigma}}$ \\
\hline क्ञ & $\begin{array}{l}0 \\
\dot{N}\end{array}$ & ๓ழ & $\stackrel{\varphi}{\dot{\leftarrow}}$ \\
\hline 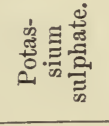 & $\stackrel{\text { ล }}{m} \mid$ | & 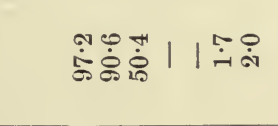 & $\stackrel{\overbrace{}}{\stackrel{\sim}{-}}$ \\
\hline 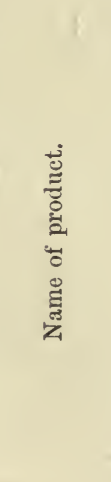 & 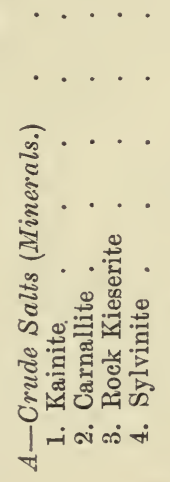 & 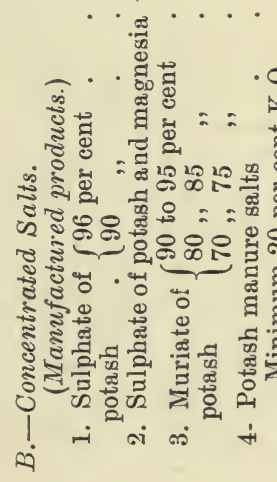 & 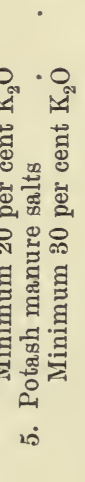 \\
\hline
\end{tabular}


Common Salt is usually regarded as possessing no real manurial value, but as owing what merit it posseśses to its action in promoting the decomposition of the potash, lime and magnesia compounds already present in the soil. It has an undoubtedly good effect on certain crops, particularly mangolds and cabbages. It probably also has an effect, in common with all soluble salts, upon the physical properties of the soil and upon its power of retaining water. Waste salt from fish-curing, bacon-curing, elc., has a value because of the nitrogen and potash which it contains, the substances being derived partly from the organic matter and partly from the saltpetre which is also used in "curing". Salt is sometimes used in mixed manures; solutions of common salt undoubtedly have a greater solvent action than water upon phosphates and silicates.

Gypsum, or Land Plaster (American), $\mathrm{CaSO}_{4} \cdot 2 \mathrm{H}_{2} \mathrm{O}$, has been found to give good results when applied to fields of clover or turnips. It may act as a source of sulphur, but in all probability its action is indirect, and its good effects are due to the liberation of potash from the double silicates in the soil. Its action in promoting nitrification has already been mentioned. ${ }^{1}$ Where superphosphates (of which calcium sulphate is a large constituent) are employed, its application is not required.

Lime, Chalk, Marl, or Limestone.-These substances-consisting mainly of oxide, hydrate, or carbonate of lime, but always containing small and varying quantities of magnesia, phosphoric acid and iron oxide-are employed as manures. The important function performed by calcium carbonate in the process of nitrification has already been discussed. ${ }^{2}$

The chief effect of the application of lime or its carbonate to a soil is to accelerate nitrification and thus to enable the crop to draw upon the nitrogenous stores already present in the soil. Another action of value is its neutralising effect upon the organic acids in peaty soils, the presence of which is unfavourable to any but coarse, undesirable plants. It also acts by replacing the potash in the silicates. Although caustic lime (i.e., $\mathrm{CaO}$ or $\mathrm{CaH}_{2} \mathrm{O}_{2}$ ) speedily becomes converted into the carbonate when applied to the soil, it always has a more energetic action than chalk or limestone. This is due to its solubility producing a more uniform distribution throughout the soil before precipitation as calcium carbonate occurs, than it is possible to obtain by the mere mechanical admixture of the soil with even finely powdered chalk or limestone.

Lime made from magnesian limestone, and therefore containing magnesia, is not so suitable for agricultural purposes as a purer product. This is usually stated to be due to the fact that so long as the bases are in the caustic state, i.e., as hydroxide, they have an injurious effect upon vegetation, and magnesia is said to combine with carbon dioxide much less readily than lime does. Consequently, a

1 Vide p. 64.

${ }^{2}$ Vide p. 64. 
lime containing much magnesia may retain its caustic condition (because of the $\mathrm{MgH}_{2} \mathrm{O}_{2}$ ) in the soil for a much longer time than a pure lime would under the same conditions.

Too heavy or too frequent dressings with lime produce harm by exhausting the stores of nitrogenous matters contained in the humus of the soil.

The very valuable flocculating effects of lime upon clay have already been discussed. ${ }^{1}$

Ferrous Sulphate, $\mathrm{FeSO}_{4} .7 \mathrm{H}_{2} \mathrm{O}$, known commercially as "copperas " and "green vitriol," is not often used as a manure. Iron is usually sufficiently abundant in a soil. Griffiths ${ }^{2}$ greatly extols the application of small quantities (up to $\frac{1}{2}$ cwt. per acre) of ferrous sulphate as a top-dressing for meadows, and also for beans, cabbages, potatoes, mangolds and cereals. He found that the iron sulphate increased the amount of chlorophyll in the green portions of the plant, that the crops were larger, richer in solid matter, albuminoids and phosphates, and that the growth of mosses, etc., was hindered or prevented. He also claims that the iron, to a certain extent, performs the functions of potash in the plant, and that in many cases ferrous sulphate may advantageously be substituted for kainite or other potash manures. Continental experimenters have confirmed in many instances the claims of ferrous sulphate as a manure. In addition to its specific action, it, like other sulphates, probably supplies sulphur.

Gas Lime.-In the preparation of coal-gas, various sulphur compounds are expelled by distillation from the coal, and though a considerable proportion of these are collected in the ammonia-liquor and tar, some find their way into the gas, and inasmuch as they are highly objectionable there, purification has to be resorted to. One of the common methods of removing sulphuretted hydrogen and carbon disulphide from the coal gas is to pass it into chambers containing layers of slaked lime, when the following reactions occur :-

$$
\begin{aligned}
\mathrm{CaH}_{2} \mathrm{O}_{2}+\mathrm{H}_{2} \mathrm{~S} & =\mathrm{CaS}+2 \mathrm{H}_{2} \mathrm{O} \\
\mathrm{CaS}+\mathrm{CS}_{2} & =\mathrm{CaCS}_{3} .
\end{aligned}
$$

Simultaneously the carbon dioxide is also removed-

$$
\mathrm{CaH}_{2} \mathrm{O}_{2}+\mathrm{CO}_{2}=\mathrm{CaCO}_{3}+\mathrm{H}_{2} \mathrm{O} \text {. }
$$

Small quantities of cyanogen are also absorbed.

The spent lime is a complex mixture-calcium sulphide, sulphocarbonate, sulphite, carbonate, thiocyanate and hydrate being the chief ingredients, with varying small quantities of ammonia, cyanides, ferrocyanides, etc. Many of these compounds are powerful plant poisons, and fresh gas lime is extremely destructive to all plant life. On exposure to air and rain, especially if mixed with soil, absorption of oxygen takes place, and the sulphides, sulphites, etc., are oxidised first into thiosulphate and finally into sulphate:-

${ }^{1}$ Vide p. 45.

2 Jour. Chem. Soc., 1885, Trans., 54 ; 1886, Trans., 121. 


$$
\begin{gathered}
\mathrm{CO}_{2}+2 \mathrm{CaS}+3 \mathrm{O}=\mathrm{CaS}_{2} \mathrm{O}_{3} \\
\text { Calcium thiosulphate. } \\
\mathrm{CaSO}_{3}+\mathrm{O}=\mathrm{CaSO}_{4} .
\end{gathered}+\mathrm{CaCO}_{3} .
$$

The composition of fresh gas lime (from London gasworks) is, according to Guyard $^{1}$ :-

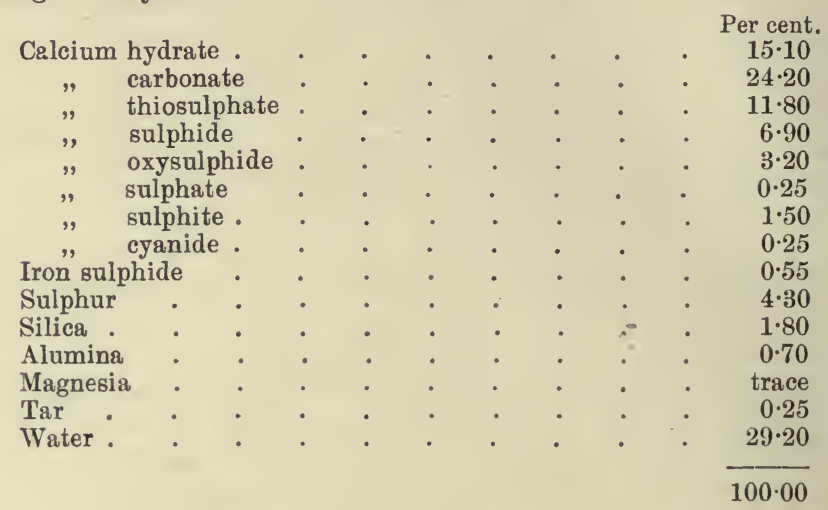

If the unoxidised sulphur compounds remain in gas lime until its application to the land, great harm and sometimes total destruction of vegetation may ensue. In view, then, of the uncertainty of its action, its general use cannot be recommended.

Copper Sulphate.-Though this substance cannot act as a direct plant food and has seldom (or perhaps never) been used as a manure, some results obtained when spraying crops for disease or for the purpose of destroying charlock, etc., seem to indicate that it acts as a powerful stimulus to the growth of certain plants, for in many cases distinctly beneficial effects have been observed from its use in the case of grain crops and potatoes, where no charlock or disease was present.

Catalytic Manures.-Under this name Bertrand ${ }^{2}$ proposes to. include certain substances, which, though, so far as is known, not. capable of directly supplying food to the plant, have been found to. act favourably upon many crops. The best example is perhaps manganese salts, to which reference has already been made (p. 14). Zinc compounds have been found to act favourably on the growth of mushrooms ; boron, iodine, fluorine and bromine compounds have also been found to have beneficial effects upon the yield of certain crops. But. the costliness of most of these compounds is against their general use for manurial purposes. 724 .

${ }^{1}$ Bull. Soc. Chim. xxv. 103; Jour. Chem. Soc., 1876, 123.

2 Seventh Inter. Congr. App. Chem., London, 1909, Jour. Soc, Chem. Ind., 1909, 


\section{CHAPTER VIII.}

\section{Application of Manures.}

In this chapter the general principles to be observed in the use of manures will be briefly discussed, but only those points in which a knowledge of the chemistry and physics is involved, will be dealt with. For details of the mechanical methods of spreading, ploughing, or harrowing in, of manures, reference must be made to the authorities on practical agriculture.

GENERAL MANURES.-Farm-yard Manure.-The system of manuring by means of the live stock of the farm, was, until the introduction of artificial manures, the only way in which the fertility of the land was maintained, and even at the present day, in districts where farming has long been established, it is the mainstay of the farmer.

It is true, that in this country the great changes in the relative values of wheat and other cereals to those of fat stock and dairy cows, have rendered the old farmer's aspect of cattle as being manuremaking machines-chiefly valuable to him in producing farm-yard manure to be used in the growth of corn-no longer tenable. Farmyard manure indeed, is now to be 1 egarded rather as a bye-productthough an important one-than as the main object of stock-feeding.

This, however, does not in any degree lessen the importance of giving every consideration and attention to its conservation and proper utilisation on the farm, if the best results are to be achieved and the fertility of the land maintained.

In pastoral farms, the excreta are restored directly to the land with little or no loss during the greater portion of the year, and if, during the period when stall feeding is necessary, the crops, grown on the farm, are supplemented by purchased concentrated foods, e.g., cakes, the land on the whole, may suffer little loss of fertilising material, provided the farmyard manure be carefully preserved and restored to the soil. The losses in potash, nitrogen and phosphates carried off the farm in the animal carcasses, milk, cheese, eggs, etc., sold, may in such cases be counterbalanced by the supplies of these materials provided by the purchased foods.

Fresh, long, farm-yard manure, containing much little-altered litter should be ploughed in, preferably in the autumn, on heavy compact soil, so as to render the texture of the soil more open and porous. Short, well-rotted dung should be used generally in the spring on open porous soils, where its valuable ingredients, being in a readily available 
condition, can soon be utilised by the crop and where the deficiency of retentive power of the soil may not lead to much loss in drainage.

On grass land, where top-dressing is the only practicable method of applying manures, there are obvious reasons for. preferring short, well-rotted manure.

On arable land, farm-yard manure is usually ploughed in, some time before the crop is sown, but on light soils, especially where the subsoil is porous, it is often spread in the furrows immediately before potatoes are planted. The water-retentive power of the bulky organic matter of the manure is then often of importance in dry seasons.

The heat produced by the decay and fermentation of farm-yard manure, of which advantage is taken in the construction of hot-beds under frames, in the cultivation of certain vegetables, though doubtless produced in the field, cannot be of much importance under ordinary farming practice, since any rise of temperature due to this cause must be extremely small. Nevertheless, the very heavy dressings often used with potatoes, in some cases reaching thirty or forty tons per acre, may owe some of their efficiency to this cause.

Farm-yard manure, sea-weed, and other bulky organic manures require to be used in very large dressings. Ten, twenty, or even up to thirty-five tons per acre are not unusual quantities, but obviously much depends upon the crop to be grown. In market gardening, especially according to the recently boomed French gardening system, immensely greater quantities are employed. In this last-mentioned method, the heat produced by fermentation becomes an important factor.

Green Manuring.-One of the great advantages of manuring with farm-yard manure-viz., the addition to the soil of a large quantity of bulky organic matter, with a consequent improvement in its texture and water-retaining power-can, in a great measure, be obtained in another way, by the practice of green manuring. This consists in sowing some rapidly growing crop, which can often be done in the autumn after the main crop has been harvested on the land, and, before it ripens, ploughing it in. In this way, organic carbonaceous matter is added to the soil, which will eventually form humus. The nitrates formed in the soil during the growth of the crop are, to a great extent, absorbed by the crop, and are prevented from being washed out in the drainage.

The production of nitrates is usually greatest in autumn, and land without a crop upon it suffers a considerable loss of nitrates at this season. With the "catch crop" the nitrates, which would otherwise be lost, are retained, and built up into complex organic compounds. These can subsequently, when the remains of the crop decay, undergo nitrification and again afford a steady supply of nitrates.

The improvement in porosity, water-retaining power, and other physical properties, is often very considerable; while, if the "catch crop" grown be a leguminous one, the soil should not only be saved from loss of nitrates, but should actually be enriched in nitrogen, owing to the free nitrogen of the air being assimilated by the legume by the aid of the Bacillus radicocola in its root nodules. 
Repeated comparisons made at Woburn, ${ }^{1}$ however, indicate that no advantage is gained by growing and ploughing in a leguminous crop as against a non-leguminous one. The green crops tried were tares and mustard, and the subsequent yields of wheat were in favour of the mustard.

It was proved, however, that the growth of tares gave a greater gain of nitrogen to the soil than that of mustard, and the results obtained are difficult to explain, as general experience, as well as theory, agree in indicating a decided advantage of leguminosa over other crops for green manuring.

Various crops may be used for green manuring. In England, mustard, rape, tares, barley and rye are often employed, while in Germany, lupines have been successfully used and have converted large tracts of comparatively worthless sand into fertile land.

It must be remembered, however, that green manuring under the most favourable conditions can only improve the physical condition of the soil and enrich it in organic matter and nitrogen, but cannot effect any increase in its inorganic constituents. The stores of phosphates, potash and lime in the soil are not augmented, though these constituents are probably rendered more available. Its utility in preventing losses by drainage, however, is undoubted.

In warm climates, many leguminous crops are well suited for the purpose. Cow-peas, Vigna catjang, velvet beans, Mucuna utilis, and the soy bean, Glycine hispida, have all proved successful in this capacity.

Sometimes the catch crops are eaten off in the early winter by stock, penned on the ground, before the land is ploughed. In this case, the benefit to the soil, especially as regards increasing its store of bulky organic matter, is considerably less than when the whole crop is ploughed in, though the same saving of loss of nitrates in the drainage is effected.

The nitrogen in the portion of the crop eaten by the animals is partially returned to the land in their excrement, and is in a form (chiefly urea) which quickly becomes available again.

In cases of soils extremely poor in organic matter, the plan of growing a crop with the aid of manures and then ploughing it in, is sometimes resorted to and results in rapidly enriching and improving the soil.

CONCENTRATED MANURES. - In the case of artificial manures, which are costly, i.e., of high price per ton, very different dressings ale required. It will be convenient, perhaps, to deal with the commoner special manures separately, but a few remarks applicable to them in general may first be made. Since uniformity of distribution of a manure in the soil is almost invariably desirable, all artificial manures should be finely ground and, whenever possible, dry. As the quantity to be applied per acre is often only about $1 \mathrm{cwt}$. it is advisable to mix the manure with some diluent before application. Dry, sandy 
soil, or sifted ashes are often used for this purpose. The manure, thus diluted, can be distributed, either broadcast or by special manure drills. In some cases, drills, which sow both seed and manure at the same time, are employed.

As a general rule, separate application for each artificial manure would probably be best for their utilisation, but often, in order to save trouble and cost, they are mixed before application and sown in one operation.

In mixing artificial manures there are certain points which should be borne in mind or losses and damage may be sustained.

Sulphate of ammonia, for example, should not be mixed with any manure containing free alkali. Basic slag, lime, or wood ashes would, in contact with sulphate of ammonia, lead to evolution of free ammonia and thus loss of nitrogen.

Acid manures, superphosphate or double superphosphate or dissolved bones, if mixed with nitrate of soda or nitrate of lime, evolve nitric acid vapours, which act corrosively on brass or metal work and lead to losses of nitrogen.

The addition of lime, basic slag, basic nitrate of lime, or wood ashes to superphosphate or dissolved bones, leads to the conversion of the soluble acid calcium phosphate of the latter into insol:able forms, with consequent injury to the ready distribution, through solution in water, which is the great advantage of the latter manures.

Even the addition of any form of tricalcium phosphate, e.g., bone flour to superphosphate, should not be done except just before the mixture is sown, or the soluble phosphates of the latter will undergo reversion to the less valuable " reverted phosphate".

Another point to be borne in mind in using concentrated artificial manures, is that direct contact of a considerable quantity of any soluble. saline matter with the roots of a growing plant is dangerous, since it is liable to induce plasmolysis in the root-cells and thus kill the plant (vide Chap. xi., p. 226). Cases have come under the writer's notice, where large numbers of transplanted tobacco-plants have been killed outright by ignorance of this fact, and where a small quantity of a concentrated soluble manure was placed in each hole, in direct contact with the roots of the plant. Solutions of above a certain concentration will destroy a plant when in contact with its roots, whatever be the nature of the dissolved substance.

Nitrogenous Manures.-(a) Nitrate of soda.-Abundant supplies of nitrates tend to prolong the period of growth of most plants and to favour the formation of foliage rather than seed. They also tend to favour the production of large, succulent roots in the case of root-crops, which, weight for weight, are of much lower feeding value than the same roots grown with a less abundant supply of nitrates. Caution therefore is necessary in the use of this manure, especially in cases where early ripening of seed or fruit is of importance.

On pastures or meadows, applications of nitrates favour the growth of graminea at the expense of leguminosa and may in this way, if used in excess, injure the herbage and thus damage the quality, though greatly increasing the quantity of the crop. 
Nitrate of soda is almost always used as a top dressing, and, as a rule, it should not be applied to a soil until the crop is sufficiently well provided with a root system to permit of the fertiliser being absorbed by the crop. If applied too early, there is great risk of loss through leaching. For the same reason, several small dressings are more economical than the same weight applied at once.

From $\frac{1}{4}$ to 1 cwt. per acre, applied in spring, is usually the dressing for cereals, but in the case of barley for malting purposes, only limited supplies of nitrates should be given or the quality of the grain may suffer.

On permanent meadows, up to 2 or 3 cwt. is often used, best applied in two or three dressings, but if farm-yard manure has been applied recently, not more than $1 \mathrm{cwt}$. should be used.

For mangolds and cabbages, $4 \mathrm{cwt}$. or more per acre is often employed with advantage.

For turnips, swedes and potatoes, about $1 \mathrm{cwt}$. is usually employed, of course along with other manures. In orchards, nitrates should be very sparingly used, if at all, or abundant woody growth and little fruit will be produced.

(b) Sulphate of ammonia.-The sources and preparation oi this manure and of nitrate of soda have already been described (vide p. 132). Owing to its greater concentration in nitrogen, less total dressings than with nitrate of soda are usually employed; theoretically $66 \mathrm{lb}$. of sulphate of ammonia contain the same amount of nitrogen as $85 \mathrm{lb}$. of nitrate of soda, so that the equivalent of $1 \mathrm{cwt}$. of the latter would be $86.8 \mathrm{lb}$. or $0.776 \mathrm{cwt}$. of sulphate of ammonia. In practice $\frac{3}{4} \mathrm{cwt}$. is often taken as equivalent to $1 \mathrm{cwt}$. of nitrate.

Since, in most cases, the utilisation of sulphate of ammonia by plants has to be preceded by its nitrification, it does not act as such a powerful stimulant to plant growth as nitrate of soda, but in suitable soils affords a steadier and more sustained supply of nitrogen. For this reason, and also because it suffers much less loss by being washed out in the drainage water, it can, with economy, be applied in relatively larger dressings at a time. But due regard must be paid to the demands which it makes upon the soil for lime, in order to allow of its nitrification.

\section{Comparative Merits of Nitrate of Soda and Sulphate of Ammonia.}

Numerous experiments on the relative advantages of nitrate of soda and sulphate of ammonia as sources of nitrogen have been made. The general results may be summarised thus :-

1. Nitrate of soda is quicker in its action, being already capable of yielding its nitrogen to the crop.' Sulphate of ammonia must first undergo nitrification in the soil before it can be utilised to any extent by the plant. For this process to occur it is necessary that some basic material (generally calcium carbonate) be present in order to (1) combine with the sulphuric acid of the sulphate (the calcium sulphate formed is carried off in the drainage water), and (2) assist in nitrification by forming calcium nitrate. For these reasons, sulphate of ammonia 
can only successfully be applied to soil containing a sufficiency of calcium carbonate, and its repeated application entails a considerable loss of lime (equal to 100 of calcium carbonate for every 132 of sulphate of ammonia applied, or if the lime required for nitrification be included, twice this amount) in the drainage water:-

$$
\begin{gathered}
\left(\mathrm{NH}_{4}\right)_{2} \mathrm{SO}_{4}+\mathrm{CaCO}_{3}=\mathrm{CaSO}_{4}+\left(\mathrm{NH}_{4}\right)_{2} \mathrm{CO}_{3} \text { and } \\
\left(\mathrm{NH}_{4}\right)_{2} \mathrm{CO}_{3}+4 \mathrm{O}_{2}+\mathrm{CaCO}_{3}=\mathrm{Ca}\left(\mathrm{NO}_{3}\right)_{2}+2 \mathrm{CO}_{2}+4 \mathrm{H}_{2} \mathrm{O}
\end{gathered}
$$

Soils deficient in lime compounds can be more suitably manured with nitrate of soda.

2. Nitrate of soda is easily washed into the subsoil by rain, and in wet seasons a considerable amount of it is lost. It should only be applied when the plant can assimilate it. Sulphate of ammonia, though equally soluble in water, is not washed out by rain to any appreciable extent, but is held by the humus and perhaps by the hydrated silicates and the ferric hydroxide until nitrification occurs. For this reason, sulphate of ammonia is most useful to shallow-rooted plants, while nitrate of soda tends to encourage deep rooting. Sulphate of ammonia is therefore preferable in wet seasons and gives the best results when applied at the time of sowing, or even before. Nitrification can only take place in the presence of sufficient, and is favoured by increased, moisture, short of complete saturation, so that in dry seasons sulphate of ammonia is not so suitable as nitrate of soda.

3. On soils very rich in calcium carbonate, ammonium sulphare, if used as top dressing, may suffer decomposition with loss by volatilisation of ammonium carbonate, especially in dry weather. This loss can be prevented by ploughing or harrowing the sulphate into the soil immediately after its application.

4. Both nitrate of soda and sulphate of ammonia will only yield the best results when the soil is abundantly supplied with the necessary mineral constituents of plant food.

With sulphate of ammonia, however, it is more necessary to supply potash, for with many soils, the use of nitrate of soda appears to render potash manuring unnecessary, at least, for a time. This may be due to its action in favouring deep rooting, the necessary potash being obtained from the subsoil, or partly to its action in rendering the potash of the silicates of the soil more available or, perhaps to the possibility of sodium performing, to some extent, the functions of potassium, in the plant itself.

5. Nitrate of soda is best applied in several small dressings, while sulphate of ammonia may generally be applied in one. The usual quantities are from 1 to $1 \frac{1}{2} \mathrm{ewt}$. of the former and 100 to $150 \mathrm{lb}$. of the latter per acre, but with certain crops, e.g., mangolds and potatoes, larger quantities may be used.

6. Nitrate of soda, by repeated applications, has a strong deflocculating effect upon clay and thus injures the physical or mechanical properties of some soils.

7. The repeated application, year after year, of sulphate of ammonia to grass land, tends to induce an acid or peaty character in the surface 
soil which is injurious to the plants, unless lime or other basic substance be used to correct it.

(c) Calcium cyanamide can be used in much the same way as sulphate of ammonia and appears to be capable of giving the same results. Its injurious effect upon plants, noticed in the earlier pot experiments which were regarded as indications that it should only be applied some considerable time before the seed is sown, do not appear to be of any importance on the large scale, and unless excessive quantities be employed, no injury from this cause is likely to occur. Any unchanged calcium carbide which may be present, is probably injurious to plants, but this would soon disappear after application to damp soil. Calcium cyanamide absorbs moisture and carbon dioxide on exposure to air; hence the percentage of nitrogen is lower in samples which have been exposed to the air for some time, than in the fresh material. The variety containing calcium chloride (known sometimes as "nitrogen lime " as distinguished from the other variety " lime nitrogen ") increases in weight on exposure more rapidly than the other.

(d) Nitrate of lime.-This substance closely resembles nitrate of soda in its action and the remarks made about that substance apply almost entirely to this manure. It differs, however, in being more hygroscopic and should therefore be preserved as much as possible from exposure to the air and used in the fresh condition. The fact that it contains lime gives it certain advantages over the sodium salt. It is used in about the same quantities per acre as nitrate of soda, and, in many experimental trials, has been found to yield equal or slightly better results.

Phosphatic Manures.-These manures differ from nitrates of soda or lime in one important respect-that they are retained tenaciously by soil and are thus in little danger of suffering loss by drainage. They can therefore be applied before the crop requires them, but here again, it must be remembered that comparatively fresh applications are far more effective than residues from dressings applied to the soil some time before. In the latter case, some of the phosphates are "reverted" and pass into states of combination, perhaps with the iron oxide or alumina of the soil, which do not readily yield them up again to the plants' roots.

As already explained, there are three chief forms of phosphates. present in the various phosphatic manures:-

(a) Soluble phosphates-as in superphosphates and dissolved bones. In these manures, the distribution of the valuable ingredient is to a large extent accomplished by the solubility, in the water of the soil, of the monocalcium tetrahydrogen phosphate, though this substance is soon converted into insoluble forms by the action of certain soil constituents-mainly by calcium carbonate or ferric oxide. But its initial solubility in water secures for the phosphoric acid a far more complete distribution through the soil, than could be obtained by any mechanical stirring.

But as these manures are acid, their repeated application to soil seriously diminishes its store of basic material and renders necessary 
periodic dressings with lime or lime-containing manures, e.g., basic slag. This is particularly the case with light sandy soils. Superphosphates are the quickest in action of all the phosphatic manures and, for this reason, are very largely used. Whenever it is necessary to supply a crop with a rapid supply of phosphoric acid, to tide it over a particularly critical period where the conditions are unfavourable for growth, e.g., during drought, or during the attacks of insect pests, superphosphates are the most suitable manures to use.

Abundant supplies of phosphates encourage root development and early formation of seed.

As a rule, superphosphates should be applied to the soil some time before the plant is ready to assimilate them, in order that the acidity of the manure may be neutralised by the bases in the soil.

As to quantities per acre-this, as with all manures, must depend upon the fertility of the soil and the special needs of the crop. For cereals, small dressings- 1 or 2 cwt. per acre-are sufficient, but for turnips 3 or 4 cwt. or, in Scotland, up to 7 or 8 cwt. of superphosphate per acre, best applied a month or two before sowing, are often used with success.

The objections to mixing superphosphates with nitrate of soda or nitrate of lime because of the liberation of nitric acid, or with lime, wood ashes, or basic slag or even with bone meal, because of the "reversion " of the phosphoric acid, have already been discussed. It may, however, be mixed without harm with sulphate of ammonia, or with sulphate of potash.

(b) Basic slag.-This cheap source of phosphoric acid should in all cases be applied some time before the crop, and, indeed, is often found to exert a considerable influence during the second and third years after its application. Of great importance is its fineness of grist. Its effects are most pronounced on damp, peaty soils, rich in organic matter and poor in lime. On pastures and meadows it is especially suitable and often exerts an effect similar to a nitrogenous manure. This is probably due to two causes-(1) the effect of its free lime in promoting nitrification of the organic matter of the soil and (2) its favouring influence upon the growth of leguminous plants which are thereby enabled to increase nitrogen-fixation from the air.

Basic slag, on account of its cheapness, slowness of action, and the almost invariably beneficial effects of free lime on soils, may be used with advantage, in comparatively large dressings-up to 6 or $8 \mathrm{cwt}$. per acre.

It must not be mixed with sulphate of ammonia but may be used along with nitrate of soda or potash salts. The slight tendency, which such mixtures show to form little hard balls, may be lessened by the addition of sawdust or peat.

(c) Insoluble phosphates. - These manures should be finely divided and in any case are slow in action. Bones should be used as meal or dust, since "quarter-inch bones" and "half-inch bones," which were formerly much used, remain unchanged for many years in some soils. Mineral phosphates are of little use unless extremely finely divided and even then are slow in action. Indeed this class of manure tends 
rather to improve the condition and general fertility of the land, than to feed the next crop which is put upon it. Pastures, turnips, tobacco, vines and hops are often manured with bone meal or bone dust and up to 4 or 5 cwt. per acre is the usual dressing. The manure should be applied some time before the crop requires the phosphoric acid.

Potash Salts.-These are retained by the soil with great tenacity, and little or no loss through drainage need be feared. Potash manures can therefore safely be applied in the autumn, either as top dressings, or drilled in with other manures.

They are needed mainly on sandy and peaty soils, and the crops which most readily respond are potatoes and leguminosa. For corn, clover, grasses and turnips it does not appear to be of importance whether the chloride or sulphate of potash be employed, but sugarbeet, potatoes and tobacco should not be manured with the chloride. The effects of this substance ure, in the case of beets, to diminish the proportion of cane sugar, with potatoes, to render them waxy, and with tobacco to cause the finished product to burn badly.

Potash manures are not applied in large quantities, from 1 to 2 cwt. of the sulphate or muriate, or up to 5 or 6 cwt. of kainite being the usual dressings per acre. With the last mentioned, the introduction of considerable quantities of magnesium and sodium salts along with the potash, may, in some cases, be injurious, and due regard muşt be paid to this fact. Where drainage is small, a brackish condition of the soil may easily be induced by the prolonged use of kainite. 


\section{CHAPTER IX.}

\section{The Analysis and Valuation of Manures.}

IN this chapter, before discussing very briefly some; of the methods used for the determination of the valuable constituents of manures, a short account of the usual methods of expressing the results of a chemical analysis of manures will be given. Some of these methods are merely conventional and involve the use of certain terms which are no longer used in the same sense in modern scientific nomenclature. Take, for example, a superphosphate ; the usual old-fashioned method of expressing its composition is as follows :-

\section{ANALYSIS OF A SUPERPHOSPHATE.}

Monocalcium phosphate (equal to bone phosphate rendered soluble)

Insoluble phosphate

Hydrated sulphate of lime

Organic matter and water

Alkaline salts

Silica .

Per cent.

The explanation of some of these terms has already been given (vide p. 147), but may perhaps with advantage be repeated here.

By "monocalcium phosphate" in the above analysis is meant all the phosphates soluble in water, expressed as monocalcium phosphate (not, as would be correct, as $\mathrm{CaH}_{4} \mathrm{P}_{2} \mathrm{O}_{3}$, but totally falsely as $\mathrm{Ca} \mathrm{P}_{2} \mathrm{O}_{6}$, which is the formula for calcium metaphosphate). Consequently, the percentage amount of "monocalcium phosphate," in order to give the equivalent amount of "bone phosphate," i.e., $\mathrm{Ca}_{3} \mathrm{P}_{2} \mathrm{O}_{8}$, must be multiplied by $120+62+128=310$, and divided by $40+62+96=198$.

By " insoluble phosphate" in the analysis, is meant the total of tricalcium (and trimagnesium) phosphate, $\mathrm{Ca}_{3} \mathrm{P}_{2} \mathrm{O}_{8}$ (insoluble in solution of ammonium citrate), and dicalcium phosphate, $\mathrm{Ca}_{2} \mathrm{H}_{2} \mathrm{P}_{2} \mathrm{O}_{8}\left(=\mathrm{CaHPO}_{4}\right)$, together with the phosphoric acid in combination with iron and aluminium (soluble in solution of ammonium citrate), all expressed in terms of tricalcium phosphate. The phosphoric acid soluble in ammonium citrate solution is known as "reverted," "retrograde," or " reduced".

The "hydrated sulphate of lime" obviously refers to the compound identical in composition with gypsum, $\mathrm{CaSO}_{4} .2 \mathrm{H}_{2} \mathrm{O}$.

"Organic matter and water" requires no explanation; it is loss on ignition after deducting the water contained in the "hydrated sulphate of lime," which would also be expelled; why this allowance is made 
for mere water of crystallisation in the case of calcium sulphate and no allowance for the necessary water of constitution of the monocalcium tetrahydrogen phosphate, $\mathrm{CaH}_{4} \mathrm{P}_{2} \mathrm{O}_{8}$, it is difficult to understand.

"Alkaline salts" is another unsatisfactory item; it is hard to say exactly what it means.

"Silica " usually represents the matter insoluble in acids and often consists mainly of real silica, $\mathrm{SiO}_{2}$, though it may contain other mineral fragments.

A much more scientific and in every respect more satisfactory way of reporting such an analysis, adopted in more recent work, is as follows :-

Total phosphorus pentoxide.

Per cent.

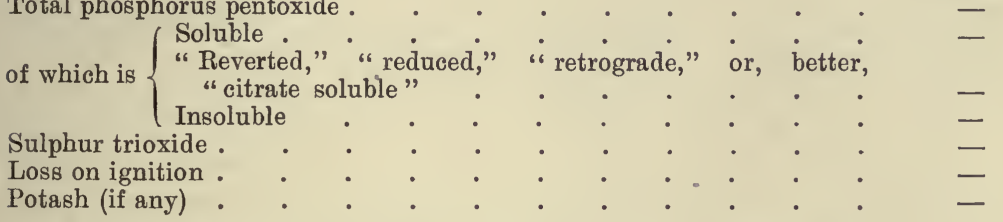

In the case of nitrogenous manures it is often the practice to give the nitrogen as equal to - per cent of ammonia; if the percentage of nitrogen is given as well, this plan is perhaps permissible, but it would be much more intelligible to give the latter than the former. The percentage of ammonia equivalent to the nitrogen present should therefore not be given alone, especially in analyses of organic manures or those containing nitrates. If the nitrogen content be stated, no error as to its state of existence can be conveyed, and its equivalent in ammonia or nitrogen pentoxide is easily calculated, since $\mathrm{N}=\mathrm{NH}_{3}$ $=\frac{\mathrm{N}_{2} \mathrm{O}_{5}}{2}$ or 14 of nitrogen correspond to 17 of ammonia or 54 of nitrogen pentoxide.

The most complete way would be as follows :-

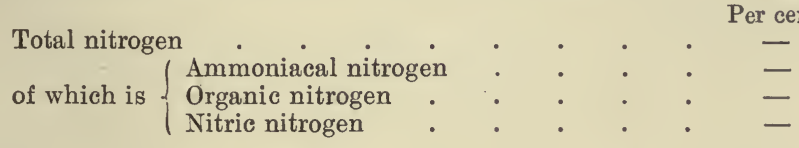

The analysis of a manure is usually directed to the determination of the amounts of one or more of the three substances, nitrogen, phosphorus pentoxide, or potash present, and to the detection of the presence, and, if necessary, the determination of the amount, of any possibly harmful or objectionable ingredients.

The following table gives a list of most of the commercial manures, with their valuable and objectionable ingredients :- 


\section{I.-NITROGENOUS MANURES.}

\begin{tabular}{|c|c|c|}
\hline Name. & Constituents of value. & Harmful constituents. \\
\hline $\begin{array}{r}\text { Dried flesh } \\
,, \text { blood }\end{array}$ & & \\
\hline $\begin{array}{l}\text { Shoddy and woollen } \\
\text { waste } \\
\text { Hair, horn and leather } \\
\text { waste }\end{array}$ & Organic nitrogen. & Oily matters. \\
\hline $\begin{array}{l}\text { Rape and other oil-seed } \\
\text { cakes }\end{array}$ & $\begin{array}{l}\text { Organic nitrogen (phosphoric } \\
\text { acid). }\end{array}$ & Oil. \\
\hline $\begin{array}{l}\text { Sulphate of ammonia } \\
\text { Nitrate of soda } \\
\text { Nitrate of potash }\end{array}$ & $\begin{array}{l}\text { Ammoniacal nitrogen. } \\
\text { Nitric nitrogen. } \\
\text { Nitric nitrogen and potash. }\end{array}$ & $\begin{array}{l}\text { Thiocyanates, arsenic. } \\
\text { Perchlorates, chlorides. }\end{array}$ \\
\hline & $\begin{array}{l}\text { Ammoniacal and organic } \\
\text { nitrogen. }\end{array}$ & \\
\hline Calcium cyanamide . & & $\begin{array}{l}\text { Calcium carbide, sul- } \\
\text { phides. }\end{array}$ \\
\hline Nitrate of lime. & Nitric nitrogen. & \\
\hline
\end{tabular}

\section{II.-PHOSPHATIC MANURES.}

\begin{tabular}{|c|c|c|}
\hline Name. & Constituents of value. & Harmful constituents \\
\hline $\begin{array}{l}\text { Basic slag } \\
\text { Phosphorite and coprolites }\end{array}$ & $\begin{array}{l}\text { Citrate-soluble phosphorus } \\
\text { pentoxide (lime), also de- } \\
\text { gree of fineness of divi- } \\
\text { sion. } \\
\text { Insol a ble phosphorus } \\
\text { pentoxide. }\end{array}$ & $\begin{array}{l}\text { Iron and alumina ; } \\
\text { fluorides, if for } \\
\text { "super." manu- } \\
\text { facture. }\end{array}$ \\
\hline
\end{tabular}

\section{III.-NITROGENOUS PHOSPHATIC MANURES.}

\begin{tabular}{|l|l|l|}
\hline $\begin{array}{l}\text { Bone dust and bones } \\
\text { Spent animal charcoal } \\
\text { Fish manure }\end{array}$ & $\begin{array}{c}\text { Insoluble phosphorus pent- } \\
\text { oxide and organic nitrogen. }\end{array}$ & Sand. \\
$\left.\begin{array}{l}\text { Nitrogenous guanos } \\
\text { Dissolved ", } \\
\text { Ammoniated ," } \\
\text { Dissolved bones }\end{array}\right\}$ & $\begin{array}{c}\text { Soluble, citrate-soluble and } \\
\text { insoluble phosphorus } \\
\text { pentoxide, organic and } \\
\text { ammoniacal nitrogen. }\end{array}$ & $\begin{array}{c}\text { Arsenic, excessive quan- } \\
\text { tity of calcium sul- } \\
\text { phate. }\end{array}$ \\
\hline
\end{tabular}




\section{IV.-POTASH MANURES.}

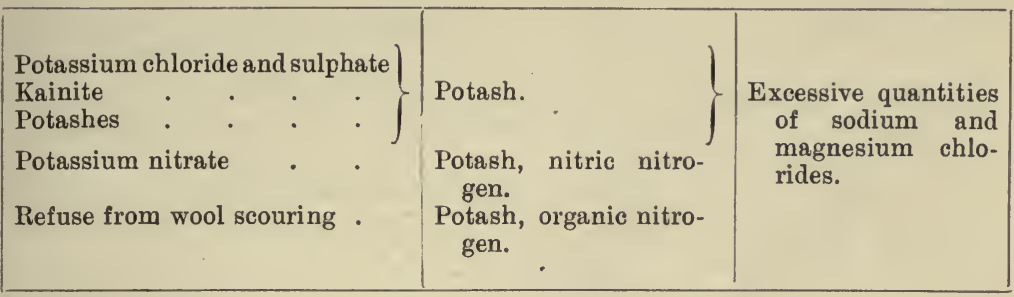

In addition, the general manures, e.g., farm-yard manure and seaweeds, contain all constituents of plant food, together with large quantities of decaying organic matter and water.

For full descriptions of the methods used in the analysis of manures the reader must refer to some treatise on the subject-only an outline can be given here.

Determination of Nitrogen. - The method to be employed depends upon the possible state of existence of the nitrogen in the manure.

Organic Nitrogen, such as occurs in farm-yard manure, sea-weed, guano, fish meal, bones, rape-seed meal and cake, etc. The most satisfactory method is the Kjeldahl process, which may be performed exactly as described under soil analysis, p. 85. The result gives the amount of nitrogen existing as organic compounds and as ammonia, and in most cases a portion of that existing as nitrates. As in soil analysis, the nitric nitrogen can be wholly included if salicylic acid be added (vide p. 88).

Ammoniacal Nitrogen.-This can be estimated by distillation with magnesia, $\mathrm{MgO}$, conveniently in a current of steam, and receiving the evolved ammonia in a measured quantity of decinormal sulphuric acid. Potash or soda would also liberate ammonia from ammonium salts, but they would, in addition, decompose a portion of the organic nitrogenous substances, if such were present.

Nitric Nitrogen.-In manures containing a large proportion of this constituent, e.g., sodium nitrate, the determination can conveniently be made by means of Lunge's nitrometer, an instrument in which the volume of nitric oxide, $\mathrm{NO}$, evolved on shaking up the nitrate with strong sulphuric acid and mercury can be measured. Another satisfactory method of determining nitrate is by Schlösing's method with ferrous chloride and hydrochloric acid. Other methods for the determination of nitric nitrogen are based upon its reduction to ammonia and subsequent distillation with alkali. This reduction may be brought about by treatment in alkaline solution with zinc and iron (Möckern's process), or in presence of sulphuric acid by reduced iron 
(Ulsch's method), or by treatment with a mixture of sulphuric acid, salicylic acid and sodium thiosulphate (Forster's method).

In many cases nitrate of soda is valued by "refraction," i.e., by determining the total percentage amount of the impurities present. The substances usually present in Chili saltpetre are-moisture, insoluble matter, chlorine, sulphuric acid, magnesia and perchlorate. These constituents are determined by the usual processes. A word or two may be said about the determination of the perchlorate, a substance whose presence and importance in nitrate has only recently been realised. Five grammes of the dried sample are heated for a quarter of an hour over a Bunsen lamp with 7 or 8 grammes of pure calcium hydroxide in a covered crucible. The mass is then transferred to a measuring flask, made up to $128 \mathrm{cc}$. with water, digested for an hour, and filtered ( 3 cc. is taken as the volume of the undissolved matter, so that $125 \mathrm{cc}$. of solution are really taken). To $100 \mathrm{cc}$. of the filtrate (= 4 grammes of the sample), dilute nitric acid is added until exactly neutral and the chloride present is then determined by titration with silver nitrate. After deducting the chlorine present originally as chloride (determined by direct titration without treatment with lime), the chlorine found is calculated to perchlorate. ${ }^{1}$

In the case of most manures the determinations of the various constituents are made by the usual quantitative methods, but in some cases shorter and easier, though perhaps less accurate, methods are employed. A few of these rapid methods may be mentioned.

Phosphoric Acid.-In the presence of aluminium, iron and calcium in ordinary analytical work it is generally considered necessary to first precipitate the phosphoric acid with ammonium molybdate, wash the yellow precipitate until the above-mentioned metals are removed, redissolve the precipitate in ammonia, and precipitate with magnesia mixture. Instead of this somewhat tedious and costly process, it is possible by the addition of citric acid to the original solution, followed by magnesia mixture and ammonia, to keep the iron, aluminium and lime in solution and obtain all the phosphoric acid as magnesium ammonium phosphate. The method is only suitable when the quantity of phosphoric acid is fairly large and that of iron and aluminium not considerable.

The phosphoric acid of a manure may be present in three states of combination, as already stated:-

\section{Water-soluble phosphates. \\ 2. Citrate-soluble phosphates. \\ 3. Insoluble phosphates.}

The methods of determining the first and third require little or no explanation. For the second the residue after washing with water is used. It is extracted with a solution of ammonium citrate of specified strength, for a specified time, and at a specified temperature.

The ammonium citrate solution employed is usually of specific

${ }^{1}$ Blattner and Brasseur, Chem. Zeitung, 1900, 767. 
gravity 1.09 at $20^{\circ}$ and contains about 370 grammes of crystallised citric acid, neutralised with ammonia, in two litres of water (American), or 333 grammes citric acid (Petermann), or about 360 grammes (Halle process) in two litres.

The temperature and time of digestion recommended by different workers vary : $30^{\circ}$ or $40^{\circ}$ for half an hour (Frankland); $50^{\circ}$ for half an hour (Halle station); $35^{\circ}$ to $40^{\circ}$ for one hour (Norway stations); $65^{\circ}$ for half an hour (American official chemists).

In any case, the liquid is filtered and washed, and the phosphoric acid in the residue determined as usual.

Thus, direct determinations are made of-

(1) Phosphoric acid soluble in water.

(2) Total phosphoric acid.

(3) Phosphoric acid insoluble in ammonium citrate.

The difference between (2) and (3) gives the citrate and watersoluble phosphoric acid, and by subtracting (1) the citrate-soluble or "reverted" phosphoric acid is obtained.

In the case of basic slag, the tetracalcium phosphate is soluble in citric solution, but as there is always more or less free lime present, Wagner recommends that sufficient citric acid be added to neutralise the free lime in 5 grammes of the slag, and then $200 \mathrm{cc}$. of acid ammonium citrate (made by dissolving 160 grammes of citric acid in water, adding 27.93 grammes of real $\mathrm{NH}_{3}$ and diluting to 1 litre). After filtering, the phosphorus pentoxide in solution is estimated by separation with ammonium molybdate solution and precipitation by magnesia mixture as usual.

Potassium in presence of sulphuric acid, iron, lime and magnesia. - Usually the above bases and the sulphuric acid have first to be removed by means of ammonia, ammonium carbonate or oxalate, and barium chloride, necessitating the subsequent removal of the ammonium compounds and excess of barium. By direct addition of platinum chloride to the hydrochloric acid solution of the original substance, evaporation to dryness, and washing, first with a little platinum chloride solution, then with alcohol, next with a 20 per cent solution of ammonium chloride, to which sufficient solid $\mathrm{K}_{2} \mathrm{PtCl}_{6}$ has been added to saturate it, and lastly again with alcohol, a pure double chloride of potassium and platinum may be obtained.

THE VALUATION OF MANURES FROM ANALYSIS.-FrOM the percentage amount of the valuable constituent in a single manure and its commercial value per ton, it is easy to calculate the cost of the actual valuable ingredient per lb., or, as is perhaps more usual in this country, "per unit," i.e., the value per ton of each per cent.

For example, take nitrate of soda, containing, say, 15.75 per cent nitrogen, and assume its price per ton to be $£ 8$.

Nitrogen, in this form, costs- 
$8 \times 20 \times 100$

$2240 \times 15.75=0.457 \mathrm{~s}$. per lb. $=5.484 \mathrm{~d}$. per lb.

or its value "per unit" $=\frac{8 \times 20}{15 \cdot 75}=10 \cdot 2 \mathrm{~s} .=10 \mathrm{~s} .2 \frac{1}{2} \mathrm{~d}$.

In sulphate of ammonia, containing, say, 24.5 per cent of "ammonia," equal to $20 \cdot 2$ per cent nitrogen, if its price be taken at $£ 12$ per ton, nitrogen costs-

$$
\frac{12 \times 20 \times 100}{2240 \times 20.2}=0.53 \mathrm{~s} \text {. per lb. }=6.36 \mathrm{~d} \text {. per l lb. }
$$

or its value "per unit" $=\frac{12 \times 20}{20 \cdot 2}=11 \cdot 83 \mathrm{~s} .=11 \mathrm{~s} .10 \mathrm{~d}$.

The two methods of expressing values are related to each other in a simple manner. It is evident that the price "per unit," since it refers to the price per ton for each per cent of the constituent in question, is really the price of $\frac{1}{10 \sigma}$ of a ton of the actual manurial constituent. In other words, it is the price of $22.4 \mathrm{lb}$. Obviously the price per lb. multiplied by $22 \cdot 4$ will give the equivalent price "per unit".

In a similar way, the value of phosphorus pentoxide and potassium can be calculated from the market prices of the various phosphatic and potash manures. As in the case of nitrogen, the values obtained vary in the case of different manures.

Tables are sometimes published giving the value of the three principal manurial substances per unit in various commercial manures. The following table, calculated from one given in the Transactions of

\begin{tabular}{|c|c|c|c|c|c|}
\hline \multirow{2}{*}{ Mannre. } & \multicolumn{2}{|c|}{ Price per ton. } & \multirow{2}{*}{$\begin{array}{l}\text { Valuable con- } \\
\text { stituent. }\end{array}$} & $\begin{array}{l}\text { Value } \\
\text { per wuit. }\end{array}$ & \multirow{2}{*}{$\begin{array}{l}\text { Value } \\
\text { per lb. } \\
d .\end{array}$} \\
\hline & $£$ s. d. & $£$ s. d. & & s. d. & \\
\hline Sulphate of ammonia ( 24 & & 11 17 6 & Nituren & & \\
\hline $\begin{array}{l}\text { Nitrate of soda (19 per } \\
\text { cent ammonia) }\end{array}$ & & $\begin{array}{lll}9 & 0 & 0\end{array}$ & Nitrogen & $1110_{2}^{*}$ & $0_{3}^{\frac{1}{3}}$ \\
\hline Peruvian guano $\cdot$ & 500 to & $\begin{array}{lll}9 & 0 & 0\end{array}$ & $\mathrm{P} 0 \mathrm{O}$ & $\begin{array}{rr}16 & 0 \\
2 & 10+\end{array}$ & $8 \frac{4}{2}$ \\
\hline Bone meal & 5100, & $\begin{array}{lll}6 & 0 & 0\end{array}$ & $\begin{array}{l}\text { Nitrogen } \\
\mathrm{P}_{2} \mathrm{O}_{5} \text { (insoluble) }\end{array}$ & $\begin{array}{rr}13 & 0 \\
2 & 10 \frac{1}{2}\end{array}$ & $\begin{array}{l}\frac{1}{2} \\
7 \\
1 \frac{1}{2}\end{array}$ \\
\hline Steamed bone flour & $\begin{array}{lll}4 & 0 & 0\end{array}$ & 4150 & $\begin{array}{l}\text { Nitrogen } \\
\mathrm{P}_{2} \mathrm{O}_{5} \text { (insoluble) }\end{array}$ & $\begin{array}{rl}12 & 0 \\
2 & 6\end{array}$ & $\begin{array}{l}6 \frac{1}{2} \\
1 \frac{1}{3}\end{array}$ \\
\hline Dissolved bones . & $5 \quad 500$, & 5100 & $\begin{array}{l}\mathrm{Nitrogen}_{2} \\
\mathrm{P}_{2} \mathrm{O}_{5} \text { (soluble) } \\
\mathrm{P}_{2} \mathrm{O}_{5} \text { (insoluble) }\end{array}$ & $\begin{array}{rr}15 & 6 \\
4 & 10 \\
3 & 7\end{array}$ & $\begin{array}{l}8 \frac{1}{3} \\
2 \\
2\end{array}$ \\
\hline Superphosphates. & 2100, & $\begin{array}{lll}3 & 13 & 0\end{array}$ & $\mathrm{P}_{2} \mathrm{O}_{5}$ (soluble) & $4 \quad 1 \frac{1}{2}$ & $2 \frac{1}{4}$ \\
\hline Thomas slag . & 150, & $\begin{array}{lll}2 & 2 & 6\end{array}$ & $\mathrm{P}_{2} \mathrm{O}_{5}^{\circ}$ (insoluble) & $26{ }^{2}$ & $1 \frac{1}{3}$ \\
\hline $\begin{array}{l}\text { Muriate of potash (50 per } \\
\left.\text { cent } \mathrm{K}_{2} \mathrm{O}\right) \\
\text { Sulphate of potash }(5 \dot{2}\end{array}$ & & 8150 & $\mathrm{~K}_{2} \mathrm{O}$. & 36 & 2 \\
\hline per cent $\mathrm{K}_{2} \mathrm{O}$ ) & & $\begin{array}{lll}9 & 15 & 0\end{array}$ & $\mathrm{~K}_{2} \mathrm{O}$ & $\begin{array}{ll}3 & 9 \\
9\end{array}$ & 2 \\
\hline Kainite $\left(12\right.$ per cent $\left.\mathrm{K}_{2} \mathrm{O}\right)$ & & $\begin{array}{lll}2 & 5 & 0\end{array}$ & $\mathrm{~K}_{2} \mathrm{O}$ & $\begin{array}{ll}3 & 7 \frac{7}{2}\end{array}$ & 2 \\
\hline
\end{tabular}


the Highland and Agricultural Society of Scotland, 1910, may serve as an example. It is based on the prices current at Glasgow or Leith, except in the case of basic slag, where prices are those at place of production.

The figures in brackets after the name of the manure indicate the trade guarantees. Obviously such tables can only have a transient and local importance, since prices of manures are subject to considerable fluctuation.

In ordinary tables of this kind, the values per unit of "ammonia" and "phosphates" (i.e., $\mathrm{Ca}_{3} \mathrm{P}_{2} \mathrm{O}_{8}$ ) are usually given, and not those of nitrogen and phosphorus pentoxide, as in the above table. The latter plan certainly appears preferable, except on the ground of custom, since such substances as nitrate of soda and many organic manures contain none of their nitrogen in the form of ammonia ; and, similarly, superphosphate and basic slag contain most of their phosphorus pentoxide in forms other than tricalcium phosphate. Perhaps the same argument applies to the other manurial constituent-potassium -(though to a less degree), since in some manures it exists as chloride and not as potash.

It may perhaps be useful to give an example of the application of the table of "unit value" to the calculation of the money value of a manure from its analysis.

Suppose a sample of dissolved bones to yield the following numbers on analysis:-

Total phosphorus pentoxide.

Soluble

Insoluble "

Nitrogen

Per cent.

$17 \cdot 1$

$8 \cdot 6$

$8 \cdot 5$

$2 \cdot 5$

Its value per ton would be calculated as follows:-

Per cent. Value "per unit".

$8 \cdot 6 \times 4 \mathrm{~s} .10 \mathrm{~d}$. Value of soluble phosphorus pentoxide $=2 \stackrel{£}{\mathrm{~s}} \mathrm{~d}$.

$8.5 \times 3 \mathrm{~s} .7 \mathrm{~d}$., insoluble $, \quad, \quad=1105 \frac{1}{2}$

$2.5 \times 15$ s. 6d. $\quad, \quad$ nitrogen . $\quad . \quad \cdot \quad=1189^{2}$

$£ 5 \quad 10 \quad 97$

In America, the plan of expressing the trade value of manurial ingredients in price per pound is general. The following table gives the estimated trade values ${ }^{1}$ :-

Nitrogen in ammonium salts

,, nitrates

, dry and fine fish, meat, blood, etc.

,, fine bone and tankage

,, cotton-seed meal, castor cake, etc.

, , medium bone and tankage .

,, coarse bone and tankage

,, hair, horn and coarse fish refuse

Phosphorus pentoxide, soluble in water

Cents per lb. or $\mathrm{d}$.

$\begin{array}{ll}19 & 9 \frac{1}{2} \\ 14 \frac{1}{2} & 7 \frac{1}{4} \\ 18 \frac{1}{2} & 9 \frac{7}{4} \\ 16 \frac{1}{2} & 8 \frac{1}{4} \\ 15 & 7 \frac{1}{2} \\ 12 & 6 \\ 7 & 3 \frac{1}{2} \\ 6 & 3 \\ 6 & 3 \\ 5 \frac{1}{2} & 2 \frac{3}{1} \\ 5 \frac{1}{2} & 2 \frac{3}{4} \\ 3 & 1 \frac{1}{2} \\ 2 & 1 \\ 5 & 2 \frac{1}{2} \\ 2 & 1 \\ 5 & 2 \frac{1}{2} \\ 4 \frac{1}{2} & 2 \frac{1}{4}\end{array}$

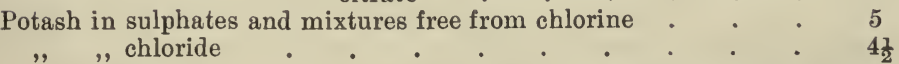

${ }^{1}$ Quoted by Wiley from Bull. 51, 1894, of the Mass. Agric. Exp. Station. 
-while the manurial constituents of foods are valued as follows :-

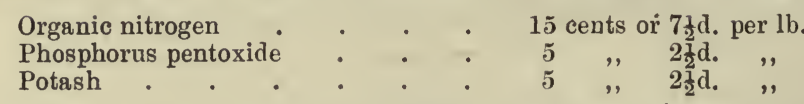

It must be clearly understood that the above method of valuing manures is based only upon trade prices and in no way depends upon the results of agricultural experience.

Tables have been constructed, giving the relative value of the same manurial constituent when applied to land in various forms, as measured by the increase in the crop produced. For example, according to experiments by Wagner in 1886 with wheat, barley and flax, the effect of the various forms of phosphatic manures upon plants abundantly supplied with potash and nitrogen are represented by the following numbers ${ }^{1}$ :-

\begin{tabular}{|c|c|c|c|c|c|}
\hline Superphosphate & - & ${ }^{\circ}$ & - & - & \\
\hline Raw guano & . & . & . & . & \\
\hline Bone meal & . & . & . & . & \\
\hline Coprolite powder & . & . & - & . & \\
\hline Thomas slag, finest & t. & • & . & - & \\
\hline ", fine & . & • & • & - & \\
\hline ", coars & e powder & . & . & . & \\
\hline
\end{tabular}

Field experiments with manures are highly valued in agriculture and undoubtedly furnish valuable, though somewhat empiric, information. In many of these trials the manures are taken at the usual trade valuation, and it is highly probable that, in a large number of cases, the phosphoric acid of superphosphates appears to yield better results than it really does, because of the trade custom of ignoring the insoluble phosphates present in a mineral superphosphate and only reporting that existing in the soluble form. It therefore often happens when a superphosphate containing a stated percentage of "soluble phosphates" is employed in comparison with an equal quantity of phosphates in, say, bones or basic slag, that the "super" plot gets the benefit of the insoluble phosphates in the manure, which may amount to 4 or 5 per cent.

${ }^{1}$ Vide Thomas Phosphate Powder, by Prof. Wagner, Darmstadt, 1887. 


\section{CHAPTER X.}

\section{The Chemical Constituents of Plants.}

Is the introductory chapter an account of the elements which enter into the composition of plants has been given, and in the succeeding chapters on the atmosphere, soils and manures, the sources from which plants obtain the necessary supplies of their food have been discussed at some length. The ultimate constituents of plants have thus already been considered. Their proximate constituents, i.e., the actual chemical compounds existent in the various parts of a plant, remain to be described. In this chapter, a short account of the chemistry of the chief compounds which are found in most plants will be given. To some of these substances brief allusion has already been made under "Carbon" in Chap. I., p. 8.

The following is a list of the various classes into which these compounds may be conveniently divided :-

I. Carbohydrates.

II. Fats and waxes.

III. Organic acids and their salts.

IV. Essential oils and resins.

V. Inorganic salts.

VI. Nitrogenous substances.

(i) Albuminoids.

(ii) Amino-acids and amino-compounds.

(iii) Alkaloids.

(iv) Cyanogenetic glucosides.

VII. Chlorophyll and other colouring matters.

\section{I.-THE CARBOHYDRATES.}

An important group of compounds, the members of which constitute the larger portion of the dry matter of most plants. They are neutral bodies and contain only the elements carbon, oxygen and hydrogen, the two latter being generally present in the proportion of 16 to 2 , i.e., the same as in water. As a rule they contain 5 or 6 , or some multiple of 5 or 6 , carbon atoms, and many of them exhibit optical activity, i.e., they rotate the plane of polarised light to the right $(+)$ or to the left $(-)$. 
Many members of the group of carbohydrates have been prepared. They may be conveniently divided into the following classes :-

I. Monosaccharoses. - This class includes compounds containing from 2, e.g., biose, CHO. $\mathrm{CH}_{2} \mathrm{OH}$, to 9 carbon atoms-e.g., nonose, CHO. $(\mathrm{CHOH})_{7} \cdot \mathrm{CH}_{2} \mathrm{OH}$. The members of interest from the present standpoint are those containing 5 or 6 carbon atoms, i.e., the pentoses and hexoses.

In the following list of these two groups, those members which are of importance as occurring in plants are printed in black type. The others have been prepared artificially.

(a) Aldoses, i.e., compounds containing the group

Pentoses, $\mathrm{C}_{5} \mathrm{H}_{10} \mathrm{O}_{5}$, l-arabinose, $\mathrm{CHO} .(\mathrm{CHOH})_{3} \cdot \mathrm{CH}_{2} \mathrm{OH}$

$\begin{array}{cc}d \text {-arabinose } & ", \\ \text { l-xylose } & ", \\ d \text {-xylose } & \text {-ribose } \\ d \text {-lyxose } & ", \\ \text { Hexoses, } \mathrm{C}_{6} \mathrm{H}_{12} \mathrm{O}_{6}, & \text { d-glucose, } \mathrm{CHO}(\mathrm{CHOH})_{4} \cdot \mathrm{CH}_{2} \mathrm{OH}\end{array}$

$\begin{array}{cc}d \text {-arabinose } & ", \\ \text { l-xylose } & ", \\ d \text {-xylose } & \text {-ribose } \\ d \text {-lyxose } & ", \\ \text { Hexoses, } \mathrm{C}_{6} \mathrm{H}_{12} \mathrm{O}_{6}, & \text { d-glucose, } \mathrm{CHO}(\mathrm{CHOH})_{4} \cdot \mathrm{CH}_{2} \mathrm{OH}\end{array}$

$\begin{array}{cc}d \text {-arabinose } & ", \\ \text { l-xylose } & ", \\ d \text {-xylose } & \text {-ribose } \\ d \text {-lyxose } & ", \\ \text { Hexoses, } \mathrm{C}_{6} \mathrm{H}_{12} \mathrm{O}_{6}, & \text { d-glucose, } \mathrm{CHO}(\mathrm{CHOH})_{4} \cdot \mathrm{CH}_{2} \mathrm{OH}\end{array}$

$\begin{array}{cc}d \text {-arabinose } & ", \\ \text { l-xylose } & ", \\ d \text {-xylose } & \text {-ribose } \\ d \text {-lyxose } & ", \\ \text { Hexoses, } \mathrm{C}_{6} \mathrm{H}_{12} \mathrm{O}_{6}, & \text { d-glucose, } \mathrm{CHO}(\mathrm{CHOH})_{4} \cdot \mathrm{CH}_{2} \mathrm{OH}\end{array}$

$\begin{array}{cc}d \text {-arabinose } & ", \\ \text { l-xylose } & ", \\ d \text {-xylose } & \text {-ribose } \\ d \text {-lyxose } & ", \\ \text { Hexoses, } \mathrm{C}_{6} \mathrm{H}_{12} \mathrm{O}_{6}, & \text { d-glucose, } \mathrm{CHO}(\mathrm{CHOH})_{4} \cdot \mathrm{CH}_{2} \mathrm{OH}\end{array}$

$\mathrm{H}$<smiles>CC=[Co]</smiles>

l-glucose

d-mannose

$l$-mannose

d-galactose

l-galactose

$d$-gulose

l-gulose

$d$-idose

$l$-idose

$d$-talose

l-talose

(b) Ketoses, i.e., compounds containing the group $\mathrm{O}=\mathrm{C} /$

Pentose, $l$-arabinulose, $\mathrm{CH}_{2} \mathrm{OH} . \mathrm{CO} .(\mathrm{CHOH})_{2} \cdot \mathrm{CH}_{2} \mathrm{OH}$

Hexoses, d-fructose, $\mathrm{CH}_{2} \mathrm{OH} . \mathrm{CO} \cdot(\mathrm{CHOH})_{3} \cdot \mathrm{CH}_{2} \mathrm{OH}$

$l$-fructose

d-sorbose

$l$-sorbose

$d$-tagatose

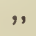

" -

,

,

The prefixes lævo-( $(l-)$ and dextro- $(d-)$, originally used to indicate the direction of rotation of the plane of polarised light by solutions of the various sugars, are now, by Fischer, employed to indicate the configurations assigned to their constitutional formulæ, and in the hexoses, are descriptive of the position of the hydrogen atom attached to the third carbon atom.

Thus- 
<smiles>O=CC(O)C(O)C(O)C(O)CO</smiles>

$d$-glucose.<smiles>O=CC(O)C(O)C(O)C(O)CO</smiles>

$l$-mannose.<smiles>O=CC(O)C(O)C(O)C(O)CO</smiles>

$d$-galactose.<smiles>O=C(CO)C(O)C(O)C(O)CO</smiles>

$d$-fructose.

In all cases the dextro- and lævo- forms are enantiomorphs, i.e., the formula of one is the mirror-image of that of the other.

This use of the terms leads to several unfortunate contradictionsthus $d$-fructose is strongly lævo-rotatory, while $l$-arabinose is strongly dextro-rotatory.

According to recent investigations by Armstrong, Lowry and others, it appears probable that there are two isomeric forms of $d$-glucose which possess the following constitution:-
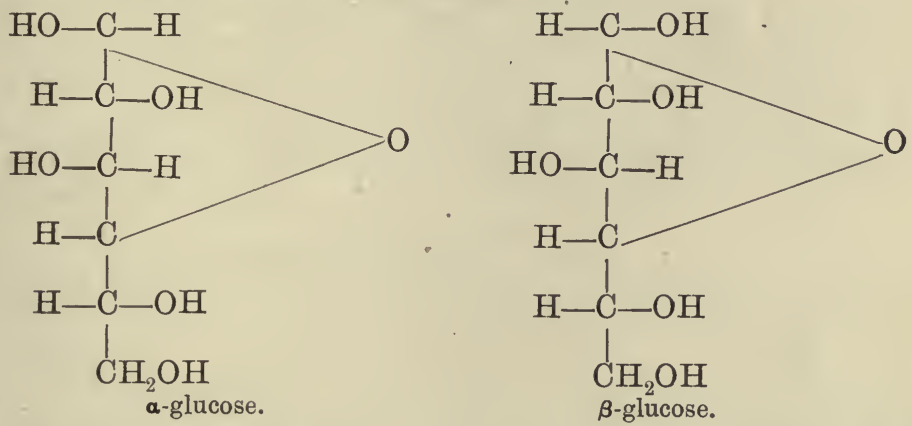

The only difference here, is in the relative positions of the hydroxyl and hydrogen attached to the uppermost carbon atom.

II. Disaccharoses, $\mathrm{C}_{12} \mathrm{H}_{22} \mathrm{O}_{11}$. These compounds contain twelve atoms of carbon and consist of a combination of two hexoses. By hydrolysis-brought about by acids or enzymes-they split up into their component hexoses, which may be either aldoses or ketoses.

In some disaccharoses, the aldehyde or ketone groups retain their functions and the sugar is then capable of reducing copper salts; in others, these groups become inactive and the sugar is then devoid of reducing power.

(a) Reducing sugars :-

Maltose-glucose $\alpha$-glucoside.

Gentiobiose-glucose $\beta$-glucoside.

Lactose-glucose $\beta$-galactoside.

Melibiose-glucose galactoside.

Turanose-glucose and fructose. 
(b) Non-reducing sugars :-

Sucrose-glucose and fructose.

Trehalose-glucose and glucose.

The constitution of the disaccharoses is not so well established as that of the monosaccharoses. The following formulæ have been provisionally accepted :-

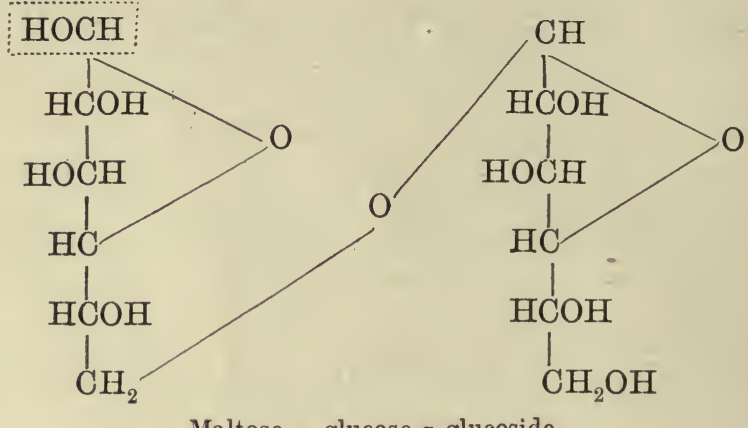

Maltose $=$ glucose $a$-glucoside.

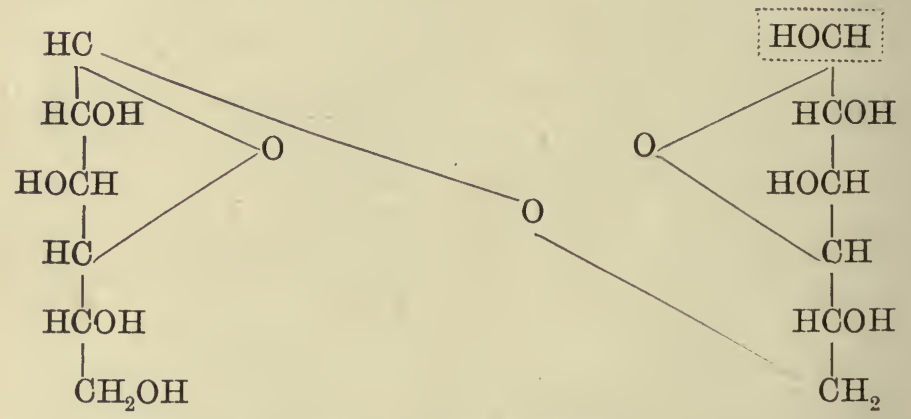

Lactose $=$ glucose $\beta$-galactoside.

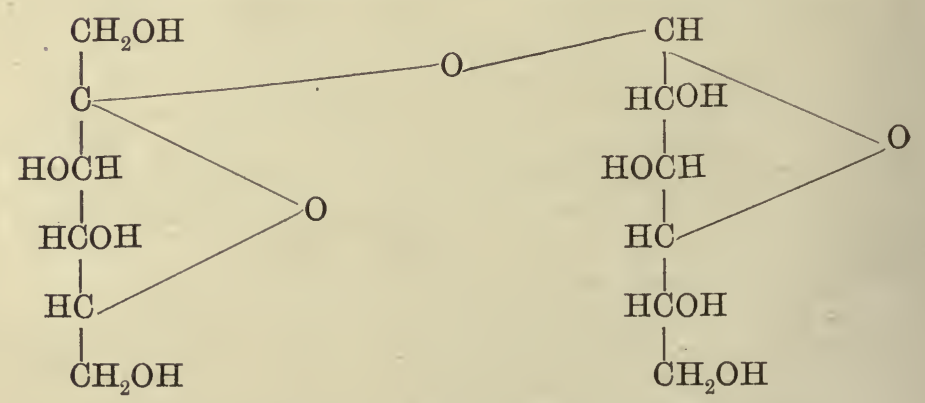

Sucrose $=$ fructose and glucose. 

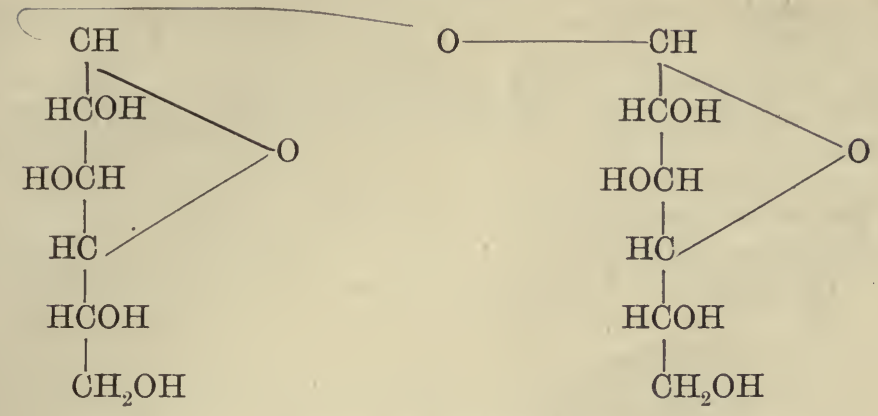

Trehalose $=$ glucose and glucose.

It will be noted that maltose and lactose still retain the aldehydic function, for the groups enclosed in dotted lines easily pass, by a wandering of the hydrogen atom of the hydroxyl to the third next. carbon atom, into a true aldehyde group, and are therefore possessed of reducing powers, but in sucrose and trehalose there are neither aldehyde nor ketone groups and so these latter sugars are non-reducing.

III. Trisaccharoses, $\mathrm{C}_{18} \mathrm{H}_{32} \mathrm{O}_{16}$. Several have been prepared, but the only one which need be mentioned here is Raffinose which is a compound of galactose, glucose and fructose and is strongly dextro-rotatory. It possesses no reducing action and, by acids, is hydrolysed first into melibiose and fructose and finally into glucose, galactose and fructose.

IY. Tetrasaccharoses, $\mathrm{C}_{24} \mathrm{H}_{42} \mathrm{O}_{21}$.

Stachyose is a combination of fructose, glucose and two molecules of galactose.

Y. Polysaccharoses, $\left(\mathrm{C}_{6} \mathrm{H}_{10} \mathrm{O}_{5}\right)_{n}$. These are complex bodies resulting from the combination of large numbers of molecules of the monosaccharoses, but whose constitution and molecular weights are unknown. The more important divisions are the polypentoses or pentosans and the polyhexoses or hexosans, but intermediate substances, i.e., compounds containing both pentoses and hexoses, are also known.

The following are important polysaccharoses :-

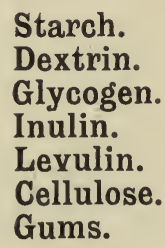

Resembling the carbohydrates in character are many other compounds occurring in plants. Among these may be mentioned :- 
The methyl pentoses, $\mathrm{C}_{6} \mathrm{H}_{12} \mathrm{O}_{5}$, Rhamnose, Chinoyose and Fucose.

Erythritol, $\mathrm{C}_{4} \mathrm{H}_{10} \mathrm{O}_{4}$.

Adonitol, $\mathrm{C}_{5} \mathrm{H}_{12} \mathrm{O}_{5}$.

Mannitol, Dulcitol and Sorbitol, $\mathrm{C}_{6} \mathrm{H}_{8}(\mathrm{OH})_{6}$.

Perseitol, $\mathrm{C}_{7} \mathrm{H}_{9}(\mathrm{OH})_{\tau}$.

The Furfuroids.

Lignone or Lignose.

Pectin substances.

The Glucosides and similar bodies.

\section{The monosaccharoses-}

1. The pentoses, $\mathrm{C}_{5} \mathrm{H}_{10} \mathrm{O}_{5}$. The most important are $l$-arabinose and $l$-xylose.

Arabinose.-This rarely, if ever, occurs free in plants but is easily obtained by the hydrolysis of araban, which is one of the gum-like constituents of many vegetable tissues.

It is a crystalline solid with intensely sweet taste, very soluble in hot, but much less soluble in cold, water and insoluble in alcohol. Its constitution is represented by the formula :-

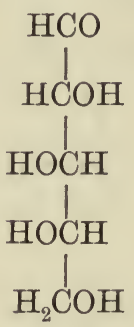

It is therefore $l$-arabinose though it is strongly, dextro-rotatory. The dextro-form has been obtained artificially.

Xylose.-This, too, does not occur ready formed in plants but results from the hydrolysis of xylan, the main constituent of wood gum. It resembles arabinose in properties but dissolves in hot alcohol.

Like arabinose it is an aldose and reduces copper salts. Ribose is another isomeric pentose obtained artificially. Xylose and ribose have the following constitutional formulæ:-
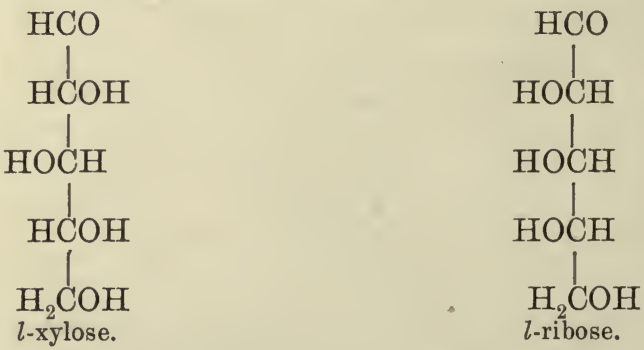
The methyl pentoses.-Fucose, $\mathrm{C}_{5} \mathrm{H}_{9}\left(\mathrm{CH}_{3}\right) \mathrm{O}_{5}$, has been obtained from a sea-weed (Fucus nodosis). It occurs as its polymeride, fucosan, in the cell walls of many sea plants. It is a crystalline, sweet, very soluble substance, yielding methyl furfurol on distillation with hydrochloric acid.

Rhamnose, $\mathrm{C}_{5} \mathrm{H}_{9}\left(\mathrm{CH}_{3}\right) \mathrm{O}_{5} \cdot \mathrm{H}_{2} \mathrm{O}$, is not found in the free state in plants, but occurs very frequently in compounds analogous to the glucosides, from which dilute acids or alum solution set the sugar free. As quercitrin it has been found in many plants, e.g., in sumach, hops, tea-leaves, ash and horse-chestnut:-

$$
\underset{\text { Quercitrin. }}{\mathrm{C}_{21} \mathrm{H}_{20} \mathrm{O}_{11}}+2 \mathrm{H}_{2} \mathrm{O}=\underset{\text { Rhamnose. }}{\mathrm{C}_{6} \mathrm{H}_{14} \mathrm{O}_{6}}+\underset{\text { Quercetin. }}{\mathrm{C}_{15} \mathrm{H}_{10} \mathrm{O}_{7}} \text {. }
$$

Many other glucoside-like bodies have been obtained from plants, some yielding glucose as well as rhamnose.

Rhamnose forms hard crystals, very soluble in water, has a sweet taste, but leaves a bitter after-taste. It loses its water of crystallisation at about $105^{\circ}$. By reduction it forms the penta-hydric alcohol Rhamnite or Rhamnitol, $\mathrm{C}_{6} \mathrm{H}_{14} \mathrm{O}_{5}$, a sweet, soluble substance.

Rhamnose, like glucose, is coloured yellow by alkalies and reduces copper salts. It is coloured violet-blue by sulphuric acid and $\alpha$-naphthol.

2. The hexoses, $\mathrm{C}_{6} \mathrm{H}_{12} \mathrm{O}_{6}$. The hexoses occur widely distributed in the vegetable kingdom, being found in the free state (as in ripe fruits) or in combination with organic acids as glucosides.

They are produced by the hydrolysis (i.e., the addition of the elements of water) of the disaccharoses, polysaccharoses, or of the glucosides. The hydrolysis is usually effected by unorganised ferments or by the action of hot acids.

They are generally crystallisable substances, soluble in water, possessing a sweet taste, and nearly insoluble in alcohol. They generally exhibit optical activity, i.e., they rotate the plane of polarised light.

They show the reactions of alcohols and ketones or aldehydes, and possess the power, in presence of alkalies, of reducing cupric oxide to cuprous oxide. With phenyl-hydrazine, $\mathrm{H}_{2} \mathrm{~N} \cdot \mathrm{NH}\left(\mathrm{C}_{6} \mathrm{H}_{5}\right)$, the hexoses yield, in presence of acetic acid, crystalline precipitates known as osazones :-

$$
\begin{aligned}
& \mathrm{C}_{6} \mathrm{H}_{12} \mathrm{O}_{6}+3 \mathrm{H}_{2} \mathrm{~N} \cdot \mathrm{NH} . \mathrm{C}_{6} \mathrm{H}_{5} \\
& =\mathrm{C}_{6} \mathrm{H}_{10} \mathrm{O}_{4} \cdot\left(\mathrm{N} . \mathrm{NH} \cdot \mathrm{C}_{6} \mathrm{H}_{5}\right)_{2}+2 \mathrm{H}_{2} \mathrm{O}+\mathrm{NH}_{3}+\mathrm{NH}_{2} \cdot \mathrm{C}_{6} \mathrm{H}_{5} \\
& \text { Glucosazone. } \\
& \text { Aniline. }
\end{aligned}
$$

Many of the hexoses are capable of fermentation under the influence of yeast, Saccharomyces cerevisia, yielding alcohol and carbon dioxide as the chief products.

$$
\mathrm{C}_{6} \mathrm{H}_{12} \mathrm{O}_{6}=2 \mathrm{C}_{2} \mathrm{H}_{6} \mathrm{O}+2 \mathrm{CO}_{2} \text {. }
$$

Small quantities of amyl alcohol, $\mathrm{C}_{5} \mathrm{H}_{11} \mathrm{OH}$, glycerol, $\mathrm{C}_{3} \mathrm{H}_{5}(\mathrm{OH})_{3}$, and succinic acid, $\mathrm{C}_{2} \mathrm{H}_{4}(\mathrm{COOH})_{2}$, are also formed. Glucose, mannose, $d$-galactose and $d$-fructose are thus affected, while sorbose, gulose, $l$-fructose and the other hexoses do not ferment with yeast. 
Mannose, $\mathrm{C}_{6} \mathrm{H}_{12} \mathrm{O}_{6}$, is the aldehyde of mannitol or mannite, $\mathrm{C}_{6} \mathrm{H}_{14} \mathrm{O}_{6}$, a sweet substance occurring in many plants, especially in the manna-ash (Fraxinus ornus), the dried sap of which constitutes manna. The sugar is obtained by oxidising mannitol by means of platinum black. It can also be obtained from the reserve cellulose contained in many seeds, by the action of dilute sulphuric acid.

Glucose, $\mathrm{C}_{6} \mathrm{H}_{12} \mathrm{O}_{6}=\mathrm{CH}_{2} \mathrm{OH}$.(CHOH) $)_{4}$. $\mathrm{CHO}$, also called dextrose and grape sugar, occurs in many fruits, generally associated with fructose. It is formed by the hydrolysis of polysaccharoses, e.g., starch, dextrin and cellulose, of cane sugar, or of glucosides.

Commercially, glucose is made by boiling starch with dilute sulphuric acid. So obtained, it is used in brewing and in the manufacture of jams and sweetmeats.

It crystallises with difficulty and is much less sweet than cane sugar. It reduces copper solutions and easily undergoes fermentation.

Its compounds with lime and baryta, $-\mathrm{C}_{6} \mathrm{H}_{12} \mathrm{O}_{6} \cdot \mathrm{CaO}$ and $\mathrm{C}_{6} \mathrm{H}_{12} \mathrm{O}_{6} \cdot \mathrm{BaO}$, are insoluble in alcohol.

Gulose, Galactose, Talose and Idose are isomeric sugars. All these bodies are, like mannose and glucose, aldohexoses, i.e., contain the group $\mathrm{HCO}$.

The chief keto-hexoses are :-

Fructose, $\mathrm{C}_{6} \mathrm{H}_{12} \mathrm{O}_{6}=\mathrm{CH}_{2} \mathrm{OH} \cdot(\mathrm{CHOH})_{3} \cdot \mathrm{CO} \mathrm{CH}_{2} \mathrm{OH}$, also called levulose and fruit sugar, occurs in most sweet fruits. It is produced, together with an equal amount of glucose, by the hydrolysis of cane sugar :-

$$
\mathrm{C}_{12} \mathrm{H}_{22} \mathrm{O}_{11}+\mathrm{H}_{2} \mathrm{O}=\underset{\text { Dextrose. }}{\mathrm{C}_{6} \mathrm{H}_{12} \mathrm{O}_{6}}+\underset{\text { Levulose. }}{\mathrm{C}_{6} \mathrm{H}_{12} \mathrm{O}_{6}}
$$

Since cane sugar is dextro-rotatory and levulose more lævo-rotatory than dextrose is dextro-rotatory, the mixture resulting from the hydrolysis of cane sugar rotates the plane of polarisation to the left. Hence the name invert sugar which is given to the mixture. Fructose is also formed by the action of hot water upon inulin.

Its constitution has already been given.

Sorbinose or Sorbose occurs in the berries of the mountain ash, probably as sorbitol, $\mathrm{C}_{6} \mathrm{H}_{14} \mathrm{O}_{6}$. It is a crystalline, very sweet substance, turned yellow by alkalies, and capable of reducing copper solutions. It is not fermentable by yeast.

The disaccharoses. - These sugars consist of two molecules of hexoses united together with the elimination of a molecule of water. They, therefore, possess the composition $\mathrm{C}_{12} \mathrm{H}_{22} \mathrm{O}_{11}$. They are probably to be regarded as ethers, i.e., the two hexose groups are probably connected together through an atom of oxygen. Cane sugar has no reducing power on copper salts and forms no osazone; it, therefore, probably contains no aldehyde nor ketone groups. Milk sugar and maltose yield these reactions and probably contain the aldehyde group-CHO.

The decomposition of the disaccharoses into hexoses by the addition of a molecule of water (hydrolysis) can be brought about by 
the action of unorganised ferments or enzymes, e.g., diastase, ptyalin, invertase, or by boiling with water and a little acid.

Cane Sugar, Saccharose, Saccharobiose, $\mathrm{C}_{12} \mathrm{H}_{22} \mathrm{O}_{11}$, the most important sugar, occurs in many plants; in large quantities in the sugar-cane, in the maple, in beetroot and in sorghum cane. The juice of the sugar-cane (Saccharum officinarum) contains from 16 to 18 per cent. of its weight of sugar. Beets contain from 7 to 16 per cent. Cane sugar is also present in the juice of unripe maize, in many palms, in many roots, e.g., turnips and mangolds, in the sap of the lime and birch, in the nectar of flowers, and, mixed with glucose and fructose, in many fruits.

Commercial sugar is chiefly prepared from the sugar-cane, the beet and the sugar-maple. The properties of sugar are well known and need not bo described here. It melts at $160^{\circ}$, and at $190^{\circ}$ or $200^{\circ}$ changes to a brown uncrystallisable substance known as caramel, used in colouring. It does not reduce copper salts. Boiled with dilute acids or by the action of certain ferments, it is converted into a mixture of glucose and levulose (inversion). It combines with lime and baryta to form sparingly soluble saccharates, e.g., $\mathrm{C}_{12} \mathrm{H}_{22} \mathrm{O}_{11}$. CaO. $2 \mathrm{H}_{2} \mathrm{O}$ and $\mathrm{C}_{12} \mathrm{H}_{22} \mathrm{O}_{11} \cdot 3 \mathrm{CaO}$. These substances are decomposed by carbon dioxide, yielding a metallic carbonate (insoluble) and sugar. Cane sugar in plants is mainly contained in the stalks, while the hexoses occur chiefly in the fruits.

Milk Sugar, $\mathrm{C}_{12} \mathrm{H}_{22} \mathrm{O}_{11}+\mathrm{H}_{2} \mathrm{O}$, will be described in Chap. XV.

Maltose, Malt Sugar, Maltobiose, $\mathrm{C}_{12} \mathrm{H}_{22} \mathrm{O}_{11}+\mathrm{H}_{2} \mathrm{O}$, is formed by the action of diastase upon starch, dextrin being simultaneously produced. Maltose is a crystalline substance which undergoes fermentation under the influence of yeast, being first converted by an enzyme, maltase, present in the yeast or malt, into glucose. It reduces copper solutions and in most of its properties closely resembles glucose. It is probably the form in which starch and other carbohydrates undergo translocation in plants.

The other disaccharoses are less important.

Trehalose, $\mathrm{C}_{12} \mathrm{H}_{22} \mathrm{O}_{11}+2 \mathrm{H}_{2} \mathrm{O}$, has been found in many fungi and in ergot of rye.

Melibiose is obtained from the trisaccharose, raffinose, by hydrolysis with dilute acids or certain yeasts. By hydrolysis it is hydrolysed into glucose and galactose. Melibiose is not hydrolysed by maltase, invertase, or lactase but is by emulsin or by an enzyme, melibiase, which is present in bottom fermentation yeasts but not in top yeasts.

The trisaccharoses, $\mathrm{C}_{18} \mathrm{H}_{32} \mathrm{O}_{16^{\circ}}$. The only member of this group which need be mentioned is Raffinose, which occurs in beets and in other plants. By strong acids, it is hydrolysed into fructose, glucose and galactose, while weak acids yield fructose and melibiose. Invertase converts it into fructose and melibiose but emulsin hydrolyses it to sucrose and galactose. Raffinose resembles cane sugar and has no reducing power. It crystallises in prisms containing three molecules of water.

It may be regarded as- 


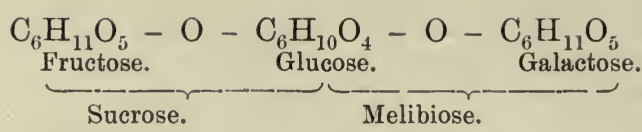

The Tetrasaccharoses, $\mathrm{C}_{24} \mathrm{H}_{42} \mathrm{O}_{21}$. The only example which need be given is Stachyose or manneotetrose which occurs in Stachys tuberifera and in manna. By hydrolysis it splits up into fructose, glucose and two molecules of galactose.

The Polysaccharoses, $\left(\mathrm{C}_{6} \mathrm{H}_{10} \mathrm{O}_{5}\right)_{\mathrm{n}}$. Starch or Amylum. This substance is very widely distributed in plants and serves as a reserve material for the nourishment of the growing portions. It exists in the form of granules, which vary greatly in size and form in different plants.

The starch from any one source may show considerable differences in the size of its granules, but their form and general appearance is always the same and may be readily recognised under the microscope.

Of the common starches, that from potatoes has the largest granules, varying from 07 to 03 millimetre in diameter, while wheat starch varies from $\cdot 045$ to $\cdot 003$ millimetre, and rice starch from 0075 to 0050 millimetre in diameter.

The granule is made up of a cell wall of starch cellulose and an interior mass of granulose. So long as the cell wall is uninjured, starch will not dissolve in cold water, but by bruising the cell wall, or better, by causing the granules to swell up and burst, the contents, granulose, escape and yield with the water a kind of viscid solution known as starch paste.

The temperature at which this swelling up of the granule occurs varies with different starches; it usually commences about $50^{\circ}$ and is completed about $70^{\circ} \mathrm{C}$.

Starch is converted by free iodine, in the presence of water, into a blue or violet-coloured substance. Starch paste is coloured deep blue by iodine, the colour being deeper the lower the temperature; even below the boiling-point of water the colour disappears entirely, but reappears on cooling. The blue substance is said to have the composition $\left[\left(\mathrm{C}_{6} \mathrm{H}_{10} \mathrm{O}_{5}\right)_{4} \mathrm{I}\right]_{4}$. HI and the presence of hydriodic acid or an iodide is said to be essential to its formation. ${ }^{1}$

Starch unites with the alkaline earths to form definite compounds which are insoluble in dilute alcohol. In the case of barium the precipitate has the composition $\mathrm{BaO} \cdot\left(\mathrm{C}_{6} \mathrm{H}_{10} \mathrm{O}_{5}\right)_{4}$. A volumetric method of estimating starch has been based upon this reaction. ${ }^{2}$

When starch is heated for half an hour in glycerine to $190^{\circ}$ it is converted into soluble starch, which can be precipitated from aqueous solution by the addition of alcohol. The white powder so formed is soluble in water, and according to Brown and Morris ${ }^{3}$ has a molecular weight of 32,400 , i.e., it has the formula $\left(\mathrm{C}_{6} \mathrm{H}_{10} \mathrm{O}_{5}\right)_{200}$.

${ }^{1}$ Mylius, Ber. 20, 688; Jour. Chem. Soc., 1887, Abstracts, 568.

${ }^{2}$ Asboth, Chem. Zeit., 11, 785 ; Jour. Chem. Soc., 1887, Abstracts, 868.

3 Jour. Chem. Soc., 1889, Trans., 449. 
Dextrin, $\left(\mathrm{C}_{6} \mathrm{H}_{10} \mathrm{O}_{5}\right)_{40}$ (?).-By the action of dilute acids in the cold, by the limited action of diastase (the ferment found abundantly in malt, etc.) upon starch paste, or by the action of a temperature of $210^{\circ}$ to $280^{\circ}$ upon dry starch, dextrin is produced, a substance easily soluble in water and giving no blue with iodine solutions.

Amylo-dextrin, with the composition $\mathrm{C}_{12} \mathrm{H}_{22} \mathrm{O}_{11} \cdot 12 \mathrm{C}_{6} \mathrm{H}_{10} \mathrm{O}_{5}$ (i.e., consisting of one group of maltose and twelve of dextrin), malto-dextrin, $\mathrm{C}_{12} \mathrm{H}_{22} \mathrm{O}_{11} .4 \mathrm{C}_{6} \mathrm{H}_{10} \mathrm{O}_{5}$, and other intermediate products are formed. They have been examined and described by Brown and Morris. ${ }^{1}$

Commercial dextrin or "British gum " is obtained by heating starch to $210^{\circ}$ or higher, or by moistening starch with a mixture of nitric and hydrochloric acids and heating it to $100^{\circ}$ or $125^{\circ}$. It is used as a substitute for gum arabic and probably is a complex mixture.

Dextran or fermentable gum, found in beetroots, is amorphous, soluble in water, and can be converted into dextrose by boiling with dilute acids.

Lichenin, found in Iceland moss, is soluble in hot water, but separates in flocks on cooling.

Glycogen, $\left(\mathrm{C}_{6} \mathrm{H}_{10} \mathrm{O}_{5}\right)_{\mathrm{n}}$, occurs in the liver and many other parts of the animal, and is present in certain fungi. It is a white powder, having a composition $\left(\mathrm{C}_{6} \mathrm{H}_{10} \mathrm{O}_{5}\right)_{2} \cdot \mathrm{H}_{2} \mathrm{O}$, and losing its water at $100^{\circ}$. It is soluble in water and gives a red colour with iodine. By the action of acids it is converted into dextrose, and diastase converts it into dextrin, maltose and dextrose.

Inulin, $\left(\mathrm{C}_{36} \mathrm{H}_{62} \mathrm{O}_{31}\right)_{2}$, or $\left(\mathrm{C}_{6} \mathrm{H}_{10} \mathrm{O}_{5}\right)_{12}+2 \mathrm{H}_{2} \mathrm{O}$ occurs in many plants, particularly in tubers of dahlias and Jerusalem artichokes and the roots of dandelion and chicory. It is a white powder, soluble in hot, but nearly insoluble in cold water or in alcohol. It is not coloured blue by iodine, and by the action of dilute acids is converted into levulose. According to Brown and Morris, ${ }^{2}$ its molecular weight is 1980 , corresponding to the formula above given. By the action of heat, inulin forms substances similar to the dextrins. On hydrolysis it yields fructose.

Levulin, $\left(\mathrm{C}_{6} \mathrm{H}_{10} \mathrm{O}_{5}\right)_{\mathbf{n}}$, occurs associated with inulin in dahlias and artichokes. It is also found in immature grain, particularly in rye and in oak bark. It is an amorphous, deliquescent substance, yielding a mixture of dextrose and levulose by treatment with acid.

Triticin is a similar substance found in couch-grass. Other substances obtained from different sources have been described, but their individuality is not very marked.

Cellulose is the substance which constitutes the main portion of the frame-work of plants. It occurs in numerous forms, and in plants is always mixed or combined with other products of growth, from which it can usually be separated by taking advantage of its inertness and resistance to most reagents. By treating the plant tissues with chlorine, boiling with alkaline solutions, washing, treating with dilute acid, water, alcohol and ether, a residue of nearly pure cellulose is usually 
obtained. Its composition corresponds to the empiric formula $\mathrm{C}_{6} \mathrm{H}_{10} \mathrm{O}_{5}$. Ordinary air-dried specimens always contain 7 to 9 per cent of hygroscopic moisture. It is insoluble in most solvents, but can be obtained in solution by means of zinc chloride or ammoniacal copper oxide. The solubility of cellulose in these solutions is taken advantage of in the arts, the former being used in the preparation of the "carbon filament" of incandescent electric lamps, and the latter in the manufacture of "Willesden" waterproof paper. Cellulose appears to have at the same time faint acid and basic properties; it will absorb and retain either bases or acids.

By the action of caustic soda solutions (exceeding 10 per cent $\mathrm{Na}_{2} \mathrm{O}$ ) ordinary cotton fibre (practically cellulose) is converted into a compound which, on treatment with water, is decomposed, a molecule of water apparently taking the place of $\mathrm{Na}_{2} \mathrm{O}$. The properties of the fibre are changed considerably, it swells laterally or thickens with a corresponding shrinkage in length, its tensile strength is increased, and it possesses greater affinities for dyes. These facts were discovered by Mercer many years ago, and cotton fabrics so treated have lately been extensively made. They are sold as "mercerised cotton". If cotton be treated with a solution containing 15 per cent of caustic soda, squeezed, and placed in a bottle with about 40 per cent of its weight of carbon disulphide, $\mathrm{CS}_{2}$, a substance is produced after three or four hours which will dissolve in water on standing. This cellulose thiocarbonate, $\mathrm{CS}_{\mathrm{SNa}} \mathrm{O}_{\mathrm{S}}\left(\mathrm{C}_{6} \mathrm{H}_{10} \mathrm{O}_{5}\right)_{\mathrm{n}}$, spontaneously decomposes, especially in contact with a large amount of water, giving a jelly or coagulum. Heating also effects the coagulation. This product lends itself to many useful applications and is employed commercially under the name of "Viscose".

By the action of nitric acid, or better, a mixture of nitric and sulphuric acids, cellulose is converted into various nitro-derivatives or nitrates, some of which are of great value in the arts.

Gun-cotton is chiefly cellulose hexa-nitrate, $\mathrm{C}_{12} \mathrm{H}_{14}\left(\mathrm{NO}_{3}\right)_{6} \mathrm{O}_{4}$, and is valued for its explosive properties. Pyroxylin or collodion is mainly tetra-nitrate, $\mathrm{C}_{12} \mathrm{H}_{16}\left(\mathrm{NO}_{3}\right)_{4} \mathrm{O}_{6}$, and penta-nitrate, $\mathrm{C}_{12} \mathrm{H}_{15}\left(\mathrm{NO}_{3}\right)_{5} \mathrm{O}_{5}$. These substances are soluble in ether and alcohol and are then known as collodion. This is employed in surgery and photography, also in the manufacture of celluloid, which is a mixture of nitrocellulose and camphor.

Parchment paper is obtained by immersing ordinary unsized paper in sulphuric acid and then washing it with water. It closely resembles true parchment in strength and apparently has the outer part of its cellulose altered into a substance known as amyloid. A similar change is produced by zinc chloride solution, and since amyloid is, like starch, coloured blue by iodine, a solution of iodine in concentrated zinc chloride forms a useful reagent for the identification of cellulose.

By the action of sulphuric acid cellulose is eventually converted into dextrin and dextrose.

Gums, $\left(\mathrm{C}_{6} \mathrm{H}_{10} \mathrm{O}_{5}\right)$ n, are very widely distributed in plants. They are amorphous and either dissolve in water or absorb it and swell up when 
immersed in it. They are not coloured by iodine, and by boiling with dilute acids they yield sugars, often arabinose or xylose.

Some of the substances are employed in the arts, e.g., gum arabic, the exudation from the bark of several species of acacia. This substance contains 3 or 4 per cent of ash (mainly lime), and as its principal constituent arabin or arabic acid, a white solid soluble in water, of highly complex constitution $\left(\mathrm{C}_{89} \mathrm{H}_{142} \mathrm{O}_{72}\right.$ or $\left.\mathrm{C}_{78} \mathrm{H}_{120} \mathrm{O}_{63}{ }^{1}\right)$. Very similar bodies are found in nearly all vegetable tissue. Wood gum, the name given to the substance occurring in wood, the straw of cereals, etc., is a substance of this class. By boiling with dilute acids or alkalies, some gums yield pentose sugars, - arabinose, xylose, or lyxose, $\mathrm{C}_{5} \mathrm{H}_{10} \mathrm{O}_{5}$. They, therefore, belong to the class of bodies for which the name pentosan has been proposed, of the composition $\left(\mathrm{C}_{5} \mathrm{H}_{8} \mathrm{O}_{4}\right)_{\mathrm{n}}$. It appears ${ }^{2}$ that the effect of boiling arabin with dilute acid is to add gradually the elements of water and to cause the splitting off of a sugar molecule, leaving a residue known as arabinosic acid, which, by further boiling, loses another sugar molecule, giving a lower acid- $\beta$-arabinosic acid-and so on, until finally an acid of the formula $\mathrm{C}_{23} \mathrm{H}_{38} \mathrm{O}_{22}$ is left.

$$
\text { finally } \quad \begin{aligned}
& \mathrm{C}_{78} \mathrm{H}_{120} \mathrm{O}_{63}+\mathrm{H}_{2} \mathrm{O}=\mathrm{C}_{5} \mathrm{H}_{10} \mathrm{O}_{5}+\mathrm{C}_{73} \mathrm{H}_{122} \mathrm{O}_{59} ; \\
& \mathrm{O}_{59}+13 \mathrm{H}_{2} \mathrm{O}=10 \mathrm{C}_{5} \mathrm{H}_{10} \mathrm{O}_{5}+\mathrm{C}_{23} \mathrm{H}_{38} \mathrm{O}_{22} \text {. }
\end{aligned}
$$

Some gums, on boiling with dilute sulphuric acid, yield not only arabinose or xylose, as above, but galactose, $\mathrm{C}_{6} \mathrm{H}_{12} \mathrm{O}_{6}$, as their main product. Hence gum is a name which includes both pentosans and hexosans (i.e., polysaccharoses, which yield pentose and hexose sugars).

The total amount of the pentosans present in various plants has been determined by Tollens, Chalmot, Günther, Stone and others. The following table gives some of their results :-

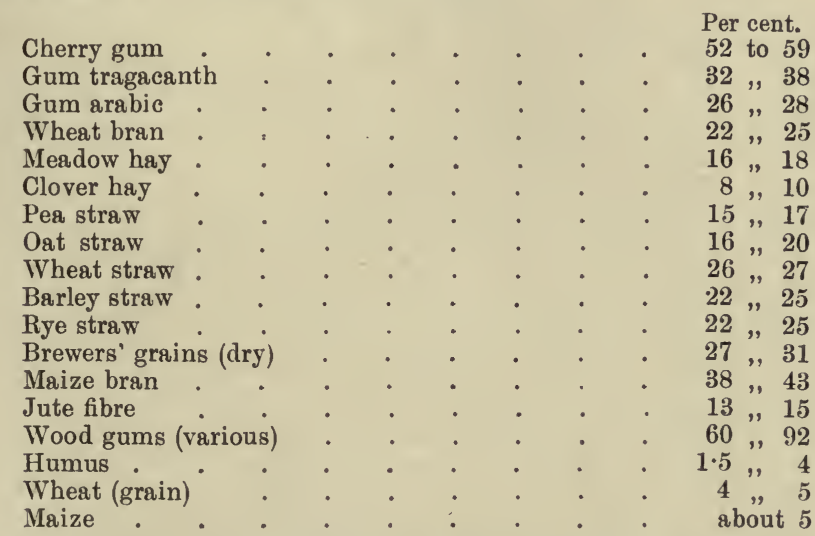

By prolonged boiling with hydrochloric acid, pentosans yield furfurol (furfuraldehyde) by the removal of water from the pentoses first formed :-

${ }^{1}$ O'Sullivan. ${ }^{2}$ O'Sullivan, Jour. Chem. Soc., 1882, 41. 


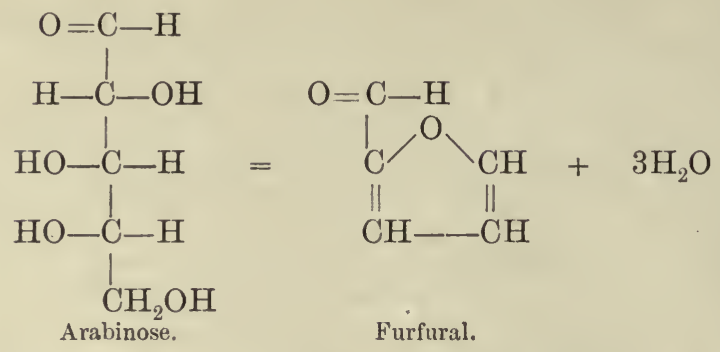

By collecting the distillate and causing the furfural to combine with phloroglucinol, a solid body which can be weighed is obtained. The red colouration formed when a pentose is heated with a solution of phloroglucinol in strong hydrochloric acid is often used as a test for the presence of a pentose.

\section{The Carbohydrate Alcohols.}

Erythritol, $\mathrm{C}_{4} \mathrm{H}_{6}(\mathrm{OH})_{4}$, occurs in algæ and mosses. It has a sweet taste, melts at $126^{\circ}$ and is optically inactive.

Adonitol, $\mathrm{C}_{5} \mathrm{H}_{7}(\mathrm{OH})_{5}$, occurs in certain plant saps, e.g., in Adonis vernalis and can be obtained by the reduction of ribose. Similar sweet substances, arabitol and xylitol, can be obtained by the reduction of arabinose and xylose respectively, but do not occur naturally.

Mannitol, $\mathrm{C}_{6} \mathrm{H}_{8}(\mathrm{OH})_{6}$, occurs in many plants, notably in the manna ash, Fraxinus ornus, and in fungi. It melts at $168^{\circ}$ and is dextro-rotatory. It can be prepared by reducing mannose with sodium amalgam.

Dulcitol, an isomeric substance, also occurring in plants, is optically inactive and melts at $188^{\circ}$. It can be prepaled by the reduction of galactose.

Sorbitol, a thild isomer, occurs in the berries of the mountain ash, Sorbus aucuparia, and in the sap of many trees. It melts at $110^{\circ}$ and, on oxidation, yields sorbose.

Perseitol, $\mathrm{C}_{7} \mathrm{H}_{9}(\mathrm{OH})_{7}$, occurs in the Avocado pear, Persea gratissima, is lævorotatory and melts at $180^{\circ}$. It corresponds to the sugar, manno-heptose, $\mathrm{C}_{7} \mathrm{H}_{14} \mathrm{O}_{7}$.

Yolemitol, an isomeride of perseitol, melting at $154^{\circ}$ and dextrorotatory, occurs in Lactarius volemus and in the rhizomes of certain primula.

The Furfuroids. - By this name Cross and Bevan ${ }^{1}$ refer to the substances present in cereal straw, jute fibre and other vegetable products, which, when subjected to acid hydrolysis, give furfuraldehyde. The term includes the pentoses and pentosans proper, but also another group of bodies-pentose derivatives-to which the authors just quoted ascribe the constitution-

${ }^{1}$ Jour. Chem. Soc., 1896, Trans., 804, 1604; 1897, Trans., 1001. 


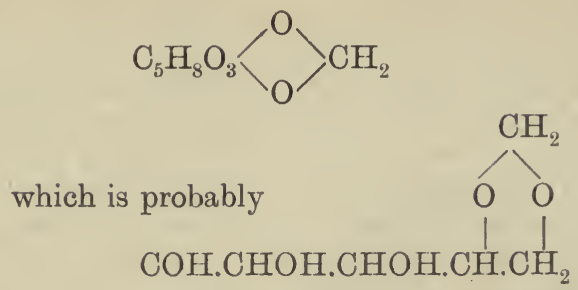

These bodies are capable of fermentation with yeast, yielding alcohol; in this respect they differ from the pentoses, which are apparently incapable of true alcoholic fermentation, though under certain conditions they appear to be assimilated by the yeast plant and to be destroyed.

It is probable that the pure pentoses and pentosans are not digestible (Ebstein), while these "furfuroid" bodies of the type just described appear to be so. ${ }^{1}$ From these results it seems that the plan generally employed of determining the "total pentoses and pentosans" by distillation with dilute hydrochloric acid and precipitation of the furfuraldehyde as osazone gives numbers which include these furfuroid substances described above and which probably possess greater value as food stuffs than the pentoses and pentosans.

Lignose or Lignone (Cross and Bevan).-Lignification is the conversion of cellulose into woody fibre in the plant, a change which greatly alters the physical properties of the materials. According to Cross and Bevan, this change is accompanied by a chemical change which may be empirically represented as loss of water-

$$
\underset{\text { Cellulose. }}{2 \mathrm{C}_{6} \mathrm{H}_{10} \mathrm{O}_{5}}=\underset{\text { Ligno-cellulose. }}{\mathrm{C}_{12} \mathrm{H}_{18} \mathrm{O}_{9}}+\mathrm{H}_{2} \mathrm{O} \text {. }
$$

The ligno-cellulose, however, is, like cellulose, a highly complex substance, and probably consists of a compound of cellulose proper with lignone, an unsaturated substance containing ketone and aldehyde groups.

Ligno-cellulose therefore gives furfuraldehyde on treatment with boiling hydrochloric acid and consequently probably contains either pentosans or, more likely, furfuroids.

The ligno-celluloses are probably partially digested by the herbivora, and it is probable that the hippuric acid so characteristic of the urine of these animals is derived from the digested ligno-cellulose of their food. According to Cross and Bevan ${ }^{2}$ the process of lignification in a plant is characterised by the formation of groups of the form-

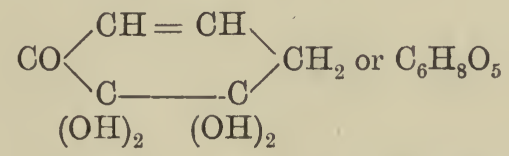

${ }^{1}$ Cross, Bevan and Smith, Jour. Chem. Soc., 1897, Trans., 1003 ; also Cross, Bevan and Remington, Jour. Soc. Chem. Ind., 1900, 307.

${ }^{2}$ Cellulose, 1895, p. 77. 
These groups remain in combination with the original cellulose as ligno-cellulose.

The same authors hold that the cellulose of cereal-straws, esparto grass, etc., is not normal cellulose, but oxy-cellulose. These substances contain more oxygen than cellulose, and probably $\mathrm{CO}$ groups. They yield furfural on treatment with hydrochloric acid and give a characteristic rose-red colour on treatment with solutions of aniline salts. The name hemi-cellulose has been proposed for another class of cellulose, which occurs in many plants and which differs from ordinary cotton cellulose in being much more readily hydrolysed both by acids and by enzymes.

Pectin Substances. - This is the name given to the coagulable substances present in many fruit juices, stems, roots, etc. They are generally said to contain more oxygen in proportion to hydrogen than is present in a true carbohydrate, but according to Tromp de Haas and Tollens, ${ }^{1}$ who analysed specimens of pectin derived from apples, cherries, rhubarb, currants, plums and swedes, the ratio of oxygen to hydrogen does not differ materially from the number $(8: 1)$ observed in true carbohydrates. The percentage of carbon varies from 41 to 45 per cent. Pectins by hydrolysis yield pentoses and hexoses. Tollens regards them as consisting of carbohydrates in union with acids.

Pectose is the parent member of the group; it occurs associated, or perhaps combined, with the cellulose as pecto-cellulose, and is insoluble. It is particularly abundant in unripe fruits.

Pectin, a product of the hydrolysis of pectose, is soluble in water and yields solutions which readily gelatinise. It is produced during the ripening of fruits, etc., hydrolysis being brought about either by the vegetable acids present or by an enzyme known as pectase.

By further hydrolysis, effected by boiling water or alkalies, metapectin, parapectic acid and pectic acid, are produced. The exact composition of these substances has not been determined, as recent work has not corroborated the analyses of the earlier investigators.

The Glucosides are compounds which, on hydrolysis with acids or enzymes, yield glucose and one or more other products. They are glucose ethers of alcohols, phenols, acids, etc., and have the general formula :-

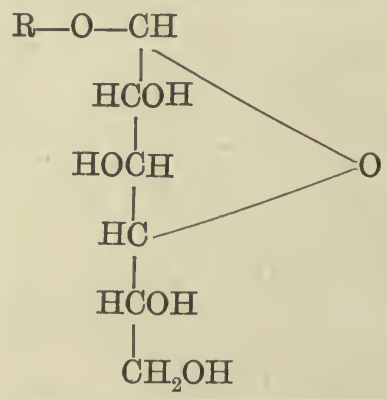

where $R$ is an organic radicle.

${ }^{1}$ Annalen, 1895, 286, 278. 
Glucosides are widely distributed in plants, where they are generally accompanied by the enzymes which are capable of hydrolysing them ; generally, however, the glucoside and the enzyme are contained in different cells and interaction only occurs when the plant tissue is mechanically injured.

A large number of glucosides have been found in various plant tissues, from which water or alcohol will usually extract them.

As examples, the following may be mentioned:-

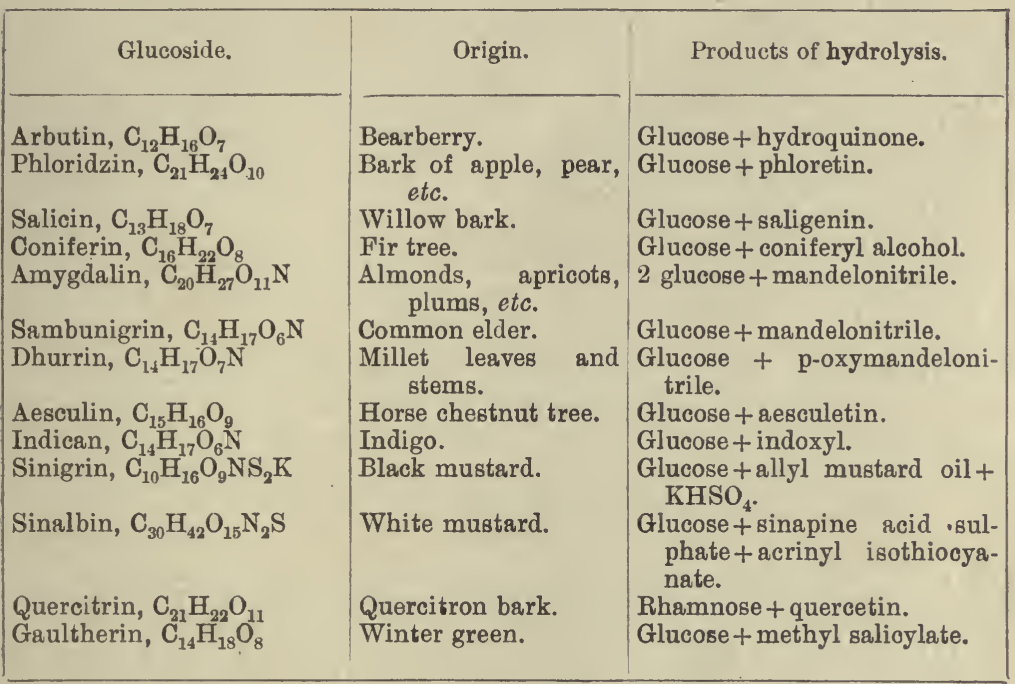

Many of the nitrogen-containing glucosides, e.g., amygdalin and dhurrin, on further hydrolysis, yield their nitrogen as hydrocyanic acid and are thus poisonous (see later in this chapter).

In some cases, the non-sugar constituents of the glucosides are antiseptic in properties and may thus protect the plant against bacterial attack in case of injury to the tissues.

\section{II.-THE FATS AND WAXES.}

- The constitution of the fats has already been briefly described (p. 8). They are glyceryl salts of the fatty acids. The true fatty acids are members of a series of which formic acid, H. $\mathrm{COOH}$, is the first member, acetic acid, $\mathrm{CH}_{3} . \mathrm{COOH}$, the second, propionic acid, $\mathrm{C}_{2} \mathrm{H}_{5} . \mathrm{COOH}$, the third, and so on, each member differing from its predecessor by $\mathrm{CH}_{2}$. The general formula for a fatty acid would therefore be $\mathrm{C}_{\mathrm{n}} \mathrm{H}_{2 \mathrm{n}+1} \cdot \mathrm{COOH}$ and its structure would be represented most simply and generally by $\mathrm{H}-\left(\mathrm{CH}_{2}\right)_{\mathrm{n}}-\mathrm{COOH}$.

Such acids are saturated, i.e., cannot combine with other chemical elements or radicals by addition. Included under the title "fatty acids" and occurring in many vegetable fats are acids of a very different type, e.g., crotonic acid, $\mathrm{C}_{3} \mathrm{H}_{5}$. $\mathrm{COOH}$ or $\mathrm{CH}_{2}: \mathrm{CH} \cdot \mathrm{CH}_{2} \cdot \mathrm{COOH}$, a member of a 
series possessing the general formula $\mathrm{C}_{\mathrm{n}} \mathrm{H}_{2 \mathrm{n}-1} \cdot \mathrm{COOH}$ and characterised by containing some doubly linked carbon atoms. In such cases the acids are said to be unsaturated, because under suitable conditions they can combine with hydrogen or other element, the double linkage between the carbon atoms being replaced by the usual single linkage. The fatty acids can thus be divided into two great divisions - the saturated and the unsaturated acids.

The following are a few of the more important fatty acids :-

\section{Saturated Acids.}

(a) Acetic or stearic acid series. - General formula $=\mathrm{C}_{\mathrm{n}} \mathrm{H}_{2 \mathrm{n}+1}$. $\mathrm{COOH}$ :-

(1) Formic acid, H.COOH,

(2) Acetic acid, $\mathrm{CH}_{3} \cdot \mathrm{COOH}$,

(3) Butyric acid, $\mathrm{C}_{3} \mathrm{H}_{7} . \mathrm{COOH}$,

(4) Capric acid, $\mathrm{C}_{9} \mathrm{H}_{19} \cdot \mathrm{COOH}$,

(5) Myristic acid, $\mathrm{C}_{13} \mathrm{H}_{27} \cdot \mathrm{COOH}$,

(6) Palmitic acid, $\mathrm{C}_{15} \mathrm{H}_{31} \cdot \mathrm{COOH}$,

(7) Stearic acid, $\mathrm{C}_{17} \mathrm{H}_{35}$. $\mathrm{COOH}$, occurs in nettles, ants, etc. vinegar; etc.

" butter.

" butter and in cocoanut oil.

" cocoanut oil and in spermaceti.

" palm oil.

" tallow and many oils.

\section{Unsaturated Acids.}

(ß) Oleic acid series. - General formula $=\mathrm{C}_{\mathrm{n}} \mathrm{H}_{2 \mathrm{n}-1}$. $\mathrm{COOH}$ :-

(1) Crotonic acid, $\mathrm{C}_{3} \mathrm{H}_{5} . \mathrm{COOH}, \quad$ occurs in croton oil.

(2) Oleic acid, $\mathrm{C}_{17} \mathrm{H}_{33} . \mathrm{COOH}$,

" olive and other oils.

(3) Brassic acid, $\mathrm{C}_{21} \mathrm{H}_{41}$. $\mathrm{COOH}$,

(4) Ricinoleic acid, $\mathrm{C}_{17} \mathrm{H}_{32}(\mathrm{OH}) \cdot \mathrm{COOH}, \quad$ ", castor oil.

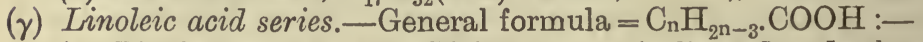

(1) Linoleic acid, $\mathrm{C}_{17} \mathrm{H}_{31}$. $\mathrm{COOH}$, occurs in linseed and other "drying " oils.

(ס) Propiolic acid series. - General formula $=\mathrm{C}_{\mathrm{n}} \mathrm{H}_{2 \mathrm{n}-5} \cdot \mathrm{COOH}:-$

(1) Linolenic acid, $\mathrm{C}_{17} \mathrm{H}_{29} \cdot \mathrm{COOH}$, occurs in linseed and other drying oils.

The essential difference between the saturated and unsaturated fatty acids lies in their susceptibility to the action of external agencies. The saturated compounds have no power to combine additively with oxygen, chlorine, etc., while the unsaturated compounds, in many instances, easily unite with these elements. The readiness with which the unsaturated fatty acids absorb oxygen and the amount which they can absorb, both increase with the number of doubly linked carbon atoms contained in a molecule. Thus linolenic acid, $\mathrm{C}_{17} \mathrm{H}_{29} . \mathrm{COOH}$, oxidises more readily and to a greater extent than oleic acid, $\mathrm{C}_{17} \mathrm{H}_{33}$. $\mathrm{COOH}$. As the oxidation products are solid or stiff, viscid substances, oils containing much of these unsaturated acids are known as drying oils, whilst oils containing chiefly saturated fatty acids or acids containing only one pair of doubly linked carbon atoms, e.g., oleic acid, are known as non-drying 
oils. The former are used in the arts in the manufacture of oil-cloth, linoleum and paints, the latter for lubrication.

Glyceryl, $\mathrm{C}_{3} \mathrm{H}_{5}^{\prime \prime \prime}=-\mathrm{CH}_{2} \cdot \stackrel{\mathrm{CH}}{\mathrm{C}} \cdot \mathrm{CH}_{2}$-is not known in the free state, but its hydroxide, $\mathrm{C}_{3} \mathrm{H}_{5}(\mathrm{OH})_{3}$, is the well-known substance glycerine, or, as it is systematically called, glycerol.

Glycerol, $\mathrm{C}_{3} \mathrm{H}_{5}(\mathrm{OH})_{3}$, is a colourless, viscid liquid of sweetish taste. It has a specific gravity of 1.27 and mixes with water in all proportions. It is hygroscopic, and articles smeared with glycerine are kept moist, both because of its non-volatility and also because it absorbs water from the air.

Glycerol is made from oils or fats by a process which shows clearly the constitution of these substances.

The oil or fat is boiled with caustic soda solution, when decomposition occurs, the sodium of the alkali taking the place of the glyceryl group, the latter uniting with the- $\mathrm{OH}$ of the sodium hydrate. A sodium salt of the fatty acid and glycerol are thus produced, and being soluble, remain mixed in solution. In order to separate them the sodium salts are precipitated by the addition of common salt, in a solution of which they are insoluble. The sodium salts rise to the surface and, on cooling, form a solid cake, constituting soap.

From the solution below, the glycerine can be recovered by evaporation and distillation in vacun. Taking olive oil, which consists mainly of glyceryl oleate, $\mathrm{C}_{3} \mathrm{H}_{5}\left(\mathrm{C}_{18} \mathrm{H}_{33} \mathrm{O}_{2}\right)_{3}$, as example, the reaction may be thus expressed :-

$$
\underset{\text { Glyceryl oleate. Sodium hydrate. }}{\mathrm{C}_{3} \mathrm{H}_{5}\left(\mathrm{C}_{18} \mathrm{H}_{33} \mathrm{O}_{2}\right)_{3}+3 \mathrm{Nadium} \text { oleate. }}+\underset{\text { Glycerol. }}{3 \mathrm{NaC}_{18} \mathrm{H}_{33} \mathrm{O}_{2}}+\mathrm{C}_{3} \mathrm{H}_{5}(\mathrm{OH})_{3}
$$

Glycerine is also prepared by the hydrolysis of fats by means of superheated steam. Again taking olive oil as example, the reaction would be-

$$
\underset{\text { Glyceryl oleate. }}{\mathrm{C}_{3} \mathrm{H}_{5}\left(\mathrm{C}_{18} \mathrm{H}_{33} \mathrm{O}_{2}\right)_{3}}+\underset{\text { Water. }}{3 \mathrm{H}_{2} \mathrm{O}}=\underset{\text { Oleic acid. }}{3 \mathrm{HC}_{18} \mathrm{H}_{33} \mathrm{O}_{2}}+\underset{\text { Glycerol. }}{\mathrm{C}_{3} \mathrm{H}_{5}(\mathrm{OH})_{3}}
$$

Although in the above example olive oil has been assumed to be glyceryl oleate, it must be clearly understood that this is not true and that all the oils are mixtures of the glyceryl salts of several fatty acids. Thus in linseed oil, glyceryl compounds of linolenic and isolinolenic, linoleic, oleic, stearic and palmitic acids have been found. It is not definitely known whether, in the oils, these substances are mixed or whether they are chemically combined, e.g., whether, say, the first three compounds are present as such, i.e., as-

$$
\mathrm{C}_{3} \mathrm{H}_{5}\left(\mathrm{C}_{18} \mathrm{H}_{29} \mathrm{O}_{2}\right)_{3}, \mathrm{C}_{3} \mathrm{H}_{5}\left(\mathrm{C}_{18} \mathrm{H}_{31} \mathrm{O}_{2}\right)_{3} \text {, and } \mathrm{C}_{3} \mathrm{H}_{5}\left(\mathrm{C}_{18} \mathrm{H}_{33} \mathrm{O}_{2}\right)_{3} \text {, }
$$

or whether they may be present as $\mathrm{C}_{3} \mathrm{H}_{5}\left\{\begin{array}{l}\mathrm{C}_{18} \mathrm{H}_{29} \mathrm{O}_{2} \\ \mathrm{C}_{18} \mathrm{H}_{31} \mathrm{O}_{2} \\ \mathrm{C}_{18} \mathrm{H}_{33} \mathrm{O}_{2}\end{array}\right.$

In plants, the oils are chiefly found in the seed or fruit, though small quantities are contained in the straw and roots. Some seeds are valued chiefly for the oil which they yield, e.g., rape, cotton-seed 
linseed, castor. There are three chief methods employed in the extraction of oil :-

(1) Pressure ; the most generally employed.

(2) Extraction by volatile solvents.

(3) Boiling the bruised seed or fruit with water.

(1) By pressure.-By this method the seeds are cleaned, often deprived of their husks or shells ("decorticated "), crushed and ground, often heated and moistened, and then subjected to intense pressure in hydraulic presses. The crushed seeds are placed either in horsehair bags or in moulds and are pressed, first at the ordinary temperature, whereby "cold drawn oil " is obtained, and then after heating, "hot drawn oil " is extracted. The oil obtained is refined by heating it to a temperature of about $160^{\circ} \mathrm{C}$, in order to coagulate albuminoid matter, and sometimes by treatment with a little sulphuric acid. The residue left in the press constitutes "oil-cake" and usually contains from 6 to 15 per cent of oil.

It is used for feeding or manurial purposes, since, in addition to the oil, it contains the albuminoid and mineral matter present in the seed.

(2) In extraction by solvents the crushed seeds (in bags or cages) are treated with solvents, such as petroleum naphtha or carbon disulphide; in such a way that the fresh seeds are treated first with the solvent already highly charged with oil, while the fresh solvent comes first into contact with the seeds, which are almost deprived of oil. In this way, a much more complete exhaustion of the seed is obtained, leaving a residue almost devoid of oil, and therefore of much less value as a feeding stuff than the usual oil-cake.

(3) Extraction by boiling with water is sometimes used in the extraction of castor oil (mainly by the natives of the countries where the seed is grown) and of olive oil. The oil in such cases is merely skimmed off the top of the water.

The Waxes are substances probably occurring in small quantities in many plants. They are generally analogous to the fats in composition, except that instead of the trivalent glyceryl group they contain monovalent groups; they therefore yield monovalent alcohols on treatment with alkalies. The alcohols obtained in this way are usually complex bodies containing a large number of carbon atoms, e.g., ceryl alcohol, $\mathrm{C}_{27} \mathrm{H}_{56} \mathrm{O}$. (?). The waxes are solids melting below $100^{\circ}$, non-volatile, and insoluble in water, but soluble in ether.

Possessing a structure in some respects similar to the fats is a substance, Lecithin, found in many seeds, e.g., beans and peas, and in fungi. This substance, of which probably several varieties occur, has a constitution which may be typified by the following formula:-

$$
\mathrm{C}_{3} \mathrm{H}_{5}\left\{\begin{array}{l}
\mathrm{C}_{18} \mathrm{H}_{35} \mathrm{O}_{2} \\
\mathrm{C}_{18} \mathrm{H}_{35} \mathrm{O}_{2} \\
\mathrm{HPO}_{4} \cdot \mathrm{C}_{2} \mathrm{H}_{4}(\mathrm{OH}) \cdot \mathrm{N}\left(\mathrm{CH}_{3}\right)_{3}
\end{array}\right.
$$

-which may be regarded as the distearyl glycerophosphate of the base, choline, $\mathrm{C}_{2} \mathrm{H}_{4}(\mathrm{OH}) \cdot \mathrm{N}\left(\mathrm{CH}_{3}\right)_{3} \cdot \mathrm{OH}$. 
Phytosterol, $\mathrm{C}_{26} \mathrm{H}_{43} \mathrm{OH}$, which closely resembles cholesterol found in animals, occurs in the seeds of peas, beans and almonds, in wheat and maize, and in many vegetable oils. It is a solid crystalline substance, melting at $133^{\circ}$ and soluble in hot alcohol, in ether, carbon disulphide, or chloroform. It is volatile. Its constitution is not understood, but it probably is a monacid alcohol.

\section{III.-THE ORGANIC ACIDS AND THEIR SALTS.}

A large number of organic acids have been detected in various vegetable products, occurring generally as potassium, sodium, or calcium salts, though sometimes in the free state or in combination with organic bases. Numerous acids have been detected in various vegetables; only a few typical ones can be considered here. The organic acids are characterised by containing one or more "carboxyl" groups, . $\mathrm{COOH}$.

The following may be taken as examples:-

Formic acid, H.COOH.

Oxalic acid, $\mathrm{COOH} . \mathrm{COOH}$.

Tartaric acid, $\mathrm{COOH} \cdot \mathrm{CH}(\mathrm{OH}) \cdot \mathrm{CH}(\mathrm{OH}) \cdot \mathrm{COOH}$.

Malic acid, $\mathrm{COOH} \cdot \mathrm{CH}(\mathrm{OH}) \cdot \mathrm{CH}_{2} \cdot \mathrm{COOH}$.

Citric acid, $\mathrm{CH}_{2}(\mathrm{COOH}) \cdot \mathrm{C}(\mathrm{OH})(\mathrm{COOH}) \cdot \mathrm{CH}_{2}(\mathrm{COOH})$.

Succinic acid, $\mathrm{CH}_{2}(\mathrm{COOH}) \cdot \mathrm{CH}_{2}(\mathrm{COOH})$.

Fumaric acid, $\mathrm{CH}(\mathrm{COOH}): \mathrm{CH}(\mathrm{COOH})$.

For the properties, methods of preparation, and constitution of these acids the reader is referred to any modern textbook on organic chemistry. The free acids themselves often occur in plants, particularly in fruits, e.g., malic acid, occurring in apples, mountain-ash berries, gooseberries, red currants, blackberries and sour or morella cherries.

In other cases, acid potassium or calcium salts are the cause of the acidity, e.g., potassium hydrogen tartrate in grapes, acid potassium malate in sweet cherries. In many fruits several organic acids or their salts occur in association, e.g., gooseberries, currants and cherries contain both malic and citric acids, while mountain-ash berries and tamarinds contain malic, citric and tartaric acids.

Oxalates of potassium and, particularly, of calcium are extremely widely distributed in the vegetable kingdom, the latter occurring often in the solid, crystalline state in the cells of plants. The crystals of the calcium salt have the composition $\mathrm{CaC}_{2} \mathrm{O}_{4} \cdot 3 \mathrm{H}_{2} \mathrm{O}$ and are soluble in saccharine solutions. Acid potassium oxalates, $\mathrm{KHC}_{2} \mathrm{O}_{4}$ and $\mathrm{KHC}_{2} \mathrm{O}_{4}$ $+\mathrm{H}_{2} \mathrm{C}_{2} \mathrm{O}_{4}$, occur in solution in the sap of certain plants, e.g., sorrel, rhubarb.

Tannic acid or tannin is very abundantly distributed in the vegetable .kingdom. It varies in composition and properties according to its origin.

Tannin was formerly looked upon as a glucoside, but the tannic acid, its chief constituent, was looked upon as an anhydro-acid. ${ }^{1}$

${ }^{1}$ Schiff, Ann., 170, 43. 
Gallo-tannic acid, for example, is said to have the constitution $\mathrm{C}_{6} \mathrm{H}_{2}(\mathrm{OH})_{3}$. CO.O. $\mathrm{C}_{6} \mathrm{H}_{2}(\mathrm{OH})_{2}$. $\mathrm{COOH}$.

It is hydrolysed by dilute acids or by ferments, with the production of gallic acid, $\mathrm{C}_{6} \mathrm{H}_{2}(\mathrm{OH})_{3} . \mathrm{COOH}$.

The natural tannins, however, are usually associated or combined with glucose, and, on hydrolysis, yield glucose in addition to gallic acid. Fischer and Freudenberg ${ }^{1}$ now regard tannin, not as a glucoside, but as a pentacid derivative of glucose, resulting from the combination of 1 molecule of glucose with 5 molecules of digallic acid $\left(\mathrm{C}_{76} \mathrm{H}_{52} \mathrm{O}_{46}\right)$.

Tannin is present in almost all plants, occurring in the bark, leaves, root, or fruit. Its origin and function in the plant are muchdebated questions. By some investigators it is thought to be formed by chlorophyll from carbon dioxide and water, and, in many ways, to resemble starch in its relationship to the plant. The tannins possess a strongly astringent taste, give intense blue- or green-black colours with ferric chloride solution, and possess the power of converting gelatin into an insoluble substance (leather). They tend to absorb oxygen, especially in presence of alkalies, giving a dark-brown colouration.

The nature of the acids present in the root hairs of plants does not appear to have been much investigated. Probably a number of acids are present in most cases, the predominating one varying with the species of plant. Dyer ${ }^{2}$ has investigated the amount of acidity of the liquid contained in the root hairs of a large number of plants. He expresses his results in terms of hydrogen and in the equivalent of citric acid. He found, as is to be expected, considerable variations, but the average of about 100 different plants gave-

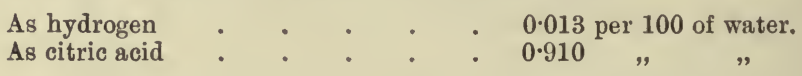

\section{IV.-ESSENTIAL OILS AND RESINS.}

These are excretions or secretions of plants, sometimes normal, sometimes as the result of injury or disease. To them the characteristic odours of certain plants are due.

The essential oils and resins often occur associated in the plant, and the latter may be regarded as products of oxidation of the former.

They are present in various parts of the plant, sometimes being distributed over all portions, as in many coniferous trees, while in many cases they are confined to particular organs, e.g., the petals of the flowers, the rind of the fruit, the bark, or the roots. Their function is difficult to understand. When present in the flower, they may serve as an attraction to insects and thus favour cross fertilisation. When present in the leaves or twigs they may serve to render the tissues unpalatable to animals and thus protect the plant from injuries by grazing animals or parasitic insects.

The oils can be extracted from the vegetable tissues in several ways, all of which may be classed as belonging to three principal types: 1. Expression. 2. Distillation. 3. Extraction with a solvent.

${ }^{1}$ Ber. 1912, 45, 915 ; Jour. Chem. Soc., 1912, Abstracts, i. 471.

2 Jour. Chem. Soc., 1894, Trans., 115. 
The essential oils are, as a rule, very slightly soluble in water, but sufficiently so to impart to the water a strong odour. They are generally readily soluble in or miscible with ether, chloroform and most organic solvents.

The density is usually less than that of water though some are heavier than that liquid. Most of them are optically active, and have a high refractive power. Chemically they show great variation. As a rule, the essential oil derived from any one source is a mixture of several compounds and the relative proportions of the constituents are liable to considerable variation.

In the essential oils, many chemical compounds of very different constitution have been detected.

They may be divided into the following groups:-

1. Terpenes.

2. Camphors.

3. Benzene derivatives.

4. Aliphatic or open chain compounds.

The chemistry of the essential oils is, however, too complicated to allow of anything but the merest sketch being given here.

1. Terpenes.-These are the most abundant constituents in many essential oils. They are, with the exception of camphene, volatile liquids of the empiric formula $\mathrm{C}_{10} \mathrm{H}_{16}$. Many isomeric bodies of this composition exist, differing greatly in odour, density, optical activity and other properties. Some of the best known are-

Pinene, which occurs as a dextro-rotatory form in American turpentine and as a lævo-rotatory body in French turpentine. Its specific gravity is about 0.85 and it boils about $155^{\circ}$. Its probable constitution is thought to be-

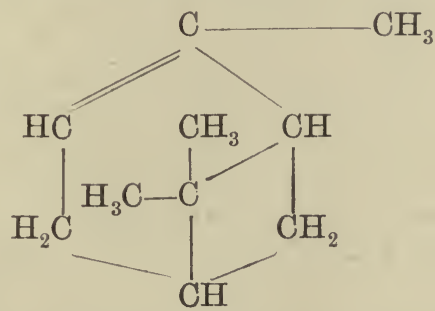

Limonene is a large constituent of many essential oils. It occurs as dextro-limonene in oils of orange, lemon, bergamot, dill, etc., and as lævo-limonene in Russian peppermint oil and oils of certain pines. Its specific gravity is about 0.844 , it boils at $177^{\circ}$ to $188^{\circ}$ and has a rotation of about $\pm 105^{\circ}$. An inactive form is known as dipentene. Its probable constitution is-<smiles>C=C(C)C(/C=C\C)CC</smiles> 
Sylvestrene occurs in Swedish and Russian turpentines and in other pine oils. It boils at $176^{\circ}$ to $177^{\circ}$, has a specific gravity of 0.85 , and is dextro-rotatory. It is probably-

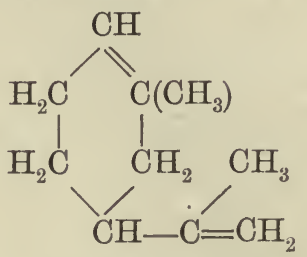

Phellandrene occurs in many eucalyptus oils, oil of elemi, and of fennel. Two isomers are said to exist, which have been named $\alpha$ and $\beta$, and two optical isomers of $a$-phellandrene are known. They all boil at $170^{\circ}$ and have a specific gravity of about 0.848 . Their constitution is probably-<smiles>CC1=CCC(C(C)C)C=C1</smiles>

$\alpha$-phellandrene.

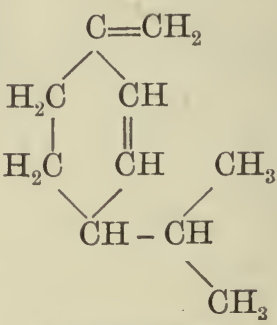

$\boldsymbol{\beta}$-phellandrene.

Sesquiterpenes. - These are bodies of the empiric composition $\mathrm{C}_{15} \mathrm{H}_{24}$; many are known but their constitutions have not been thoroughly made out. They are liquids boiling about $250^{\circ}$ to $269^{\circ}$, and of specific gravity about 0.90 to 0.936 . Cadinene, found in oils of cade, patchouli, etc. ; Caryophyllene, from oil of cloves; Cedrene, from oil of cedar wood; Humulene, in oil of hops ; Santalene in oil of santal wood, and Zingiberene in oil of ginger are examples of sesquiterpenes.

Olefinic Terpenes and Sesquiterpenes.-A few compounds, resembling the terpenes and sesquiterpenes, have been isolated from essential oils, but differ essentially in having an open chain structure. As an example myrcene, found in oils of bay and sassafras, may be cited. This has a specific gravity of 0.81 and rapidly oxidises by exposure to air.

It probably has the constitution-<smiles>C=CC(=C)CCC=C(C)C</smiles>

2. The Camphors.-These may be regarded as the oxidation products of the terpenes. They may be divided into alcohols and ketones. As types of the former, borneol and terpineol, both of which have the composition $\mathrm{C}_{10} \mathrm{H}_{17} \mathrm{OH}$ and menthol, $\mathrm{C}_{10} \mathrm{H}_{19} \mathrm{OH}$, may be cited, while. 
camphor, $\mathrm{C}_{10} \mathrm{H}_{16} \mathrm{O}$ and menthone, $\mathrm{C}_{10} \mathrm{H}_{18} \mathrm{O}$, may serve as examples of the ketones.

Borneol occurs in Borneo camphor and can be obtained as crystals which melt at $203^{\circ}$ and boil at $212^{\circ}$. It can be obtained from camphor by reduction with sodium and, conversely, by oxidation yields camphor.

Terpineol occurs in several isomeric forms and has been found in oil of cardamons, etc.

Menthol occurs in oil of peppermint. It melts at $43^{\circ}$, boils at $212^{\circ}$ and has a specific gravity of $0 \cdot 89$.

These alcohols form esters with organic acids, and their acetates, in particular, often occur in nature.

Camphor occurs in the wood of Laurus camphora. It is a colourless crystalline substance, soluble in alcohol, melting at $175^{\circ}$ and boiling at $204^{\circ}$. It has a rotation of $\pm 44^{\circ}$. Its constitution has been the subject of much investigation an $\bar{d}$ has been proved by Bredt ${ }^{1}$ and Aschan ${ }^{2}$ to be as follows :-

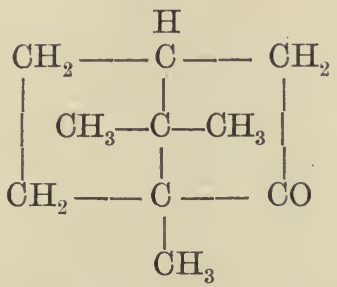

showing it to be a ketone. Borneol is the corresponding alcohol.

3. Benzene Derivatives.-A hydrocarbon, para-methyl isopropyl benzene, known as cymene, $\mathrm{C}_{6} \mathrm{H}_{4}\left(\mathrm{CH}_{3}\right)\left(\mathrm{C}_{3} \mathrm{H}_{7}\right)$, occurs in Roman caraway oil.

- Many phenols and phenolic ethers occur in essential oils, among which the most important are-

Eugenol, allyl oxymethyl hydroxybenzene, $\mathrm{C}_{6} \mathrm{H}_{3}\left(\mathrm{C}_{3} \mathrm{H}_{5}\right)\left(\mathrm{OCH}_{3}\right) \mathrm{OH}$, found in oils of cloves, allspice, bay and cinnamon, a liquid of specific gravity $1 \cdot 07$, boiling at $247^{\circ}$;

Safrol, allyl dioxymethylene benzene, $\mathrm{C}_{6} \mathrm{H}_{3}\left(\mathrm{C}_{3} \mathrm{H}_{5}\right)$ : $\left(\mathrm{O}^{-\mathrm{CH}_{2}} \mathrm{O}\right)$, occurring in oils of camphor and sassafras ;

Apiol, dimethoxydioxymethylene allyl benzene, $\mathrm{C}_{6} \mathrm{H}\left(\mathrm{OCH}_{3}\right)_{2}$ : $\left(\mathrm{O} . \mathrm{CH}_{2} \mathrm{O}\right) \cdot\left(\mathrm{C}_{3} \mathrm{H}_{5}\right)$, found in parsley and dill oils;

Thymol and carvacrol, methyl isopropyl hydroxybenzene, $\mathrm{C}_{6} \mathrm{H}_{3}\left(\mathrm{CH}_{3}\right)\left(\mathrm{C}_{3} \mathrm{H}_{7}\right) \mathrm{OH}$, occurring in thyme oil. The former is a solid, melting at $44^{\circ}$ and boiling at $230^{\circ}$, the latter a thick oil boiling at $236^{\circ}$.

Of aldehydes of benzene derivatives the following occur naturally :-

Benzaldehyde, $\mathrm{C}_{6} \mathrm{H}_{5} \mathrm{COH}$, is the chief constituent of the oils of bitter almonds, peach and plum kernels, and of other members of the prunus family. Its specific gravity is 1.05 and it boils at $179^{\circ}$.

\footnotetext{
${ }^{1}$ Ann., 289, 15 ; Jour. Chem. Soc., 1894, Abstracts, i. 141.

${ }^{2}$ Ann., 316, 196 ; Jour. Chem. Soc., 1901, Abstracts, i. 477.
} 
Salicyl aldehyde, $\mathrm{C}_{6} \mathrm{H}_{4}(\mathrm{OH})(\mathrm{COH})$, an oily liquid of specific gravity $1 \cdot 172$, boiling at $196^{\circ}$, occurs in oil of spiraa and in other oils.

Anisic aldehyde, $\mathrm{C}_{6} \mathrm{H}_{4}\left(\mathrm{OCH}_{3}\right)(\mathrm{COH})$, occurs in oils of anise and fennel. It boils at $248^{\circ}$.

Cinnamic aldehyde, $\mathrm{C}_{6} \mathrm{H}_{5}(\mathrm{CH}: \mathrm{CH} \cdot \mathrm{COH})$, is the chief constituent of oils of cassia and cinnamon. It boils at $247^{\circ}$.

A ketone, carvone (or carvol), $\mathrm{C}_{10} \mathrm{H}_{14} \mathrm{O}$, occurs in oils of caraway and dill. It is isomeric with carvacrol. It boils at $225^{\circ}$ and has a specific gravity of 0.962 . Its constitution is probably-

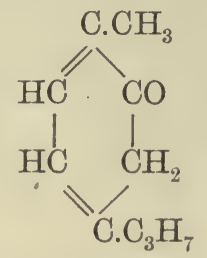

Acids derived from benzene occurring in essential oils, chiefly in the form of esters, are benzoic acid, $\mathrm{C}_{6} \mathrm{H}_{5} \mathrm{COOH}$; salicylic acid, $\mathrm{C}_{6} \mathrm{H}_{4}$ $(\mathrm{OH})(\mathrm{COOH})$; and cinnamic acid, $\mathrm{C}_{6} \mathrm{H}_{5} \cdot \mathrm{CH}: \mathrm{CH} . \mathrm{COOH}$. Methyl salicylate, $\mathrm{C}_{6} \mathrm{H}_{4}(\mathrm{OH}) \mathrm{COOCH}_{3}$, boiling at $226^{\circ}$ and of specific gravity $1 \cdot 20$, is the main constituent of the oils of winter-green and birch.

4. Aliphatic or Open Chain Compounds.-A large number of compounds falling under this heading have been found in various essential oils. Foremost among these may be placed geraniol, $\mathrm{C}_{10} \mathrm{H}_{18} \mathrm{O}$, which is probably- $\left(\mathrm{CH}_{3}\right)_{2} \mathrm{C}: \mathrm{CH} . \mathrm{CH}_{2} \cdot \mathrm{CH}_{2} \mathrm{C} \cdot\left(\mathrm{CH}_{3}\right): \mathrm{CH} . \mathrm{CH}_{2} \mathrm{OH}$, linalol an isomeric body, probably-

$$
\mathrm{CH}_{3} \cdot \mathrm{C}\left(\mathrm{CH}_{8}\right) \text { :CH.CH} \cdot \mathrm{CH}_{2} \cdot \mathrm{C}\left(\mathrm{CH}_{3}\right)(\mathrm{OH}) \cdot \mathrm{CH}: \mathrm{CH}_{2}
$$

and Nerol, another isomer, probably-

$$
\begin{gathered}
\mathrm{CH}_{3} \cdot \mathrm{C} \cdot \mathrm{CH}_{2} \cdot \mathrm{CH}_{2} \cdot \mathrm{CH}: \mathrm{C}\left(\mathrm{CH}_{3}\right)_{2} \\
\text { HC. } \mathrm{CH}_{2} \mathrm{OH}
\end{gathered}
$$

the stereo-isomer of geraniol.

These three bodies are alcohols; derived from them are the aldehydes-a-citral (geranial or geranaldehyde)-

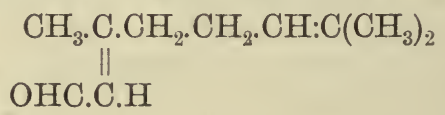

and $\beta$-citral (neral)-

$$
\begin{aligned}
& \mathrm{CH}_{3} \cdot \text { C. } \mathrm{CH}_{2} \cdot \mathrm{CH}_{2} \cdot \mathrm{CH}: \mathrm{C}\left(\mathrm{CH}_{3}\right)_{2} \\
& \text { H.C.CHO }
\end{aligned}
$$

Another alcohol, citroneilol, $\mathrm{C}_{10} \mathrm{H}_{20} \mathrm{O}$, and its aldehyde, citronellal, $\mathrm{C}_{10} \mathrm{H}_{18} \mathrm{O}$, are also important constituents of many sweet-scented essential oils. 
Many aliphatic alcohols, in some cases free, but more commonly as esters, occur in essential oils.

Many fatty acids also are found, chiefly as esters of organic radicles, e.g., the acetates of linalol, geraniol, borneol, menthol are of common occurrence. Hydrocyanic acid, $\mathrm{HCN}$, occurs in bitter almond oil. Sulphur compounds are characteristic of several essential oils derived from cruciferous plants, e.g., vinyl sulphide, $\left(\mathrm{C}_{2} \mathrm{H}_{3}\right)_{2} \mathrm{~S}$, boiling-point $101^{\circ}$, occurs in oil of Allium ursinum; allyl sulphide, $\left(\mathrm{C}_{3} \mathrm{H}_{5}\right)_{2} \mathrm{~S}$, boiling-point $140^{\circ}$, occurs in oil of garlic; allyl isothiocyanate, $\mathrm{C}_{3} \mathrm{H}_{5} \mathrm{NCS}$, boilingpoint $201^{\circ}$, is the chief constituent c $f$ oil of mustard. They all possess a most disagreeable odour.

Many of these substances are not present as such in the plant, but in union with glucose and other substances as the compounds known as glucosides; e.g., almonds do not contain any benzaldehyde, but amygdalin, $\mathrm{C}_{20} \mathrm{H}_{27} \mathrm{NO}_{11}$, which in presence of water and under the action of an enzyme, emulsin, splits up into benzaldehyde, hydrocyanic acid and glucose-

$$
\mathrm{C}_{20} \mathrm{H}_{27} \mathrm{NO}_{11}+2 \mathrm{H}_{2} \mathrm{O}=\mathrm{C}_{6} \mathrm{H}_{5} \mathrm{CHO}+\mathrm{HCN}+2 \mathrm{C}_{6} \mathrm{H}_{12} \mathrm{O}_{6} \text {. }
$$

Similarly, allyl-isothiocyanate is not present as such in mustard seeds, but as a compound, potassium myronate, $\mathrm{KC}_{10} \mathrm{H}_{18} \mathrm{NS}_{2} \mathrm{O}_{10}$. This, under the action of an enzyme, myrosin, is split up as follows :-

$$
\mathrm{KC}_{10} \mathrm{H}_{18} \mathrm{NS}_{2} \mathrm{O}_{10}=\mathrm{C}_{3} \mathrm{H}_{5} \mathrm{NCS}+\mathrm{KHSO}_{4}+\mathrm{C}_{6} \mathrm{H}_{12} \mathrm{O}_{6} \text {. }
$$

The Resins are now regarded as the products of the oxidation of terpenes rather than the mother substances from which terpenes are derived. They have no uniformity of constitution, as is the case with the fats, but present wide differences in chemical character. They may be divided into-

1. The balsams, which consist of resinous substances associated with terpenes. Canada balsam, obtained from Pinus balsama of South America, and crude turpentine or Venice turpentine, from many pines, are good examples.

Crude turpentine consists of ordinary rosin or colophony dissolved in turpentine oil. Rosin consists mainly of sylvinic acid, $\mathrm{C}_{20} \mathrm{H}_{30} \mathrm{O}_{2},{ }^{1}$ a monobasic acid, whose sodium salt is used in the manufacture of cheap soaps.

2. The solid or hard resins.-These are amorphous substances of vitreous character, which contain very little terpene. They consist chiefly of esters, alcohols, anhydrides and acids of the aromatic series, generally of very complex character. In addition there are present certain substances which are neither hydrocarbons, esters, alcohols, anhydrides, nor acids, and which are called resenes. Many different bodies of this class have been isolated and analysed, but their constitution is not known, e.g., from copal a substance, $\mathrm{C}_{25} \mathrm{H}_{38} \mathrm{O}_{4}$, from dragon's blood, $\mathrm{C}_{20} \mathrm{H}_{40} \mathrm{O}_{4}$. Many other substances of complicated character have been obtained from the hard resins.

To the class of hard resins belong many substances of great im-

${ }^{1}$ Fahrion, Zeit. für angew. Chemie,' 1901, 3 Dec. 
portance in varnish making, etc., e.g., copal, dammar, elemi, sandarach, amber.

3. The gum resins.-These are mixtures of gums and resins, and some are of value in the arts, e.g., ammoniacum, asafœida, gamboge, myrrh, scammonium.

\section{V.-THE INORGANIC SALTS.}

In the introductory chapter a list of the elements essential to plant life was given. It now remains to discuss what is known of the functions of the inorganic elements in the nutrition of plants.

Sulphur is a constituent of proteids and therefore may be said, in a measure, to be present in the organic portions of a plant. It is left in the ash chiefly as sulphate, though, as the author has observed, sometimes as sulphide. The presence of sulphates in solution can generally be detected in the sap.

ii : Phosphorus occurs in plant ashes as phosphates, and in that form it is absorbed from the soil. In the living plant, however, it undoubtedly exists partially as organic compounds, e.g., as lecithin (vide p. 198), and it seems to move in the plants in company with the proteids. It is always most abundant in the seeds. Liberal supplies of phosphates favour root development and tend to early maturity.

Silicon is probably taken into the plant as alkaline silicates. It is always found in the ash, sometimes in large quantities, as silica, $\mathrm{SiO}_{2}$, or silicates. Indeed in many plants, e.g., the cereals and grasses, large deposits of silica occur in the outer walls of the stems and leaves; but it appears that the plant derives little benefit by this and can thrive vigorously without. siliceous food.

Chlorine occurs in all plants, but it cannot be proved to be essential, except perhaps in buckwheat and mangolds. Its presence seems to aid in the hydrolysis of starch.

Potassium is absorbed as various soluble salts and apparently exists in the plant in combination with organic acids, though some saps contain the nitrate, chloride and sulphate. It is always most abundant in the parts of the plant where assimilation is most active, i.e., leaves and twigs. It seems to be absolutely indispensable for the production of starch, sugar, etc., but what part it plays in their production is not known.

Calcium seems to aid in the conversion of starch into sugar. It probably exists in combination with organic acids; indeed crystals of calcium oxalate or carbonate are often found in the cells. One of its functions may be to combine with, and render harmless, the vegetable acids formed in the plant. It is found chiefly in the leaves.

Magnesium is fairly uniformly distributed; little was known of its functions ; but the recent discovery by Willstätter ${ }^{1}$ and his collaborators that it is an essential constituent of chlorophyll, shows how important it is to the vegetable organism.

Iron is usually present only in small proportion, but it is quite

Vide Chlorophyll, p. 216. 
indispensable. Plants deprived of iron are unable to produce chlorophyll.

Sodium, though always present in the ash, does not appear to be essential to the vital processes. It cannot fulfil the functions of potassium.

The metals mentioned above, in addition to the special functions in connection with assimilation and other processes, act also an important part as carriers of nitric acid; when the nitrogen is elaborated into proteids, the metals unite with organic acids, which yield carbonates on ignition. ${ }^{1}$ It has been found that the richer a plant is in nitrogen, the larger is the amount of bases left as carbonate in the ash.

\section{VI.-NITROGENOUS SUBSTANCES.}

(i) Albuminoids.-This word is used in different senses by different writers; by some it is employed as synonymous with proteid, by others as the name of a small class of nitrogenous substances, differing from the true albumins (e.g., gelatin and mucin). Using the term proteid as the generic name for the large group which may be called "Albuminous substances," it becomes difficult to define the exact meaning of the word. They are of highly complex constitution, generally non-crystallisable, and contain carbon, hydrogen, oxygen, nitrogen and sulphur. They occur in all living matter, being essential constituents of protoplasm.

The ultimate composition of proteids varies between the following limits (Hoppe-Seyler):-

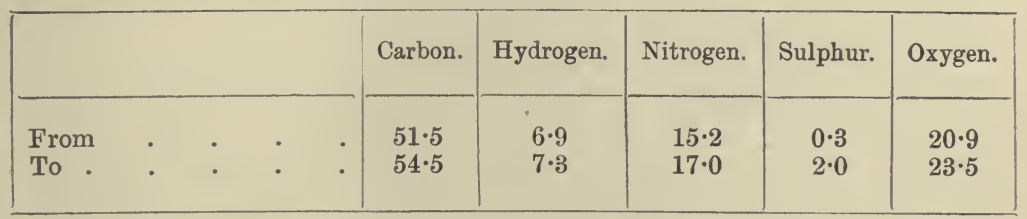

In vegetable tissues, certain crystallisable proteids have been detected, ${ }^{2}$ especially in the aleurone grains (e.g., of castor-oil seeds).

Many schemes for their classification have been drawn up. The following is one often adopted and includes both animal and vegetable proteids $^{3}$ :-

I. Protamines, e.g., salmine, sturine, clupeine, cyprinine.

II. Histones, e.g., those of the thymus and of blood corpuscles.

III. Albumins, e.g., egg albumin, serum albumin, plant albumins.

IV. Globulins, e.g., serum globulin, fibrinogen, fibrin, edestin, crystalline vegetable globulins.

V. Glutelins, e.g., legumin, conglutin, amandin; soluble in dilute alkali.

${ }^{1}$ Lawes and Gilbert, Phil. Trans., 192 (1900), 207.

${ }^{2}$ Hartig, 1885 ; Vines.

${ }^{3}$ Vide Plimmer, Chemical Constitution of the Proteins, 1908. 
VI. Gliadins, e.g., wheat gliadin, hordein, zein; soluble in 70 to 80 per cent alcohol.

VII. Phosphoproteins, e.g., caseinogen, vitellin.

VIII. Scleroproteins, e.g., keratin, gelatin, elastin, fibroin.

IX. Conjugated proteins, e.g.,-

(i) Nucleoproteins, nucleic acid with protein.

(ii) Chromoproteins, colouring substance with protein, e.g., hæmoglobin.

(iii) Glucoproteins, carbohydrate with protein, e.g., mucin.

$\mathrm{X}$. Protein derivatives -

(i) Metaproteins, e.g., acid albumin, alkali albumin.

(ii) Proteoses, e.g., caseose, albumose, globulose.

(iii) Peptones, e.g., fibropeptone.

(iv) Polypeptides, e.g., glycyl-alanine, leucyl-glutamic acid.

Chiefly by the labours of Fischer and his pupils during the last twelve years, it has been shown that the protein molecules are built ap of a series of amino acids. The following is a list of the chief of these compounds which have been derived from the hydrolysis of proteins :-

Mono-amino-monocarboxylic acids.

1. Glycine $($ Glycocoll $)=$ amino-acetic acid, $\mathrm{C}_{2} \mathrm{H}_{5} \mathrm{NO}_{2}$,

$$
\mathrm{CH}_{2}\left(\mathrm{NH}_{2}\right) \cdot \mathrm{COOH}
$$

2. Alanine $=a$-amino-propionic acid, $\mathrm{C}_{3} \mathrm{H}_{7} \mathrm{NO}_{2}$, $\mathrm{CH}_{3} \cdot \mathrm{CH}\left(\mathrm{NH}_{2}\right) \cdot \mathrm{COOH}$

3. Valine $=a$-amino-isovalerianic acid, $\mathrm{C}_{5} \mathrm{H}_{11} \mathrm{NO}_{2}$, $\left(\mathrm{CH}_{3}\right)_{2} \mathrm{CH} . \mathrm{CH}\left(\mathrm{NH}_{2}\right) \cdot \mathrm{COOH}$

4. Leucine $=a$-amino-isocaproic acid, $\mathrm{C}_{6} \mathrm{H}_{13} \mathrm{NO}_{2}$, $\left(\mathrm{CH}_{3}\right)_{2} \mathrm{CH} . \mathrm{CH}_{2} . \mathrm{CH}\left(\mathrm{NH}_{2}\right) . \mathrm{COOH}$

5. Isoleucine $=\alpha$-amino- $\beta$-methyl- $\beta$-ethyl propionic acid, $\mathrm{C}_{6} \mathrm{H}_{13} \mathrm{NO}_{2}$, $\left(\mathrm{CH}_{3}\right)\left(\mathrm{C}_{2} \mathrm{H}_{5}\right) \mathrm{CH}$. $\mathrm{CH}\left(\mathrm{NH}_{2}\right)$. $\mathrm{COOH}$

6. Phenylalanine $=\beta$-phenyl- $\alpha$-amino-propionic acid, $\mathrm{C}_{9} \mathrm{H}_{11} \mathrm{NO}_{2}$, $\mathrm{C}_{6} \mathrm{H}_{5} \cdot \mathrm{CH}_{2} \cdot \mathrm{CH}\left(\mathrm{NH}_{3}\right) \cdot \mathrm{COOH}$

7. Tyrosine $=\beta$-para-hydroxyphenyl- $\alpha$-amino-propionic acid,

$$
\text { HO. } \mathrm{C}_{6} \mathrm{H}_{4} \cdot \mathrm{CH}_{2} \cdot \mathrm{CH}\left(\mathrm{NH}_{2}\right) \cdot \mathrm{COOH}
$$

8. Serine $=\beta$-hydroxy- $a$-amino-propionic acid, $\mathrm{C}_{3} \mathrm{H}_{7} \mathrm{NO}_{3}$, $\mathrm{CH}_{2}(\mathrm{OH}) \cdot \mathrm{CH}\left(\mathrm{NH}_{2}\right) \cdot \mathrm{COOH}$

9. Cysteine $=\beta$-sulph-hydro- $\alpha$-amino-propionic acid, $\mathrm{C}_{3} \mathrm{H}_{\tau} \mathrm{NO}_{2} \mathrm{~S}$, $\mathrm{CH}_{2}(\mathrm{SH}) \cdot \mathrm{CH}\left(\mathrm{NH}_{2}\right) \cdot \mathrm{COOH}$

Mono-amino-dicarboxylic acids.

10. Aspartic acid = amino-succinic acid, $\mathrm{C}_{4} \mathrm{H}_{7} \mathrm{NO}_{4}$, $\mathrm{COOH} \cdot \mathrm{CH}_{2} \cdot \mathrm{CH}\left(\mathrm{NH}_{2}\right) \cdot \mathrm{COOH}$

11. Glutamic acid $=a$-amino-glutaric acid, $\mathrm{C}_{5} \mathrm{H}_{9} \mathrm{NO}_{4}$,

$\mathrm{COOH} \cdot \mathrm{CH}_{2} \cdot \mathrm{CH}_{2} \cdot \mathrm{CH}\left(\mathrm{NH}_{2}\right) \cdot \mathrm{COOH}$ 
Diamino-monocarboxylic acids.

12. Arginine $=a$-amino- $\delta$-guanidine valerianic acid, $\mathrm{C}_{6} \mathrm{H}_{14} \mathrm{~N}_{4} \mathrm{O}_{2}$,

$\mathrm{NH}: \mathrm{C}\left(\mathrm{NH}_{2}\right) \cdot \mathrm{NH} \cdot \mathrm{CH}_{2} \cdot \mathrm{CH}_{2} \cdot \mathrm{CH}_{2} \cdot \mathrm{CH}\left(\mathrm{NH}_{2}\right) \cdot \mathrm{COOH}$

13. Lysine $=a-\epsilon \cdot$ diamino-caproic acid, $\mathrm{C}_{6} \mathrm{H}_{14} \mathrm{~N}_{2} \mathrm{O}_{2}$, $\mathrm{NH}_{2} \cdot \mathrm{CH}_{2} \mathrm{CH}_{2} \cdot \mathrm{CH}_{2} \cdot \mathrm{CH}_{2} \cdot \mathrm{CH}\left(\mathrm{NH}_{2}\right) \cdot \mathrm{COOH}$

14. Caseinic acid $=$ diamino-trioxydodecanic acid, $\mathrm{C}_{12} \mathrm{H}_{26} \mathrm{~N}_{2} \mathrm{O}_{5}$.

15. Ornithine $=a-\delta$-amino-valerianic acid, $\mathrm{C}_{5} \mathrm{H}_{12} \mathrm{~N}_{2} \mathrm{O}_{2}$, $\mathrm{NH}_{2} \cdot \mathrm{CH}_{2} \cdot \mathrm{CH}_{2} \cdot \mathrm{CH}_{2} \cdot \mathrm{CH}\left(\mathrm{NH}_{2}\right) \cdot \mathrm{COOH}$

Diamino-dicarboxylic acid.

16. Cystine $=$ dicysteine $=\operatorname{di}(\beta$ thio- $\alpha$-amino-propionic acid $)$, $\mathrm{C}_{6} \mathrm{H}_{12} \mathrm{~N}_{2} \mathrm{O}_{4} \mathrm{~S}_{2}$, $\mathrm{COOH} \cdot \mathrm{CH}\left(\mathrm{NH}_{2}\right) \cdot \mathrm{CH}_{2} \cdot \mathrm{S}-\mathrm{S} \cdot \mathrm{CH}_{2} \cdot \mathrm{CH}\left(\mathrm{NH}_{2}\right) \cdot \mathrm{COOH}$

Heterocyclic amino-carboxylic acids.

17. Histidine $=\alpha$-amino- $\beta$-iminazole propionic acid, $\mathrm{C}_{6} \mathrm{H}_{9} \mathrm{~N}_{3} \mathrm{O}_{2}$, $\mathrm{CH}=\mathrm{C}-\mathrm{CH}_{2} \cdot \mathrm{CH}\left(\mathrm{NH}_{2}\right) \cdot \mathrm{COOH}$<smiles>C1CNCN1</smiles>

18. Proline $=a$-pyrrolidine carboxylic acid, $\mathrm{C}_{5} \mathrm{H}_{9} \mathrm{NO}_{2}$,

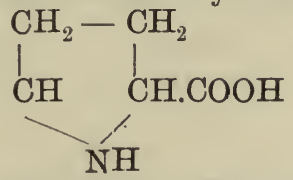

19. Oxyproline = hydroxy-pyrrolidine carboxylic acid, $\mathrm{C}_{5} \mathrm{H}_{9} \mathrm{NO}_{3}$ $\mathrm{HOCH}-\mathrm{CH}_{2}$<smiles>CCNC(C)C(=O)O</smiles>

20. Tryptophane $=\beta$-indole- $\alpha$-amino-propionic acid, $\mathrm{C}_{11} \mathrm{H}_{12} \mathrm{~N}_{2} \mathrm{O}_{22}$ $\mathrm{C}-\mathrm{CH}_{2} \cdot \mathrm{CH}\left(\mathrm{NH}_{2}\right) \cdot \mathrm{COOH}$<smiles></smiles>

The methods used in the hydrolysis of proteins and in the identification and determination of the products are too complex and involved to permit of any description here. Much work on this subject has been done recently, especially in Germany by Fischer, Abderhalden, Kossel and others and in America by Osborne, Hart and others.

The results show that the various proteins are built up of very varying proportions of the amino-acids. 
The protamines, which have been found chiefly in fish sperm, consist very largely of arginine and other diamino-acids. The histones yield about 30 per cent of diamino-acids.

The albumins contain no glycine, but the globulins yield up to 3 or 4 per cent of this substance.

The crystallised vegetable globulins, e.g., edestin, found in hemp seed, cotton seed and sunflower seed, yield about the same quantity of glycine as the animal globulins (serum globulin and fibrin), the glutelins, e.g., legumin, amandin, phaseolin and maize glutelin, much less and the gliadins, practically none. The phospho-proteins, e.g., caseinogen, also contain no glycine, but the scleroproteins, e.g., gelatin, elastin, fibroin and keratin, are very rich in glycine, alanine and other mono-amino acids.

Of special interest is the occurrence of tryptophane in proteins, because of its being apparently an indispensable constituent of the food of animals. It appears to be present in most proteins, though its amount has only seldom been determined; but its absence from the gliadin of maize-zein-is alleged to render that substance incapable of forming the sole nitrogenous nutriment of animals.

The proteids are extremely complex, therefore, in constitution and any detailed account of them would be beyond the scope of this volume. Indeed, the subject has an extensive literature of its own. As showing the great complexity of these substances, the simplest formula which will indicate the composition of globin, for example, has been calculated to be $\mathrm{C}_{726} \mathrm{H}_{1174} \mathrm{~N}_{194} \mathrm{~S}_{3} \mathrm{O}_{214}$. Some reference to certain important vegetable proteins will be made in subsequent chapters when dealing with crops and with the feeding of animals.

Proteids are optically active, being lævo-rotatory. They are precipitated by acids and by potassium ferrocyanide, by basic lead acetate, by mercuric chloride, by copper sulphate, by saturation of the liquid with ammonium sulphate or magnesium sulphate, or by alcohol.

The following are general qualitative tests for proteids :-

1. Heated with strong nitric acid they yield a yellow colouration which becomes orange on the addition of alkali (xantho-proteic reaction).

2. Millon's reagent (an acid solution of nitrate of mercury) gives a precipitate which turns red on heating.

3. With excess of strong sodium hydrate solution and a small quantity of copper sulphate a violet colour is obtained, becoming deeper on warming. (Biuret reaction.)

4. Adamkiewicz's reaction. The proteid is dissolved in glacial acetic acid and strong sulphuric acid is added, when a violet colour is produced. It has been shown ${ }^{i}$ that the acetic acid only pro'duces this reaction if it contains as an impurity, glyoxylic acid, $\mathrm{HCO} . \mathrm{COOH}$, and that a better method of performing the test is to reduce oxalic acid by means of a little sodium amalgam, thereby forming glyoxylic acid, add a few drops of this solution to that of the proteid, and then sulphuric acid.

${ }^{3}$ Hopkins and Cole, Proc. Roy. Soc., 1901, 21. 
The usual method of estimating proteids in analysis is by determining the amount of nitrogen present, and then assuming that this nitrogen constitutes about 16 per cent of the weight of the albuminoids. The percentage of nitrogen found is therefore multiplied by $6 \cdot 25$, and the product is given as the percentage of albuminoids. This only gives approximate values, since all proteids do not contain exactly 16 per cent of nitrogen. The following table gives the percentage of nitrogen found in various proteids and the factor which, multiplied by the percentage of nitrogen found, will give the amount of albuminoid present $^{1}:-$

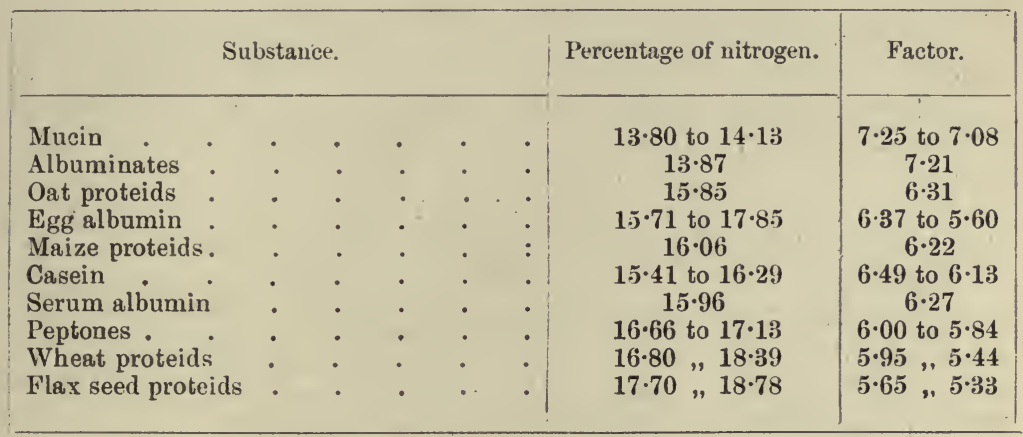

(ii) The Simpler Amino-Compounds. - Under this heading may be conveniently grouped together those substances which were formerly classed as Amides. They are compounds of much less complexity than the proteids and are, for the most part, to be regarded as derivatives of ammonia, $\mathrm{NH}_{3}$, by the replacement of one atom of hydrogen by an organic radicle.

They include many of the amino-acids already mentioned as products of the hydrolysis of proteids.

The simpler amino-compounds occur widely distributed in the vegetable kingdom, being especially abundant in immature plants. In many cases, they are transition compounds formed in the synthesis of the proteids. Being soluble in water and diffusible, they can readily pass through the cell walls of plants, which is not the case with the colloidal proteids. Hence they permit of the transference of nitrogenous matter from one part of a plant to another. In all processes involving such translocation, these simpler amino-compounds ar e formed by the hydrolysing action of enzymes upon the proteids, to be followed by the re-formation of the latter in the new locality. Hence the simpler amino-compounds are to be most readily detected in plant tissues during germination and during seed formation. They are products of both katabolism and anabolism. A few of the more common of these compounds may be briefly described and may be taken as types of many others that have been found in plants.

1. Asparagine, which is really amino-succinamic acid, 
$\mathrm{C}_{2} \mathrm{H}_{3}\left(\mathrm{NH}_{2}\right)\left\{\begin{array}{l}\mathrm{CO} . \mathrm{NH}_{2} \\ \mathrm{CO} . \mathrm{OH}\end{array}\right.$ is found in the juice of the asparagus, in many fruits, roots and tubers, in the young shoots of vetches, beans, peas, etc. Asparagine crystallises in prisms with one molecule of water. It has a cooling, unpleasant taste, and is soluble in about 80 parts of water. By boiling with alkalies or other bases, aspartic acid or amino-succinic acid, $\mathrm{C}_{2} \mathrm{H}_{3}\left(\mathrm{NH}_{2}\right)(\mathrm{COOH})_{2}$, is formed, with evolution of ammonia.

Dilute hydrochloric acid produces the same acid and ammonium chloride, the nitrogen of the amide $\left(-\mathrm{CONH}_{2}\right)$ group being converted into ammonia. This is a general reaction with amides.

2. Glutamine, amino-glutamic acid, $\mathrm{NH}_{2} \cdot \mathrm{CO} \cdot \mathrm{C}_{3} \mathrm{H}_{5}\left(\mathrm{NH}_{2}\right) \cdot \mathrm{COOH}$, is found in beetroot, in the shoots of the vetch and in the pumpkin. It crystallises in slender white needles, which contain no water of crystallisation. It is very soluble in hot water, but insoluble in absolute alcohol.

3. Choline, hydroxyethyl - trimethyl-ammonium hydroxide, $\mathrm{C}_{2} \mathrm{H}_{4}(\mathrm{OH}) \cdot \mathrm{N}\left(\mathrm{CH}_{3}\right)_{3} \cdot \mathrm{OH}$, occurs in cotton seed, in beets, in hops and in many other plants. It is a syrupy liquid with a strong alkaline reaction. It appears to possess poisonous properties, which are sometimes apparent when cotton seed is used as a food for very young animals. It forms a characteristic reddish yellow crystalline compound with platinum tetrachloride, $\left(\mathrm{C}_{5} \mathrm{H}_{14} \mathrm{ON}\right)_{2} \mathrm{PtCl}_{6}$.

4. Betaine, inner anhydride of trimethyl glycocoll, is said to have the composition-

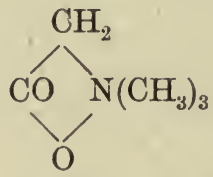

It is found in beet juice, in mangolds and in cotton seed. It is formed by the oxidation of choline. It crystallises with one molecule of water.

Many derivatives of betaine have been prepared artificially ${ }^{1}$ and one-trigonelline, occurs in fenugreek. ${ }^{2}$ Trigonelline has the constitution-

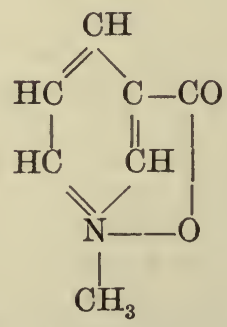

5. Allantoin, $\mathrm{C}_{4} \mathrm{H}_{6} \mathrm{~N}_{4} \mathrm{O}_{3}$, found principally in animal products, has

${ }^{1}$ Willstätter, Ber. 1902, 584 ; Jour. Chem. Soc., 1902, Abstracts, i. 266.

2 Jahns, Ber. 1885, 2518; Jour. Chem. Soc., 1886, Abstracts, 85. 
been detected in certain vegetables, e.g., in plane-tree leaves, in the sprouts of many young plants and in cereals, It crystallises in prisms, soluble in hot water and in alcohol, and has a neutral reaction. It is a di-ureide of glyoxylic acid and has the constitution-

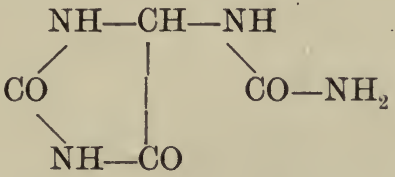

The simpler amino-compounds, the "amides" of food analyses, are generally regarded as not being capable of forming flesh in an animal, but only to function in fat formation or heat production. Remembering that proteids, by hydrolysis, are converted into amino-acids in the process of digestion and that these are subsequently built up into proteids in the animals, it would appear probable that the "amides" of a food, if present in sufficient variety, might take some part in the building up of nitrogenous tissue. Indeed, recent experiments tend to show that this is the case under certain conditions, or at least that "amides" can, to a certain extent, replace a portion of the albuminoids in a ration.

They cannot, nevertheless, be regarded as possessing the same value as true albuminoids and, in the analysis of products rich in " amides," distinction has to be made between the nitrogen existing in the two classes of compounds. The total nitrogen in the foodstuff is determined by the Kjeldahl process (vide Chap. V, p. 85). Another portion of the food is then digested with water containing, in suspension, recently precipitated copper hydroxide. This renders the true albuminoids insoluble but permits the "amides" to dissolve. The precipitate is filtered off, washed, and a nitrogen determination by Kjeldahl's process made in the residue. This is assumed to be the nitrogen existing as real albuminoids.

(iii) The Alkaloids. - These substances are nitrogenous bases, possessed usually of powerful therapeutic properties. They are very numerous and in constitution are generally to be regarded as derived from ammonia, $\mathrm{NH}_{3}$, by the replacement of a part of or all the hydrogen by complex groups. With few exceptions, e.g., nicotine, coniine and sparteine, they contain oxygen. They exist in the plant probably as salts of organic acids. They are only slightly soluble in water, more so in alcohol. They are found in various parts of plants and may be extracted by digesting the finely divided material with dilute sulphuric acid, nearly neutralising the solution with alkali, boiling down, and adding alcohol, when most of the gums, mucilage, etc., are precipitated and the alkaloids remain in solution.

Some of the more important alkaloids are-

Coniine, $\mathrm{C}_{8} \mathrm{H}_{17} \mathrm{~N}=$ propyl piperidine, $\mathrm{C}_{5} \mathrm{H}_{10}\left(\mathrm{C}_{3} \mathrm{H}_{7}\right) \mathrm{N}$.

Nicotine, $\mathrm{C}_{10} \mathrm{H}_{14} \mathrm{~N}_{2}=\beta$-pyridyl- $\alpha$ - $\mathrm{N}$-methylpyrrolidine, $\mathrm{C}_{5} \mathrm{H}_{4} \mathrm{~N} \cdot \mathrm{C}_{4} \mathrm{H}_{7} \mathrm{~N}\left(\mathrm{CH}_{3}\right)$ 
Morphine, $\mathrm{C}_{17} \hat{\mathrm{H}}_{19} \mathrm{NO}$.

Strychnine, $\mathrm{C}_{21} \mathrm{H}_{22} \mathrm{~N}_{2} \mathrm{O}_{23}$.

Quinine, $\mathrm{C}_{20} \mathrm{H}_{24} \mathrm{~N}_{2} \mathrm{O}_{3}$.

Caffeine or Theine, $\mathrm{C}_{8} \mathrm{H}_{10} \mathrm{~N}_{4} \mathrm{O}_{2 .}$.

(Trimethyl xanthine, 1.3.7).

Theobromine, $\mathrm{C}_{7} \mathrm{H}_{8} \mathrm{~N}_{4} \mathrm{O}_{2}$.

(Dimethyl xanthine, 3.7).

The two latter compounds are important constituents of certain plants-tea, maté, coffee and cocoa. They are intimately related in chemical constitution with xanthine, $\mathrm{C}_{5} \mathrm{H}_{4} \mathrm{~N}_{4} \mathrm{O}_{2}$, found in many animal products and in certain plants; with guanine, $\mathrm{C}_{5} \mathrm{H}_{5} \mathrm{~N}_{5} \mathrm{O}$, found in guano and with uric acid, $\mathrm{C}_{5} \mathrm{H}_{4} \mathrm{~N}_{4} \mathrm{O}_{3}$. The following formulæ will illustrate the connection:-<smiles>O=C1NC2NC(=O)NC2N1</smiles>

Uric acid.<smiles>O=c1[nH]c2nc[nH]c2[nH]1</smiles>

Xanthine.<smiles>N=C1NC(=O)C12CN=CN2</smiles><smiles></smiles><smiles>Cn1c2c(n(C)c1=O)C(=O)N=N2</smiles>

Theine or Caffeine.

The functions of the alkaloids in plants is not known; as foodstuffs they have no value, but their therapeutic effect is often of great importance.

(iv) The Cyanogenetic Glucosides.-More than a hundred species of plants have been found to contain compounds which readily eyolve hydrocyanic acid when distilled with water. In many cases, it has been shown that this is due to the presence in the plant of compounds containing glucose, some other organic radicle and hydrocyanic acid and that the latter is liberated when the compounds are hydrolysed by acids or by enzymes.

The best known of these cyanogenetic glucosides are-

Amygdalin, a substance found in bitter almonds and in the seeds of many other plants. This has been proved to undergo the following changes on hydrolysis:- 
(1) $\mathrm{C}_{20} \mathrm{H}_{27} \mathrm{O}_{11} \mathrm{~N}+\mathrm{H}_{2} \mathrm{O}=\mathrm{C}_{6} \mathrm{H}_{12} \mathrm{O}_{6}+\mathrm{C}_{14} \mathrm{H}_{17} \mathrm{O}_{6} \mathrm{~N}$

Amygdalin. Glucose. Mandelic nitrile glucoside or prunasin.

(2) $\mathrm{C}_{14} \mathrm{H}_{17} \mathrm{O}_{6} \mathrm{~N}+\mathrm{H}_{2} \mathrm{O}=\mathrm{C}_{6} \mathrm{H}_{12} \mathrm{O}_{6}+\mathrm{HCN}+\mathrm{C}_{6} \mathrm{H}_{5} \cdot \mathrm{CHO}$ Prussic acid. Benzaldehyde.

The first reaction can be effected by the enzymes, maltase present in yeast and amygdalase present in emulsin, the second by the enzymes, emulsin present in almonds and prunase present in plums as well as in emulsin. Emulsin is capable of decomposing amygdalin, in one process (probably because it contains two enzymes) ${ }^{1}$ into the products, glucose (dextro-glucose), hydrocyanic acid and benzaldehyde.

The last two substances, being volatile, are the chief constituents of the essential oil of bitter almonds.

Either amygdalin or some closely related substance occurs in the seeds of many fruits, e.g., in those of the apple and of the mountain ash berry.

Elderberries (the fruit of Sambucus nigra) have been shown ${ }^{2}$ to contain a glucoside, sambunigrin, identical with the intermediate compound, mandelic nitrile glucoside, formed in the hydrolysis of amygdalin.

Dhurrin was found in the common sorghum (Sorghum vulgare) or great millet. ${ }^{3}$ It is present in the young immature plants, the amount attaining a maximum when the plants are about a foot in height. On hydrolysis by hot dilute acid, or by emulsin, it yields glucose, hydrocyanic acid and para-hydroxybenzaldehyde in accordance with the equation-

$$
\mathrm{C}_{14} \mathrm{H}_{17} \mathrm{O}_{7} \mathrm{~N}+\mathrm{H}_{2} \mathrm{O}=\mathrm{C}_{6} \mathrm{H}_{12} \mathrm{O}_{6}+\mathrm{HCN}+\mathrm{C}_{6} \mathrm{H}_{4}(\mathrm{OH}) \cdot \mathrm{CHO}
$$

Young sorghum plants have often been known to be poisonous to cattle, doubtless due to their yielding prussic acid, for the enzyme necessary for the above hydrolysis is present in the plant. Many plants related to the millets have been found to yield hydrocyanic acid, e.g., Guinea grass (Panicum naximum) and maize (Zea mays), but the quantity present is inconsiderable, even at the stages of growth where it attains its maximum.

Lotusin was obtained by Dunstan \& Henry ${ }^{4}$ from the leguminous annual plant, Lotus arabicus, which, though poisonous at certain stages of its growth, yields, near maturity, a valuable and harmless fodder.

Lotusin is hydrolysed by heating with hydrochloric acid, or by an enzyme, lotase, also present in the plant, with the following result :-

$$
\underset{\text { Lotusin. }}{\mathrm{C}_{28} \mathrm{H}_{31} \mathrm{O}_{16} \mathrm{~N}}+\underset{\text { Lotoflavin. }}{2 \mathrm{H}_{2} \mathrm{O}}=\underset{\text { d-glucose. }}{\mathrm{C}_{15} \mathrm{H}_{10} \mathrm{O}_{6}}+\mathrm{HCN}+\underset{\text { din }}{2 \mathrm{C}_{6} \mathrm{H}_{12} \mathrm{O}_{6}}
$$

Lotoflavin is a yellow dye resembling quercetin.

Phaseolunatin, present in Lima or Rangoon beans (the seeds of

${ }^{1}$ H. E. and E. F. Armstrong and Horton, Proc. Roy. Soc., May 16, 1912.

${ }^{2}$ Bourquelot and Danjon, Compt. rend., 1905, 141, 598.

${ }^{3}$ Dunstan \& Henry, Phil. Trans., 1902, A. 199, 399.

${ }^{+}$Phil. Trans., 1901, B. 194, 515. 
Phaseolus lunatus), occurs also in young flax plants. Its composition and hydrolysis are indicated by the following equation :-

$$
\underset{\text { Phaseolunatin. }}{\mathrm{C}_{10} \mathrm{H}_{17} \mathrm{O}_{6} \mathrm{~N}}+\underset{\text { d-glucose. }}{\mathrm{H}_{2} \mathrm{O}}=\underset{\text { Acetone. }}{\mathrm{C}_{6} \mathrm{H}_{12} \mathrm{O}_{6}}+\mathrm{HCN}+\underset{\left(\mathrm{CH}_{3}\right)_{2} \mathrm{CO}}{\mathrm{HCN}}
$$

It is thought probable that the hydrocyanic acid yielded by Cassava root (from which tapioca is obtained), the Ceara rubber plant and the Para rubber plant is derived from the same compound.

Many other plants are known to yield small quantities of hydrocyanic acid. Thus, the leaves and stems of the sweet potato, Ipomcea batatas, which have often been noticed, in Queensland, to be poisonous, have been found to yield from 0.014 to 0.019 per cent of their weight of prussic acid.

The young shoots of oats, wheat and barley and many of the graminece have been carefully examined but found to be free from any cyanogenetic compounds.

The functions of the cyanogenetic compounds in plants are not known, though some investigators consider it probable that they are transitional products, produced perhaps by the action of formaldehyde upon nitrates, from which, first, amino-acids are derived, and that these latter in turn, serve as materials from which the proteids are built up.

\section{VII.-CHLOROPHYLL.}

This substance is the essential constituent of all the green-coloured portions of plants and is the medium by which the assimilation of carbon compounds from carbon dioxide and water, by the aid of energy derived from light, takes place.

Its nature and constitution have formed the subject of many researches. In many plants it occurs associated with other colouring substances, of which carrotene, $\mathrm{C}_{40} \mathrm{H}_{56}$, and xanthophyll, $\mathrm{C}_{40} \mathrm{H}_{56} \mathrm{O}_{2}$, are the most important. The former can be obtained in copper-coloured leaflets, which appear red by transmitted light; the latter is similar in appearance to carrotene but transmits yellow light. Both readily absorb oxygen (up to 34 or 36 per cent of their weight) and are converted into colourless substances. ${ }^{1}$

Pure chlorophyll, obtained from plants by Willstätter and Hug, ${ }^{2}$ is a bluish-black, lustrous, glistening powder which melts somewhat indefinitely between $93^{\circ}$ and $106^{\circ}$. It is soluble in ether, giving a greenish-blue fluorescent liquid; soluble also in alcohol or in benzene and pyridine.

Its composition is $\mathrm{C}_{55} \mathrm{H}_{72} \mathrm{O}_{6} \mathrm{~N}_{4} \mathrm{Mg}$ and its ash consists of pure magnesia.

Willstätter regards as the fundamental constituent a compound which he calls chlorophyllin and which has the composition, $\mathrm{C}_{31} \mathrm{H}_{29} \mathrm{~N}_{4}$ $\mathrm{Mg}(\mathrm{COOH})_{3}$.

1 Willstätter \& Mirg, Ann., 1907, 355, 1; Jour. Chem. Soc., 1907, Abstracts, i. 865.

${ }^{2}$ Ann., 1910, 378, 18 ; 1911, 380, 177 ; 1911, 382, 129 ; Jour. Chem. Soc., 1911, Abstracts, i. 140, 393 and 659 . 
True chlorophyll, as it exists in the leaves, is amorphous and is phytyl chlorophyllide, i.e. :-

$$
\text { COOH. } \mathrm{C}_{31} \mathrm{H}_{29} \mathrm{~N}_{4} \mathrm{Mg}\left(\mathrm{COOCH}_{3}\right) \cdot \text { COO. } \mathrm{C}_{20} \mathrm{H}_{39}
$$

but when kept in alcoholic solution it is converted by an enzyme, chlorophyllase, present in almost all plants, into crystalline chlorophyll, which is ethyl chlorophyllide, thus :-

$$
\begin{gathered}
\mathrm{C}_{31} \mathrm{H}_{29} \mathrm{~N}_{4} \mathrm{Mg}(\mathrm{COOH})\left(\mathrm{COOCH}_{3}\right) \cdot\left(\mathrm{COOC}_{20} \mathrm{H}_{39}\right)+\mathrm{C}_{2} \mathrm{H}_{5} \mathrm{OH}=\underset{\text { Phytol. }}{\mathrm{C}_{20} \mathrm{H}_{33} \mathrm{OH}} \\
+ \text { COOH. } \mathrm{C}_{31} \mathrm{H}_{29} \mathrm{~N}_{4} \mathrm{Mg}\left(\mathrm{COOCH}_{3}\right) \mathrm{COOC}_{2} \mathrm{H}_{5}
\end{gathered}
$$

Willstätter thinks that ordinary chlorophyll contains two components, one of which, by removal of magnesia, yields phyto-chlorin, $\mathrm{C}_{34} \mathrm{H}_{34} \mathrm{O}_{5} \mathrm{~N}_{4}$, and the other phyto-rhodin, $\mathrm{C}_{34} \mathrm{H}_{34} \mathrm{O}_{7} \mathrm{~N}_{4}$.

Many other interesting derivatives of chlorophyll have recently been obtained by Willstätter and his collaborators.

The view that chlorophyll and hæmatin, the colouring matter of blood, are both probably derivatives of pyrrole-

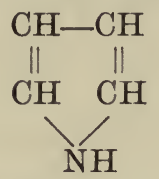

enunciated by Schunck and Marchlewski in $1896^{1}$ seems to receive strong confirmation from recent investigations. ${ }^{2}$

Moreover, Küster finds that hæmatin has the composition $\mathrm{C}_{34} \mathrm{H}_{34} \mathrm{O}_{5} \mathrm{~N}_{4} \mathrm{Fe}$, which corresponds to some of the chlorophyll derivatives, iron replacing magnesium.

It would seem, therefore, that the red colouring matter of the blood of animals, hæmatin, finds an exact analogue in the green coloured substance so characteristic of plants, the only difference being in the metal with which the organic radicle is combined.

Possibly in plants, there is the same necessity for the presence of iron, in the earlier stages of the formation of chlorophyll and only at the end of the synthetic process, is its replacement by magnesium effected.

That the replacement of iron by magnesium in this complex organic molecule should produce such a complete change in the properties and functions of the compound is remarkable. In chlorophyll, where magnesium is present, the characteristic function of the compound is the decomposition of carbon dioxide in the presence of water and with the energy derived from light, with the probable formation of hydrogen peroxide and formaldehyde and the immediate decomposition of the former into water and oxygen (this is probably effected by enzymes associated with the protoplasm of the leaves) and the polymerisation of the latter into sugar.

1 Jour. Chem. Soc., 1896, Abstracts, i. 574.

2 Malarski and Marchlewski, Jour. Chem. Soc., 1910, Abstracts, i. 692, also Willstätter and Asahina, Jour. Chem. Soc., 1912, Abstracts, i. 41. 
In hæmatin, on the other hand, where iron replaces magnesium, the function of the substance is to act as a carrier of oxygen from the free oxygen of the air to the carbonaceous matter in the tissues of the animal. This property of carrying oxygen is possessed by many iron compounds and is, perhaps, not difficult to explain.

Chlorophyll and its derivatives give characteristic absorption spectra, the black bands formed in the continuous spectrum of white light which has been filtered through a solution of chlorophyll showing the particular rays which are absorbed and whose energy is utilised in the assimilative processes of the plant (vide next chapter).

Many other coloured or colour-yielding substances occur in plants, but their importance in reference to the life of the plant in most cases, is small or not understood. 


\section{CHAPTER XI.}

\section{The Plant.}

For a description of the structure and general life-history of plants the reader will naturally turn, not to a work on agricultural chemistry, but to a treatise on botany. Nevertheless, a brief account of the functions of the various parts and their special adaptation for carrying on the processes of life may usefully be given here.

Germination.-A seed is essentially a germ or embryo, together with a store of reserve material from which the future plant is to be formed (endosperm or cotyledons). The embyro is the only portion of the seed which is really alive, the endosperm, e.g., of barley or wheat, is merely a store of food ${ }^{1}$; hence it is possible to transplant the embyro from one seed to another without destroying its power of growth. The nature of the food stored in a seed varies; there is always a considerable amount of albuminoid matter and either starch or fat.

Seeds suffer little change by keeping, provided they be protected from moisture; if not already dry they lose water, and in some cases carbon dioxide, but these changes soon cease and no further loss occurs. Vitality may be retained for several years. When placed under suitable conditions, seeds germinate. The most important circumstances affecting germination are-

(1) Moisture.

(2) Temperature.

(3) Access of oxygen.

(4) Removal of carbon dioxide.

Moisture is essential and acts by producing considerable swelling. accompanied by a rise of temperature.

A suitable temperature is also requisite. As a rule, no germination occurs below $3^{\circ}$ or above $49^{\circ}$. The limits as well as the optimum temperature vary with different seeds.

For every plant there can be found three important temperatures, viz., the minimum, optimum and maximum temperatures, at which growth occurs or at which germination proceeds.

Thus, the following table gives the three points for the germination of several plants, in degrees centigrade :-

${ }^{1}$ Stoward, however, has shown that the purely endospermic tissues of barley and maize respire, absorb oxygen and evolve carbon dioxide, thus affording evidence of vitality, even in these cells (Ann. of Botany, 1908, 415). 


\begin{tabular}{|c|c|c|c|c|c|c|c|c|c|c|}
\hline & & & & & & & & Minimum. & Optimum. & Maximum. \\
\hline Wheat & . & . & . & . & . & . & . & 5 & 31 & 42 \\
\hline Barley & . & . & . & . & . & . & . & 5 & 31 & 40 \\
\hline Maize. & . & . & . & . & . & . & $\therefore$ & $9 \cdot 4$ & 34 & 46 \\
\hline Peas. & . & . & . & . & . & . & . & $6 \cdot 6$ & 31 & 39 \\
\hline Pumpkins & . & . & . & . & . & . & . & 13 & 34 & 46 \\
\hline
\end{tabular}

So, too, the growth of the seedlings is influenced in a similar manner, the temperatures, however, being somewhat lower, especially as regards the maximum temperature at which growth occurs. This is usually about $38^{\circ}$, but with maize, pumpkins and tropical plants, of course, may be higher - up to about $45^{\circ}\left(113^{\circ} \mathrm{F}\right.$.). Certain low forms of plant-life have limits much below and much above these temperatures. Some alge will grow in sea waier at $0^{\circ} \mathrm{C}$. or even below, while some thermophilic bacteria flourish at $75^{\circ} \mathrm{C}$. and have an optimum temperature of growth about $70^{\circ} \mathrm{C}$.

The rate of growth of seedlings is found to be very small near their minimum temperature and to increase gradually with a rise of temperature, the rate of increase rising rapidly as the optimum temperature is approached and diminishing very rapidly soon after this is passed, until it finally ceases at the maximum temperature.

In South Africa, temperatures are liable to great and rapid oscillations. The shade temperatures in the afternoon of a clear sunny winter's afternoon may reach $80^{\circ} \mathrm{F}$. $(26.6 \mathrm{C}$.), while shortly before sunrise there may be a keen frost. Now plants are able to adapt themselves to extremes of temperature, provided the changes occur gradually, but such rapid alternations must be very injurious to almost all plants. In the summer, both day and night, temperatures are much higher, and the temperature of the surface soil and of the leaves of plants must often be high, probably far above the maximum temperature of growth.

Thus, in the case of winter crops (grown with irrigation), it must often happen that the time during which the plant is at or near its optimum temperature must be restricted to comparatively short periods in the mornings and evenings, during the rest of the twenty-four hours the temperatures being too low or too high to allow of much growth.

Moreover, the adjustment of the organs of the plant to suit these rapid changes of temperature must be difficult.

We consequently find that many English plants, which in the English climate are able to withstand greater extremes of temperature (but more gradual in their alternation), will not live through a Transvaal winter, even when well watered. This, for example, is the case with many grasses.

Any circumstance which tends to increase the suddenness of the transition from the too low to the too high temperatures will still further retard the growth of plants. Such a circumstance is the screening off 
of the rays of the rising sun, and it has been alleged that such rays possess some occult beneficial influence upon that growth. ${ }^{1}$

The writer feels fully convinced that the injury effected upon plants by being deprived of the early rays of the sun, arises chiefly from their being hurried through the temperature at which maximum growth is possible. The abundance of sunshine which one is apt to. consider so valuable an aid to plant growth in sunny South Africa would thus seem to be in excess of their requirements, and probably the country would be more productive if there were less of it.

Transpiration through the leaves is also very active in this dry climate, and direct experiment by the writer in 1904, showed that a potato plant exhaled 467 grammes of water for each gramme of solid matter formed. This was in ordinary soil without manure. Another experiment showed that only 284 grammes of water for each gramme of solid matter. were given off from a potato plant grown on soil manured with $800 \mathrm{lb}$. basic slag and $100 \mathrm{lb}$. potassium nitrate per acre.

Now a plant exhaling moisture rapidly during the hot part of the day, when the whole plant and its roots have been heated by the sun, suddenly has its rate of transpiration checked by the cooling of its. leaves after sunset. Its roots, however, are still active in absorption of water from the hot soil, and undoubtedly disturbances in the pressure of the sap, often of an injurious character, must be set up. Such disturbances may give rise to rupture of some of the cells of the plant, and is probably the cause of a "disease" which has long puzzled pathologists-viz., "Bitter pit" in apples.

During germination oxygen is actually absorbed in considerable quantity, carbon dioxide being exhaled.

The process of oxidation produces heat, and a considerable rise of temperature may be observed when many seeds germinate together (e.g., in malting barley). During this slow combustion, the fats and carbohydrates are consumed, but the proteid matters remain undiminished in quantity.

In germination, various enzymes present in the seed commence to act (diastase, which has the power of converting starch into maltose: and dextrose, is a typical one), whereby the reserve materials in the seed are converted into soluble substances, capable of transportation in the sap. The embryo increases rapidly in size, sending upwards a, plumule, which will eventually produce the stem, and downwards a radicle, destined to form the root. The direction of growth of the plumule and radicle is determined by gravitation, for if seeds be germinated while subjected to centrifugal force (say on a rotating wheel), the plumule grows towards and the radicle away from the centre of rotation. As soon as the plumule reaches the surface of the soil and becomes exposed to light, chlorophyll is produced in it and assimilation commences. The radicle, too, develops root-hairs and becomes. capable of taking in plant food from the water of the soil.

Before describing the chemical changes which occur in plants, it may render the matter clearer if a few terms which are used in physiology be explained.

${ }^{1}$ Rawson, Transvaal Agric. Journal, April and July, 1906. 
Metabolism refers to all chemical changes which occur in or are produced by living matter. These are further subdivided into-

(1) Anabolism or constructive metabolism, including all processes in which complex compounds are built up from simpler ones by the aid of living organisms. The final stage of all anabolic processes is the formation of protoplasm. In the case of plants, the most characteristic anabolic process is the synthesis of carbohydrates from carbon dioxide and water. This is the first portion of the process of assimilation.

(2) Katabolism or destructive metabolism, including all chemical ehanges resulting in the formation of the more simple from the complex. A type of such katabolic processes is the absorption of oxygen and the liberation of carbon dioxide; this occurs most markedly in animals, but is also an essential function of plants. The process is known as respiration.

The products of metabolism are classed as plastic products, which can be utilised again in anabolism, and waste products, which cannot be again used, and in which are either excreted or secreted in the insoluble form within the body of the plant or animal.

The main parts of a plant are-

(1) The roots.

(2) The stem.

(3) The leaves.

(4) The flowers and seeds.

A brief account of the functions of these will now be given :-

1. The Roots. - The radicle formed from the seed naturally grows downward, i.e., in the direction towards the force of gravitation or other force acting upon it. Soon, however, it branches, and the secondary roots generally grow laterally. From these roots, in turn, other branches are formed, and in the neighbourhood of the growing point of a root, root-hairs are sent out among the particles of the soil. These root-hairs have thin walls through which water can readily pass. rearrying with it the dissolved matter which it may contain, provided that matter be capable of passing through the membranous walls (i.e., be a crystalloid). The constituents of the sap, often including free vegetable acids, pass outwards from the root-hairs and aid in the solution of certain constituents of the soil, which, when dissolved, diffuse into the root. ${ }^{1}$ All the crystalloid constituents of soil-water in this way enter the root and are carried in the sap to other parts of the plant, where they are absorbed, if required, in order to build up the tissues of the plant. If not so utilised they remain in the sap and thus prevent the entrance, by diffusion, of additional matter of the same kind.

\section{Diffusion and Osmosis.}

A few words may here be said about the phenomena of diffusion and osmotic pressure. Diffusion, as is well known, refers to the process

${ }^{1}$ Recent experiments lead to the conclusion that the solvent action of root-hairs upon soil is mainly to be attributed to the carbon dioxide evolved by them and not to the escrpe of their acid sap. 
by which a substance, dissolved in a solvent, moves from the more concentrated to the less concentrated portions of the liquid. This movement is an indication of a motion which is constantly occurring in the particles of a dissolved substance, but which is only readily apparent when more of the substance moves in one direction or into a given space than moves in the other direction or out of it.

Graham in 1850, investigated the rates of diffusion of various compounds in aqueous solution and found great differences with different substances. Many crystallisable substances moved comparatively rapidly, while colloidal bodies, e.g., gum, albumin, tannin, moved with extreme slowness. He found, moreover, that colloidal bodies, either in solution or when thoroughly wetted with water, allowed crystalloids to diffuse freely, but practically stopped all diffusion of dissolved colloids.

The practical application of this phenomenon to the separation of crystalloids from colloids is known as dialysis and is usually accomplished by means of a vessel, the bottom of which is composed of animal or vegetable parchment. The mixture of the two dissolved substances is placed within this vessel, which is then floated upon pure water; the crystalloid passes through the membrane, but the colloid does not. The diffusion of the crystalloid goes on with diminishing speed until the concentration of the solution within and without the dialyser becomes equal. Even then, it is to be clearly understood, the action probably does not cease; but, since just as much leaves the inner vessel in a given time as enters it, the process does not readily show itself.

By repeatedly renewing the water in the outer vessel the whole of the crystalloid may be removed from the liquid within the dialyser, while the amount of colloid is not appreciably diminished.

Many animal and vegetable membranes, consisting as they do of colloidal matter, capable of swelling in water, allow of ready diffusion of water through them.

Most of these membranes, too, offer little resistance to the diffusion of dissolved crystalloids, but stop that of dissolved colloids. Some, however, while permitting water to diffuse through readily, almost entirely stop dissolved matter of all kinds-even crystalloids.

In all cases of diffusion it is obvious that any dissolved substances move from the stronger solution to the weaker one, so that equality in concentration is approached. In many cases the attainment of this equality is facilitated by the movement of a greater quantity of the solvent from the weak to the strong solution. Certain substances, when arranged as a partition between a solution and the solvent, will permit of the passage of the solvent only, but not the dissolved substance. Perfect semi-permeable membranes, as they are termed, are not known, but a near approach to them can be made artificially by produsing a precipitate of copper ferrocyanide in the walls of a porous earthfnware cell. If such a cell be filled with a solution, closed, and its int srior be connected with a manometer, it will, when immersed in the sclvent, show the production of considerable pressure, in some cases umounting to several atmospheres. The pressure attained in 
any experiment will, when it has become constant, be found to vary directly with the concentration and to increase with a rise of temperature. This osmotic pressure, as it is termed, has been shown to be analogous to gaseous pressure and to be amenable to the laws of Boyle and Charles.

It is to be noted that osmotic pressure is only developed with the aid of a more or less semi-permeable membrane and that the solvent moves to the place where the osmotic pressure is greatest. A clearer idea of this latter, apparently paradoxical, effect may be obtained by the aid of the following analogy :-

Imagine a confined space to contain a large number of rapidly moving solid bodies, e.g., small shot, oscillating about and hitting and rebounding from each other and from the walls. The impact of the shot upon the walls would exert a certain pressure per unit area. Into the same space let a number of oscillating plastic clay balls be introduced and suppose that where a shot strikes a clay ball, the two adhere and move about together. This would go on, until each clay ball became attached to a certain number of pellets and complexes, consisting of a central mass of clay, adhering to a certain number of shot, and each complex moving about, comparatively slowly, would be formed. Let the pressure on the walls be made equal to what it was before. Next imagine a similar adjacent space to contain only small shot in a sufficiently concentrated condition to give the same pressure, per unit area, on the walls as in the first space.

It is obvious that the concentration of the freely moving small shot will be much greater than in the first chamber, for the impact of a clay ball with its captive pellets will be equal to that of many separate pellets. But an impervious wall separating the two compartments would not be subjected to any excess of pressure on either side. Now let this dividing wall be replaced by a net with meshes large enough to readily permit the passage of the free shot, but small enough to entirely stop that of the clay complexes. It would now be found that the crowdedness of the free shot, at first much greater in the second compartment, would tend to equalise itself throughout the whole space, but the clay complexes would still be confined to the first compartment and the netting would, after a time, receive an equal amount of bombardment from the shot on each side, but, in addition, would have, on one side only, the heavier impact of the clay complexes. The same would also apply to the walls of the first compartment. Here, then, would be the production of a greater pressure on one side of the net than on the other, although to start with, the pressures on each side were equal.

The process would go on until the pressure set up was sufficient to expel, through the net, as many free pellets per unit time from the side where the crowdedness of such free pellets was smaller, as had entered, without the aid of the extra pressure, from the side where the concentration of free pellets was greater. Equilibrium would then be attained and no further change of pressure would be noted, except for the gradual tendency to uniform distribution of pressure consequent upon any imperfection of the net. 
In this analogy, the small shot represent the particles of the solvent (e.g., water), the clay balls, those of the dissolved substance and the clay complexes, the molecular aggregates resulting from the association of the dissolved substance with some of the solvent, while the net represents the semi-permeable membrane.

In reality, the mechanism, by which the membrane effects the stoppage of the motion of the dissolved substance and permits the passage of the solvent, may be very different to a net-work and the difference between the particles of dissolved matter and of the solvent may not be one of size, but the analogy will still serve to explain the phenomenon.

The cell walls of plants, or rather their protoplasmic linings, are probably composed of an approximately semi-permeable membrane; hence if they are surrounded with a solution of less concentration than their contents, they will receive more liquid than they will lose, and the pressure within the cell will be increased; on the other hand, if the solution outside be more concentrated than that within, more liquid will leave than will enter, and the cell will shrink. The outer part of the cell walls (cellulose) is not merely semi-permeable, but allows of free diffusion. It, however, has not much power of extension and so acts as a nearly rigid and strongly elastic envelope for the protoplasm. It is the strain set up by turgescence of the cells which is the chief cause of the rigidity and firmness of vegetable tissues in spite of their high water content. (A turnip, for example, though so firm and hard, contains far more water and less solid matter than milk or beer.)

The stems and leaves of plants owe their stiffness and erectness to the same cause-the strain produced by the elasticity of the cellulose envelopes on the one hand and the water-distended state of their protoplasmic contents on the other. When this turgescence relaxes, e.g., by evaporation, the plant wilts and droops, becoming quite flaccid.

A solution within a cell composed of a semi-permeable membrane and closed by a manometer, if immersed in the pure solvent, takes in the latter until the osmotic pressure is in equilibrium with the pressure produced by the mercury column of the manometer. If more mercury be added to the manometer some of the solvent will be forced out; on the other hand, if the mercury column be shortened more. solvent will enter and the volume of liquid within the cell will increase. It is found that the pressure produced by a given weight of dissolved substance per litre of solution, at a given temperature, is exactly equal to the pressure which would be exerted by the substance if it could exist as a gas under the same conditions as to volume and temperature. This latter, in the case of different substances, varies inversely with the molecular weight of the substance. Consequently it is found that two solutions exert an equal osmotic pressure when there are present in a given volume of the solution the same number of molecules of the dissolved substances. In the case of most metallic salts and the stronger acids in aqueous solution, this law is subject to a correction, because of the dissociation of these compounds into ions, each of which acts as a molecule. ${ }^{1}$

1 Vide p. 76. 
A living vegetable cell has been employed as a means of detecting the equality of the osmotic pressures existing in two solutions. If the cell be surrounded with a solution in which the number of molecules of dissolved substance per unit volume be greater than that in the sap within it, the water will pass through the protoplasm out of the cell, and the protoplasm will shrink from the rigid cellulose wall. This phenomenon is known as plasmolysis and can be observed under the microscope. With a certain strength of liquid the cell contents will be in equilibrium, i.e., no water will leave or enter. Solutions of different salts have the same osmotic pressure or are isotonic if they are in equilibrium with the sap of the same cell.

As already stated, perfect semi-permeable membranes are not known, and all membranes that have been observed permit of a slight amount of diffusion of the dissolved matter as well as of the solvent through them.

It is therefore probable that diffusion of dissolved substances from without and the setting up of osmotic pressure within the roots are processes opposed to each other, and their simultaneous occurrence is possible only because the roots are neither truly semi-permeable membranes on the one hand, nor merely porous colloidal bodies, permitting of free diffusion, on the other.

The living protoplasm of a vegetable cell thus permits of slight diffusion of its contents outwards and of the dissolved matters present in the surrounding liquid, inwards, though at the same time showing the production of internal osmotic pressure owing to the fact that the liquid within itself is more concentrated in solid matter (i.e., contains more molecules of dissolved substances per unit volume) than the liquid without. In the spring, when the plant juices become richer in dissolved matter (probably owing to the activity of ferments contained in the tissues leading to the production of sugar from starch, amides from albuminoids, etc.), the osmotic pressure, aided by a rise in temperature, becomes greatly increased, and, as a consequence, the roots of the plant, taking in large quantities of water from the soil, while losing comparatively little by diffusion, set up root pressure, which forces the sap up into the stem and leaves.

The magnitude of this root pressure in certain plants has been measured and found to rise sometimes to three or four atmospheres.

It is through the roots, by diffusion, that the mineral matters and the nitrogen (in the form of nitrates) required by a plant are taken in and forced, largely by osmotic pressure (due, mainly, not to them, but to the organic constituents present in the sap), up into the stem and leaves.

The diffusion of substances in solution from one part of the plant to another is made easier and does not tend to set up osmotic pressure between different parts of the plant, because of the fact revealed by the researches of Gardiner ${ }^{1}$ and others that the protoplasm is continuous from cell to cell, the continuity being maintained by fine threads passing through minute perforations in the cell walls. Through

${ }^{1}$ Proc. Roy. Soc., 62 (1897), 100. 
these small apertures, diffusion of dissolved matter in the protoplasm itself will take place at a rate probably far greater than is proportional to their area. The apertures, in fact, as suggested by Brown and Escombe, ${ }^{1}$ play a similar part to the stomata in the leaves in promoting diffusion without interfering with the structural advantages of the cell walls. ${ }^{2}$

2. The Stem, from our present aspect, may be regarded as the mere means of communication between the roots and the leaves. It, however, serves many other purposes, e.g., often as a receptacle for reserve material or for excreted matters, and to some extent, when green, as an assimilative agent.

3. The Leaves are the seat of the most important chemical changes occurring in the plant. It is here that the reactions characteristic of vegetable life mainly take place-the formation of carbohydrates from carbon dioxide and water, of amides and albuminoids from the same constituents and the nitrates and sulphates taken in through the roots. They also fulfil another most important function -as a means by which the water absorbed by the root may be got rid of by evaporation. This process of transpiration, as it is called, takes place at a rate which depends upon several circumstances, among others, upon the hygrometric state of the atmosphere round the leaf. The absorption of carbon dioxide and the evaporation of water take place mainly through the minute openings on the exterior of the leaf known as stomata. Each stoma is provided with two guard cells, by the varying turgescence of which the size of the opening can be regulated. If the guard cells become flaccid, as they tend to do by excessive loss of water by transpiration and also in the dark, they more nearly close the opening-the stoma-between them and so lessen the passage of water vapour outwards and of carbon dioxide inwards. The space below the epidermis of a leaf is surrounded by cells which contain chlorophyll, and it is the energy of light absorbed by this colouring substance which effects the decomposition of carbon dioxide. It is found that the assimilation of carbon dioxide is most active in just those rays of the spectrum of white light which are absorbed by a solution of chlorophyll. This is well shown in the accompanying diagram, Fig. 6, which gives the relative assimilation by plants in different parts of the spectrum (continuous line), and also the relative absorption by a solution of chlorophyll (dotted line). It will be seen that the two curves correspond very closely. ${ }^{3}$

The next diagram ${ }^{4}$ (Fig. 7) gives the distribution of the intensities of the various rays of the solar spectrum as regards assimilation of carbon (continuous line-__-), brightness as measured by the eye (broken line - . - - -), heating effects (dotted line.................), and chemical action on silver salts (broken and dotted line-.-..-.-).

These two diagrams do not agree as to the position of the maxi-

${ }^{1}$ Phil. Trans., 193 (1900), 280.

${ }^{3}$ Engelmann, Bot. Zeitung, 1884, 80.
2 Vide p. 229.

${ }^{4}$ Sachs, Plant Physiology, p. 305. 
mum assimilation, the former placing this in the orange red, where the darkest absorption band of chlorophyll actually occurs ; the latter on the greenish side of the yellow, where the rays brightest to the eye occur. The former diagram is probably the more correct.

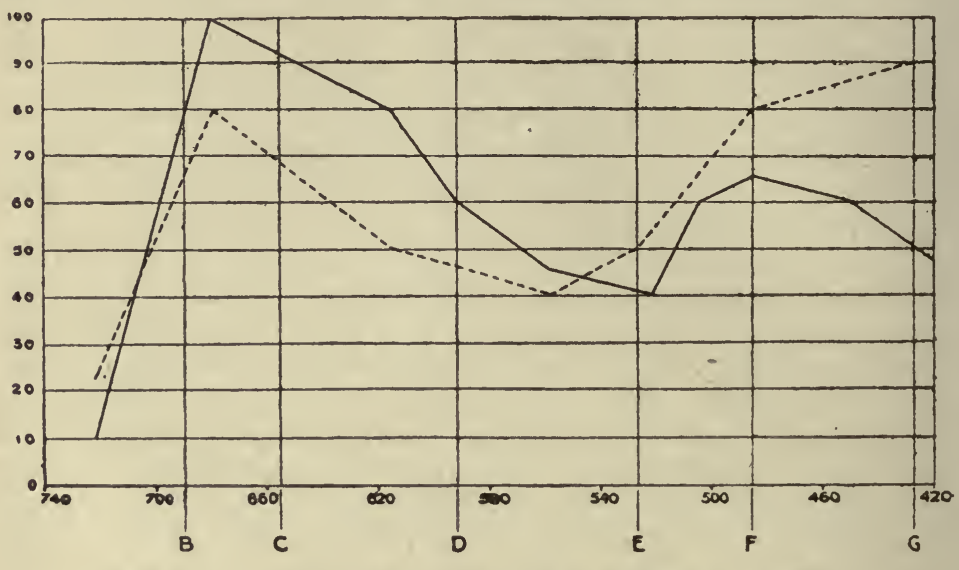

Red | Orange | Yellow | green I Blue

FIG. 6.-Assimilation of carbon and chlorophyll absorption.

In connection with the action of light upon plants, it may be pointed out that though light of low refrangibility (i.e., near the red end of the spectrum) is undoubtedly most active in promoting carbon assimilation, yet light of short wave length (i.e, from the violet end of

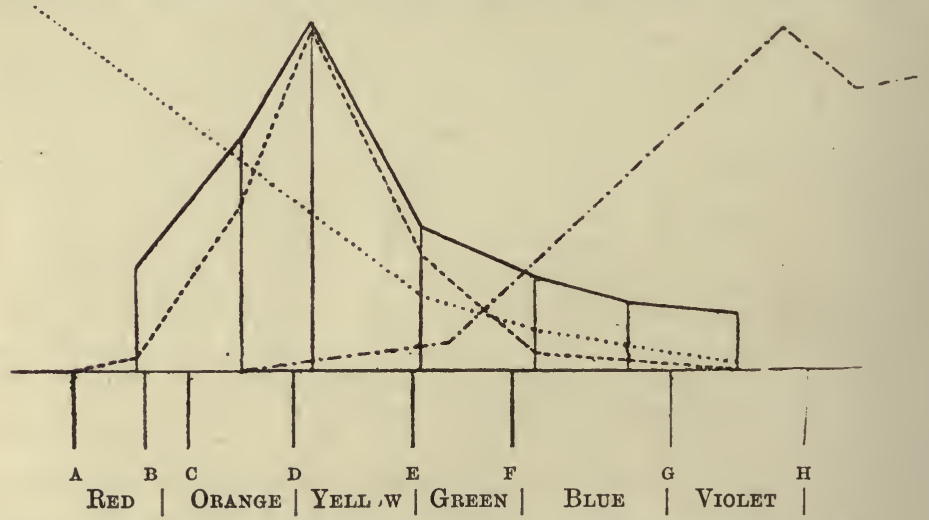

FIG. 7.-Distribution of assimilatory power, light, heat and chemical action.

the spectrum) is of most importance in directing the motion of the leaves or of affecting the growth in length of the shoots.

With reference to our knowledge of the method by which the carbon dioxide of the atmosphere is brought into contact with the 
chlorophyll-containing cells, considerable advances have recently been made. Blackman in $1895^{1}$ described experiments by which he proved that carbon dioxide found its way into (in assimilation) and out of (in respiration) the leaves almost exclusively by the stomata, and not, as was generally believed, by diffusion through the cuticle and epidermis. When the rate at which carbon dioxide is absorbed by a vigorously growing leaf in sunlight is taken into account, and also the very limited area of the stomatal slits, it is difficult to realise how the necessary interchange through these slits can take place. Brown and Escombe ${ }^{2}$ found that a leaf of Catalpa bignioides can absorb from ordinary air, containing three parts per 10,000 of carbon dioxide, about 07 cc. (N.T.P.) of carbon dioxide per square centimetre of leaf surface, per hour. On each square centimetre there were 14,500 stomata, and each stoma, when fully open, had an area of 0000618 square millimetre. Consequently the united area of the stomatal openings only amounted to 0.9 per cent of the whole surface. Hence, if all the absorption took place by diffusion through these openings, diffusion of carbon dioxide through them must have taken place at the rate of about 7.77 cc. per square centimetre, per hour. With strong caustic soda solution they found that the rate of absorption of carbon dioxide from normal air by a free surface varied from $0.12 \mathrm{cc}$. to 0.177 cc. per square centimetre, per hour. So that a leaf of catalpa in sunlight, absorbs carbon dioxide at about half the speed at which it would if covered with a continually renewed film of caustic soda solution, and if all absorption occurs through the stomata the carbon dioxide must move about fifty times as fast through the openings as it would if they were filled with a strong solution of caustic soda.

Brown and Escombe have shown, however, that, when an absorbent surface is covered with a diaphragm placed some distance above it, the rate of diffusion of a gas from the outside air into the absorbing chamber, per unit area, increases enormously with a diminution of size of the aperture. This fact is understood by applying the kinetic theory of gases to the problem. The chance of any given molecule of carbon dioxide moving by virtue of its kinetic motion into the cell is proportional to the area of the opening; but once within the cell its chance of moving out again is less and less as the size of the aperture diminishes. Now the rate of diffusion through an aperture is the difference between the number of molecules which move in and out in a given time.

The number of molecules, so long as the temperature remains constant, moving inwards is solely dependent upon-

(1) The area of the aperture-say A.

(2) The partial pressure of the carbon dioxide in the atmosphere outside-say P.

The number of molecules moving outwards similarly depends upon-

(1) The area of the aperture-A.

(2) The partial pressure of the carbon dioxide in the chamber-say $\mathrm{P}^{\prime}$. Let $x=$ number of molecules entering in one second and $y=$ number leaving in one second.

${ }^{1}$ Phil. Trans., vol. 186 (1895), 485.

${ }^{2}$ Ibid., vol. 193 (1900), 232. 
Then $x=k$ AP.

and $y=k \mathrm{AP}^{\prime}$.

Of these quantities $\mathrm{A}$ is common, $\mathrm{P}$ is constant, about 0003 of an atmosphere, but $\mathrm{P}^{\prime}$ depends upon the ratio of $x$ to the rapidity with which the carbon dioxide is absorbed. This last will be proportional to the area of the absorbing surface-say $\mathrm{S}$.

$$
\therefore \mathrm{P}^{\prime}=c \frac{k \mathrm{AP}}{\mathrm{S}}
$$

Now the rate of diffusion is-

$$
\begin{aligned}
x-y & =k \mathrm{AP}-k \mathrm{AP}^{\prime} \\
& =k \mathrm{AP}-k \mathrm{~A}\left(c \frac{k \mathrm{AP}}{\mathrm{S}}\right)
\end{aligned}
$$

Dividing by $k \mathrm{P}$ it is seen that the rate of diffusion is proportional to-

$$
\mathrm{A}-\frac{c k}{\mathrm{~S}} \mathrm{~A}^{2}
$$

or, per unit area, to-

$$
1-\frac{c k}{\mathrm{~S}} \mathrm{~A}
$$

Hence the smaller the value of the area of the aperture the greater is the amount of diffusion per unit area. The essential point in connection with this phenomenon is that by means of small apertures it is possible to have, on the one side, air containing practically its full amount of carbon dioxide, while on the other, the inside, the air is kept practically devoid of that gas ; consequently very little diffuses outwards, provided the aperture be very small compared with the area of the absorbing surface. ${ }^{1}$

In the cases of the leaves of two plants, Catalpa bignioides and Helianthus annuus, Brown and Escombe made approximate measurements of the superficial area of the spongy absorptive surfaces of the cells of the parenchyma and of the area of the stomata opening into the space. They found a ratio in the case of the sunflower of about $212: 1$, in the case of catalpa of $1159: 1$.

In the case of Helianthus the maximum rate of absorption of carbon dioxide by direct measurement was about 0.134 cc. per square centimetre of leaf surface per hour. This, according to Brown and Morris, would result if the partial pressure of the carbon dioxide within the intercellulair space were reduced by only about 6 per cent. If the absorption of carbon dioxide were perfect and able to keep the partial pressure at practically nil the amount of absorption of a helianthus leaf should be about 2 or 2.5 cc. carbon dioxide per square centimetre per hour if the stomata be fully opened, or the area of the openings might be reduced to $\frac{1}{15}$ of their maximum and yet allow of the maximum observed absorption.

${ }^{1}$ This explanation, based on the kinetic theory of gases, appears to the author to be clearer and more in accordance with what he believes to be the true mechanism of tha phenomenon than the more elaborate and more mathematical conception described by Brown and Escombe, in which the process of diffusion is pictured as analogous to a flux or flow of carbon dioxide through the aperture. 
What has been said about absorbed carbon dioxide is equally true of the evolved oxygen in assimilation or of carbon dioxide in respiration.

Diffusion is also quite capable of accounting for the transpiration of water through the stomata, and the outward movement of water or oxygen would thus not interfere with the inward passage of the carbon dioxide.

With reference to the chemical reactions which attend the assimilation of carbon dioxide by plants much work has been done. The chlorophyll granules frequently enclose starch granules, and for a long time it was thought that starch was the first body formed in the assimilative act, and that sugar, also detected in leaves, was formed entirely from starch by hydrolysis.

It was shown in 1886 by Meyer ${ }^{1}$ that leaves floated on solutions of sugar were able to produce starch. From levulose (10 per cent solution) almost all the leaves tried produced starch, a smaller proportion were able to utilise dextrose, while still fewer could form starch from galactose. Baeyer, in 1870, suggested that the formation of carbohydrates by leaves was probably effected by the formation of formaldehyde, $\mathrm{O}=\mathrm{CH}_{2}$, and its subsequent polymerisation. Very little evidence in favour of this view was forthcoming, however; indeed Bokorny in $1888^{2}$ showed that formaldehyde itself would not act as a source of starch owing to its poisonous action. In $1891^{3}$ he succeeded in using as a nutrient a dilute solution of sodium hydroxymethylsulphonate, $\mathrm{CH}_{2}(\mathrm{OH}) \cdot \mathrm{SO}_{3} \mathrm{Na}$, which readily splits up into formaldehyde and sodium hydrogen sulphite-

$$
\mathrm{CH}_{2}(\mathrm{OH}) \cdot \mathrm{SO}_{3} \mathrm{Na}=\mathrm{OCH}_{2}+\mathrm{NaHSO}_{3} \text {. }
$$

By the addition of sodium or potassium phosphate the injurious effect of the acid sulphite upon the plant could be prevented, and he then found that the leaves of Spirogyra majuscula were able to form starch from a very dilute solution of this formaldehyde derivative. Baeyer's hypothesis was thus confirmed.

According to Brown and Morris ${ }^{4}$ cane sugar is probably the first sugar formed in the process of assimilation. This view is supported by the recent work of Parkin on the assimilation of the leaves of the snowdrop. ${ }^{5}$ Its formation proceeds until the cell-sap attains a certain concentration, varying. in different plants, when starch granules begin to form from it. These are intended as reserve materials and become attacked by the diastase, present in all leaves, as soon as the sugar solution, by diffusion to other portions of the plant, sinks below a certain concentration. It is thought that inversion of the cane sugar into dextrose and levulose precedes its translocation from cell to cell and that maltose is the chief product of the diastatic action on starch; that, of the invert sugar formed in the plant, the dextrose is first used

${ }^{1}$ Bot. Zeit., 1886, Nos. 5 and 6 ; Jour. Chem. Soc., 1886, Abstracts, 902.

${ }^{2}$ Land wirt. Versuchs-Stat., 1889.

${ }^{3}$ Ber. deut. bot. Gesell., 1891, 103 ; Jour. Chem. Soc., 1891, Abstracts, 1539.

+ Jour. Chem. Soc., 1893, Trans., 604.

${ }^{5}$ Biochem. Jour., 1911, 6, 1; Jour. Chem. Soc., 1911, Abstracts, ii. 1127. 
up in respiration and tissue formation, and consequently that levulose enters the stem of the plant in larger quantities than dextrose.

Usher \& Priestley ${ }^{1}$ have adduced evidence that the interaction of carbon dioxide and water in the presence of chlorophyll yields, first of all, formaldehyde and hydrogen peroxide :-

$$
\mathrm{CO}_{2}+3 \mathrm{H}_{2} \mathrm{O}=\mathrm{HCHO}+2 \mathrm{H}_{2} \mathrm{O}_{2}
$$

that the hydrogen peroxide is quickly destroyed by enzymes which they showed were present in all green leaves, evolving oxygen, and that the formaldehyde is as rapidly polymerised, by the living protoplasm, into carbohydrates.

The formation of carbohydrates, though perhaps the most important function of the leaves, is by no means their only one.

In addition there are two processes which may be briefly described-transpiration of water and formation of nitrogenous organic substances.

Transpiration is effected, as already stated, chiefly through the stomata; but exhalation of aqueous vapour occurs from almost all the exposed parts of plants. The activity of transpiration depends chiefly upon the temperature, the humidity of the air, and the amount of light received by the plant. It is increased by a rise of temperature or by brighter light, but diminishes with greater humidity of the air around. It is also regulated by the size of the aperturesthe stomata-through which the greater quantity of the transpiration is effected. These openings are altered in size according to the greater or less turgidity of the guard cells.

In consequence of this escape of water from the leaves, a diminished pressure is often set up in the upper parts of a plant, so that the root pressure is aided in driving water from below. Transpiration is thus active in producing the rise of sap and the consequent bringing up of the mineral matters absorbed by the roots into the leaves, there to be elaborated into nutritive materials.

The amount of water evaporated by a plant increases if the soil water or culture fluid is very dilute. Oats were found to evaporate 515 grammes of water for each gramme of dry produce when grown in a 3 per cent nutritive solution, but 688 grammes of water in 0.25 per cent solution. ${ }^{2}$

Direct determinations by the author of the water transpired by a potato plant growing in soil, gave 467 grammes for each gramme of solid matter formed. This was on unmanured soil in the very dry atmosphere of the Transvaal in 1904. A parallel experiment, on soil well manured with basic slag and potassium nitrate, gave 284 grammes of water transpired for each gramme of dry matter formed.

The building up of nitrogenous, proteid matter from carbohydrates and nitrates or ammonium salts is not thoroughly understood. It is generally stated that the presence of light is essential to this process and that the production of proteids from nitrates and sulphates requires the energy of light to bring about the necessary reduction of

${ }^{1}$ Proc. Roy. Soc., 1906, 77, 369 ; Jour. Chem. Soc., 1906, Abstracts, ii. 299.

${ }^{2}$ Heinrich, Ann. Agron., 1897, 186 ; Jour. Chem. Soc., 1897, Abstracts, ii. 424. 
nitrogen and sulphur from their oxidised compounds. ${ }^{1}$ Experiments made recently, especially in Japan, show that barley. French beans and potatoes are able to produce proteids from nitrates in complete darkness, provided they be supplied with a sufficient amount of sugar ; with small quantities of sugar no proteids were formed. Hence the necessity of light in proteid formation really depends upon the production of abundance of carbohydrates. Asparagine is probably an intermediate product between nitrates and proteids and accumulates in the plant if the conditions for proteid production are not favourable. ${ }^{2}$

Since asparagine seems undoubtedly to be produced from proteids when translocation of nitrogenous matter takes place, it appears that amides are products both of anabolism and katabolism. ${ }^{3}$ It has been shown that in many plants the leaves cut in the morning contain much less starch and nitrogenous material than similar leaves cut in the evening, proving that during the night there is a transference of starch and albuminoids stored during the day in the leaves, to other parts of the plant. ${ }^{4}$

The Flowers and Seeds. - The formation of flowers and seeds is a process which, in many plants, is the final act of their vitality. During flowering, true respiration, i.e., oxidation of carbonaceous matter and evolution of carbon dioxide, takes place more rapidly than usual, and in some cases to an extent sufficient to bring about a sensible rise of temperature. It must be remembered that respiration goes on during the whole of a plant's active existence, but during daylight is more than counterbalanced by the assimilative process already described.

In certain plants-biennials-preparation for the great work of seed formation occupies the whole of their first year's life. A large store of reserve material is accumulated, either in the root or stem, and during the second year this is utilised in the production of a flower stem and seeds.

During the formation of seed a concentration of nutritive matter from the stem, root and foliage into the seed takes place, and the main portions of the plant are thus robbed of most of their important constituents. In many plants the maximum amounts of nutritive matters are found in the leaves, stems, etc., immediately before flowering.

A store of food material, intended for the nourishment of a new plant, accumulates in the seed. Albuminoids are always present, together with phosphorus, sulphur, potassium, chlorine and the other elements essential to plant life. Of carbonaceous matter, however, two varieties occur. Some seeds contain large amounts of carbohydrates, chiefly starch, while others are practically devoid of starch, but contain fats or oils in large proportion.

${ }^{1}$ Godlewski, Jour. Chem. Soc., 1897, Abstracts, ii. 583.

${ }^{2}$ Kinoshita, Jour. Chem. Soc., 1896, Abstracts, ii. 54 ; Suzuki, Jour. Chem. Soc., 1899, Abstracts, ii. 323.

3 Vide Wassilieff, Ber. deut. botan. Gesell., 1908; Jour. Chem. Soc., 1908, Abstracts, ii. 1976, and Scurti and Parrozzini, Gazzetta, 1908, 216 ; Jour. Chem. Soc., 1908, Abstracts, ii. 417.

${ }^{4}$ Suzuki, Jour. Chem. Soc., 1897, Abstracts, ii. 580. 


\section{CHAPTER XII.}

\section{Crops.}

IN this chapter will be given a short account of the chemical characteristics of the chief crops of the farm. Some of the crops described cannot be grown successfully in temperate climates, e.g., England, but are included because of their importance as food stuffs. A brief description of the chemistry of some of the more important fruits is also embodied.

Crops may be grouped according to various methods. The following classification will be adopted here :-

1. Those in which the seed (or fruit) is the portion of the plant most valued.

These may be sub-divided into-

(a) Cereals-wheat, barley, oats, rye, maize, rice, millet, sorghum.

(b) Leguminous seeds-beans, peas, lentils, lupines, earth nuts, soy beans, cow peas.

(c) Miscellaneous seeds-buckwheat, cottonseed, linseed, hempseed, rape seed, castor seed, sunflower seed.

(d) Fruits-apples, pears, plums, apricots, peaches, cherries, currants, citrus fruits, melons, pumpkins, grapes, bananas, pine-apples.

2. Those in which the root or tuber is the most valued productturnip, swede, mangold, beet, potato, carrot, parsnip, sweet potato, artichoke.

3. Those in which the stem and foliage are of most importance. These include-

(a) Gramineous crops.

(b) Leguminous fodder crops.

(c) Miscellaneous fodder crops.

\section{CLASS 1. GRAIN CROPS AND FRUITS.}

(a) The Cereals. - These are characterised by containing much less nitrogen than leguminous or root crops, and by the richness of their seed in carbohydrates, particularly starch.

They are also remarkable for the large amount of silica which is usually present in the outer portions of the leaves and straw. This silica, which is apparently not essential, is absorbed as soluble silicates, the metals, probably chiefly potassium, being used in the plant, the 
silica being thus merely an excretion. Potash and lime are also present to a less extent in cereals than in other farm crops. Owing to their modest demands for potash, lime and nitrogen, cereals will grow for many seasons in succession upon soil which has become so exhausted as to yield little or no return when planted with leguminous or root crops. They, however, appear to depend for their nitrogen entirely upon nitrates in the soil, and as their growth is practically over before the great season for nitrification begins, they derive great benefit from nitrogenous manures.

Wheat (Triticum vulgare), being usually autumn sown, has a longer period of growth than barley or oats and is consequently better able to supply itself with the necessary food from the soil. With a wheat crop, however, the land loses the spring tillage, which is conducive to nitrification, and therefore nitrogenous manures are perhaps more required by wheat than by the other cereals.

Wheat straw is remarkable for the excessively large amount of silica and small amount of nutritive matter which it often contains.

Wheat is particularly fitted for human food owing to the light, spongy and palatable bread which can be made from wheat flour. This is due to the richness of the grain in gluten and the peculiarity of this gluten as compared with that occurring in the other cereals.

According to Osborne and Voorhees, the proteids of the wheat grain consist mainly of gliadin and glutenin, together with smaller quantities of a globulin, an albumin and a proteose. The average nitrogen content of these proteids is $17 \cdot 6$, so that the factor for converting nitrogen into proteid in the case of wheat should be, not 6.25 , but only $5 \cdot 68$. If this were adopted it would diminish the proteid item in analyses and correspondingly increase the soluble carbohydrates. On hydrolysis, the wheat proteids yield relatively large amounts of glutamic acid, proline and leucine, but small quantities of lysine and arginine; tryptophane and histidine are present and a considerable amount of ammonia.

The proportion of total protein in wheat varies considerably, spring wheat containing more than winter varieties, hard or durum wheats also being high in protein content. Climate, too, has an enormous influence upon the proportion of protein in the grain; samples grown from the same seed in different districts often show a variation of 50 per cent in their protein content.

The analyses given of wheat from various countries (p. 236), compiled by König, will indicate the sort of variations shown.

The actual amounts of moisture found are given in the following table but the figures for all other constituents are calculated to a basis of 13.37 per cent of moisture, so as to render comparison easier.

In the case of wheat grown in Kansas, a protein content of 22 per cent is by no means uncommon; such wheats are hard and horny, while in England and Scotland, where the plant takes longer to mature, the grain is soft and starchy and may contain as low as 10 , or even less, per cent of proteins.

The "strength" of wheat flour, i.e., its capacity for yielding large 


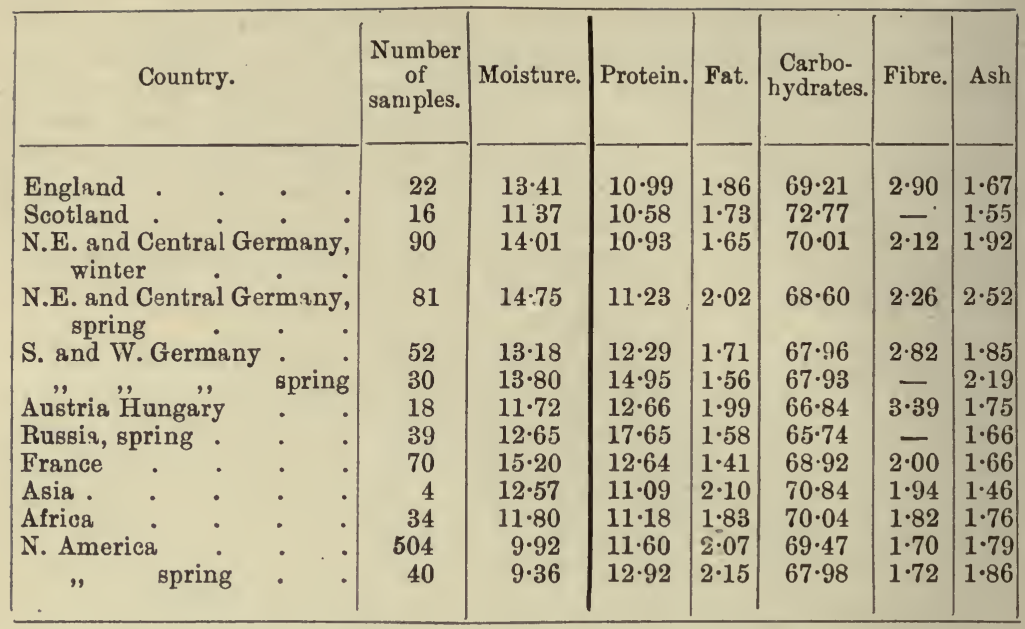

well-shaped loaves in baking, is determined, according to Wood ${ }^{1}$ by two factors: (1) the amount of carbon dioxide evolved in the dough, which is determined by the amount of sugar present in the flour, together with that produced by the action of the diastase while the dough is rising, and (2) the consistency of the gluten. This last, however, does not depend entirely upon the amount or chemical composition of the gluten, but partly depends upon the acidity and salt content of the liquid in the dough.

Wheat grows best on a firm seed bed and therefore is suited to soils containing a fair amount of binding constituents-clay or humus, rather than to open, sandy soils.

Rye (Secale cereale) closely resembles wheat in composition and requirements. In England it is not often grown for grain but on the continent of Europe it forms a large proportion of the food of the peasantry.

The proteids of rye have been examined by Osborne, who found them to consist mainly of a gliadin, soluble in alcohol, edestin, a proteose, soluble in salt solution, an unidentified proteid insoluble in salt solution and a small quantity of a water-soluble leucosin. The average nitrogen content of the rye proteids is $17 \cdot 6$, so that the nitrogen in rye should be multiplied by $5 \cdot 68$ instead of $6 \cdot 25$, to give the protein.

König gives, as the average composition-

\begin{tabular}{|c|c|c|c|c|c|c|}
\hline & Water. & Protein. & Fat. & Carbohydrates. & Fibre. & Ash. \\
\hline Average of 173 analyses & $11 \cdot 15$ & $10 \cdot 81$ & $1 \cdot 77$ & $70 \cdot 21$ & $1 \cdot 78$ & $2: 06$ \\
\hline Spring rye (11 samples) & $12 \cdot 00$ & $12 \cdot 90$ & $1 \cdot 98$ & $68 \cdot 11$ & $1 \cdot 71$ & $1 \cdot 93$ \\
\hline
\end{tabular}

${ }^{1}$ Jour. Agric. Science, 1907, 2, 139, 267. 
Barley (Hordeum distichum, two rowed; $H$. vulgare, four and six rowed). This crop, generally spring sown, is suited to light land, well provided with plant food, though not too rich in nitrogen. Barley is grown chiefly for malting purposes or for cattle food, though in some countries it is used for bread making. For malting, uniformity of grain is one of the most important points; a low protein content is also desirable, so that regular distribution of the manure on the land and avoidance of excessive supplies of nitrogen are important points in its cultivation. The wide and narrow eared types of the two-rowed variety are the favourite brewing barleys.

König gives as the mean of 120 analyses of German barley-

$\begin{array}{lccccc}\text { Water. } & \text { Protein. } & \text { Fat. } & \text { Carbohydrates. } & \text { Fibre. } & \text { Ash. } \\ 14.05 & 9.88 & 1.80 & 66.75 & 4.77 & 2 \cdot 75\end{array}$

while Hall found, as the mean of 21 analyses of Chevalier barley-

$\begin{array}{llllll}16.23 & 9 \cdot 69 & 1.65 & 66.06 & 4 \cdot 10 & 2 \cdot 27\end{array}$

The protein content ranges from 8 per cent, or even lower, in first class malting barleys, to 10 or 11 per cent, or even more, in low quality malting barleys, though obviously the latter would have the higher value for feeding purposes.

Osborne ${ }^{1}$ found that the proteids of barley consisted of insoluble proteids, 41 per cent, hordein, 37 per cent, leucosin, 3 per cent, and edestin and proteose, 19 per cent. Hordein, on hydrolysis, yields much the same products as the gliadin of wheat or rye.

The carbohydrates of barley grain consist chiefly of starch (about 55 per cent of the dry matter), sugars about 4 per cent (including sucrose, dextrose and raffinose) and pentosans and furfuroids.

Barley divested of its outer, fibrous coating constitutes "pearl barley" used for culinary purposes.

The straw of barley is more palatable, digestible and nourishing than that of wheat or rye and is much used as cattle food.

Oats (Avena sativa) are capable of ripening in cooler climates than most of the other cereals. Many varieties are known. The grain in its finished state, retains a considerable proportion of huskvarying from about 19 per cent of the whole in some old Scotch varieties to 27 per cent in some of the newly introduced varieties.

Oats are characterised by a high proportion of oil, albuminoids, ash and crude fibre. They are liable to considerable variation in composition, however.

Osborne found that the proteids of the oat consisted chiefly of three-soluble in alcohol, common salt solution, and alkali respectively-the mean nitrogen content of these three proteids being 16.4 per cent, so that the factor for converting nitrogen into proteid would be $6 \cdot 1$.

The straw of oats is even better as a cattle food than that of barley. Oat-hay, made by cutting the crop while still green and before the grain is ripened, is largely used as food for horses, mules and cattle in some countries, e.g., S. Africa and America.

1 Jour. Amer. Chem. Soc., 1895, 435. 
The following analyses, compiled chiefly by Wiley, König and Hendrick, may serve to show the variability in composition :-

\begin{tabular}{|c|c|c|c|c|c|c|}
\hline & Water. & Protein. & Fat. & Carbohydrates. & Fibre. & Ash. \\
\hline Scotch, old varieties $(40)$ & $12 \cdot 2$ & $15 \cdot 0$ & $8 \cdot 6$ & - & - & - \\
\hline " new varieties (38) & 121 & $14 \cdot 5$ & $6 \cdot 9$ & - & - & - \\
\hline American (22) . & $12 \cdot 1$ & $10 \cdot 1$ & $6 \cdot 2$ & $68 \cdot 6$ & $9 \cdot 3$ & 2.99 \\
\hline French (196) & $13 \cdot 5$ & $9 \cdot 5$ & $3 \cdot 5$ & $62 \cdot 5$ & $9 \cdot 2$ & $3 \cdot 26$ \\
\hline Mid. and N. German (31) & $12 \cdot 5$ & $10 \cdot 8$ & $5 \cdot 3$ & $58 \cdot 2$ & $10 \cdot 3$ & $3 \cdot 29$ \\
\hline S. and S. W. German (16) & $13 \cdot 4$ & $11 \cdot 4$ & $5 \cdot 3$ & $58 \cdot 1$ & $9 \cdot 9$ & $3 \cdot 18$ \\
\hline World's Fair Exhibits (72) & $10 \cdot 0$ & $12 \cdot 1$ & $4 \cdot 4$ & $58 \cdot 3$ & $11 \cdot 9$ & $3 \cdot 35$ \\
\hline
\end{tabular}

Maize, Indian Corn, or "Mealies" (Zea mays) is one of the most important cereals.

The grain is largely used for human food, as food for cattle, horses and mules, and the green leaves and stalk can be used as fodder.

By fine grinding, after removal of the bran, it yields "corn flour" or "maizena," used as a substitute for arrowroot and in cookery. The unripe grain on the cob is considered a delicacy by some people. The spathes or sheaths of the cob can be made into paper.

The plant is a majestic one, sometimes attaining a height of 12 or $15 \mathrm{ft}$. The male flower is borne at the top of the stem in a feathery panicle, while the female flowers, usually 2 or 3 on each shoot, grow out from the axils of the leaves enveloped in a membranous sheath, the long, often pink, styles hanging out from the tops of the sheaths as silky filaments. After fertilisation (the pollen often being wind borne), the female flowers each form an ear or "cob" consisting of a central conical woody core, with the grain arranged regularly around it and enveloped in several spathes.

Many varieties are known, differing in shape, size, colour, number of rows on the cob, and other properties.

The varieties may be classed into five types:-

1. Dent corn, in which the starchy main mass of the grain is enveloped, except at the top, by a horny layer. As the white floury inner starch dries, contraction occurs which is resisted by the horny layers, and therefore produces an indentation at the top of the grain. This gives the grain a supposed resemblance to a tooth, hence the name dent.

2. Flint corn, in which the white flowery starch is entirely surrounded by the horny layer. The grain therefore remains smooth and convex at the top. Flint corn has a translucent appearance and may be white or coloured.

3. Pop corn, in which nearly all the starch is horny.

4. Soft corn or bread corn, in which there is practically none of the horny coating. The grain remains smooth on drying, since contraction is uniform. This variety is opaque in appearance.

5. Sweet corn or sugar corn, in which the starch is partially replaced 
by sugar (glucose). Such grain is translucent, and owing to the great shrinkage in drying, very wrinkled.

Maize requires a warm climate and abundant sunshine. In most soils the manures needed appear to be phosphates, lime, potash and nitrogen, in the order given.

In chemical composition, the maize grain varies considerably in the different types. As a rule the proportion of fat is dependent upon that of the germ in the grain, while the nitrogenous matter is chiefly determined by the proportion of horny matter present.

The following table gives the average composition of various types, all the figures, except those for water, having being calculated to a basis of an average content of 13.32 per cent of moisture :-

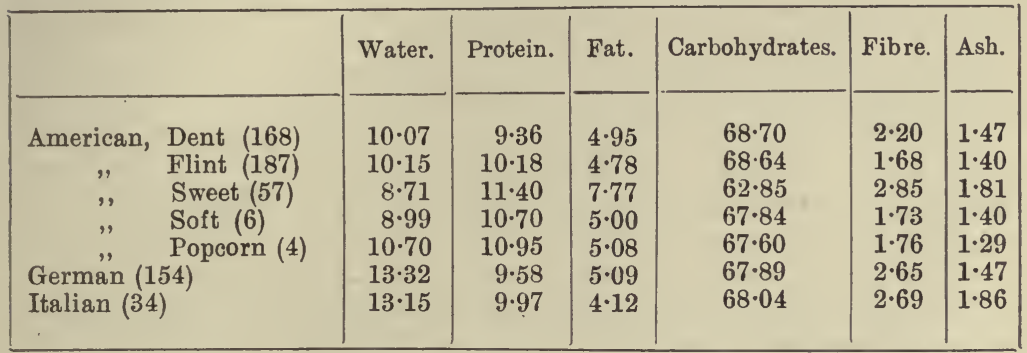

The proteids of maize, according to Osborne ${ }^{1}$ consist chiefly of zein and a proteid soluble in dilute potash solution, together with small quantities of maysin, a globulin, an edestin and a proteose. Zein, on hydrolysis, yields large quantities of leucine, glutamic acid, proline, phenylalanine, tyrosine and alanine but no tryptophane, glycine, or lysine.

To the absence of tryptophane, the inability of zein to serve as the sole nitrogenous food of animals is attributed by Willcock and Hopkins. ${ }^{2}$

Others attribute the ill effects of zein upon animals to the presence of phenylalanine and tyrosine, from which phenolic compounds are readily split off, and to the poisonous effects of the phenols thus formed.

The carbohydrates of maize consist chiefly of starch, but sucrose, glucose, dextrin and pentosans are also present. In the immature, sweet corn, the sugar may amount to as much as 9 or 10 per cent.

Rice (Oryza sativa) is a most important crop in many hot countries and forms the staple food of many millions of human beings. It is generally cultivated in hot, swampy, unhealthy districts, but one variety-upland or hill rice-will grow at an altitude of $6000 \mathrm{ft}$. and without irrigation. Organic nitrogenous manures and superphosphates appear to be the chief manures used. Whole rice or "paddy" is fairly rich in protein, fat and ash, but when deprived of its brown

${ }^{1}$ Jour. Amer. Chem. Soc., 1897, 19, 525. 2 2 Jour. Physiol., 1906, 35, 88. 
husk and subjected to a milling process which also removes products known as "rice bran" and "rice polish," the familiar white grain of commerce is left, which consists mainly of starch.

The following analyses are typical :-

\begin{tabular}{|c|c|c|c|c|c|c|}
\hline & Marsh rice. & Mountain rice. & White rice. & Husks. & Bran. & "Polish." \\
\hline Moisture & dried & dried & $12 \cdot 4$ & $8 \cdot 2$ & $9 \cdot 7$ & $10 \cdot 0$ \\
\hline Protein . & $7 \cdot 0$ & $8 \cdot 7$ & $7 \cdot 4$ & $3 \cdot 6$ & $12 \cdot 1$ & $11 \cdot 7$ \\
\hline Fat . & $2 \cdot 3$ & $2 \cdot 6$ & 0.4 & 0.7 & $8 \cdot 8$ & $7 \cdot 3$ \\
\hline Carbohydrates & $84 \cdot 7$ & $85 \cdot 5$ & $79 \cdot 2$ & $38 \cdot 6$ & $49 \cdot 9$ & $59 \cdot 0$ \\
\hline Crude fibre . & $4 \cdot 6$ & $2 \cdot 0$ & 0.2 & $35 \cdot 7$ & $9 \cdot 5$ & $6 \cdot 3$ \\
\hline Ash . & $1 \cdot 4$ & $1 \cdot 2$ & 0.4 & $13 \cdot 2$ & 10.0 & $6 \cdot 7$ \\
\hline
\end{tabular}

Millet.-Many plants are included under this name. Common millet (Panicum miliaceum) is an annual, grown chiefly for fodder.

"Pearl millet" or "Kaffir manna corn" (Pennisetum spicatum) is also grown for forage in America. Its seed, grown on a spike-like head, is small, but contains a large amount of protein (12 per cent in a Transvaal sample).

"Italian " or "golden millet," "German millet," and "Hungarian grass " are varieties of Setaria italica, which grow to a height of 3 or $4 \mathrm{ft}$. and have broad leaves.

Boer manna or foxtail millet (Choetochloa italica) is grown as a forage crop, and makes useful hay if cut before maturity.

Sorghum.-Of this there are several varieties which are largely grown both for forage and for grain.

"Kaffir corn," Andropogum sorghum or Sorghum vulgare, is largely grown in South Africa, the grain being used as food for horses, poultry and natives. It is also largely employed in the manufacture of Kaffir beer by the natives.

Durra or dhoura, Egyptian corn, Jerusalem corn, Guinea corn and broom corn, are varieties of this crop grown in various hot countries.

Broom corn is so called because the panicles after removal of the grain are used in the manufacture of brooms and brushes.

Most members of the millets and sorghums are liable to contain, especially in their immature stage, glucosides, which, when hydrolysed, yield hydrocyanic acid. Cases of poisoning of cattle fed upon young sorghum are fairly common. Up to two grains of hydrocyanic acid per pound has been found to occur in the green material, and it is thought that anything exceeding half a grain of hydrocyanic acid per pound of green fodder may give rise to poisoning.

The following are analyses of the seeds of several millets and sorghums :- 


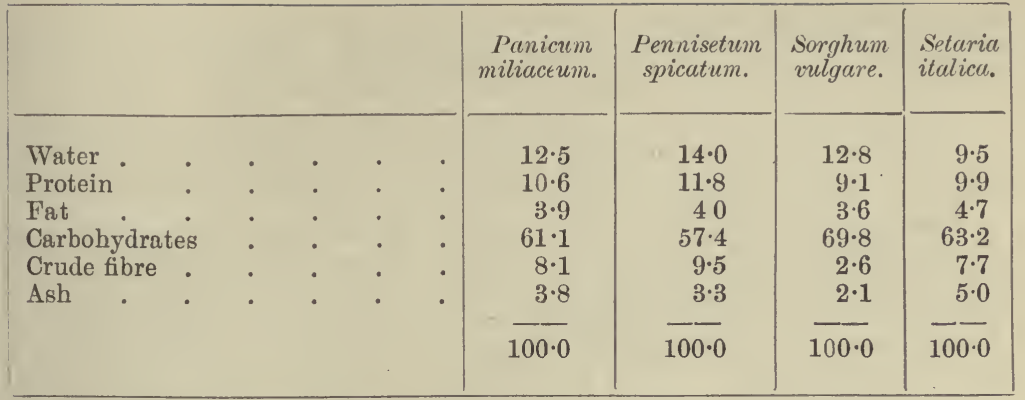

(b) Leguminous Seeds.-The leguminosa differ from the cereals in containing much more nitrogenous matter and lime and in being poorer in silica and phosphoric acid.

The principal leguminous crops grown for the sake of their seed in Britain are beans and peas, but in warmer countries many other legumes are available.

Field Beans (Vicia faba) generally do best on heavy lands, being sometimes planted in the autumn (winter beans) but often in the spring.

Many species of leguminous plants are known as "beans" the chief varieties grown as farm crops (chietly in tropical or subtropical climates) being Phaseolus vulgaris, kidney or haricot beans; $P$. lunatus, Lima or Java beans; P. radiatus, Adzuki beans; Glycine hispida, Soy or Soja beans; Mucuna utilis, velvet beans.

All beans are rich in protein and form valuable, concentrated foods for men and animals. The occurrence of a poisonous cyanogenetic glucoside in Lima beans has already been referred to (vide p. 215).

The Pea.-The field pea (Pisum arvensis), the garden pea, $P$. sativus, and the edible-podded pea, $P$. macro-carpus, are the chief species, of which there are many varieties.

The soil for peas should be rich in lime, but not toa rich in nitrogen, otherwise the yield of seed is small.

The "Chick Pea" (Cicer arietinum) or "gram" of India furnishes a seed which may be used as food. The crop is well adapted for dry hot climates. The haulms, however, are of little use as forage.

"Cow Pea" (Vigna catjang or Dolichos sinensis) rather resembles a bean than a pea. The seed may be used as food, or the whole plant, cut before the seed is ripe, forms a most nutritious hay, greatly relished by stock. The plant withstands drought very well and attains maturity rapidly.

"Pea Nuts," "Ground Nuts," or "Monkey Nuts" (Arachis hypogca) grow well in hot countries. After flowering, the stalk bends over and enters the soil, beneath which the seeds ripen. In harvesting, the crop is ploughed up and the plant and pods forked out. Several varieties are known, some with two, others with three 
or four seeds in each pod. The seeds are used as hurnan food, and very largely for the extraction of arachis oil, of which they contain from 40 to 54 per cent. The foliage makes good hay.

Lentils (Lens esculenta) furnish seeds which are valued for culinary purposes, while the "vines" form a good fodder for cattle.

Lupines (Lupinus spp.) are more often used as green manure than as food, since they contain a bitter alkaloidal substance which is distasteful and may be poisonous. Three species, viz., white (Lupinus albus), blue (L. hirsutus or angustifolins) and yellow (L. luteus), are chiefly used. They grow well in sandy soils, and when ploughed in, furnish large additions of organic matter rich in nitrogen.

The characteristic of leguminous crops-their power of obtaining nitrogen from the air, by the aid of bacteria inhabiting nodules on their roots - has already been described.

The following analyses will show the general composition of leguminous seeds :-

\begin{tabular}{|c|c|c|c|c|c|c|c|c|c|}
\hline & & & & Water. & Protein. & Fat. & Carbohydrates. & Fibre. & Ash. \\
\hline Field beans & & & & $14 \cdot 3$ & $25 \cdot 4$ & $1 \cdot 5$ & $48 \cdot 5$ & $7 \cdot 1$ & $3 \cdot 2$ \\
\hline Lima or Java be & an & & - & $10 \cdot 4$ & $18 \cdot 1$. & 1.5 & $65 \cdot y^{1}$ & - & $4 \cdot 1$ \\
\hline Broad beans, drj & & & & $13 \cdot 5$ & $25 \cdot 3$ & $1 \cdot 7$ & $48 \cdot 3$ & $8 \cdot 1$ & $3 \cdot 1$ \\
\hline Kidney beans, di & & & & $11 \cdot 2$ & $22 \cdot 7$ & $1 \cdot 9$ & $56 \cdot 4$ & $4 \cdot 2$ & $3 \cdot 6$ \\
\hline Soy beans & & & . & $10 \cdot 9$ & $37 \cdot 6$ & $16 \cdot 9$ & $24 \cdot 4$ & $5 \cdot 9$ & $4 \cdot 1$ \\
\hline Broad beans, fre & & & & $58 \cdot 9$ & $9 \cdot 4$ & $0 \cdot 6$ & $29 \cdot 1^{1}$ & - & $2 \cdot 0$ \\
\hline Kidney beans an & d & & & $89 \cdot 2$ & $2 \cdot 3$ & $0 \cdot 3$ & $5 \cdot 5$ & 1.9 & 0.8 \\
\hline Peas, dried . & & . & . & $14 \cdot 0$ & $22 \cdot 5$ & $1 \cdot 6$ & $53 \cdot 7$ & $5 \cdot 4$ & $2 \cdot 8$ \\
\hline Peas, green & & & . & $74 \cdot 6$ & $7 \cdot 0$ & 0.5 & $15 \cdot 2$ & $1 \cdot 7$ & $1 \cdot 0$ \\
\hline Cow peas, dried & & & 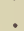 & $13 \cdot 0$ & $21 \cdot 4$ & $1 \cdot 4$ & $54 \cdot 7$ & $4 \cdot 1$ & $3 \cdot 4$ \\
\hline Pea nuts, dry & $\bullet$ & & . & $7 \cdot 2$ & $27 \cdot 0$ & $43 \cdot 0$ & $19 \cdot 3$ & $2 \cdot 3$ & $2 \cdot 2$ \\
\hline Lentils, dry . & 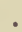 & & . & $14 \cdot 0$ & $25 \cdot 5$ & 1.9 & $52 \cdot 2$ & $3 \cdot 4$ & $3 \cdot 0$ \\
\hline Lupines, yellow & & & 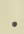 & $14 \cdot 0$ & $38 \cdot 3$ & $4 \cdot 4$ & $25 \cdot 4$ & $14 \cdot 1$ & $3 \cdot 8$ \\
\hline Lupines, blue & & & 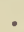 & $14 \cdot 0$ & $29 \cdot 5$ & $6 \cdot 2$ & $36 \cdot 2$ & $11 \cdot 2$ & $2 \cdot 9$ \\
\hline Lupines, white & $\bullet$ & & . & $14 \cdot 0$ & $29 \cdot 4$ & $7 \cdot 2$ & $34 \cdot 2$ & $12 \cdot 2$ & $3 \cdot 0$ \\
\hline
\end{tabular}

${ }^{1}$ Inclusive of fibre.

(c) Miscellaneous Seeds.-Buckwheat (Polygonum fagopyrum) is largely grown in the warmer parts of Europe and America, the seed being used largely for poultry food and also in cattle and pig feeding. It is also used for human food in the form of meal. Its flowers yield much honey to bees, and when cut green it yields an excellent fodder.

Cotton (Gossypium herbaceum) is largely grown for its lint and seed. It requires a warm climate, and does best when frequent rains and a damp atmosphere prevail during its early stages of growth, and hot dry weather during the ripening of the seed.

The seed is enveloped in the lint contained in a boll, which is about the size of a hen's egg. About $300 \mathrm{lb}$. of lint and $650 \mathrm{lb}$. of seed per acre is the usual crop in America.

The seed is very nitrogenous and contains from 20 to 30 per cent 
of oil. The "cake" left after expression of the oil forms a valuable and much used feeding stuff, being very rich in protein and in phosphoric acid.

Flax or Linseed (Linum usitatissimum) is grown either for seed or fibre. For the former, a warm climate is generally best, and the sowing is somewhat thin-25 to $30 \mathrm{lb}$. per acre. For the latter, moist, cooler countries are best, and the seeding is thicker-about $100 \mathrm{lb}$. per acre. In America, a fair yield appears to be about 16 bushels (of $56 \mathrm{lb}$. per bushel) of seed and about $2000 \mathrm{lb}$. of straw.

Linseed is chiefly valued for the oil which it contains-30 or 40 per cent-while the cake left after the extraction of the oil is very rich in nitrogenous and mineral matter and forms a valuable food for cattle. Linseed oil absorbs oxygen from the air and is, perhaps, the best type of a "drying" oil. It is extensively used in the manufacture of paints and linoleum.

Castor Seeds (Ricinus communis).-The plant in warm countries is a perennial and grows to a tree 20 or $30 \mathrm{ft}$. high. In cooler climates, with winter frosts, it can only be grown as an annual. It grows well in almost any soil, but best in a rich, sandy one. The plants commence to bear when four or five months old. The seeds, whose resemblance to a tick gave rise to the botanical name, are contained in a woody capsule. The seeds vary much in size and colour, . according to variety of plant, and usually contain about 50 per cent of oil, which is largely used as a lubricant, for burning, as a medicine, and in the manufacture of soap. The cake left after expressing the oil is generally used as a manure, since it is very poisonous to animals. Immunity, however, to the poison may be acquired, or the poisonous materal, ricin, may be extracted from the cake and it may then be used as a food.

Sunflower (Helianthus annuus) is grown for poultry food or for the sake of the oil which it contains. The plants attain a height of 10 or $12 \mathrm{ft}$., and the seed-heads are about $12 \mathrm{in}$. in diameter and yield about half a pound of seed each. The seed contains a kernel (about half its weight), which contains from 30 to 50 per cent of oil. The oil is used as a substitute for olive oil in cookery, for making soap, and has been employed in adulterating margarine. It is a semidrying oil and is not suitable, therefore, for lubricating purposes. The cake left when the oil is expressed from the seed is a valuable cattle food.

The following analyses show the average composition of some of these seeds :-

\begin{tabular}{|c|c|c|c|c|c|c|c|c|}
\hline & & & Water. & Protein. & Fat. & Carbohydrates. & Fibre. & Ash. \\
\hline Buskwheat & - & & $15 \cdot 6$ & $11 \cdot 3$ & $2 \cdot 6$ & $54 \cdot 8$ & $14 \cdot 4$ & $2 \cdot 8$ \\
\hline Cotton seed & - & . & $10 \cdot 0$ & $21 \cdot 2$ & $25 \cdot 8$ & $19 \cdot 2$ & $19 \cdot 3$ & $4 \cdot 4$ \\
\hline Linseed & . & . & $7 \cdot 1$ & $24 \cdot 2$ & $36 \cdot 5$ & $22 \cdot 9$ & $5 \cdot 5$ & $3 \cdot \overline{8}$ \\
\hline Castor seed. & . & . & $5 \cdot 1$ & $17 \cdot 9$ & $46 \cdot 7$ & $12 \cdot 6$ & $15 \cdot 0$ & $2 \cdot 7$ \\
\hline Sunflower seed & • & . & $7 \cdot \overline{5}$ & $14 \cdot 2$ & $32 \cdot 3$ & $14 \cdot 5$ & $28 \cdot 1$ & $3 \cdot 4$ \\
\hline
\end{tabular}


(d) Fruits.-These are hardly to be classed as ordinary farm crops, but as in some countries great importance is attached to "fruit farming," they may receive brief mention and consideration here. As a rule, they are the produce of perennial plants-trees or shrubsand are therefore not so amenable to cultivation and manuring as the usual farm crops. Their extensive root development enables them to search for food through a larger mass of soil, so that they will often grow on land which may be too poor in plant food to yield payable crops of the usual farm products. They, nevertheless, draw upon the supplies of plant food in two ways :-

(1) To form their fruit, which is usually removed from the tree and lost to the land.

(2) To be locked up in the tissues of the trees. The trunk, branches, roots and leaves all require nitrogen, potash, phosphoric acid, lime and other constituents obtained from the soil. In the case of deciduous trees, the falling leaves restore, annually, a considerable portion of plant food to the soil.

The amount of manurial ingredients removed in fruit is, on the whole, small. American estimates give the following as the weight, in pounds, contained in $1000 \mathrm{lb}$. of the fresh fruits named :-

\begin{tabular}{|c|c|c|c|c|c|c|c|c|}
\hline & & & & & Nitrogen. & Potash. & Lime. & Phosphorus pentoxide. \\
\hline Apple & . & . & . & . & 1.05 & $1 \cdot 40$ & $0 \cdot 11$ & 0.33 \\
\hline Apricot & . & . & . & . & 1.94 & $3 \cdot 01$ & $0 \cdot 16$ & 0.66 \\
\hline Banana & . & . & . & . & 0.97 & $6 \cdot 80$ & $0 \cdot 10$ & $0 \cdot 17$ \\
\hline Cherry & . & - & . & . & $2 \cdot 29$ & $2 \cdot 77$ & 0.20 & 0.72 \\
\hline Fig. & . & . & . & . & $2 \cdot 38$ & $4 \cdot 69$ & 0.85 & 0.86 \\
\hline Grape & . & . & . & . & $1 \cdot 26$ & $2 \cdot 55$ & 0.25 & $0 \cdot 11$ \\
\hline Olive & . & . & . & . & $5 \cdot 60$ & $9 \cdot 11$ & $2 \cdot 43$ & 1.25 \\
\hline Orange & . & . & : & : & $1 \cdot 83$ & $2 \cdot 11$ & 0.97 & 0.53 \\
\hline Peach & . & . & . & . & $1 \cdot 20$ & $3 \cdot 94$ & $0 \cdot 14$ & 0.85 \\
\hline Pear & . & . & . & . & 0.90 & $1 \cdot 34$ & $0 \cdot 19$ & 0.34 \\
\hline Plum & $\dot{0}$ & $\therefore$ & : & : & $1 \cdot 81$ & $3 \cdot 41$ & 0.25 & 0.75 \\
\hline
\end{tabular}

Fruits are usually rich in water and their dry matter often consists largely of sugar, to which their sweetness is due, pentosans, pectins, vegetable acids, of which malic, $\mathrm{C}_{2} \mathrm{H}_{3}(\mathrm{OH})(\mathrm{COOH})_{2}$, citric, $\mathrm{CH}_{2}$ $(\mathrm{COOH}) \cdot \mathrm{C}(\mathrm{OH})(\mathrm{COOH}.) \mathrm{CH}_{2}(\mathrm{COOH})$, tartaric, $\mathrm{CH}_{2} \cdot(\mathrm{COOH}) \cdot \mathrm{CH}(\mathrm{OH})$. $\mathrm{CH}(\mathrm{OH}) \cdot \mathrm{CH}_{2}(\mathrm{COOH})$ and oxalic acid, $\mathrm{COOH} \cdot \mathrm{COOH}$, are the chief, and small quantities of essential oil, to which their characteristic flavours are mainly due.

The following figures show the average compositions of several of the more common fruits, the free acid being given in terms of malic acid, except in the case of the grape (tartaric acid) and the citrus fruits (citric acid) :- 


\begin{tabular}{|c|c|c|}
\hline 这 & मأ $\dot{0} \dot{0} \dot{0} \dot{0} \dot{0} \dot{0} \dot{0} \dot{0} \dot{0} \dot{0} \dot{0} \dot{0} \dot{0} \dot{0} \dot{0} \dot{0} \dot{0} \dot{0} \dot{0} \dot{0} \dot{0} \dot{0} \dot{0}$ & $\ddot{\dot{0}} \dot{0}$ \\
\hline 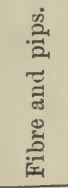 & 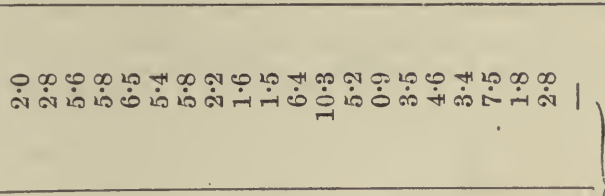 & \multirow{2}{*}{ 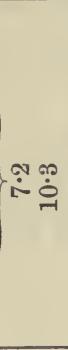 } \\
\hline 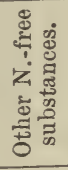 & 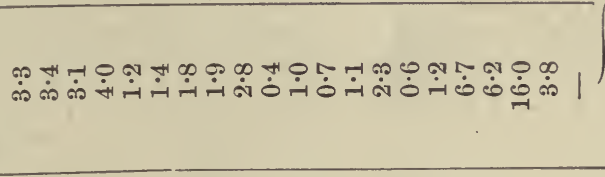 & \\
\hline 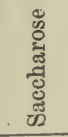 & 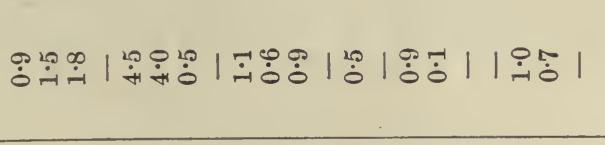 & $\stackrel{\infty}{\dot{\sigma}} 1$ \\
\hline 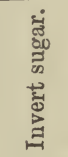 & 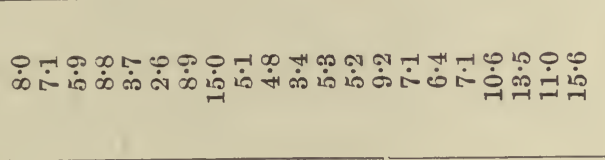 & $\stackrel{\infty}{\dot{\omega}} \dot{0}$ \\
\hline 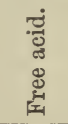 & ர் & $\stackrel{-1}{\pi}$ \\
\hline 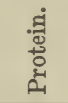 & 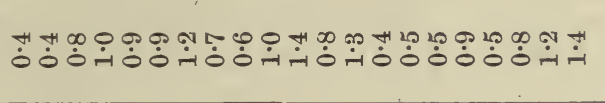 & $\ddot{\dot{r}}$ \\
\hline 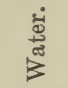 & 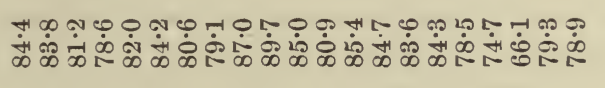 & $\underset{\infty}{\infty} \stackrel{\infty}{\dot{\sim}}$ \\
\hline 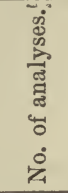 & 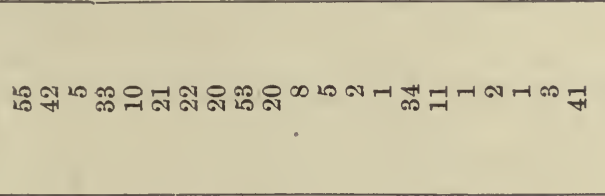 & $8 \%$ \\
\hline 节 & 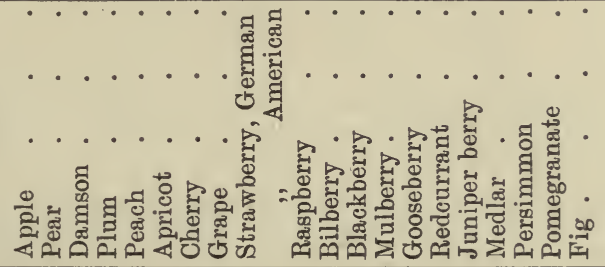 & 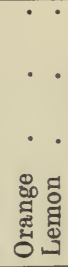 \\
\hline
\end{tabular}

Nuts are very different in composition from the succulent fruits, being much drier, far richer in protein and oil and in all respects more concentrated. 
The following shows the composition of the edible portion of several varieties:-

\begin{tabular}{|c|c|c|c|c|c|c|c|c|}
\hline & & & Water. & Protein. & Fat. & Carbohydrates. & Fibre. & Ash. \\
\hline Almond . & • & - & $4 \cdot 8$ & $21 \cdot 0$ & $54 \cdot 9$ & $15 \cdot 3$ & $2 \cdot 0$ & $2 \cdot 0$ \\
\hline Beeohnut . & - & - & $4 \cdot 0$ & $21 \cdot 9$ & $57 \cdot 4$ & \multirow{2}{*}{\multicolumn{2}{|c|}{$\begin{array}{r}13 \cdot 2 \\
7 \cdot 0\end{array}$}} & $3 \cdot 5$ \\
\hline Brazil nut. & . & . & $5 \cdot 3$ & $17 \cdot 0$ & $66 \cdot 8$ & & & $3 \cdot 9$ \\
\hline Chestnut, fresh & - & - & $45 \cdot 0$ & $6 \cdot 2$ & $5 \cdot 4$ & $40 \cdot 3$ & $1 \cdot 8$ & $1 \cdot 3$ \\
\hline , dried & . & 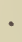 & $5 \cdot 9$ & $10 \cdot 7$ & $7 \cdot 0$ & $71 \cdot 5$ & $2 \cdot 7$ & $2 \cdot 2$ \\
\hline Cocoanut . & . & & $14 \cdot 1$ & $5 \cdot 7$ & $50 \cdot 6$ & \multirow{2}{*}{\multicolumn{2}{|c|}{$\begin{array}{l}27 \cdot 9 \\
13 \cdot 0\end{array}$}} & $1 \cdot 7$ \\
\hline Filbert, dried & . & . & $3 \cdot 7$ & $15 \cdot 6$ & $65 \cdot 3$ & & & $2 \cdot 4$ \\
\hline Walnut, dried & . & . & $2 \cdot 5$ & $18 \cdot 4$ & $64 \cdot 4$ & $11 \cdot 6$ & $1 \cdot 4$ & $1 \cdot 7$ \\
\hline Acorn, fresh & . & 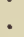 & $50 \cdot 0$ & $3 \cdot 3$ & $2 \cdot 4$ & $36 \cdot 3$ & $6 \cdot 8$ & $1 \cdot 2$ \\
\hline " dried & - & & $15 \cdot 0$ & $5 \cdot 7$ & $4 \cdot 1$ & $61 \cdot 6$ & $11 \cdot 6$ & $2 \cdot 0$ \\
\hline
\end{tabular}

\section{Class 2. ROOT CROPS.}

In these crops, the valuable portion is the large store of organic matter which the plants produce during the first year, either in their underground stem or in enlargements (tubers) on their roots, this reserve being intended to serve as a source of material from which, in the second year, the flowering stem, flower and seed may be formed.

The chief English crops of this type are: the turnip (Brassica Napus, Linn. or Brassica rapa rapifera, Metzger), the swede (Brassica campestris rutabaga, Linn. or Brassica Napus esculenta, D.C.), the mangold or beet (Beta vulgaris), the potato (Solanum tuberosum), the carrot (Daucus carota), the parsnip (Pastinaca sativa), and the radish (Raphanus sativa). Other crops, growing in warmer countries, which may be mentioned here are the sweet potato (Ipomoea batatas or Batata edulis) and the Jerusalem artichoke (Helianthus tuberosus).

The Turnip grows best in cool, damp climates; in hot, dry countries the roots become woody and fibrous.

The average composition of the root is-

$\begin{array}{ccccccc}\text { Water. } & \text { Protein. } & \text { Fat. } & \text { Sugar. } & \text { Other N-free extract. } & \text { Fibre. } & \text { Ash. } \\ 90.67 & 1.12 & 0.24 & 2.55 & 3.55 & 1.11 & 0.76\end{array}$

but great variations are shown. The important factors affecting the composition, are, in order of importance, season, variety, size of root, district and soil.

But even in the same variety, grown apparently under the same conditions and with roots of approximately the same size, variations in composition in individual roots are often found, especially in the amount of sugar present.

The "protein," (i.e., total nitrogen $\times 6.25$ ), of turnips includes from 27 to 50 per cent of the total nitrogen in forms other than proteids, viz., as amino-compounds and nitrates.

The sugars present are chiefly glucose and sucrose, the former 
predominating. The "other $\mathrm{N}$-free extractives" include pectins, pentosans and cellulose.

Turnips are not so hardy as swedes, have rougher leaves of greener colour, which are attached directly to the root and generally have roots with white, sometimes yellow flesh. They contain more water than swedes.

The Swede resembles the turnip in general characters but has bluer leaves, attached to a distinct "neck".

There are many varieties, differing in colour, appearance, size and composition.

König gives as the average composition-

$\begin{array}{ccccccc}\text { Water. } & \text { Protein. } & \text { Fat. } & \text { Sugar. } & \text { Other N-free extract. } & \text { Fibre. } & \text { Ash. } \\ 88.88 & 1.39 & 0.18 & 3.02 & \mathbf{4} .35 & \mathbf{1 . 4 4} & 0.74\end{array}$

In Scotland and the north of Fngland, swedes (and turnips) are richer in solid matter, especially sugar, than the same varieties grown in the south.

The upper half of a root is richer in solid matter than the lower.

In 1904,1 five varieties of swedes were grown simultaneously in Cambridgeshire ( 1 centre), Norfolk ( 2 centres) and Ross-shire (4 centres), and the resulting crops were examined for sugar content.

The mean values were: Cambridgeshire ( 5 crops) 6.2 per cent, Norfolk (10 crops) 6.7 per cent, Ross-shire (20 crops) $7 \cdot 2$ per cent of sugar in the roots.

The effect of season is very great. Thus in 1900, Collins found an average of 6.26 per cent of sugar in twelve varieties of swedes, while in 1901, the same varieties yielded an average of only 4.05 per cent sugar. The effect of manuring is great so far as the yield is concerned but only small in its influence on the composition of the crop (unless through altering the average size of the roots). In all cases, large roots, produced by liberal manuring, are more watery, poorer in sugar, less nutritious, keep worse, and contain a larger proportion of their nitrogen in the non-proteid form, than small ones. Turnips and swedes depend chiefly upon the surface soil and have only limited powers of attacking the insoluble phosphates, though they are generally able to supply themselves with potash. Phosphatic manures, especially superphosphates, and nitrogenous manures,-nitrate of soda, or sulphate of ammonia, - are usually most efiective.

Mangolds and Beets are deeper rooted and better equipped for supplying themselves with food. The supply of nitrogen is often the limiting factor in determining the crop. Being rich in ash constituents and heavy croppers-often yielding twenty-five to thirty tons per acre-they are probably the most exhausting crop grown. They do best in warm, fairly dry climates and in deep, somewhat tenacious soils. Many varieties have been obtained by careful selection. Mangolds (the anglicised form of Mangel-wurzel) or field-beets may be divided into long, tankard and globe forms, of each of which there are many varieties.

${ }^{1}$ Cambridge Univ. Dept. of Agric., Guide to Expts., 1906. 
Being originally derived from a plant which grew on the sea-shore, they still seem to appreciate chlorides and are benefited by applications of common salt.

The Sugar Beet is a variety which has been developed, by careful selection, especially for its richness in sucrose. Many varieties are grown and under favourable conditions, the roots may contain from 15 to 20 per cent of their weight of sugar. It is found that roots not exceeding $2 \mathrm{lb}$. in weight are most suitable. The sugar beet industry has been enormously developed in Germany, Russia, France, Austria and the United States and beet sugar is gradually but surely replacing cane sugar. Of recent years public attention in England has been directed to this crop and it has been demonstrated that it is quite possible to grow abundant crops, rich in sugar, in many parts of lingland. The sugar beet grows best in a warm, moderately damp summer, followed by a dry hot autumn and prefers a deep medium loam well supplied with calcium carbonate, but with not too liberal a supply of nitrogen.

The following figures, according to Kellner, represent the average composition of mangolds and sugar beets :-

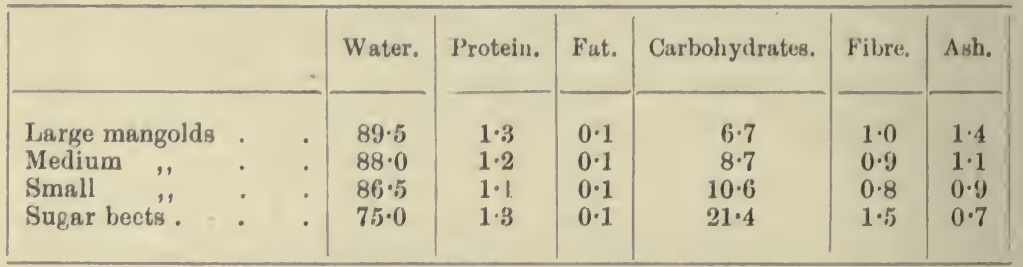

A considerable proportion of the nitrogen of the mangold exists in the root in the form of nitrates, especially soon after harvesting; on keeping, the nitrates diminish, the nitrogen being converted into organic compounds-amino- or partially, perhaps, proteid bodies.

The leaves of mangolds and beet contain much oxalic acid, which, when the leaves are largely eaten by animals, may cause poisonous effects. This is more likely to occur with horses and pigs than with ruminants and the danger may be lessened by sprinkling, over the leaves, some fincly divided calcium carbonate.

The chief carbohydrate in beets is sucrose, but the tri-saccharose, raffinose, is present in small quantity, especially if growth has been checked by frost, or other cause.

The Potato.- In this crop the valued product is the tuber or enlargement on the underground stems. The potato can be grown over a wide range of climates, but its foliage is sensitive to frost. The best soil is a deep, warm, well-drained one, free from acidity and rich in potash and nitrogen. Farm-yard manure, often placed in contact with the "sets," is a favourite dressing and in dry seasons is often especially useful in retaining moisture. Potatoes are propagated by planting tubers, which should be about the size of a hen's egg, or, if larger, the tubers may be cut. From 12 to $15 \mathrm{cwt}$. of sets per acre are usually required. Potatoes are a surface feeding crop and hence require abundant supplies of plant food. Sulphate of ammonia, superphos- 
phate or slag, and sulphate of potash are the artificial manures generally used. Potash manures containing chlorides, e.g., muriate of potash and kainite, are said to render potatoes waxy.

The berry of the potato, as well as the leaves or haulms and, to a much less extent, the tubers, contain a poisonous substance solanine, $\mathrm{C}_{52} \mathrm{H}_{93} \mathrm{NO}_{18}$, which, by the action of acids, splits up into sugar and solanidine, $\mathrm{C}_{40} \mathrm{H}_{61} \mathrm{NO}_{2}$.

The amount of solanine in potatoes is not sufficient to do harm, but, in the shoots from stored potatoes, the amount of this substance so concentrates itself, that poisoning of animals eating the shoots may occur. Still more dangerous are the berries and even the haulms.

Potatoes are liable to considerable fluctuation in composition, the proportion of water being especially variable. Wet seasons, liberal supplies of nitrogen, or large quantities of potassium chloride (e.g., kainite) tend to make the tubers watery and poor in starch. Of the total nitrogen in potatoes, about two-fifths is present in non-proteid forms.

The following figures (Kellner) give the average composition of potatoes :-

\begin{tabular}{|c|c|c|c|c|c|c|c|}
\hline & i & Water. & Protein. & Fat. & Carbohydrates. & Fibre. & Ash. \\
\hline Dry, good quality & . & $74 \cdot 0$ & $2 \cdot 1$ & 0.1 & 21.9 & 0.8 & $1 \cdot 1$ \\
\hline Medium & . & $75 \cdot 0$ & $2 \cdot 1$ & $0 \cdot 1$ & $21 \cdot 0$ & 0.7 & $1 \cdot 1$ \\
\hline Watery & . & $83 \cdot 0$ & $1 \cdot 6$ & $0 \cdot 1$ & $13 \cdot 9$ & 0.6 & 0.8 \\
\hline
\end{tabular}

The amount of dry matter and of starch in potatoes can be estimated with sufficient accuracy for commercial purposes by a determination of the specific gravity of the tubers.

A considerable quantity ( 8 or $10 \mathrm{lb}$.) of the well-cleaned potatoes is weighed as accurately as possible in a wire basket. The latter is then wholly immersed in water and the weight again determined. The weight of the potatoes in air, divided by the loss of weight when weighed in water, gives the specific gravity. The following table, compiled by German investigators, gives approximately the relation between specific gravity, total solid matter and starch :-

\begin{tabular}{|c|c|c|}
\hline Specific gravity. & Dry matter, per cent. & Starch, per cent. \\
\hline $\begin{array}{l}1 \cdot 080 \\
1 \cdot 085 \\
1 \cdot 090 \\
1 \cdot 095 \\
1 \cdot 100 \\
1 \cdot 105 \\
1 \cdot 110 \\
1 \cdot 115 \\
1 \cdot 120 \\
1 \cdot 125 \\
1 \cdot 130 \\
1 \cdot 135 \\
1 \cdot 140 \\
1 \cdot 145\end{array}$ & $\begin{array}{l}19 \cdot 7 \\
20 \cdot 7 \\
21 \cdot 8 \\
22 \cdot 9 \\
24 \cdot 0 \\
25 \cdot 0 \\
26 \cdot 1 \\
27 \cdot 2 \\
28 \cdot 3 \\
29 \cdot 3 \\
30 \cdot 4 \\
31 \cdot 5 \\
32 \cdot 5 \\
33 \cdot 6\end{array}$ & $\begin{array}{l}13 \cdot 9 \\
14 \cdot 9 \\
16 \cdot 0 \\
17 \cdot 1 \\
18 \cdot 2 \\
19 \cdot 2 \\
20 \cdot 3 \\
21 \cdot 4 \\
22 \cdot 5 \\
23 \cdot 5 \\
24 \cdot 6 \\
25 \cdot 7 \\
26 \cdot 7 \\
27 \cdot 8\end{array}$ \\
\hline
\end{tabular}


This table, which assumes that all potatoes contain 5.8 per cent of solid matter other than starch, can obviously have no claim to absolute accuracy, but, for practical purposes, the method has proved very useful.

The Sweet Potato is the tuber of a convolvulus-like plant, Ipomoea batatas, which grows in hot countries. It thrives best in light friable soils, rich in organic matter, and, once established, will yield several crops in successive years. It is propagated by cuttings. The tubers, which sometimes attain a great size, are used in the same way as ordinary potatoes, but are sweeter and less watery. The foliage is eaten greedily by animals, but sometimes contains a cyanogenetic glucoside which renders it poisonous, especially to pigs. From 0.014 to 0.019 per cent of hydrocyanic acid has been found in the green material (i.e., from 1 grain to 1.33 grains per pound).

The following analyses show the average composition of sweet potatoes and their "vines":-

\begin{tabular}{|c|c|c|c|c|c|c|}
\hline & Water. & Protein. & Fat. & Carbohydrates. & Fibre. & Ash. \\
\hline Tubers & $71 \cdot 1$ & $1 \cdot 5$ & $0 \cdot 4$ & $24 \cdot 7$ & $1 \cdot 3$ & $1 \cdot 0$ \\
\hline Stem and leaves & $41 \cdot 6$ & $7 \cdot 6$ & $2 \cdot 1$ & $29 \cdot 3$ & $13 \cdot 6$ & $5 \cdot 8$ \\
\hline
\end{tabular}

Artichokes. - The Jerusalem artichoke is the tuber of Helianthus tuberosus, and resembles the potato in composition except that it contains inulin and lævulin instead of starch, and is usually more watery. Its average composition is-

$$
\begin{array}{cccccc}
\text { Water. } & \text { Protein. } & \text { Fat. } & \text { Carbolydrates. } & \text { Fibre. } & \text { Ash. } \\
79.6 & 1.5 & 0.2 & 16.9 & 0.7 & 1.1
\end{array}
$$

The globe artichoke (Cynara scolymus) is another kind of plant which is grown for the sake of its unripe flower heads of thistle-like character, a portion of which is edible after boiling.

The Carrot, Daucus carota, and the Parsnip, Pastinaca sativa, are sometimes grown as farm crops and furnish excellent, succulent food for animals. The former is somewhat difficult to grow, on account of its slow growth in the early stages and the danger of the crop being overgrown by weeds. Several varieties are known, but the typical red or yellow carrot is rich in a colouring substance, carrotene, $\mathrm{C}_{40} \mathrm{H}_{56}$.

The Radish, Raphanus sativa, of which there are several varieties, is a cruciferous plant, grown rather as a market-garden crop than on the farm. Average composition of the carrot, parsnip and radish :-

\begin{tabular}{|c|c|c|c|c|c|c|c|c|c|}
\hline & & & & Water. & Protein. & Fat. & Carbohydrates. & Fibre. & Ash. \\
\hline Carrot & 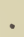 & . & . & $87 \cdot 0$ & 1.2 & $0 \cdot 2$ & $9 \cdot 3$ & $1 \cdot 3$ & $1 \cdot 0$ \\
\hline Parsnip & . & . & . & $83 \cdot 2$ & $1 \cdot 2$ & $0 \cdot 3$ & $13 \cdot 0$ & $1 \cdot 4$ & $1 \cdot 0$ \\
\hline Radish & . & . & . & $86 \cdot 9$ & $1 \cdot 9$ & $0 \cdot 1$ & $8 \cdot 4$ & $1 \cdot 6$ & $1 \cdot 1$ \\
\hline
\end{tabular}




\section{Class 3. FODDER CROPS.}

In these the seeds are of little importance, the foliage and stems being the main parts. They include gramineous (grasses), leguminous and other plants.

Meadow and Pasture Crops.-These consist of very variable mixtures of different plants. The grasses are usually predominant in quantity, and they, in general chemical properties, resemble the cereals. Their ash is rich in silica and potash, but poor in lime; while in the organic portion they contain comparatively little nitrogen, but are rich in carbohydrates. The roots of grasses are mainly confined to the surface soil, so that application of manure must be made if grass land is not to diminish in fertility. Moreover, the root débris of grass land by its accumulation gradually produces a peaty or humic character in the upper portion of the soil, with consequent nitrification and loss of calcium. Hence manuring with bones, lime, or basic slag, or other calcareous substances is generally advantageous.

Liberal additions of nitrate of soda, potash salts and phosphates produce very heavy crops of hay by encouraging the growth of coarse grasses ; but clover and some of the finer grasses are thereby diminished and the quality of the hay deteriorates.

Leguminous Crops, e.g., clovers, trefoil and lucerne, are also present in or linary grass land, but in varying amount. These fodder leguminous crops have the same general characteristics as the leguminous grain crops. Their growth is greatly favoured by additions of potash and lime compounds and by stinting the nitrogenous manuring; the clovers, etc., having an independent supply of nitrogen, are thus able to outgrow their competitors, the grasses. As already stated, leguminous plants are remarkable for the large amounts of nitrogenous matter, lime and potash which they contain. The lime is mainly contained in the leaves. Silica is almost absent. Clover, lucerne, etc., are also grown as crops upon arable land with valuable after-effects. The land is thereby actually enriched in nitrogen, notwithstanding the fact that a very large amount of nitrogen is removed in the crop. The nitrogen is obtained from the air in the manner already described. The beneficial effect of the growth of clover upon the soil has long been known and utilised in agriculture; but it was not until after many laborious researches had been made, that the explanation of the fact was discovered by Hellriegel and Wilfarth about $1888 .{ }^{1}$

By repeated cropping of land with clover a condition known as "clover sickness" is often set up. The seed in the summer germinates and grows well until the autumn or winter, when the plants die off rapidly, and, in many cases, a minute eel-worm attacks the root and stem. Whether these nematoids (Tylenchus) are the cause or a consequence of the disease appears to be uncertain. Clover sickness has also been ascribed to certain fungi. It is said that deficiency of the soil in potash and lime is a predisposing cause of this disease.

${ }^{1}$ Vide p. 67. 

oats.

Other plants are sometimes grown for fodder, e.g., rye, vetches and

The following table shows the average composition of many fodder plants in the fresh condition :-

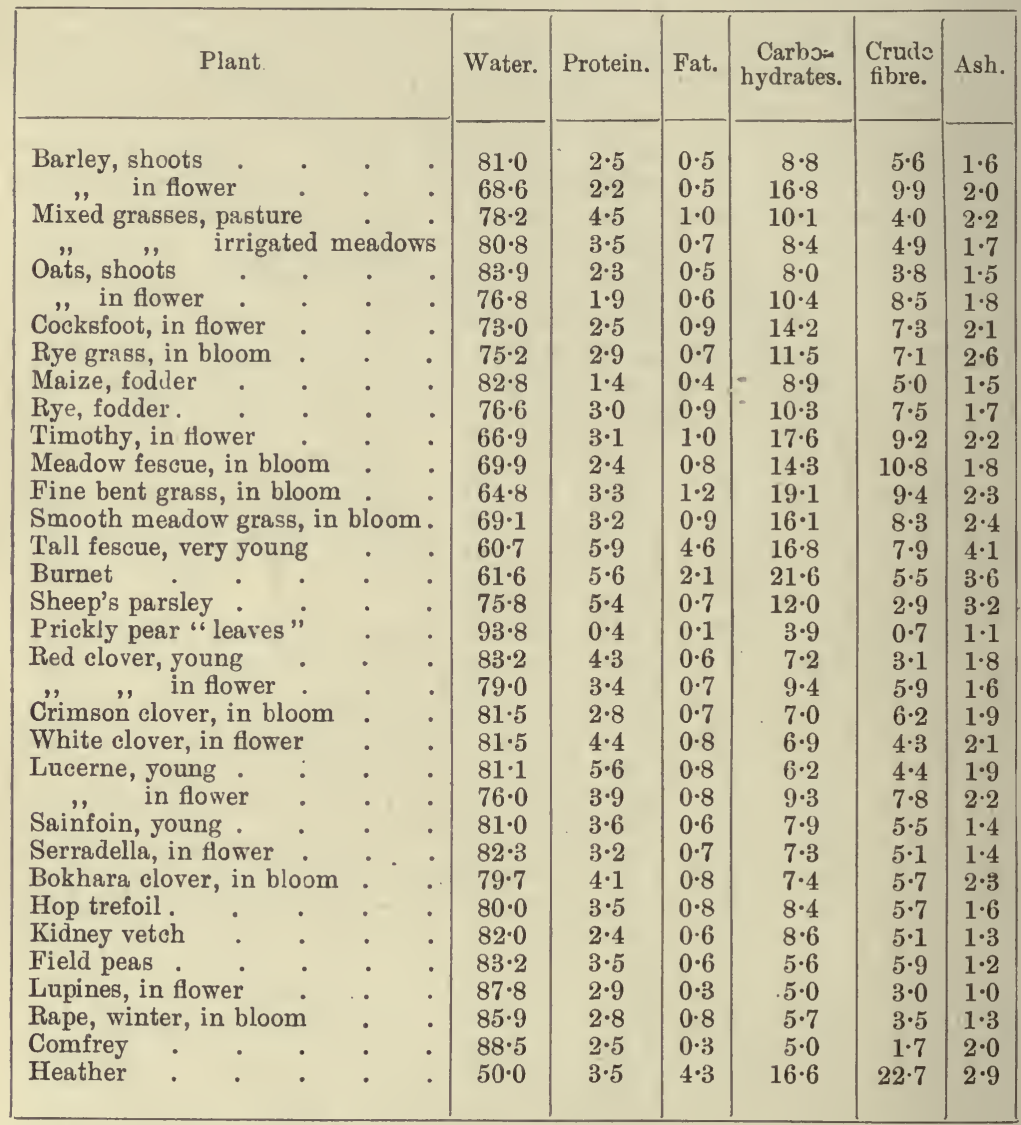

In some cases the fodder crop is eaten green by animals; but more generally, it is preserved for future use, either by being made into hay or silage.

Hay-making consists in drying the plants by exposure to sun and air to such an extent as to greatly check fermentation, which, in the presence of moisture, soon occurs in vegetable matter. This fermentation is due to the action of micro-organisms and is accompanied by absorption of oxygen from the air and consequent evolution of heat. During hay-making the most important change is the loss of water; this naturally varies considerably with the nature of the crop, its ripeness, etc. Ordinary meadow grass will usually contain about 75 per cent of water, while the hay from it, in the stack, may contain about 
16 per cent. One hundred tons of grass will yield from 30 to 40 tons of hay, while the same weight of freshly cut clover will yield, on an average, about 33 tons of hay.

Of great importance is the time of cutting. Since fodder crops are essentially straw, the proper time is before the nutrient ingredients are moved from the foliage into the seed. Hence hay should be cut when the grasses are flowering. If grass is left until too ripe, the resulting hay is found to be poorer in albuminoids and ash, though richer in carbohydrates and indigestible fibre.

The changes in Timothy grass during ripening are well seen from the following table ${ }^{1}$ :-

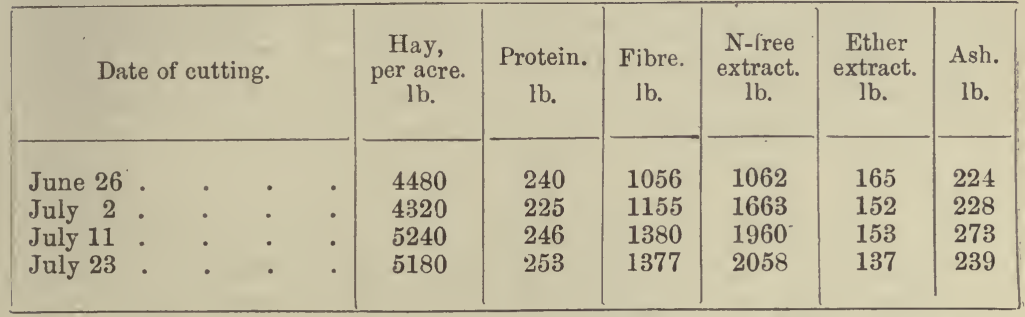

It will be seen that the nitrogenous matters are practically not increased by the later growth, but that carbohydrates and fibre are largely augmented after blossoming. On June 26, the grass was in full bloom ; on July 23 , its seeds were almost ripe.

Grass and clover are always abundantly supplied with microorganisms, including bacteria, moulds and yeasts; these act upon the sap and woody fibre of the grass when cut, producing oxidation and evolving carbon dioxide and small quantities of other gases. The act of oxidation is attended with the evolution of heat. These changes take place in the open air with little rise of temperature, because the heat is carried away by conduction and convection almost as fast as it is evolved. Moreover the activity of the micro-organisms soon diminishes if the materials dry.

An investigation into the changes produced in grass by fermentation was made in 1897 by Emmerling. ${ }^{2} \quad$ Freshly cut grass of the following composition, calculated on the dry matter-

$$
\begin{aligned}
& \text { Proteids } \\
& 11.80 \\
& \text { Ash . . . . . . . . } 762 \\
& \text { Ether extract . . . . . . . . } 1.86 \\
& \text { Woody tissue . . . . . . . . } 26 \cdot 40 \\
& \text { Non-nitrogenous extract } \quad . \quad \text {. } \quad . \quad \text {. } \quad . \quad 52 \cdot 32
\end{aligned}
$$

-was placed in a large vessel provided with thermometer and delivery tube. In twenty-four hours the temperature rose several degrees; during four weeks a slow current of carbon dioxide (64 per cent) and nitrogen (36 per cent) was evolved.

${ }^{1}$ Hunt, Bul. 5, U.S. Dept. of Agric.

2 Ber., 1897, 1869; Jour. Chem. Soc., 1897, Abstracts, ii. 579. 
The grass at this point had the composition-

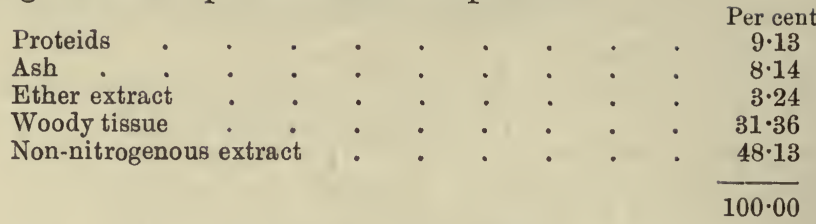

It had a pleasant hay-like odour. Many moulds, bacteria and micrococci were observed. The increase in the ether extract is attributed to organic acids formed from the carbohydrates.

No doubt such changes as above described take place during the process of hay-making; but usually they can only proceed to a very limited extent, owing to the desiccation of the grass by sun and wind.

When the partially dried grass is collected in stacks or barns, however, further desiccation is almost prevented, and the processes of fermentation recommence. If the hay still contain much moisture these processes proceed so rapidly that the very limited circulation of air in the stack does not carry the heat away as fast as it is produced, the temperature rises, fermentation is thereby favoured, and the temperature gets higher and higher.

While most organisms are killed by a temperature about $60^{\circ}$, it has been shown that certain bacteria, present in surface soil can work energetically at $70^{\circ}$ or higher. Eventually, however, even they will be killed by the high temperature, and direct oxidation of some substances of the hay must then commence.

A further exaltation of temperature then ensues until, under favourable conditions, the actual ignition point of the hay is reached and the mass begins to inflame. Generally, however, the highest temperature is reached near the centre of the stack, where access of air is difficult and slow; consequently a smouldering combustion rather than actual flaming results.

The conditions most favourable to the dangerous heating of haystacks are not exactly known, but undoubtedly the presence of a certain amount of moisture is one of the most important. Obviously, then, one of the best methods of preventing the firing of haystacks is to thoroughly dry the hay before stacking it. This cannot always be done, nor is it entirely satisfactory, for if over-dried, grass does not ferment sufficiently to develop the aroma, flavour and colour which are desirable in good hay. If hay has to be stacked while somewhat green, one of two methods is generally adopted:-

(1) To mix salt with it. This probably acts by preventing or hindering the growth of the micro-organisms. At the same time it renders the hay more palatable and also probably lessens the risk of its becoming mouldy.

(2) To ventilate the stack. This is probably the more efficient method. It is generally effected by including in the hay, at the time of stacking, a sack or sacks filled with hay, placed vertically and drawn upwards from time to time as the stack rises. Another method, often employed in Scotland, is to erect, in the centre of the site chosen for 
the stack, an open conical structure composed of wooden scantlings meeting at a point. The stack is then built round and above this. These methods depend for their efficiency not upon checking the heat production, as the first one does, but upon the removal of the evolved heat by circulation of air.

The odour of hay, upon which its palatability largely depends, is probably due partly to the products of fermentation, among which compound ethers are probably present, and partly to coumarin, $\mathrm{C}_{9} \mathrm{H}_{6} \mathrm{O}_{2}$ or $\mathrm{C}_{6} \mathrm{H}_{4} /{ }_{\mathrm{CO}}^{\mathrm{CH}}:{ }_{\mathrm{CH}}^{\mathrm{CH}}$ which occurs in woodruff (Asperula odorata), in Bokhara clover (Melilotus), in sweet-scented vernal grass (Anthoxanthum odoratum), and probably in many other plants.

Coumarin is a crystalline solid with a characteristic odour (that of new-mown hay), is slightly soluble in water, and very soluble in alcohol. Its odour becomes very pronounced when plants containing it are dried.

Ensilage or Silage is made by preserving green fodder in a closely compacted condition so as to prevent access of air as much as possible and so hinder the various fermentative changes from proceeding beyond a certain stage. Originally, all silos consisted of pits or buildings of stone or wood, in which the materials could be stored and subjected to high pressure. It is now a common practice to simply stack the fodder in the green state, treading or pressing it down as much as possible, and finally weighting it with stones or earth. In all cases the outside of the silo, where air has access, becomes so rotten as to be useless, but the amount of waste is not very great.

The changes which occur in the silo are in many respects similar to those in the stack, but fermentation is limited in a different manner-by air exclusion, while in a stack it is chiefly from lack of sufficient moisture. Consequently, it is found that the relative progress of different organisms is different in the two cases. Moreover in a silo, the predominant character of the fermentation, and consequently of the silage, depends largely upon the management. If the silo be made slowly, so that a considerable amount of heating may occur before the weighting expels the air, the temperature rises so high (up to $55^{\circ}$ or $60^{\circ}$ ) that the bacteria which produce acids (e.g., acetic, lactic and butyric acids) are destroyed. The resulting product is then known as "sweet" silage. If the silo be built with little delay and compressed at once, the temperature does not rise so high, and the acetic, lactic and other acid-producing bacteria are not killed, but produce their characteristic products, thus leading to the formation of "sour" silage.

The changes in composition which fodder undergoes during fermentation in a silo, lead to a loss of carbohydrates, partly as gaseous products and partly by conversion into insoluble "fibre". Except by mechanical loss, say by juices running from the silo, the mineral matter undergoes no change; the albuminoids are slightly lessened, probably by conversion into amides, and even into ammonium salts. 
The composition of clover and rye grass, when cut and after being in the silo for ninety days, is given by Wilson and Harper ${ }^{1}$ as follows :-

\begin{tabular}{|c|c|c|c|c|}
\hline & \multicolumn{2}{|c|}{ Clover (means of 8 analyses). } & \multicolumn{2}{|c|}{ Rye grass. } \\
\hline & Fresh. & Silage. & Fresh. & Silage \\
\hline Water . & $79 \cdot 5$ & $80 \cdot 1$ & $47 \cdot 1$ & $74 \cdot 3$ \\
\hline The solids dried at $100^{\circ}$ containe & $20 \cdot 5$ & $19 \cdot 9$ & 529 & $25 \cdot 7$ \\
\hline Albuminoids & $16 \cdot 5$ & $17 \cdot 4$ & $\dot{8} \cdot 5$ & $7 \cdot 1$ \\
\hline Non-albuminoid $\mathrm{N} \times 6.25$ & 3.9 & $4 \cdot 5$ & $3 \cdot 6$ & $2 \cdot 9$ \\
\hline Carbohydrates (by difference) & $46 \cdot 3$ & $37 \cdot 5$ & $48 \cdot 8$ & $45 \cdot 7$ \\
\hline Fibre. & $23 \cdot 8$ & $30 \cdot 2$ & $30 \cdot 5$ & $36 \cdot 8$ \\
\hline Ash : & $9 \cdot 5$ & $10 \cdot 5$ & $8 \cdot 6$ & $7 \cdot 5$ \\
\hline Per cent, non-albd. $\mathrm{N}$ of total $\mathrm{N}$. & $19 \cdot 0$ & $20 \cdot 6$ & $30 \cdot 1$ & $28 \cdot 9$ \\
\hline
\end{tabular}

They calculate the following:-

\begin{tabular}{|l|c|c|c|c|c|c|}
\hline & $\begin{array}{c}\text { Albumi- } \\
\text { noids. }\end{array}$ & $\begin{array}{c}\text { Non.alb. } \\
\mathrm{N} \times 6.25\end{array}$ & $\begin{array}{c}\text { Carbo- } \\
\text { hydrates. }\end{array}$ & Fibre. & Ash. & Total. \\
\hline $\begin{array}{c}100 \text { lb. dry matter of } \\
\text { clover when put in- } \\
\text { to silo contain } \\
\text { Ditto, when taken out }\end{array}$ & 16.5 & 3.9 & 1.3 & 23.8 & $9 \cdot 5$ & 100.0 \\
\hline 15.7 & 40 & 33.9 & $27 \cdot 4$ & $9 \cdot 5$ & 90.5 \\
\hline
\end{tabular}

Experiments were also made on the digestibility of the albuminoids of the fresh fodder and the silage, using "pepsin " and "pancreatine ". The following table gives the results :-

\begin{tabular}{|c|c|c|c|c|c|c|c|}
\hline & & \multicolumn{3}{|c|}{$\begin{array}{l}\text { Fresh fodder. } \\
\text { In } 100 \text { parts of dry matter. }\end{array}$} & \multicolumn{3}{|c|}{$\begin{array}{c}\text { Silage } \\
\text { In } 100 \text { parts of dry matter. }\end{array}$} \\
\hline & & 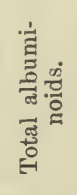 & 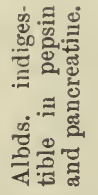 & 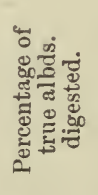 & 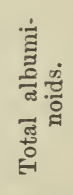 & 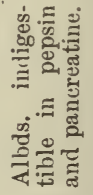 & 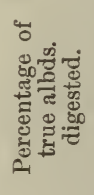 \\
\hline Clover (mean of 8 ) & . & $16 \cdot 6$ & $3 \cdot 06$ & $81 \cdot 5$ & $17 \cdot 4$ & $7 \cdot 5$ & $56 \cdot 4$ \\
\hline Rye grass & · & $8 \cdot 5$ & $1 \cdot 84$ & $78 \cdot 3$ & $7 \cdot 1$ & $3 \cdot 2$ & $54 \cdot 2$ \\
\hline
\end{tabular}

Thus, though the loss in albuminoids is very small, the diminution in digestibility is serious. The authors suggest that silage should only be made of fodder comparatively low in albuminoids and that clover

${ }^{1}$ Jour. Soc. Chem. Ind., 1891, 115. 
and other highly nitrogenous crops should be either used as pasture or made into hay.

The following analyses of silage and hay from various sources may be useful ; they are mainly from Kellner :-

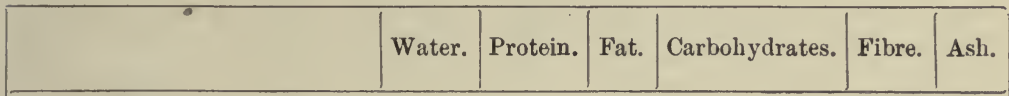

(a) Silage from pits.

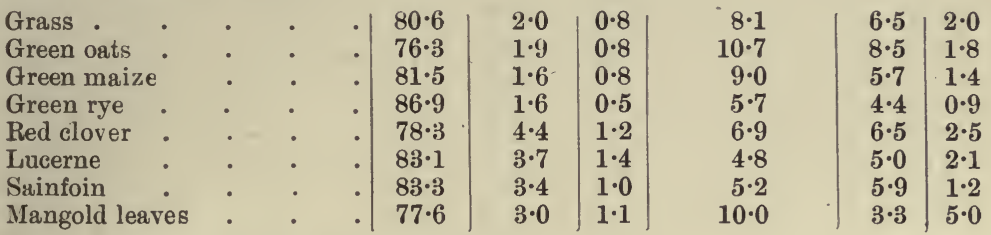

(b) Silage from clamps or heaps.

\begin{tabular}{|c|c|c|c|c|c|c|c|c|c|}
\hline Buckwheat & - & . & . & $70 \cdot 3$ & $2 \cdot 4$ & 0.8 & $16 \cdot 5$ & $7 \cdot 8$ & $2 \cdot 2$ \\
\hline Grass . & - & . & . & $68 \cdot 0$ & $3 \cdot 8$ & $2 \cdot 7$ & $12 \cdot 9$ & $9 \cdot 9$ & $2 \cdot 7$ \\
\hline Green maize & - & - & - & $81 \cdot 8$ & $2 \cdot 0$ & $1 \cdot 2$ & $7 \cdot 8$ & $5 \cdot 5$ & $1 \cdot 7$ \\
\hline Lucerne & . & - & - & $72 \cdot 5$ & $4 \cdot 0$ & $3 \cdot 2$ & $6 \cdot 1$ & $10 \cdot 7$ & $3 \cdot 5$ \\
\hline Lupines & . & . & 1 & $80 \cdot 3$ & $2 \cdot 9$ & $1 \cdot 0$ & $4 \cdot 9$ & $9 \cdot 5$ & $1 \cdot 4$ \\
\hline Red clover & - & - & & $70 \cdot 0$ & $5 \cdot 6$ & $2 \cdot 0$ & $11 \cdot 6$ & $8 \cdot 5$ & $2 \cdot 3$ \\
\hline \multicolumn{10}{|l|}{ Hays. } \\
\hline \multicolumn{2}{|c|}{ Meadow hay, poor } & - & - & $14 \cdot 3$ & $7 \cdot 5$ & $1 \cdot 5$ & $38 \cdot 2$ & $33 \cdot 5$ & $5 \cdot 0$ \\
\hline \multirow{2}{*}{ Oato outin } & medium & - & - & $14 \cdot 3$ & $9 \cdot 2$ & $2 \cdot 0$ & $39 \cdot 7$ & $29 \cdot 2$ & $5 \cdot 4$ \\
\hline & very good & & - & $15 \cdot 0$ & $11 \cdot 7$ & $2 \cdot 8$ & $41 \cdot 6$ & $21 \cdot 9$ & $7 \cdot 0$ \\
\hline \multicolumn{2}{|c|}{ Oats, cut in flower } & - & $\cdot$ & $11 \cdot 5$ & $7 \cdot 5$ & $2 \cdot 4$ & $42 \cdot 4$ & $30 \cdot 1$ & $0 \cdot 1$ \\
\hline \multicolumn{2}{|c|}{ Rye grass, cut in flower } & . & - & $14 \cdot 3$ & $10 \cdot 2$ & $2 \cdot 7$ & $36 \cdot 1$ & $30 \cdot 2$ & $6 \cdot 5$ \\
\hline \multirow{2}{*}{ Red clover, } & - & • & - & $14 \cdot 3$ & $8 \cdot 5$ & $2 \cdot 4$ & $41 \cdot 1$ & $23 \cdot 5$ & $5 \cdot 2$ \\
\hline & goor. & - & • & $15 \cdot 0$ & $11 \cdot 1$ & $2 \cdot 1$ & $37 \cdot 7$ & $28 \cdot 9$ & $5 \cdot 1$ \\
\hline \multirow{2}{*}{," } & nedium & - & • & $16 \cdot 0$ & $12 \cdot 3$ & $2 \cdot 2$ & $38 \cdot 2$ & $26 \cdot 0$ & $5 \cdot 3$ \\
\hline & very good & - & • & $16 \cdot 5$ & $15 \cdot 3$ & $3 \cdot 2$ & $35 \cdot 8$ & $22 \cdot 2$ & $7 \cdot 0$ \\
\hline \multicolumn{3}{|c|}{ Lucerne, before flowering } & • & $16 \cdot 0$ & $16 \cdot 2$ & $2 \cdot 4$ & $31 \cdot 1$ & $27 \cdot 0$ & $7 \cdot 3$ \\
\hline Sainfoin & , , & & - & $15 \cdot 8$ & $15 \cdot 4$ & $3 \cdot 2$ & $34 \cdot 0$ & $24 \cdot 9$ & $6 \cdot 7$ \\
\hline
\end{tabular}

The analyses on the following page, by the author, of South African grown hays, may be of interest.

The botanical names of the plants in the following table are-

Oats, Avena sativa.

Boer manna, Setaria italica.

Teff grass, Eragrostis abyssinica.

Veld grasses, mixed grasses.

Sweet grass, chiefly Chloris virgata.

Rhodes grass, Chloris guyana.

Teosinte, Euchloena mexicana.

Blue grass, Andropogon hirtus.

Golden millet and green moha are Setaria spp.

Broom corn, Panicum crus-galli.

Cow pea, Vigna catjang. 


\begin{tabular}{|c|c|c|c|c|c|c|c|}
\hline & & Water. & Protein. & Fat. & Carbohydrates. & Fibre. & Ash. \\
\hline Oat hay & . & $8 \cdot 0$ & $5 \cdot 6$ & $3 \cdot 9$ & $44 \cdot 0$ & $34 \cdot 3$ & $4 \cdot 2$ \\
\hline Boer manna hay . & . & $8 \cdot 3$ & $5 \cdot 0$ & $1 \cdot 9$ & $46 \cdot 1$ & $30 \cdot 9$ & $7 \cdot 8$ \\
\hline Teff grass hay . & . & $9 \cdot 0$ & $6 \cdot 0$ & $1 \cdot 2$ & $40 \cdot 2$ & $38 \cdot 0$ & $5 \cdot 6$ \\
\hline Veld hay . & - & $8 \cdot 1$ & $3 \cdot 4$ & $1 \cdot 2$ & $43 \cdot 9$ & $38 \cdot 0$ & $5 \cdot 4$ \\
\hline Sweet hay . & . & $7 \cdot 5$ & $7 \cdot 6$ & $1 \cdot 0$ & $37 \cdot 7$ & $38 \cdot 1$ & $8 \cdot 1$ \\
\hline Rhodes grass hay & . & $9 \cdot 0$ & $9 \cdot 2$ & $1 \cdot 3$ & $29 \cdot 3$ & $42 \cdot 5$ & $8 \cdot 7$ \\
\hline Teosinte hay . & . & $11 \cdot 5$ & $7 \cdot 9$ & $1 \cdot 5$ & $8 \cdot 0$ & $31 \cdot 4$ & $9 \cdot 7$ \\
\hline Blue grass hay . & . & $8 \cdot 0$ & $4 \cdot 4$ & $1 \cdot 3$ & $41 \cdot 8$ & $38 \cdot 5$ & $6 \cdot 0$ \\
\hline Golden millet hay & . & $7 \cdot 9$ & $11 \cdot 1$ & $1 \cdot 0$ & $29 \cdot 5$ & $41 \cdot 0$ & $9 \cdot 5$ \\
\hline Green moha hay. & . & $8 \cdot 0$ & $10 \cdot \tilde{5}$ & $1 \cdot 2$ & $35 \cdot 4$ & $35 \cdot 6$ & $9 \cdot 3$ \\
\hline Broom corn hay. & . & $9 \cdot 7$ & $6 \cdot 8$ & $1 \cdot 2$ & $38 \cdot 8$ & $34 \cdot 8$ & $8 \cdot 7$ \\
\hline Lucerne hay . & . & $8 \cdot 0$ & $15 \cdot 5$ & $2 \cdot 3$ & $30 \cdot 5$ & $34 \cdot 8$ & $8 \cdot 9$ \\
\hline Cow pea hay . & - & $8 \cdot 2$ & $13 \cdot 2$ & $2 \cdot 4$ & $39 \cdot 4$ & $30 \cdot 5$ & $6 \cdot 3$ \\
\hline Velvet bean hay. & . & $9 \cdot 3$ & $13 \cdot 3$ & $2 \cdot 6$ & $39 \cdot 2$ & $27 \cdot 6$ & $7 \cdot 8$ \\
\hline Maple pea hay & . & $8 \cdot 0$ & $16 \cdot 3$ & $2 \cdot 4$ & $35 \cdot 2$ & $31 \cdot 2$ & $6 \cdot 9$ \\
\hline Tall fescue hay. & . & $9 \cdot 1$ & $13 \cdot 6$ & $10 \cdot 7$ & $38 \cdot 8$ & $18 \cdot 4$ & $9 \cdot 4$ \\
\hline Burnet hay. & . & $9 \cdot 4$ & $13 \cdot 3$ & $4 \cdot 9$ & $50 \cdot 8$ & $13 \cdot 1$ & $8 \cdot 5$ \\
\hline Sheep's parsley hay & & $11 \cdot 5$ & $10 \cdot 9$ & $2 \cdot 7$ & $43 \cdot 6$ & $10 \cdot 6$ & $11 \cdot 7$ \\
\hline Vetches & • & $9 \cdot 4$ & $20 \cdot 6$ & $4 \cdot 0$ & $36 \cdot 2$ & $21 \cdot 2$ & $8 \cdot 6$ \\
\hline Lupines (blue) . & $\theta^{\circ}$ & $8 \cdot 2$ & $17 \cdot 1$ & $2 \cdot 7$ & $41 \cdot 7$ & $22 \cdot 0$ & $8 \cdot 3$ \\
\hline Lupines (white) . & . & $7 \cdot \overline{8}$ & $14 \cdot 1$ & $2 \cdot 8$ & $50 \cdot 1$ & $17 \cdot 4$ & $7 \cdot 8$ \\
\hline
\end{tabular}

Velvet bean, Mucuna utilis.

Maple pea, Pisum arvensis.

Tall fescue, Festuca elatior.

Burnet, Sanguisorba minor.

Sheep's parsley, Petroselinum sativum.

Vetches, Vicia villosa.

Lupines, blue, Lupinus hirsutus.

Lupines, white, Lupinus albus.

ROTATION OF CROPS. - In freshly opened-up country, the first settlers sometimes grow the same crop year after year. But such a practice is never successful for long, and in all countries where farming has become established, the practice of rotation has become general. The advantages of a rotation are partly convenience in carrying on the work of the farm by distributing the labour of ploughing, drilling, hoeing and harvesting over a considerable portion of the year, partly the variety of crops that can be grown and partly, perhaps mainly, advantages which concern the supply of plant-food from the soil. It is chiefly to these last points that consideration will be given here.

Some crops depend almost entirely upon the surface soil for their nourishment, while others are deep-rooted and find the major portion of their food in the sub-soil. By alternating such crops the whole of the soil can be laid under contribution for supplies of plant food. Examples of shallow-rooted crops are seen in the grasses, barley and oats, potatoes and turnips, while mangolds, beets, red clover, lucerne, wheat and rye penetrate far lower in the soil.

Then, too, though all crops require the same kind of food from the soil, they require very different quantities, and in some cases an 
abundance of one constituent, e.g., nitrogen, may actually diminish the value of a crop, e.g., barley for malting, though another crop-say mangolds-would be greatly benefited by such liberal supplies of nitrogen.

The table on the following page gives, according to Warington's estimates, the weight, in pounds, of the chief substances removed from an acre of land by an average crop of the various plants.

Inspection of the figures will show that the demands of different crops upon the soil for nitrogen, lime, phosphoric acid and potash are very different. A crop of mangolds, for example, removes about three times as much nitrogen, nearly ten times as much potash and more than twice as much phosphoric acid as a crop of cereals. So, too, while a supply of about $50 \mathrm{lb}$. of nitrogen per acre will satisfy the requirements of cereals or potatoes, twice that quantity is required by a crop of turnips, swedes, beans, or clover. In the case of the last two crops, however, this is not necessarily derived from the soil, since leguminose have their own supply of nitrogen and, as a matter of fact, it is well known that the land is left richer in nitrogen after such a crop has been removed.

Crop residues-roots and leaves-left in the soil after the removal of a crop, afford suitable food for another crop of a ditlerent species, but do not serve nearly so well for a second crop of the same species. Moreover, insect pests and diseases, to which a crop is liable, are very likely to be carried on from year to year if the same crop be grown in succession, but tend to die out if the affected crop be followed by others upon which the pest cannot prey.

Sometimes, several years are required before the land becomes free from the germs of a particular disease-causing organism, but crops which are not subject to the disease can be grown successfully in the interim. "Clover sickness," to which certain land is subject, affords a good example, and "finger-and-toe" in turnips is another.

Still another great advantage of a system of rotation is the opportunities it affords of periodically freeing the land from weeds. While root crops occupy the land, hoeing between the drills can be made nearly as effective in getting rid of weeds as the less profitable practice of "bare fallowing".

Many systems of rotation are practised in different districts. One of the favourite ones is that known as the Norfolk rotation, which, in its simplest form, consists in-

1. Turnips or swedes, or mangolds or potatoes.

2. Barley.

3. Clover, or beans or peas.

4. Wheat.

Various modifications are introduced into this system to suit particular circumstances. Barley may be replaced by oats or even by wheat, and the clover or "small seeds"- often clover and ryegrassmay be left on the land for two years. Where clover sickness is prevalent, beans, peas, or vetches are grown every eighth year instead of clover, and where finger-and-toe exists, mangolds or potatoes replace turnips alternately. 


\begin{tabular}{|c|c|c|c|c|c|c|c|c|c|}
\hline & Nitrogen. & Total ash. & $\mathrm{K}_{2} \mathrm{O}$ & $\mathrm{Na}_{2} \mathrm{O}$ & $\mathrm{CaO}$. & MgO. & $\mathrm{P}_{2} \mathrm{O}_{5}$ & Cl. & $\mathrm{SiO}_{2}$ \\
\hline $\begin{array}{l}\text { Wheat, } 30 \text { bushels } \\
\text { straw, } 1 \frac{1}{2} \text { tons }\end{array}$ & $\begin{array}{l}34 \\
16\end{array}$ & $\begin{array}{r}30 \\
142\end{array}$ & $\begin{array}{r}9 \cdot 3 \\
19 \cdot 5\end{array}$ & $\begin{array}{l}0 \cdot 6 \\
2 \cdot 0\end{array}$ & $\begin{array}{l}1 \cdot 0 \\
8 \cdot 2\end{array}$ & $\begin{array}{l}3 \cdot 6 \\
3 \cdot 5\end{array}$ & $\begin{array}{r}14 \cdot 2 \\
6 \cdot 9\end{array}$ & $\begin{array}{l}0 \cdot 1 \\
2 \cdot 4\end{array}$ & $\begin{array}{r}0 \cdot 6 \\
96 \cdot 3\end{array}$ \\
\hline Total crop & 50 & 172 & $28 \cdot 8$ & $2 \cdot 6$ & $9 \cdot 2$ & $7 \cdot 1$ & $21 \cdot 1$ & $2 \cdot 5$ & $96 \cdot 9$ \\
\hline $\begin{array}{c}\text { Barley, } 40 \text { bushels. } \\
\text {,, straw, } 2450 \mathrm{lb} .\end{array}$ & $\begin{array}{l}35 \\
14\end{array}$ & $\begin{array}{r}46 \\
111\end{array}$ & $\begin{array}{r}9 \cdot 8 \\
25 \cdot 9\end{array}$ & $\begin{array}{l}1 \cdot 1 \\
3 \cdot 9\end{array}$ & $\begin{array}{l}1 \cdot 2 \\
8 \cdot 0\end{array}$ & $\begin{array}{l}4 \cdot 0 \\
2 \cdot 9\end{array}$ & $\begin{array}{r}16 \cdot 0 \\
4 \cdot 7\end{array}$ & $\begin{array}{l}0 \cdot 5 \\
3 \cdot 6\end{array}$ & $\begin{array}{l}11 \cdot 8 \\
56 \cdot 8\end{array}$ \\
\hline Total crop & $\overline{49}$ & $\overline{157}$ & $35 \cdot 7$ & $\overline{5 \cdot 0}$ & $\overline{9 \cdot 2}$ & $\overrightarrow{6 \cdot 9}$ & $\overline{20 \cdot 7}$ & $\overline{4 \cdot 1}$ & $68 \cdot 6$ \\
\hline Oats, 45 bushels & 34 & $\begin{array}{r}51 \\
140\end{array}$ & $\begin{array}{r}9 \cdot 1 \\
37 \cdot 0\end{array}$ & $\begin{array}{l}0 \cdot 8 \\
4 \cdot 6\end{array}$ & $\begin{array}{l}1 \cdot 6 \\
9 \cdot 8\end{array}$ & $\begin{array}{l}3 \cdot 6 \\
5 \cdot 1\end{array}$ & $\begin{array}{r}13 \cdot 0 \\
6 \cdot 4\end{array}$ & 0.5 & $\begin{array}{l}19 \cdot 9 \\
65 \cdot 4\end{array}$ \\
\hline 10. & 10 & 140 & & - & $\div$ & -1 & & 01 & \\
\hline Total crop & 52 & 191 & $46 \cdot 1$ & $5 \cdot 2$ & $11 \cdot 4$ & $8 \cdot 7$ & $19 \cdot 4$ & $6 \cdot 6$ & $85 \cdot 3$ \\
\hline $\begin{array}{l}\text { Maize, } 30 \text { bushels } \\
\quad, \quad \text { straw, } 1 \text { ton }\end{array}$ & $\begin{array}{l}28 \\
15\end{array}$ & $\begin{array}{l}22 \\
99\end{array}$ & $\begin{array}{r}6 \cdot 5 \\
29 \cdot 8\end{array}$ & 0.2 & 0.5 & $3 \cdot 4$ & $\begin{array}{r}10 \cdot 0 \\
8 \cdot 0\end{array}$ & $0 \cdot 2$ & 0.5 \\
\hline Total crop & 43 & 121 & $36 \cdot 3$ & & & & $\overline{18 \cdot 0}$ & & \\
\hline Meadow hay, $1_{\frac{1}{2}}$ tons & 49 & 208 & $50 \cdot 9$ & $9 \cdot 2$ & $32 \cdot 1$ & $14 \cdot 4$ & $12 \cdot 3$ & $14 \cdot 6$ & $56 \cdot 9$ \\
\hline Red clover hay, 2 tons . & 98 & 258 & $83 \cdot 4$ & $5 \cdot 1$ & $90 \cdot 1$ & $28 \cdot 2$ & $24 \cdot 9$ & $9 \cdot 8$ & $7 \cdot 0$ \\
\hline Field beans, 30 bushels. & 78 & 58 & $24 \cdot 3$ & $0 \cdot 6$ & $2 \cdot 9$ & $4 \cdot 2$ & $22 \cdot 8$ & $1 \cdot 1$ & 0.4 \\
\hline , haulms, 1 ton. & 29 & 99 & $42 \cdot 8$ & $1 \cdot 7$ & $26 \cdot 3$ & $5 \cdot 7$ & $6 \cdot 3$ & $4 \cdot 3$ & $6 \cdot 9$ \\
\hline Total crop & 107 & 157 & $67 \cdot 1$ & $2 \cdot 3$ & $29 \cdot 2$ & $9 \cdot 9$ & $29 \cdot 1$ & $5 \cdot 4$ & $7 \cdot 3$ \\
\hline Turnips, roots, 17 tons. & 61 & 18 & $108 \cdot 6$ & $17 \cdot 0$ & $25 \cdot 5$ & $5 \cdot 7$ & $22 \cdot 4$ & $10 \cdot 9$ & $2 \cdot 6$ \\
\hline ," leaves, 5 tons & 49 & 146 & $40 \cdot 2$ & $7 \cdot 5$ & $48 \cdot 5$ & $3 \cdot 8$ & $10 \cdot 7$ & $11 \cdot 2$ & $5 \cdot 1$ \\
\hline Total crop & 110 & 364 & $148 \cdot 8$ & $24 \cdot 5$ & 740 & $9 \cdot 5$ & $33 \cdot 1$ & $22 \cdot 1$ & $7 \cdot 7$ \\
\hline $\begin{array}{c}\text { Swedes, roots, } 14 \text { tons } \\
,, \quad \text { leaves, } 2 \text { tons }\end{array}$ & $\begin{array}{l}70 \\
28\end{array}$ & $\begin{array}{r}163 \\
75\end{array}$ & $\begin{array}{l}63 \cdot 3 \\
16 \cdot 4\end{array}$ & $\begin{array}{r}22 \cdot 8 \\
9 \cdot 2\end{array}$ & $19 \cdot 7$ & $\begin{array}{l}6 \cdot 8 \\
2 \cdot 4\end{array}$ & $\begin{array}{r}16 \cdot 9 \\
4 \cdot 8\end{array}$ & $\begin{array}{l}6 \cdot 8 \\
8 \cdot 3\end{array}$ & $3 \cdot 1$ \\
\hline Total crop & & & 79.7 & 39.0 & 49.4 & 9.0 & 21.7 & $5 \cdot 1$ & 6.7 \\
\hline 10 tal crop & 98 & & $19^{\circ}$ & 320 & $42^{4} 4$ & 92 & 21.8 & 0.1 & $0 . \%$ \\
\hline $\begin{array}{cl}\text { Mangolds, roots, } 22 \text { tons } \\
,, & \text { leaves, } 9 \text { tons }\end{array}$ & $\begin{array}{l}98 \\
51\end{array}$ & $\begin{array}{l}426 \\
254\end{array}$ & $\begin{array}{r}222 \cdot 8 \\
77 \cdot 9\end{array}$ & $\begin{array}{l}69 \cdot 4 \\
49 \cdot 3\end{array}$ & $\begin{array}{l}15 \cdot 9 \\
27 \cdot 0\end{array}$ & $\begin{array}{l}18 \cdot 3 \\
24 \cdot 2\end{array}$ & $\begin{array}{l}36 \cdot 4 \\
16 \cdot 5\end{array}$ & $\begin{array}{l}42 \cdot 5 \\
40 \cdot 6\end{array}$ & $\begin{array}{l}8 \cdot 7 \\
9 \cdot 2\end{array}$ \\
\hline Total crop . & $\overline{149}$ & 680 & $\overline{300 \cdot 7}$ & $118 \cdot 7$ & $\overline{42 \cdot 9}$ & $\overline{42 \cdot 5}$ & $\overrightarrow{52 \cdot 9}$ & $83 \cdot 1$ & $17 \cdot 9$ \\
\hline Potatoes, tubers, 6 tons. & 46 & 127 & $76 \cdot 5$ & $3 \cdot 8$ & $3 \cdot 4$ & $6 \cdot 3$ & $21 \cdot 5$ & $4 \cdot 4$ & $2 \cdot 6$ \\
\hline
\end{tabular}


In the high-farming districts of Scotland, a six-course rotation is often followed :-

1. Turnips or swedes, with farm-yard manure and artificials.

2. Barley, wheat, or oats, unmanured.

3. Seeds for hay, often with artificials.

4. Oats, often top dressed with 1 cwt. of nitrate.

5. Potatoes with farm-yard manure and artificials.

6. Wheat, unmanured.

Where high-class malting barley is grown, as on the east coast of England, wheat often follows roots, in order to diminish the supplies of nitrogen left in the soil, before barley is sown. The Norfolk rotation then becomes a five-course one.

\section{Note on the Analysis of Crops.}

A few remarks about the usual method of analysing crops and other foodstuffs may be given here. Almost all analyses of foods, which have been published until quite recently, were made by a method introduced by Henneberg in 1864, generally known as the "Weende" method. According to this plan, the constituents are reported as-

Water.

Proteids or nitrogenous matters.

Fat or ether extract.

"Nitrogen-free extract" or "soluble carbohydrates".

Crude fibre.

Ash.

The water and ash are determined by general methods, the nitrogenous matter by a determination of the total nitrogen and multiplying this by 6.25 , and the "fat" by ether extraction. The "crude fibre" is then determined by treating a portion of the sample, from which the fat has been extracted, with boiling dilute sulphuric acid (containing 1.25 per cent real acid) for half an hour, washing the residue until free from acid, and again boiling for half an hour with a solution containing 1.25 per cent of sodium hydrate. The whole is then filtered and the residue thoroughly washed, dried at $110^{\circ}$, and weighed. The residue is next completely incinerated, when the loss of weight gives the "fibre".

The method used in the determination of the remaining item, "the nitrogen-free extract," in these analyses, is least satisfactory of allbeing simply to take the difference between the sum of the percentages of the other constituents and 100.

In the form just described, thousands of analyses have been published, and, though the results are of considerable value, they cannot be considered satisfactory.

Water.-The assumption that only water is expelled by heating a food to a temperature of about $100^{\circ}$ is certainly not warranted, as many organic compounds undergo change below this temperature; moreover, many fats and oils absorb oxygen and consequently increase in weight when exposed to air. The latter objection can be overcome by drying in a current of hydrogen. 
Ash.-In this case, as in all vegetable and animal matter, the ash left on incineration has not the composition of the inorganic compounds present in the plant or animal. This objection, however, is not a very important one.

Fat.- Since this is really the matter soluble in ether, it is better described as "ether extract". In the case of many substances, chorophyll, resins, waxes and organic acids, e.g., lactic acid, are dissolved by ether and are included in the "ether extract". In some instances the amounts of these non-fatty substances may be considerable in proportion to the true fat.

Nitrogenous matter.- However accurate the determination of nitrogen may be, the tigures given under this head can never be very trustworthy. In the first place, all the nitrogen in a substance is not usually present as albuminoids, but may be partly as simple aminocompounds, ammonium salts, or nitrates. Then, too, all albuminoids do not contain the same proportion of nitrogen, and therefore multiplying by 6.25 does not give a correct measure of their amount. A method of distinguishing between the nitrogen existing as true albuminoids and that as amides, etc., has already been described.

Crude fibre. - The method used in the estimation of this item is obviously based upon an assumption that from a material freed from fat by ether extraction, dilute sulphuric acid and dilute sodium hydrate will effect the solution of all matter which could be removed in the digestive processes of an animal; it evidently cannot yield any really satisfactory results. Moreover, the amount of the "fibre" obtained depends very much upon the state of subdivision of the material and upon other circumstances, and the residue obtained often contains nitrogenous substances.

Non-nitrogenous extractives. - This item, like all those obtained by difference, is liable to the accumulated errors of all the direct determinations, some of which, e.g., the fibre, are probably very great.

According to Stone ${ }^{1}$ the results obtained by the Weende method are very incorrect. He examined specimens of wheat and maize, both by the usual conventional methods and by determining the various carbohydrates actually present. Some of the results by the two methods are given below.

Air-dry material (per cent) :-

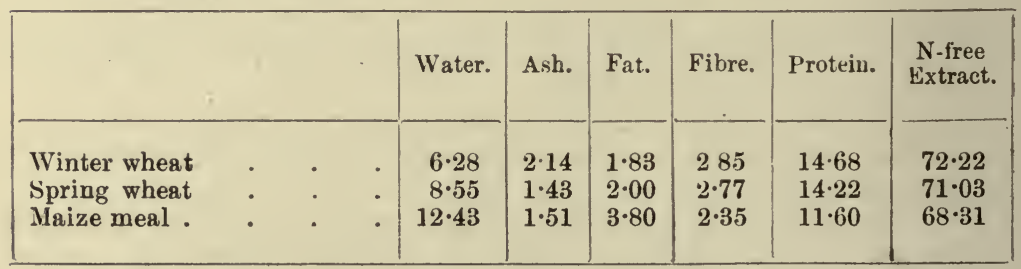

Under the last column (obtained by difference) it is generally assumed that starch, digestible cellulose and sugars are included.

${ }^{1}$ Bull. No. 34 (1896), Office of Experiment Stations, U.S. Dept. of Agric. 
By actually determining the percentages of the various carbohydrates, Stone obtained the following numbers :-

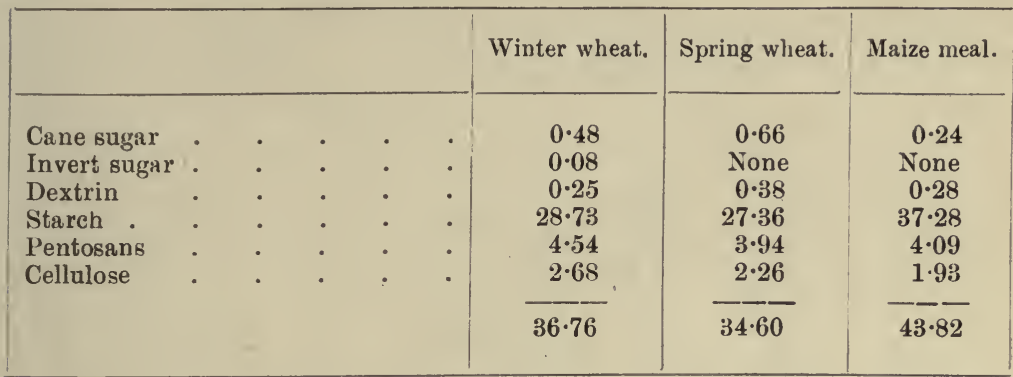

It is thus evident that 35 or 36 per cent. of the whole material in the case of wheat and about 24.5 per cent. in the case of maize, is not estimated and exists in the plant in some other form than those of the carbohydrates mentioned.

This is a remarkable result, and the subject merits further investigation.

In many instances in modern analyses, the amounts of pentoses and pentosans in foods are determined. These bodies appear to be much less digestible than the other carbohydrates. ${ }^{1}$

The following analyses ${ }^{2}$ will illustrate the occurrence of pentosans in fodder :-

\begin{tabular}{|c|c|c|c|c|c|c|c|c|c|c|}
\hline & & & & 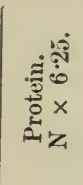 & 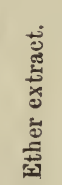 & $\dot{\overrightarrow{\tilde{n}}}$ & 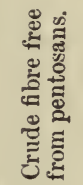 & 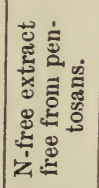 & 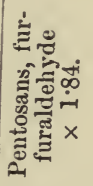 & 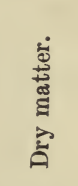 \\
\hline Meadow hay & . & . & . & $11 \cdot 70$ & $3 \cdot 60$ & $7 \cdot 03$ & $21 \cdot 09$ & $37 \cdot 63$ & $18 \cdot 95$ & $93 \cdot 26$ \\
\hline Clover hay & • & : & : & $13 \cdot 90$ & $2 \cdot 31$ & 6.01 & $33 \cdot 74$ & $28 \cdot 00$ & $16 \cdot 04$ & $92 \cdot 04$ \\
\hline Rye straw & $\cdot$ & . & : & $3 \cdot 24$ & $2 \cdot 28$ & $4 \cdot 31$ & $37 \cdot 61$ & $23 \cdot 47$ & $29 \cdot 09$ & $93 \cdot 20$ \\
\hline Lupine straw & . & . & . & $5 \cdot 80$ & $1 \cdot 36$ & $3 \cdot 76$ & $45 \cdot 34$ & $22 \cdot 91$ & $20 \cdot 22$ & $92 \cdot 80$ \\
\hline
\end{tabular}

${ }^{1}$ Stone, Agric. Sci., 7, 6.

2 Düring, Jour. Chem. Soc., 1897, Abstracts, ii. 588. 


\section{CHAPTER XIII.}

\section{The Animal.}

THE body of an animal, from a chemical standpoint, consists of a very intimate mixture of compounds, some of which are little understood and apparently highly complex in character. The body may be considered as made up of lifeless products of metabolism (e.g., fat cells, horny matter, earthy portions of bone) permeated by the really living substance, protoplasm. The latter is highly aqueous and contains proteids, with smaller quantities of carbohydrates, fats and salts.

The elements contained in the animal body are the same as those found in plants, but their relative proportions differ considerably. Sodium, chlorine and fluorine particularly appear to be of much greater importance to animals than to plants.

The proximate constituents of animals also resemble those of plants.

They may be divided into-

(1) Inorganic compounds, consisting mainly of water, various acids (e.g., hydrochloric acid) and numerous salts (e.g., calcium phosphate, sodium chloride).

(2) Organic compounds-

(a) Proteids, e.g., albumin, myosin.

(b) Amides, e.g., urea, and amino-compounds, e.g., creatine.

(c) Fats.

(d) Carbohydrates, e.g., glycogen.

(e) Other compounds.

The general characteristics of some of these substances have been given in the chapter on the constituents of plants. Reference must be made to some work on physiological chemistry for further details.

The chemical composition of the whole bodies of animals was investigated by Lawes and Gilbert in 1848-1859. ${ }^{1}$

The table on the following page embodies some of their results.

It will be seen from the figures that the nitrogenous matter is the most constant in quantity and that the water and fat vary inversely with each other. The amount of ash is chiefly dependent upon the proportion of bone to the rest of the body. 
PERCENTAGE COMPOSITION OF THE WHOLE BODIES OF ANIMALS.

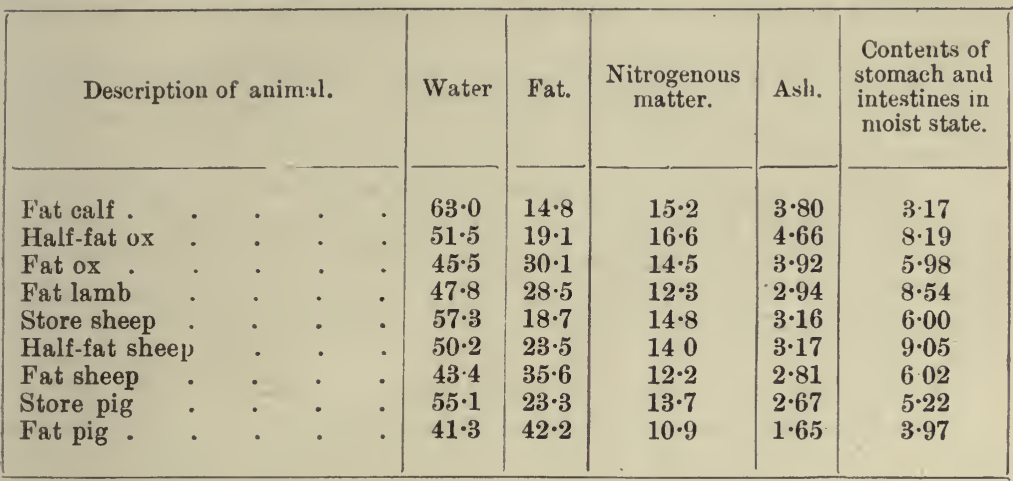

Among the most important parts of the animal body, the following may be mentioned :-

(1) The blood.

(2) The bones.

(3) The muscles.

(4) The connective tissues.

Blood consists of a transparent colourless liquid, the blood plasma, in which an immense number of solid particles, the red and colourless corpuscles, are suspended. When taken from the body, unless special precautions are observed, blood coagulates or clots with a rapidity which varies with different animals and also with the temperature; if cooled quickly, coagulation is retarded; the blood of the horse coagulates more slowly than that of other animals.

In clotting, a separation into a clear yellow liquid-blood serumand a red solid-blood clot-occurs. This separation is brought about by the coagulation of a proteid-fibrinogen-which exists in blood plasma and which can be removed by beating the blood during clotting. Blood serum thus differs from blood plasma in containing no fibrinogen and a smaller quantity of calcium, magnesium and phosphoric acid.

Blood serum is of a sticky consistency, of alkaline reaction, and has a specific gravity of about $1 \cdot 028$. It contains fats, soaps, cholesterol, $\mathrm{C}_{26} \mathrm{H}_{43} \mathrm{OH}$, lecithin, $\mathrm{C}_{2} \mathrm{H}_{4}(\mathrm{OH})\left(\mathrm{CH}_{3}\right)_{3} \mathrm{~N} . \mathrm{HPO}_{4} \cdot \mathrm{C}_{3} \mathrm{H}_{5}:\left(\mathrm{C}_{18} \mathrm{H}_{35} \mathrm{O}_{2}\right)_{2}$, albuminoids, glucose and traces of urea, uric acid, creatine, lactic acid and hippuric acid.

The following analyses of serum were made by Hammarsten :-

\begin{tabular}{|c|c|c|c|c|c|c|c|c|}
\hline \multicolumn{6}{|c|}{$\begin{array}{l}\text { Serum from } \\
\text { blood of }\end{array}$} & $\begin{array}{l}\text { Total } \\
\text { solids. }\end{array}$ & $\begin{array}{l}\text { Total albuminoid } \\
\text { substances. }\end{array}$ & $\begin{array}{l}\text { Fat, lecithin, } \\
\text { salts, etc. }\end{array}$ \\
\hline Man & . & . & . & . & $\cdot$ & $9 \cdot 20$ & $7 \cdot 62$ & 1.59 \\
\hline Horse & . & . & . & . & . & $8 \cdot 60$ & $7 \cdot 26$ & $1 \cdot 34$ \\
\hline $0 x$ & . & . & . & . & . & $8 \cdot 97$ & $7 \cdot 50$ & $1 \cdot 47$ \\
\hline Hen & . & . & . & . & . & $5 \cdot 40$ & 3.95 & $1 \cdot 45$ \\
\hline
\end{tabular}


The ash of serum (about 0.85 per cent) consists chiefly of common salt $(0.6$ to 0.7 per cent), with small quantities of potash, lime and magnesia.

The rapidity with which blood coagulates after leaving the body varies, as already stated, with different animals and with the conditions under which it is kept. Coagulation is retarded by cooling, by diminishing the amount of oxygen or increasing that of carbon dioxide, by the addition of acids, alkalies, egg-albumin, sugar, gum, glycerine, or oil. Coagulation is facilitated by warmth, by contact with foreign bodies (e.g., by stirring or beating), by free admission of air, by addition of a small quantity of water, or by the addition of ferric salts, alum, etc.

The spontaneous clotting of blood after removal from the animal is assigned to different causes by different authorities. According to Schmidt it is due to the action of an enzyme-fibrin-ferment, produced probably by the destruction of the white corpuscles, upon the fibrinogen. Another view attributes to the separation of calcium phosphate a large share in the process (Freund), while a third assigns oxidation as the chief cause. The last theory has not received much support.

The solid portion of coagulated blood consists chiefly of red and white corpuscles entangled in a network of fibrin.

The red corpuscles consist usually of circular, biconcave discs. In birds, amphibia, fishes and some few mammals, e.g., the camel, they are elliptical and biconvex. Their size varies considerably in different animals, being largest in the amphibia. In man they have an average diameter of 007 to 008 millimetre (= about $\frac{1}{2} 00$ inch) and a maximum thickness of 0019 millimetre. They are heavier than the plasma, having a specific gravity of about 1.09.

The average number in the blood of man is about $5,000,000$, in that of woman about $4,000,000$, per cubic millimetre. By treatment with water, ether, or other substances, blood corpuscles lose their colouring matter and leave a residue known as the stroma of the red corpuscles. This consists of nitrogenous matter and often retains the form of the original corpuscles.

The colour of blood depends upon hamoglobin and its compound with oxygen-oxyhcemoglobin. Hæmoglobin consists largely of albumin (about 96 per cent), the other characteristic component being a colouring matter known as hamochromogen (about 4 per cent), containing iron.

Hæmoglobin from different animals differs somewhat in composition. Hammarsten gives the following analyses:-

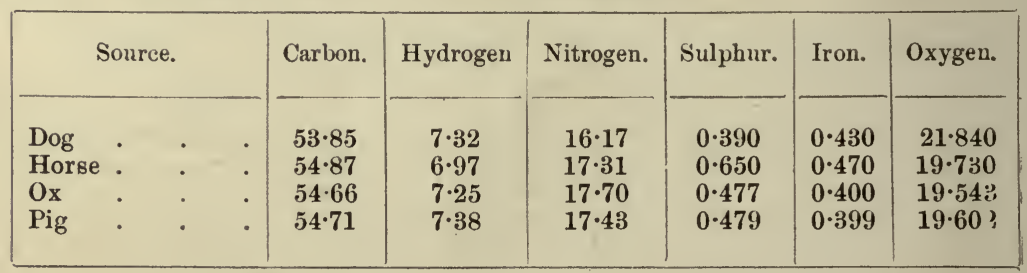


It has been calculated that the molecular weight of hæmoglobin must be about 14,000 , and a formula which would represent the composition of hæmoglobin from the dog has been given as $\mathrm{C}_{636} \mathrm{H}_{1025} \mathrm{~N}_{164}$ $\mathrm{FeS}_{3} \mathrm{O}_{181}$. Hæmoglobin has the power of uniting with oxygen, with carbon monoxide, or with nitric oxide. The stability of the compounds is in the order named and each compound appears to be composed of one molecule of hæmoglobin with one of the gas.

Oxyhcemoglobin is readily obtained in crystals of a bright red colour and soluble in water. It appears to act as a weak acid. A dilute solution shows a characteristic absorption spectrum, containing two chief dark bands, one on the Fraunhofer line D and the other near E.

By the action of reducing agents (e.g., ammoniacal ferrous tartrate), or by the passage of an indifferent gas, or even by exposure in a vacuum, oxyhæmoglobin is deprived of oxygen and hiemoglobin is produced. This is darker and more purple in colour and more soluble in water. It readily absorbs oxygen again from the air.

By the decomposition of hæmoglobin, the protein portion is separated and a colouring substance named hremochromogen is obtained, which, by oxidation, becomes hamatin. This last substance is said to have the composition $\mathrm{C}_{34} \mathrm{H}_{35} \mathrm{~N}_{4} \mathrm{FeO}_{5}$, and is a dark brown or black solid, insoluble in water, acids, alcohol, or ether, but easily soluble in alkalies. The close similarity between this formula and that deduced from the recent investigations of Willstätter, for chlorophyll, is very significant (vide p. 216). By concentrated sulphuric acid, hæmatin is converted, with removal of iron, into a purple-red substance known as hamato-porphyrin, which is said to be $\mathrm{C}_{16} \mathrm{H}_{18} \mathrm{~N}_{2} \mathrm{O}_{3}$.

In addition to the red corpuscles, blood contains colourless corpuscles or leucocytes. These are of lower specific gravity than the red corpuscles, more variable in size and form, and much less numerous, the relative numbers being one colourless corpuscle to 300 or 500 red ones. They consist of fragments of protoplasm and contain several albuminoids, glycogen or animal starch, lecithin and cholesterol.

Blood plays an important part in the process of respiration. It is through the blood that the animal organism receives the oxygen so essential for the vital function.

When blood is placed in vacuo, gases are given off, their composition and amount varying considerably according to the particular part of the body from which the sample was collected. The following table represents the average gaseous contents of arterial and venous blood. One hundred volumes of blood yield-

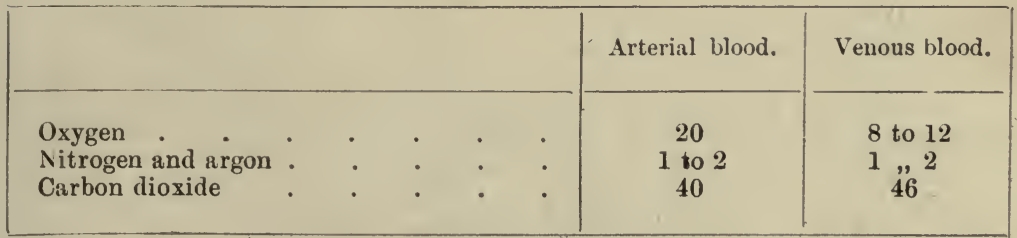

The nitrogen and argon are simply in solution in the blood just as 
they would be in water; but with oxygen and carbon dioxide the quantities present are much greater than can be explained by simple solution.

In the case of oxygen, for example, the amount present does not vary appreciably with the pressure of the gas in the lungs, whereas the amount of a gas dissolved by a liquid is directly proportional to the pressure of the gas. The greater portion of the oxygen (probably all but about one volume per 100 volumes of blood) is in the state of combination with hæmoglobin. The oxyhæmoglobin is, however, easily dissociated, and if the quantity of dissolved oxygen be diminished from any cause, the combined oxygen is diminished proportionately. The great bulk of the oxygen of the blood is thus to be found in the red corpuscles, while only a small quantity is in the plasma.

With carbon dioxide the case is different. Of the 40 to 46 volumes of the gas present in 100 volumes of blood about two are in the state of simple solution, the remainder in a state of weak combination, partly with the hæmoglobin of the red corpuscles, but mainly as bicarbonates in solution in the plasma.

Respiration consists in bringing air into close proximity to the blood stream in the lungs, separation being only maintained by the thin walls of the capillaries and air cells or alveoli. The air in the alveoli is not renewed by mechanical expulsion due to inspiration and expiration, but by diffusion from and into the bronchial tubes.

The partial pressure of the dissolved carbon dioxide in the venous blood is greater than that in the air of the alveoli; consequently the blood plasma loses carbon dioxide, thus producing dissociation of the bicarbonates in solution. The partial pressure of the dissolved oxygen in the venous blood is, however, less than that of the alveolar air, and consequently the plasma takes in oxygen. This disturbs the equilibrium between the dissolved oxygen of the blood plasma and the combined oxygen of the oxyhrmoglobin, causing the formation of more of the latter with a simultaneous diminution of the former. The blood plasma is thus able to take in a further quantity of oxygen from the air. In this way it is probable that all the oxygen which goes into the blood in the lungs does so by passing through the stage of dissolved oxygen in the plasma.

At the same time the air in the lungs becomes saturated with aqueous vapour at the temperature of the body.

The number of respirations per minute varies with the age, etc., of the animal. For adult animals the following is the average :-

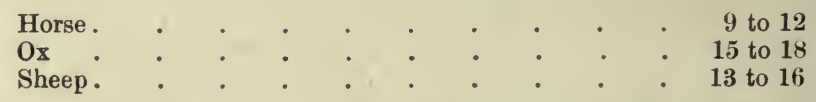

The change produced in the composition of air by respiration is indicated in the table on the following page, which gives the average composition of air before and after inspiration.

The most important changes undergone by the air are the loss of oxygen and the gain in carbon dioxide and aqueous vapour. Oxygen by its union with carbon gives rise to its own volume of carbon dioxide. 


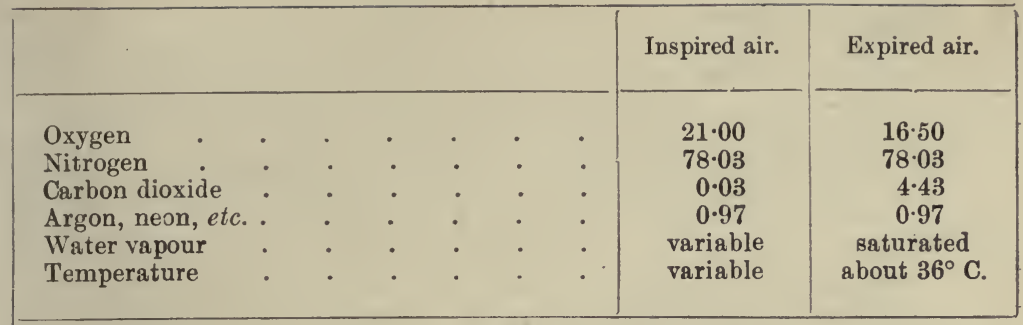

The increase in the volume of carbon dioxide during respiration is, however, almost always less than the decrease in that of oxygen. The ratio, $\frac{\mathrm{CO}_{2} \text { evolved }}{\mathrm{O}_{2} \text { absorbed }}$, is known as the respiratory quotient. It varies with circumstances, particularly with the food and the amount of muscular exertion. It is usually about 0.9 . The disappearance of oxygen is probably due to its being used to oxidise hydrogen to water (say from fats and proteids in the food), and also in the formation of certain waste products, e.g., urea.

Seat of oxidation in the body.-Although almost all the oxygen absorption of the body occurs in the lungs (a small amount also through the skin), the act of union with the combustible matter derived from the food and the consequent heat production do not occur there. It is not in the lungs nor even in the blood that the combustion and formation of carbon dioxide occur, but in the tissues themselves.

Bones.-Bone consists mainly of an earthy substance permeated by an albuminoid known as ossein. Bones are also intersected by blood-vessels, nerves, etc. The marrow of bones consists mainly of fat and albumin.

The proportion between the organic matter of bone and its mineral constituents is liable to considerable variation, according to the quantities of blood-vessels, nerves, marrow and water which may be, present.

Usually from 30 to 50 per cent of the weight of bone is lost on burning. The composition of similar bones (the metatarsus) of several animals were examined by the writer in connection with an investigation of the disease known as "osteoporosis," and the results may be here given.

The bones of three healthy mules were found to contain, on the average-

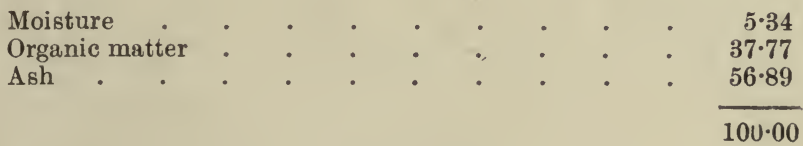

The organic matter contained-

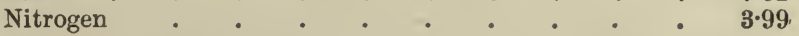


The ash contained--

Lime . . . . . . . . . $32 \cdot 28$

Phosphorus pentoxide . . . . . . . 21.86

Silica . . . . . . . . . . 0.09

The ratio of nitrogen to ash $=1: 14 \cdot 3$.

With four animals which had died of osteoporosis, the figures were-

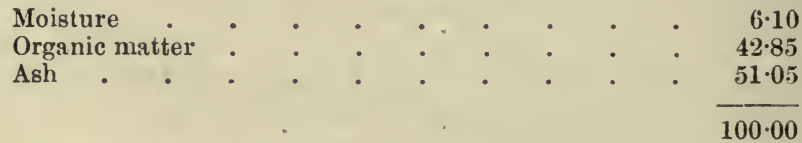

The organic matter contained-

Fat . . . . . . . . . 9.08

Nitrogen $\div \quad \div \quad \div \quad \div \quad \div \quad \div 42$

The ash contained-

Lime . . . . . . . . . . $27 \cdot 74$

Phosphorus pentoxide . $\quad . \quad+\quad . \quad \div \quad 19 \cdot 71$

Silica . . . . . . . . . 013

The ratio of nitrogen to ash $=1: 11 \cdot 0$.

The bones of the diseased animals were thus richer in moisture, organic matter, nitrogen and silica, but much poorer in ash, lime and phosphorus pentoxide than those of the normal animals.

. Similar and equally concordant results were found with donkeys and horses.

The ratio of nitrogen to ash in the bones is the most significant point, since it is really a measure of the proportion of ossein to inorganic matter: the proportion of fat present may be liable to accidental variation.

The inorganic matter left as ash consists mainly of calcium phosphate, but includes also carbonates, chlorides and fluorides of calcium and magnesium.

The following table gives the percentage composition of the ash of bones of various animals ${ }^{1}$ :-

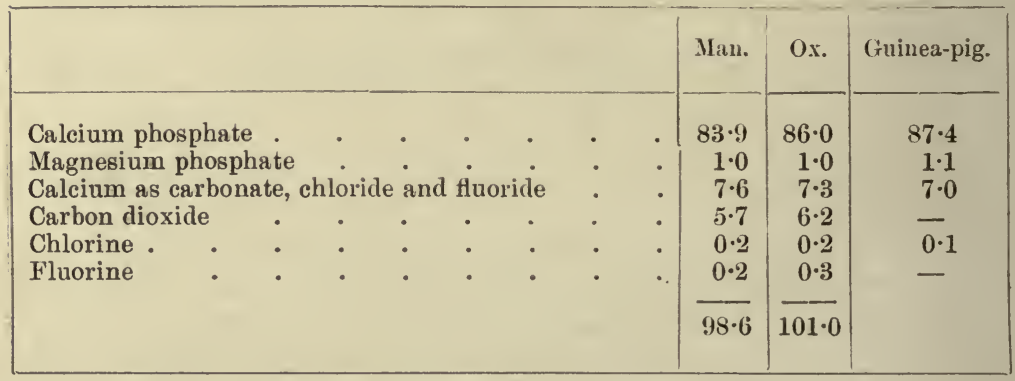

${ }^{1}$ Hammarsten, Physiological Chemistry, p. 239. 
The proportions of valuable manurial substances in bones has already been given. ${ }^{1}$

The Fatty Tissue.- This consists of cells, the walls of which are composed of a proteid substance resembling elastin, filled with fat which, during life, is in the fluid state. The fat consists mainly of glyceryl esters of stearic, oleic, palmitic, and other fatty acids; but, in addition, free fatty acids are present in small amount. Animal fats resemble in constitution the vegetable oils already described. ${ }^{2}$

Fats from different animals, or even from different parts of the same animal, have very different properties, especially as to consistency and melting-point. These depend upon the relative amount of the glycerides of high melting-point (e.g., stearin, melting-point about $63^{\circ}$, and palmitin, melting-point $62^{\circ}$ ), and those of low melting-point (olein, melting-point about $-5^{\circ}$ ).

The average proportions of fat, water and membrane (cell walls, etc.) are given by Hammarsten as follows :-

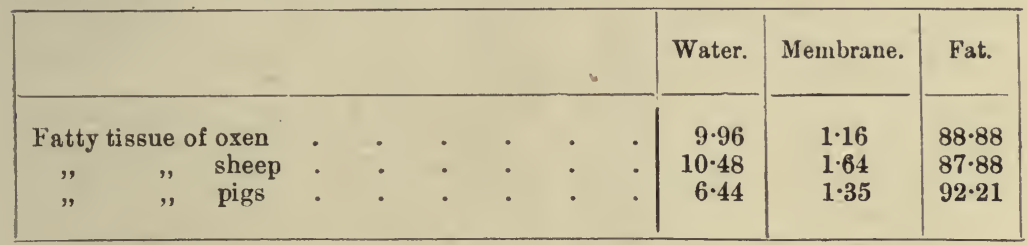

Fat may be produced in the animal from the fat, proteids or carbohydrates contained in the food. It forms a valuable reserve, from which the animal can draw in times of scarcity of food, being the most concentrated form in which energy can be stored in the body.

Muscle.-Muscular fibre consists of a sheath composed of elastin and the contents, mainly albumins.

Myosin is the principal albuminous constituent of the dead muscle. Its amount varies from 3 to 11 per cent. It is a globulin, is soluble in neutral salt solutions, and coagulates at $56^{\circ}$.

Other albuminoids are found in muscle, of which musculin, musclestroma and myoglobin are the chief.

There are also "nitrogenous extractives" present, the chief being creatine, (methyl-guanidine acetic acid), $\mathrm{NH}: \mathrm{C}\left(\mathrm{NH}_{2}\right) \cdot \mathrm{N}\left(\mathrm{CH}_{3}\right) \cdot \mathrm{CH}_{2}$. $\mathrm{COOH}+\mathrm{H}_{2} \mathrm{O}$; hypoxanthine or sarcine, $\mathrm{C}_{5} \mathrm{H}_{4} \mathrm{~N}_{4} \mathrm{O}$; xanthine, $\mathrm{C}_{5} \mathrm{H}_{4} \mathrm{~N}_{4} \mathrm{O}_{2}$; guanine, $\mathrm{C}_{5} \mathrm{H}_{5} \mathrm{~N}_{5} \mathrm{O}$; and carnine, $\mathrm{C}_{7} \mathrm{H}_{8} \mathrm{~N}_{4} \mathrm{O}_{3}+\mathrm{H}_{2} \mathrm{O}$.

These substances constitute the chief ingredients of the various commercial "extracts of meat". Though they cannot apparently act as true foods, they have an important function to play with regard to the palatability and digestibility of the foods in which they occur.

Muscle also contains inosite or inositol, $\mathrm{C}_{6} \mathrm{H}_{12} \mathrm{O}_{6}+\mathrm{H}_{2} \mathrm{O}$ (hexahydroxy-hexamethylene), glycogen, $\mathrm{C}_{6} \mathrm{H}_{10} \mathrm{O}_{5}$, a sugar (probably glucose and most likely formed, after death, from glycogen), and sarcolactic acid, $\mathrm{CH}_{3} \cdot \mathrm{CH}(\mathrm{OH}) \cdot \mathrm{COOH}$. Fat is also present, together with lecithin. 
The gases present in muscle consist mainly of carbon dioxide, with traces of nitrogen.

Of the mineral constituents, potassium and phosphoric acid are the chief ; sodium, magnesium, calcium, chlorine and iron are also present. Sulphates are found in the ash, but probably are derived from the sulphur of the proteids.

Detailed analyses of muscle are rarely made, most published analyses having for their object the determination of the nutritive value rather than the true composition.

The following analyses are quoted by Hammarsten :-

\begin{tabular}{|c|c|c|c|c|c|c|c|}
\hline & & & & & Mammaliaus. & Birds. & $\begin{array}{l}\text { Cold-blooded } \\
\text { animals. }\end{array}$ \\
\hline Solids . & . & . & . & . & 21.7 to 25.5 & $22 \cdot 7$ - to $28 \cdot 2$ & $20 \cdot 0$ \\
\hline Water . & - & - & . & . & $74 \cdot 5,78 \cdot 3$ & $71 \cdot 7,, 77 \cdot 3$ & $80 \cdot 0$ \\
\hline Myosin . & . & . & . & . & $3.5,10 \cdot 6$ & $2 \cdot 98,, 11 \cdot 1$ & 2.97 to 8.7 \\
\hline Stroma . & . & . & . & . & $7 \cdot 8,, 16 \cdot 1$ & $8 \cdot 8,18.4$ & $7 \cdot 0,, 12 \cdot 1$ \\
\hline Alkali-album & ainate & . & . & . & $2 \cdot 9, " 3 \cdot 0$ & - & - \\
\hline Creatine & & . & . & . & $0 \cdot 2$ & $3 \cdot 4$ & $2 \cdot 3$ \\
\hline Xanthine bo & dies & . & . & - & 0.04 to 0.07 & 0.07 to 0.13 & - \\
\hline Inosite . & . & . & . & . & 0.003 & - & - \\
\hline Glycogen & . & . & 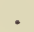 & . & 0.4 to 0.5 & - & 0.3 to 0.5 \\
\hline $\begin{array}{l}\text { Lactic acid } \\
\text { - and a very }\end{array}$ & varia & & $\dot{0}$ & at of fat & $0.04,0.07$ & - & - \\
\hline
\end{tabular}

Living muscle has an alkaline reaction, but after death a change occurs, and it acquires an acid reaction, due probably to the formation of sarcolactic acid.

When muscle contracts, oxidation goes on at an accelerated rate and more carbon dioxide is produced and carried away in the blood which bathes the muscle. The consequent increased production of heat is consumed, partly in doing the mechanical work performed by the muscle and partly in raising the temperature.

The glycogen and sugar are the chief sources from which this energy is derived. Fat may be consumed if the carbohydrates are in insufficient quantity; but although early experimenters concluded that muscular exertion increased the quantity of nitrogenous waste from the body, more recent researches tend to show that this is not the case. The nitrogenous waste is chiefly excreted in the form of urea in the urine and sweat.

Connective Tissue.-This material, which constitutes the main ingredient in the tendons, ligaments, cartilages, skin, etc., of the animal body, consists essentially of gelatine-yielding substances, of which the following are the chief

(1) Elastin, an insoluble substance containing little or no sulphur. Its composition, according to analyses quoted by Hammarsten, is about- 


$$
\begin{array}{cccc}
\text { Carbon. } & \text { Hydrogen. } & \text { Nitrogen. } & \text { Oxygen. } \\
54 \cdot 3 & 7 \cdot 2 & 16 \cdot 7 & 21 \cdot 8 \text { per cent. }
\end{array}
$$

(2) Collagen, an insoluble body yielding gelatine by long boiling with water. It contains about $0 \cdot 6$ per cent sulphur.

Hammarsten gives the following :-

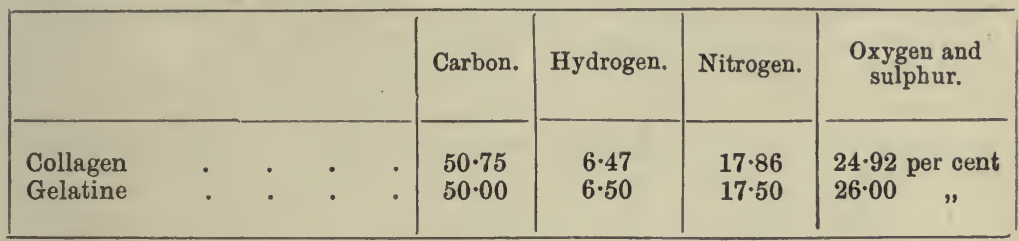

On decomposition, it yields albuminous substances and a large quantity of glycocoll [amino-acetic acid, $\mathrm{CH}_{2}\left(\mathrm{NH}_{2}\right) \cdot \mathrm{COOH}$ ], sometimes called sugar of glue.

(3) Keratin.-This is the chief constituent of horns, hoofs, skin, feathers, hair, wool and nails. Obtained from different sources, it shows a variation in composition; in general, it resembles collagen or gelatine, but differs from those substances in containing much more sulphur (4 or 5 per cent), part of which is in a very loose state of combination and may be removed by alkalies or even by boiling with water. Keratin is insoluble in water, alcohol, or ether, but can be dissolved by heating with water to $150^{\circ}$ or $200^{\circ}$ under pressure.

DIGESTION.-The food of an animal is rarely in a form capable of direct absorption into the system. Before it can be taken into the blood stream and utilised in the body, it is usually necessary that certain chemical changes should be produced so as to render its constituents soluble and diffusible. These changes are brought about by the process of digestion, which consists mainly in breaking down insoluble, complex carbon compounds into simpler, soluble substances, chiefly by the aid of enzymes or unorganised ferments. Digestion is accomplished partly by mechanical, partly by chemical means.

The process commences with mastication-the food is submitted to a comminuting action by the teeth and tongue and at the same time is mixed with saliva. This is a very dilute solution, of faint alkaline reaction, containing various substances, secreted by special glands and poured into the mouth. It has been estimated that an ox secretes $112 \mathrm{lb}$. of saliva daily. The results of investigations as to the composition of saliva show it to contain only from 0.4 to 1 per cent of solid matter. In human saliva, potassium thiocyanate is usually present, its average amount being probably about 01 per cent.

Alkaline chlorides, phosphates and sulphates are also present, together with mucin, a proteid body of slimy consistency. Of special importance is the characteristic enzyme of the saliva-ptyatin or salivary diastase. This enzyme, which works most rapidly at about $30^{\circ}$ and is destroyed at about $65^{\circ}$ or $70^{\circ}$, has powers similar to those of plant diastase, i.e., it converts starch, first into soluble starch, next into dextrin, and finally into maltose. The conversion of the starch of food into sugar is commenced, but not completed, in the mouth. 
The food next passes into the stomach, which in ruminating animals is divided into several parts and from which the food can be brought back into the mouth to undergo further mastication ("chewing the cud "). In the stomach, gastric juice is brought into contact with the food. This is a colourless or slightly yellow liquid secreted in the stomach, containing free hydrochloric acid and chlorides and phosphates of calcium, magnesium and the alkalies. Its characteristic constituents, however, are the enzymes, pepsin, which has the power of converting proteids into albumoses and peptones, thereby rendering them soluble and diffusible, and rennet or chymosin, which coagulates casein. These enzymes have not been obtained in a pure state and to some extent probably exist as "zymogens," i.e., substances which yield the true enzymes on treatment with an acid.

The composition of the gastric juice of various animals is given by Hammarsten thus :-

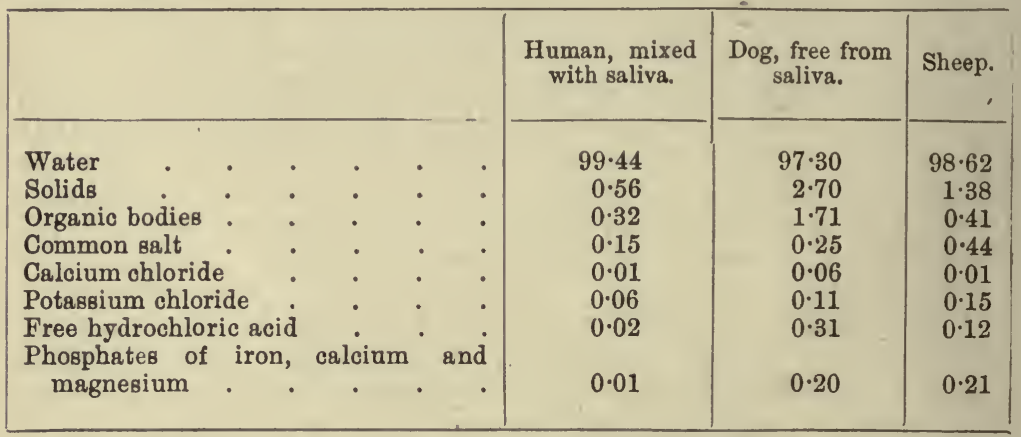

How the free hydrochloric acid of the gastric juice is secreted from the alkaline blood is not exactly known. Maly's theory is that the carbon dioxide of the blood sets free minute traces of hydrochloric acid from chlorides, possibly through the intervention of phosphates, thus :-

$$
\begin{aligned}
& \mathrm{Na}_{2} \mathrm{HPO}_{4}+\mathrm{CO}_{2}+\mathrm{H}_{2} \mathrm{O}=\mathrm{NaHCO}_{3}+\mathrm{NaH}_{2} \mathrm{PO}_{4} \\
& \mathrm{NaH}_{2} \mathrm{PO}_{4}+\mathrm{NaCl}=\mathrm{Na}_{2} \mathrm{HPO}_{4}+\mathrm{HCl}
\end{aligned}
$$

-and that the acid so formed diffuses from the blood into the gastric juice, being possibly held there in weak combination with pepsin.

Pepsin is apparently a nitrogenous substance like other enzymes, and is destroyed by boiling, though in the dry state it is said to be able to bear a temperature of over $100^{\circ}$ without losing its activity. Its characteristic property is its power of converting, in acid but not in alkaline solutions, albuminous bodies into soluble peptones and albumoses. A solution containing about 0.1 to 0.3 per cent of hydrochloric acid is most favourable for its action.

The proteid swells up and becomes transparent and finally dissolves. In the case of pepsin from most warm-blooded animals, activity ceases below $3^{\circ}$ and is at a maximum about $40^{\circ}$. Salicylic acid and phenol hinder digestion by pepsin, while arsenious acid is said to promote it. By the movements of the walls of the stomach, 
the food is kneaded and incorporated with the gastric juice, the pulpy mass produced being known as chyme. The chyme then passes into the intestines. The proteids are the principal constituents of the food affected by the gastric juice, though the melting of the fat and the removal of the cell walls from fatty tissue are important physical changes. In the case of animals fed upon starchy foods, a slight amount of hydrolysis, resulting in the formation of sugar and also of lactic acid, is said to occur in the stomach. The chief effect, however, may be said to be the action on the proteids.

The secretion of the glands of the intestines has a strong alkaline reaction and thus tends to neutralise the acidity of the chyme. It has also the property of inverting cane sugar and maltose. The secretions of the pancreas and the liver are next brought into contact with the chyme.

Pancreatic juice is a viscid liquid of alkaline reaction containing albumin, fat, soaps, alkaline carbonates, phosphates, lime, magnesia and iron. Its characteristic constituents, however, are three enzymes -a diastatic one, a lipolytic or fat-splitting one, and a proteolytic one.

The composition of pancreatic juice appears to be very variable; the amount of total solids, for example, has been observed to vary from 1.5 to 11.5 per cent.

Hammarsten states that the solid matter in the pancreatic juice. of the horse varies from 0.9 to 1.8 per cent, in that of the sheep from 1.4 to 3.7 per cent, and in that of the rabbit from 1.1 to 2.6 per cent, whilst in that of man it is about 2.4 per cent.

The amount of ash, chiefly common salt, appears to be generally from 0.6 to 0.8 per cent.

The most important constituents are, of course, the enzymes.

(1) The pancreatic diastase or amylopsin.-This body is similar in many respects to ptyalin, but appears to be distinct from it. It acts upon starch more energetically, even attacking and dissolving unboiled starch. It yields dextrin and maltose.

(2) The fat-splitting enzyme, steapsin, or pialyn.-This enzyme has the power of hydrolysing the fats (i.e., decomposing them into glycerol and free fatty acids, which, in the alkaline liquid, probably form soaps), and at the same time, of emulsifying them.

The hydrolytic process only affects a very small amount of the fats ; but the emulsification extends to nearly the whole quantity present, the soaps formed in the first process greatly facilitating the formation of the emulsion.

(3) The proteolytic enzyme, trypsin.-This acts, like pepsin, in digesting proteids; it differs from the ferment of the gastric juice, however, in acting best in an alkaline solution, and in being more rapid in its action, especially towards fibrin and elastin. In the pancreas itself, little or no trypsin exists, but a zymogen known as trypsinogen occurs. This body, by the action of acids, water, alcohol, or of an enzyme, enterokinase, contained in intestinal juice, splits off trypsin.

There is some evidence of the existence of a milk-curdling ferment in the pancreatic juice. 
Changes in the Intestines.-As already stated, the intestinal secretions are alkaline, and in such a medium bacteria can readily flourish. Bacteria therefore, are usually abundant after the food has passed out of the range of the antiseptic gastric juice. Bacteria effect various changes of a putrefactive character. Carbohydrates undergo the lactic fermentation, cellulose is split up into carbon dioxide and methane, while butyric acid and even free hydrogen are also produced. In ruminants the amount of methane produced in these changes is enormous. As much as 700 litres per day has been collected from a fattening ox (Kellner). Other bacteria produce hydrolysis of fats, yielding valeric acid, $\mathrm{C}_{4} \mathrm{H}_{9} \cdot \mathrm{COOH}$, or isobutyric acid, $\mathrm{C}_{3} \mathrm{H}_{7} \mathrm{COOH}=$ $\mathrm{CH}\left(\mathrm{CH}_{3}\right)_{2}$. $\mathrm{COOH}$.

Other microbes act upon the proteids, producing fatty acids and amino-acids, also bodies of the aromatic series, of which indole, skatole, tyrosine and phenol may be mentioned.

Indole, $\mathrm{C}_{6} \mathrm{H}_{4}^{\prime}$ $52^{\circ}$, soluble in hot water, very soluble in alcohol or ether. It has a peculiar odour and acts as a weak base. It is found associated with skatole in fæces. It gives a characteristic red precipitate with nitric acid.

Skatole, methyl indole, $\mathrm{C}_{6} \mathrm{H}_{4} \backslash \underset{\mathrm{NH}}{\mathrm{C}\left(\mathrm{CH}_{3}\right)} \backslash \mathrm{CH}$, also a crystalline body, melts at $95^{\circ}$. It is slightly soluble in water and readily soluble in alcohol or ether. It, like indole, is volatile in steam and has a most disagreeable fæcal smell. With nitric acid it gives a white precipitate.

Phenol, $\mathrm{C}_{6} \mathrm{H}_{5} \mathrm{OH}$, and Para-cresol, $\mathrm{C}_{6} \mathrm{H}_{4}\left(\mathrm{CH}_{3}\right) \mathrm{OH}$, have also been detected in fæces and result from bacterial action in the intestines.

The Bile. - This product is to be regarded both as a secretion and an excretion of the liver. It is continuously poured into the intestines, though the rate of its discharge varies with circumstances. A reserve is usually stored in the gall bladder, with which many animals are provided.

According to a table given by Gamgee, the amount of bile and bile solids (in grammes) secreted per 24 hours, per kilogram of body weight, in the case of different animals is as follows :-

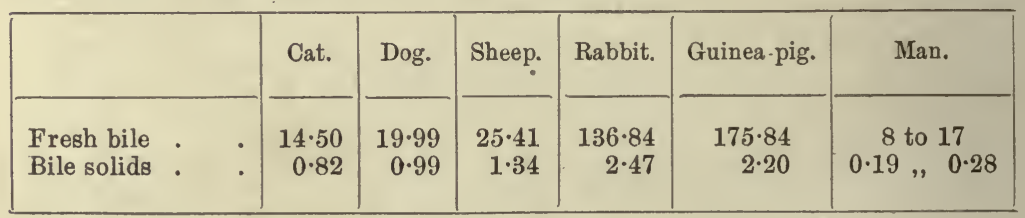

The liver is characterised by containing glycogen, $\mathrm{C}_{6} \mathrm{H}_{10} \mathrm{O}_{5}$, which may be regarded as a reserve nutritive material. Its amount in the liver varies considerably, being greatly increased after the consumption 
of food rich in carbohydrates, sometimes rising to 10 or 12 per cent; normally, however, it is probably between 1 and 4 per cent. It disappears during starvation. It is an amorphous, white, tasteless powder.

Bile is a reddish yellow (especially in carnivorous animals) or green (in herbivora) fluid, with faint alkaline reaction and bitter taste. That found in the gall bladder is more concentrated than that obtained directly from the liver. Bile contains sodium and potassium salts of the so-called bile acids, mucin, or other albumin (to which its viscidity is due), bile pigments, lecithin, cholesterol, fats, soaps and mineral matter.

The bile acids are chiefly glycocholic acid, $\mathrm{C}_{26} \mathrm{H}_{43} \mathrm{NO}_{6}$, and taurocholic acid, $\mathrm{C}_{26} \mathrm{H}_{45} \mathrm{NO}_{7} \mathrm{~S}$. These are both monobasic acids and give, with strong sulphuric acid and cane sugar (or better with a minute trace of furfurol), characteristic colour reactions (Pettenkofer's reaction). The liquid becomes successively cherry red, dark red and finally purple violet. The acids and their alkaline salts have a strong bitter taste. Solutions of sodium or potassium salts of both acids have solvent powers for soaps, lecithin and cholesterol.

The acids undergo hydrolysis, taurocholic acid the more readily, yielding, in the one case, glycocoll and cholalic acid, and in the other taurine and cholalic acid, thus :-

$$
\mathrm{C}_{26} \mathrm{H}_{43} \mathrm{NO}_{6}+\mathrm{H}_{2} \mathrm{O}=\mathrm{CH}_{2}\left(\mathrm{NH}_{2}\right) \mathrm{COOH}+\mathrm{C}_{24} \mathrm{H}_{40} \mathrm{O}_{5}
$$

and $\mathrm{C}_{26} \mathrm{H}_{45} \mathrm{NO}_{7} \mathrm{~S}+\mathrm{H}_{2} \mathrm{O}=\mathrm{CH}_{2}\left(\mathrm{NH}_{2}\right) \cdot \mathrm{CH}_{2} \cdot \mathrm{SO}_{2} \cdot \mathrm{OH}+\mathrm{C}_{24} \mathrm{H}_{40} \mathrm{O}_{5}$.

Glycocoll-glycine-amino-acetic acid- $\mathrm{CH}_{2}\left(\mathrm{NH}_{2}\right) \cdot \mathrm{COOH}$, is a crystalline body, of sweet taste, very soluble in water, and of acid reaction. It is also produced by the decomposition of hippuric acid, $\mathrm{C}_{6} \mathrm{H}_{5} \mathrm{CO} . \mathrm{NH} . \mathrm{CH}_{2} . \mathrm{COOH}$, and in the pancreatic digestion of gelatine.

Taurine, amino-ethyl sulphonic acid, $\mathrm{NH}_{2} \cdot \mathrm{CH}_{2} \cdot \mathrm{CH}_{2} \cdot \mathrm{SO}_{2} \cdot \mathrm{OH}$, is a crystalline, tasteless body, soluble in water, insoluble in alcohol, and af neutral reaction.

Cholalic acid, $\mathrm{C}_{24} \mathrm{H}_{40} \mathrm{O}_{5}$, a monobasic acid, is very slightly soluble in cold water. It has the characteristic bitter taste of the bile acids.

The bile pigments are chiefly bilirubin and biliverdin.

These pigments appear to be formed from hæmoglobin, or rather hæmatin, but contain no iron.

Bilirubin, $\mathrm{C}_{32} \mathrm{H}_{36} \mathrm{~N}_{4} \mathrm{O}_{6}$, is a reddish-yellow substance, insoluble in water but soluble in alcohol or chloroform. It is also soluble in alkalies. It is found in bile, especially in that of the carnivora, and also occurs, in combination with calcium, in gall-stones. On exposure to air, alkaline solutions absorb oxygen and become green (biliverdin).

Biliverdin, $\mathrm{C}_{32} \mathrm{H}_{36} \mathrm{~N}_{4} \mathrm{O}_{8}$, is an amorphous green substance, insoluble in water but soluble in alcohol and in alkalies. It is found in bile, in shells of birds' eggs, and sometimes in 'gall-stones. Other colouring substances, e.g., bilipurpurin, $\mathrm{C}_{32} \mathrm{H}_{34} \mathrm{~N}_{4} \mathrm{O}_{5}$, have been found in bile.

The mineral matters include potassium, sodium, calcium, magnesium, iron and often traces of copper and zinc; phosphates and chlorides are also present.

Bile undoubtedly plays an important part in the digestion of fats. If the bile be prevented from entering the alimentary canal, the fæces 
become light-coloured, much more putrescent, and contain a large amount of fat. Bile has a slight solvent power upon fats, as is evidenced by the well-known use of ox-gall for removing greasy stains from textile fabrics. It also possesses, in a well-marked degree, the property of aiding the pancreatic and intestinal juices in bringing about the emulsification of fats; this is probably by virtue of its alkalinity and the power possessed by bile acids and their salts of dissolving lime soap and cholesterol. Bile is said to be possessed of antiseptic properties and to regulate the putrefaction which occurs in the intestines. It is also a laxative.

Bile is to a great extent reabsorbed in the intestines and only a portion is expelled in the fæces.

The Fæces of an animal contain the undigested portions of its food, together with the products of their decomposition under the influence of the enzymes and bacteria present in the alimentary canal, and some portions of the digestive Huids themselves; mucus and epithelial cells from the walls of the intestines are also present.

Small quantities of fat, cholesterol, and calcium and magnesium salts of fatty acids also occur, while the specific odour is due to the presence of skatole and indole or their derivatives, though sometimes sulphuretted hydrogen, ammonia, amines and other volatile substances are present. A dark-brown reduction product of bilirubin known as hydro-bilirubin, $\mathrm{C}_{32} \mathrm{H}_{40} \mathrm{~N}_{4} \mathrm{O}_{7}$, is said to be often present.

Absorption of Digested Food.-Water and inorganic compounds, e.g., common salt, are absorbed without change. Little or no absorption takes place in the mouth or gullet. It commences in the stomach, but is mainly accomplished in the intestines. The absorption is not merely a physical process of diffusion; the living cells through which it occurs exercise a selective action and in many cases produce important chemical changes in the substance being absorbed.

Absorption of carbohydrates. - These are probably entirely absorbed as glucose, the necessary changes being produced in the food by the enzymes in the saliva, pancreatic juice and intestine as already described. A portion at once enters the blood stream and is conveyed to the tissues, while another portion is probably stored as a reserve in the liver, in the form of glycogen.

Absorption of fats. - A small portion of the fat in the food is saponified; but, as already stated, the greater portion is merely emulsified. The lacteals of the intestine are the absorbents for fat, and exactly how the minute globules pass through the walls of the intestine is not understood. When fatty acids are fed to an animal the contents of the lacteals contain fat, so that glycerine must have come from some other portion of the food and fat must be synthesised.

Absorption of proteids. - Soluble proteids are often absorbed unchanged; in general, however, the proteids are converted into peptones and albumoses by the action of either pepsin or trypsin. The extraordinary fact is that in the blood no peptones can be found; indeed, if they be injected into the blood stream, poisonous effects are at once 
produced. The epithelial cells must, during absorption, change the peptones and albumoses back again into the original proteids.

The length of the alimentary canal varies greatly in different animals, being comparatively short in carnivora and very long in herbivora. The usual length of the intestines of the various farm animals and the percentage ratio of the capacity of the stomach to the total capacity of stomach and intestines are as follows:-

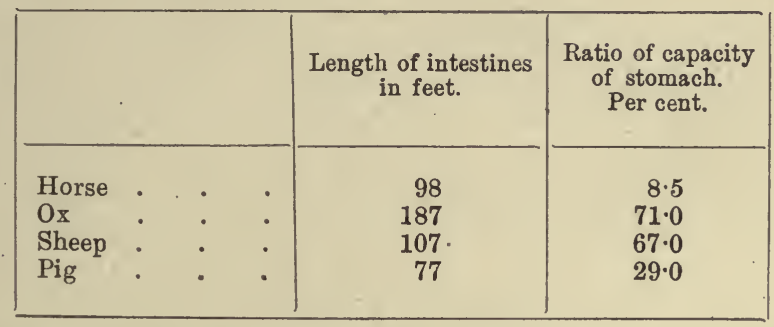

The Urine.-This is, perhaps, the most important excretion of the animal body, since in it are the nitrogenous waste products, the water and the soluble mineral salts derived from the food or the breaking down of tissue. It is formed (or, probably more correctly, extracted) from the blood by the kidneys, which contain several albuminous bodies, fat, xanthine, urea, uric acid, glycogen, leucine, inosite, taurine and cystine. Urine varies greatly in composition with the breed of animal, the food, quantity of exercise, amount of water taken, and many other circumstances. In carnivora and man, urine is usually acid, while in herbivora it is neutral or alkaline.

The specific gravity varies greatly; its determination furnishes an important means of estimating the total solids present. In the case of human urine, variations from 1.002 to 1.040 have been observed. The characteristic constituent of urine is urea or carbamide, $\mathrm{CO}\left(\mathrm{NH}_{2}\right)_{2}$, which is more abundant in the urine of carnivora than in that of herbivora.

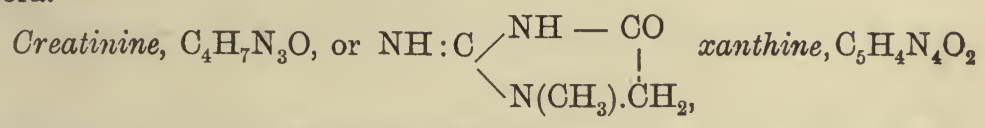

and smaller quantities of allied substances also occur in the urine of man and some mammalia.

$$
\text { Uric acid, } \left.\mathrm{C}_{5} \mathrm{H}_{4} \mathrm{~N}_{4} \mathrm{O}_{3} \text {, or } \mathrm{CO}_{\text {NH. }}^{\stackrel{\mathrm{CH} . \mathrm{NH}}{\text { NH.CO }}}\right\rangle^{\dot{\mathrm{C}} \mathrm{NH}}
$$

occurs abundantly in the excrements of birds and serpents, also in the urine of carnivora and man, and, to a very small extent, in that of the herbivora. Uric acid is a dibasic acid, and both the acid and its acid salts are very slightly soluble in water. In certain diseases, e.g., gout, deposits of uric acid and urates are formed in the body. 
Hippuric acid, benzoylamino-acetic acid, $\mathrm{C}_{9} \mathrm{H}_{9} \mathrm{NO}_{3}$, or $\mathrm{C}_{6} \mathrm{H}_{5}$. CO. NH. $\mathrm{CH}_{2} \cdot \mathrm{COOH}$. This substance is found.(to the amount of about 2 per cent) in the urine of horses, cattle and many herbivora ; it is also present in human urine (usually about 0.5 per cent), and, during starvation, in that of carnivora.

Hippuric acid readily decomposes (under hydrolysis), giving benzoic acid and amino-acetic acid (glycocoll)$\mathrm{C}_{6} \mathrm{H}_{5} \mathrm{CO} \cdot \mathrm{NH} \cdot \mathrm{CH}_{2} \cdot \mathrm{COOH}+\mathrm{H}_{2} \mathrm{O}=\mathrm{C}_{6} \mathrm{H}_{5} \cdot \mathrm{COOH}+\mathrm{CH}_{2}\left(\mathrm{NH}_{2}\right) \cdot \mathrm{COOH}$.

It is probably from the phenyl derivatives present in hay, grass and many fruits and berries that hippuric acid is formed in the animal. Moreover, the hydrolysis of proteids yields certain phenyl derivatives, e.g., phenylalanine, which may produce benzoic acid and thus hippuric acid on oxidation.

Other derivatives of benzene occur in the urine, especially of herbivora ; thus, phenyl sulphuric acid, $\mathrm{C}_{6} \mathrm{H}_{5} . \mathrm{O} . \mathrm{SO}_{2} . \mathrm{OH}$, occurs as potassium salt. Cresyl sulphuric acid, $\mathrm{C}_{6} \mathrm{H}_{4}\left(\mathrm{CH}_{3}\right) \cdot \mathrm{O} \cdot \mathrm{SO}_{2} \cdot \mathrm{OH}$, and pyrocatechin sulphuric acid, $\mathrm{C}_{6} \mathrm{H}_{4}(\mathrm{OH}) \cdot \mathrm{O} . \mathrm{SO}_{2} . \mathrm{OH}$, also occur in the urine of horses. Indoxyl sulphuric acid, $\mathrm{C}_{8} \mathrm{H}_{6} \mathrm{~N}$.O. $\mathrm{SO}_{2} \cdot \mathrm{OH}$, or indican, is also found in urine, especially of herbivora. By warming with acids, its potash salt yields indoxyl and potassium acid sulphate :-

$$
\mathrm{C}_{8} \mathrm{H}_{6} \mathrm{~N} \text {.O. } \mathrm{SO}_{2} \cdot \mathrm{OK}+\mathrm{H}_{2} \mathrm{O}=\mathrm{C}_{8} \mathrm{H}_{6} \mathrm{~N}(\mathrm{OH})+\mathrm{KHSO}_{4} \text {. }
$$

On oxidation, e.g., by bleaching powder, indoxyl yields indigo :$2 \mathrm{C}_{8} \mathrm{H}_{6} \mathrm{~N} . \mathrm{OH}+\mathrm{O}_{2}=\mathrm{C}_{16} \mathrm{H}_{10} \mathrm{~N}_{2} \mathrm{O}_{2}+2 \mathrm{H}_{2} \mathrm{O}$. 


\section{CHAPTER XIV.}

\section{Foods and Feeding.}

MANY references have already been made to the chief constituents of the food of animals. In this chapter will be given a summary of some of the chief facts relating to the composition, digestibility and other properties of foods and to the principles upon which the construction of rations for farm animals, under various circumstances, is based.

The Composition of Foods. - In addition to the crops grown on the farm, the compositions of which have already been discussed in Chapter XII, many purchased foods are used in feeding animals. Many of these are bye-products, obtained either in the preparation of flour, meal, etc., from grain of all sorts, or residues left after the expression or extraction of oil from oil-bearing seeds.

The constituents of foods are usually divided into-

1. Non-nitrogenous $\left\{\begin{array}{l}\text { Soluble carbohydrates } \\ \text { Crude fibre } \\ \text { Fats or oils } \\ \text { Mineral matter }\end{array}\right.$

2. Nitrogenous $\left\{\begin{array}{l}\text { Albuminoids or proteids } \\ \text { Amino-compounds and amides }\end{array}\right.$

This plan of reporting analyses of foods, though unsatisfactory in some respects, has been generally adopted and the great majority of published analyses are expressed in its terms.

The imperfections of the method, as regards carbohydrates, crude fibre and albuminoids have already been alluded to in the chapters on Crops and the Constituents of Plants.

The composition of the usual farm crops has already been given but it remains to briefly describe the chemical nature of certain byeproducts used as foodstuffs on the farm.

Bye-products from Oil-bearing Seeds.-Prominent among these are the residues left after the expression or extraction of oil from oil-bearing seeds. These are known under the general name of "oil cakes," among which the more important are-

Linseed cake.-The composition of linseed has already been given. In the manufacture of linseed oil the crushed seed is treated by one of two processes-(1) simple pressure aided by heat, or (2) extraction by means of petroleum naphtha. In the latter process, which is 
largely replacing the older one, especially in America, the solvent is removed by means of steam, and the pressed residue is then ground and sent into the market as oil meal or linseed meal. The new process meal is richer in protein and carbohydrates, but much poorer in fat. It is also less digestible than the old process meal.

Properly ripened linseed is free from starch, though the immature seed contains a small quantity. Many weed seeds, perhaps accidentally mixed with the linseed, are usually rich in starch. As a rule the oil extractor is careful to exclude all foreign matters from the seed because of their retaining the oil, which is very valuable. The presence of starch, therefore, in linseed cake or meal generally indicates adulteration after the extraction of the oil.

Occasionally the husks of the castor-oil seed occur in linseed cakes (probably through aecident), and such cakes are often poisonous. A method for the detection of such admixture is described by Leather. ${ }^{1}$

As a rule, Russian and English cakes are richest in oil, while the American products excel in nitrogenous compounds. Indian cakes are poorest in albuminoids, and American ones, owing to the higher pressures employed in their manufacture, are deficient in oil.

A point of some interest is the almost universal occurrence of a cyanogenetic glucoside, linamarin, identical with phaseolunatin, in linseed cake. Fortunately, the hydrolysing enzyme, capable of liberating hydrocyanic acid from this substance, which is present in the seed, is destroyed by the high temperature employed during the extraction of the oil, so that the cake is rarely, if ever, poisonous from this cause. $^{2}$ Indeed, the minute quantities of prussic acid liberated may exert a beneficial, medicinal effect upon the animals. ${ }^{3}$

Linseed cake is, deservedly, one of the most popular feeding stuffs among cattle feeders.

Cotton-seed cake.-For composition of the seed see p. 243.

Two varieties of cake are made-decorticated, in which the envelopes of the seed, with the adhering particles of cotton, are removed before expressing the oil ; and undecorticated, in which the whole seed is subjected to hydraulic pressure. The latter is naturally of much less value than the former.

The "hulls" removed in the process of "decortication" are used locally as food for cattle, but in England are not of much importance.

Decorticated cotton cake is a concentrated and valuable food for all farm animals except pigs and calves. In the case of the animals mentioned, sickness and death have frequently resulted from feeding with cotton cake or meal. The cause of the poisonous effect does not appear to be known, though it has been attributed to choline, which is present in cotton seed. ${ }^{4}$ According to Crawford (1910) the toxic effects are due to the presence of salts of pyrophosphoric acid, $\mathrm{H}_{4} \mathrm{P}_{2} \mathrm{O}_{7}$.

Cotton-seed cake, fed to dairy cows, increases the firmness and whiteness of the butter, but if used too freely causes the butter to give

1 Jour. Roy. Agric. Soc., 1892.

${ }^{2}$ Vide Fienry \& Auld, Jour. Soc. Chem. Ind., 1908, 428.

${ }^{3}$ Ey:e \& Armstrong, Brit. Assoc., 1912 ; Nature, Nov. 14, 1912, 319. Vide p. 212. 
the reactions for cotton-seed oil, thus giving rise to the suspicion of its being adulterated with margarine.

Rape-seed cake.-This product is little used as food, especially in England, owing to its being not very palatable. It becomes particularly obnoxious to the taste when moistened, owing to the production of mustard oil. Its composition, however, shows it to have a high nutritive value. When the oil has been extracted by means of solvents, the cake is largely used as a manure.

Earth-nut or pea-nut cake.-This is a valuable food, largely employed on the Continent, though little used in England or America. It is particularly rich in proteids.

Palm-nut cake or meal is also employed on the Continent as a food, being appetising, digestible and of good keeping property. It is much valued for dairy cows.

Sunflower-seed cake.-Sunflower seed is a valuable crop in certain parts of Russia and contains about 20 per cent of oil. When this is extracted by pressure, the residue, containing from 9 to 14 per cent of oil and from 30 to 45 per cent of albuminoids, is sometimes used as a cattle food.

Corn oil cake or germ oil meal is the residue left after the extraction (by pressure) of the oil from maize germ. This product is largely produced and used as a food in America. It is rich in proteids and fat and very digestible. Attempts have lately been made to introduce this and other maize bye-products into England, particularly for dairy cows.

Soy-bean cake, the residue left after the extraction of oil from Soy bean, is a valuable, highly nitrogenous food. When the oil is expressed from the beans, the cake usually retains from 6 to 10 per cent of oil, but when the extraction is done by solvent, the resulting "meal" contains only about 2.5 per cent of oil.

Castor-seed cake contains a poisonous substance, which, however, can be rendered harmless by the action of superheated steam. It is rarely or never used as food in England.

Almond cake is a valuable food, but is not obtainable in any large quantity.

Cocoa-nut meal and cake, residues left after the extraction or expression of oil from the flesh of the cocoa-nut, are highly prized as foods, especially for dairy cattle.

Sesame cake is also a good food, though somewhat liable to become rancid on keeping.

Bye-products from Starch Manufacture.-Starch is obtained from potatoes, maize, rice, or wheat, in almost all cases by crushing the raw material with water, separating the fibrous, horny, or woody parts by means of sieves and recovering the starch granules from the milkylooking liquid by sedimentation. The fibrous portions, generally known as "sludge," are then utilised as cattle food, either in the wet condition, in which state the product is very liable to ferment and putrefy, or after drying.

Bye-products from the Manufacture of Sugar. - In the manufacture of beet sugar, the slices of root after the extraction of the sugar 
by water, are used as food, sometimes in the fresh wet state, sometimes after drying. They may also be made into silage or sour fodder. Unless dried, they are very watery, and, in any case, are low in protein and fat.

Molasses, both from beet juice and sugar-cane juice, are used as cattle foods. They are chiefly valuable for the cane sugar which they contain, though raffinose is also present to the extent of 3 or 4 per cent, or in some cases up to 15 or 16 per cent. The nitrogenous portion of molasses is chiefly composed of non-protein substances and the ash is very rich in potash. Nitrates are also present. The amount of water present varies greatly-from about 15 to 30 per cent being usual. If too dilute, it is very apt to go sour. The best way of using molasses is to mix it with warm water and then pour it over the dry food.

Many plans of mixing molasses with dry materials so as to obtain a solid product have been tried and a number of preparations are on the market. Sometimes dried beet slices are used; dried grains, wheat bran, certain oil cakes, or meals (e.g., palm-nut meal, cocoa-nut meal), shredded sugar cane and peat moss have also been used for absorbing the molasses and producing a food convenient to handle.

In most cases, the value of these foods is determined only by the amount of soluble carbohydrates they contain, and their use in large quantities is not to be recommended, on account of the injurious effects liable to be caused by the excessive quantities of potash compounds present.

Bye-products from Breweries and Distilleries.-Malt culms or coombs are the shoots of barley produced when the grain germinates, after soaking in water, in the production of malt. They are separated when the malt is dried in the kilns and furnish a useful food for dairy cows, pigs, fattening oxen and horses. They are generally moistened or scalded with water. Malt culms contain much non-protein nitrogenous matter and sugar.

Brewers' grains are the residues left after the barley or other grain has been "mashed," i.e., extracted with hot water, for the production of wort.

They are used either in the fresh, very wet, condition or after drying. In the former state, they are very liable to ferment and become mouldy.

Dried grains afford good food for horses, cattle, or sheep.

Distillery waste, if from cereals, also affords a valuable food, but is very watery, while that from potatoes is liable to cause digestive troubles. When dried, the distillery waste from cereals is rich in nitrogenous matter and carbohydrates.

Bye-products from the Milling of Cereals.-In the preparation of human foodstuffs from grain many bye-products are obtained, some of which are important as feeding materials for farm animals.

The milling of wheat is the most elaborate and yields a large number of different products. In the modern roller mill processes, the number of operations is great and the whole procedure complex. 
Eventually, the various products are graded and sold as "patent flour," "straight flour," "low grade or bakers' flour," "bran," "shorts," "sharps" or "middlings" and "screenings".

The proportions of these products vary somewhat, according to the quality of grain used and the details of the milling, but in general, 100 parts by weight of uncleaned wheat yield about-

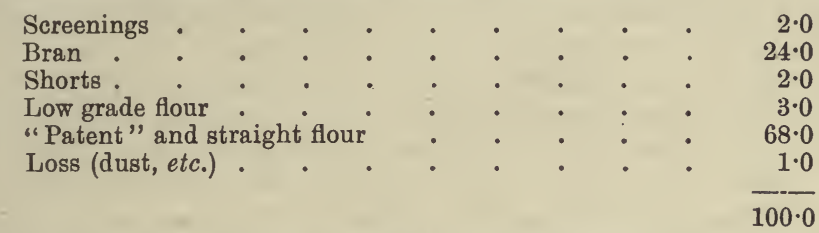

Only the bran and shorts should, properly, be used as farm foods, but often the screenings, containing much rubbish-e.g., small stones, mouse dung, weed seeds, fragments of straw and wood, and rust spores - together with refuse matter derived from the other sources than wheat, are ground up and sold as bran.

The bye-products from the milling of oats-in the preparation of oatmeal and groats, or of barley, in the preparation of pearl barley-are less important and less valuable, and consist largely of the outer husks.

Rice bran and oat bran, indeed, are not really brans but consist of the ground husks with some meal, and usually the germs.

Rice polish, a finely divided material, is highly nitrogenous and rich in phosphoric acid.

From maize, various bye-products are obtained, both in the production of "corn flour" and in the manufacture of starch and glucose.

Maize bran is the husk or hull of Indian corn.

Gluten meal is the highly nitrogenous portion of the grain which lies immediately below the husk.

Germ meal or cake is the nitrogenous and fatty residue left after the expression of "corn oil " from the embryo of maize.

Various other products, known as "gluten feed," "glucose meal," "starch refuse," "starch feed," etc., largely sold in America, are also obtained from maize.

Digestibility of Foods. - The value of a food depends not only upon the quantities of its nutritious constituents, but also upon the extent to which those constituents are actually utilised by the animals which are fed upon it, or in other words upon the digestibility of its nutrients.

To determine this, direct experiments with animals have been made. Such experiments consist in supplying known quantities of food to animals and making careful determinations of the amounts of the various food constituents present in the food and in the solid excrement voided by the animal during the experimental period.

Various precautions have to be taken in order to arrive at reliable results, e.g., it is necessary to administer the food for several days before the experiment really begins, in order to ensure the complete expulsion of the residues from previous feeding. With the ruminants and horses, 
this preliminary period should be from 6 to 8 days; with pigs, 4 to 6 days are sufficient. The experiment proper, during which all the food, of known composition, is carefully weighed and all solid excrement both weighed and analysed, should also last for at least a week or 10 days so as to eliminate accidental variations.

Even with the most careful attention to accuracy in such experiments, the results are not entitled to any great reliance, for there are several factors which invalidate their correctness. The dung does not consist entirely of undigested food, but contains some residues from the digestive fluids and which therefore have undergone digestion and are products of metabolism in the same way as the constituents of the urine. These secretions increase the nitrogenous and fatty constituents of the fæces and thus tend to give too low values for the digestibility of the proteids and fats of the food supplied.

The proportion of each food constituent digested out of 100 supplied, is known as the "digestion coefficient". " It is to be noted that what is really determined by experiments of the kind just discussed is the difference between the total food and the fæces, for which the term availability has been proposed, while true digestibility is the difference between the total food and the undigested residue. For a determination of the latter, no accurate method has yet been devised, because of the impossibility of distinguishing between the undigested residue of the food and the matter derived from digestive secretions.

The digestibility or availability of a food has no reference to the ease or rapidity with which it can be assimilated, nor to any effect it may have upon the health or comfort of the animal receiving it. These are points on which the aroma and flavour of the food and the individuality of the animal have more influence than the true digestibility. Flavour, aroma and palatability are factors, which, though almost impossible to measure, are of great practical importance in the feeding of animals. They often depend upon apparently slight differences in the cońditions under which the food has been prepared or stored. Such apparently trivial circumstances as absence or presence of slight mouldiness, faint taints with distasteful flavours, etc., while without appreciable effect upon either the composition or digestibility of the food, have often a marked influence upon its success in fattening animals. Foods which are eaten with relish are almost invariably more successful than similar foods, which, from any cause, have become distasteful.

The digestibility of a given food differs considerably with different kinds of animal and even with different individuals of the same breed.

The ruminants, by virtue of their more thorough mastication and longer alimentary canal, are better able to digest coarse fibrous foods than the horse or the pig. The difference becomes less with the more concentrated foods and is most marked when the crude fibre of the food is alone considered.

Gentle exercise rather increases digestibility but hard work distinctly lowers it. This has been clearly shown by the exhaustive experiments of Grandeau and his associates with horses.

The quantity of food supplied to an animal has little influence on 
the proportion digested unless the diet be made very generous, when the digestibility distinctly diminishes.

The addition of non-nitrogenous substances, especially carbohydrates, to a ration often causes a considerable diminution in the digestibility (or rather availability) of the original ration. This is probably largely accounted for by the increased quantities of intestinal and other digestive juices present in the fæces, and the consequent greater richness of the latter in waste nitrogenous matter. The intestinal bacteria too, would probably be nourished by the added carbohydrates, which would thus protect the cellulose, etc., of the original food and cause it to be passed in greater quantity.

Varied quantities of fat have little influence upon the digestibility of food, so long as the fat is intimately incorporated with the food and its total amount is kept below about $1 \mathrm{lb}$. per $1000 \mathrm{lb}$. body weight per day. If, however, either of these conditions be not fulfilled, the repellent action of the oily matter upon the digestive fluids leads to a considerable waste in undigested food.

Increased quantities of protein cause no diminution of digestibility of the other food constituents. On the contrary, to rations rich in carbohydrates, such an addition often materially enhances the digestibility of the carbohydrates.

It is evident, from what has been said, that "digestion coefficients," however carefully determined, cannot claim to have much reliability when applied to any particular food or any individual animal. It is therefore unreasonable to claim for them any degree of exactness. The following tables, giving average digestion coefficients in various foods, have been derived from American and German investigations and may be used as rough guides for obtaining the digestibility of foods of the same general character as those named in the tables:-

AVERAGE DIGESTION COEFFICIENTS IN VARIOUS FOODS.

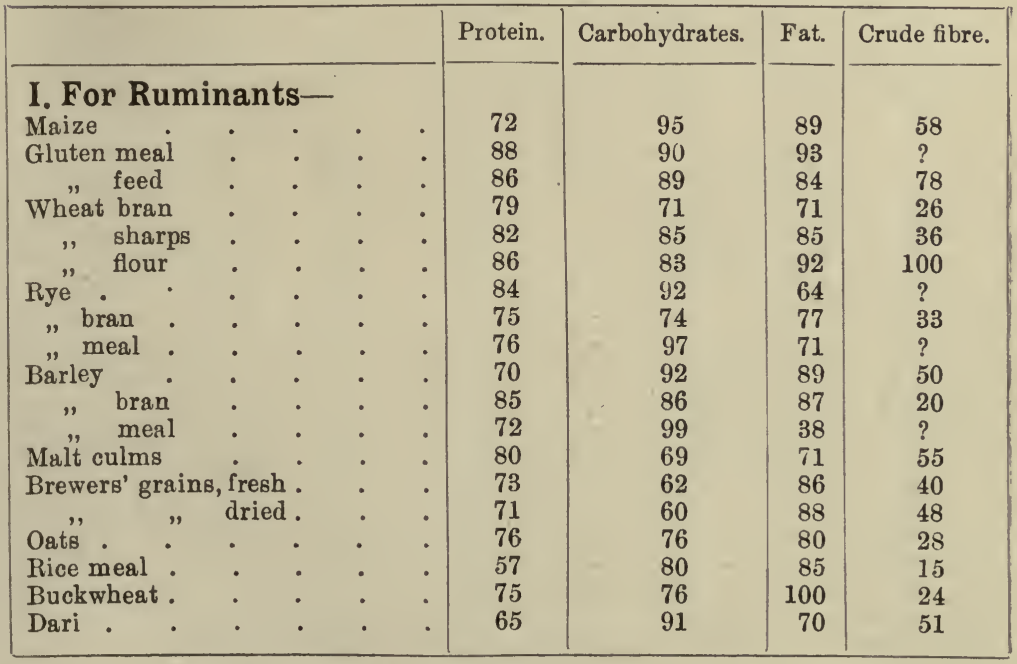




\begin{tabular}{|c|c|c|c|c|c|c|c|}
\hline & & & & Protein. & Carbohydrates. & Fat. & Crude fibre. \\
\hline I. For Rumin & ant & $\mathbf{s}(\operatorname{con} t$ & $t d)$. & & & & \\
\hline Linseed $\quad$. & . & . $\quad$. & • & 91 & 55 & 86 & 60 \\
\hline " cake & . & . & . & 86 & 78 & 92 & 32 \\
\hline$"$ meal, e & atract & ed . & • & 84 & 82 & 95 & 54 \\
\hline Cotton seed & $\cdot$ & . & & 68 & 50 & 87 & 76 \\
\hline$" \quad$ " cake & decc & orticate & ted & 86 & 67 & 94 & 28 \\
\hline$"$ " " & und & ecortic & cated & 77 & 52 & 93 & 18 \\
\hline Earthnut cake & · & . $\quad$. & • & 90 & 84 & 90 & 9 \\
\hline Palmnut cake & . & . & . & 75 & 77 & 98 & 39 \\
\hline Cocoa-nut cake & · & . & - & 78 & 83 & 97 & . 63 \\
\hline Sunflower seed & ake & . $\quad$. & . & 90 & 71 & 88 & 30 \\
\hline Rape cake & · & $\cdot$ & - & 81 & 76 & 79 & 8 \\
\hline Peas . & - & . & - & 86 & 93 & 65 & 46 \\
\hline Pea meal . & . & . & - & 83 & $73=$ & 85 & $?$ \\
\hline Field beans & . & - & . & 87 & 91 & 83 & 58 \\
\hline Soja beans . & . & . & - & 89 & 69 & 90 & 36 \\
\hline Locust beans & . & . & . & 68 & 95 & 53 & $?$ \\
\hline Horse chestnuts & . & . & . & 60 & 93 & 85 & ? \\
\hline Acorns & . & - & - & 83 & 91 & 88 & 62 \\
\hline Pasture grass, i & a spri & & . & 75 & 79 & 66 & 73 \\
\hline Meadow grass, J & une & . & . & 70 & 75 & 62 & 66 \\
\hline ",$"$ Oc & tober & . & - & 56 & 61 & 46 & 62 \\
\hline Green mize, ri & & . & - & 73 & 67 & 75 & 72 \\
\hline " sorghum & . & . & - & 62 & 78 & 85 & 60 \\
\hline Rye, young & . & - & - & 79 & 71 & 74 & 80 \\
\hline Oats, in flower & & . & - & 75 & 63 & 70 & 60 \\
\hline ", grain half & ripe & . & . & 68 & 61 & 67 & 44 \\
\hline Barley, in full $\mathrm{f}$ & ower & & . & 70 & 73 & 62 & 56 \\
\hline " grain ha & If ripe & & & 73 & 70 & 58 & 65 \\
\hline Red clover, befo & re flor & wering & & 74 & 83 & 65 & 60 \\
\hline$", \quad$ in flo & wer & . $\quad$. & & 69 & 72 & 61 & 50 \\
\hline ,,$\quad$ end & f flor & wering & & 59 & 71 & 45 & 39 \\
\hline Lucerne, in flow & er & .. & . & 81 & 72 & 45 & 41 \\
\hline Sainfoin, begin & aing $t$ & o flowe & & 73 & 78 & 67 & 42 \\
\hline Crimson clover, & in $\mathrm{flo}$ & ower. & . & 77 & 75 & 66 & 56 \\
\hline Vetches & · & - & • & 71 & 76 & 59 & 44 \\
\hline Meadow hay, go & & . & . & 65 & 68 & 57 & 63 \\
\hline , , me & dium & . & - & 57 & 51 & 64 & 59 \\
\hline$" \Rightarrow$ poc & & & . & 50 & 59 & 49 & 55 \\
\hline Timothy hay, or & in $f$ & dower. & & 57 & 64 & 58 & 59 \\
\hline$", \quad, \quad$ aft & er flo & wering & & 45 & 60 & 52 & 47 \\
\hline Cocksfoot hay & & . & - & 60 & 55 & 54 & 60 \\
\hline Red clover hay, & rich & . & • & 65 & 70 & 63 & 49 \\
\hline , , , & nediu & $\mathrm{m}$ & • & 54 & 64 & 53 & 46 \\
\hline Alsike hay, cut & in flo & wer & - & 66 & 71 & 50 & 54 \\
\hline White clover ha & $y$, ful & 1 flower & & 73 & 70 & 51 & 51 \\
\hline Lucerne hay, in & early & flower & & 76 & 68 & 46 & 42 \\
\hline$", \quad, \quad$ in & full fl & ower. & & 68 & 62 & 53 & 45 \\
\hline Sainfoin hay, in & early & flower & & 73 & 78 & 67 & 42 \\
\hline Maize silage & - & . & . & 51 & 67 & 80 & 71 \\
\hline Sainfoin silage & - & - & - & 50 & 53 & 74 & 29 \\
\hline Wheat straw & . & . & - & 4 & 37 & 31 & 50 \\
\hline Barley straw & - & - & • & 25 & 53 & 39 & 54 \\
\hline
\end{tabular}




\begin{tabular}{|c|c|c|c|c|c|c|c|}
\hline & & & & Protein. & Carbohydrates. & Fat. & Crude fibre. \\
\hline I. For Rumin & ants & (cont & td.) - & & & & \\
\hline Rye straw . & - & - & . & 23 & 39 & 36 & 55 \\
\hline Oat straw. & . & - $\quad$. & . & 33 & 46 & 36 & 54 \\
\hline Rice straw . & - & - $\quad$. & . & 45 & 32 & 47 & 57 \\
\hline Bean straw & - & - $\quad$. & $\cdot$ & 49 & 68 & 57 & 43 \\
\hline Pea straw, good & . & - $\quad$. & . & 60 & 64 & 46 & 52 \\
\hline Soja bean straw & & . $\quad$. & $\cdot$ & 50 & 66 & 60 & 38 \\
\hline Potatoes .. & . & . & . & 51 & 90 & $?$ & $?$ \\
\hline Mangolds . & . & - $\quad$. & . & 70 & 95 & $?$ & 37 \\
\hline Sugar beets & - & . $\quad$. & . & 72 & 97 & ? & 34 \\
\hline Turnips . & - & . & . & 73 & 92 & $?$ & 51 \\
\hline Swedes & - & - & - & 62 & 99 & 93 & 100 \\
\hline Cabbages . & - & - & - & 80 & 95 & 84 & 74 \\
\hline Meat meal . & . & . & . & 93 & - & 98 & - \\
\hline Fish meal . & . & . $\quad$. & . & 90 & 一 & 76 & - \\
\hline Cows' milk. & - & - $\quad$. & - & 94 & 97 & 100 & 一 \\
\hline II. For Hors & es- & & & & & . & \\
\hline Oats . . & . & . & - & 80 & 75 & 71 & 29 \\
\hline Barley & - & . $\quad$. & - & 80 & 87 & 42 & 100 \\
\hline Maize. & - & - $\quad$. & . & i76 & 92 & 61 & 40 \\
\hline Field beans & - & . & - & 86 & 94 & 13 & 65 \\
\hline Peas . . & $\cdot$ & . & . & 83 & 89 & 7 & 8 \\
\hline Sorghum vulgar & & . $\quad$. & - & 42 & 74 & 61 & 29 \\
\hline Linseed cuke & . & - $\quad$. & . & 88 & 94 & 53 & $?$ \\
\hline Linseed & . & . & - & 75 & 98 & 52 & $?$ \\
\hline Meadow hay, goc & & . & . & 63 & 65 & 22 & 48 \\
\hline " $\quad$, mec & dium & . & . & 58 & 58 & 18 & 39 \\
\hline , , poo & or & - & . & 55 & 52 & 29 & 38 \\
\hline Red clover hay & . & - & $\cdot$ & 56 & 63 & 29 & 37 \\
\hline Lucerne hay & - & . & . & 73 & 70 & 14 & 46 \\
\hline Wheat straw & - & • & $\cdot$ & 28 & 28 & - & 18 \\
\hline Carrots & . & - & - & 99 & 94 & - & - \\
\hline Potatoes & . & - & . & 88 & 99 & - & 9 \\
\hline III. For Pigs & s- & & & & & & \\
\hline Barley & - & - & . & 75 & 89 & 49 & 12 \\
\hline Maize & . & - & . & 84 & 94 & 74 & 41 \\
\hline Wheat & - & . & . & 80 & 83 & 70 & 60 \\
\hline Sorghum vulgar & re & - & . & 60 & 83 & 72 & 20 \\
\hline Rice . & . & . & . & 86 & 100 & 70 & - \\
\hline Ground peas & . & - & . & 90 & 96 & 49 & 70 \\
\hline Wheat bran & - & - & . & 75 & 66 & 72 & 33 \\
\hline Barley bran & - & . & . & 83 & 94 & 74 & 24 \\
\hline Rye bran : & . & . & . & 66 & 74 & 58 & 9 \\
\hline Buckwheat bran & . & . & . & 81 & 96 & 89 & 27 \\
\hline Rice meal . & & . & . & 58 & 78 & 76 & - \\
\hline Brewers' grains, & dried & . & . & 63 & 52 & 49 & 15 \\
\hline Linseed cake me & al & - & . & 86 & 85 & 80 & 12 \\
\hline Potatoes & - & - & - & 76 & 98 & - & 55 \\
\hline Meat meal . & . & . & . & 97 & - & 86 & - \\
\hline Sour milk . & . & . & . & 96 & 98 & 95 & - \\
\hline
\end{tabular}


The pig possesses good digestive power for highly concentrated foods, but the shortness of its digestive canal seriously lessens the amount of crude fibre and of bulky fodder which it can digest.

Horses show similar inferiority in digestive power when compared with ruminants. With protein, however, they are, on the whole, as well able to deal, but with carbohydrates, fats and especially fibre they are distinctly inferior to cattle and sheep.

Fodder is subject to the greatest variation in digestibility, being almost always most digestible when young. This is true, manifestly, with reference to the "fibre," which becomes less and less digestible as the plant becomes more lignified, but also applies to the proteids, fat and starch. This is well seen by reference to the digestion coefficients for hay and green grass, clover, etc., in the table just given.

Albuminoid Ratio.- It is found that the digestibility of some constituents may be altered by the addition to the food of an increased quantity of one constituent. This is only true under certain circumstances, viz., when the albuminoid ratio of the food is changed so as to fall outside certain limits, which differ with the particular animal considered. By albuminoid ratio or nutritive ratio is meant the ratio of the digestible albuminoids to the digestible non-albuminoids expressed in equivalent of starch. The calculation of the starch equivalent of fat, sugar, etc., is based upon the results of calorimetric experiments, i.e., the quantities which will produce, by their combustion, an equal amount of heat.

By placing an animal in a respiration calorimeter, so arranged that everything which enters and leaves may be measured, the quantities of various dry foodstuffs which will produce, in the body of the animal, as much heat as 100 parts of fat has been determined. The following table gives the results as compared with those obtained by direct oxidation of the food in a combustion calorimeter ${ }^{1}$ :-

\begin{tabular}{|c|c|c|c|}
\hline & & $\begin{array}{l}\text { As determined } \\
\text { with animals. }\end{array}$ & $\begin{array}{l}\text { As determined in com- } \\
\text { bustion calorimeter. }\end{array}$ \\
\hline Myosin & . & 225 & 213 \\
\hline Lean meat. & . & 243 & 235 \\
\hline Starch & . & 232 & 229 \\
\hline Cane sugar & . $\quad$. & 234 & 235 \\
\hline Grape sugar & .. & 256 & 255 \\
\hline
\end{tabular}

The agreement between these two sets of numbers is as close as can be expected.

Rubner gives the following as the approximate heats of combustion of the three principal classes of food:-

${ }^{1}$ Rubner, quoted by Atwater, Bull. 21, U.S. Dept. of Agric. Atwater found, as a mean, that the heats of combustion of the available fat, protein and carbohydrates of foods were represented by 9400,4400 , and 4100 thermal units (Rep. of the Storrs Agric. Expt. Station, 1899). These numbers agree well with the older numbers obtained by Rubner in $\mathbf{1 8 8 5}$. 


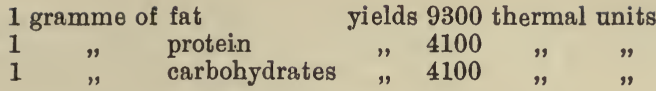

-or in other words, 1 gramme of fat would, by union with oxygen, evolve heat sufficient to raise the temperature of 9300 grammes of water through $1^{\circ} \mathrm{C}$., while a gramme of protein or carbohydrates would, on burning, suffice to heat 4100 grammes of water through $1^{\circ} \mathrm{C}$. The numbers given are averages, and in any particular case slightly higher or lower values might be obtained.

The ratios of the heat-producing powers of the three foodstuffs thus are, approximately-

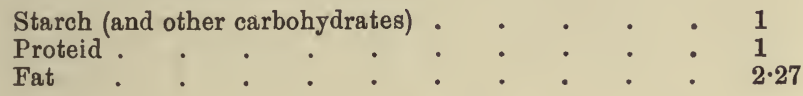

-or $1: 1: 2 \cdot 3$.

The albuminoid or nutritive ratio of a food is therefore calculated from its digestible constituents, thus :-

Albuminoids

Carbohydrates + fibre +0.6 amides + (fat $\times 2 \cdot 2)$.

In many cases the ratio is taken as $\frac{\text { Digestible nitrogenous matter }}{\text { Carbohydrates + fibre }+(\text { fat } \times 2 \cdot 3)}$, but the former method is probably a more accurate one.

It is found that the nutritive ratio of the food of an animal must not fall outside certain limits (which vary with circumstances) or either its health and condition suffer, or waste of food is entailed. Before discussing the subject further, however, it is advisable to give a table of the digestible constituents of the important foodstuffs.

Such a table can be calculated from the tables already given, since the two factors governing it are obviously the composition of the foods and digestibility of their constituents.

In the following table, the total constituents of a large number of foodstuffs are given, together with the average amounts of digestible nutrients present in 100 parts by weight of the food.

The figures are chiefly calculated from German (as compiled by Kellner) and American sources. The "simpler amino-compounds" refer to the non-proteid nitrogenous compounds formerly known as "amides" in food analyses. These substances are soluble and are therefore to be regarded as completely digestible. The figures in the column headed "starch equivalent" are obtained by taking the percentage figures for digestible constituents thus-

Digest. proteids + sol. carbohydrates + crude fibre $+2 \cdot 2 \times$ fat + $0.6 \times$ "amides," and, subject to a due supply of proteids being maintained, afford the best criterion of the relative feeding values of various foodstuffs.

According to Kellner, however, it is not in all foods that the feeding value corresponds to the starch equivalent. In cereal and leguminous seeds, the agreement. between actual feeding value and starch 


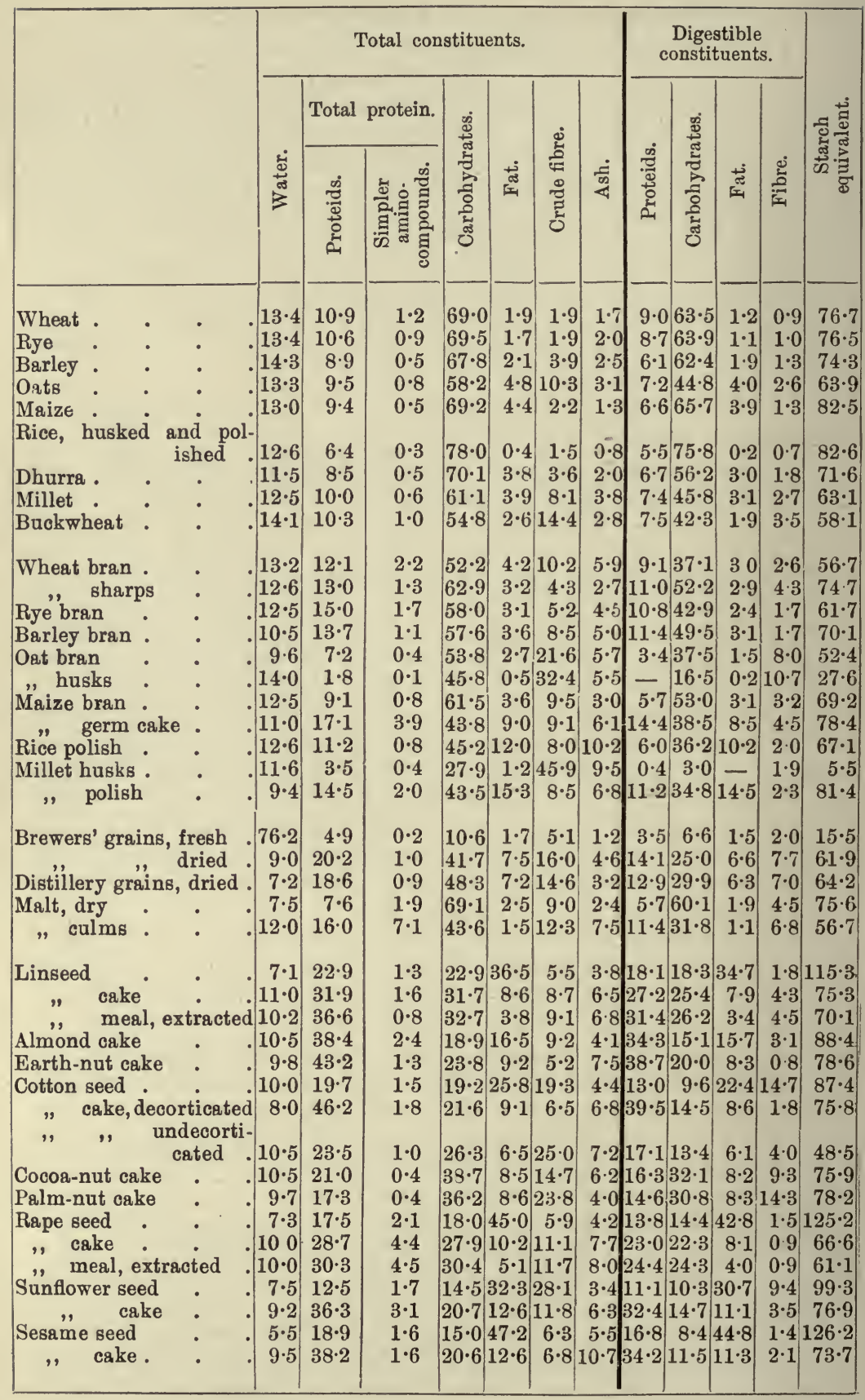




\begin{tabular}{|c|c|c|c|c|c|c|c|c|c|c|c|c|c|}
\hline & \multicolumn{7}{|c|}{ Total constituents. } & \multicolumn{4}{|c|}{$\begin{array}{l}\text { Digestible } \\
\text { constituents. }\end{array}$} & \multirow{3}{*}{ 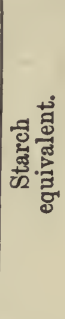 } \\
\hline & & \multirow[b]{2}{*}{ 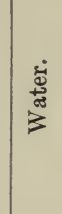 } & \multicolumn{2}{|c|}{ Total protein. } & \multirow{2}{*}{ 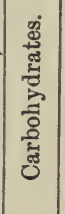 } & \multirow[b]{2}{*}{$\underset{c=1}{\mathbb{\pi}_{i=1}}$} & \multirow{2}{*}{ 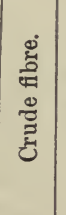 } & \multirow[b]{2}{*}{ कू } & \multirow[b]{2}{*}{ 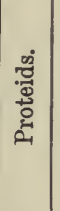 } & \multirow{2}{*}{ 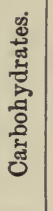 } & \multirow[b]{2}{*}{ 我 } & \multirow[b]{2}{*}{ 竞 } & \\
\hline & & & 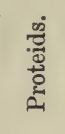 & 总宫害 & & & & & & & & & \\
\hline Pea & & $14 \cdot 0$ & $20 \cdot 0$ & $2 \cdot 5$ & $53 \cdot 7$ & $1 \cdot 6$ & $5 \cdot 4$ & $2 \cdot 8$ & $16 \cdot 9$ & $49 \cdot 9$ & $1 \cdot 0$ & $2 \cdot 5$ & $73 \cdot 0$ \\
\hline Field beans . & & $14 \cdot 3$ & & & $48 \cdot 5$ & $1 \cdot 5$ & $7 \cdot 1$ & $3 \cdot 2$ & $19 \cdot 3$ & $44 \cdot 1$ & $1 \cdot 2$ & $4 \cdot 1$ & 71 . \\
\hline Lentils . & e & $14 \cdot 0$ & $22 \cdot 7$ & $2 \cdot 8$ & $52 \cdot 2$ & $1 \cdot 9$ & $3 \cdot 4$ & $3 \cdot 0$ & $19 \cdot 1$ & $48 \cdot 5$ & $1 \cdot 2$ & 1.8 & $73^{\circ}$ \\
\hline Lupines, blue & . & $14 \cdot 0$ & $26 \cdot 5$ & $3 \cdot 0$ & $36 \cdot 2$ & $6 \cdot 2$ & $11 \cdot 2$ & $2 \cdot 9$ & $23 \cdot 3$ & $31 \cdot 2$ & $5 \cdot 21$ & $10 \cdot 1$ & $77 \cdot \varepsilon$ \\
\hline ,, yellow & . & $14 \cdot 0$ & $34 \cdot 5$ & $3 \cdot 8$ & $25 \cdot 4$ & $4 \cdot 4$ & $14 \cdot 1$ & $3 \cdot 8$ & $30 \cdot 6$ & $21 \cdot 9$ & $3 \cdot 81$ & $12 \cdot 7$ & $75 \cdot 9$ \\
\hline oja beans. & • & $10 \cdot 0$ & $29 \cdot 9$ & $3 \cdot 3$ & $30 \cdot 2$ & $17 \cdot 5$ & $4 \cdot 4$ & $4 \cdot 7$ & $26 \cdot 2$ & $20 \cdot 8$ & $15 \cdot 8$ & $1 \cdot 7$ & $85 \cdot 5$ \\
\hline eans & & $\cdot 0$ & $5 \cdot 0$ & 0.8 & $69 \cdot 0$ & $1 \cdot 3$ & $6 \cdot 4$ & $2 \cdot 5$ & $3 \cdot 2$ & $65 \cdot 5$ & 0.7 & $3 \cdot 7$ & 74 . \\
\hline Horse chestnuts, & dry & $18 \cdot 8$ & $5 \cdot 2$ & $1 \cdot 7$ & $53 \cdot 7$ & $2 \cdot 4$ & $4 \cdot 0$ & $2 \cdot 6$ & $2 \cdot \overline{4}$ & $48 \cdot 4$ & $2 \cdot 0$ & $1 \cdot 2$ & $57 \cdot 4$ \\
\hline Acorns, fresh & 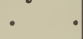 & $50 \cdot 0$ & $2 \cdot 8$ & 0.5 & $36 \cdot 3$ & $2 \cdot 4$ & $6 \cdot 8$ & $1 \cdot 2$ & $2 \cdot 2$ & $32 \cdot 6$ & $1 \cdot 9$ & $4 \cdot 1$ & 43 \\
\hline Past & • & $80 \cdot 0$ & $2 \cdot 7$ & 8 & $9 \cdot 7$ & 0.8 & $4 \cdot 0$ & $2 \cdot 0$ & $1 \cdot 7$ & $7 \cdot 3$ & 0.4 & $2 \cdot 6$ & $13 \cdot 0$ \\
\hline shoots & . & $81 \cdot 0$ & & & $8 \cdot 8$ & 0.5 & $5 \cdot 6$ & $1 \cdot 6$ & $1 \cdot 5$ & $6 \cdot 4$ & 0.3 & $3 \cdot 1$ & 11.9 \\
\hline Oats, shoots . & . & $83 \cdot 9$ & 2 . & 0 & $8 \cdot 8$ & 0.5 & $3 \cdot 8$ & $1 \cdot 5$ & $1 \cdot 4$ & $5 \cdot 2$ & 0.4 & $2 \cdot 3$ & $10 \cdot 0$ \\
\hline, in flower & & $76 \cdot 8$ & $1 \cdot 7$ & $0 \cdot 2$ & $10 \cdot 4$ & $0 \cdot 6$ & $8 \cdot 5$ & $1 \cdot 8$ & $1 \cdot 2$ & $6 \cdot 5$ & 0.4 & $4 \cdot 9$ & $13 \cdot 6$ \\
\hline ripe . & & $53 \cdot 6$ & $3 \cdot 1$ & 0.3 & $20 \cdot 4$ & $1 \cdot 2$ & $18 \cdot 6$ & $2 \cdot 8$ & $2 \cdot 1$ & $12 \cdot 6$ & 0.8 & $9 \cdot 3$ & $26 \cdot 0$ \\
\hline Cocksfoot, in flon & & & 2 & & $14 \cdot 2$ & 0.9 & $7 \cdot 3$ & $2 \cdot 1$ & $1 \cdot 0$ & $9 \cdot 5$ & 0.4 & $4 \cdot 3$ & $16 \cdot c$ \\
\hline Maize. & & & $1 \cdot 0$ & 0 . & $8 \cdot \overline{9}$ & 0.4 & $5 \cdot 0$ & $1 \cdot 5$ & $0 \cdot 3$ & $5 \cdot 5$ & $0 \cdot 2$ & $2 \cdot 7$ & $9 \cdot 1$ \\
\hline Rye grass, in blo & & & $2 \cdot 4$ & $0 \cdot 5$ & $11 \cdot 5$ & $0 \cdot 7$ & $7 \cdot 1$ & $2 \cdot 6$ & $1 \cdot 3$ & $7 \cdot 4$ & 0.3 & $4 \cdot 0$ & $13 \cdot 7$ \\
\hline Timothy, in flow & & $66 \cdot 9$ & $2 \cdot 5$ & $0 \cdot 6$ & $17 \cdot 6$ & $1 \cdot 0$ & $9 \cdot 2$ & $2 \cdot 1$ & $1 \cdot 0$ & $11 \cdot 1$ & 0.5 & $4 \cdot 8$ & $18 \cdot 4$ \\
\hline Red clover, ver & ung & $83 \cdot 2$ & $3 \cdot 0$ & $1 \cdot$ & $7 \cdot 2$ & $0 \cdot 6$ & $3 \cdot 1$ & $1 \cdot 8$ & $2 \cdot 1$ & $6 \cdot 0$ & 0.4 & $2 \cdot 1$ & $11 \cdot 9$ \\
\hline $\begin{array}{r}\text { begin } \\
\text { flow }\end{array}$ & & & $2 \cdot 6$ & 0 . & $8 \cdot 0$ & $0 \cdot 7$ & $5 \cdot 2$ & $1 \cdot 6$ & $1 \cdot 7$ & $6 \cdot 3$ & 0.5 & 3.0 & \\
\hline Red clover, in ful & flow & $79 \cdot 0$ & $2 \cdot 9$ & & $9 \cdot 4$ & $0 \cdot 7$ & $5 \cdot 9$ & $1 \cdot 6$ & $1 \cdot 7$ & $6 \cdot 7$ & 0.4 & $2 \cdot 6$ & 12 \\
\hline Alsike, in full flo & ve & $81 \cdot 8$ & $2 \cdot 2$ & 0.6 & $7 \cdot 0$ & $0 \cdot 7$ & $6 \cdot 2$ & $1 \cdot 5$ & $1 \cdot 0$ & $5 \cdot 0$ & 0.4 & 30 & $10 \cdot 3$ \\
\hline $\begin{array}{l}\text { Crimison clover, } \\
\text { White clover, }\end{array}$ & flower & $81 \cdot 5$ & $2 \cdot 2$ & 0. & $7 \cdot 0$ & $0 \cdot 7$ & $6 \cdot 2$ & $1 \cdot 9$ & 1.5 & $5 \cdot 2$ & 0.5 & $3 \cdot 5$ & $11 \cdot 7$ \\
\hline to $\mathrm{fl}$ & $\mathrm{W}$ & $31 \cdot 5$ & $3 \cdot 5$ & $0 \cdot 9$ & $6 \cdot 9$ & 0.8 & $4 \cdot 3$ & $2 \cdot 1$ & $1 \cdot 9$ & $4 \cdot 7$ & 0.5 & $2 \cdot 6$ & 10 . \\
\hline Lucerne, very yo & ang & $81 \cdot 1$ & $4 \cdot 0$ & $1 \cdot 6$ & $6 \cdot 2$ & $0 \cdot 8$ & $4 \cdot 4$ & $1 \cdot 9$ & $2 \cdot 7$ & $4 \cdot 7$ & $0 \cdot 4$ & $2 \cdot 0$ & 11 \\
\hline & & $76 \cdot 0$ & $3 \cdot 0$ & $1 \cdot 5$ & $9 \cdot 6$ & 0.8 & $6 \cdot 8$ & $2 \cdot 3$ & $1 \cdot 7$ & $6 \cdot 3$ & 0.4 & $2 \cdot 9$ & 12 . \\
\hline Lucerne, in full & lower & $76 \cdot 0$ & $2 \cdot 7$ & & $9 \cdot 3$ & 0.8 & $7 \cdot 8$ & $2 \cdot 2$ & $1 \cdot 5$ & $5 \cdot 7$ & 0.4 & $3 \cdot 5$ & 12 . \\
\hline Sair & & $80 \cdot 0$ & 28 & & $7 \cdot 8$ & $0 \cdot 6$ & $6 \cdot 9$ & $1 \cdot 2$ & $1 \cdot 6$ & $4 \cdot 8$ & $0 \cdot 3$ & $3 \cdot 2$ & $10 \cdot 7$ \\
\hline Ser & & & $2 \cdot 6$ & & $7 \cdot 3$ & $0 \cdot 7$ & $5 \cdot 1$ & $1 \cdot 4$ & $1 \cdot 5$ & $4 \cdot 0$ & 0.5 & $2 \cdot 5$ & 9.5 \\
\hline Bok & flo & & $3 \cdot 1$ & $1 \cdot$ & $7 \cdot 4$ & 0.8 & $5 \cdot 7$ & $2 \cdot 3$ & $1 \cdot 6$ & $5 \cdot 0$ & 0.4 & $2 \cdot 8$ & $10 \cdot 9$ \\
\hline in flowe & & & 2 & & $7 \cdot 2$ & 0.5 & $5 \cdot 1$ & $1 \cdot 5$ & $1 \cdot 4$ & $4 \cdot 9$ & $0 \cdot 3$ & $2 \cdot 3$ & $9 \cdot 8$ \\
\hline Pea & & & $\mathbf{3}$ & & $5 \cdot 1$ & 0.5 & $4 \cdot 5$ & $1 \cdot 4$ & $1 \cdot 9$ & $3 \cdot 2$ & 0.3 & $2 \cdot 3$ & $8^{\circ}$ \\
\hline Field beans, in fl & wer & & $2 \cdot 4$ & $0 \cdot 8$ & $5 \cdot 7$ & $0 \cdot 8$ & $3 \cdot 3$ & $2 \cdot 0$ & $1 \cdot 5$ & $4 \cdot 1$ & 0.5 & $1 \cdot 6$ & $8 \cdot 8$ \\
\hline $\mathrm{Buc}$ & & & & & $7 \cdot 8$ & $0 \cdot 6$ & $4 \cdot 3$ & $1 \cdot 1$ & $1 \cdot 1$ & $5 \cdot 2$ & 0.3 & 2.5 & 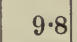 \\
\hline Hes & & & 2.8 & 0. & $16 \cdot 6$ & $4 \cdot 3$ & $22 \cdot 7$ & $2 \cdot 9$ & 0.7 & $8 \cdot 6$ & $1 \cdot 5$ & $7 \cdot 0$ & $20 \cdot 0$ \\
\hline , in $\mathrm{f}$ & ower & 85.9 & $2 \cdot 1$ & 0.7 & $5 \cdot 7$ & 0.8 & $3 \cdot 5$ & $1 \cdot 3$ & $1 \cdot 3$ & $3 \cdot 9$ & 0.5 & 1.9 & $8 \cdot 6$ \\
\hline $\operatorname{tard}, \mathrm{i}$ & flowe & $85 \cdot 1$ & $2 \cdot 3$ & $0 \cdot 6$ & $7 \cdot 3$ & 0.4 & $2 \cdot 9$ & $1 \cdot 4$ & $1 \cdot 3$ & $4 \cdot 9$ & $0 \cdot 2$ & 1.5 & 8 . \\
\hline & . & $48 \cdot 7$ & $4 \cdot 6$ & $0 \cdot 7$ & $18 \cdot 1$ & $1 \cdot 1$ & $24 \cdot 0$ & $2 \cdot 8$ & $1 \cdot 5$ & 10.9 & 0.5 & $9 \cdot 6$ & 23 . \\
\hline nfrey & . & $88 \cdot 5$ & 1.9 & $0 \cdot 6$ & $5 \cdot 0$ & 0.3 & $1 \cdot 7$ & $2 \cdot 0$ & 0.9 & $3 \cdot 7$ & 0.2 & 0.8 & $6 \cdot 2$ \\
\hline & . & $84 \cdot 7$ & 1.9 & 0.6 & $8 \cdot 1$ & $0 \cdot 7$ & $2 \cdot 4$ & $1 \cdot 6$ & $1 \cdot 2$ & 6.5 & 0.4 & 1.7 & $10 \cdot 7$ \\
\hline Kohlrabi leaves & . & & $1 \cdot 3$ & $1 \cdot 5$ & $7 \cdot 1$ & 0.4 & $1 \cdot 6$ & $1 \cdot 6$ & $0 \cdot 4$ & $5 \cdot 7$ & $0 \cdot 2$ & 0.9 & $8 \cdot 3$ \\
\hline
\end{tabular}




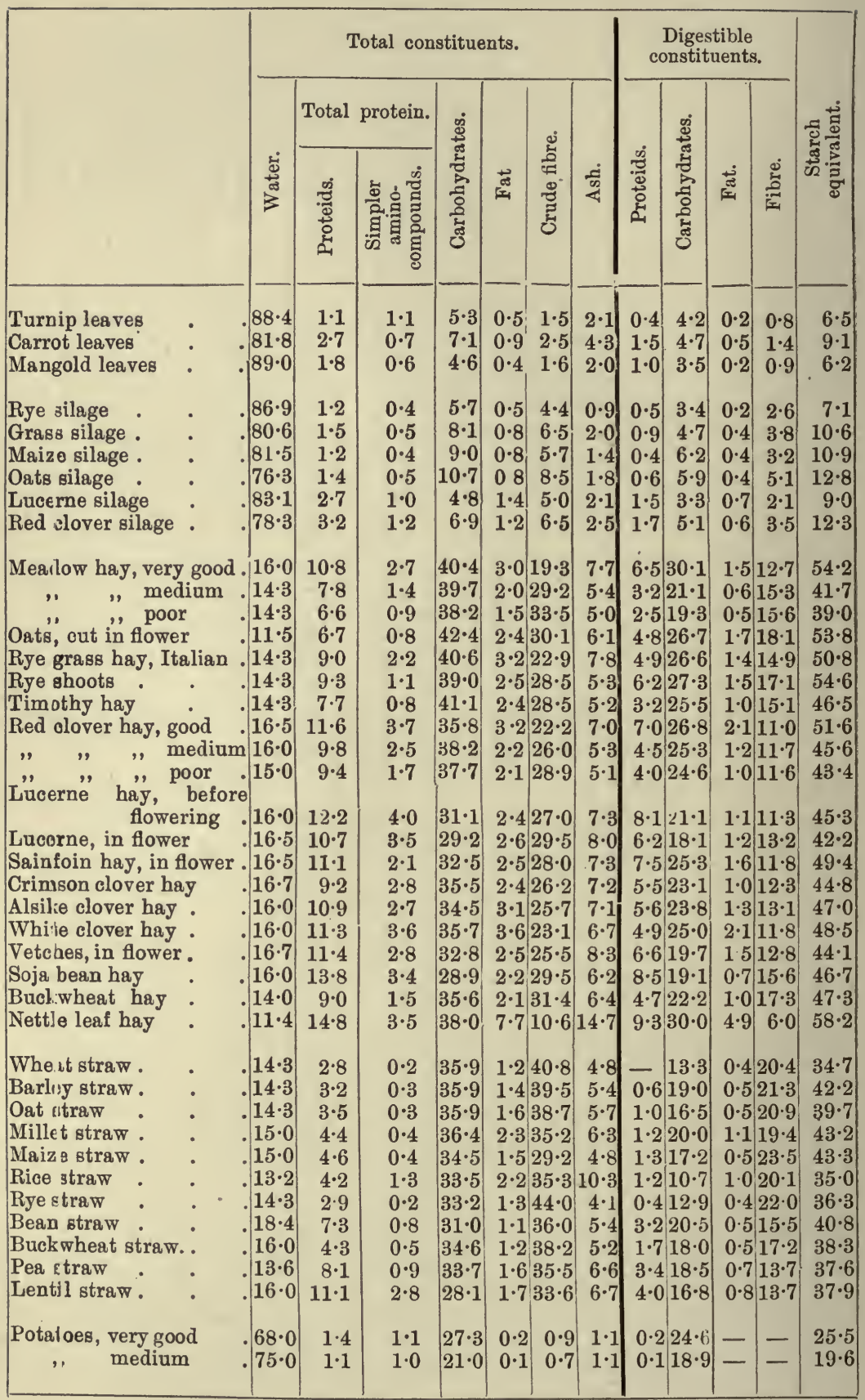




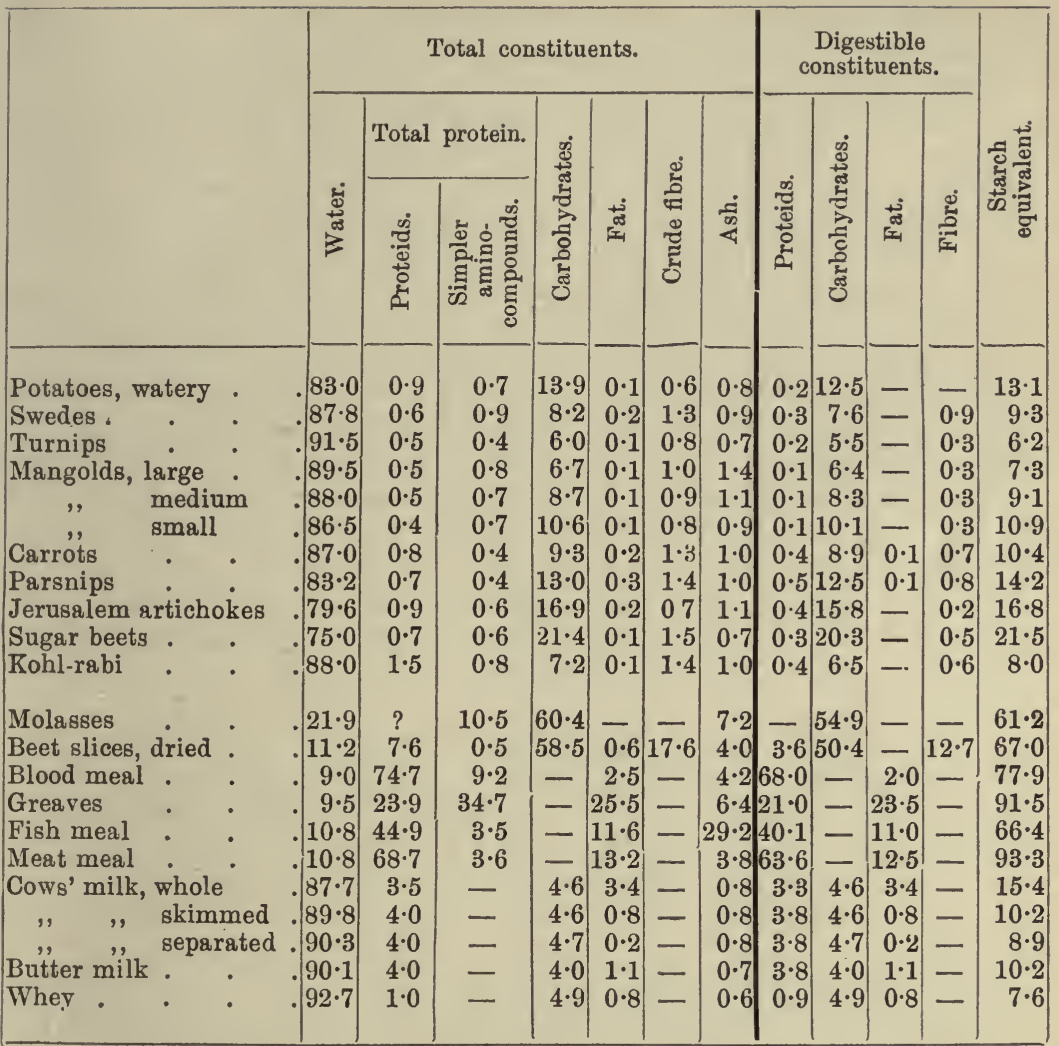

equivalent is close, in green fodders-grasses and leguminous plantsthe former is from 80 to 90 per cent of the latter, in silage and root crops it is usually from 70 to 80 per cent, in hays from 60 to 70 per cent, while in straws it ranges from 30 to 50 per cent. In certain woody "foods," e.g., husks, sawdust, the energy expended in their mastication and digestion is greater than that yielded by their food constituents ; such material may therefore be said to possess a negative value as foodstuffs.

This table can obviously lay claim to no great accuracy; the great variations in composition of different samples of foodstuffs of the same type, as well as the often great differences in digestibility of its constituents render it impossible to obtain data which shall always be reliable. Moreover, as has been shown, digestibility varies very much with different animals.

Importance of "Albuminoid Ratio."-It has been usual in the past to attach great importance, in discussing the framing of rations of fattening animals, to the ratio of albuminoids to non-albuminoids in the digestible portion of the food. A considerable amount 
of ambiguity, however, has always enveloped this ratio, some writers considering "crude protein," i.e., total nitrogen $\times 6 \cdot 25$, others being careful to restrict the term albuminoid to the true proteids present.

From a careful study of all the published accounts of feeding experiments conducted in Britain with cattle and sheep ${ }^{1}$ the author found that there was little correlation between the true albuminoid ratios of the food supplied and the average gain in live weight and came to the conclusion that too much importance has been attached to this ratio. Provided the animals received sufficient proteid to meet their requirements, the gain in live weight then depended mainly upon the amount of digestible non-albuminoids they consumed.

The writer deduced from a consideration of the results that for cattle of over $900 \mathrm{lb}$. live weight, a daily supply of 1.0 to $1.2 \mathrm{lb}$. of digestible proteid (i.e., real albuminoids) per $1000 \mathrm{lb}$. live weight was sufficient for the animals' requirements and that the average daily gain in live weight per $1000 \mathrm{lb}$, then depended mainly upon the supply of non-albuminoids. Expressing these in starch equivalent, about 15 or $16 \mathrm{lb}$ per $1000 \mathrm{lb}$. live weight, per day, seemed to be capable of yielding about the maximum daily average gain-1.8 lb. per $1000 \mathrm{lb}$. per day. These figures were derived from results obtained with about 750 animals.

With sheep, the results obtained with over 2000 animals led to the conclusion that about $1.75 \mathrm{lb}$. digestible real albuminoids per day per $1000 \mathrm{lb}$. live weight was the most suitable amount, while for nonalbuminoids expressed as starch, about $18 \mathrm{lb}$. per $1000 \mathrm{lb}$. per day gave the maximum average daily gain in live weight, viz., abóut $3 \mathrm{lb}$. per $1000 \mathrm{lb}$. This applies to adult sheep of live weight of $100 \mathrm{lb}$. or upwards.

Experiments with animals are subject to many disturbing circumstances and even where every care has been taken, contradictory results are often obtained when the experiments are repeated. The effects of accidental differences, individual peculiarities of the animals used, and other circumstances difficult or impossible to control, are often very great and sometimes entirely overshadow and conceal those of the nature of the feeding which the experiment was designed to determine. The larger the number of animals used in the experiment, other things being equal, the greater is the reliance that can be placed upon the results. Though the experiments reviewed by the writer in the papers just cited, were directed to very diverse objects, it is probable that the general principles deducible from the results are freer from the disturbing influences of individual peculiarities of the animals, than any single experiment could be.

Fig. 8 shows the averages of the daily supply of real albuminoids per $1000 \mathrm{lb}$. live weight, plotted against daily increase in live weight per $1000 \mathrm{lb}$., with cattle exceeding $900 \mathrm{lb}$. live weight. Each small black column at the base of the diagram indicates, by its height, the number of animals which received per day an amount of real albuminoids intermediate between the quantities represented by the

${ }^{1}$ Vide Trans. High. and Agric. Soc., Scotland, 1909, 196; 1910, 168 and 178. 
vertical lines-ordinates-between which the black column lies. The scale is such that a black column reaching to the height of the line $1 \mathrm{lb}$. of increase in live weight per $1000 \mathrm{lb}$. per day, would represent 250 animals. The total number of animals referred to in the diagram is 750 .

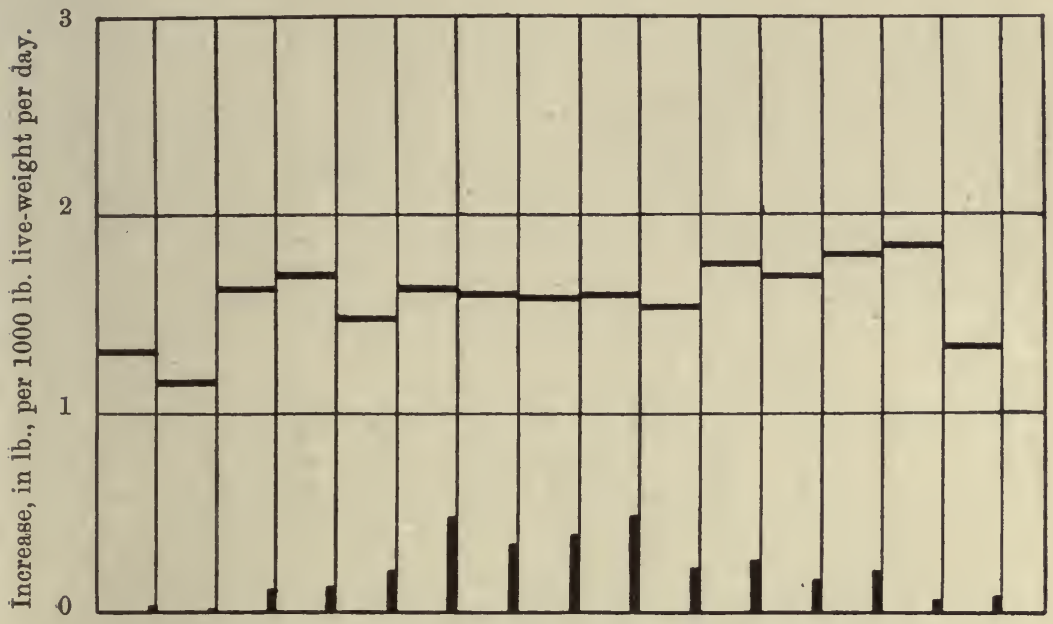

$\begin{array}{llllllllllllllll}0.2 & 0.4 & 0.6 & 0.8 & 1.0 & 1.2 & 1.4 & 1.6 & 1.8 & 2.0 & 2.2 & 2.4 & 2.6 & 2.8 & 3.0 & 3.2\end{array}$ Albuminoids, in lb., consumed per $1000 \mathrm{lb}$. live-weight per day.

Fig. 8.-Bullock-feeding experiments.

It will be seen that when the amount of digestible albuminoid supplied reaches about 1.0 to $1.2 \mathrm{lb}$. per day, the increase in live weight per day becomes practically a maximum and that additional albuminoids produce no greater rate of increase.

Fig. 9 shows the correlation between total non-albuminoids, expressed as starch, per $1000 \mathrm{lb}$. live weight per day and increase in live weight per $1000 \mathrm{lb}$. per day. It will be seen that the daily gain of live weight 'steadily increases with the increase in the daily supply of non-albuminoids until the latter amounts to 15 or $16 \mathrm{lb}$., after which there is a diminution. This diagram is constructed on the same general lines as Fig. 8, except that the spaces between the ordinates each represent $1 \mathrm{lb}$. of non-albuminoids, whereas in Fig. 8 they each represent $0 \cdot 2 \mathrm{lb}$. of real albuminoids.

Figs. 10 and 11 give summaries of the results obtained with over 2000 sheep of, at least, $100 \mathrm{lb}$. live weight each. In this case, pounds of food constituents per $100 \mathrm{lb}$. live weight per week and increase in live weight per $100 \mathrm{lb}$. per week are the quantities plotted against each other. The black vertical columns represent numbers of animals in the respective sections, a height up to $1 \mathrm{lb}$. increase in live weight, in this case, representing 1000 animals. It will be seen that with sheep a distinct correlation between digestible albuminoids consumed and live weight increase can be traced, and that as Fig. 10 shows, a supply 
of 1.0 to $1.2 \mathrm{lb}$. albuminoids per $100 \mathrm{lb}$. live weight per week, produced, on the average, the maximum rate of increase.

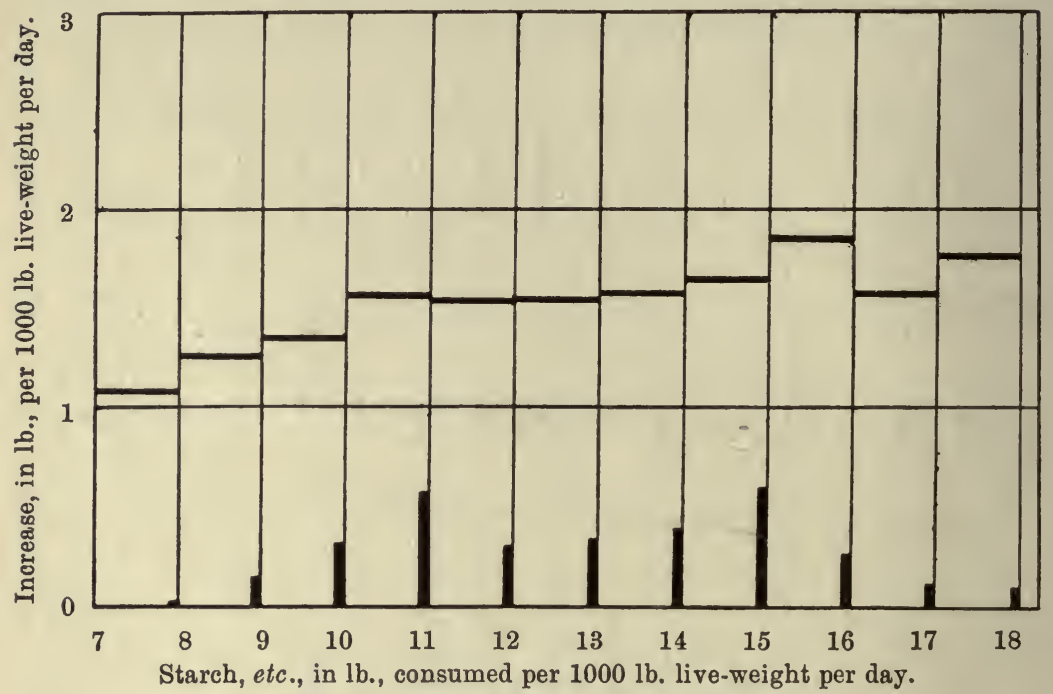

Fra. 9.-Bullock-feeding experiments.

In Fig. 11 the correlation is even better, 12 or $13 \mathrm{lb}$. of non-albuminoids, expressed as starch, giving the maximum rate of increase.

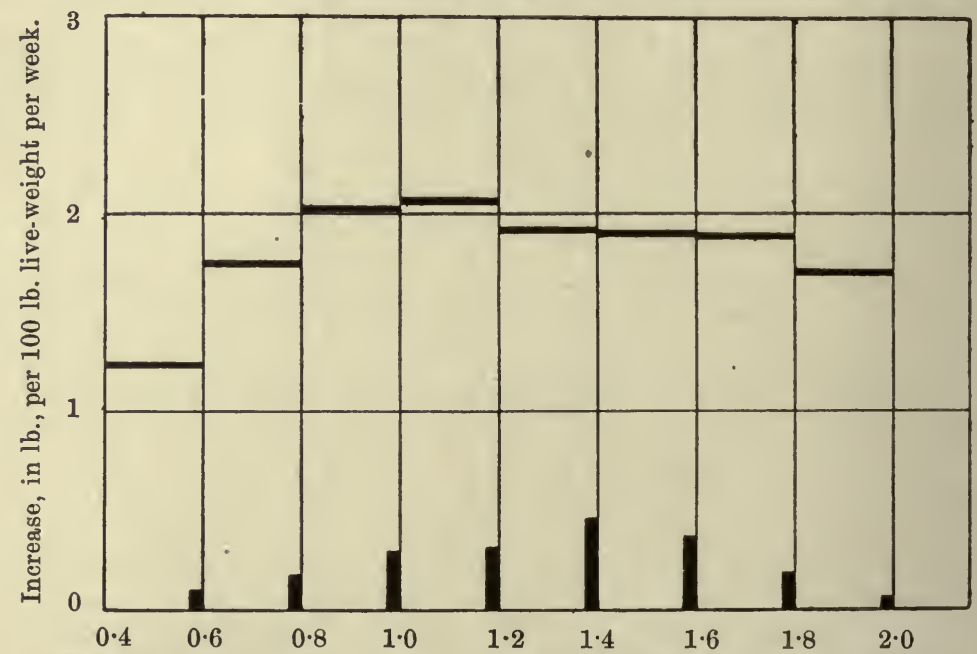

Digestible albuminoids, in lb., consumed per $100 \mathrm{lb}$. live-weight per week. FIG. 10.-Sheep-feeding experiments.

To render the results with sheep comparable with those with bullocks it is only necessary to multiply the figures for the former by 
10 and divide by 7 . In this way the comparison yields, as giving the best results-

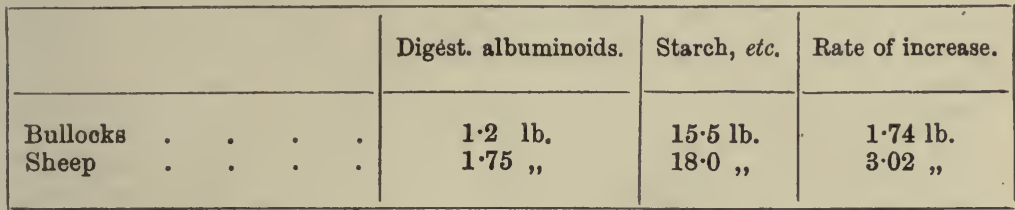

all the figures referring to $1000 \mathrm{lb}$. live weight per day. It is thus

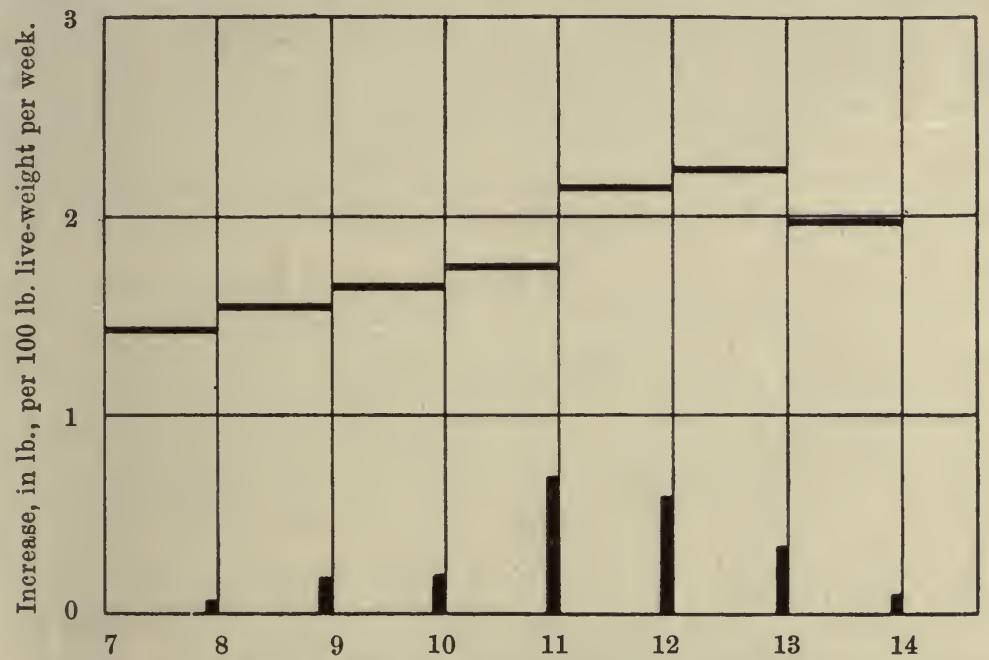

Digestible non-albuminoids, expressed as starch, in lb., "consumed per $100 \mathrm{lb}$. live-weight per week.

Fig. 11.-Sheep-feeding experiments.

seen that sheep require more food per unit weight than cattle, but make better use of their food and fatten, relatively, more rapidly.

Relative Feeding Yalue of the Foods Used.-From the large array of figures accumulated in the course of the calculation of the composition of the rations in this review of feeding trials, the writer attempted to deduce the relative feeding values of a number of commonly used feeding stuffs. Though the experiments were not all designed with this object, it is probable that the deductions drawn from such large numbers of experiments are fairly reliable.

With sheep, the following table gives the average weekly gain, per head, of the animals receiving a considerable quantity of the various foodstuffs in their daily rations:- 


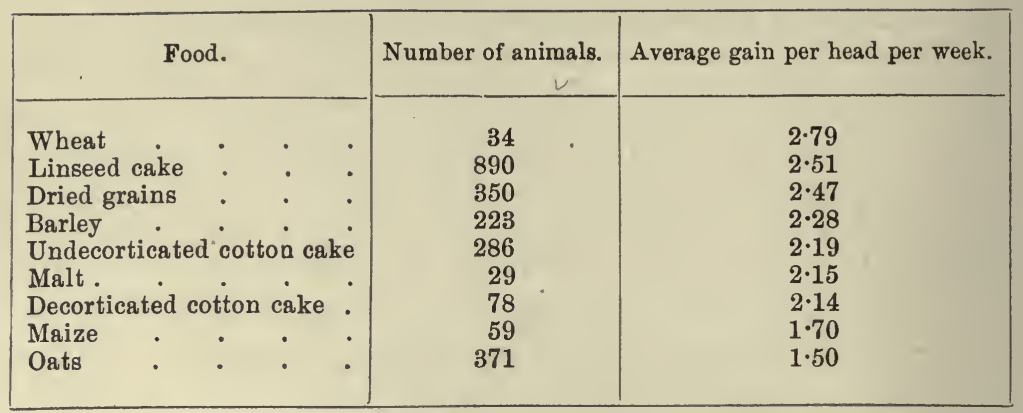

In many cases, these foods were given in admixture with other concentrated foods and, to some extent, the figures may therefore be thereby rendered less reliable, but in cases where the number of sheep receiving the food is large, the results are probably representative. That good results attend the use of linseed cake and dried grains and that poor effects are given by oats and maize are probably quite safe deductions.

Another advantage attending the use of linseed cake is also pointed out by many experiments, viz., that the animals so fed "kill" better than others, i.e., show a higher percentage of carcass to live weight.

With cattle, linseed cake, undecorticated cotton cake and decorticated cotton cake show the same order as with sheep, though the differences between them are less. As regards coarse fodders, the most noticeable point brought out in both the bullock and sheep feeding trials, is the excellent results obtained by the use of clover hay. With cattle, clover hay used in 15 lots, gave an average daily gain of $2.13 \mathrm{lb}$. per head and produced $1 \mathrm{lb}$. of increase at the expense of $7.01 \mathrm{lb}$. of total digestible matter, as against an average for the whole of the cattle feeding trials of $1.803 \mathrm{lb}$. and $9.0 \mathrm{lb}$. respectively.

With sheep, 384 animals receiving clover hay gave an average weekly increase of $2.58 \mathrm{lb}$. per head (as against $2.06 \mathrm{lb}$. of the remaining 2390 sheep), and for each $1 \mathrm{lb}$. of increase, consumed 6.2 lb. of total digestible matter (against $7 \cdot 43 \mathrm{lb}$. consumed by the remainder).

This very pronounced effect of clover hay is worthy of attention by stock-feeders. It is probably partly due to the high content of albuminoids (though the rations of which it formed part had, as a rule, only a fairly wide "albuminoid ratio"), but is mainly to be attributed to its richness in ash constituents, particularly lime (vide infra).

As to roots, mangolds proved better than swedes, and the results indicate that for cattle, from 80 to $100 \mathrm{lb}$. per head per day and for sheep, about $14 \mathrm{lb}$. per head per day, was the most successful allowance.

Amides are usually stated as being used in the body simply as heat producers and to be incapable of acting like albuminoids as flesh formers. Though undoubtedly inferior to albuminoids, it appears from recent experiments that amides do to a certain extent perform the functions of these substances. They certainly lessen the con- 
sumption of albuminoids and greatly diminish the waste of nitrogenous tissue when albuminoids are fed in insufficient quantity, probably by acting instead of the latter as food for intestinal micro-organisms. Zuntz, Kellner and others have found that the addition of simple amino-compounds to a ration poor in albuminoids led to an actual gain of nitrogenous tissue in the animal and also to a greatly enhanced digestion of the crude fibre supplied. This latter effect is attributed to a stimulation of the activity of the intestinal bacteria which are known to play an important part in the breaking down of cellulose and fibre.

It is quite possible, too, that these amino-compounds actually take part in the synthesis of proteids by combination with other aminocompounds present in the food, or obtained by hydrolysis, in the alimentary canal, from real albuminoids.

It is therefore not quite satisfactory to disregard the amides of a food, nor even to assign to them, as is often done, the functions of heat producers only. From the last aspect, asparagine has only about half the value of starch, when due allowance is made for the nitrogen excreted as urea.

In other foods, especially in mangolds, a large proportion of the nitrogen exists as nitrates, ${ }^{1}$ and thus probably is devoid of all feeding properties. In calculating the nutritive ratio of a food, therefore, whereever possible the amount of digestible albuminoids should be used and the amides considered as non-albuminoids and equal to about half their weight of starch, but it must be remembered that the amino-compounds may act in the way described and that the ratio, so calculated, is probably wider than the real one.

Standard Rations. - Food is used by an animal for three purposes :-

(1) To repair and renew tissue.

(2) To furnish heat and energy.

(3) To promote growth and increase.

The relative proportions in which these three functions consume the food taken, is obviously very different, according to whether the animal is merely existing at rest, is working, fattening, or producing milk.

Many attempts to determine the amounts of the various food constituents required by animals under different conditions have been made. One of the earliest and best-known sets of standards are those prepared by Wolff in 1864. They have been much used as guides in framing rations.

The following table of standard rations has been drawn up by Kellner and, in it, distinction is made between true albuminoids and total nitrogenous matter:-

1 This was strikingly demonstrated by an observation made by the author in 1900 that some pulped mangold, kept for some weeks in a stoppered bottle, evolved nitric oxide, doubtless as the result of the action of some denitrifying organism upon the nitrates. A similar production of nitric oxide has been noticed from the pulp of the sugar beet. 
FEEDING STANDARDS PER DAY AND PER 1000 LB. LIVE WEIGHT.

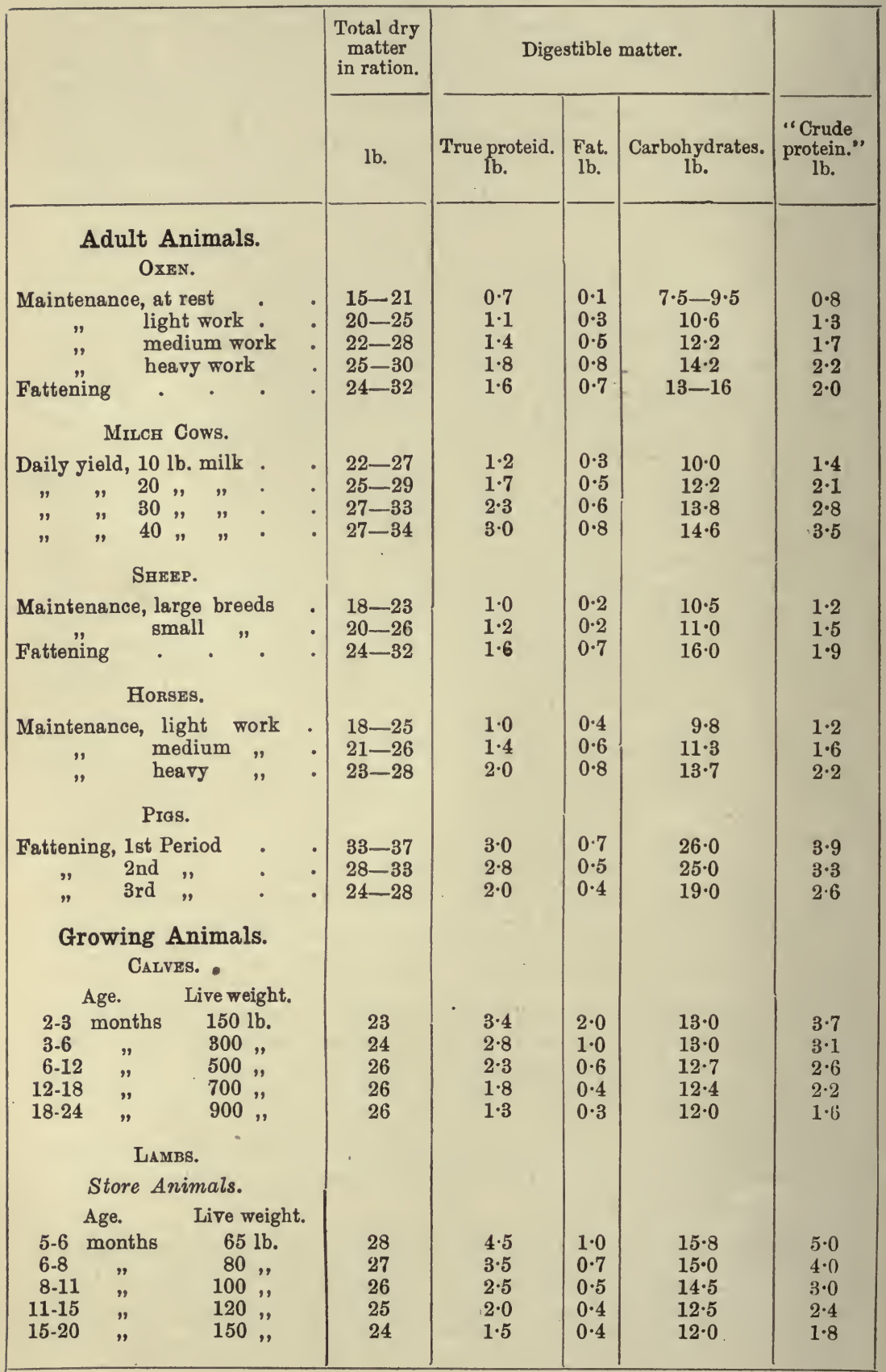




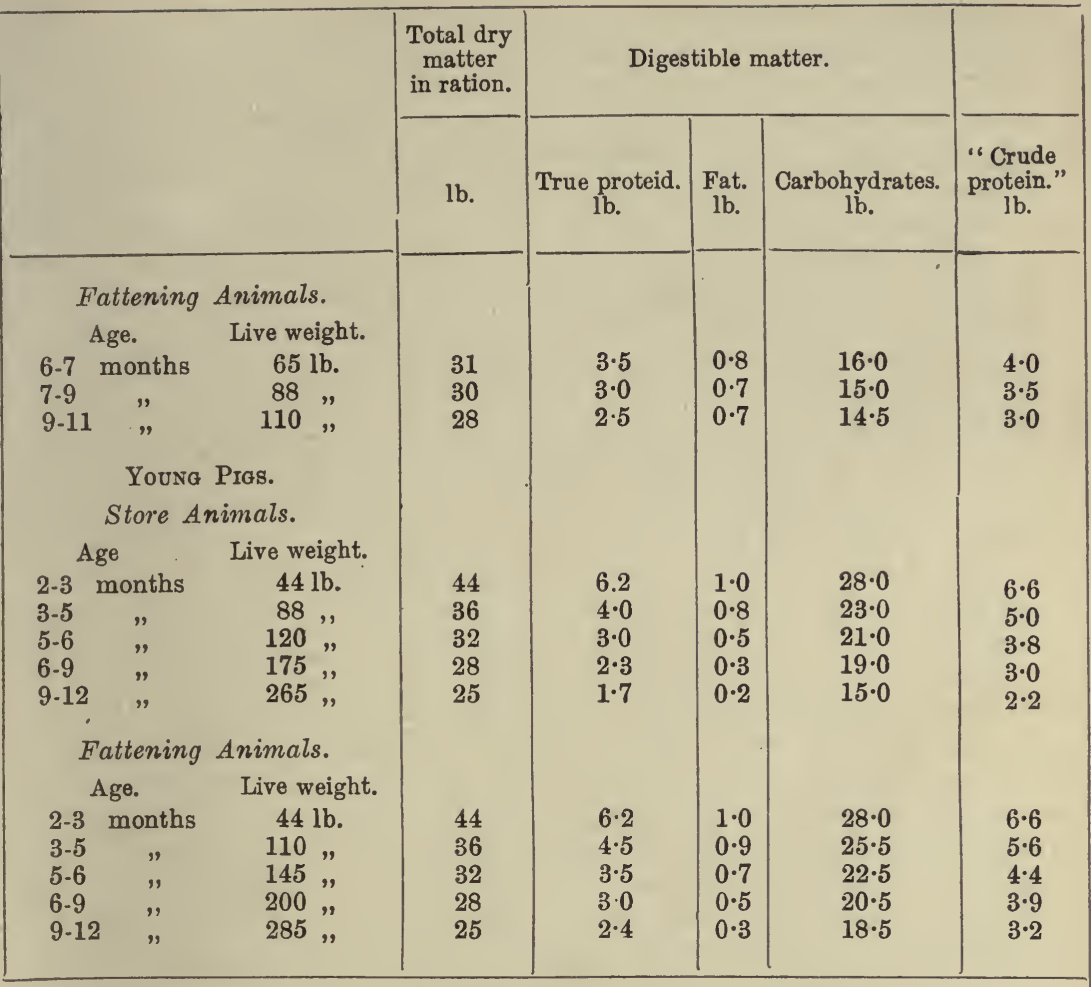

Ash Constituents of Foods. - In addition to the protein, carbohydrates and fat, which are usually regarded as the most important constituents of food, the mineral constituents are of great importance to animals. These are often popularly spoken of as "bone formers," but, beyond admitting that a certain proportion of " ash " is necessary in various foodstuffs, little attention has hitherto been paid to this matter.

The author, from a study of the bones of animals suffering from a disease-osteoporosis-only too prevalent in the South African Colonies, has recently ${ }^{1}$ called attention to several important matters with reference to the composition as well as the amount of the ash constituents of foodstuffs.

The ash constituents of the food are utilised in the animal in two ways.

1. As truly formative materials. - The bones, teeth and other hard parts of animals consist largely of phosphates, fluorides, carbonates

1 See Journal of Comparative Pathology and Therapeutics-March, 1907, pp. 35-48 ; Journ. of Agric. Science, 1909; Jour. Royal Inst. of Public Health, 1909; Seventh Intern. Congress of Applied Chemistry, 1909 ; Illustrated Poultry Record, 1910 and others. 
and chlorides of calcium and magnesium. These substances are therefore essential constituents of food.

2. As necessary for digestive, respiratory and other processes.-The blood contains iron; the saliva, gastric juice and other secretions contain potassium. Chlorine and hydrochloric acid are essential ingredients in the gastric juice ; the thyroid gland contains iodine.

Consider first the substances required for the formation and renewal of bone. The largest and most important mineral constituents are phosphoric acid and lime. In normal bone, these are present in the proportions of one molecule of phosphorus pentoxide $\left(\mathrm{P}_{2} \mathrm{O}_{5}\right)$ to three molecules of lime ( $\mathrm{CaO})$, i.e., 142 to 168 by weight; but as some of the lime of bones is also present as carbonate in bone ash, the proportions by weight are generally about 1 of phosphorus pentoxide to 1.5 of lime. It would seem reasonable, therefore, to expect that the food of an animal, in order to serve for the nutrition of bone, should contain phosphorus pentoxide and lime in about this ratio.

So, too, cows' milk, which we may assume to be particularly adapted for the requirements of a young animal, contains the two above-mentioned constituents in approximately equal proportions by weight, while common salt is also present in about the same amount.

Since phosphorus is also required for the formation of other tissues, e.g., the brain, we may conclude that the ideal food of an animal should contain about equal proportions of lime and phosphorus pentoxide.

Now, in England, the above considerations have perhaps not often much importance, because of the variety of food given to horses and cattle; but in South Africa, where oat hay-i.e., oats cut just before they are ripe, and dried-forms the sole food of many horses and mules, sometimes supplemented by a few mealies (i.e., maize grain), they become, in the author's opinion, of great importance.

Now, in the seeds of most plants there is much more phosphorus pentoxide than lime, while the proportions vary very much in the foliage of different plants.

In the following table are given the ratios of phosphorus pentoxide to lime present in many foodstuffs, from the analyses of Wolff and Warington:-

\begin{tabular}{|c|c|c|c|c|c|c|c|c|}
\hline & . & & & & \multicolumn{3}{|c|}{ Ratio $\mathrm{P}$} & $\mathrm{CaO}$ \\
\hline Lucerne hay & - & & & & & 1 & : & $4 \cdot 78$ \\
\hline Crimson clover & . & & & & & 1 & : & $4 \cdot 45$ \\
\hline Red clover. & . & & & & & 1 & : & $3 \cdot 60$ \\
\hline Meadow hay & . & & & & . & 1 & : & $2 \cdot 55$ \\
\hline Oat straw & . & & & & & 1 & & $1 \cdot 81$ \\
\hline Oat grain . & . & & & & & 1 & & $0 \cdot 16$ \\
\hline Oats, whole plar & at (green & & & & & 1 & & 0.77 \\
\hline Oats, whole plan & at (ripe) & & • & & & 1 & & 0.62 \\
\hline Barley, whole pl & ant & & • & & & 1 & & 0.44 \\
\hline Mealies (maize) & grai & & & & & 1 & & 0.0 \\
\hline
\end{tabular}

Cereals are thus remarkable for the preponderance of phosphorus pentoxide over lime which they contain. Thus, while it is probable that in the whole food of an animal the phosphorus pentoxide ought not to exceed the lime, it is evident that in the usual South African 
ration for horses and mules-oat hay or oat hay and mealies-it exceeds the lime greatly, in most cases the ratio being about $1: 0.5$.

The author has good reason for concluding that many of the bone diseases so prevalent in animals, and the sparse development of bone which characterises the usual South African horse, are largely attributable to their usual diet. As long ago as 1891, Weiske ${ }^{1}$ showed that rabbits fed on oats only, produced very small, weak, brittle bones, while similar animals fed upon oats and hay developed normal skeletons.

Whether the disease, osteoporosis, is really caused by the exclusive cereal diet so often given to horses and mules in South Africa or not, there can be little doubt that animals, now fed exclusively upon oat hay or oat hay and mealies, would be far healthier and better nourished if such foods as lucerne, or even grass hay, formed part of their diet. The author's analyses show that many crops growing well in that country, e.g., cow peas, velvet beans, or even many grasses, would be far preferable to oat hay from this point of view.

It has not been sufficiently recognised that it is the composition and not the amount of the ash constituents that is important in bone formation. As an example of this fallacy, bran serves excellently. This material is rich in ash and is often extolled on that account as being peculiarly well fitted for bone nutrition. As a matter of fact it contains about 3.3 per cent of phosphorus pentoxide and only about 0.3 per cent of lime, or 1 of phosphorus pentoxide to 0.09 of lime, and from the point of view just discussed, ought to prove very unsuitable for promoting bone formation. This is really the case, as is proved by the existence of a peculiar bone disease known as "bran disease," "shorts disease," or "miller's horse rickets," which is often observed in millers' horses, and which is undoubtedly caused by feeding with excessive quantities of bran.

Another point of importance is the supply of adequate quantities of the mineral ingredients required for the formation of the digestive juices of an animal.

Kellner estimates the daily requirement of a cow of average weight at $\frac{3}{4}$ to $1 \frac{1}{2}$ oz. common salt, that of a horse at $\frac{1}{2}$ to $1 \mathrm{oz}$., of a sheep or pig at $\frac{1}{8}$ to $\frac{1}{4} \mathrm{oz}$, but when foods difficult of digestion are used, these quantities may be doubled.

Kellner further estimates that for a fattening ox, $1 \mathrm{oz}$. of phosphorus pentoxide and $2 \mathrm{oz}$. of lime per day per $1000 \mathrm{lb}$. live weight are sufficient, while with full-grown fattening sheep only $0.02 \mathrm{oz}$. and $0 \cdot 2 \mathrm{oz}$. per $1000 \mathrm{lb}$. live weight per day, respectively, were thought to be sufficient. With growing animals, these amounts are, doubtless, far too small.

In England, where the food of animals is usually very varied, the necessity of supplying salt, though often recognised, is not so important perhaps as in South Africa, where in some districts the provision of some form of "lick" is indispensable if the animals are to be maintained in health. So, too, for poultry, especially if kept in confine-

${ }^{1}$ Landwirtschaftliche Versuchs-Stationen, 39, 241. 
ment and fed merely on grain, the supply of salt, phosphates, lime and potash seems to be of great importance.

"Licks," often consisting mainly of salt and sulphur, are largely used by stock farmers.

A commercial cattle lick, examined by the writer and extensively advertised in South Africa, was found to consist mainly of common salt, phosphate of lime and free sulphur, with small quantities of silica, potash, sulphuric acid and magnesia.

Another point of some interest is the bulk of the food, especially for ruminating animals. American experiments have shown that while it is possible to successfully feed cows on concentrated foods (maize meal) only, for several months together, during which time chewing the cud entirely ceases, yet with calves, rumination is essential and death ensues if coarse forage be withheld, ${ }^{1}$ even though abundance of milk and grain be supplied.

Quantity of Water Consumed in Proportion to Dry Food. -This varies considerably in different animals and with different conditions. According to Warington ${ }^{2}$ the normal amounts are-

$$
\begin{gathered}
\text { For sheep } \\
\text { ", horses } \\
\text { "cattle }
\end{gathered}
$$

$2: 1$

2 to $3: 1$

$4: 1$

With sheep, when fed on succulent food, no water to drink is, as a rule, required. In dry climates, however, a sheep will drink from 1 to 6 quarts of water per day. With roots, in winter, much more water than is necessary is taken, even though none be drunk, and the addition of a little dry food-meal or cake-is decidedly economical.

With horses, the proportion of water consumed varies greatly with the amount of work done by the animal and with other circumstances. With the Paris cab horses, Grandeau found the average proportion of water to dry matter in the food to be $2 \cdot 1: 1$ when at rest and $3 \cdot 6: 1$ when working.

With fattening oxen, American experiments ${ }^{3}$ showed that from 1.6 to $3.4 \mathrm{lb}$. of water per lb. of dry matter were consumed and that the largest amount of water was drunk when the food was richest in protein.

With milch cows, the average amount of water to each pound of dry food is $4 \mathrm{lb}$., according to American experiments; but here again a ration with a narrow albuminoid ratio requires more water than one with a wide one. Thus, at the Wisconsin Station in 1886, it was found that with food having an albuminoid ratio of $1: 5.5$ there were $4.33 \mathrm{lb}$. of water drunk for each pound of dry matter, while with a ratio of $1: 8.6$ only $2.41 \mathrm{lb}$. were taken. A cow will usually drink from 8 to 10 gal. per day, but if roots be supplied the quantity will, of course, be considerably diminished.

With pigs, the usual proportion of water consumed does not appear to have often been recorded. In 1887, at Copenhagen, trials

${ }^{3}$ Vide Bulletins of the Utah (No. 46) and Illinois (21) Expt. Stations.

${ }^{2}$ Chemistry of the Farm.

${ }^{3}$ Georgeson, Bull. 34 and 39, Kansas Expt. Station. 
showed no advantage or disadvantage between excessive quantities of water and an ad libitum supply. On the other hand, experiments conducted at the Yorkshire College Farm at Garforth in the early part of 1900 showed a decided advantage in curtailing the water supplied to fattening pigs. Two pens of six pigs each were fed with a mixture of equal weights of barley meal and "sharps". In one case the mixture was soaked for some days in four times its weight of water, while in the other only twice its weight of water was used. The former was fed to the pigs in a sloppy condition, the latter was of the consistency of oat-meal porridge. Both lots were allowed as much of the food as they would eat, and the animals receiving the drier food had access to a water trough. In eight weeks the pen getting the wetter food increased by $334 \mathrm{lb}$., while the other gained $458 \mathrm{lb}$. (live weights). The pigs of the former consumed $1904 \mathrm{lb}$. of food, while those of the latter ate $2254 \mathrm{lb}$. The proportions of food consumed to weight gained were-

In those getting much water . . . . . . $5 \cdot 7$

" " " little " . . . . . . 4.9

The pigs fed on the drier food thus made $124 \mathrm{lb}$. more increase in live weight and yielded about $102 \mathrm{lb}$. more pork, while each pound of increase in live weight was obtained by the expenditure of $08 \mathrm{lb}$. of food less than with the other animals. The extra food cost about $19 \mathrm{~s}$. , but the value of the increased quantity of pork was about $42 \mathrm{~s} .6 \mathrm{~d}$., leaving a net gain of 23s. $6 \mathrm{~d}$. for the pen receiving the drier food.

Money Yalue of the Constituents of Foodstuffs. - Attempts have been made to fix money values to the albuminoids, carbohydrates and fat present in foodstuffs, so as to permit of the calculation of the value of a food from the results of its analysis, as has been done in the case of manures (vide Chap. IX).

The results of these attempts have not been entirely satisfactory, nor indeed can they be expected to be, since many of the most valuable properties of foodstuffs, e.g., flavour or palatability, cannot satisfactorily be expressed quantitatively. Samples of food of desirable flavour and much relished by animals may often command a price much higher than could be deduced from their composition.

Wolff, long ago, deduced the ratios of the values of digestible carbohydrates, fats and protein in many concentrated foodstuffs at $1: 3: 2 \cdot 4$.

König gave $1: 2 \cdot 9: 2 \cdot 7$, while in various States of America most discordant values were obtained, possibly owing to great local variations in prices.

In 1891 a long paper was read before the Surveyors' Institute on the subject by Kinch. ${ }^{1}$ He points out that the physiological ratio of values of protein to carbohydrates would be about $6: 1$, since a ration having an albuminoid ratio of $1: 6$ is most generally suitable for feeding.

By considering a large number of foodstutfs and taking into account their relative consumption, he arrives at the ratio of $1: 2.5: 2.5$

${ }^{1}$ Abstract in Jour. Soc. Chem. Ind., 1892, 701. 
as the values of digestible carbohydrates, fats and protein, the latter including both albuminoids and amides, the error introduced by including the latter as protein being counterbalanced by the fact that the manurial value of the undigested nitrogenous matter has been ignored.

He further estimates the value of digestible carbohydrates at 1.24 shilling "per unit", per ton, or say, practically, 1s. 3d. "per unit" per ton.

The values of the three chief ingredients of feeding stuffs thus become-

\begin{tabular}{|c|c|c|c|}
\hline & & Per lb. & Per unit per ton. \\
\hline $\begin{array}{l}\text { Digestible carbohydrates } \\
\quad, \quad \text { fat } \\
\quad, \quad \text { albuminoids and amides }\end{array}$ & $: \quad:$ & $\begin{array}{r}d . \\
0.66 \\
-1.66 \\
-1.66\end{array}$ & $\begin{array}{ll}\text { s. } & \text { d. } \\
1 & 3 \\
3 & 1 \frac{1}{2} \\
3 & 1 \frac{1}{2}\end{array}$ \\
\hline
\end{tabular}

By adding the percentages of digestible fat and digestible protein together, multiplying their sum by $2 \cdot 5$, and adding the percentage of digestible carbohydrates, the number of "food units" in the food is obtained.

To calculate the value per ton, it is then only necessary to multiply the food units by $1 \mathrm{~s}$. $3 \mathrm{~d}$.

It will be found, in practice, that if it be assumed that the total carbohydrates be worth 1s. per unit and the total fat and albuminoids 2s. 6d. per unit, the value, calculated per ton on this basis, will be roughly correct.

It is obvious that accuracy is not possible in such calculations and that the values are liable to great fluctuations.

- The Manurial Value of Foods.-When food is supplied to an adult animal which is not increasing in weight nor producing milk or wool, the whole of the manurial constituents of the food will be recovered in the excreta, and, if subsequent loss by fermentation or drainage be prevented, may be restored to the land.

It is otherwise with growing, fattening, or milk-producing animals. In such cases a portion, and sometimes a considerable portion, of the nitrogen, phosphoric acid and potash is employed in forming the increase, and only the residue remains in the excreta for use as manure.

The proportion of the total nitrogen of the food retained by an animal varies greatly, not only with the individual, but also with the composition of the food.

A young ealf fed on milk will retain as much as 69 or 70 per cent of the nitrogen in its food, while a horse will, if full grown, excrete the whole.

According to Lawes and Gilbert, ${ }^{1}$ the proportion of the total nitrogen of the food, retained in the fattening increase of oxen and sheep, varies from about 3 per cent with decorticated cotton cake (containing 6.6 per cent of total nitrogen) to as high as 14 per cent with 
oat. straw (containing only 0.5 per cent of total nitrogen). With many foods, it averages about 5 or 6 per cent of the total nitrogen in the food. With phosphoric acid, the same investigators found that from 3 or 4 per cent (with bran, malt culms, etc.) to 19 or 20 per cent (with maize, rice meal, barley straw, oat straw, etc.) of the total present in the food, was retained by fattening oxen and sheep. With potash, the corresponding figures were 0.3 or 0.4 per cent (with roots) to 3 or 4 per cent (with malt, maize, etc.).

The Rothamsted experiments, as summarised by Warington, ${ }^{1}$ yielded the following results :-

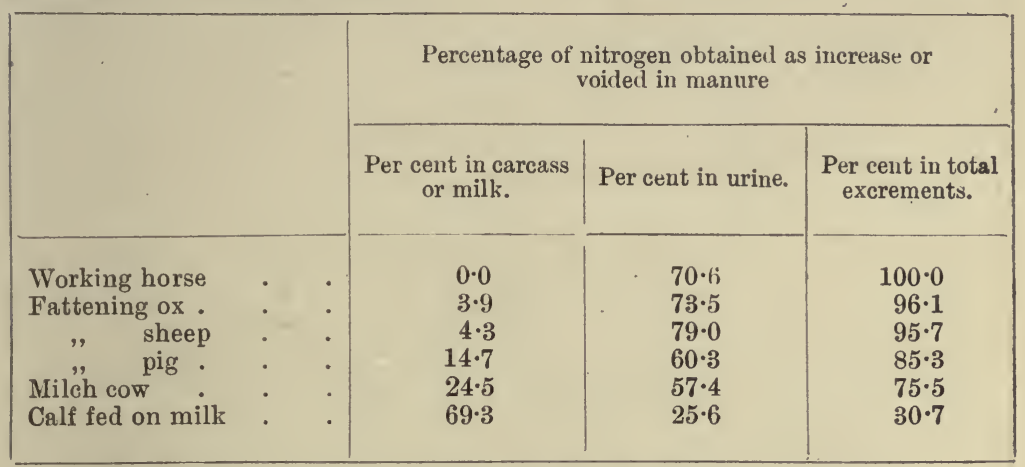

With the ash constituents the following were the results :-

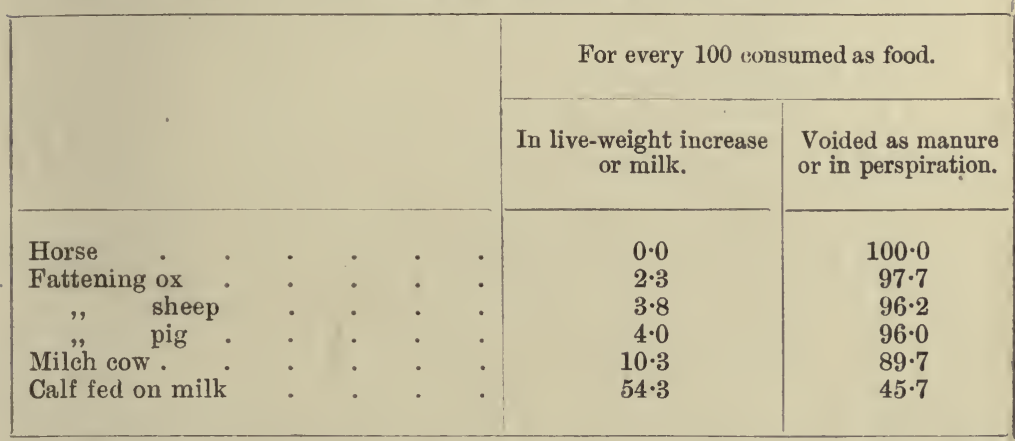

Lawes and Gilbert ${ }^{2}$ give the average manurial value per ton of the common feeding stuffs, as deduced from experiments, assuming that they are supplied to fattening sheep and oxen.

Hall and Voelcker have recalculated this table, bringing the values more up to date (1902). They assume that half the nitrogen, threequarters of the phosphoric acid, and all the potash of the foods supplied are voided in the excrement, that each year after the application of the dung, half its original value remains in the land and that nitrogen is worth 12s. per unit, phosphorus pentoxide 3s. per unit, and potash 4s. per unit. The table on the next page then shows the compensation value for each ton of the commoner foodstuffs consumed on the farm.

${ }^{1}$ Chemistry of the Farm, $162 . \quad{ }^{3}$ Jour. Roy. Agric. Soc., 1885, 600. 


\begin{tabular}{|c|c|c|c|c|c|}
\hline \multirow{6}{*}{\multicolumn{2}{|c|}{ 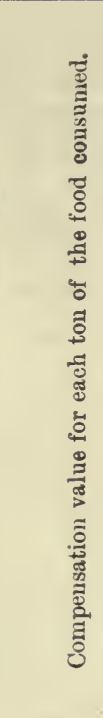 }} & ¿ & $\overline{-}=a m a n$ & \multirow[b]{2}{*}{ 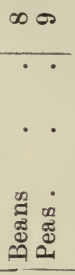 } & \multirow{2}{*}{ 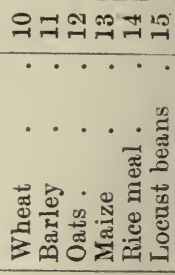 } \\
\hline & & $\underset{3}{3}$ & 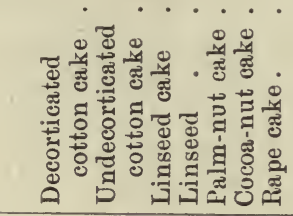 & & \\
\hline & & 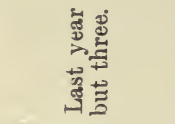 & 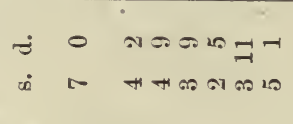 & $\begin{array}{l}=10 \\
=20\end{array}$ & 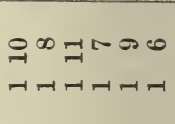 \\
\hline & & 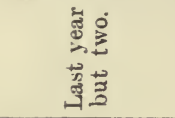 & 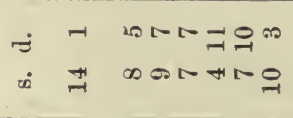 & $\begin{array}{l}=0 \\
=0\end{array}$ & 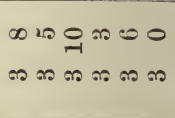 \\
\hline & & 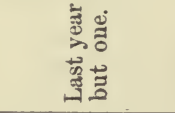 & 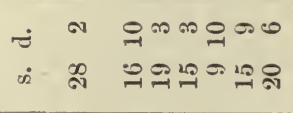 & $\begin{array}{l}\varrho_{-1}^{\infty} \\
20\end{array}$ & 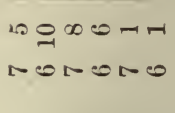 \\
\hline & & 范志 & 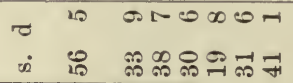 & $\begin{array}{l}\infty \pi \\
-\pi \cong\end{array}$ & 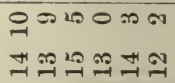 \\
\hline \multirow{10}{*}{ 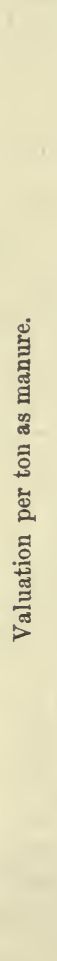 } & \multirow{2}{*}{ न्म } & 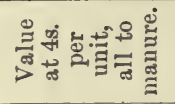 & 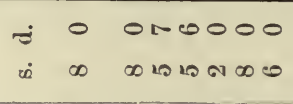 & No금 & 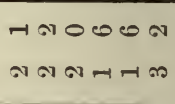 \\
\hline & & 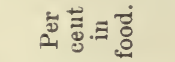 & 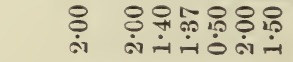 & $\stackrel{\leftrightarrow 0}{-}$ & 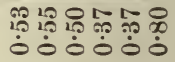 \\
\hline & \multirow{3}{*}{ 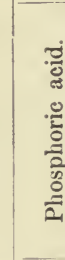 } & 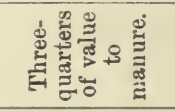 & 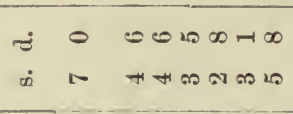 & $\begin{array}{l}0= \\
N=1\end{array}$ & 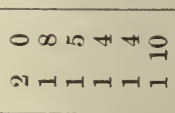 \\
\hline & & 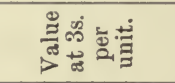 & $\begin{array}{l}\text { m a bohm } \\
\text { म }\end{array}$ & $\rightarrow \infty$ & 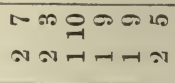 \\
\hline & & 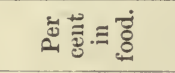 & 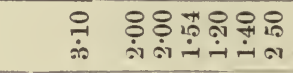 & $\begin{array}{l}0.90 \\
\stackrel{-1}{-10} 0 \\
0\end{array}$ & 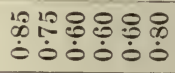 \\
\hline & \multirow{3}{*}{ 㟧 } & 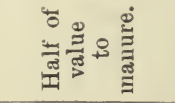 & 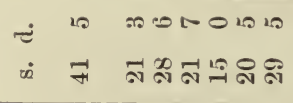 & $\begin{array}{l}\text { On } \\
\text { नีत }\end{array}$ & 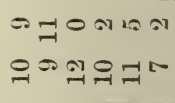 \\
\hline & & 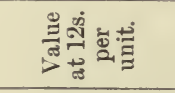 & 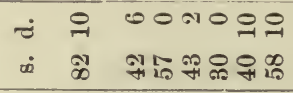 & 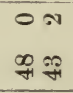 & 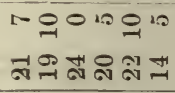 \\
\hline & & ڤ & 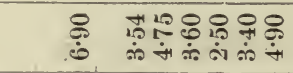 & 88 & 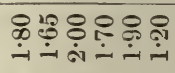 \\
\hline & & $\frac{\dot{3}}{8}$ & 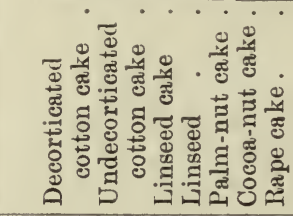 & 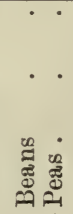 & 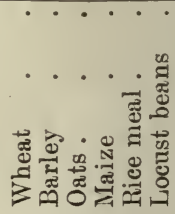 \\
\hline & & 之ं & T a m a & $\infty \in$ & 어ㅁㅛㅛ \\
\hline
\end{tabular}




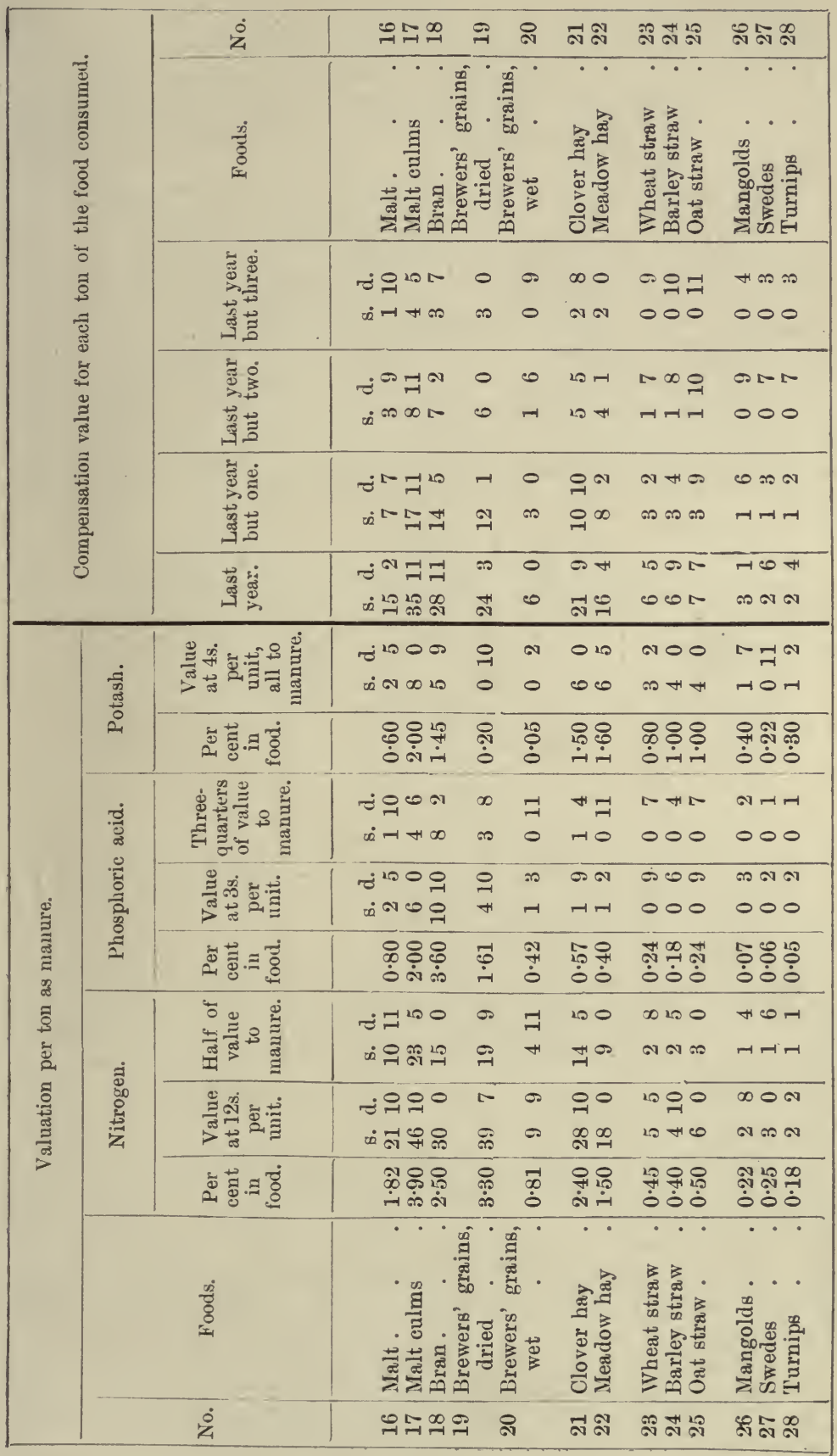




\section{CHAPTER XV.}

\section{Milk and Milk Products:}

MILK is the natural secretion of the special glands of a female, intended: for the nourishment of the new-born. The mammary glands are, in general, only developed in the female and are active in producing their secretion for a certain period after parturition. In certain abnormal instances, however, males have been known to produce milk, but such. casès are rare.

The milks of different animals differ considerably, both in the constituents present and in the proportions of the constituents.

The milk of the cow is the most important and has been studied in greatest detail.

The constituents of milk are usually divided into-

$$
\begin{aligned}
& \text { Water, } \\
& \text { Fat, } \\
& \text { Albuminoids, } \\
& \text { Sugar, } \\
& \text { Ash. }
\end{aligned}
$$

A short account of the chemical nature of these constituents (excluding water) may be here given.

Fat.-The fat present in milk resembles in general constitution the true animal and vegetable fats already described (see p. 197). Like them it consists of a mixture or compound of the glyceryl salts of fatty acids.

It differs, however, from other oily substances in the eharacter of the fatty acids present.

In milk fat, considerable quantities of acid radicals of low molecular weight are present, besides the stearic, oleic and other heavy acids found in other fats.

In common with most natural fats, it is probably a mixture, though whether each acid radical is present as a distinct glyceryl salt or whether two or three different acid radicals may be attached to the same glyceryl group is uncertain. The latter hypothesis is probably more correct.

The proportions of the various fatty acids found in butter are subject to considerable variation according to the food; they are said also to vary with the season of the year. The fat of milk given by cows, 
soon after calving is said to be much richer in volatile fatty acids than that of cows in the later stages of lactation.

Assuming that the glyceryl salts are present as separate individuals (which, as already stated, is probably not the case), the chief constituents of butter fat are given by Richmond ${ }^{1}$ as follows :-

Glyceryl tributyrate, $\mathrm{C}_{3} \mathrm{H}_{5}\left(\mathrm{C}_{4} \mathrm{H}_{7} \mathrm{O}_{2}\right)_{3}$ tricaproate, $\mathrm{C}_{3} \mathrm{H}_{5}\left(\mathrm{C}_{6} \mathrm{H}_{11} \mathrm{O}_{2}\right)$ tricaprylate, $\mathrm{C}_{3} \mathrm{H}_{5}\left(\mathrm{C}_{8} \mathrm{H}_{15} \mathrm{O}_{2}\right)_{3}$ tricaprate, $\mathrm{C}_{3} \mathrm{H}_{5}\left(\mathrm{C}_{10} \mathrm{H}_{19} \mathrm{O}_{2}\right)_{3}$ trilaurate, $\mathrm{C}_{3} \mathrm{H}_{5}\left(\mathrm{C}_{12} \mathrm{H}_{23} \mathrm{O}_{2}\right)_{3}$ trimyristate, $\mathrm{C}_{3} \mathrm{H}_{5}\left(\mathrm{C}_{14} \mathrm{H}_{27} \mathrm{O}_{2}\right)_{3}$ tripalmitate, $\mathrm{C}_{3} \mathrm{H}_{5}\left(\mathrm{C}_{16} \mathrm{H}_{31} \mathrm{O}_{2}\right)_{3}$ tristearate, $\mathrm{C}_{3} \mathrm{H}_{5}\left(\mathrm{C}_{18} \mathrm{H}_{35} \mathrm{O}_{2}\right)_{3}$ trioleate, $\mathrm{C}_{3} \mathrm{H}_{5}\left(\mathrm{C}_{18} \mathrm{H}_{33} \mathrm{O}_{2}\right)_{3}$, etc.

According to the analyses of C. A. Browne ${ }^{2}$ the fatty acids derived from 100 grammes of butter consisted of-

Dihydroxystearic acid, $\mathrm{HC}_{18} \mathrm{H}_{33}(\mathrm{OH})_{2} \mathrm{O}_{2}$

Oleic acid, $\mathrm{HC}_{18} \mathrm{H}_{33} \mathrm{O}_{2}$

Stearic acid, $\mathrm{HC}_{18} \mathrm{H}_{35} \mathrm{O}_{2}$

Palmitic acid, $\mathrm{HC}_{16} \mathrm{H}_{31} \mathrm{O}_{2}$

Myristic acid, $\mathrm{HC}_{14} \mathrm{H}_{27} \mathrm{O}_{2}$

Lauric acid, $\mathrm{HC}_{12} \mathrm{H}_{23} \mathrm{C}_{2}$

Capric acid, $\mathrm{HC}_{10} \mathrm{H}_{19} \mathrm{O}_{2}$

Caprylic acid, $\mathrm{HO}_{8} \mathrm{H}_{15} \mathrm{O}_{2}$

Caproic acid, $\mathrm{HC}_{6} \mathrm{H}_{11} \mathrm{O}_{2}$

Butyric acid, $\mathrm{HC}_{4} \mathrm{H}_{7} \mathrm{O}_{2}$

$$
\begin{aligned}
& \text {. } \quad \begin{array}{c}
\text { Grammes. } \\
1.00
\end{array} \\
& 32 \cdot 50 \\
& 1.83 \\
& 38 \cdot 61 \\
& 9 \cdot 89 \\
& 2 \cdot 57 \\
& 0.32 \\
& 0 \cdot 49 \\
& 2 \cdot 09 \\
& 5 \cdot 45
\end{aligned}
$$

The following table gives the results of analyses, of butter fat and of "margarine" and suet ${ }^{3}$ :-

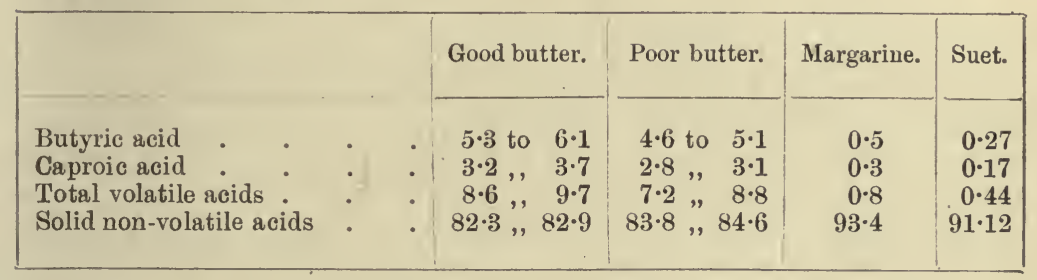

Blyth and Robertson ${ }^{4}$ have separated butter into a solid crystalline fat and an oil, in the proportions of about 45.5 of butter oil to 54.5 of butter crystals. They ascribe the formula$\mathrm{C}_{3} \mathrm{H}_{5}\left\{\begin{array}{l}\mathrm{C}_{4} \mathrm{H}_{7} \mathrm{O}_{2} \\ \mathrm{C}_{16} \mathrm{H}_{31} \mathrm{O}_{2} \text { to the solid crystalline body and conclude that butter } \\ \mathrm{C}_{18} \mathrm{H}_{34} \mathrm{O}_{2}{ }_{5}\end{array}\right.$

${ }^{1}$ Dairy Chemistry, p. 35.

2 Jour. Chem. Soc., 1900, Abstracts, ii. 55.

${ }^{3}$ Violette, Jour. Chem. Soc., 1891, Abstracts, 869.

Proc. Chem. Soc., 1889, 5. meant.

5 So given in the "Proceedings"; probably oleic acid radical, $\mathrm{C}_{18} \mathrm{H}_{33} \mathrm{O}_{2}$, is 
is mainly made up of compound and not of simple triglycerides. Seigfeld ${ }^{1}$ has shown that alcohol does not extract tributyrin (easily soluble in alcohol) from butter fat and therefore comes to the same conclusion. Caldwell and Hurtley ${ }^{2}$ also failed to find any tributyrin in butter fat.

All the acids, with the exception of the oleic acid, are saturated compounds of the general formula $\mathrm{C}_{n} \mathrm{H}_{2 n+1}$. $\mathrm{COOH}$. Acids of low molecular weight are liquids, soluble in water and volatile in steam, such as butyric acid, $\mathrm{C}_{3} \mathrm{H}_{7} \mathrm{COOH}$, eaproic acid, $\mathrm{C}_{5} \mathrm{H}_{11} \mathrm{COOH}$, and caprylic acid, $\mathrm{C}_{7} \mathrm{H}_{15} \mathrm{COOH}$, whilst capric and lauric acids are very slightly soluble and volatile.

The acids of higher molecular weight are solid, insoluble in water, and non-volatile.

Milk fat, in addition to the above, contains traces of cholesterol, $\mathrm{C}_{26} \mathrm{H}_{43} \mathrm{OH}$, lecithin, $\mathrm{C}_{3} \mathrm{H}_{5} \cdot\left(\mathrm{C}_{18} \mathrm{H}_{35} \mathrm{O}_{2}\right)_{2} \cdot\left[\mathrm{HPO}_{4} \cdot \mathrm{N}\left(\mathrm{CH}_{3}\right)_{3} \mathrm{C}_{2} \mathrm{H}_{4}(\mathrm{OH})\right]$ (not more than 0.5 per cent of the fat), and a colouring substance of unknown composition, which has been called "lacto-chrome". Milk fat is a variable mixture of chemical compounds and therefore liable to considerable variation in properties. Moreover, its physical constants, e.g., melting-point, are not sharply defined. It is insoluble in water, though capable of dissolving about $\frac{1}{300}$ of its weight of water. It is non-volatile at $100^{\circ}$, but in contact with air, absorbs oxygen and thus increases in weight; this, no doubt, is because of the unsaturated fatty acid (oleic acid) present. It melts between $29.5^{\circ}$ and $33^{\circ} \mathrm{C}$. (Richmond) and is therefore liquid in the animal. Its specific gravity varies, but is usually 0.930 at $15^{\circ}$, compared with water at the same temperature ; at $\frac{37 \cdot 8^{\circ}}{37 \cdot 8^{\circ}}$ (liquid) $=0.9118$; at $\frac{39 \cdot 5^{\circ}}{39 \cdot 5^{\circ}}=0.9113$.

Solid fat is heavier, volume for volume, than the liquid form at the same temperature (Richmond) ; so that, evidently, contraction occurs at the moment of solidification. By very slow cooling of melted butter fat, a partial separation of the various glyceryl salts occurs, the portion solidifying first being characterised by containing less volatile acids and less oleic acid or other unsaturated acids than the portion remaining liquid.

The index of refraction of milk fat varies from $1 \cdot 4550$ to 1.4586 at $35^{\circ}$; the heat of combustion of 1 gramme is 9231.3 calories. $^{3}$ It is soluble in hydrocarbons, in ether, carbon disulphide, acetone, nitrobenzene and in warm amyl alcohol.

The composition of butter fat is liable to considerable variation, being affected by the food, period of lactation, and other conditions affecting the cows. It has been observed that large quantities of cotton cake have a marked effect upon the butter and cause it to become harder and whiter, and to give the reactions for cotton-seed oil. This effect has been noticed within twenty-four hours after feeding

I Milchw. Zentr., 1910, 6, 122 ; Jour. Chem. Soc., 1910, Abstracts, ii. 327.

2 Jour. Chem. Soc., 1909, Trans., 853.

${ }^{3}$ Stohmann \& Langbein, Jour. Chem. Soc., 1891, Abstracts, 11. 
with cotton cake commenced. ${ }^{1}$ Sesame-oil cake, almond cake and cocoanut-oil cake used as food for cows alter the iodine value and percentage of volatile fatty acids of the butter fat. ${ }^{2}$ Reference to the change in composition of butter fat with advancing lactation has already been made.

The fat exists in the milk as minute globules of diameters varying from 0016 to 010 millimetre. The number of globules in milk is astonishingly great, being estimated by different observers at from 1.52 to 11.4 millions in the cubic millimetre. The globules vary greatly in size in any particular sample, but certain breeds of cows are remarkable for the preponderance of large-sized or of small-sized globules. It has been suggested that the fat globules are surrounded by an albuminous membrane, but this theory does not receive much support at present, and the generally accepted view is that the fat is in the form of a true emulsion, each globule being surrounded by a layer of liquid, held in position by surface attraction.

Rancidity.-When butter fat becomes rancid, the chief change is probably the hydrolysis of a portion of the fat into free acids and glycerol, e.g., $\mathrm{C}_{3} \mathrm{H}_{5}\left(\mathrm{C}_{4} \mathrm{H}_{7} \mathrm{O}_{2}\right)_{3}+3 \mathrm{H}_{2} \mathrm{O}=\mathrm{C}_{3} \mathrm{H}_{5}(\mathrm{OH})_{3}+3 \mathrm{HC}_{4} \mathrm{H}_{7} \mathrm{O}_{2}$. The glycerol probably oxidises to acroleïn, $\mathrm{C}_{3} \mathrm{H}_{4} \mathrm{O}$, or acrylic acid, $\mathrm{C}_{3} \mathrm{H}_{4} \mathrm{O}_{2}$. The fatty acids remain free, and those which are volatile, e.g., butyric acid, give rise to the odour of rancid butter. Oleic acid and other unsaturated acids are oxidised, yielding substances some of which are soluble in water, and which cause butter which has become rancid to give a brown colouration when dissolved in warm alkali.

Albuminoids.-Much work has been done in connection with the detection and separation of the proteids present in milk, and very different views as to their number and nature are held by various investigators.

Duclaux affirms that casein is the only proteid present, but that it exists in three forms-casein in suspension, colloidal casein and casein in solution. The latter is found in the filtrate when milk is passed through a porous earthenware cell, while the other two are retained. The amount of the soluble casein is about one-eighth of the total proteid. The colloidal casein is that found in whey after the rennet has precipitated the suspended casein. He quotes the numbers ${ }^{3}$ on the following page as the results of an examination of milk and the whey formed from it.

Hammarsten (1872-1877) describes two albuminoids-casein and albumin; Halliburton ${ }^{4}$ also gives two-caseinogen and albumin.

Euglıng and Sebelien ${ }^{5}$ in addition found globulin. Danilewsky and Radenhausen (1880) described at least five proteids as present in milk. The presence of casein or caseinogen, albumin and globulin is

${ }^{1}$ Thorpe, Jour. Chem. Soc., 1900, Abstracts, ii. 237.

${ }^{3}$ Baumert and Falke, Zeitschrift Untersuch. d. Nährungs- \& Genussm., 1898, 665.

${ }^{3}$ Compt. Rend., 98, 438 ; Jour. Chem. Soc., 1884, Abstracts, 762.

4Chemical Physiology. $\quad{ }_{5}^{5}$ Jour. Soc. Chem. Ind., 1886, 387. 


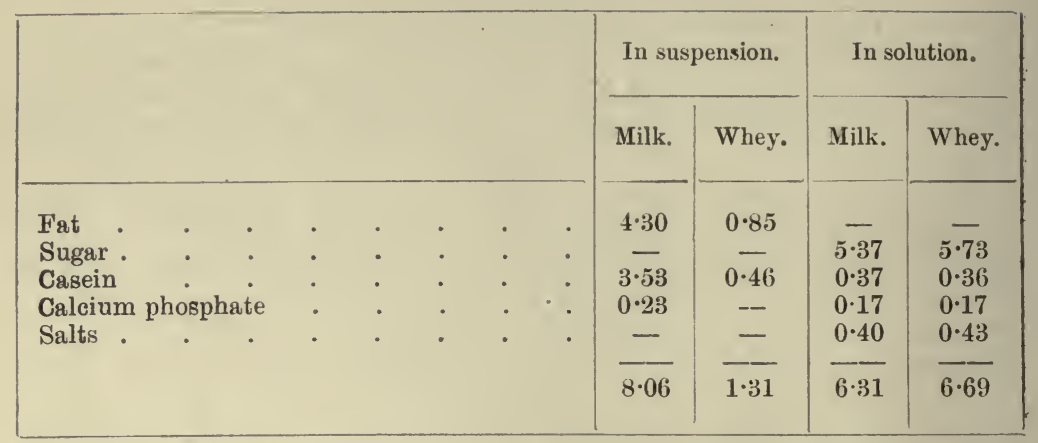

generally admitted, while one or two others are possibly present in very small proportion.

Casein or, according to modern nomenclature, caseinogen, is a white amorphous body, devoid of taste or smell, insoluble in water, alcohol, or ether, soluble in dilute alkalies or solutions of alkaline carbonates or phosphates. It is insoluble in dilute, but dissolves in strong, acids.

It is capable of uniting with calcium salts, particularly the phosphate, with which it is associated in milk and from which it is freed with difficulty.

According to Halliburton's nomenclature, casein is the name given to the curd formed by the action of rennet upon milk. In the milk caseinogen exists and can be precipitated by acids.

Various analyses of casein have been published. The following, by Chittenden and Painter, may be taken as typical :-

Carbon
Hydrogen :
Oxygen
Nitrogen :
Phosphorus :
Sulphur

Caseinogen is capable of coagulation in two ways-by the action of an acid, less acid being required at high than at low temperatures; or by the action of the enzyme contained in rennet, known as rennin, lab, chymosin, or pixine. This ferment is found in the stomachs of a large number of animals, being generally more abundant in young than in adult individuals. It, or a ferment possessed of similar powers, is found in birds, fishes and in many plants; also as a product of the action of certain bacteria.

In the case of acid coagulation, the curd formed consists of the unaltered caseinogen and is almost free from calcium compounds.

With rennet the effect is very different; the caseinogen is changed into two proteids, one of which only is readily coagulated, the other with difficulty. The former is at once coagulated by the calcium salts (mainly phosphate) present in cows' milk, and forms, with the entangled fat, the curd; the latter goes into the whey and can be coagulated by heating to $95^{\circ}$ or $100^{\circ}$. The curdling of milk by rennet is thus dependent upon the presence of calcium phosphate in the milk. 
Hammarsten has proved that in the absence of calcium phosphate or other salts of the alkaline earths, rennet will not curdle milk.

Under ordinary circumstances, rennet acts best at about $35^{\circ}$ and is killed or destroyed at $70^{\circ}$.

The albumin of milk closely resembles serum albumin of blood. It is in complete solution in milk but is coagulated at $72^{\circ}$, or by saturation with sodium sulphate at $30^{\circ}$, or ammonium sulphate at ordinary temperatures, but not by magnesium sulphate at $40^{\circ}$. It is also precipitated by copper, mercury, or lead salts, by tannin and by alcohol.

Its composition, according to Sebelien, ${ }^{1}$ is-

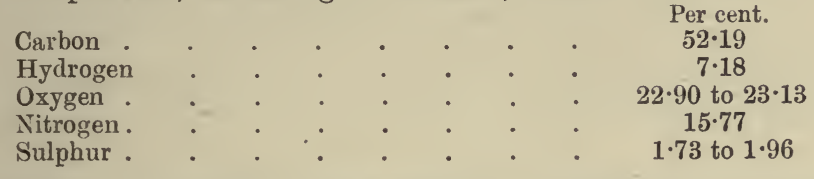

It differs in composition from casein in containing no phosphorus, more carbon, and more than twice as much sulphur.

Many other proteids have been described as occurring in cows' milk, but some doubt as to whether they are not formed by the action of the reagents employed upon the casein or albumin has been expressed. As an illustration of the complexity of the method adopted for the separation and preparation of some of the proteids, the following account of two proteids analysed and described by Storch may be given. ${ }^{2}$ Skimmed milk was mixed with three times its volume of saturated solution of sodium sulphate and a few drops of egg albumin and heated to $100^{\circ}$. The coagulated casein was filtered off, and to the filtrate more sodium sulphate solution, a trace of acetic acid and solid sodium sulphate in excess were added, when a substance, A, was precipitated; to the filtrate strong acetic acid was added, when another precipitate, B, was formed, and the liquid was then found to be free from proteids.

Substance A (the yield of which was about 2 per cent of the milk) was found to contain calcium and to be soluble in water, from which acetic acid reprecipitates it free from calcium and insoluble in water, though soluble in alkalies. Substance B was free from calcium and insoluble in water; its amount corresponded to about 0.3 per cent of the milk. A was coagulated by rennet, $\mathrm{B}$ was not. On analysis of the purified substances the following figures were obtained :-

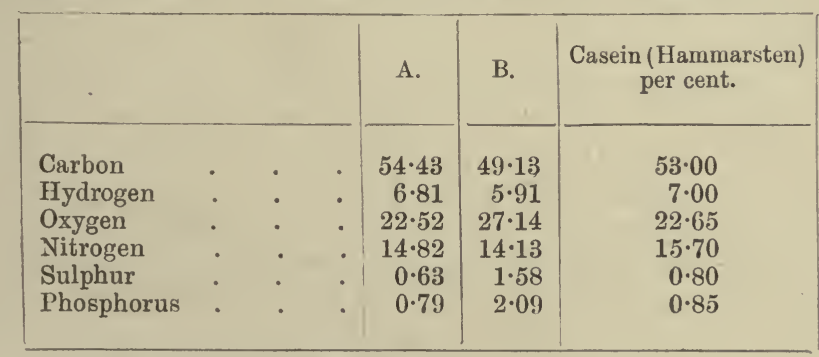

1 Jour. Soc. Chem. Ind., 1886, 387.

${ }^{2}$ Jour. Chem. Soc., 1897, Abstracts, ii. 420 ; 1900, Abstracts, i. 266. 
A globulin (Eugling) and a fibrin (Babcock) have also been described as occurring in small quantities in milk. For all ordinary purposes, however, the proteids of milk may be considered as being composed mainly of casein or caseinogen and lact-albumin, the amount of the latter being usually about one-seventh of that of the former.

According to some investigators ${ }^{1}$ milk contains a substance-carnic acid, $\mathrm{C}_{10} \mathrm{H}_{15} \mathrm{~N}_{3} \mathrm{O}_{5}$-in union with phosphoric acid, the amount in cows' milk being 0.056 per cent, in human milk 0.124 per cent, of phosphorcarnic acid or nucleon. The compound phosphorcarnic acid is said also to occur in plants, especially during germination and blossoming.

Milk Sugar. - Lactose or Lacto-biose-occurs in the milk of animals in varying quantities. It has not, with certainty, been detected in plants.

The hydrated substance, $\mathrm{C}_{12} \mathrm{H}_{22} \mathrm{O}_{11}+\mathrm{H}_{2} \mathrm{O}$, forms large transparent rhombic or monoclinic crystals, which possess well-marked cleavage. Its specific gravity is 1.534 . It possesses a faint sweet taste. The crystals are stable at $100^{\circ}$, but at about $130^{\circ}$ they begin to lose water, and decompose at $180^{\circ}$ with partial charring.

Milk sugar dissolves in 5.87 parts of water at $10^{\circ}$ or in 2.5 parts at $100^{\circ}$. The solution saturated at $10^{\circ}$ contains 14.5 per cent of sugar and has a specific gravity of $1 \cdot 055$. By spontaneous evaporation, the solution becomes supersaturated and does not deposit crystals until it contains over 21 per cent of sugar. On cooling hot saturated solutions down to ordinary temperatures in closed vessels, no crystallisation occurs and a highly supersaturated solution is obtained. The crystals are insoluble in alcohol or ether, but very soluble in hot acetic acid.

Lactose resembles glucose in possessing reducing properties, as shown by its action upon ammoniacal silver solution in the cold and upon alkaline copper solutions on heating. This is in consequence of its containing an aldehyde group, and on hydrolysis, either by dilute acids or by an enzyme known as lactase, it yields glucose and galactose.

Its constitution has already been given (vide p. 182).

Milk sugar does not readily undergo alcoholic fermentation, but by the action of certain yeasts, aided perhaps by the hydrolysing enzyme, lactase, it can be induced to do so.

It is much more prone to undergo the lactic fermentation. This is brought about by micro-organisms, which are always abundant in dairies, etc., though probably all are not of the same kind. The chemical change involved is apparently of a very simple character-

$$
\mathrm{C}_{12} \mathrm{H}_{22} \mathrm{O}_{11}+\mathrm{H}_{2} \mathrm{O} .=4 \mathrm{C}_{2} \mathrm{H}_{4}(\mathrm{OH}) \mathrm{COOH} \text {, }
$$

but in many cases other products are formed and much more complicated reactions must occur.

Milk sugar is prepared from whey or from milk by removing the nitrogenous matter and fat by means of mercuric nitrate, precipitating

${ }^{1}$ Wittma :ck and Siegfried, Jour. Che.n. Soc., 1897, Abstracts, ii. 220, and Stoklasa, ditto, 573. 
the mercury from the filtrate by addition of caustic soda and sulphuretted hydrogen, and evaporating the clear liquid until the milk sugar crystallises out on cooling.

The reaction of milk towards indicators depends, of course, greatly upon the indicator.

Fresh milk is usually described as amphoteric when tested with delicate litmus paper, i.e., it turns red litmus blue and blue litmus red. Towards phenol-phthalein milk is distinctly acid. It should always be borne in mind that the nature of the reaction of a product containing organic acids and acid phosphates, as milk does, depends mainly upon the character of the indicator used. On keeping, milk almost invariably becomes more and more acid, owing to the activity of the lactic bacilli, the development of acidity being more rapid in warm than in cold weather. The average acidity of milk as sold, probably corresponds to less than 0.2 per cent lactic acid. As the acidity increases, a sour taste becomes perceptible (at about 0.40 per cent) and when the amount reaches $0 \cdot 7$ per cent, coagulation or curdling is produced. However long it may be kept, milk rarely develops an acidity exceeding 2 per cent lactic acid.

The Ash of Milk is white and contains the inorganic constituents, together with some products resulting from the oxidation of the sulphur, phosphorus and carbon existing in the proteids and other organic compounds. In the milk, the ash constituents doubtless exist in very different states of combination to those in which they are left in the ash. The amount of ash in milk is usually about 0.7 per cent and its composition varies slightly.

Schrodt and Hansen ${ }^{1}$ give the following numbers as the extremes of seven analyses of the mixed milk of ten cows taken at various times of the year:-

Potash :
Soda
Lime
Magnesia
Ferric oxide :
Sulphur trioxide
Phosphorus pentoxide
Chlorine

Of the ash, about one-third is usually soluble in water and consists mainly of alkaline chlorides and carbonates. Much of the basic material of the ash exists in the milk in association with the casein and in union with citric acid.

Citric acid is present in cows' milk to the extent of about 01 per cent ${ }^{2}$ and crystals of calcium citrate are sometimes found in condensed milk. The presence of the citric acid probably accounts for a portion of the calcium phosphate of milk being in solution.

The gases contained in milk are chiefly carbon dioxide, oxygen

${ }^{1}$ Jour. Chem. Soc., 1884, Abstracts, 1397.

${ }^{2}$ Henkel and Soxhlet, Jour. Chem. Soc., 1889, Abstracts, 178. 
and nitrogen. From a litre of milk, Pflüger (1869) obtained 1 cc. oxygen, 76 cc. carbon dioxide and 7 cc. nitrogen.

COWS' MILK.-Cows' milk, being the most important from a commercial and agricultural standpoint, has been studied much more thoroughly than the milk of other animals.

Cows' milk is a white, or yellowish white, opaque liquid of sweet taste. Its specific gravity varies usually between 1.027 and 1.034, but in certain cases may be outside these limits.

When freshly drawn and quickly cooled, milk has a certain specific gravity, but shows a decided increase in density (about $\cdot 0005$ ) on keeping at the same temperature for some hours. This phenomenon, known as Recknagel's phenomenon, ${ }^{1}$ has been attributed to a molecular change in the casein and to the presence of air bubbles, which gradually escape; but is more likely to be due, as suggested by Richmond, to the fact that the fat globules, liquid at the temperature of the cow, do not at once solidify on cooling, but remain for some time in a super-cooled liquid condition. Since contraction occurs when milk fat solidifies, their slow solidification during standing would cause an increase in density.

The maximum density of milk is, unlike that of water, coincident with its freezing-point, about $-0.55^{\circ} \mathrm{C}$. or $-0.3^{\circ} \mathrm{C}$. (Fleischmann). It expands when heated at a rate which, naturally, is dependent upon its composition, but is usually about 0002 for each degree Centigrade.

When milk is partially frozen, the solid and liquids show considerable differences in composition. If the milk be kept at rest, the usual rise of cream leads to the uppermost layers of spongy ice containing a high proportion of fat, but the real ice, actually frozen upon the walls of the containing vessel is poorer in fat and much poorer in solids-notfat than the remaining liquid portion of the milk.

Mai found ${ }^{2}$ that when 10 litres of milk were kept in a vessel exposed to a temperature of $-15^{\circ} \mathrm{C}$. for thirty hours, the various portions had the following composition:-

\begin{tabular}{|c|c|c|c|c|c|c|}
\hline & & & & Sp. gravity. & Fat. & Solids-not-fat. \\
\hline Original milk & . & . & . & $1 \cdot 0318$ & $3 \cdot 7$ & $8 \cdot 94$ \\
\hline Upper spongy ice $(0.6$ litre $)$ & . & . & - & $1 \cdot 0256$ & $11 \cdot 6$ & $8 \cdot 30$ \\
\hline Hard ice, on walls (7 litres) & . & . & . & $1 \cdot 0201$ & $2 \cdot 9$ & $5 \cdot 75$ \\
\hline Flaid portion ( $2 \cdot 4$ litres) & . & . & . & $1 \cdot 0534$ & $3 \cdot 3$ & $14 \cdot 17$ \\
\hline Milk, thawed and re-mixed & . & . & . & $1 \cdot 0320$ & $3 \cdot 6$ & $8 \cdot 97$ \\
\hline
\end{tabular}

It is evident that the distribution of the suspended matter, particularly the fat, is determined by purely mechanical (gravitational)

${ }^{1}$ Berichte, 14, 2684. ii. 580 .

2 Zeitsch. Nahr. Genussm., 1912, 23,250 ; Jour. Chem. Soc., 1912, Abstracts, 
causes, but that that of the dissolved matters obeys the general rule of the freezing of solutions; viz., the frozen solid portion is poorer indissolved matter than that remaining liquid.

According to Fleischmann ${ }^{1}$ the co-efficient of expansion of milk increases with the temperature and with the proportion of solid matter present. He found that the variations in volume of ordinary milk (of specific gravity 1.0315 at $15^{\circ}$ ) were as follows :-

\begin{tabular}{|c|c|c|c|}
\hline \multirow{9}{*}{ become } & \multicolumn{2}{|c|}{$1,000,000$ volumes at } & $0^{\circ} \mathrm{C}$. \\
\hline & $1,000,030$ & $"$ & $1^{\circ} \mathrm{C}$. \\
\hline & $1,000,391$ & & $4^{\circ} \mathrm{C}$ \\
\hline & $1,001,273$ & " & $10^{\circ} \mathrm{C}$. \\
\hline & $1,002,134$ & " & $15^{\circ} \mathrm{C}$. \\
\hline & $1,003,800$ & " & $20^{\circ} \mathrm{C}$. \\
\hline & $1,006,414$ & $"$ & $30^{\circ} \mathrm{C}$. \\
\hline & $1,014,277$ & " & $50^{\circ} \mathrm{C}$. \\
\hline & $1,019,243$ & " & $60^{\circ}$ \\
\hline
\end{tabular}

When milk is heated, the albuminoids apparently suffer decomposition and sulphuretted hydrogen is evolved.

The specific heat of milk is about 0.847 . Its refractive index (i.e., of the milk serum) is usually about $1 \cdot 35$. Skimmed milk and whey show very similar numbers.

Chemical Composition.-Cows' milk varies considerably in composition, its quality being dependent upon many circumstances, e.g., food, health, breed and age of the animals.

The mean composition is given by Richmond ${ }^{2}$ as-

Water
Fat
Milk sugar
Casein
Albumin
Ash .
Citric acid

$$
\begin{gathered}
\text { Per cent. } \\
87 \cdot 10 \\
3 \cdot 90 \\
4 \cdot 75 \\
3 \cdot 00 \\
0 \cdot 40 \\
0 \cdot 75 \\
0 \cdot 10
\end{gathered}
$$

Colostrum.-The first milk after calving is known as colostrum, or "beestings," and is essentially different from normal milk.

It is a yellow liquid, with strong pungent taste, containing large numbers of small clusters or cells-" colostrum granules "-which vary in diameter from .005 to .025 millimetres and apparently result from the breaking up of the milk glands.

Eugling ${ }^{3}$ gives the composition of the colostrum of 22 cows as varying between-

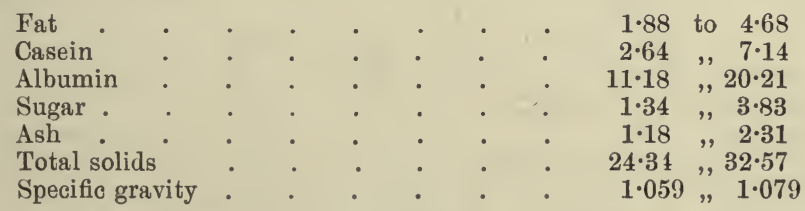

The fat of colostrum has a higher melting-point $\left(40^{\circ}-46^{\circ}\right)$ and

${ }^{1}$ The Book of the Dairy, 1895, 13.

${ }^{2}$ Dairy Chemistry, 120.

3 Jour. Chem. Soc., 1879, Abstracts, 815 ; also Ladenburg's Handwörterbuch der Chemie. 
contains less of the volatile fatty acids than ordinary milk fat. The sugar present is largely grape sugar. Urea has been found in colostrum. The ash differs from that of normal milk in the smaller amount of potash and the much larger quantity of phosphorus pentoxide (up to 41.4 per cent). The liquid secreted by a cow gradually changes, day by day, until in four or five days it approaches normal milk in composition, though the "colostrum granules" can be detected in the milk for fourteen days or more after calving. The rapidity with which colostrum gradually passes into normal milk is well shown by the following analyses by Eugling:-

\begin{tabular}{|c|c|c|c|c|c|c|c|c|c|}
\hline \multicolumn{4}{|c|}{. } & $\begin{array}{l}\text { Total } \\
\text { solids. }\end{array}$ & Fat. & Casein. & Albumin. & Sugar. & Ash. \\
\hline \multicolumn{3}{|c|}{ Immediately after calving } & 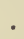 & $26 \cdot 8$ & $3 \cdot 5$ & $2 \cdot 6$ & $16 \cdot 6$ & $3 \cdot 0$ & $1 \cdot 2$ \\
\hline After 10 & lours & . & . & $21 \cdot 2$ & $4 \cdot 7$ & $4 \cdot 3$ & $9 \cdot 3$ & 1.4 & $1 \cdot 6$ \\
\hline ,, 24 & , & . & . & $19 \cdot 4$ & $4 \cdot 7$ & $4 \cdot 5$ & $6 \cdot 3$ & $2 \cdot 9$ & $1 \cdot 0$ \\
\hline$" 48$ & ,, & . & . & $14 \cdot 2$ & $4 \cdot 2$ & $3 \cdot 3$ & $2 \cdot 3$ & 3.5 & $0 \cdot 9$ \\
\hline , 72 & , & . & . & $13 \cdot 4$ & $4 \cdot 1$ & $3 \cdot 3$ & $1 \cdot 0$ & $4 \cdot 1$ & $0 \cdot 8$ \\
\hline
\end{tabular}

\section{Yariations in Composition.}

Influence of breed.-Great variations, especially in the.proportion of fat, are shown by the milks of different races. The following numbers were obtained at the New York Experiment Station in $1891^{1}$ :-

AVERAGE COMPOSITION OF MILK.

\begin{tabular}{|c|c|c|c|c|c|c|c|}
\hline Breeds. & $\begin{array}{c}\text { No. of } \\
\text { analyses. }\end{array}$ & Water. & Fat. & Sugar. & Casein. & Ash. & $\begin{array}{l}\text { Total } \\
\text { solids. }\end{array}$ \\
\hline Jersey & 238 & $84 \cdot 60$ & $5 \cdot 61$ & $5 \cdot 15$ & $3 \cdot 91$ & 0.743 & $15 \cdot 40$ \\
\hline Guernsey & 112 & $85 \cdot 39$ & $5 \cdot 12$ & $5 \cdot 11$ & $3 \cdot 61$ & 0.753 & $14 \cdot 60$ \\
\hline Devon & 72 & $86 \cdot 26$ & $4 \cdot 15$ & $5 \cdot 07$ & $3 \cdot 76$ & 0.760 & $13 \cdot 77$ \\
\hline Ayrshire & 252 & 86.95 & $3 \cdot 57$ & $5 \cdot 33$ & $3 \cdot 43$ & 0.698 & $13 \cdot 06$ \\
\hline $\begin{array}{c}\text { American Holder- } \\
\text { ness }\end{array}$ & 124 & $87 \cdot 37$ & $3 \cdot 55$ & $5 \cdot 01$ & $3 \cdot 39$ & 0.698 & $12 \cdot 63$ \\
\hline Holstein Friesian. & 132 & $87 \cdot 61$ & $3 \cdot 46$ & $4 \cdot 84$ & $3 \cdot 39$ & 0.735 & $12 \cdot 39$ \\
\hline
\end{tabular}

Vieth ${ }^{2}$ gives the following averages :-

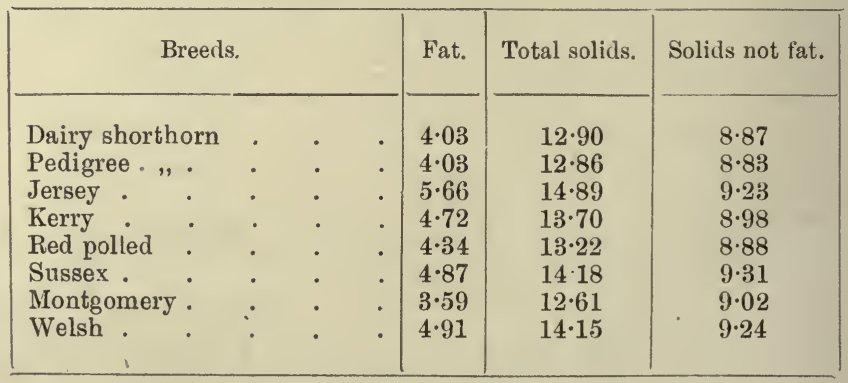

${ }^{1}$ Vide Report of Director, p. 141.

${ }^{2}$ Quoted by Richmond, Dairy Chemistry, p. 125. 
Another important point in which the milks of cows of different breeds differ, is in the average size of the fat globules. In any one sample of milk the globules are very varied in size, but their average dimensions can be estimated. At the New York Experiment Station in 1891, a large number of measurements of the size of globules of fat in the milk of cows of various breeds was made; the results are briefly summarised in the following table:-

AVERAGE DIAMETER OF MILK GLOBULES FROM COWS OF VARIOUS BREEDS DURING WHOLE PERIOD OF LACTATION.

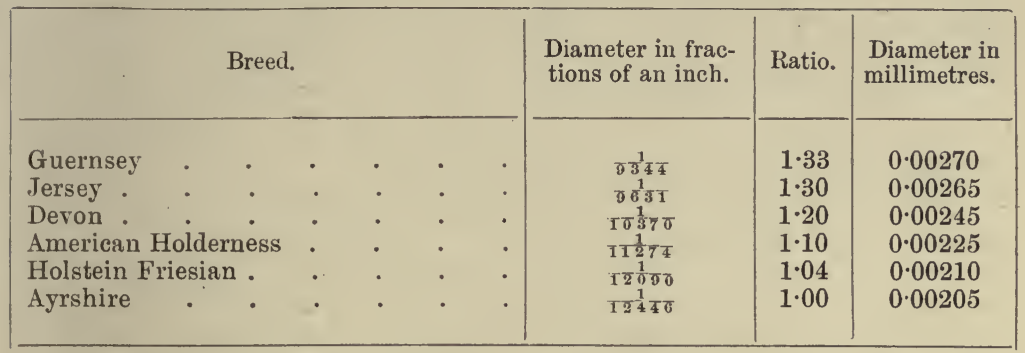

In all cases, globules much larger (and also smaller) than the dimensions given occur, but in the milk of Guernsey and Jersey cows the larger globules constitute the greater portion of the total fat in the milk, while in that of Ayrshire cows the large globules are very few and constitute only a small proportion of the total fat present.

These facts have an important influence on the readiness with which the removal of cream can be effected, for it is obvious that large globules possess greater buoyancy and therefore rise to the surface much more rapidly than the small ones. In fact the very small ones probably never separate at all.

Morning's milk is said to have larger globules than evening's milk. ${ }^{l}$ Change from dry winter food to green food in spring increases the size of the globules. ${ }^{2}$

Influence of period of lactation.-As a general rule it seems that the proportion of solids in milk diminishes for a short time after calving, then begins to increase and continues to do so to the eighth or ninth month after calving. The figures on the following page are from the experiments at New York Experiment Station already alluded to and give the average results obtained with 14 cows.

The American observers also note a marked diminution in the average size, but a great increase in the number of fat globules with the advance of lactation.

The author's experience agrees with the results of the American investigation when stall-fed animals are considered. The results of about 700 analyses of the milk of 17 cows made in the spring of 1900 ,

I Woll, Agric. Science, 1892, 441.

${ }^{2}$ Schnellenberger, Milch Zeitung, 1893, 817. 
COMPOSITION OF MILK DURING EACH MONTH OF LACTATION.

\begin{tabular}{|c|c|c|c|c|c|c|c|c|c|}
\hline \multicolumn{5}{|c|}{ Period of lactation. } & Fat. & Casein. & Sugar. & Ash. & Total solids. \\
\hline First mo & inth & . & . & . & $4 \cdot 86$ & $3 \cdot 53$ & $5 \cdot 00$ & $0 \cdot 69$ & $14 \cdot 09$ \\
\hline Second &, & . & . & . & $4 \cdot 13$ & $3 \cdot 05$ & $5 \cdot 20$ & 0.72 & $13 \cdot 13$ \\
\hline Third &, & $0^{\circ}$ & . & . & $4 \cdot 03$ & $3 \cdot 23$ & $5 \cdot 01$ & 0.71 & $13 \cdot 04$ \\
\hline Fourth & ", & - & . & - & $4 \cdot 22$ & $3 \cdot 42$ & $5 \cdot 06$ & 0.70 & $13 \cdot 36$ \\
\hline Fifth & , & . & . & . & $4 \cdot 23$ & $3 \cdot 32$ & $5 \cdot 29$ & $0 \cdot 70$ & $13 \cdot 56$ \\
\hline Sixth & $"$ & . & - & . & $4 \cdot 35$ & $3 \cdot 61$ & $5 \cdot 24$ & 0.73 & 13.90 \\
\hline Seventh & ", & - & - & - & $4 \cdot 39$ & $3 \cdot 51$ & $5 \cdot 42$ & $0 \cdot 74$ & $14 \cdot 08$ \\
\hline Eighth & $"$ & . & - & . & $4 \cdot 39$ & $3 \cdot 51$ & $5 \cdot 35$ & $0 \cdot 74$ & $14 \cdot 00$ \\
\hline Ninth & " & . & . & . & $4 \cdot 51$ & $3 \cdot 80$ & $5 \cdot 13$ & $0 \cdot 71$ & $14 \cdot 17$ \\
\hline Tenth & $"$ & - & - & - & $4 \cdot 46$ & $3 \cdot 81$ & $5 \cdot 39$ & $0 \cdot 73$ & $14 \cdot 41$ \\
\hline
\end{tabular}

classified according to the month of lactation of the cows when the milk was collected, gives the following table:-

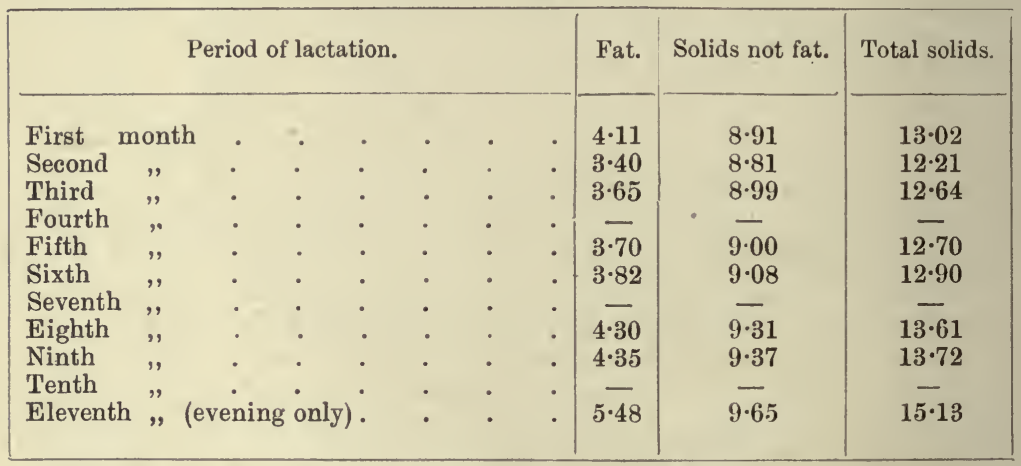

With cows at pasture, however, it appears that while the fat and to some extent the proteids of milk show the change described, the amount of solids-not-fat show a general tendency to diminish with advancing lactation. In an investigation " involving some 2500 analyses, conducted by the writer in 1902-May 25 to July 26-the results, when tabulated according to months of lactation of the cows, give as the average values for the solids-not-fat in the milk, the following figures:-

\begin{tabular}{|c|c|c|c|}
\hline \multicolumn{2}{|c|}{ Period of lactation. } & & Per cent of solids not fat in milk. \\
\hline $\begin{array}{l}\text { First month } \\
\text { Second ," } \\
\text { Third ", } \\
\text { Fourth , } \\
\text { Fifth ", } \\
\text { Sixth ", } \\
\text { Seventh ," }\end{array}$ & $\begin{array}{ll}\cdot & \cdot \\
\cdot & \cdot \\
\cdot & \cdot \\
: & \cdot \\
\cdot & \cdot \\
\cdot & \cdot\end{array}$ & . & $\begin{array}{l}9 \cdot 02 \\
8 \cdot 99 \\
8 \cdot 88 \\
8 \cdot 83 \\
8 \cdot 75 \\
8 \cdot 64 \\
8 \cdot 43\end{array}$ \\
\hline
\end{tabular}

${ }^{1}$ Trans. High. and Agric. Soc. Scotland, 1903, 135. 
Crowther and Ruston ${ }^{1}$ obtained results in general agreement with those just quoted, their figures being, $9 \cdot 17,8 \cdot 96,8 \cdot 88,8 \cdot 86,8 \cdot 89,8 \cdot 77$ and 8.67 , while for the eighth, ninth and tenth months they found $8.60,8.66$ and 8.67 per cent. The proportions of ash and of milk sugar appear to undergo but little change with advancing lactation.

The changes in composition of milk with advance of lactation differ considerably in individual cows, but on the average, milk is richest in fat, total solids and albuminoids in the earliest and latest stages of lactation and is most watery about the second or third month. The fat not only alters in amount but also in constitution, for it seems clearly proved that with cows far advanced in lactation, the proportion of volatile fatty acids in the fat becomes distinctly smaller and sometimes gives rise to the suspicion that butter made from it has been sophisticated.

Influence of food.-The character of the food of a cow has an influence on the quantity and quality of the milk only between narrow limits, unless incipient starvation be induced. Rich, palatable, concentrated food is conducive to an increase both in the quality and quantity of the milk, but only up to a certain point. It is usually asserted that the use of succulent or sloppy food to stall-fed cows inereases the quantity but reduces the quality of the milk; but according to Danish and American experiments this is not true. At Copenhagen (20th Report, 1890), for example, experiments conducted with $636 \mathrm{cows}$ for three years showed that the addition of $40 \mathrm{lb}$. of mangels or $50 \mathrm{lb}$. of turnips per day increased the daily milk yield by over $2 \mathrm{lb}$., while the animals increased in weight and consumed $3.08 \mathrm{lb}$. less straw daily; but no appreciable alteration in the composition of the milk could be detected. The writer found that the addition of $40 \mathrm{lb}$. of brewers' grains to the food of cows at pasture had certainly no effect in increasing the amount of water in their milk. Tangl and Zaitschik ${ }^{2}$ also failed to find any change in the composition of milk when the food of the cows was changed from a dry to a very watery one.

Many investigations as to the influence of food upon milk production have been made in America. ${ }^{3}$ The. majority of these have been directed to contrasting the effects of rations with wide and with narrow albuminoid ratios, and the results show that a distinct improvement both in the quality and quantity of the milk can clearly be detected when the food of the cows is changed to a more nitrogenous ration. Thus in tests including some 150 animals the mean results on the next page were obtained.

It is very doubtful whether these changes, clear and distinct though they are, are of more than a temporary character.

In $1901,{ }^{4}$ the writer carried out investigations upon the effects of

1 Trans. High. and Agric. Soc. Scotland, 1911.

2 Landw. Versuchs-Stat., 1911, 74, 183.

3 Vide Reports of the Storrs Agric. Expt. Station, 1894-7.

${ }^{4}$ Trans. High. and Agric. Soc. Scotland, 1902, 284. 


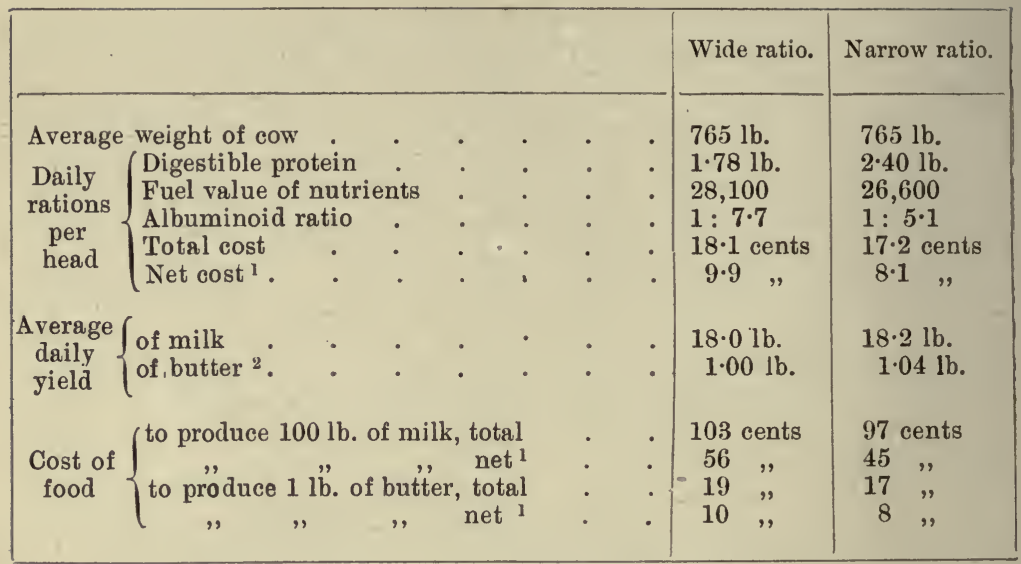

changes of food upon cows at pasture, upon the composition of their milk.

He found that the addition of a food rich in albuminoids (gluten meal) produced an increase of 3.75 per cent in the quantity of milk, a very slight increase, 0.03 per cent, in the proportion of fat and of 0.08 per cent in that of solids-not-fat; that a food rich in carbohydrates (maize meal) gave an increase of 2.95 per cent in the yield of milk, but that the fat content of the milk was diminished by 0.18 per cent and the solids-not-fat by $0: 03$ per cent.

The improvement in the amount and quality of milk which usually ensues when cows are turned out to pasture in the early spring is not to be attributed entirely to the change of food, but largely to the more healthy and natural character of the conditions of life and, perhaps most of all, to the increased quantity of food which the animals then consume. In England, the change in the milk when the cows are turned out to grass is usually said to be an increase in quantity, but with a lower fat content. Broadly speaking, it may be said that if the cows are sufficiently fed, a change of food produces, at most, a temporary effect upon the quality of the milk.

The flavour of milk and butter and especially the chemical character of the milk-fat are greatly affected by certain foods. Certain oil cakes, if used in large quantities, have a marked effect upon the melting-point, iodine value, proportion of volatile acids and other characteristics of the fat of milk. Foods with strong flavours often impart their characteristics to milk.

Influence of season.-According to the numerous analyses of Richmond and Vieth, ${ }^{3}$ the winter's milk is richest, the summer's poorest, while milk in spring and autumn is of intermediate quality.

${ }^{1}$ Total cost of food, less value of obtainable manure.

${ }^{2}$ Assuming butter to contain 82.4 per cent fat and 96.3 per cent of the total fat of the milk to be obtained as butter.

${ }^{3}$ Dairy Chemistry, 127. 
They found the average amount of fat to be at its maximum $(4 \cdot 30$ per cent) in November, at its minimum ( 3.79 per cent) in June; the solids-not-fat showed a maximum (8.92 per cent) in October and a minimum (8.71 per cent) in August.

The writer's experience with the herd at Garforth, gave the following average figures:-

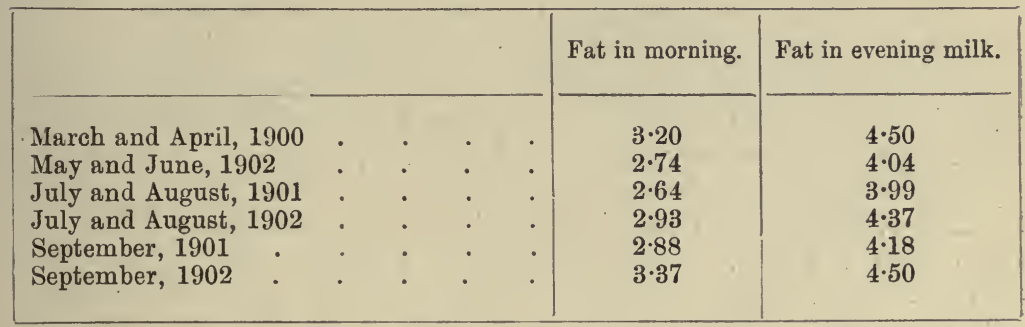

indicating that the fat content is lowest in summer. The actual influence of season, however, in all these results is obscured by those of food, conditions of existence-whether at pasture or in stall-and other circumstances.

Influence of time and manner of milking.-In most cases cows are milked twice a day-morning and evening. The intervals between the two milkings are usually unequal, being often ten or eleven hours and fourteen or thirteen hours respectively. It is almost invariably found that the proportion of fat is distinctly greater in evening's than in morning's milk, and in some cases the difference is very great. The author ${ }^{1}$ has shown that by altering the intervals between the milkings, a considerable change in the proportion of fat in the milk occurs. Thus five cows, milked at intervals of fifteen hours and nine hours as is usual at Garforth, gave at each milking an average of-

\begin{tabular}{|c|c|c|c|c|}
\hline & & & At 6 a.m. & At 3 p.m. \\
\hline $\begin{array}{l}\text { Aggregate yield } \\
\text { Fat content of milk }\end{array}$ & . & . & $\begin{array}{l}97 \mathrm{lb} \text {. } \\
2 \cdot 94 \text { per cent }\end{array}$ & $\begin{array}{l}64 \cdot 1 \mathrm{lb} \text {. } \\
4 \cdot 50 \text { per cent }\end{array}$ \\
\hline
\end{tabular}

These were then milked at intervals of twelve and a half and eleven and a half hours for five weeks. During the last of these weeks the average results were-

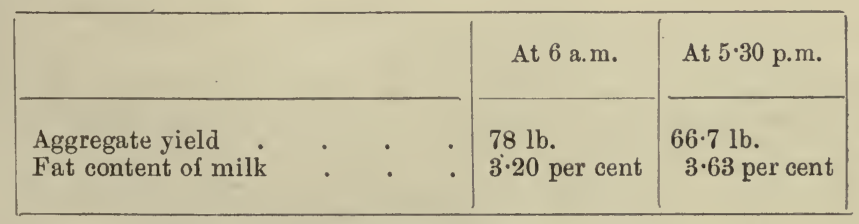

1 Trans. High. and Agric. Soc. Scotland, 1903. 
After changing back to the old times of milking, the same cows gave-

\begin{tabular}{|ll|c|c|}
\hline & & At 6 a.m. & At $3 \mathrm{p.m}$. \\
\hline $\begin{array}{llll}\text { Aggregate yield } \\
\text { Fat content of milk }\end{array}$ & $\cdot$ & $\begin{array}{c}76.9 \mathrm{lb} . \\
2.90 \text { per cent }\end{array}$ & $\begin{array}{c}54.0 \mathrm{lb} . \\
4.48 \text { per cent }\end{array}$ \\
\hline
\end{tabular}

In May, 1908, in connection with a milking contest at an agricultural show in the Transvaal, the writer had a somewhat striking example of the effect of very unequal intervals preceding the milkings upon the proportion of fat in the milk.

The average of two morning milkings of four cows (milked at 9 a.m.) gave $110.2 \mathrm{lb}$. of milk containing 2.57 -per cent of fat, while that of three evening milkings (at 5 p.m.) of the same animals gave $67.7 \mathrm{lb}$. of milk containing 5.08 per cent of fat. Here the intervals were sixteen hours and eight hours, and, as the figures show, the percentage of fat in the milk was approximately inversely as the intervals preceding the milkings.

To summarise the four sets of figures just quoted, we have-

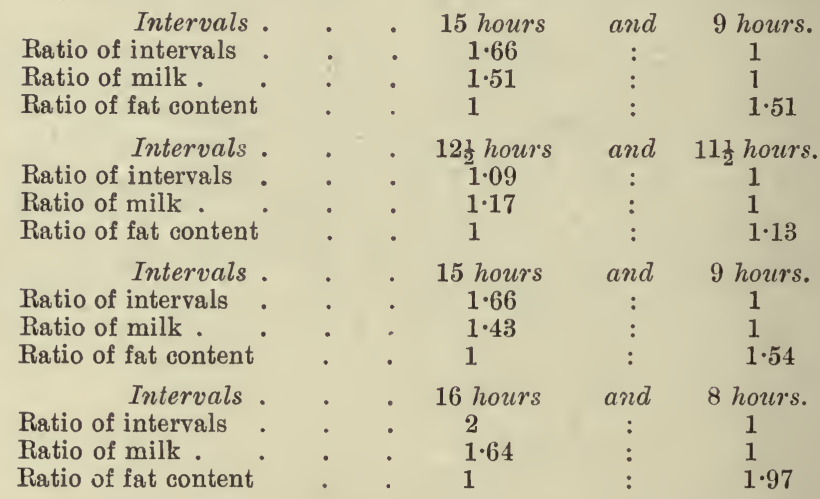

These figures and many others which have been obtained in the course of the writer's investigations show that the percentages of fat in the milk are approximately inversely as the lengths of the intervals of time preceding the milkings. Collins ${ }^{1}$ has deduced the following expression to calculate the probable difference in percentage of fat in morning and evening milk:-

$$
\mathrm{E}-\mathrm{M}=\frac{e-m}{4}-0.2
$$

where E represents percentage of fat in evening milk, $M$ that in morning milk, $e$ the time in hours between the evening milking and the morning milking, and $m$ the time in hours from the morning to the evening milking. But it would appear that it is the ratio between the

${ }^{1}$ Proceedings of the Durham Philos. Soc., 1911, pt. 1. 
percentages of fat in the evening and morning milks that is affected, rather than the actual difference between them.

If cows could be milked at equal intervals of twelve hours, there would probably be little difference, either in yield or in percentage of fat, between the morning and evening product. Whenever the exigencies of trade necessitate very unequal intervals, there is always great risk of the milk taken after the long interval being deficient in fat

By milking three cows four times a day, at intervals of six hours, for four days and analysing the milk, the following average figures were obtained :-

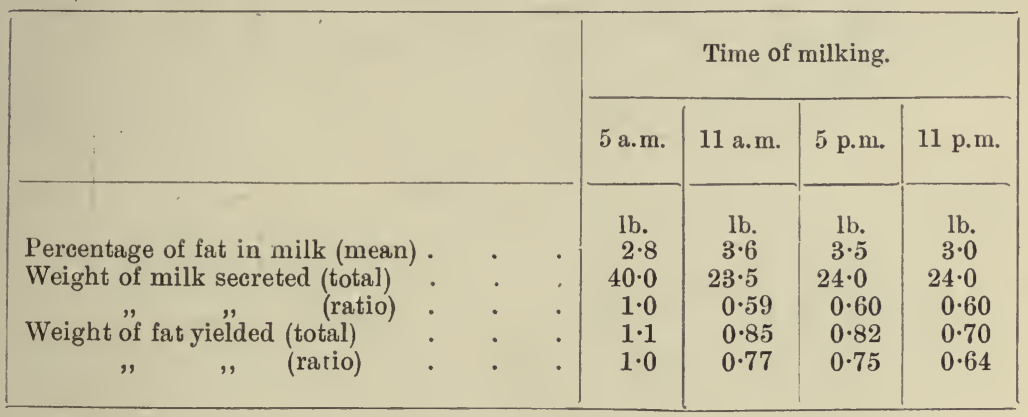

From these results it appears that the milk secreted between 5 a.m. and 5 p.m. is much richer in fat but smaller in quantity than that secreted at night, and that by far the largest amount is secreted in the six hours after 11 p.m.

But the results may be affected to some extent by the unequal intervals, 15 hours and 9 hours, to which the cows had long been accustomed, having some influence upon their manner of secretion. Other experiments have shown that cows, which have become habituated to a certain set of conditions, retain the same manner of secretion for some time after the conditions have been changed.

It is also well known that the milk first drawn from a cow at milking time is very poor in fat ("fore milk"), while the last portion ("strippings" or "afterings") is very rich. Cases in which the "fore milk" contains less than 0.5 per cent of fat have been noticed, while "strippings" will sometimes contain as much as 10 per cent. It is also found that the size, as well as the number of fat globules per unit volume, increases as the milking proceeds. This is probably due to a partial "creaming" taking place in the udder, since the production of milk seems to be a continuous process.

The writer has also noticed that, with many cows, the milk yielded by the separate quarters of the udder differs very considerably, both in fat content (which appears to be capricious in its distribution), and also in solids-not-fat, and that it is the milk sugar which shows the largest variation.

For example, the following results were obtained with the evening milk of one cow, the initial letters referring to the right fore-quarter, 
right hind-quarter left fore-quarter and left hind-quarter, respectively :-

\begin{tabular}{|c|c|c|c|c|c|c|c|c|c|c|c|}
\hline & & & & & & & & R.F. & R.H. & L.F. & L.H. \\
\hline \multicolumn{12}{|c|}{ I.-Proportion of Fat. } \\
\hline October 24th & . & . & . & . & . & . & . & $5 \cdot 2$ & $5 \cdot 0$ & $4 \cdot 3$ & $3 \cdot 8$ \\
\hline,$\quad 28$ th & & . & . & . & . & . & . & $3 \cdot 9$ & $4 \cdot 4$ & $3 \cdot 4$ & $3 \cdot 2$ \\
\hline November 1st & . & . & . & • & • & . & . & $5 \cdot 6$ & $5 \cdot 3$ & $4 \cdot 5$ & $3 \cdot 7$ \\
\hline Mean & - & . & . & . & . & - & • & $4 \cdot 9$ & $4 \cdot 9$ & $4 \cdot 1$ & $3 \cdot 6$ \\
\hline \multicolumn{12}{|c|}{ II.-Proportion of Albuminoids. } \\
\hline October 24 th & . & . & . & . & . & . & . & $3 \cdot 76$ & $3 \cdot 77$ & $3 \cdot 57$ & $3 \cdot 65$ \\
\hline$\because \quad 28$ th & . & . & . & . & . & . & & $3 \cdot 55$ & $3 \cdot 60$ & $3 \cdot 45$ & $3 \cdot 39$ \\
\hline November 1st & - & . & . & . & • & . & ${ }^{\circ}$ & $3 \cdot 73$ & $3 \cdot 69$ & $3 \cdot 55$ & $3 \cdot 38$ \\
\hline Mean & • & - & . & . & - & . & . & $3 \cdot 68$ & $3 \cdot 69$ & $3 \cdot 52$ & $3 \cdot 47$ \\
\hline \multicolumn{12}{|c|}{ III.-Proportion of Sugar. } \\
\hline October 24th & . & - & . & 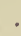 & . & . & . & $5 \cdot 0$ & $5 \cdot 0$ & $4 \cdot 5$ & $2 \cdot 7$ \\
\hline 28th & . & . & . & . & . & . & 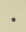 & $4 \cdot 7$ & $4 \cdot 9$ & $4 \cdot 6$ & $3 \cdot 6$ \\
\hline November 1st & • & . & . & $\cdot$ & . & . & . & $4 \cdot 6$ & $4 \cdot 8$ & $4 \cdot 4$ & $3 \cdot 6$ \\
\hline Mean & - & • & . & • & $\cdot$ & . & - & $4 \cdot 76$ & $4 \cdot 90$ & $4 \cdot 50$ & $3 \cdot 30$ \\
\hline IV.-Proportion o & 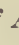 & & & & & & & & & & \\
\hline November 1st & - & - & . & • & • & . & '. & $0 \cdot 69$ & $0 \cdot 70$ & $0 \cdot 69$ & $0 \cdot 74$ \\
\hline
\end{tabular}

It is thus clear that the milk from the left hind-quarter of this cow was much poorer in milk sugar and slightly poorer in fat and albuminoids than that from the other quarters.

A similar phenomenon, in varying degree, was shown by many other cows, and, in nearly all cases, the quarter which gave the smallest total quantity of milk was lowest in solids-not-fat. It was, however, not always the left hind-quarter of the udder which showed this deficiency.

Still more remarkable, in one case at least, the quarter of the udder which gave the deficient milk changed between the end of July and the beginning of November, and as marked a deficiency was then noted in another quarter.

That the proportion of fat in the milk from the separate quarters should vary is not surprising, but that the soluble matter in the milk, elaborated from the same blood stream, should show these large differences is very difficult to understand.

Influence of other circumstances.-In addition to the influences just discussed, there must be many others of which little is known.

There seems to be little doubt that the average composition of the milk yielded by a cow is mainly dependent upon the individuality of the animal, but even when all known disturbing causes are eliminated, her milk will be found to vary greatly from day to day. 
The great fluctuations in the fat content of the milk of a cow, kept under as constant conditions as it is possible to secure, were called attention to by the writer in $1901^{1}$ and the results, obtained from the examination of the morning and evening milk from each of 17 cows, have figured largely in many prosecutions for alleged milk adulteration.

This investigation showed, in a most emphatic manner, that morning's milk was much poorer in fat than the evening milk from the same cow, when the intervals between the milkings were unequal, but that the percentage of fat in either the morning or evening milk was liable to enormous variation from day to day, even when the conditions were, so far as they could be controlled, unchanged.

When the mixed milk of many cows is analysed, these fluctuations are often, to a great extent, masked, since they rarely occur in the same direction, simultaneously in many animals.

The results have been entirely corroborated, both by further investigations by the writer and by others. The fluctuations are greatest in cows yielding much milk; with advancing lactation they generally tend to become less marked.

These irregularities are shown by the percentage of fat only, the other constituents exhibiting little variation. The yield of milk varies. somewhat, but there is little correlation between yields at, say, successive morning milkings and percentages of fat in the morning milks.

To show the character of the variations, the results given by the analyses of the morning and evening milks of two cows out of the nineteen studied, in 1901, for forty consecutive days, are represented graphically in Figs. 12 and 13, the cows whose milks are represented being in the 134th day (Fig. 12) and the 70th day (Fig. 13) of lactation at the time the experiment began. The upper lines in the diagrams represent the percentage amounts of solids-not-fat in the morning (dotted line) and evening (continuous line) milks each day; the lower continuous line gives the percentage of fat in the evening, the lower dotted line that in the morning milk, while the vertical columns represent by their height ( 1 per cent corresponding to $10 \mathrm{lb}$. milk) the weight of milk yielded at each morning (shaded column) and evening (black column) milking.

As the diagrams show, variations of 1 per cent of fat in the milk from successive morning or evening milkings are not infrequent, so that when the milk of individual cows is concerned, even the "appeal to the cow," so often regarded as reliable, in actions for alleged tampering with milk, may furnish misleading evidence. In the mixed milk of many cows, the fluctuations are much less marked, but even in this case, great differences in fat content áre shown between morning and evening milk, if the intervals be very unequal.

As to the cause of these great variations in the proportions of fat in the milk of a cow from day to day, little is really known. Since the casein, albumin, milk sugar and ash do not share in the irregularities, it seems obvious that variations in the activity of the fat-producing organs, i.e., the mammary gland itself, must be the cause. But as to

${ }^{1}$ Trans. High. and Agric. Soc. Scotland, 1901, 218. 
what induces these irregularities, little knowledge has been obtained. The writer, some years ago, suggested that they were probably con-
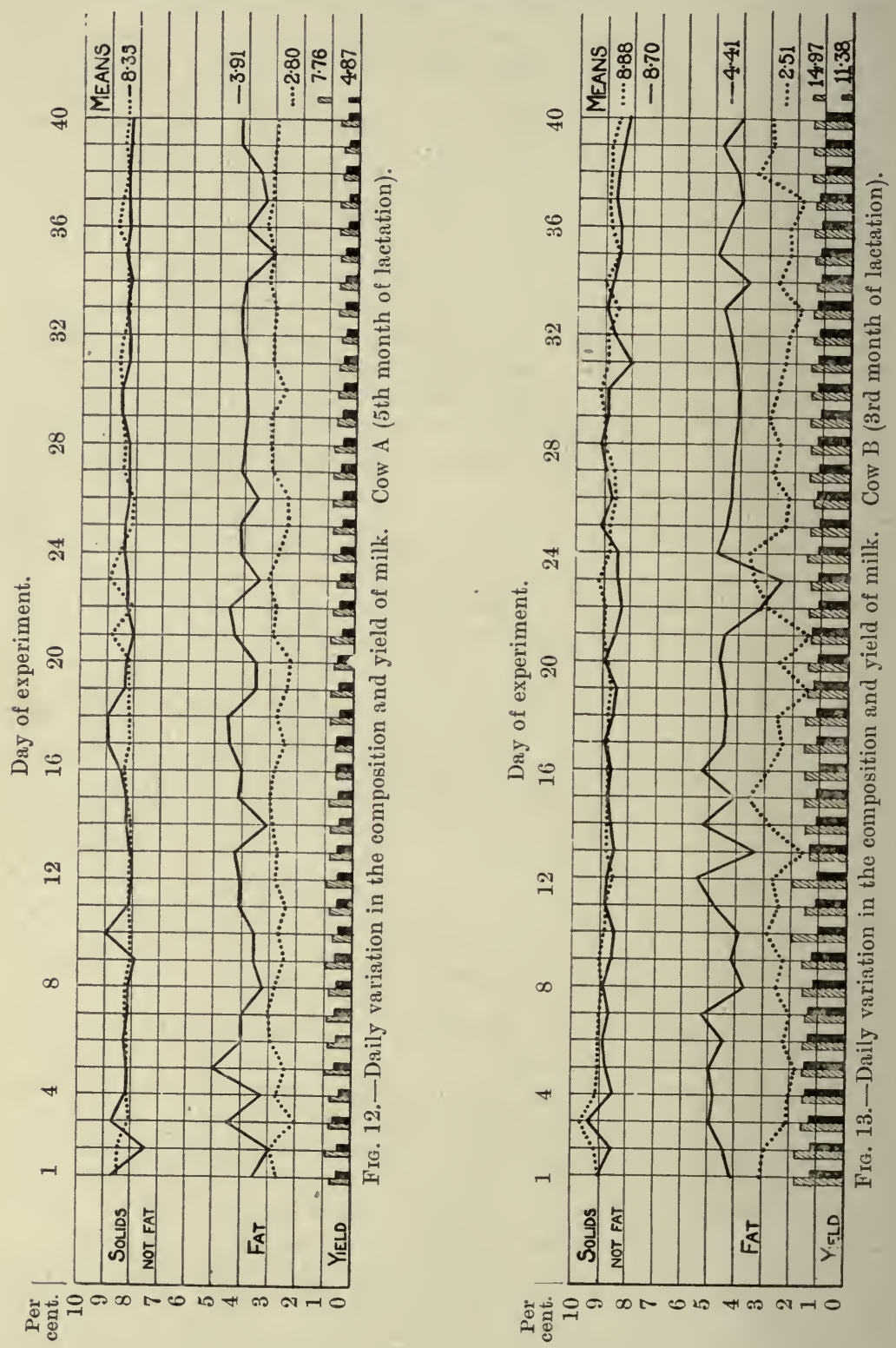

nected with changes in the placidity or contentedness of the animals, and, though the hypothesis has given rise to some amusement and has 
formed the subject of several humorous skits, ${ }^{1}$ he still adheres to the opinion.

At periods of sexual excitement, cows often show considerable irregularity in their milk, both in quantity and quality, and there can be little doubt that such circumstances as palatable or distasteful food, comfortable or comfortless housing, freedom or otherwise from annoyance by insects or dogs, and other conditions affecting the placidity of existence, may exert considerable influence upon the physiological processes going on in the animal and thus affect the secretion of milk.

THE MILK OF OTHER ANIMALS. - The following table gives the average composition of the milk of various mammals, mainly from analyses compiled by Richmond ${ }^{2}$ :-

\begin{tabular}{|c|c|c|c|c|c|c|c|c|}
\hline & & & & Water. & Fat. & Sugar. & Proteids. & Ash. \\
\hline Cow & . & • & . & $87 \cdot 10$ & $3 \cdot 90$ & $4 \cdot 75$ & $3 \cdot 40$ & 0.75 \\
\hline Goat ${ }^{8}, 6$ & . & . & . & $86 \cdot 04$ & $4 \cdot 63$ & $4 \cdot 22$ & $4 \cdot 35$ & $0 \cdot 76$ \\
\hline Ewe ${ }^{3}, 6$ & . & . & . & $79 \cdot 46$ & $8 \cdot 63$ & $4 \cdot 28$ & $6 \cdot 68$ & 0.97 \\
\hline Buffalo & . & . & . & $82 \cdot 63$ & $7 \cdot 61$ & $4 \cdot 72$ & $4 \cdot 14$ & 0.90 \\
\hline Woman & . & . & . & $88 \cdot 20$ & $3 \cdot 30$ & $6 \cdot 80$ & $1 \cdot 50$ & 0.20 \\
\hline Mare. & . & . & . & $89 \cdot 80$ & $1 \cdot 17$ & $6 \cdot 89$ & $1 \cdot 84$ & $0 \cdot 30$ \\
\hline Ass $*$ & . & . & . & $90 \cdot 12$ & $1 \cdot 26$ & $6 \cdot 50$ & $1 \cdot 66$ & 0.46 \\
\hline Bitch . & . & . & . & $75 \cdot 44$ & $9 \cdot 57$ & $3 \cdot 09$ & $11 \cdot 15$ & 0.73 \\
\hline Cat & . & . & . & $81 \cdot 63$ & $3 \cdot 33$ & $4 \cdot 91$ & 9.08 & 0.58 \\
\hline Rabbit 6 & . & . & . & $69 \cdot 50$ & $10 \cdot 45$ & 1.95 & $15 \cdot 54$ & $2 \cdot 56$ \\
\hline Camel . & . & . & . & $86 \cdot 85$ & $3 \cdot 07$ & $5 \cdot 59$ & $4 \cdot 00$ & 0.77 \\
\hline Elephant 5 & . & . & . & $67 \cdot 85$ & $19 \cdot 57$ & $8 \cdot 84$ & $3 \cdot 09$ & 0.65 \\
\hline Sow . & • & . & . & $84 \cdot 04$ & $4 \cdot 55$ & $3 \cdot 13$ & $7 \cdot 23$ & $1 \cdot 05$ \\
\hline Reindeer ${ }^{7}$ & . & . & . & $67 \cdot 20$ & $17 \cdot 10$ & $2 \cdot 81$ & $11 \cdot 40$ & $1 \cdot 49$ \\
\hline Porpoise & . & & ${ }^{\circ}$ & $41 \cdot 11$ & $48 \cdot 50$ & $1 \cdot 33$ & $11 \cdot 19$ & 0.57 \\
\hline Whale. & - & • & • & $48 \cdot 67$ & $43 \cdot 67$ & & 11 & $0 \cdot 46$ \\
\hline
\end{tabular}

The constituents shown in the above table not only vary in amount. but also in nature; the fat, particularly, differs in different animals. The fat of human milk, for example, is much poorer in volatile acids but richer in unsaturated acids than the fat of cows' milk. Laves ${ }^{8}$ found in the fat of human milk only 1.4 per cent of volatile acids, including only a mere trace of butyric acid. The fat globules are smaller than in cows' milk.

Casein from different milks is also found to differ, especially in the. manner of its coagulation under the influence of rennet or of acids.

The sugar of the milk of certain animals, too, apparently differs:

${ }^{1}$ For example, see Moonshine, February 8, 1902 ; Punch, May 13, 1903.

2 Dairy Chemistry, p. 323.

${ }^{3}$ See Voelcker, Jour. Chem. Soc., 1882, Abstracts, 541 ; also Sartori, Jour. Chem. Soc., 1891. Abstracts, 951. less fat.

¿ See Sshlossmann, Jour. Chem. Soc., 1897, Abstracts, ii. 574, who found much

${ }^{5}$ See Doremus, Jour. Chem. Soc., 1891, Abstracts, 98.

${ }^{6}$ See also Pizzi, Jour. Chem. Soc., 1896, Abstracts, ii. 120.

7 Werenskiold, Expt. Stn. Record, 1896, 713.

${ }^{8}$ Jour. Chem. Soc., 1894, Abstracts, ii. 392. 
essentially from lactose ; e.g., the sugar in mares' milk is easily susceptible to alcoholic fermentation. According to Richmond, ${ }^{1}$ the milk of the gamoose, or Egyptian water-buffalo, contains a sugar distinct from lactose. This, however, has been denied by Porchers. ${ }^{2}$

\section{MILK PRODUCTS.}

Many valuable products are derived from milk, the most important being the following :-

1. Cream and skim-milk.

2. Butter and butter-milk.

3. Cheese and whey.

4. Condensed milk.

5. Koumiss.

6. Kephir.

Cream.-The fat globules of milk, being lighter than the liquid in which they are suspended, tend to separate and collect near the surface of the milk, when the latter is allowed to remain motionless under the action of gravity. The rapidity with which the separation of the milk into two layers-one rich in fat globules and the other almost devoid of them-occurs, depends upon many conditions. One of the most important is the size of the globules. The milk of Guernsey or Jersey cows quickly throws up its cream owing to the large size of the fat globules, while that of Ayrshire cows is slow in yielding cream.

Another factor of importance is the difference in the magnitude of the forces acting upon the aqueous and fatty portions of the milk. Under ordinary conditions this (depending upon gravitation) is practically constant (though differing to a small extent according to the latitude); but, by imparting rapid rotation, centrifugal force of far greater magnitude than the force of gravitation can be brought to bear upon the milk. The separation of the lighter fat from the heavier aqueous portion then becomes very rapid. This is the principle of the milk separators which are coming so rapidly into use. For details, the reader is referred to any modern treatise on dairy work.

Another method of facilitating the separation of cream is known as " deep setting," in which the milk, while yet warm, is placed in cans about 18 in. deep, which are then surrounded with cold water or, better, ice. In this case, the whole of the fat will be found on the surface after about twelve hours.

It is not quite easy to understand why the fat globules should collect at the surface more quickly when the milk is thus cooled than under ordinary conditions. As fat contracts and expands with changes of temperature more rapidly than water, a low temperature would tend to lessen the buoyancy of the fat globules, and on that account tend to lengthen the time necessary for their coming to the surface.

The writer is of opinion that the explanation of the action observed is to be found in the gentle convection currents which are set up by the cooling action of ice or water on the walls of the can. The milk in contact with the walls of the vessel, as it cools, becomes heavier and

' Jour. Chem. Soc., 1890, Trans., $754 . \quad$ 'Bull. Soc. Chim., 1903, 828. 
slowly sinks to the bottom, the warmer and therefore lighter milk rising in the more central portion of the vessel to make way for it, while the milk nearer the surface is slowly drawn outwards towards the walls of the vessel and sinks. In this way, a very slow circulation probably takes place, and, during the whole time, the fat globules are tending to rise to the surface, from which, on account of their levity, they will not be moved by the gentle downward currents. In this way, the fat globules accumulate quickly at the surface, behaving in much the same way as if the milk were set in a very shallow vessel, the buoyancy of the globules having, so to speak, only to do the work of raising them out of the slow current of milk which is continually passing beneath the cream layer. Another factor which may aid in the process is the persistence of the fat, during rapid cooling, in its liquid, and therefore lighter, form, while the aqueous portions of the milk are rendered denser as they cool. As has already been stated, liquid fat is of lower specific gravity than solid fat at the same temperature, and there is some evidence that super-cooling of fat globules readily occurs. In ordinary setting, assuming that the same period elapses before the fat solidifies, the aqueous portion of the milk will not differ so much in density from the fat globules for so long a time, as when the milk is quickly cooled.

Another possible way in which the quick cooling facilitates the rise of the fat, may be in its preventing or delaying the coagulation of the small quantity of fibrin which, according to Babcock, is present in milk and which, by entangling the fat globules, hinders their rise under ordinary conditions of setting.

Many other advantages attend the practice of cold setting, among which the very important one of lessening the fermentation of the milk sugar and of hindering all bacterial growth, both in the cream and in the skim-milk, by the low temperature and shorter time of setting, may be mentioned.

The composition of cream is liable to enormous variation, the proportion of fat fluctuating between 9 or 10 per cent and 60 or even 70 per cent.

If obtained at low temperature, the amount of fat is usually small -about 20 per cent; by shallow setting, it may vary from 15 to 40 per cent; whilst with the separator, by adjusting the rate at which the milk passes away, almost any richness of cream may be obtained.

The aqueous portion of cream contains the usual solids of milk almost in the same proportion as in milk itself. The amount of solids not fat is usually slightly higher than in milk, due probably to evaporation of water during the setting. This is especially the case with "clotted cream," prepared by the Devonshire method, and whose composition is more uniform than that of ordinary cream. According to Richmond, the average composition of this substance is-water $3 \pm \cdot 26$ per cent, fat $58 \cdot 16$, ash $0 \cdot 60$, solids not fat $7 \cdot 52$.

The specific gravity of cream can only conveniently be directly determined if its fat is below 30 per cent. If stiffer than this, it must be diluted with an equal volume of separated milk and the specific gravity of the mixture taken. Richmond gives the following numbers:- 


\begin{tabular}{|c|c|c|c|}
\hline Specific gravity. & Per cent fat. & Specific gravity. & Per cent fat. \\
\cline { 2 - 3 } & $29 \cdot 0$ & $1 \cdot 0125$ & $21 \cdot 3$ \\
$1 \cdot 0035$ & $26 \cdot 0$ & $1 \cdot 0130$ & $20 \cdot 8$ \\
$1 \cdot 0070$ & $24 \cdot 0$ & $1 \cdot 0210$ & $13 \cdot 5$ \\
$1 \cdot 0090$ & & \\
\hline
\end{tabular}

-and he gives, as a formula connecting the specific gravity and percentage of fat in cream, the following :-

$$
\mathrm{F}=32.0-0.892 \frac{\mathrm{G}}{\mathrm{D}},
$$

where $\mathrm{F}=$ per cent of fat, $\mathrm{G}=$ lactometer reading (i.e., specific gravity $\times 1000-1000$ ) and $\mathrm{D}=$ true specific gravity.

This formula does not apply to clotted cream.

Skimmed Milk is similar in composition to ordinary milk, with the exception that it contains little or no fat. The other constituentswater, sugar, casein, etc.- - though preserving the same ratio to each other, are slightly raised in percentages. Skimmed milk from shallow setting usually contains anything between 0.4 and 2 per cent of fat, while with a good separator, the amount is usually from 0.05 to 0.3 per cent. Its specific gravity is usually between 1.034 and 1.037. Its average composition, as given by Fleischmann, is-

\begin{tabular}{|c|c|c|}
\hline & Setting. & Separator. \\
\hline $\begin{array}{l}\text { Water } \\
\text { Fat } \\
\text { Proteids } \\
\text { Milk sugar } \\
\text { Ash }\end{array}$ & $\begin{array}{r}89 \cdot 85 \\
0 \cdot 75 \\
4 \cdot 03 \\
4 \cdot 60 \\
0 \cdot 77\end{array}$ & $\begin{array}{c}90 \cdot 30 \\
0 \cdot 25^{1} \\
4 \cdot 00 \\
4 \cdot 70 \\
0 \cdot 75\end{array}$ \\
\hline & 00 & 00 \\
\hline
\end{tabular}

Butter is produced by agitating or "churning" milk, or, more generally, cream, until the fat globules coalesce. The resulting semisolid mass which separates from the butter-milk, consists largely of completely continuous fat, a few of the original globules, however, remaining. Under the microscope, many spherical globules are visible, which, according to recent observations, consist of minute drops of enclosed butter-milk or water and not of fat.

The effect of churning is purely mechanical ; the fat globules are, by violent motion, knocked together and adhere, thus giving rise to larger, irregular masses, which, in turn, collide together or with other fat globules. In this way the masses of fat gradually increase in size, portions of the aqueous liquid becoming enclosed during their forma-

${ }^{1}$ In the author's experience, separated milk generally contains much less fat than this. With good management, probably not more than $0 \cdot 1$ per cent of fat should be left in the separated milk. 
tion. At first, the increase in size of the fat particles and their irregular shape give rise to increased viscosity (this phenomenon is sometimes known as "going to sleep "); but as the particles grow larger they tend to separate more completely from the butter-milk and float, the contents of the churn becoming mobile. The butter grains are then, by working, pressed together, and more and more of the butter-milk is separated from the fat. In order that the amount of liquid retained by the butter may be small, it is necessary that the temperature should be carefully adjusted. The optimum temperature, however, depends partly upon the temperature at which the cream has been for some time prior to the churning and the rapidity with which it has been raised or lowered. Richmond gives the following as most suitable :-

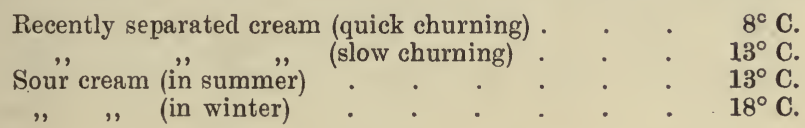

Fleischmann recommends $13^{\circ}$ for sweet ${ }^{\circ}$ cream, $16^{\circ}$ for sour cream.

If churned at too high or too low a temperature, the butter contains a higher proportion of water. According, however, to American experiments, the optimum temperature for churning varies with the breed of cows and also with their food, being higher when cotton seed or cotton-seed meal is used. It seems to be generally admitted that "ripened," i.e., sour, cream, gives a higher yield of butter and churns more readily than sweet cream.

Opinions greatly differ as to the relative quality of butter from sweet and from ripened cream, but it is generally agreed that the best flavour and aroma in butter can only be obtained from the use of properly ripened cream (vide infra), though disagreeable flavours are also liable to be produced owing to the products of undesirable microorganisms. Moreover, if the cream be very sour, and especially if it be sour before removal from the milk, the resulting butter will probably contain a large amount of casein, and, on this account, will more readily become rancid.

Salt is usually added to butter, both as a condiment and also to check decomposition. The amount used varies greatly, from a mere trace up to 7 per cent being found.

It is difficult to give any average composition of such a variable product; usually it varies between the following limits :-

\begin{tabular}{|c|c|c|c|c|c|c|c|c|c|}
\hline & . & . & . & . & . & . & . & & $\begin{array}{l}\text { Per cent. } \\
78.0 \text { to } 94.0\end{array}$ \\
\hline Water & $\cdot$ & . & • & . & . & ${ }^{\circ}$ & : & . & $5 \cdot 0,16 \cdot 0$ \\
\hline Casein & • & • & • & . & . & • & • & . & $0.5,3.0$ \\
\hline Ash .. & $\theta^{\circ}$ & . & . & . & . & • & . & . & $0 \cdot 1,, 4.0$ \\
\hline Sugar & . & $=$ & . & . & . & . & . & . & $0.2,, 0.7$ \\
\hline
\end{tabular}

The butter from ripened cream is usually richer in casein and water than that from fresh cream. It is generally stated that salt butter contains a higher proportion of water than fresh, but according to Richmond this is not so; although salt butter appears to be wetter and, on being cut, allows brine to flow out, thus giving it a wet appear- 
ance, the amount of water is said by Richmond to be less, on the average, than in unsalted butter.

"Pickled" butter, however, made by warming butter and kneading it with brine, may contain a very high percentage of water. Sixteen per cent of water is usually taken as the upper limit in good butter, though this may be exceeded by Irish "pickled" butter.

The following table gives the average results of the analyses of various kinds of butter by Vieth :-

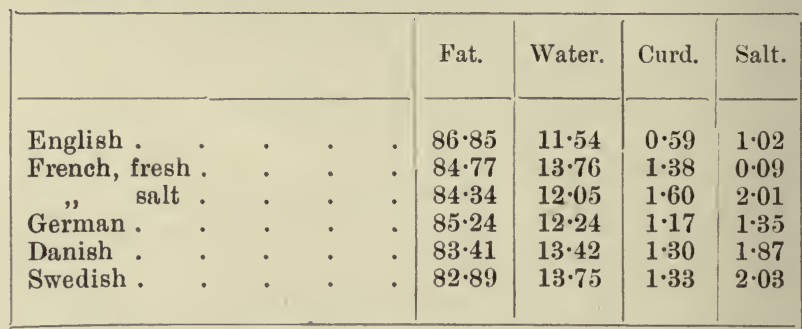

Butter is sometimes-e.g., in certain districts in Ireland and Scotland-made by churning whole milk. In all cases the milk is allowed to go sour first, and the character of the butter produced is very variable. The yield of butter is said, on the average, to be higher than that from sour cream by the old setting method, but less than that from sour separated cream.

"Milk blended butter" is the name given to a product obtained by kneading butter in milk and usually contains an excessive quantity of water and too much casein to keep well. It is illegal to sell butter containing more than 16 per cent of water.

In America, rancid butter is sometimes converted into a product known as "renovated," "process," "boiled," "aerated," or "sterilised " butter, by melting it and separating the fat from the water, salt and casein. The clean fat is next heated and air is blown through it in order to remove the unpleasant smell ; the fluid fat is then churned into an emulsion with fresh milk, quickly cooled by ice and the granular mass worked, salted and made up as butter.

Oleo-margarine, margarine, or butterine, a butter substitute, is made by churning "oleo oil" with lard (sometimes a little butter and occasionally cotton-seed oil or arachis oil) and milk in a warm condition, until the whole is emulsified. The mass is then quickly cooled, salted, coloured with annatto and made up like butter. The oleo oil is prepared from clarified beef fat, by melting it and slowly cooling it to about $30^{\circ}$, when it separates into solid stearin and liquid olein and palmitin. The stearin is then removed by a press and the mixture of olein and palmitin thus obtained.

Margarine, like "renovated" butter, when heated in a test tube or dish over a flame, bumps and splutters violently, while pure butter evolves its water as steam or " boils" quietly but with much frothing or foaming. The most reliable test, however, by which to distinguish genuine butter from its substitutes, is a determination of the volatile fatty acids present. 
Butter-milk resembles skim-milk in composition, but has a peculiar flavour of its own and is generally acid. Its fat content varies considerably and is usually less with ripened than with fresh cream. The fat also varies according to the efficiency with which the churning has been performed.

Its composition will probably be between the limits-

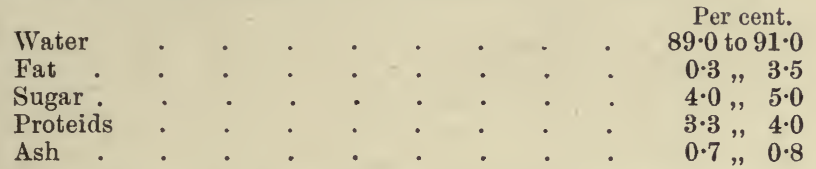

The losses of fat in butter-making occur in the skimmed milk, in the butter-milk, and in mechanical loss of butter. In American stations, the loss varied from 7 to 25 per cent. When the separator was not used, the loss was greatest with Ayrshire and Holstein cows and least with Guernseys and Jerseys.

Cheese is formed from milk by coagulating the casein, which entangles and carries down with it the greater portion of the fat, while the sugar, albumin and a portion of the casein remain in the whey.

The coagulation of the casein may be brought about, as already described, either by acids or, more usually and with a better product, by rennet. The curd, after separation from the whey, is pressed and allowed to "ripen," a process somewhat obscure, but probably dependent upon micro-organisms.

The composition of both curd and whey will naturally vary with that of the milk from which they are formed, whether this be whole milk, skim-milk, or milk enriched by the addition of cream.

The curd and whey from whole milk have the following average composition :-

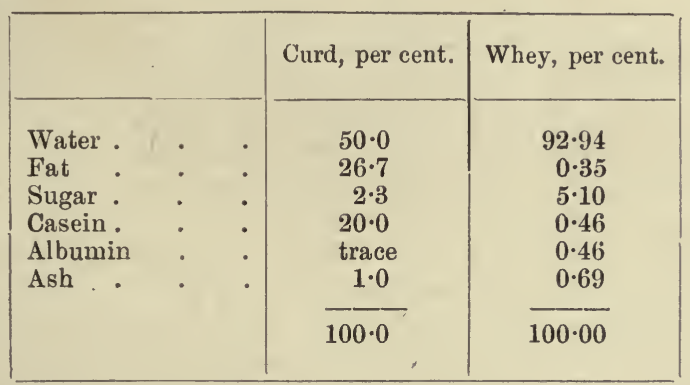

The character of the curd produced depends largely upon the temperature at which the rennet is introduced, also upon the acidity of the milk.

As already stated, rennet acts most rapidly at about $37^{\circ}$ (or $40^{\circ}$ according to Fleischmann), and if the milk be about this temperature, the curd is firm and hard, while milk at low temperatures or at about $50^{\circ}$, yields soft curd. The more acid the milk, the more rapid is the action of rennet. 
In some cases cheese is made without rennet, by simply allowing the milk or cream to turn sour and thus bring about the coagulation of the casein. This method is chiefly used for the preparation of cream cheese.

Soft cheeses are made by coagulating with rennet at a low temperature (about $25^{\circ}$ to $30^{\circ}$ ). They always contain a considerable quantity of water. Brie, Camembert and Neufchâtel are types of this class.

Hard cheeses are formed when the coagulation takes place at about $35^{\circ}$.

The quality of a cheese largely depends upon the amount of fat in it. Some hard cheeses are made from enriched milk, i.e., milk to which additional cream has been added. Stilton cheese is an example.

From whole milk, Cheddar, Cheshire and Wensleydale, Gruyère, Edam and Gorgonzola cheeses are made.

From mixtures of whole milk and skiñmed milk, Gloucester, Leicester and (sometimes) Cheddar, also Parmesan and (often) Edam cheeses are derived.

From skimmed milk, various poor cheeses, e.g., Limburg and Danish, are produced, but are of little value or importance.

Roquefort cheese is made from sheep's milk, as are several other varieties. ${ }^{1}$

The general practice in making a cheese is to hasten the ripening of the milk by the addition of a "starter," consisting of sour milk containing large numbers of the lactic bacterium, or a pure culture of the lactic ferment. When lactic fermentation has proceeded far enough, i.e., when the proportion of lactic acid in the milk reaches a certain amount (determined most safely by titration with standard soda solution, and often about $0 \cdot 2$ per cent lactic acid) it is ready for curdling. By trial with a small quantity of the milk at about $30^{\circ}$, the amount of rennet required to cause coagulation in the desired time is then determined, and this quantity is then added to the main mass. If the cheese be wanted to cure rapidly, the rennet should cause coagulation in about 20 minutes; if a slow curing be desired, in about 40 minutes. When the curd is solid, the temperature is raised to about $37^{\circ}$ and kept constant until a hot iron, placed in contact with the curd and drawn away, pulls off threads about half an inch in length. This usually occurs in about one or two hours after the milk is heated to $37^{\circ}$.

The whey is then run off and the curd stirred and turned, to allow the whey to escape. The curd is next reduced in a mill, salted and pressed in moulds. The cheeses are then stored away at a temperature of $15^{\circ}$ to $18^{\circ}$ and allowed to ripen. ${ }^{2}$

The changes which occur during ripening are little understood, although recently, an enormous number of researches have been made on the subject. Considerable loss of water occurs, the milk sugar of the whey left adhering to the curd is converted into lactic acid, but the most obscure changes are those which affect the proteid matter. The original casein is converted into other more digestible and

1 Sartori, Jour. Chem. Soc., 1891, Abstracts, 951.

2 For a detailed account of Cheddar cheese-making, see a Report by Lloyd, published by the Board of Agriculture, 1899. 
palatable nitrogenous bodies, consisting probably of peptones and albumoses. Exactly how these changes are brought about is still a matter of uncertainty.

Freudenreich ${ }^{1}$ asserts that the lactic bacteria are able to decompose casein and thinks that these organisms play the most important part in the ripening of cheese. This view has been supported by the investigations of Lloyd ${ }^{2}$ and Campbell. ${ }^{3}$ On the other hand, Babcock and Russell announced, in 1897, the discovery of a proteolytic enzyme or unorganised ferment, to which they have given the name, galactase, and to which they ascribe the chief share in the ripening of cheese. This enzyme is present in the milk of all animals, possesses the power of peptonising casein, and in many respects resembles trypsin, the enzyme of the pancreatic juice. It is more active in alkaline than in acid solutions. By its action on casein, there are formed albumoses, peptones, amides and ammonia. ${ }^{4}$ Freudenreich has repeated and confirmed Babcock and Russell's experiments. ${ }^{5}$ He finds that formalin or a temperature of $75^{\circ}$ weakens the action of galactase.

Duclaux, as long ago as $1880,{ }^{6}$ ascribed the ripening of cheese to changes in the casein produced by enzymes, but the latter were thought by him to be produced by the life-processes of micro-organisms. It seems probable that this view is also true so far as some of the changes in cheese are concerned.

The following are analyses of several varieties of cheese quoted by Wiley ${ }^{i}:-$

\begin{tabular}{|c|c|c|c|c|c|c|c|c|c|}
\hline & & & & & $\begin{array}{l}\text { Water, } \\
\text { per cent. }\end{array}$ & $\begin{array}{l}\text { Casein, } \\
\text { per cent. }\end{array}$ & $\begin{array}{c}\text { Fat, } \\
\text { per cent. }\end{array}$ & $\begin{array}{l}\text { Sugar, } \\
\text { per cent. }\end{array}$ & $\begin{array}{c}\text { Ash, } \\
\text { per cent }\end{array}$ \\
\hline Cheddar & . & . & . & - & $34 \cdot 4$ & $26 \cdot 4$ & $32 \cdot 7$ & $2 \cdot 9$ & $3 \cdot 6$ \\
\hline Cheshire & 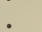 & . & . & . & $32 \cdot 6$ & $32 \cdot 5$ & $26 \cdot 0$ & $4 \cdot 5$ & $4 \cdot 3$ \\
\hline Stilton & . & . & : & . & $30 \cdot 4$ & $28 \cdot 9$ & $35 \cdot 4$ & $1 \cdot 6$ & $3 \cdot 8$ \\
\hline Brie & 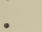 & . & . & . & $50 \cdot 4$ & $17 \cdot 2$ & $25 \cdot 1$ & $1 \cdot 9$ & $5 \cdot 4$ \\
\hline Neufchâte & & . & . & . & $44 \cdot 5$ & $14 \cdot 6$ & 33.7 & $4 \cdot 2$ & $3 \cdot 0$ \\
\hline Roquefort & & . & . & . & $31 \cdot 2$ & $27 \cdot 6$ & $33 \cdot 2$ & $2 \cdot 0$ & $6 \cdot 0$ \\
\hline Edam . & . & . & . & . & $36 \cdot 3$ & $24 \cdot 1$ & $30 \cdot 3$ & $4 \cdot 6$ & $4 \cdot 9$ \\
\hline Swiss & . & . & . & : & $35 \cdot 8$ & $24 \cdot 4$ & $37 \cdot 4$ & - & $2 \cdot 4$ \\
\hline Cream & . & . & . & . & $38 \cdot 6$ & $25 \cdot 4$ & $30 \cdot 2$ & $2 \cdot 0$ & $4 \cdot 0$ \\
\hline
\end{tabular}

The above analyses are of the type usually made, but are not satisfactory, inasmuch as they do not differentiate between the various nitrogenous compounds present, some of which are almost valueless as food. Recently, attempts have been made to get more detailed results. ${ }^{8}$ As an example, Stutzer gives the results of his investigation of the nitrogenous constituents of Camembert and of Swiss cheeses as follows ; the total nitrogen in each was distributed thus :-

\footnotetext{
${ }^{1}$ Landw. Jahr. der Schweiz, 1897 ; also 1898, 279.

2 Board of Agriculture, Report on Cheddar cheese-making, 1899.

3 Trans. High. and Agric. Soc. Scotland, 1898.

${ }^{4}$ Jour. Chem. Soc., 1900, Abstracts, ii. 712.

${ }^{5}$ Ibid.

${ }^{6}$ Ibid., 1882, Abstracts, 436.

7 Agricultural Analyses, Vol. III, 524.

${ }^{8}$ Stutzer, Jour. Chem. Soc., 1896, Abstracts, ii. 683.
} 


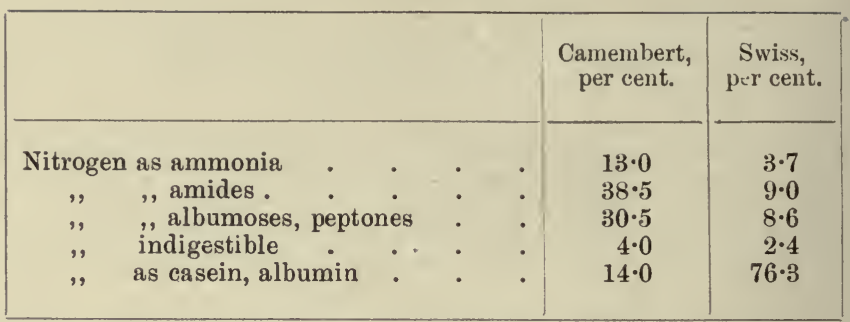

In the Camembert, the ripening process had proceeded very far, while the Swiss cheese was comparatively fresh.

Ripened cheese often yields more matter soluble in ether than cheese in the unripened state and has given rise to the view that fat is produced from protein during ripening. Nierenstein ${ }^{1}$ has shown that in ripened Cheddar cheese, cholesterol, cadaverine and amino-valeric acid are formed (from proteins) which are soluble in ether and after making allowance for these, there is no evidence of fat-formation from protein during ripening.

In America, cheese is graded according to the proportion of fat it contains. Thus "full cream" cheese must contain not less than 32 per cent of milk fat, "three-fourths cream" cheese at least 24 per cent, "half cream" cheese a minimum of 16 per cent and "onefourth" cream cheese at least 8 per cent of fat. All samples containing less than 8 per cent of milk fat must be described as "skimmed milk" cheese.

In some cases, the proportion of fat is increased by the addition of foreign fat, e.g., lard. Such cheese is known technically as "filled cheese".

Pasteurised or sterilised milk cannot be used in cheese-making.

Condensed Milk.-This is milk which has been concentrated by evaporation in a partial vacuum (so as to perform the operation at a low temperature) and to which sugar, either cane sugar or sometimes glucose, has been added. The extent of the concentration is usually to about one-fourth the original bulk. Sometimes no sugar is employed, but generally about one pound is added to each gallon of milk.

Whole milk and separated milk are both employed in the manufacture of condensed milk.

The composition of various forms is usually about-

\begin{tabular}{|c|c|c|c|c|c|c|}
\hline & $\begin{array}{c}\text { Water, } \\
\text { per cent. }\end{array}$ & $\begin{array}{c}\text { Fat, } \\
\text { per cent. }\end{array}$ & $\begin{array}{c}\text { Nilk } \\
\text { sugar, } \\
\text { per cent. }\end{array}$ & $\begin{array}{c}\text { Cane } \\
\text { sugar, } \\
\text { per cent. }\end{array}$ & $\begin{array}{c}\text { Proteids, } \\
\text { per cent. }\end{array}$ & $\begin{array}{c}\text { Ash, } \\
\text { per cent. }\end{array}$ \\
\hline $\begin{array}{c}\text { Sweetened, from whole } \\
\text { milk }\end{array}$ & 25 & 11 & 14 & 37 & 10 & 2 \\
$\begin{array}{c}\text { Sweetened, from skim- } \\
\text { milk. } \\
\text { Unsweetened, from whole } \\
\text { milk. }\end{array}$ & 29 & 1 & $15 \cdot 5$ & 40 & 11 & $2 \cdot 5$ \\
\hline
\end{tabular}

${ }^{1}$ Proc. Roy. Soc., 1911, B. 83, 301 ; Jour. Chem. Soc., 1911, Abstracts, ii. 326. 
The sweetened product keeps better, especially after the hermetically sealed tins, in which the product is sent out, have been opened.

The directions on these tins generally recommend the contents to be mixed with from five to seven volumes of water. The resulting mixture is obviously much poorer in fat and proteids than genuine milk.

The degree of concentration and the fat content vary greatly in the different commercial brands.

Milk Powder is made by evaporating milk in thin layers under reduced pressure, and scraping off the resulting film. The fat in the residue renders the production of a powder difficult, because of its viscosity, and in much of the yellowish-white commercial product, the amount of fat present is less in proportion to the other constituents than would be present in the residue obtained from whole milk. The powder shaken up with water yields a fairly good substitute for fresh milk.

Koumiss is an alcoholic beverage produced from milk by fermentation. As already stated, lactose does not readily undergo alcoholic fermentation. The sugar of mares' milk, however, readily ferments, and an alcoholic liquid can be prepared by the addition of a little koumiss, or even sour milk, to mares' milk. Such beverages have been long known in Tartary.

By the addition of a small quantity of cane sugar and yeast to cows' milk, a similar beverage can be prepared.

The casein at first coagulates, but afterwards partly redissolves, and does not appear to be so liable to coagulation under the influence of gastric juice as is that of fresh milk. Koumiss is thus very easily digested and acts both as a stimulant and as a food ; it is therefore used for invalids. Ginzberg ${ }^{1}$ finds that the lactic and alcoholic fermentation proceed concurrently, and that the casein is partially hydrolysed and robbed of its mineral constituents.

The following analyses of koumiss are given by Wiley :-

\begin{tabular}{|c|c|c|c|c|c|c|c|}
\hline & $\begin{array}{l}\text { Water, } \\
\text { per cent. }\end{array}$ & $\begin{array}{l}\text { Sugar, } \\
\text { per cent. }\end{array}$ & $\begin{array}{l}\text { Alcohol, } \\
\text { per cent. }\end{array}$ & $\begin{array}{c}\text { Fat, } \\
\text { per cent. }\end{array}$ & $\begin{array}{l}\text { Proteid, } \\
\text { per cent. }\end{array}$ & $\begin{array}{l}\text { Carbon } \\
\text { dioxide, } \\
\text { per cent. }\end{array}$ & $\begin{array}{l}\text { Acidity, } \\
\text { per cent. }\end{array}$ \\
\hline $\begin{array}{c}\text { From cows' milk } \\
\text {,, mares' , }\end{array}$ & $\begin{array}{l}89 \cdot 32 \\
91 \cdot 87\end{array}$ & $\begin{array}{l}4 \cdot 38 \\
0 \cdot 79\end{array}$ & $\begin{array}{l}0 \cdot 76 \\
2 \cdot 89\end{array}$ & $\begin{array}{l}2 \cdot 08 \\
1 \cdot 19\end{array}$ & $\begin{array}{l}2 \cdot 56 \\
1 \cdot 91\end{array}$ & $\begin{array}{c}0.83 \\
-\end{array}$ & $\begin{array}{l}0 \cdot 47 \\
1 \cdot 04\end{array}$ \\
\hline
\end{tabular}

The acidity is expressed in terms of lactic acid. The proteids are partly casein, but also contain albumoses. The carbon dioxide gives an effervescent character to the bottled koumiss.

Kephir is a similar product made in the Caucasus from cows' milk. The "kephir" grains which are used to start the fermentation are evidently impregnated with micro-organisms and are placed in the milk until fermentation commences. After this they are dried and

${ }^{1}$ Biochem. Zeitsch., 1910, 1; Jour. Chem. Soc., 1911, Abstracts, ii. 140. 
kept for future use. Their origin appears to be unknown. Many organisms have been found in kephir grains, including bacteria and yeasts. It has been stated that the kephir contains an enzyme-lactase - which has the power of hydrolysing milk sugar, thereby producing glucose and galactose, and that yeast then attacks the former as in ordinary alcoholic fermentation. Kephir can be prepared from cows' milk by the simultaneous action of beer yeast and Bacillus bulgaricus. The reactions resemble those of the preparation of Koumiss but do not proceed so far (Ginzberg, l. c.).

Kephir resembles koumiss in composition, but contains less alcohol and albumoses and more casein.

Milk Preservation.-Milk is peculiarly liable to undergo change under the influence of micro-organisms, for the growth of which it serves as an excellent medium. In the udder, milk is normally free from micro-organisms, but, unless special precautions are taken, within a very short time after milking it absolutely teems with them.

In many cases examined, milk, within a few minutes of milking, has been found to contain thousands of organisms per cubic centimetre. The organisms, or their spores, are derived from the air, the hands of the milker, the hair or teats of the cow, and particularly from the vessels in which the milk is received.

The rate at which the bacteria multiply is largely dependent upon the temperature. It was found that after fifteen hours at $15^{\circ}$, milk contained 100,000 bacteria per cubic centimetre, while the same milk kept fifteen hours at $25^{\circ}$, contained $72,000,000$ per cubic centimetre, and at $35^{\circ}, 165,000,000$ per cubic centimetre. ${ }^{1}$

The importance of quickly cooling milk is thus evident, since usually it is desirable to hinder as much as possible the growth of bacteria. The micro-organisms which find their way into milk are of various types; in most cases, perhaps, the majority are such as convert milk sugar into lactic acid, while organisms of almost all kinds may be found, many objectionable and some highly dangerous. The first evident effect of the growth of organisms is usually the souring and consequent curdling of the milk.

It is obvious, therefore, that if the milk is to be kept for any length of time some means of preventing the growth of these organisms must be taken. Two chief methods suggest themselves: (1) To prevent the entrance of the germs, or (2) to use some means which will either kill them or prevent their growth.

The first method is almost impracticable on the large scale, but the second is often adopted. This is either by "sterilisation " or "Pasteurisation ".

In the former process the milk is heated to a sufficiently high temperature (about $115^{\circ} \mathrm{C}$.) to destroy all germs. This is usually effected in steam under pressure. The milk is then kept excluded from the air, or air which has filtered through a thick layer of cotton wool may be admitted. Milk so prepared will not sour and may be kept indefinitely. Unfortunately certain undesirable changes are pro-

${ }^{1}$ Miquel, Central-B. für Agricult.-Chem., 1890, 575. 
duced in the milk by this treatment. The taste and smell are altered, a portion of the calcium citrate and the albumin are precipitated, and the casein (probably by the precipitation of the calcium compounds) becomes much less coagulable by rennet. Moreover, the milk becomes brown, and the enzyme, originally present in the milk, which has the power of giving a blue colouration with hydrogen peroxide and paraphenylene diamine, $\mathrm{C}_{6} \mathrm{H}_{4}\left(\mathrm{NH}_{2}\right)_{2}$, is destroyed. The fat rises much less readily, and the cream layer, though very thin, is richer in fat than ordinary cream, containing often over 40 per cent instead of 20 to 30 per cent as in the case of fresh cream.

In Pasteurising, a lower temperature-about $60^{\circ}$ or $80^{\circ}$-is employed, and the milk is subjected to this two or three times, with intermediate cooling. The taste and properties of the milk are not so much altered by this treatment, but the albumin is changed, so that practically all of it is precipitated along with the casein on the addition of salts, e.g., magnesium sulphate. The casein, when precipitated from sterilised or Pasteurised milk, is much more finely divided than that from fresh milk. It is therefore probably more easily digested, especially by young children.

The tendency to rickets in young children which is said to be induced by feeding them upon cows' milk cannot be due to deficiency of lime, since cows' milk contains between six and seven times as much of that substance as is present in human milk. The same is true of phosphorus pentoxide. By Pasteurisation or sterilisation, the lime is partially precipitated and the writer found that the ratio of lime to 100 parts of $\mathrm{P}_{2} \mathrm{O}_{5}$ was-

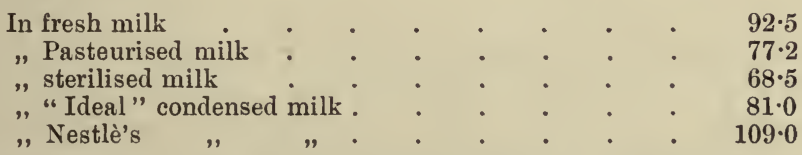

and has suggested that it is this ratio that is important as affecting bone formation and nutrition. ${ }^{1}$

The chief difference between human milk and cows' milk is in the character of the curd which is produced by rennet or the gastric juice of young children; the former yields a finely divided mass, while the latter gives a closely adherent, heavy clot, probably much less easily digested. This difference is ascribed, not to a difference in the casein or even in its amount, but to the different amounts of calcium present. Human milk contains about 0.03 per cent $\mathrm{CaO}$, while in cows' milk there is about 0.16 per cent $\mathrm{CaO}$. It has been shown that the coagulation of casein by rennet is dependent upon the presence of calcium compounds and that in their absence no coagulation occurs. ${ }^{2}$ Hence it has been proposed to render cows' milk more like human milk, and therefore more suitable for feeding infants, by the removal of a portion of the lime ("humanised milk"). This, it is said, can be done by adding about 0.5 per cent of sodium citrate. The addition of lime water, it may be noted, though it delays curdling by reason of its

1 Jour. Roy. Inst. Public Health, 1909.

${ }^{2}$ Arthus and Pages, 1890. 
alkalinity, would not improve the character of the curd when it is formed. Another somewhat curious fact is that cows' milk contains more lime than an equal volume of lime water (which contains about 0.13 per cent), so that the idea that the addition of lime water aids in supplying materials for the formation of bone is founded on a misconception.

Other Methods of Preserving Milk.-As already stated, it is possible to prevent the growth of micro-organisms in milk by the addition of antiseptics, and this is often practised, especially in hot weather, when their growth is apt to be very rapid. The chief antiseptics employed in preserving milk, butter and cream are-

Boric acid or borax, $\mathrm{H}_{3} \mathrm{BO}_{3}$, or $\mathrm{Na}_{2} \mathrm{~B}_{4} \mathrm{O}_{7} \cdot 10 \mathrm{H}_{2} \mathrm{O}$.

Salicylic acid, $\mathrm{C}_{6} \mathrm{H}_{4}(\mathrm{OH}) \mathrm{COOH}$.

Formaldehyde, $\mathrm{H}_{2} \mathrm{CO}$, generally as "Formalin".

The use of preservatives of any kind is probably not a wholesome practice, for though the growth of most of the micro-organisms is prevented, all change is not stopped. Moreover there is considerable probability that, with children particularly, the use of preservatives is attended with danger to digestion. Many of the substances used as preservatives have been shown ${ }^{1}$ to have an injurious action upon digestive enzymes.

Sodium carbonate or bicarbonate is sometimes added to milk as a preservative. In reality it does not thus act, but merely prevents the lactic acid, formed by fermentation, from coagulating the casein, and by neutralising the acid as fast as it is formed, probably aids the change of the sugar into lactic acid.

Milk as a Medium for the Spread of Disease.-Milk is peculiarly well fitted as a nutrient for the growth of micro-organisms. As has already been stated, the number of organisms present in ordinary samples is enormous. Fortunately, the majority of these bacteria are harmless so far as their effect upon health is concerned, but unfortunately milk very readily acts as a conveyer of pathogenic organisms.

Diphtheria, scarlet fever, typhoid and especially tuberculosis ${ }^{2}$ have been in many instances communicated by milk. Careful Pasteurisation of all milk is greatly to be desired, and already dairies are being started in various parts of England in which the milk is submitted to a modified Pasteurisation. The milk is heated in bulk to a temperature of $60^{\circ}$ to $65^{\circ}$ and maintained at this temperature for twenty minutes, then quickly cooled and sent out to the consumer, best in closed glass bottles. Russell has shown that the tuberculosis bacillus may be destroyed by heating to $60^{\circ}$ for twenty minutes, provided the milk is heated under such conditions (with constant agitation and in a closed vessel) as to prevent a pellicle forming on the surface. ${ }^{3}$ The

${ }^{1}$ Leffmann, Jour. Franklin Instit., 1899, 97.

${ }^{2}$ It has recently been asserted that bovine tuberculosis is probably not communicable to man; but, though the opinion is that of the great authority, Koch, it is not yet generally accepted.

${ }^{3}$ Vide The Times, Feb. 25th, 1901. 
advantages of using a low temperature in Pasteurising have already been indicated. Milk Pasteurised at $60^{\circ}$ cannot be distinguished by taste from untreated milk, and though the rise of the cream is rendered slower, the soluble albumin of the milk is hardly diminished.

By one treatment of this kind the milk is not completely sterilised, but the pathogenic organisms are probably entirely destroyed and the keeping qualities of the milk greatly improved. 


\section{CHAPTER XVI.}

\section{The Analysis of Milk and Milk Products.}

For a detailed account of the methods employed in making a complete analysis of these substances the reader must consult a manual on analysis. Only a few of the more important determinations in the analysis of milk, butter and cheese will be described here.

MILK.-For many purposes an examination of milk directed to the estimation of the percentages of total solids and fat and the absence or presence of preservatives is sufficient.

The Amount of Fat, as already stated, is subject to greater variation than that of the other constituents, and, from a practical standpoint, is usually considered the most important criterion of the value of a sample.

Of many methods which have been described, the following are among the most reliable and best known :-

1. Adams's paper-coil method.-In this process, 5 c.c. of the milk are allowed to run from a pipette upon a strip of filter paper (from which all matter soluble in ether has previously been removed) about 22 in. long by 2 in. wide. The paper is then dried by holding it near a fire, care being taken not to scorch it. It is then rolled into a coil round a short piece of wide glass tubing sealed up at each end (containing a little mercury so that it may not float in ether) ${ }^{1}$ and introduced into a Soxhlet extractor, in which it is repeatedly treated with ether, the ether with the dissolved fat being received in a wide-mouthed small flask, previously weighed (Fig. 14). After eight or ten siphonings the flask is removed from the extractor, the ether distilled off into another condenser, the flask heated in the steam bath for an hour or so, cooled, and weighed. The increase in weight of the flask is taken as fat. The percentage is then calculated, knowing that the weight in grammes of milk taken $=5 \times$ specific gravity.

In this, as in all operations in which ether is employed, great care should be taken to avoid ignition of the heavy ether vapour. The most convenient condenser to use with the Soxhlet extractor is the form consisting of two concentric metal spheres, the inner one kept cool by a stream of cold water and the vapour passed into the narrow space between the spheres. This method of estimating fat is one of the most accurate, especially if $d r y$ ether be used.

1 This device greatly hastens the extraction, by diminishing the amount of ether required to fill the apparatus. 
2. Werner-Schmid method.-This process, requiring only very simple apparatus, is especially suited for sour milk. 10 c.c. of the milk are placed in a large test tube ("boiling tube") or, better, a 50 c.c. stoppered graduated test milk mixer; 10 c.c. of strong hydrochloric acid are added and the mixture shaken and heated in a water bath for about ten minutes until a brown colouration is produced. The whole is then cooled and 30 c.c. of water-saturated ether are added. The vessel is then closed, vigorously shaken so as to dissolve the fat, and then allowed to stand until the ether separates as a clear layer. The volume of the ethereal layer is then read off and 10 c.c. are withdrawn by means of a pipette, run into a small weighed flask, the ether distilled off, the flask dried in a steam bath, cooled and weighed. The greatest drawback to this method is the formation of a flocculent, semi-solid layer between the clear ethereal and aqueous portions in the test mixer, which renders the reading of the volume of the ether difficult.

3. Rapid Centrifugal Volumetric Methods. - Several methods have been devised in which a measured quantity of milk is treated with acids so as to dissolve the casein, etc., heated, and subjected to centrifugal force so as to bring about the separation of the fat in a fluid state; the volume of the fat is then read off and gives directly its percentage amount. These methods are very rapid, easy to carry out, and sufficiently accurate for most purposes. The best known of the modern methods are-

(a) The Leffmann-Beam process.-In this process the milk is mixed with a small quantity of a mixture of amyl alcohol, $\mathrm{C}_{5} \mathrm{H}_{11} \mathrm{OH}$, and hydrochloric acid, whereby the casein is coagulated. Strong sulphuric acid is then added, in which the casein dissolves, the whole liquid becoming hot from the action of the sulphuric acid upon the water. The amyl alcohol aids in the separation of the fat, mostprobably because it is a common solvent for fat and the acid liquor. The emulsified fat thus speedily separates and by centrifugal action forms a distinct and clear layer above the acid liquor, which usually takes a

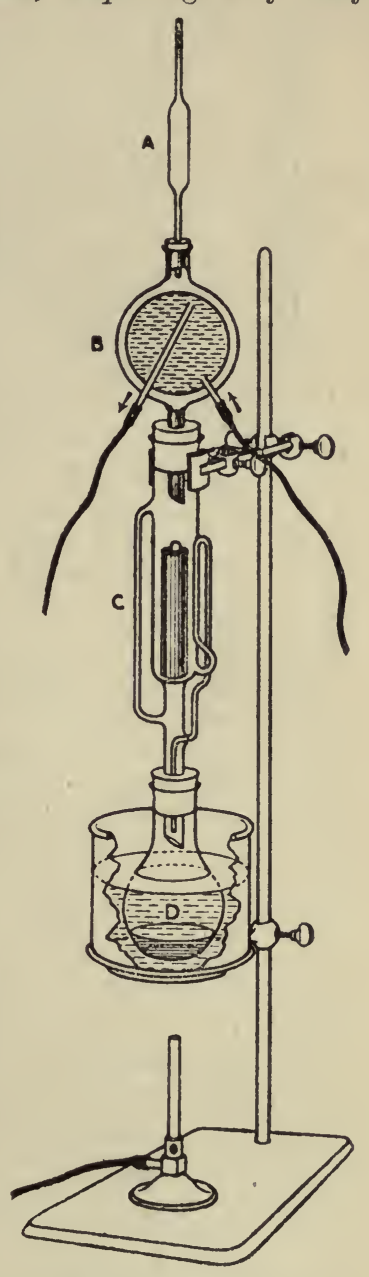

Fig. 14.-Adams's paper-coil method.

A is a pipette which acts as a condenser to the ether vapour which may escape condensation in $\mathrm{B}$. denser.

$B$ is the metal ball con-

C is the Soxhlet extractor containing the coil of paper and the glass bulb as core.

$\mathrm{D}$ is the weighed flask, in a metal water bath.

dark purple colour. The 
operation is carried out in small flask-like vessels provided with

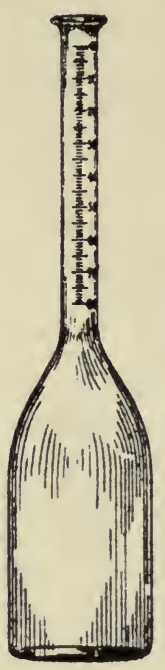

Fis. 15.-Leffmann-Beam flask. Onehalf natural size. narrow graduated necks, and the separation of the fatty layer is effected by a centrifuge driven by toothed gearing. The mode of performing the test may briefly be described thus: 15 c.c. of milk are run into the vessel from a pipette, 3 c.c. of a mixture of equal volumes of amyl alcohol and strong hydrochloric acid are then added and the whole shaken. 9 c.c. of sulphuric acid of specific gravity 1.835 at $15^{\circ} \mathrm{C}$. are then run slowly into the vessel with frequent mixing; the mixing is best done by rotating the flask in the hand, care being taken to avoid loss of the contents and also the accumulation of the heavy acid at the bottom of the vessel. In the latter case excessive darkening or even charring of a portion of the milk may occur and the test is spoiled. The whole liquid should become nearly transparent, though dark purplish in colour. The little flask is then filled with a hot mixture of equal volumes of strong sulphuric acid and water. It is then whirled for two or three minutes in the centrifuge, the handle being turned at the rate of about 80 to 100 revolutions per minute. The length of the fat layer is then read off and gives, without calculation, the percentage of fat in the milk. In reading off the fat, it will be found convenient to use a pair of ordinary dividers, the legs of which are so adjusted that one is at the lowest part of the meniscus of the upper surface of the fat, while the other is at the point where the fatty layer touches the acid. The dividers are then placed so that one leg is at the zero of the scale, when the position of the other one on the scale will give, at once, the percentage of fat present. In America, and in some dairies in England, the Babcock centrifugal method, of which the Leffmann-Beam process is a modification, is largely used.

(b) The Gerber method.-This method, which is very popular, is similar in principle to the last mentioned. The essential differences are in the apparatus used. Instead of open, flask-like vessels, corked tubes are used and the centrifuge is of simpler construction, being driven either by a string or strap, and running freely on ball-bearings, or by a steam, electric, or water motor. The materials employed are 11 c.c. of the milk, 1 c.c. of amyl alcohol and 10 c.c. of sulphuric acid of specific gravity 1.825 at $15^{\circ} \mathrm{C}$. The process is conducted in much the same way as with the Leffmann-Beam apparatus; it is generally necessary to keep the tubes warm by external heat. This can conveniently be done by means of a Bunsen burner or spirit lamp placed under the centrifuge itself during rotation. A hot-water bath, often recommended, is not so good, because of its tendency to loosen the rubber stoppers ; if they come out, the contents of the tube escape and the determination is spoiled. A white solid often separates out during the whirling of the tube and is found afterwards adhering to the cork and bottom of the tube. A quantity of this white powder was collected by the author in the autumn of 1901, washed thoroughly, 
dried and examined; it was found to be calcium sulphate. Its formation furnishes a somewhat striking proof of the large amount of calcium compounds present in cows' milk.

These rapid centrifugal methods have repeatedly been compared with the gravimetric processes for fat determinations, and the results have always proved to be in close agreement, the error being rarely more than $0 \cdot 1$ per cent.

Determination of Total Solids.-The principle of all the methods is simply to expel water, by heat, from a known amount of milk and determine the weight of the residue. Direct evaporation of milk in a dish is slow and difficult, owing to the formation of a skin, consisting mainly of proteids, upon the surface; this skin or pellicle is tough and impervious and interferes with the evaporation of the liquid below it. Many methods for avoiding the formation of the pellicle have been devised. One of the best is the following:-

A platinum dish containing about 10 grammes of recently ignited sand and a short piece of glass rod is weighed; 10 c.c. of milk are then run into it from a pipette. The dish is then placed on a water bath and the sand and milk stirred repeatedly, at intervals, until the mixture is apparently dry. Two hours further heating in a water bath or, better, in an air bath at $105^{\circ}-110^{\circ}$ is then generally sufficient to drive off all moisture. The dish is then cooled in a desiccator and weighed.

Determination of Specific Gravity.-This is usually performed by means of a modified hydrometer known as a "lactometer," the graduations usually ranging from 0 to 40 , the reading of the instrument, sometimes known as "lactometer degrees," really giving the amount by which the density of the milk exceeds 1000 when the density of water is taken as 1000 . Thus 0 on the lact-

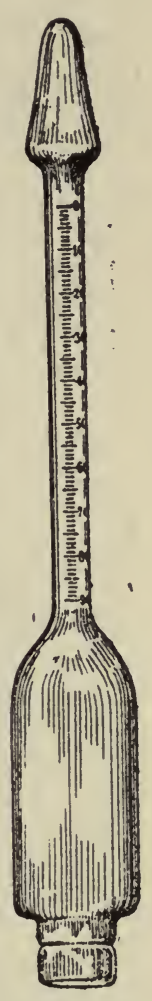
ometer scale would be the point to which the stem sinks in pure water, while 40 would be the point to which it sinks in a liquid whose specific gravity is 1.040 (water $=1$ ) or 1040 (water $=1000)$. The lactometer, though easy and convenient to use, is not capable of great accuracy.

A specific-gravity bottle holding 25 or 50 c.c. affords much greater accuracy, though a determination requires more time. It will be found most convenient to determine the weight of the empty bottle and of the bottle filled with distilled water at a temperature slightly higher than the average temperature of the room and to use these values always. In any particular case, then, only one weighing-that of the bottle filled with milk at the temperature used before-is necessary. A more rapid and very accurate method of determining the specific gravity of milk is by means of the "Westphal balance".

It has been found that the specific gravity, total solids and fat of 
a sample of cows' milk are related to each other in such a manner that it is possible to calculate the value of any one of these three quantities if the other two are known. This can be done because an increase in the solids-not-fat produces a rise in the specific gravity, while the more fat there is present, the lower will be the specific gravity. Many formulæ have been devised to facilitate the calculation. One of the most convenient is that of Richmond:-

where

$$
\mathrm{T}=1 \cdot 2 \mathrm{~F}+0 \cdot 25 \mathrm{G}+0^{\circ} 14 \text {, }
$$

$\mathrm{T}=$ percentage of total solids.

$\mathrm{F}=$ percentage of fat.

$\mathrm{G}=$ "lactometer degrees" (i.e., sp. gr. $\times 1000-1000$ ).

The results obtained for total solids from the fat and specific gravity by this formula agree closely with actual determinations.

Determination of Proteids. - The total amount of albuminoids in milk can most easily be deduced from the amount of total nitrogen. This is conveniently found by the Kjeldahl method described on p. 85. From 5 to 10 grammes of milk are taken and 20 or 25 c.c. pure sulphuric acid, the rest of the process being performed as already described in the case of soils. By multiplying the total nitrogen by $6 \cdot 38$ the total proteids are obtained, since both casein and albumin contain $15 \cdot 7$ per cent of nitrogen.

If separate determinations of the amounts of casein and albumin be required, the casein must be precipitated. This can be effected by the addition to the milk of twice its volume of saturated magnesium sulphate solution and of the powdered salt until saturation is complete. The casein can then be filtered off, washed with saturated magnesium sulphate solution, and the nitrogen in it determined by the Kjeldahl process. The percentage of nitrogen found, multiplied by 6.38 , gives the percentage of casein. The albumin can then be found by difference, for the amount of the other proteid of milk, the globulin, is so small that it may be neglected. ${ }^{1}$

Another method of precipitation of casein is the following ${ }^{2}$ :-

Ten grammes of the milk, which must not be curdled, are diluted to 100 c.c. with water and raised to $40^{\circ}$. The casein is then precipitated by adding 1.5 c.c. of a 10 per cent solution of acetic acid. The whole is well stirred, allowed to stand for a short time, and the precipitated casein washed three or four times with cold water. The nitrogen in the precipitate is then determined as before.

Determination of Milk Sugar. - This can be done either by the well-known Fehling method or by the use of the polarimeter. In either case, previous removal of the fat and proteids from the milk is necessary. If the Fehling method is to be employed, this can readily be done by the method used by van Slyke above described, but in addition, boiling the solution and filtering. For polarimetric examina-

${ }^{1}$ Sebelien, Zeits. für Physiol. Chemie, 13, 137 and 160.

2 Van Slyke, Jour. Amer. Chem. Soc., 15, 644. 
tion, an acid solution of mercuric nitrate may be employed to precipitate the proteids. ${ }^{1}$ It is prepared by dissolving mercury in twice its weight of strong nitric acid and diluting the solution with an equal volume of water. This diluted solution will serve to clarify fifty times its volume of milk.

Many methods of conducting the determination of lactose are in use. For details, a manual on quantitative analysis should be consulted One method of performing the Fehling test may be briefly described here.

Fehling's solution is best prepared when required, by mixing equal volumes of the following solutions :-

(1) A solution of 34.64 grammes of pure crystallised copper sulphate in 500 c.c. of water.

(2) A solution of 173 grammes of sodium potassium tartrate ("Rochelle salt") and 51 grammes of sodium hydrate in 500 c.c. of water.

The filtrate from the precipitated proteids is so diluted that it occupies exactly 10 times the volume of the milk taken. 50 c.c. of this filtrate are then taken, heated in a water bath, and mixed with a previously boiled mixture of $30 \mathrm{c} \mathrm{c}$. of the above copper sulphate solution, 30 c.c. of the alkaline tartrate solution, and about 120 c.c. of water. The mixture is kept on the water bath for 15 minutes and filtered through a small filter paper or a Gooch's crucible. The precipitated cupreous oxide is thoroughly washed with boiling water, next with alcohol, and finally with ether. The precipitate is then dried, transferred to a weighed porcelain crucible, and strongly ignited with free access of air, so as to oxidise it completely to cupric oxide. The amount of hydrated milk sugar corresponding to the weight of the cupric oxide is then ascertained, best by reference to a table, or approximately, by multiplying the weight of the precipitate by 0.6024 .

Adulteration of Milk.-The commonest adulterant is water. Direct proof of the presence, in a sample of milk, of added water is. very difficult, unless the water happens to contain some substance not naturally present in milk, e.g., nitrates. In such cases the detection of nitrates in the milk, say by the reaction with diphenylamine and sulphuric acid, becomes at once proof of the addition of water, though in some cases this may be due to the small quantities employed in rinsing out the milk cans, etc. The usual way of estimating the amount of added water is from a determination of the amount of solids-not-fat. By assuming that this, in genuine milk, never falls below 8.5 per cent, the percentage of added water is given by the expression-

$$
100-\frac{\mathrm{S} \times 100}{8.5}
$$

in which $\mathrm{S}=$ percentage of solids-not-fat. This gives the probable minimum amount of added water.

${ }^{1}$ Wiley, Amer. Chem. Jour., 6, 289. 
Another method of calculating the probable percentage of added water is based on the assumed constancy of the sum of the "lactometer degrees" (i.e., specific gravity $\times 1000-1000$ ) and the percentage of fat. This sum is generally about 36 and rarely falls below $34 \cdot 5$. Accepting this latter value as the minimum in genuine milk, the percentage of added water is then given by the expression-

$$
100-\frac{100(\mathrm{G}+\mathrm{F})}{34 \cdot 5},
$$

where $\mathrm{G}=$ "lactometer degrees" and $\mathrm{F}=$ percentage of fat. ${ }^{1}$

Another way in which milk is impoverished is by the removal of a portion of the fat, or, what comes to the same thing, the admixture of skimmed or separated milk. The amount of fat removed can obviously only be calculated if the amount originally present in the milk be known. The usual plan is to assume that genuine milk contains 3 per cent fat, when the percentage of the total fat removed is given by-

$$
100-\frac{\mathrm{F} \times 100}{3}
$$

It is evident, from the above figures, that the calculation of the amount of added water or proportion of fat removed from a sample of milk is based upon pure assumptions as to the real character of the original milk. When the enormous variability shown by genuine milk is taken into account, it will be seen how unieliable are the results of such calculations. The most that can be said of the results so obtained is that they probably express the lower limits of the alleged sophistication.

\section{Detection of the Presence of Preservatives.}

1. Boric acid or borax. - This is easily detected in the ash of the milk (best obtained by igniting the residue left on evaporating the milk with lime water) by the well-known cherry-red colour which is shown by turmeric paper when dipped into a dilute hydrochloric acid solution of the ash and dried at $100^{\circ}$. As a confirmatory test the reddened paper should be moistened with very dilute caustic soda solution, when a blue-black colour will be produced.

2. Salicylic acid.-About 50 c.c. of the milk are mixed with an acid solution of mercuric nitrate and the coagulated proteids and fat filtered off. The filtrate is then shaken with ether or (better) a mixture of ether and petroleum spirit, in which the salicylic acid dissolves. The ethereal solution is then evaporated and a drop of neutral ferric chloride solution added to the residue; a violet colouration then indicates the presence of salicylic acid.

3. Benzoic acid. - The milk is made alkaline with lime water and revaporated with calcium sulphate or pumice to dryness on the water lbath. The residue is then powdered, moistened with dilute sulphuric acid, and extracted with dilute alcohol. The alcoholic solution is neutralised with lime water and evaporated to small volume; the residue is then slightly acidified with dilute sulphuric acid and extracted with ether. The ethereal solution is then evaporated, when the

${ }^{1}$ Richmond, Dairy Chemistry. 
bənzoic acid is left and cun bə recognised by the odour of benzene evolved on heating it with soda-lime.

4. Formaldehyde in the form of "Formalin," which is a 40 per cent solution in water of the real formaldehyde, $\mathrm{O}=\mathrm{CH}_{w}$, is a very efficient preservative. It can be detected by Hehner's test, which consists in diluting the milk with an equal volume of water, placing the mixture in a test tube, and pouring a little sulphuric acid (specific gravity about 1.825) to which a drop of ferric chloride or other oxidising agent has been added, down the sides of the tube, so as to form a layer at the bottom. If formaldehyde be present, a violet or blue colour occurs at the surface of contact of the two layers. In this renction Hehner ${ }^{1}$ finds that the cassin of the milk takes part; it cannot, therefore, be obtained with aqueous solutions of formaldehyde.

5. Fluorides or Fluosilicates are also possiessed of good antiseptic properties. They can be detected, if present, in the ash of the milk by the usual reaction for hydrofluoric acid-its etching effect on glass when it is liberated by the action of strong sulphuric acid.

BUTTER.-With samples of genuine butter, the chief differences in chemical composition are in the proportions of water, salt and casein. These are determined by drying a weighed quantity in a flat-bottomed dish at $100^{\circ}$ until it ceases to lose weight; the loss gives the water present. The residue is then extracted repeatedly with ether, the insoluble matter dried and weighed. The weight gives the amount of casein and salt. The residue is then treated with hot water, filtered, and the amount of chlorine determined by titration with standard silver nitrate, using potassium chromate as indicator, in the usual way.

The most difficult part of such analytical processes is the taking of a satisfactory sample; the amount of water present usually varies very much in different parts of the same mass of butter. Probably the best way is to melt a considerable quantity of the butter, at as low a temper.sture as possible, in a stoppered bottle and shake it continually until it stiffens.

It the butter is to be tested for possible adulteration with other animal fats, "oleomargarine," etc., the procedure is more complicated. As already explained, butter fat differs from other natural glycerides in containing considerable quantities of fatty acid radicals of low molecular weight, e.g., butyric acid. Butyric acid and its neighbouring homologues are soluble in water and volatile in steam, while the higher fatty acids are both insoluble and non-volatile. Upon these facts most of the methods of analysis are based.

The method adopted (though numerous modifications in detail have been introduced) is essentially the digestion of a known weight (generally 5 grammes) of butter with excess of caustic soda solution, whereby glycerol and soaps are produced. The latter are then decomposed with a slight excess of dilute sulphuric acid, thus liberating the fatty acids. The liquid is then distilled until a certain proportion of it has passed over, and the acidity of the distillate is then determined by means of decinormal soda or baryta solution and phenolphthalein.

${ }^{3}$ Analyst, 1896, 92 ; Jour. Chem. Soc., 1896, Abstracts, ii. 58:. 
Aqueous soda saponifies butter very slowly and is now rarely or never used. An alcoholic solution works much more rapidly and the alcohol is readily expelled by heat before the soap is decomposed by sulphuric acid. A solution of caustic soda in glycerol saponifies the butter very quickly, especially as it can be raised to a high temperature, and the presence of the glycerol does not interfere with subsequent operations. This modification of the original Reichert process, as it is called, was introduced by Leffmann and Beam. The following reagents are used :-

Soda solution.-20 grammes of pure caustic soła are dissolved in 20 c.c. of water; 20 c.c. of the clear solution are then mixed with 180 c.c. of pure glycerol.

Sulphuric acid.-1 volume of pure acid to 4 volumes of water.

Barium hydrate.-A decinormal solution.

The sample is melted and filtered from casein, etc.; 5 grammes (about 5.75 c.c.) of the melted fat are then run into a $300 \mathrm{c} \mathrm{c}$. flask, previously thoroughly dried and weighed. After cooling, the flask and fat are weighed. Twenty c.c. of the glycerol solution of soda are then run in and the flask heated directly over the lamp. After the water (in the soda solution) has boiled off, the contents of the flask will become quite clear in a few minutes. The flask, now containing glycerol and soap, is allowed to cool and 135 c.c. of water added. When the soap is dissolved, 5 c.c. of the sulphuric acid and a piece of pumice are added, the flask is connected to a glass condenser fitted with a bulb arrangement to prevent spirting, and 110 c.c. are distilled over in half an hour. The distillate, which must be filtered if not clear, is then titrated with the alkali after addition of a few drops of phenolphthalein. Five grammes of butter treated in this way require from 24 to 34 c.c. of decinormal alkali, while 5 grammes of most animal fats require less than 1 c.c.

Commercial "margarine," which consists of animal fats churued with milk so as to acquire a flavour of butter, usually requires from 1 to 2 c.c. of decinormal alkali.

Thus a specimen of "butter," 5 grammes of whose fat gave only sufficient volatile acids to neutralise less than 24 c.c. of decinormal alkali, was considered to be open to suspicion of containing some foreign fat.

It has, however, been shown that when the cows are far advanced in lactation, and especially when fed upon poor pastures, their milk fat may give numbers much lower than this for their volatile fatty acids. ${ }^{.}$The writer's experience in South Africa also confirms this, and the same applies to the "saponification equivalent" (really a measure of the mean molecular weight of the fatty acids present). It is therefore necessary to use caution in condemning any sample of butter as being adulterated with margarine, from any data depending upon measurements of the amounts of fatty acids of low molecular weight present.

Another method of distinguishing butter fat from other fats is by

${ }^{1}$ Van Rijn. The composition of Dutch butter, 1902, see also Brownlee, Jour. Irish Dept. of Agric., April, 1910, and Crowther, Bulls. 62 and 66, Leeds Univ., 1904-1906. 
determining the amount of alkali necessary for saponification of a fixed quantity of the fat, or what is practically its reciprocal, the "saponification equivalent," i.e., the weight of fat corresponding to the gramme equivalent of the alkali. The saponification equivalent of butter, in cons squence of the low molecular weights of the acids which it contains, is much smaller than that of most other fats, the actual values found being about 247 for genuine butter and about 288 for most other fats. For other methods the reader must refer to some manual of analysis.

Butter Colouring.-The natural colouring matter of milk is apparently contained in the fat and is subject to considerable variation. The amount is usually least in winter, and, at that season, butter is often white in colour. It is a common practice to add some colouring substance to the cream in the churn, so that the colour of the butter may be deeper. The usual addition is annatto, a colouring matter obtained from the seeds of Bixa orellana.

The colouring substance is soluble in alkaline solutions and in oils. The commercial solution generally contains sodium carbonate. Other colouring matters, e.g., carrot juice, turmeric, saffron, marigold and even chrome yellow (lead chromate) have been occasionally used. The last mentioned is highly objectionable and poisonous. Its presence would be indicated by the occurrence of lead and chromium in the ash. Annatto can be detected by taking about 5 grammes of butter, dissolving it in about 50 c.c. of ether, and then shaking vigorously with about 15 c.c. of very dilute caustic soda. The whole is set aside, when it separates into two layers, the upper one consisting of an ethereal solution of fat, the lower containing the annatto, if present. Some of the lower liquid is then removed, evaporated to dryness, and the yellow residue treated with a drop of strong sulphuric acid. If annatto be present a blue or violet colour is produced, quickly changing to green, and finally to a brownish hue. Another way of separating artificial colouring matter from butter is due to Martin. A mixture of about 2 parts of carbon disulphide and 15 of alcohol is made, and five grammes of butter are treated with 25 c.c. of this liquid and the whole well shaken. On standing, the carbon disulphide, with the fat, sinks to the bottom, and the colouring substances remain in the alcohol.

CHEESE. - In cheese, the usual constituents determined in an analysis are water, ash, fat and casein, and although the last mentioned is the characteristic ingredient, the value of a sample depends far more upon the amount of fat which it contains than upon its casein content.

Water is determined by heating about 5 grammes of the sample, in thin slices, in a weighed dish containing some asbestos, which serves to absorb the melted fat. The heating should be done in a steam oven and extend over at least ten or twelve hours. The loss in weight gives the water.

$A s h$.-The residue from the previous determination is set on fire, when the asbestos will act as a wick, from which the fat will burn. The dish is then heated to a low redness until the black carbon particles disappear. 
Fat.-About 5 grammes of the cheese are rubbed up in a mortar with about 10 grammes of anhydrous copper sulphate. The mixture is introduced into a Schleicher \& Schüll's filter-paper thimble and extracted with ether for eight or ten hours in a Soxhlet extractor. The ether is then distilled off and the fat weighed.

Casein.-The total nitrogen is determined by the Kjeldahl process, ${ }^{1}$ using about 2 grammes of cheese. The percentage of nitrogen is then multiplied by $6 \cdot 38$ and the product taken as casein.

These methods are those usually employed, but are not entirely satisfactory. Attempts to differentiate between the prolucts of ripening have been made, ${ }^{2}$ but they are too complicated to be discussed here.

Milk Standards. - The establishment of a standard by which to judge of the quality and freedom or otherwise-from adulteration of a sample of milk, has received much attention and consideration. In September, 1901, the Board of Agriculture decided to take 3 per cent of fat and 8.5 per cent of solids-not-fat, as the probable lower limit in the case of genuine milk, and it was enacted by law that if a specimen did not come up to these figures a presumption should be raised that it was not genuine, by reason of the abstraction of fat or the addition of water. While these values are much below the average, and to that extent satisfactory from the producers' point of view, it must be remembered that with morning milk, when the night interval is much longer than the day one, the fat content of genuine milk may often be below this standard. Indeed, according to the experience of the author during the very dry autumn of 1901, the mixed milk of dairy shorthorn cows in the morning was far more often below than up to this standard. The cows were at pasture, but received $2 \mathrm{lb}$. decorticated cotton cake each per day. For evening milk, on the other hand, the standard for fat is very much below the average, and lower, perhaps, than the consumer has the right to expect.

The difficulty of choosing a satisfactory standard is great, and perhaps almost insuperable, when the great differences which are often shown between evening's and morning's milk are taken into account. If cows could be milked at regular intervals of twelve hours each, these differences would be greatly diminished, but unfortunately the exigencies of the trade almost necessitate great ine jualities in the intervals between milkings. A different standard fo: morning and for evening milk would, perhaps, better meet the case; but, in practice, difficulties in administering the law would arise.
1 Vide p. 85.
${ }^{2}$ Vide Chap. XV. 


\section{CHAPTER XVII.}

\section{Mrscellaneous Products Used in Agriculture.}

Is this chapter, which is necessarily disconnected and fragmentary, such substances as find applications in agriculture are briefly described from their chemical aspect, while some reference is made, in most cases, to the manner and proportion in which they are used. An alphabetical arrangement has been adopted, since the matters to be dealt with are so numerous and diverse that any connected or continuous description would be impossible. In some cases the substances mentioned have already received notice in the preceding chapters; when this is the case, reference to the place is given, so as to avoid unnecessary repetition.

Arsenious Oxide, $\mathrm{As}_{4} \mathrm{O}_{6^{\circ}}$. This substance is known in three distinct forms, viz., one amorphous or vitreous and two crystallineregular octahedra and trimetric prisms. Ordinary white arsenic consists mainly of the powdered vitreous variety, which, however, tends to pass into the heavier, octahedral form. The specific gravities of the vitreous and octahedral varieties are about 3.7 and 4.0 respectively. Their solubilities in water vary with circumstances. If water be shaken for a long time at $15^{\circ}$ with the solids, the amounts dissolved by 100 parts of water are 0.28 of the crystalline and 0.92 of the vitreous varieties, while if saturated solutions at $100^{\circ}$ be cooled to $15^{\circ}$, $2 \cdot 18$ of the crystalline and 3.33 of the vitreous form remain in solution.

Arsenious oxide dissolves readily in solutions of caustic alkalies or of alkaline carbonates, arsenites of the alkali metals being formed. "Fowler's solution " contains potassium arsenite. Arsenious acid, as the oxide is often called, and its compounds are powerful poisons both to animals and plants, but, curiously, have much less influence upon micro-organisms. Indeed, certain moulds can develop in the presence: of considerable quantities of arsenic and evolve arsenuretted hydrogen. Thus one of the most delicate tests for the presence of arsenic (Abba's: test) consists of introducing into the suspected substance a strong culture of Penicillium brevicaule and observing the garlic-like odour evolved. As little as $\frac{1}{500}$ of a milligramme can thus be detected. ${ }^{1}$

In culture solutions as little as 0.0002 per cent of arsenious acid will destroy plants. ${ }^{2}$ Arsenic acid and arsenates (compounds of $\mathrm{As}_{2} \mathrm{O}_{5}$ )

${ }^{1}$ Scholtz, Jour. Chem. Soc., 1900, Abstracts, ii. 244 ; also Abel and Buttenberg, Jour. Chem. Soc., 1900, Abstracts, ii. 299.

${ }^{2}$ Arsenic is often found in sulphuric acid and therefore in sulphate of ammonia and in superphosphate. Usually, however, care is taken to employ acid free from 
are much less injurious, for plants will grow in solutions containing as much as 0.02 per cent. ${ }^{1}$

Arsenious oxide is sometimes used in medicine as a nerve tonic, and by repeated small doses, a person may acquire the power of taking, without danger, quantities which far exceed the normal lethal dose. In such cases, however, ill effects upon the system are generally produced by continual dosing with arsenic. The administration of arsenic in small quantities often produces a plumpness and sleekness of the skin. For this reason it is often secretly given to horses by farm servants, often with fatal results. Considerable publicity was given to the prevalence of this practice in the north of Yorkshire a few years ago, and many cases of serious losses of horses occurred from this cause.

Arsenious oxide finds a more legitimate use in sheep dips, especially for foot-rot and as a vermin poison.

In South Africa enormous quantities of arsenical compounds are used for the destruction of locusts. In its adult stage-as a flying insect-the locust is difficult to deal with and reliance is chiefly placed upon methods of attacking it while in the immature, hopping stage. These "voet-gangers," as the young locusts are called, travel in vast armies across the country and devour and destroy all vegetable matter which lies in their path. The most successful method of coping with them is to spray the grass or other vegetation in front of the advancing swa'm with a solution containing sugar and arsenite of soda, the strength varying from $1 \mathrm{lb}$. of arsenite and $2 \mathrm{lb}$. of sugar to 16 gallons of water for the very young insects, to $1 \mathrm{lb}$. of arsenite and $1 \mathrm{lb}$. of sugar to 8 gallons of water for the almost full-grown voet-ganger. In this way many thousands of swarms have been destroyed. Many tons of arsenite of soda have been used, and, mainly owing to carelessness, poisoning of cattle, sheep and goats has been somewhat extensive.

The vegetation sprayed with the solution, if not eaten by the locusts, quickly dies, and if animals are not allowed access to the place until after rain has fallen, little danger of poisoning stock is experienced.

Whit ants, also very abundant and destructive in South Africa, are often de stroyed by means of arsenic.

A special apparatus is used, in which a mixture of about 9 parts of arsenious oxide with 1 part of sulphur is strongly heated by burning wood or coke, and the vapours forced, by means of a pump and flexible tubs, into the ants' nest, which is often deep below the ground.

The vapours thus introduced destroy the ants, partly by direct suf-

more than traces of arsenic in the preparation of these substances. According to Haselhoff (Jahresbericht ï. Agricultur-Chemie, 1900, 126) superphosphate made with sulphuric acid from German pyrites contains about 0.05 per cent of arsenic; with acid from Spanish pyrites, as much as $0 \cdot 149$ per cent of arsenic. He connludes that little danger exists of the arsenic in superphosphate being sufficient to do harm.

${ }^{1}$ Stoklasa, Ann. Agron., 1897, 471; Jour. Chem. Soc., 1898, Abstracts, ii. 131. 
focation, partly by condensing on the walls of the working and on the stores of food and thus rendering these poisonous to any insects which may escape suffocation.

Arsenic, generally in the soluble form of sodium arsenite, is the chief ingredient of many sheep-dips.

In many hot countries, dipping of both cattle and sheep is chiefly directed to the destruction of ticks which play so important a part in the transmission of disease. In South Africa and in Australia, practical experience has led to the conclusion that the dipping solution must contain about 0.2 to 0.3 per cent of soluble arsenious oxide in order to be effectual. Tar, soap, aloes and other substances are sometimes added to the dipping solution, but apparently have little effect upon the ticks, though they probably serve a useful purpose in rendering the liquid unpalatable and thus less likely to poison the cattle or sheep.

If animals be dipped in too strong an arsenical solution or if dipped when hot through exercise, poisoning through absorption of arsenic by the skin may ensue. Sheep are more likely to be affected than cattle or horses.

In South Africa a dip containing-

$$
\begin{aligned}
& \text { Arsenite of soda . . . . . . . } 5 \mathrm{Jb} \text {. }
\end{aligned}
$$

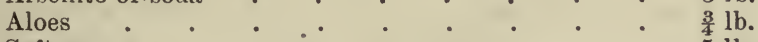

$$
\begin{aligned}
& \text { Soft soap. . . • . . . . . } 5 \mathrm{lb} \text {. }
\end{aligned}
$$

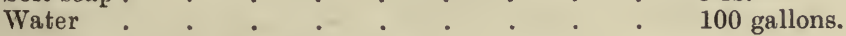

is recommended. For long woolled sheep, the soap is better omitted.

Arsenite of soda is also used, under the name of "Scrub exterminator," as a plant poison, particularly in the destruction of prickly pear.

Bleaching Powder-Chloride of Lime, $\mathrm{Ca}(\mathrm{OCl}) \mathrm{Cl}$, is used chiefly as a disinfectant. It acts by evolving hypochlorous acid, $\mathrm{HClO}$, which is a strong oxidising agent and thus able to destroy putrescible matter and micro-organisms. The hypochlorous acid is set free by the carbon dioxide of the air, thus :-

$$
2 \mathrm{C} 2 \mathrm{Cl}(\mathrm{OCl})+\mathrm{CO}_{2}+\mathrm{H}_{2} \mathrm{O}=2 \mathrm{HClO}+\mathrm{CaCl}_{2}+\mathrm{CaCO}_{3} \text {. }
$$

A more rapid and more powerful effect is produced if the bleaching powder be treated with dilute acids, when chlorine is evolved, thus:-

$$
\mathrm{CaCl}(\mathrm{OCl})+\mathrm{H}_{2} \mathrm{SO}_{4}=\mathrm{CaSO}_{4}+\mathrm{H}_{2} \mathrm{O}+\mathrm{Cl}_{2} \text {. }
$$

The chlorine acts as a most effective disinfectant. It very rapidly destroys micro-organisms, even when much diluted with air, but is, like all disinfectants, less successful with their spores. According to Fischer and Proskauer, to be effective, about 0.5 per cent of chlorine by volume should be present in the air. This would require the consumption of about $2 \mathrm{lb}$. or $3 \mathrm{lb}$. of bleaching powder per 1000 cubic feet of air space. Usually, however, about half this quantity is emploied.

Chlorine fumigation has been successfully used for disinfection after swine fever and plague. 
Other hypochlorites have been used, and a process known as the "Hermite" process, by which sea-water is electrolysed, and the fluid so obtained used for disinfecting sewage, etc., depends for its action upon the production, during electrolysis, of hypochlorites, probably chiefly of magnesium. ${ }^{1}$

Copper Salts.-Soluble copper salts are extremely poisonous to plants. In water cultures it was found that the presence of 0.0055 part of copper sulphate in 100 parts of water was sufficient to kill young wheat plants; while 0.0049 of the bromide, 0.0050 of the chloride, or 0.0061 of the nitrate produced a similar effect. ${ }^{2}$ On the other hand, insoluble copper compounds not only appear to be nonpoisonous but are often taken up by the plant. Haricot beans grew even better in nutrient solutions to which copper oxide had been added. $^{3}$ Copper is said to be often present in plants to the extent of 0.003 per cent, even on ordinary soils, while as much as 0.056 per cent may be present in the dry matter of plants growing on soils containing much copper. ${ }^{*}$ In Australia a plant-Polycarpea spirostylis - has been found to contain as much as 0.05 per cent of copper, and its presence in any district is regarded as an indication of copper in the soil. ${ }^{5}$ Large quantities of copper salts, however, appear to be injurious, especially if they be present as sulphide, in which case, by oxidation, soluble sulphate is probably slowly formed. The author found, in a soil in which fruit trees refused to grow, about 0.2 per cent of copper oxide, probably derived from pyrites.

Copper salts find their chief use in agriculture as fungicides. The most important commercial salt is the sulphate, oscurring crystallised as "blue vitriol," $\mathrm{CuSO}_{4} \cdot 5 \mathrm{H}_{2} \mathrm{O}$. This substance-which was formerly often adulterated, especially for agricultural purposes, with the much cheaper ferrous sulphate, with which it is isomorphous-is now very largely used, and the modern product is, as a rule, fairly pure.

The pure salt has a specific gravity of $2 \cdot 28$ and a solubility in 100 parts of water which varies from 31.6 at $0^{\circ}$ to 203.3 at $100^{\circ}$. At $10^{\circ}$, 100 parts of water dissolve about 37 parts, at $20^{\circ}$, about $42 \cdot 3$ parts, of the crystallised salt.

A solution containing 2 per cent of $\mathrm{CuSO}_{4} \cdot 5 \mathrm{H}_{2} \mathrm{O}$ has a specific gravity of $1 \cdot 0126$, a 4 per cent solution, $1 \cdot 0254$, and a 6 per cent solution, 1.0384. Copper sulphate is insoluble in absolute alcohol, though very slightly soluble in aqueous alcohol; it is much more soluble in glycerine.

Copper sulphate has long been used for dressing seed wheat, with a view to the prevention of such fungoid diseases as smut, rust and bunt. For this purpose each quarter of corn is moistened with 2 gallons of water in which about $2 \mathrm{lb}$. of copper sulphate crystals have been

${ }^{1}$ See Roscoe and Lunt, Jour. So?. Chem. Ind., 1895, 224.

${ }^{2}$ Coupin, Compt. Rend., 1898, 400 ; Jour. Chem. Soc., 1899, Abstracts, ii. 118.

3 Tschirch, Ann. Agron., 1895, 544 ; Jour. Chem. Soc., 1896, Abstracts, ii. 328.

* MacDougal, Exper. Stat. Record, 1899, 24 ; Jour. Chem. Soc., 1900, Abstracts, ii. 235 .

${ }^{5}$ Heckel, Jour. Chem. Soc., 1901, Abstracts, ii. 331. 
dissolved. The dressing is usually applied about 24 hours before sowing and the grain is thoroughly mixed and incorporated with the solution. Each grain of wheat becomes coated with the liquid, which on evaporation, leaves a thin film of the salt. The spores of the fungi are thus destroyed, but the copper is converted into insoluble com. pounds soon after the seed is sown and before germination of the whsat embryo commences. The corn, therefore, is not injured, though it would probably be killed outright if it were not for the action of the constituents of the soil (probably mainly the calcium carbonate) upon the copper sulphate. In America, the grain is soaked in a solution of $1 \mathrm{lb}$. copper sulphate in 24 gallons of water, for twelve hours and the for five minutes in lime water. ${ }^{1}$ Dressings of copper sulprate are also now recommended for barley and oats, for preventing smut.

Copper sulphate is also employed in solution for spraying plants, with the object of preventing fungoid diseases. For this purpose a solution containing about 0.5 per cent of the salt is usually employed. Stronger solutions would be apt to injure the foliage of certain plants.

Another use of copper sulphate is in the destruction of cruciferous weeds in cereal crops, e.g., charlock in barley or oats. This is effected by spraying the field - when the charlock plants are still small, best when two or three inches high, and before the stem and flower are formed-with a 2 or 3 per cent solution of the salt, at the rate of about 40 gallons per acre. To be successful, the operation should be performed in dry, sunny, calm weather. It is then found that the charlock leaves blacken and the plants die, while the barley and clover not only are not injured, but appear, in many cases, to be benefited by the process. This plan of dealing with charlock was apparently first tried in 1897 by Girard in France. He used a 5 per cent solution and ascribes the destruction of the charlock to the poisonous effect of the solution, which would be retained on the rough and more or less horizontal leaves of the charlock, while it would quickly run off the smooth and erect leaves of the cereals. It is doubtful whether this opinion is entitled to much weight, as clover, which also has horizontal leaves, suffers little or no damage. It is possible that the action is in some way dependent upon the presence in the charlock (as in other cruciferc) of organic sulphides or sulphocyanidss, and that some reaction of the copper upon these compounds is the cause of the injury.

Another possible explanation of the toxic action of copper and iron sulphate solutions is that, in contact with the cells of plants, osmojic pressure is set up owing to the liquid outside being more concentrated than that in the protoplasm of the cell. Water therefore leaves the protoplasm, and shrinkage occurs ("plasmolysis"), so that the vital processes of the plant are interfered with, perhaps by the destruction of the continuity of the protoplasm. If, through differences in the strength and thickness of the cell walls, this action takes place more readily in such plants as charlock, etc., than in

${ }^{1}$ Farmers' Bulletin, No. 75, U.S. Dept. of Agric. 
cereals, this explanation would seem to be sufficient to account for the facts. It receives confirmation from the discovery, recently made, that spraying with 15 or 20 per cent solutions of sodium nitrate, ammonium sulphate, or potassium chloride-salts which cannot be suspected of having any chemical toxic effects-is also effective in destroying charlock. ${ }^{1}$ (See also iron sulphate.)

Copper hydroxide, $\mathrm{Cu}(\mathrm{OH})_{2}$, is also largely employed as a fungicide for application to vines, potatoes and fruit trees. It is usually employed in the form of "Bordeaux mixture," which is made by adding lime (best in the form of "milk of lime") to copper sulphate solution. Various strengths of solution have been recommended, the proportion of copper sulphate varying from $12 \mathrm{lb}$. to $30 \mathrm{lb}$. per 100 gallons of water, that of quick-lime from $8 \mathrm{lb}$. to $20 \mathrm{lb}$. The lime should in all cases be first slaked, made into a smooth cream with water, and then poured into the copper sulphate solution with constant stirring. For many purposes it is highly important that the lime should be in excess and the mixture therefore free from any dissolved copper compounds, since these act corrosively upon the foliage. This can readily be detected by inserting a piece of bright iron or steel, when no deposit of metallic copper should form; or another easily applied test is to breathe upon the surface of a portion of the mixture, when a film of calcium carbonate should be formed, showing the presence of free calcium hydrate. The mixture should be kept constantly stirred and be applied by the sprayer as soon after its preparation as possible.

Bordeaux mixture is largely used in the preventative treatment of vines and potatoes and is highly effective.

According to $\mathrm{P}$ ckering ${ }^{2}$ Bordeaux mixture contains its copper, not as hydroxide but as basic copper sulphates. He finds that when lime water is added to a solution of copper sulphate, the precipitate, at first, consists of a basic copper sulphate, $\mathrm{SO}_{3} .4 \mathrm{CuO}$; as more lime water is added, the composition of the precipitate approaches that indicated by $\mathrm{SO}_{3} .5 \mathrm{CuO}$. With still larger quantities of lime, $\mathrm{SO}_{3} .10 \mathrm{CuO}$ is formed, together with some co-precipitated calcium sulphate.

The action of Bordeaux mixture as a fungicide, depends, according to Pickering, upon the gradual action of atmospheric carbon dioxide upon the residue left on the foliage, whereby small quantities of copper sulphate are formed :-

$$
\begin{aligned}
& \mathrm{SO}_{3} \cdot 4 \mathrm{CuO}+3 \mathrm{CO}_{2}=3 \mathrm{CuCO}_{3}+\mathrm{CuSO}_{4} \\
& \mathrm{SO}_{3} \cdot 5 \mathrm{CuO}+4 \mathrm{CO}_{2}=4 \mathrm{CuCO}_{3}+\mathrm{CuSO}_{4} \\
& \mathrm{SO}_{3} \cdot 10 \mathrm{CuO}+9 \mathrm{CO}_{2}=9 \mathrm{CuCO}_{3}+\mathrm{CuSO}_{4}
\end{aligned}
$$

$\mathrm{SO}_{3} \cdot 10 \mathrm{CuO} .4 \mathrm{CaO} . \mathrm{SO}_{3}+12 \mathrm{CO}_{2}=9 \mathrm{CuCO}_{3}+3 \mathrm{CaCO}_{3}+\mathrm{CaSO}_{4}+\mathrm{CuSO}_{4}$.

From these equations it is evident that the most effective mixture would be one in which the precipitate approximates most nearly to $4 \mathrm{CuO} . \mathrm{SO}_{3}$, since in this case the effective fungicide-copper sulphate - formed by the gradual action of the atmospheric carbon dioxide, would correspond theoretically to one-third of the total copper present,

${ }^{1}$ Heinrich, Jahresbericht über Aqricultur-Chemie, 1901, 351.

¿Juur. Chem. Soc., 1907. Trans., 1988. 
while in the usual Bordeaux mixture, the precipitate, approximating in composition to $10 \mathrm{CuO} . \mathrm{SO}_{3}, 4 \mathrm{CaO} . \mathrm{SO}_{3}$, could only yield one-tenth of its copper as copper sulphate, and this liberation of copper sulphate would probably only begin after the basic calcium sulphate had been acted upon by carbon dioxide.

In order to prepare. Bordeaux mixture containing $4 \mathrm{CuO} . \mathrm{SO}_{3}$, Pickering recommends that one gramme of crystallised copper sulphate. in solution be precipitated by the addition of 134 c.c. of saturated lime. water, and points out that such a preparation is rather more effective. than normal Bordeaux mixture made by precipitating more than double: the quantity of copper sulphate by excess of milk of lime.

On a practical scale, the mixture could be prepared by dissolving. $1 \mathrm{lb}$. of crystallised copper sulphate in $\frac{1}{2}$ to 1 gallon of water and then ad ling $13 \frac{1}{2}$ gallons of clear, saturated lime water. After thorough mixing, the liquid should be tested for soluble copper salts by filtering. a portion and adding a solution of potassium ferrocyanide. If a red. colouration be obtained, further addition of lime water should be made, or the mixture would have a corrosive action on the foliage.

This new method of preparation would seem to possess several advantages, in efficacy of the product, freedom from tendency to choke the spraying nozzles, etc., but considerable care is necessary. Unless. the lime water be really saturated, there is danger of leaving excess of copper sulphate in the final liquid, and this, of course, would be injurious to the foliage.

According to a recent paper by Barker. and Gimingham ${ }^{1}$ however, the fungicidal action of Bordeaux mixture is due to the direct action of the solid copper compounds upon the hyphe of the fungus on the surface of the leaf and not to any liberation of soluble copper compounds by the action of carbon dioxide on the precipitated basic salts.

Other copper compounds used as fungicides are-

1. "Eau celeste," which is essentially ammonio-copper sulphate, $\mathrm{CuSO}_{4} \cdot 4 \mathrm{NH}_{3} \cdot \mathrm{H}_{2} \mathrm{O}$, the well-known magnificent blue solution, formed when ammonia is added in excess to a solution of copper sulphate. The usual proportions are about $5 \mathrm{lb}$. blue vitriol and 6 or 7 pints of strong ammonia in 100 gallons of water.

2. Ammoniacal copper carbonate, made by dissolving copper carbonate in ammonia or ammonium carbonate solution. Quantities often used are-copper carbonate 10 ounces, strong ammonia 6 pints, water 100 gallons.

3. Copper sulphate and sulphur powder.-A mixture of equal weights of powdered blue vitriol and air-slaked lime is mixed with 20 times its weight of powdered sulphur.

Copper sulphate and ammonio-copper sulphate also find a limited application in veterinary practice as astringents.

Copper sulphate is also used as a disinfectant in France, a 5 per cent solution being recommended. It has been employed as a disinfectant. for cow-sheds after rinderpest, but is expensive. 
Disinfectants.-A true disinfectant is a substance which destroys the organisms (and their spores) which produce putrefaction or disease. An antiseptic, on the other hand, is a substance which prevents their growth, though it may or may not destroy them. A deodoriser is a body which absorbs or destroys the evil-smelling gases which are evolved during processes of decay.

Disinfectant; act in various ways and it is impossible to exactly correlate their germicidal action with their chemical or physical properties.

Rideal ${ }^{1}$ classifies their action thus :-

1. Free acids or salts of acid reaction retard the growth of most bacteria

2. Albumin is precipitated by soluble salts of many heavy metals, e.g., mercury, copper. 1. Such salts probably act by coagulating the protoplasm in the organisms.

3. By combining with such metals, or in cther ways, e.g., by contact with charcoal, the food of bacteria may be rendered insoluble and the organisms are thus starved.

4. Reducing agents, e.g., sulphites and ferrous salts, remove oxygen and so destroy aerobic organisms.

5. Oxidising agents, e.g., chlorine, ozone, hydrogen peroxide and permanganates, destroy by oxidation both the bacteria and their food. These are the most nearly perfect disinfectants.

6 . Some easily reducible metallic salts are assimilated by the bacteria, with the deposition of the metals within their tissues. This deposition, when it becomes great enough, kills the organisms. This happens with salts of gold and silver. In some cases, very minute quantities of these poisons promote the growth of the same organisms which larger doses quickly destroy.

7. Some substances which are germicides act in a manner which ean only be described as physiological and not chemical. To this class belong boric acid and the borates and many of the aromatic compounds.

The number of substances which have been used as disinfectants is very great and is constantly being increased.

Among them, the following may be mentioned:-

Chlorine, which is used as the free element, as hypochlorous acid, and as hydrochloric acid.

Bromine and iodine.-The former has some advantages because of its being liquid and is now sufficiently cheap to permit of its use; the latter is less convenient and too costly for general purposes. They act, like chlorine, best in the presence of moisture. Iodine trichloride, $\mathrm{ICl}_{3}$, has also been highly recommended.

Hydrofluoric acid, $\mathrm{HF}$, and especially hydrofluosilicic acid, $\mathrm{H}_{2} \mathrm{SiF}_{6}$, and the silicofluorides, are highly antiseptic.

"Salufer" is a patented disinfectant, the basis of which is silicofluoride of sodium, $\mathrm{Na}_{2} \mathrm{SiF}_{6}$. The use of hydrofluosilicic acid as a preventative of the decay of farm-yard manure has already been alluded to. Fluorides are also employed to prevent undesirable fermentations in breweries.

${ }^{1}$ Diainfection and Disinfectants, $1895,145$. 
Oxygen is the best natural disinfectant, and free admission of oxygen destroys many micro-organisms. It is by absorption of atmospheric oxygen that river water, polluted by putrefying organic matter, purifies itself. Unfortunately the process is slow.

Ozone, $\mathrm{O}_{3}$, the allotropic form of oxygen, is much more powerful in its action, and successful attempts to apply it as a disinfectant have been made.

Hydrogen peroxide, $\mathrm{H}_{2} \mathrm{O}_{2}$, is an excellent disinfectant, and, though a powerful germicide, has no influence upon enzymes, e.g., those of digestion.

When air is brought into contact with oil of turpentine in the presence of water, hydrogen peroxide is formed. Advantage is taken of this in the preparation of "Sunitas," a preparation made from terpenes and po ssessing a characteristic odour.

Sulphur dioxide, $\mathrm{SO}_{\mathrm{z}}$.-This gas, of well-known properties, is a powerful disinfectant and deodoriser. It is poisonous and very irritant when breathed, 5 per cent in air producing fatal results.

It dissolves in about $\frac{1}{50}$ of its volume of water, yielding a weak solution of the unstable sulphurous acid, $\mathrm{H}_{2} \mathrm{SO}_{3}$.

It acts in presence of water as an acid, and therefore unites with ammonia, amines, organic bases, etc. It decomposes sulphuretted hydrogen or ammonium sulphide and reduces many organic substances, generally producing colourless compounds. Hence its use in bleaching wool and straw.

By pressure, it can be condensed to a liquid and is now commercially obtainable in glass siphons (under a pressure of about three atmospheres), each of which will yield about 500 litres of gas.

The usual plan of generating the gas is by burning sulphur in air. The sulphur is often in the form of "candles," i.e., cylinders provided with a wick, or a cheaper method is to use roll sulphur placed in metal dishes and moistened, when everything is ready, with the very inflammable and volatile carbon disulphide; the ready ignition of the sulphur can thus be ensured. According to the Local Government Board's direction, $1 \frac{1}{2} \mathrm{lb}$. of sulphur should be used for an ordinary room; this probibly would yield air containing about 2 per cent of $\mathrm{SO}_{2}$.

In Belgium from 20 to 30 grammes per cubic metre are recommended (i.e., from 2 to 3 per cent). ${ }^{1}$ Considerable difference of opinion appears to exist as to the value of sulphur dioxide as a disinfectant.

Carbon disulphide, $\mathrm{CS}_{2,}$, the very volatile, inflammable liquid, with the well-known offensive odour, is poisonous both to animals and micro-organisms. Its proposed use as a means of checking nitrification in soils in the autumn his already been alluded to. On combustion it yields carbon dioxide and sulphur dioxide. With alkaline sulphiles it forms thiocarbonates or xanthates $\left(e . g ., \mathrm{K}_{2} \mathrm{CS}_{3}\right)$, which are sometimes used in treating plant diseases.

Manganate and permanyanate of soda or potash, $\mathrm{K}_{2}, \mathrm{MnO}_{4}$ and $\mathrm{KMnO}_{4}$.

Th эзз аrə powerf $x$ l oxidising agents, but bəing non-volatile, require

${ }^{1}$ Rideal, Disinfection and Disinfectants. 
to be brought into actual contact with the substance to be oxidised. All oxidisable matter, e.g., nitrites, ferrous salts and organic matter, is first attacked, before the micro-organisms are affected.

These substances form the active ingredients in "Condy's fluid".

Zinc chloride, $\mathrm{ZnCl}_{2}$, a d sliquescent and caustic white solid, very soluble in water, is a powerful disinfectant. A solution containing about 50 per cent of zinc chloride constitutes "Burnett's disinfecting fluid". A more dilute solution is often used in surgery as an antiseptic.

Carbolic acid, phenol, $\mathrm{C}_{6} \mathrm{H}_{5} \mathrm{OH}$, and its homologues, e.g., cresol, $\mathrm{C}_{6} \mathrm{H}_{4}\left(\mathrm{CH}_{3}\right) . \mathrm{OH}$, have long been used as antiseptics and disinfectants.

They are obtained from coal-tar or from the tar produced by the distillation of wood.

These substance 3 are poisonous in large quantities and when undiluted are caustic and generally deliquescent. - They are only slightly soluble in water, but by the action of alkalies they yield salt-like bodies_" carbolates" or "phenates"-which are readily soluble and easily dзcomposed by acids, even by carbonic acid, yielding again the free phenol.

Many disinfectants consist of lime or magnesia containing about 15 per cent of phenol. Such powders gradually lose their phenol on exposure to air. Pure phenol is a colourless crystalline body, melting at $41^{\circ}$ and boiling at $182^{\circ}$. With a little water it liquefies, forming a fluid hydrate, which, however, is only soluble in about fifteen times its weight of water.

Phenol is decidedly antiseptic, but recently, doubts have been expressed as to its disinfectant powers. Certain pathogenic organisms are very resistant to phenol, e.g., the typhoid bacillus can be separated from many other micro-organisms by taking advantage of its power of growing in carbolised nutrients.

Phenol is a violent plant poison, and a very dilute solution will prevent the germination of seeds. It is sometimes used as a weed destroyer.

Many of the "disinfecting powders" of commerce consist essentially of an indifferent powder, e.g., silicates or even silica, containing about 15 per cent of carbolic acid. They are often coloured pink. Sometimes calcium sulphite is also present.

Creasote or creosote is a mixture of cresol, $\mathrm{C}_{6} \mathrm{H}_{4}\left(\mathrm{CH}_{3}\right) \mathrm{OH}$, xylenol, $\mathrm{C}_{6} \mathrm{H}_{3}\left(\mathrm{CH}_{3}\right)_{2} \mathrm{OH}$, and other higher members of the series; about 1 or 2 per cent of phenol is usually present. It is colourless when fresh, but soon darkens. It possesses good antiseptic powers and is thought to be preferable to phenol. It is used in the preservation of timber.

Many preparations containing cresols are in use as disinfectants. Lysol is obtained by mixing tar-oils (chiefly cresol) with fat and saponifying with potash. It is soluble in water and is apparently an excellent antiseptic.

Wood creosote is a more powerful disinfectant than that from coal-tar. In addition to cresol and phenol it contains guaiacol, $\mathrm{C}_{6} \mathrm{H}_{4}\left(\mathrm{OCH}_{3}\right) \mathrm{OH}$, and creosol, $\mathrm{C}_{6} \mathrm{H}_{3}\left(\mathrm{CH}_{3}\right)\left(\mathrm{OCH}_{3}\right) \cdot \mathrm{OH}$. Wood creasote is very poisonous both to animals and plants. 
Many other antiseptic and disinfectant substances have been obtained from coal-tar. For an account of these substances, a treatise on organic chemistry should be consulted.

"Formalin," the commercial name for a solution of formaldehyde, $\mathrm{H}_{2} \mathrm{CO}$, in water. The nominal strength is 40 per cent of formaldehyde, and a trace of formic acid is also present. The liquid is stable in closed vessels, but loses the gas on free exposure to air.

Formaldehyde is one of the most powerful antiseptics and disinfectants. Solutions of 1 in 10,000 or 20,000 will prevent the growth of many micro-organisms and 1 per cent solutions produce absolute. sterility.

Formaldehyde is an admirable fungicide and, in sufficient quantities, acts as a powerful plant poison.

In 1897 Windisch $^{1}$ investigated the effect of various strengths of formaldehyde solutions upon the germination of cereals. In each case, 200 seeds were allowed to germinate between pieces of thick filter paper moistened with water and with $0.02,0.04,0.08,0.12$, 0.20 and 0.40 per cent formaldehyde solutions respectively.

Wheat was almost wholly destroyed by the $0 \cdot 12$ per cent solution, whilst oats were only delayed in their germination by this solution; with 0.20 per cent solutions, barley, wheat and rye were destroyed, and with $0 \cdot 40$ per cent solutions, oats also succumbed. In 1901 , he ${ }^{2}$ extended the experiments to other seeds; the 0.2 per cent solution killed flax and rape and greatly injured lupines, peas and clover, retarded the germination of horse-beans, but did not injure maize. Even a 0.4 per cent solution, which killed all other seeds, did not destroy maize.

By shorter treatment of seeds with formaldehyde, it has been attempted to destroy the smut spores in grain without injuring the seed. Kinzel ${ }^{3}$ found that a 0.1 per cent solution of formaldehyde applied for one hour to rye, wheat, oats, barley, clover and lupines had no injurious effect upon the seed, but destroyed, almost completely, the spores of fungi.

"Formalin" has been used as a preservative for foodstuffs-milk, butter, etc.; but since it combines with proteids and also has an inhibitive effect upon enzymes, its use for this purpose is not to be recommended.

Fungicides.-These are, in nearly all cases, plant poisons, but are used under such conditions or in such dilute solution that they do not injure the higher plants. Some of the more important fungicides areCopper salts, vide p. 362.

Ferrous sulphate, vide p. 372.

Mercuric chloride.-This has been recommended and used in America as a remedy for bunt or stinking smut in wheat. The seed is treated with a $0 \cdot 2$ per cent solution, conveniently made by dissolving $1 \mathrm{lb}$. of corrosive sublimate in 50 gallons of water.

Formaldehyde, vide above.-For prevention of bunt in wheat or

${ }^{1}$ Landw. Versuchs-Stat., 1897, 223 ; Jour. Chem. Soc., 1898, Abstracts, ii. 40.

2 Tbid., 1901, 241; Jour. Chem. Soc., 1901, Abstracts, ii. 466.

${ }^{3}$ Ibid., 1898, 461 ; Jour. Chem. Soc., 1898, Abstracts, ii. 302. 
smut in oats a solution of $1 \mathrm{lb}$. "formalin" in 50 or 60 gallons of water is recommended. The seed is to be soaked for two hours in this solution, which would contain about 0.08 per cent of formaldehyde.

Potassium sulphide.-The substance used is generally "liver of sulphur," a dark brown fused mass of sulphide and various polysulphides of potassium. An American recipe for smut in oats is to soak the grain for twenty-four hours in a 0.6 per cent solution (i.e., $1 \frac{1}{2} \mathrm{lb}$. of potassium sulphide in 25 gallons of water) or for two hours in 2 per cent solution.

Hot water.-It is possible, in the case of many seeds, to kill the spores of fungi by means of hot water, without injuring the seeds themselves. This is done by dipping them into water at a temperature of about $56^{\circ}$ and taking care that every grain is wetted. Ten minutes' treatment is found to suffice for destroying bunt in wheat or smut in oats. If the grain be soaked for three or four hours in cold water first, five minutes in the hot water is sufficient. For smut in barley, the temperature should not be higher than $54.5^{\circ}$.

It is said that when grain is treated with hot water or with potassium sulphide, there is an increase in the yield greater than would be produced if every infected grain were replaced by a sound one. ${ }^{1}$

Sulphur.-Used in fine powder for certain forms of mildew; occasionally as vapour (not sulphur dioxide), by heating sulphur to the boiling-point and carefully avoiding inflammation. It can only be used in this way in enclosed spaces, e.g., greenhouses. A mixture of finely-divided sulphur and lime is also employed as a remedy for mildew.

Insecticides. - In the choice of a substance to be used for the destruction of insect pests, it is necessary to consider whether the particular insects are gnawing insects, i.e., whether they actually bite away portions of the plant, or sucking insects, which derive their nourishment by imbibing the sap or juice of the plant.

If the former, any violent poison which does not harm the plant may be distributed over the leaves or stems and may be effective; in the latter, the substance must act upon the insect in some other way than as a poison, either corrosively upon its body or through its breathing apparatus.

As Food Poisons, arsenical compounds are mainly used, the favourite ones being Paris green, copper aceto-arsenite $\left[\mathrm{Cu}\left(\mathrm{C}_{2} \mathrm{H}_{3} \mathrm{O}_{2}\right)_{2} \cdot 3 \mathrm{Cu}\left(\mathrm{AsO}_{2}\right)_{2}\right.$ (?)]; London purple, chiefly .calcium arsenite and waste colouring matter; and to a less extent Scheele's green, $\left(\mathrm{CuHAsO}_{3}\right)$, and lead arsenate, made when required by mixing solutions of sodium arsenate and lead acetate. Free arsenious oxide is not suitable for the purpose, on account of its corrosive effect upon foliage. According to American experiments ${ }^{2}$ the arsenical preparations are less likely to injure the plant the less soluble the arsenic is, the order of solubility being given thus, beginning with the least soluble-lead arsenate, Scheele's green,

${ }^{1}$ Swingle, Farmers' Bulletin, 75, U.S. Dept. of Agric.

2 Marlatt, Farmers' Bulletin, 127, U.S. Dept. of Agric. 
Paris green, London purple. They are best applied in suspension in water, as a spray; but sometimes they are used in the dry state, either alone or mixed with flour. In some cases they are employed as poisoned bait, mixed with sugar and bran. For spraying, about 1 part of the solid suspended in from 1000 to 2000 parts of water is generally employed. The addition of lime is said to prevent the corrosive action of arsenic compounds upon foliage.

For sucking insects, contact poisons, as distinguished from food poisons, have to be used. Soap of any kind, but particularly potash or soft soap, in from five to twenty times its weight of water, is effective on the small scale. Pyrethrum, the ground flowers of the plant of that name, is also effective.

Flowers of sulphur, too, is useful for the purpose, as is also a solution of calcium or sodium sulphide, made by boiling sulphur with lime and water or with a solution of caustic soda.

Lime and sulphur dip, i.e., a liquid formed by boiling finely divided sulphur with lime and water, is extensively used as a sheep dip for the destruction of scab. The active constituents are the sulphide and polysulphides of calcium.

Petroleum, either alone or, better, in most cases, as an emulsion with soap and water or with sour milk, is highly recommended. The proportions used are 2 gallons of petroleum to 1 gallon of water containing half a pound of (preferably) whale-oil soap, or to 1 gallon of sour milk. The emulsion is made by means of a force-pump. For use, the emulsion is diluted with fifteen or twenty times its volume of water and applied with a sprayer.

Fumigation.-Tobacco smoke is often used in greenhouses as a means of destroying insect pests. For shrubs and trees, extensive use is now being made in America of hydrocyanic acid. The tree or shrub is enclosed in a tent made of canvas rendered gas-tight by treatment with boiled linseed-oil; and the gas is evolved by the action of dilute sulphuric acid upon potassium cyanide. From thirty to forty minutes' treatment is all that is necessary, and the quantity of pure cyanide to be used appears to be about 1 to $1 \frac{1}{2}$ ounces per 100 cubic feet of enclosed space. The cyanide should be dropped into a glass or earthenware jar containing about three times its weight of water and its own weight of commercial sulphuric acid. It is hardly necessary to say that the greatest care has to be taken to avoid breathing air containing any hydrocyanic acid. Plants are not readily injured by the gas in the dark, but when in leaf are quickly killed by it in sunlight.

Carbon disulphide, $\mathrm{CS}_{2}$, is an effective poison for most insects. It is used for low-growing plants which can be surrounded by boxes to enclose the heavy vapour given off from a small quantity (5 or 10 c.c.) of the liquid placed in a saucer. It is, however, particularly well adapted for the destruction of subterranean insects or their larvæ. For this purpose a hole from 6 to 12 inches deep is made, not too near the tree whose root is affected by the insects, and from 15 to 30 c.c. of carbon disulphide poured in. The hole is then quickly 
closed, when the vapour diffuses into the soil and destroys the insects. Carbon disulphide is also employed to rid grain of insects.

The extreme inflammability of its vapour renders carbon disulphide dangerous to use in the neighbourhood of flames.

Iron Sulphate, $\mathrm{FeSO}_{4} \cdot 7 \mathrm{H}_{2} \mathrm{O}$, copperas, green vitriol.-This substance is prepared by the action of dilute sulphuric acid upon scrap iron; sometimes by the oxidation, by means of damp air, of marcasite or white pyrites, $\mathrm{FeS}_{2}$; or as a bye-product in the manufacture of alum from "alum schists," i.e., shales containing iron pyrites.

It forms monoclinic crystals of light green colour, which effloresce and oxidise when exposed to dry air, a yellowish powder consisting of ferric hydrate and ferric sulphate being produced. One hundred parts of water dissolve-

$\begin{array}{rrrrr}60.9 & \text { parts of the crystallised salt at } & 10^{\circ} \\ 70 & " & " & " & 15^{\circ} \\ 115 & " & " & " & 25^{\circ} \\ 227 & " & " & " & 46^{\circ} \\ 263 & " & " & " & 60^{\circ} \\ 333 & " & " & & 100^{\circ}\end{array}$

The specific gravities of solutions of ferrous sulphate solutions vary with the strength, in accordance with the following table:-

Percentage of

crystallised salt.

$\begin{array}{r}5 \\ 50 \\ 15 \\ 20 \\ 25 \\ 25 \\ 30 \\ 35 \\ 40\end{array}:$ : $:$

Specific gravity of solution at $15^{\circ}$.

1.0267

1.0537

$1 \cdot 0823$

$1 \cdot 1124$

$1 \cdot 1430$

$1 \cdot 1738$

$1 \cdot 2063$

$1 \cdot 2391$

The salt is insoluble in absolute alcohol.

Iron sulphate is used in agriculture mainly as a fungicide, occasionally as a disinfectant, as a manure, ${ }^{1}$ and as a veterinary medicine.

In recent years it has been largely employed as a means of destroying charlock and runch, being used as a spray in the same manner as copper sulphate. The strength of the solution to be employed varies slightly with the age of the charlock at the time of spraying.

If the plants be treated when young, a 10 per cent solution is probably best, while for older plants a 15 per cent solution will generally be advisable; in both cases the liquid should be sprayed at the rate of about 40 gallons per acre. Mixtures of the finely-divided dry salt with marl, applied as a powder, have been tried, but with little success. ${ }^{2}$ As is the case with copper sulphate, iron sulphate appears to have a stimulating effect upon cereals, and many results, among others those obtained in the experiments conducted under the 
supervision of the Yorkshire College and the East and West Ridings Joint Agricultural Council in 1899, seem to show that, even where no charlock or runch may be present, the cereal crop is benefited by spraying. ${ }^{1}$

For severe cases of fungoid diseases, in vines, etc., a strong solution of ferrous sulphate, to which about 1 per cent of free sulphuric acid has been added, is said to be very effective.

Ferrous sulphate, like copper sulphate, is a plant poison, and its success as a fungicide (indeed, probably that of all substances used in that capacity) is probably due to the fact that the fungi are more susceptible to its action, because of their thinner walls, than the higher plants.

Mercuric Chloride, $\mathrm{HgCl}_{2}$, corrosive sublimate.-This well-known poisonous substance is one of the best disinfectants.

Since it is practically non-volatile at ordinary temperatures, it can only be applied in solution and must come into actual contact with the infected material. A solution of 1 part in 10,000 is sufficient to kill many micro-crganisms, though some spores, e.g., those of anthrax, require a 1 per cent solution. According to Lingard, ${ }^{2}$ a solution of 1 part in 960 destroys the tubercular bacillus in from four to eight hours. Mercuric chloride combines with albuminoid substances to form insoluble compounds, and this fact sometimes interferes with its success as a disinfectant of matter containing proteids. It is said that in such cases the addition of a mineral acid, e.g., hydrochloric acid, or even tartaric acid, to the solution greatly increases its effectiveness. Later experiments ${ }^{3}$ throw some doubt on this point. Mercuric chloride is a heavy crystalline substance. Its solubility in water is greatly affected by temperature. 100 parts of water dissolve-

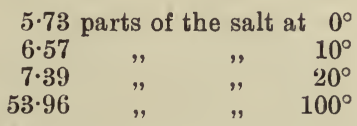

It is also soluble in alcohol, ether and glycerol. The salt melts at $288^{\circ}$ and volatilises at $303^{\circ}$; its vapour is very poisonous.

Mercuric chloride is largely employed in surgery as an antiseptic, solutions containing from 1 in 1000 to 1 in 10,000 being used.

Mercuric iodide, $\mathrm{HgI}_{2}$, and cyanide, $\mathrm{Hg}(\mathrm{CN})_{2}$, are also employed as disinfectants.

Mercury salts and mercury vapour are very poisonous to plants, mercury, even at the ordinary temperatures, giving off into the air sufficient vapour to kill many plants. ${ }^{4}$

${ }^{1}$ This effect may be either a direct manurial one, an indirect one by promoting the disintegration of the minerals in the soil, or by increasing the chlorophyll production, or, lastly, be due to the destructive action of the salt upon fungoid pests.

${ }^{2}$ Quoted by Blyth, A Manual of Public Health, 1890.

${ }^{3}$ Clark, Jour. Chem. Soc., 1901, Abstracts, ii. 526.

+ Dafert, Jour. Chem. Soc., 1901, Abstracts, ii. 269. 
Plant Poisons.-A great many substances act as plant poisons. Some, however, which when in solution are most deadly in their effects, are converted by substances present in soil into insoluble and almost harmless compounds. Others remain in a soluble form in the water of the soil for some time, and therefore are very effective as destroyers of plants.

Almost any soluble salt, if applied in strong solution, will generally kill plants, probably by producing plasmolysis.

Soluble sulphides, sulphocyanides and sulphites are extremely powerful poisons and can be used as weed-killers. Even strong brine is effective for this purpose.

Coupin investigated the poisonous effect of a large number of salts ${ }^{1}$ and determined the minimum strength of a solution which had an injurious effect in hindering (not preventing) the growth of the roots of wheat during the first 15 days.

The following are some of his results, the strengths given being the weakest which had an apparent effect:-

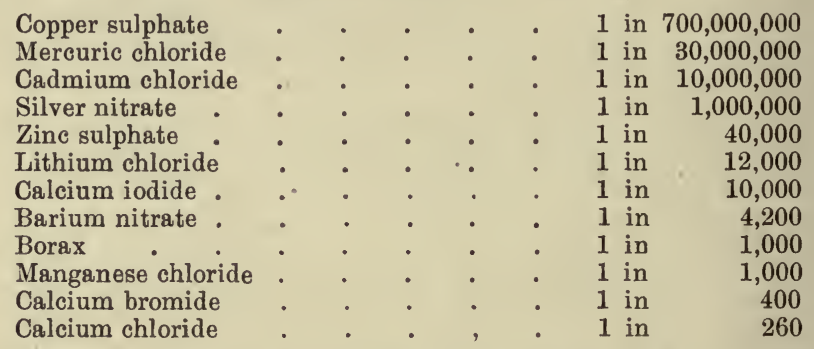

In all cases the salts are assumed to be anhydrous. The very minute quantity of copper sulphate which produces a poisonous effect is remarkable-a quantity such as no ordinary chemical test would detect.

The destruction of weeds on his land is an important task for the farmer. As a rule, the most useful and practicable methods are mechanical ones-hoeing, ploughing, etc., and only in few cases can chemical methods be employed. The destruction of charlock in barley or oat fields, by the use of differential plant poisons, affords the best example of such methods and has already been described. Appropriate manurial dressings may often serve to discourage the growth of undesirable plants and foster that of desirable ones. For example, liming "sour" grass land will, in time, change the character of the herbage by hindering the growth of such plants as delight in acid soils, e.g., the sour dock. So, too, clover in lawns or pastures may be encouraged by applications of basic slag, while repeated dressings with nitrate of soda will soon enable the grasses to choke out the leguminous plants.

Since most plant poisons render land sterile for some time, they can, as a rule, only be employed with advantage for the destruction of weeds on waste land, roadways, paths, etc.

${ }^{1}$ Compt. Rend., 1901, 645 ; Jour. Chem. Soc., 1901, Abstracts, ii. 355. 
APPENDIX.

International Atomic Weights for 1913.

\begin{tabular}{|c|c|c|c|c|c|c|c|c|c|}
\hline & & & & $0=\mathrm{I} 6$ & & & & & $0=16$. \\
\hline Aluminium & • & . & $\mathrm{Al}$ & $27 \cdot 1$ & Molybdenum & . & - & Mo & $96 \cdot 0$ \\
\hline Antimony & . & . & $\mathrm{Sb}$ & $120 \cdot 2$ & Neodymium & . & . & $\mathrm{Nd}$ & $144: 3$ \\
\hline Argon . & . & . & A & $39 \cdot 88$ & Neon & . & . & $\mathrm{Ne}$ & $20 \cdot 2$ \\
\hline Arsenic . & . & . & As & $74 \cdot 96$ & Nickel. & . & . & $\mathrm{Ni}$ & $58 \cdot 68$ \\
\hline Barium . & . & . & $\mathrm{Ba}$ & $137 \cdot 37$ & Niton $^{1}$. & . & . & $\mathrm{Nt}$ & $222 \cdot 4$ \\
\hline Bismuth . & . & . & $\mathrm{Bi}$ & $208^{\circ} 0$ & Nitrogen. & . & . & $\mathrm{N}$ & $14 \cdot 01$ \\
\hline Boron & . & . & B & $11 \cdot 0$ & Osmium . & . & . & Os & $190 \cdot 9$ \\
\hline Bromine . & . & . & $\mathrm{Br}$ & $79 \cdot 92$ & Oxygen . & 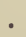 & . & $\mathrm{O}$ & $16 \cdot 00$ \\
\hline Cadmium. & . & . & $\mathrm{Cd}$ & $112 \cdot 40$ & Palladium & - & . & $\mathrm{Pd}$ & $106 \cdot 7$ \\
\hline Cæsium . & . & . & $\mathrm{Cs}$ & $132 \cdot 81$ & Phosphorus & - & . & $\mathrm{P}$ & $31 \cdot 04$ \\
\hline Calcium . & - & - & $\mathrm{Ca}$ & $40 \cdot 07$ & Platinum & - & - & $\mathrm{Pt}$ & $195 \cdot 2$ \\
\hline Carbon. & . & . & $\mathrm{C}$ & $12 \cdot 00$ & Potassium & . & . & $\mathbf{K}$ & $39 \cdot 10$ \\
\hline Cerium . & . & . & $\mathrm{Ce}$ & $140 \cdot 25$ & Praseodymiun & & & $\operatorname{Pr}$ & $140 \cdot 6$ \\
\hline Chlorine . & . & . & $\mathrm{Cl}$ & $35 \cdot 46$ & Radium. & . & • & $\mathbf{R a}$ & $226 \cdot 4$ \\
\hline Chromium & . & . & $\mathrm{Cr}$ & $52 \cdot 0$ & Rhodium & . & • & $\mathrm{Rh}$ & $102 \cdot 9$ \\
\hline Cobalt . & . & . & Co & $58 \cdot 97$ & Rubidium & . & . & $\mathrm{Rb}$ & $85 \cdot 45$ \\
\hline Columbium & . & . & $\mathrm{Cb}$ & $93 \cdot 5$ & Ruthenium & . & . & $\mathrm{Ru}$ & $101 \cdot 7$ \\
\hline Copper . & . & . & $\mathrm{Cu}$ & $63 \cdot 57$ & Samarium & - & . & $\mathrm{Sa}$ & $150^{\circ} 4$ \\
\hline Dysprosium & . & . & Dy & $162 \cdot 5$ & Scandium & . & . & $\mathrm{Sc}$ & $44 \cdot 1$ \\
\hline Erbium . & . & . & Err & $167 \cdot 7$ & Selenium & . & . & $\mathrm{Se}$ & $79 \cdot 2$ \\
\hline Europium & - & . & $\mathrm{Eu}$ & $152 \cdot 0$ & Silicon . & - & - & $\mathrm{Si}$ & $28 \cdot 3$ \\
\hline Fluorine. & . & . & $\mathbf{F}$ & $19 \cdot 0$ & Silver. & - & • & $\mathrm{Ag}$ & $107 \cdot 88$ \\
\hline Gadolinium & . & - & $\mathrm{Gd}$ & $157 \cdot 3$ & Sodium. & . & • & $\mathrm{Na}$ & 23.00 \\
\hline Gallium . & ${ }^{\circ}$ & . & $\mathrm{Ga}$ & $69 \cdot 9$ & Strontium & . & • & $\mathrm{Sr}$ & $87 \cdot 63$ \\
\hline Germanium & . & . & $\mathrm{Ge}$ & $72 \cdot 5$ & Sulphur . & . & • & $\mathrm{S}$ & $32 \cdot 07$ \\
\hline Glucinum & . & • & Gl & $9 \cdot 1$ & Tantalum & . & • & Ta & $181 \cdot 5$ \\
\hline Gold . & . & . & $\mathrm{Au}$ & $197 \cdot 2$ & Tellurium & - & - & $\mathrm{Te}$ & $127 \cdot 5$ \\
\hline Helium . & - & . & $\mathrm{He}$ & $3 \cdot 99$ & Terbium & . & b & $\mathrm{Tb}$ & $159 \cdot 2$ \\
\hline Holmium & 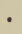 & . & Ho & $163 \cdot 5$ & Thallium & . & . & $\mathrm{TI}$ & $204 \cdot 0$ \\
\hline Hydrogen & . & . & $\mathrm{H}$ & $1 \cdot 008$ & Thorium & . & - & $\mathrm{Th}$ & $232 \cdot 4$ \\
\hline Indium . & . & . & In & $114 \cdot 8$ & Thulium & . & - & $\mathrm{Tm}$ & $168 \cdot 5$ \\
\hline Iodine . & . & . & I & $126 \cdot 92$ & Tin & . & - & $\mathrm{Sn}$ & $119 \cdot 0$ \\
\hline Iridium . & & . & Ir & $193 \cdot 1$ & Titanium & . & - & $\mathrm{Ti}$ & $48 \cdot 1$ \\
\hline Iron & ${ }^{\circ}$ & . & $\mathrm{Fe}$ & $55 \cdot 84$ & Tungsten & . & - & $\mathrm{W}$ & $184 \cdot 0$ \\
\hline Krypton. & • & . & $\mathrm{Kr}$ & $82 \cdot 92$ & Uranium & . & . & $\mathrm{U}$ & $238 \cdot 5$ \\
\hline Lanthanum & - & . & La & $139 \cdot 0$ & Vanadium & . & . & V & $51 \cdot 0$ \\
\hline Lead & - & . & $\mathrm{Pb}$ & $207 \cdot 10$ & Xenon . & . & . & $\mathrm{Xe}$ & $130 \cdot 2$ \\
\hline Litbium . & - & . & $\mathrm{Li}$ & $6 \cdot 94$ & Ytterbium & . & . & $\mathrm{Yb}$ & $172 \cdot 0$ \\
\hline Lutecium & - & . & $\mathrm{Lu}$ & $174 \cdot 0$ & Yttrium & . & - & $\mathrm{Yt}$ & $89 \cdot 0$ \\
\hline Magnesium & - & . & $\mathbf{M g}$ & $24 \cdot 32$ & Zine & . & . & $\mathrm{Zn}$ & $65 \cdot 37$ \\
\hline Manganese & - & . & Mn & $54 \cdot 93$ & Zirconium & . & - & $\mathrm{Zr}$ & $90 \cdot 6$ \\
\hline Mercury . & . & . & $\mathrm{Hg}$ & $200 \cdot 6$ & & & & & \\
\hline
\end{tabular}

${ }^{1}$ Radium emanation. 
The Connection between Various Hydrometer Scales and the True Specific Gravities of Liquids.

In England, for technical purposes, Twaddell's hydrometer is often employed. This applies to liquids heavier than water.

The relation between degrees Twaddell and true specific gravity is such that $0^{\circ} \mathrm{T}$. corresponds to a specific gravity of 1 , while the general formula is-

$$
\begin{aligned}
& d=\frac{\frac{n}{2}+100}{100} \text {, or } n=200(d-1) \\
& \text { where } d=\text { true specific gravity } \\
& \text { and } n=\text { degrees Twaddell. }
\end{aligned}
$$

Twaddell's hydrometers are, perhaps, based upon a more rational system than most of the other hydrometers. The determinations should be made at $15.5^{\circ}$.

In France, Baumé's hydrometers are in general use. For liquids heavier than water a hydrometer which sinks to $0^{\circ}$ in pure water and to $10^{\circ}$ in a 10 per cent solution of common salt, both at $17.5^{\circ} \mathrm{C}$, is employed and a uniform scale engraved on the stem. ${ }^{1}$

For liquids lighter than water, an instrument which sinks to the zero point in a solution of one part of common salt in nine parts of water, and to a point marked $10^{\circ}$ in pure water, is constructed and the graduation extended as before.

$1:$ Baumé hydrometers are purely empiric, and have nothing to recommend them; it is desirable that they should be abolished, but inasmuch as they are still extensively used in France and, to some extent, in America, it may be advisable to give the connection between their readings and true specific gravity.

The following formulæ connect together these values:-

$$
\begin{aligned}
& \text { F'or liquids heavier } \\
& \text { than water. } \\
& \text { For liquids lighter } \\
& \text { than water. } \\
& \text { At } 12.5^{\circ} \mathrm{C} \text {. } \\
& d=\frac{145 \cdot 88}{145 \cdot 88-n} \\
& d=\frac{145 \cdot 88}{135 \cdot 88+n} \\
& \text { At } 15^{\circ} \mathrm{C} \text {. } \\
& d=\frac{146 \cdot 3}{146 \cdot 3-n} \\
& d=\frac{146 \cdot 3}{136 \cdot 3+n} \\
& \text { At } 17 \cdot 5^{\circ} \mathrm{C} \text {. } \\
& d .=\frac{146 \cdot 78}{146 \cdot 78-n} \\
& d=\frac{146 \cdot 78}{136 \cdot 78+n}
\end{aligned}
$$

Other hydrometers are employed for special purposes. The principal ones in use are given in the following table:-

${ }^{1}$ Most of the modern Baumé's instruments are so constructed that in water they read $0^{\circ}$ at $15^{\circ} \mathrm{C}$. and in sulphuric acid of specific gravity 1.8427 they read $66^{\circ}$. 


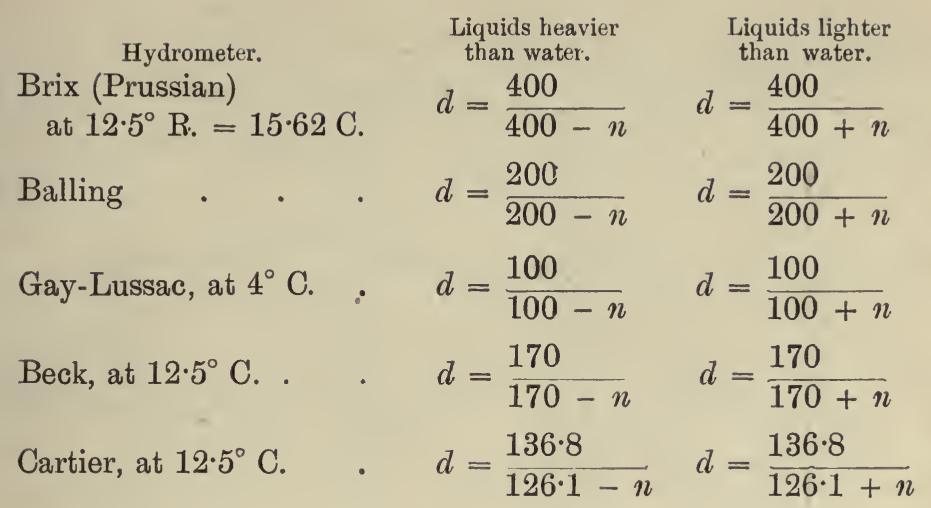

Conversion of Temperatures from one Thermometric Scale TO ANOTHER.

In this book all temperatures are stated in the Centigrade scale, and it is to be regretted that the Fahrenheit thermometer is still commonly employed in England. Though the relationship between the two is comparatively simple, it is troublesome and confusing to have two scales in use. It is perhaps hardly necessary to state here that the interval of temperature between the melting point of ice and the maximum condensing temperature of saturated aqueous vapour at the normal pressure, is divided in the Centigrade scale into 100 equal parts or degrees, in the Fahrenheit scale into 180 degrees, and that the scale commences from the melting-point of ice in the former, but from a point $32^{\circ}$ below this temperature in the latter. Hence the equations-

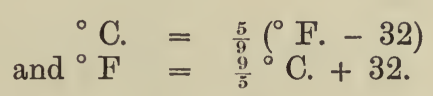

Though these formulæ are simple enough and easily remembered, when many conversions have to be made they are troublesome. A graphical method of connecting the two has been found very convenient in practice, and the diagram on p. 378 will be useful, as it enables a temperature expressed in either scale to be converted into the corresponding temperature in the other scale, without the trouble of interpolation. The graduations extend from $-35^{\circ} \mathrm{C}$. $\left(-31^{\circ} \mathrm{F}\right.$.) to $145^{\circ} \mathrm{C}$. $\left(293^{\circ} \mathrm{F}\right.$.) commencing in the lower left-hand corner and increasing in all cases as the stem is ascended. 


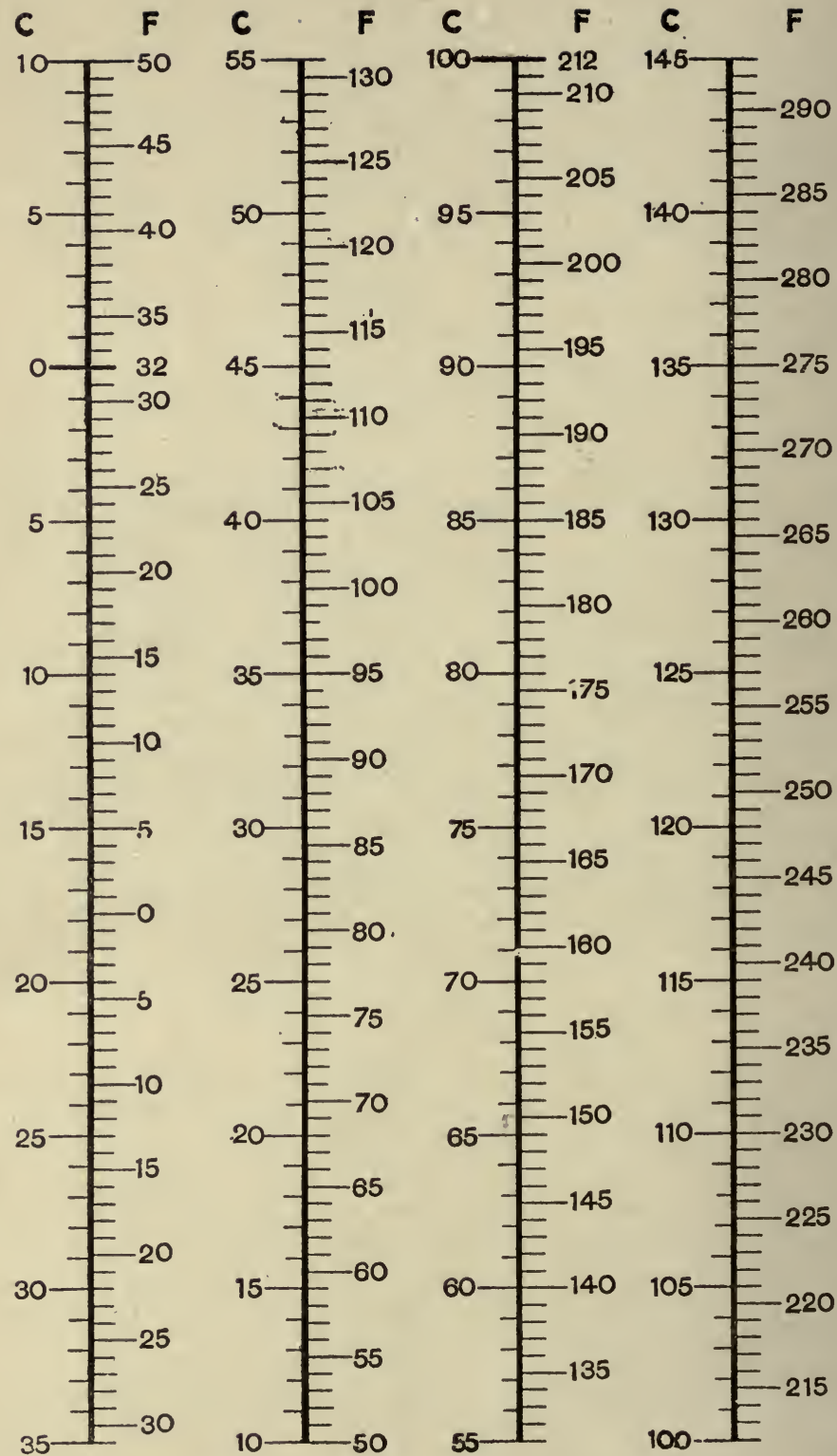

Relationship between Centigrade and Fahrenheit scales of temperature. 


\section{Table of the Solubilities of Various Salts in Water.}

The following table, giving the solubility of certain salts used in agriculture, may be useful. One hundred parts by weight of water at the temperatures stated, dissolve the following parts by weight of the various salts ${ }^{1}$ :-

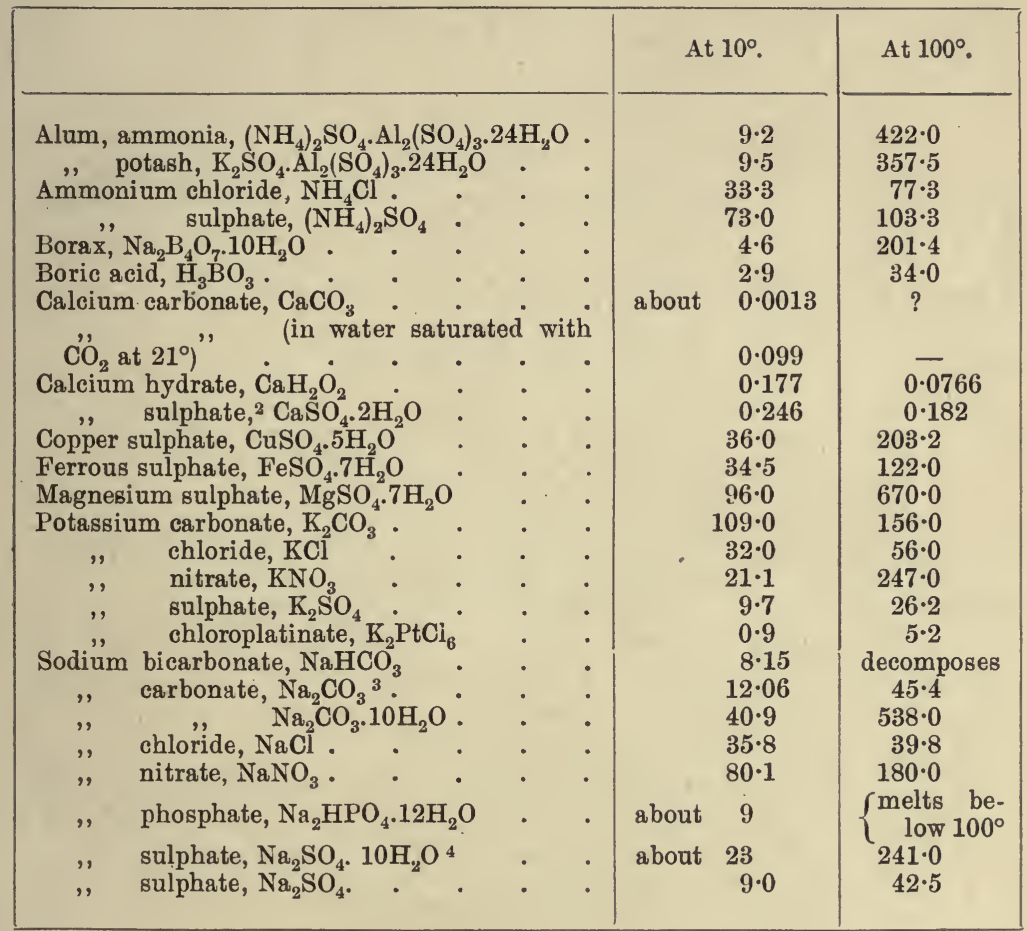

\section{The British and Metric Systems of Units of Length, Area,} Volume aNd Weight.

The inconvenience and cumbrousness of our British system of weights and measures have too often been pointed out to need further reference here; but in agricultural matters, perhaps, more than in other commercial branches, the inconsistencies of the current systems of units are strikingly evident. In addition to the disadvantages common to all our measures and weights, there are such anomalies as selling grain nominally by volume (bushels and quarters) and then

1 Taken chiefly from Comey-A Dictionary of Solubilities, 1890.

${ }^{2}$ Most soluble in water at $35^{\circ} ; 0 \cdot 279$ parts then dissolve.

${ }^{3}$ Is most soluble about $38^{\circ}$, when 100 parts of water dissolve 51.67 parts of the anhydrous salt or 1142 parts of the soda crystals.

${ }^{4}$ Is most soluble about $33^{\circ}$, when about 412 parts of the decahydrated or 50.6 of the anhydrous salt dissolve. 
fixing definite weights for these volumes, necessarily different for different kinds of grain, and what is even worse, different in different districts. However, custom in these matters is so powerful that it will probably be long before such anomalies are abolished.

The fundamental units and method of decimal multiples and submultiples of the Metric system are doubtless sufficiently familiar already to the reader. The connection between the metric units of length, area, volume and weight and those of the British system will therefore only be given here:-

\section{Units of Length.}

1 metre

1 kilometre

or

1 inch

1 foot

1 yard

1 mile
$=39 \cdot 3708$ inches $=3 \cdot 2809$ feet $=1.0936$ yards.

$=3280 \cdot 9$ feet $=1093 \cdot 63$ yards $=0 \cdot 62138$ mile.

$=2.53995$ centimetres.

$=0.30479$ metre.

$=0.91438$ metre.

$=1 \cdot 609315$ kilometres.

\section{Units of Area.}

1 sq. metre 100 sq. metres 1 are 10,000 sq. metres 1 hectare or 1 sq. inch 1 sq. foot 1 sq. yard 1 acre $=1550 \mathrm{sq}$. inches $=10 \cdot 764 \mathrm{sq}$. feet $=1 \cdot 196 \mathrm{sq}$. yards. \}$=1076 \cdot 4$ sq. feet $=119 \cdot 6$ sq. yards $=0 \cdot 0247$ acre. $=11960$ sq. yards $=2 \cdot 4711$ acres.

$=6.45137 \mathrm{sq}$. centimetres.

$=9 \cdot 290 \mathrm{sq}$. decimetres $=0.0929 \mathrm{sq}$. metre.

$=0.8361$ sq. metre.

$=0.40467$ hectare $=4046 \cdot 7$ sq. metres.

\section{Units of Volume.}

1 cub. centimetre $=0.061$ cub. inch. .

$\left.\begin{array}{l}1 \text { cub. decimetre } \\ 1 \text { litre }\end{array}\right\}=61.028$ cub. inches $=1.76$ pints $=0.22$ gallon.

1 hectolitre $\quad=6102.8$ cub. inches $=176$ pints $=22$ gallons $=$ $2 \cdot 7512$ bushels.

1 cub. metre

1 kilolitre

1 stere

or

1 cub. inch

1 cub. foot

1 pint

1 gallon

1 cub. yard

1 bushel $=61028$ cub. inches $=35 \cdot 317 \mathrm{cub}$. feet $=1 \cdot 308 \mathrm{cub}$. yards $=220 \cdot 09$ gallons $=27.512$ bushels .

$=16 \cdot 3862$ cub. centimetres.

$=28.3153$ litres.

$=567.93$ cub. centimetres.

$=4.54346$ litres.

$=0.7645$ stere $=764.513$ litres.

$=36 \cdot 3477$ litres. 
Units of Weight.

1 gramme

1 kilogram

1 metric tonne 1000 kilograms

or

1 ounce, Avoirdupois = 28.3495 grammes.

1 ounce, Troy

1 pound, Avoirdupois $=453.593$

1 hundredweight

1 ton
$=15.43235$ grains $=0.035274$ ounce Avoirdupois.

$=35 \cdot 2739$ ounces, $A v \cdot=32 \cdot 1507$ ounces, Troy $=2 \cdot 2016$ pounds Avoirdupois.

On the Continent, crop yields or manurial dressings are frequently expressed in kilograms per hectare ; in England, in pounds or tons per acre. The following connection between the two systems may therefore be found useful :-

To convert kilograms per hectare into pounds per acre, multiply by 0.89222 .

To convert pounds per acre into kilograms per hectare, multiply by $1 \cdot 1208$.

To convert kilograms per hectare into tons per acre, multiply by 0.0003984 .

To convert tons per acre into kilograms per hectare, multiply by $2510 \cdot 9$.

To convert hectolitres per hectare into bushels per acre, multiply by $1 \cdot 113$.

To convert bushels per acre into hectolitres per hectare, multiply by 0.899 .

The END. 



\section{INDEX.}

A.

Abba's test for arsenic, 359 .

Acetic acid, 8, 196.

Acetylene, 7.

Acids, amino- 114, 208.

— bile, 277.

- fatty, fermentation of, 114.

— - saturated, 195, 196.

- unsaturated, linoleic series 196.

— - oleic series of, 196.

_ - propiolic series of, 196.

— in butter-fat, 313.

- organic, 199.

- resin, 49.

Acrolein, acrylic acid, 315.

Adamkiewicz's reaction, 210.

Adams's method of fat estimation, 348.

Adonite, adonitol, 184, 192.

Adsorption, 52.

Aerobic organisms, 115.

Aesculin, 195.

Agroceric acid, 49.

Agrosterol, 49.

Air as agent in soil-formation, 41 .

- $v$. Atmosphere.

Alanine, 208.

Albite, 35.

Albumin in milk, 315.

- - - composition of, 317.

Albuminoid ratio, 290.

Albuminoids in plants, 207.

— in milk, 315 .

- digestible, in food-stuffs, 291.

- - unit value of, 308 .

- - in fodder, 256.

Albumins, 207, 210.

Alcoholic fermentation, 185.

Alcohols, carbohydrate, 192.

Aldehydes, 203.

Aldoses, 180.

Aleurone grains, 207.

Alimentary canal of various animals, 279.

"Alinit," 66.

Aliphatic compounds in essential oils, 204.

Alkaloids, 213.

Allantoin, 212.

Allyl isothiocyanate, 205.

— sulphide, 205.
Almond-nut cake, 283.

Aluminium, 12.

- phosphate, 143 .

Amandin, 210.

Amber, 206.

Amides, definition of, 8.

Amino-acids, 208.

- - formation of, in farmyard manure, 114.

of, Amino-compounds, fermentation of, 114. - - simpler, 211.

- - - function of, in animals, 213, 300.

- - - - in plants, 211.

Ammonia, determination of, in soil, 95 .

- in atmosphere, $23,24$.

- in rainfall, 26.

- oxidation of, by bacteria, 63 .

Ammoniacal copper carbonate, 365 .

- fermentation of farmyard manure, 115.

Ammoniacum, gum, 205.

Ammonio-copper sulphate $v$. "Eau céleste".

Ammonium carbamate, 116.

- carbonate in soils, 62,80 .

- citrate, solubility of phosphoric acid in, $142,150$.

- nitrate, 141.

- sulphate, 135, 165.

- - compared with sodium nitrate, 165.

- - production of, 138.

Amygdalase, 215.

Amygdalin, 195, 205, 214.

A mylodextrin, 189.

Amyloid, 190.

Amylopsin, 275.

Anabolism, 222.

Anaerobic organisms, 115.

Analyses of soils, examples of, 100.

- _ - interpretation of results of, 97.

Analysis of foods, 261.

- of manures, 170.

- of milk and milk products, 348 .

- of soils, 81 .

Anhydrite, 11.

Animal body, 264.

- - chief parts of, 265.

Animals, bodies of, composition of, 265 .

- excreta of, 106.

_ _ composition of, 108. 
Anisic aldehyde, 204.

Annatto, 357.

Antiseptic, definition of, 366 .

Ants, ant-heaps, 42.

Apatite, 9, 11, 13, 142.

Apiol, 203.

Apocrenic acid, 47.

"Appeal to the cow," 331.

Araban, 184.

Arabic acid, arabin, 191.

Arabinose, 180, 184.

- production of, from gums, 191.

Arabinosic acid, 191.

Arabinulose, 180.

Arachis oil, 242.

Arbutin, 195.

Arginine 209.

Argon, 21.

Arragonite, 36.

Arsenic, 15.

Arsenious oxide, 359.

Artichokes, 250.

Asafoetida, gum, 206.

Asbestos, 36.

Ash constituents of blood, 266.

- - of foods, 303.

— - of milk, 319.

- determination in crops, 262.

Asparagine, 114, 211.

Aspartic acid, 208.

Assimilation in plants, 227.

Atmosphere, accidental gases in, 29.

- composition of, 19.

- extent of, 17.

- height and pressure of, 17, 18.

- impurities in, 30.

- physical properties of, 18.

- solid matter in, 31.

Atomic weights, table of, 375 .

Augite, 36.

Availability of food-stuffs, 286.

Available phosphoric acid, 92.

- plant.food in soils, 91 .

- potash, 92.

Avocado pear, 192.

Azotobacter chroococcum, 66.

\section{B.}

Bacillus amylobacter, 116.

- bulgaricus, 344.

- ellenbachensis, 66.

- fluorescens, 62 .

- mycoides, 62, 63.

- nitrator, 63.

- radicocola, $68,162$.

- tuberculosis, 346.

Bacteria, aerobic and anaerobic, 115.

- classification of, 61.

- denitrifying, 69.

- in animal intestines, 276.

- in milk, 344.

- in soil formation, 43.

— in soils, 61 .
Bacteria, nitrifying, 63.

- nitrogen-fixing, 66 .

Bacterial activity, measurement of, 96 .

Bacterium denitrificans, 70.

Balsams, 205.

Barium in soils, 15.

Barley, 237.

- bye-products from, 285.

- "pearl," 237.

Barometric formula, 17.

Basalt, 37.

Basic slag, 148, 168.

- - analysis of, 175.

- - citrate-solubility of, 151.

- - production of, 152.

- superphosphate, 148.

Bats' guano, 123.

Beans, 241.

- field, 241.

"Beestings" $v$. Colostrum.

Beet, sugar, 248.

Benzaldehyde, 203.

Benzene derivatives in essential oils, 203.

Benzoic acid, 204, 354.

Bessemer process, 149.

Betäine, 212.

Bile, 276.

- acids, 277.

- pigments, 277.

Bilipurpurin, 277.

Bilirubin, 277.

Biliverdin, 277.

Biology of soils, 60 .

Biose, 180.

Biuret reaction, 210.

Bixa orellana $v$. Annatto.

Bleaching powder, 361.

Blood, 265.

— ash of, 266.

- as manure, 125.

- functions of, 267, 268.

- gases of, 267.

- plasma, 265.

- serum, 265.

Boer manna, 240.

Bone ash, 127.

- black, 127.

- earth, 38.

Bones, 269.

- ash of, 270.

- as manure, 126.

- " dissolved," 126.

Borax, as preservative, 346, 354.

"Bordeaux mixture," 364.

Boric acid, as preservative, 346, 354.

Borneol, 202, 203.

Boron, 13.

Bracken, dried, as litter, 112.

"Brak" soils, 32, 59.

Bran, 285, 305.

- disease, 305.

Brassic acid, 196.

Brewers' grains, 284.

Brie cheese, 340. 
"British gum," 189.

Carbohydrates, 179.

British system of weights and measures, 379.

Bromine as disinfectant, 366.

- digestible, in food-stuffs, 291.

Carbolic acid, $v$. Phenol.

Broom corn, 240.

Brucine, as nitrate test, 95.

Buckwheat, 242.

Bunt, 362.

Butter, 336.

- analysis of, 355 .

- colouring, 357.

— fat, 313.

- milk, 339.

— " pickled," 338.

— " "process," 338.

- rancidity of, $315,338$.

- "renovated," 338.

Butyric acid, 196, 313.

Bye-products from breweries and distilleries, 284.

_ _ - milling of cereals, 284.

- - oil-seeds, 281.

- - - starch manufacture, 283.

_ _ - sugar manufacture, 283.

\section{c.}

Cabbages, 289.

Cadaverine, 342.

Cadinene, 202.

Caffeine, 121, 214.

Cakes, oil-, $v$. Oil-cakes.

Calamine, 14.

Calcite, 36.

Calcium, 11.

- carbonate, 36.

- - action of, in nitrification, 64.

- - estimation of, in soils, 90 .

- cyanamide, $138,167$.

- fluoride, 13, 145.

- functions of, in plants, 206.

- nitrate, 140, 167.

- oxalates, 199.

- phosphate, action of, in curdling milk, 316.

— - in blood, 266.

— - in milk, 316.

- sulphate, 11, 38, 158.

Caliche, 13, 133.

Calorific powers, table of, 4 .

Calves, standard rations for, 302 .

Camembert cheese, 340 .

Camphor, 203.

Camphors, 202.

Canada balsam, 205.

Cane-sugar, 187.

Capillary tubes in soil, 56.

Capric acid, 196, 313.

Caproic acid, 313.

Caprylic acid, 313.

Caramel, 187.

Carbamide, $v$. Urea.

Carbazole, 95.

Carbon, 6.

- dioxide, in atmosphere, 22.

- - in blood, 267.

- production of, by fermentation, 185.

- - rate of absorption of, by sunflower, 230.

- disulphide, as disinfectant, 367.

- - as insecticide, 371.

Carnallite, 154.

Carnine, 271.

Carrot, 250.

Carrotene, 216, 250.

Carvacrol, 203.

Carvone, carvol, 204.

Caryophyllene, 202.

Casein, 315.

- coagulation of, $316,339,345$.

Caseinic acid, 209.

Caseinogen, 315.

Cast-iron, manufacture of, 148.

Castor-seed cake, 283.

Castor-seeds, 243.

Catalytic manures, 160.

Catch crops, 162.

Cattle-"licks," 305.

Cedrene, 202.

Cellulose, 183, 189.

- hemi-, 194.

- ligno-, 193.

- nitro-, 190.

- thiocarbonate, 190.

Centrifugal action on milk, 334, 349.

Cereals, 234.

Chabazite, 53.

Chalk, 11, 36, 158.

Charlock·spraying, 363.

Cheddar cheese, 340.

Cheese, 339.

- analysis of, 357.

- composition of, 341.

Cheeses, hard, 340.

- soft, 340 .

Chemical analysis of soils, limitations of, 90.

- constituents of plants, 179.

Chemistry, organic, meaning of, 8.

Cheshire cheese, 340 .

Chick pea, 241.

Chili saltpetre, 132.

China clay, 12.

Chinovose, 184.

Chloride of lime, $v$. Bleaching powder.

Chlorine, 12.

- as disinfectant, $361,366$.

- function of, in plants, 206.

- in rain-water, $32,73$.

Chlorite, 36.

Chlorophyll, 216.

Carbohydrate alcohols, 192.

- assimilation in relation to, 227.

- crystalline, 217. 
Chlorophyll, relation of, to haematin, Cotton, mercerised, 190. $217,267$.

Chlorophyllase, 217.

Chlorophyllin, 216.

Cholalic acid, 277.

Cholesterol, in bile, 277.

— in blood, 265.

- in cheese, 342.

- in milk, 314.

Choline, 212.

- in cotton-seed cake, 282.

Chromoproteins, 208.

Churning, 336.

Chyme, 275.

Chymosin, 274.

Cinnamic acid, 204.

- aldehyde, 204.

Citral, 204.

Citric acid, 199.

— - in milk, 319.

Citronellol, citronellal, 204.

Clay, 12.

- as soil-constituent, 45 .

- composition of, 86 .

Clostridium Pasteurianum, 67.

Clot of blood, 265.

Clover, 251.

- action on, of micro-organisms, 253.

- composition of, as silage, 256.

" Clover sickness," 251, 259.

Coal, 38.

- ash, 130.

Cocoa-nut cake, 283.

Collagen, 273.

Collodion, 190.

Colloids, 223.

Colostrum, 321.

Combustion, heat of, 3 .

- slow, 5 .

Common salt as manure, 158 .

Condensed milk, 342 .

Condy's fluid, 368.

Conglomerates, 37.

Coniferin, 195.

Coniine, 213.

Conjugated proteins, 208.

Connective tissue, 272.

Contact poisons, 371.

Copal, gum, 206.

Copper hydroxide, $v$. "Bordeaux mixture".

- occurrence of, in plants, 14.

Copper salts as fungicides, 362 .

- sulphate, action of, on crops, 160 , 362.

- - as disinfectant, 365 .

- - as fungicide, 362.

- - destruction of charlock by, 363.

Coprolites, 9, 38, 143.

- composition of, 143.

Corn-oil cake, 283.

Corpuscles, colourless, of blood, 267.

- red, of blood, 266.

Cotton, 242.

- seed cake, 282.

Coumarin, 255.

Cova, 132.

Cow-pea, 163, 241.

Cows, dairy, rations for, 302.

- excrement of, analysis of, 108.

- standard rations for, 302 .

Cows' milk, 320.

Cream cheese, 340.

— "clotted," 335.

- " ripened," 337.

- separation of, from milk, 334.

- specific gravity of, 335 .

- variation in composition of, 335 .

Creasol, creosol, 368 .

Creasote, creosote, 368 .

Creatine, in blood, 265.

- in muscle, 271.

Creatinine, 279.

Crenic acid, 47.

Cresol, para-, 276.

Cresyl sulphuric acid, 280.

Crops, classes of, 234.

- fodder, 251.

- - composition of, 252.

- grain, 234.

- leguminous fodder, 251.

- - seed, 241.

- meadow and pasture, 251.

- method of analysing, 261.

- root, 246.

- rotation of, 258.

- seed, 242.

Crotonic acid, 196.

Crude fibre, estimation of, 261.

Crum-Frankland method of nitrate estimation, 94 .

Crystalline chlorophyll, 217.

- forces, effect of, on soils, 40 .

Crystalloids, 223.

Curd, 339.

Cyanamide, 139.

Cyanogenetic glucosides, 214.

Cyano-guanidine, 139.

Cymene, 203.

Cysteine, 208.

Cystine, 209.

D.

Dairy cows, rations for, 302 .

Damaraland guano, 120.

Dammar, gum, 206.

Danish cheese, 340.

Denitrification, 69.

Dent corn, 238.

Denudation, 34 .

Deodorisers, 366.

Dextran, 189.

Dextrin, 189.

Dextrose $v$. Glucose.

Dhurra, 240.

Dhurrin, 195, 215.

Dialysis, 223. 
Diastase, 187, 189.

Dicalcium phosphate, 142.

Dicyanamide, 139.

Dicyano-diamide, 139.

Diffusion, 222.

- in soil, 54 .

Digallic acid, 200.

Digested food, absorption of, 278 .

Digestibility of foods, 285.

Digestible constituents of foodis, 291.

Digestion, 273.

- coefficients, 287.

Dihydroxy-stearic acid, 49, 313.

Diorite, 37.

Disaccharoses, 181, 186.

- configuration of, 182.

Disinfectants, 366.

Dissociation, electrolytic theory of, 77 .

Distillery waste, 284.

Double sulphate of magnesium and potassium, 156.

Drainage water, composition of, 76 .

- - lossés through, 73.

Dried blood as manure, 125.

- grains as food, 284.

Dulcitol, 184, 192.

Dung of bats, 123.

- of birds, 121.

- of farm animals, 106.

Dyer's method of soil analysis, 91 .

\section{E.}

Earth, composition of the, 15.

Earth-nut cake, 283.

Earth-worms, 41.

"Eau-céleste," 365.

Edam cheese, 340.

Edestin, 236.

Elastin, 272.

Elderberry, 215.

Electrolytic theory of dissociation, 77.

Elements, functions of inorganic, in plants, 206.

- of importance in agriculture, 2.

- of minor importance in agriculture, 13.

- relative abundance of, 15 .

Elemi, gum, 206.

Emulsin, 205, 215.

Ensilage $v$. Silage.

Enterokinase, 275.

Enzyme action during germination, 221.

Enzymes, action of, on food, 274.

- in pancreatic juice, 275.

Erythritol, 184, 192.

Essential oils, 200.

- - components of, 201.

- - containing sulphur, 205.

Eugenol, 203.

Excreta of animals, 106.

- - - composition of, 108.

" Extracts of meat," 271.
F.

Fæces of animals, 278.

"Fairy-rings," 61.

Farm-yard manure, 106, 161.

- - action of large dressing of, on soil, 71.

- - analyses of, 113.

- - fermentation of, 114.

- - gases evolved in fermentation of, 116.

- - ingredients of, 106.

- - preservation of, 117.

Fat, determination of, in crops and foodstuffs, 262.

- digestible, unit value of, 308.

- of milk, 312.

Fats, action of bile on, 278 .

- and waxes, 195.

- constitution of, 8, 195.

Fatty tissue, 271.

Feathers as manure, 128.

Feeding experiments, 296.

- standards, 301.

- value, relative, of various foods, 299.

Fehling's test, 353.

Felspar, 12, 35.

Fermentation, alcoholic, 185.

- ammoniacal, in farm-yard manure, 115.

- cellulose, in farm-yard manure, 116.

- lactic, in intestines, 277.

- - in milk, 318.

- of amino-compounds in farm-yard manure, 114.

- of carbohydrates, in farm-yard manure, 116.

- of fatty acids, in farm-yard manure, 114.

- putrefactive, in farm-yard manure, 115.

- sulphuretted hydrogen, in farm-yard manure, 116.

- of farm-yard manure, 114.

Ferments, unorganised, 187.

Ferric oxide in soil, determination of, 88.

- phosphate, 143.

Ferrous sulphate as fungicide, 372 .

- - as manure 159.

Fibre $v$. Crude fibre.

Fibrin ferment, 266.

- in milk, 318.

Fibrinogen, 265.

Field beans, 241.

" Filled cheese," 342.

"Finger and toe," 259.

Fish guano, 124.

Flax, linseed, 243.

Flint, 12.

Flint corn, 238.

Flowers, formation of, in plants, 233.

Fluorides in milk, 355.

Fluorides in phosphates, 146. 
Fluorine, 13.

Fluorspar, 13.

Fluosilicates in milk, 355.

Fodder crops, 251.

- - composition of, 252.

- pentosans in, 263.

- variation in digestibility of, 290.

Food, digested, absorption of, 278 .

- poisons, 370 .

Foods, albuminoid ratio of, 290.

- and feeding, 281.

- ash constituents of, 303.

- availability of, 286.

- composition of, 281.

- concentrated forms of, 281.

- digestibility of, 285.

- digestible albuminoid and nitrogenous matter in, 291.

- constituents of, 291.

- digestion coefficients of, 287.

- heat of combustion of, 290.

- manurial value of, 308 .

- proportion of, retained by animals, 309.

- relative feeding value of, 299.

Foodstuffs, analysis of, 261.

- bye-products used as, 281.

- calorific value of, 290.

- money value of constituents of, 307 .

"Fore milk," 329.

Formaldehyde, formalin, 369.

— as fungicide, 370 .

- as milk preservative, 346, 355.

- formation of, in plants, 231.

Formic acid, 195, 196.

Fowl dung, 121.

Fowler's solution of arsenic, 359.

Frost and thaw, action of, in soil formation, 39.

Frozen milk, 320.

Fructose, 180, 186.

Fruits, 244.

Fucose, 184, 185.

Fumaric acid, 199.

Fumigation, 371.

Fungi, action of, on organic matter in soil, 61.

Fungicides, 369

Furfuraldehyde, furfurol, 191.

- precipitation of, as osazone, 193.

Furfuroids, 184, 192.

G.

Galactase, 341.

Galactose, 180, 186.

- from gums, 191.

- from milk-sugar, 318.

Gallic acid, 200.

Gallotannic acid, 200.

Gamboge, 206.

Ganister, 149.

Gases in milk, 319.
Gases of blood, 267.

Gas.lime, 159.

Gas-liquor, 136.

Gastric juice, 274.

Gaultherin, 195.

Gentiobiose, 181.

Geraniol, 204.

Gerber tube, 351.

Gerber's process of fat estimation, 350 .

Germination, 219.

Germ meal v. Corn-oil cake.

Glaciers, action of, 40 .

Gliadins, gliadin, 208, 235.

Globe artichoke, 250.

Globulin, 207, 210.

- in milk, 315.

Gloucester cheese, 340 .

Gluco-proteins, 208.

Glucosazone, 185.

Glucose, 180, 181, 186.

- from milk-sugar, 318.

Glu cosides, 184, 185, 194.

- cyanogenetic, 214.

Glutamic acid, 208.

Glutamine, 212.

Glutelins, glutelin, 207.

Gluten in wheat, 235.

- meal, 285.

Glycerol, glyceryl hydroxide, 197.

- from hexoses, 185.

- butter-fat, 313.

Glyceryl salts in butter-fat, 313 .

Glycine v. Glycocoll.

Glycocholic acid, 277.

Glycocoll, 114, 208, 277.

Glycogen, 183, 189, 271, 276.

Glyoxylic acid, 210.

Gneiss, 38.

Gorgonzola cheese, 340.

Grain crops, 234.

Granite, 37.

Granulose, 188.

Grass, 251, 253.

Gravitation, effect of, on liquids in soil, 59.

Green manuring, 162.

"Green vitriol " $v$. Ferrous sulphate.

Grits, 37.

Ground nuts, 241.

Gruyère cheese, 340.

Guaiacol, 368.

Guanine, 121, 214, 271.

Guano, 38, 120.

— bats', 123.

- Damaraland, 120.

- fish, 124.

- meat, 127.

Guinea grass, 215.

Gulose, 180, 186.

Gum arabic, 191.

Gum resins, 206.

Gums, 190.

Gun-cotton, 6, 190

Gypsum, 11, 38. 
Gypsum, application of, to manure Hydrolysis, of hippuric acid, 280. heap, 118.

- as manure, 158.

- of lactose, 318.

- of pectins and pectose, 194.

- of pentosans, 191.

H.

- of polysaccharoses, 186.

- of proteins, 208.

- of tannin, 200.

Hrematin, 267.

Haematite, 11, 50.

Haemato-porphyrin, 267.

Haemochromogen, 267.

Haemoglobin, 266.

— oxy-, 266.

Hair as manure, 128.

Hard cheeses, 340.

Hay crops, composition of, 257.

- of xylan, 184.

Hydrometer scales, 376.

Hypoxanthine $v$. Sarcine.

\section{I.}

Ice, action of, in soil formation, 40 .

Idose, 180, 186.

Igneous rocks, 36,37 .

Indian corn $v$. Maize.

Indican, 195, 280.

Indigenous soils $v$. Sédentary soils.

Individuality of cows, 330 .

- stacks, 254.

Indole, 114, 276.

Heat of combustion, measurement of, 3 .

Helium in atmosphere, 22.

Hemicellulose, 194.

Hermite process, 362.

Hexosans, 183, 191.

Hexoses, 180, 185.

- configuration of, 181.

Hippuric acid, 280.

- - production of, from ligno-cellu. loses, 193.

Histidine, 209.

Indoxyl, indoxyl sulphuric acid, 195, 280.

Inorganic salts in plants, 206.

Inosite, inositol, 271.

Insecticides, 370.

Insects as manure, 128.

Interpretation of soil analyses. 97.

Intestines, changes in, 276.

Inulin, 183, 189.

Inversion, 187.

Invertase, 187.

Iodine, 13.

Histones, 207.

Hoof waste as manure, 128.

Hordein, 237.

Hornblende, 36.

Horn waste as manure, 128.

Horses, excrement of, 108.

- - of, amount of, 113.

- standard rations for, 302.

Human milk, 333, 345.

Humanised milk, 345 .

Humic acid, 47.

Humin, 47.

Humulene, 202.

Humus, 47.

- estimation of, in soil, 88 ,

- retentive and absorbent powers of, Isothermal layer in atmosphere, 19. 54.

Hydro-bilirubin, 278.

Hydrocarbons, paraffin, 7 .

- as disinfectant, 366

- in the animal, 304.

- presence of, in caliche, 133.

Ionisation, 77 .

Iron, 11.

- compounds in mineral phosphates, 143.

- - in soils, 50 .

- dephosphorisation of, 152.

- functions of, in animals, 267.

- - of, in plants, 206.

- sulphate $v$. Ferrous sulphate.

Irrigation, 32.

Isoleucine, 208.

Isotonic solutions, 226.

J.

- olefine, 7.

Hydrocyanic acid, 371.

- - in plants, 215,240

Hydrofluoric acid, 366.

Hydrofluosilicic acid, 366.

Hydrogen, 2.

- peroxide, 28, 232.

- - as disinfectant, 367.

Hydrolysis, acid, of furfuroids, 192.

- of cane-sugar, 187.

— of fats, 197.

- - - by steapsin, 275 .

- - - in intestines, 276.

— of glucosides, 195, 215.

Jerusalem artichoke, 189, 250.

K.

Kaffir corn, 240.

Kainite, 156.

- application of, to manure heap, 119.

Kalkstickstoff, 138.

Kaolin, 12, 36.

Katabolism, 222.

Kephir, 343.

Keratin, 273.

Ketones, 203, 204. 
Ketoses, 180.

Kidney beans, 241 .

Kieserite, 154.

Kjeldahl's process, 85 .

Koumiss, 343.

Kraal manure, 109.

Krypton in atmosphere, 22.

\section{L.}

Lab, 316.

Labradorite, 35.

Lactase, 318.

Lactic acid in milk, 318.

- fermentation in intestines, 277.

"Lacto-chrome," 314.

Lactometer, 351.

Lactose, milk-sugar, 318.

Lahn phosphate, 144.

Lambs, standard rations for, 302 .

Land plaster $v$. Gypsum.

Lauric acid, 313.

"Law of minimum," Liebig's, 100.

Lead arsenate, 370.

Leaves as litter, 112.

- assimilation by, 227. cause of rigidity of, 225 .

- functions of, 227.

- stomata of, diffusion through, 229.

Lecithin, 265, 277.

- constitution of, 198.

Leffmann-Beam's process of fat estimation, 349.

Legumin, 207.

Leguminous crops, 251.

- seed crops, 241.

Leicester cheese, 340 .

Lentils, 242.

Leucıne, 114, 208.

Leucocytes in blood, 267.

Levulin, 183, 189.

Levulose $v$. Fructose.

Lichenin, 189.

“Licks," 305.

Lignification, 193.

Lignite, 38.

Ligno-cellulose, 193.

Lignoceric acid, 49.

Lignose, lignone, 184, 193.

Lima beans, Java beans, 241.

Limburg cheese, 340.

Lime and sulphur dip, 371.

- as manure, 158.

- chloride of, 361.

- determination of, in soil, 90.

- hydrated sulphate of, 170.

Limestone, 11, 36, 158.

- as soil-constituent, 46 .

Limestones, 37.

Limitations of chemical analysis of soils, 90.

Limonene, 201.

Limonite, 50.

Linalol, 204.
Linamarin $v$. Phaseolunatin.

Linoleic acids, 196.

Linolenic acid, 196.

Linseed $v$. Flax.

- cake, 281.

- oil, 196, 243.

Lithium, 14.

Litter, 110.

Loams, 49.

Locust destruction, 360.

"London purple," 370.

Loss on ignition, estimation of, in soils, 84.

Lotusin, lotase, lotoflavin, 215.

Lucerne, 251.

Lunge's method for $\mathrm{NO}_{3}$ estimations, $94,173$.

Lupines, 242.

Lycopodium, 12.

Lysine, 209.

Lysol, 368.

Lyxose, 180.

\section{M.}

Magnesia, determination of, in soil, 90 .

Magnesian limestone, 11.

Magnesium, 11.

- function of, in plants, 206.

- in chlorophyll, 216, 217.

Magnetite, 11.

Maize, mealies, 238.

- bran, 285.

- bye-products from, 285.

- varieties of, 238.

Malic acid, 199.

Malt culms, 284.

- sugar $v$. Maltose.

Maltase, 215.

Maltodextrin, 189.

Maltose, malt sugar, maltobiose, 181,187.

Mandelo-nitrile glucoside $v$. Prunasin.

Manganates of potash and soda as disinfectants, 367 .

Manganese, 13.

Mangolds, 247.

Manna, 186.

Mannitol, 184, 186, 192.

Mannose, 180, 186.

Nianure, definition of, 104.

- farm-yard, 106.

- - application of, 161.

- Kraal, 109.

Manures, 104.

- analysis of, 170.

- application of, 161 .

- catalytic, 160.

- concentrated, application of, 163.

- determination of nitrogen in, 173.

- - of $\mathrm{P}_{2} \mathrm{O}_{5}$ in, 174.

- general, 106.

- miscellaneous, 156.

- nitrogenous, 132.

_ - application of, 164. 
Manures, organic, 120.

- phosphatic, 142.

- - application of, 167.

- potash, 153.

- - application of, 169.

- special, 132.

- valuation of, 175.

Manurial value of food-stuffs, 308 .

- - of urine, 110.

Manuring, 103.

- green, 162.

Marble, 11, 36.

Margarine, oleomargarine, butterine, 338.

Marl, 49, 158.

Marrow of bones, 269.

Mass action, 79.

Maté, 14, 214.

Maysin, 239.

Meadow crops, 251.

"Mealies" $v$. Maize.

Meat extracts, 271.

- meal, 127.

Meerschaum, 11.

Melibiase, 187.

Melibiose, 181, 187.

Membranes, semi-permeable, 223.

Menthol, 202, 203.

Menthone, 203.

Mercerised cotton, 190.

Mercuric chloride, 369, 373.

Mercury salts, effect of, on plants, 373.

Merits, comparative, of $\mathrm{NaNO}_{3}$ and $\left(\mathrm{NH}_{4}\right)_{2} \mathrm{SO}_{4}, 165$.

Metabolism, 222.

Metamorphic rocks, 36.

Metapectin, 194.

Metaprotein, 208.

Methyl pentoses, 185 .

- salicylate, 204.

Metric system of units, 379 .

Mica, 12, 35.

Micrococei, 61.

Micrococcus urea, 62.

Micro-organisms, 60.

"Middlings," 285.

Milk, acidity of, 319.

- adulteration of, 353.

- albuminoids of, 315 .

- analysis of, 348.

- and milk products, 312.

- as germ-spreading medium, 346.

- ash of, 319.

- butter-, 339.

- condensed, 342.

- constituents of, 312 .

- cows', 320.

- - composition of, 321.

- - influence of breed on, 322.

— - - of food on, 325.

- - of individuality on, 330.

- - - of manner of milking on, 327.

- - - of period of lactation on, 323.

— — - of season on, 326 .
Milk "deep setting" of, 334 .

- detection of preservatives in, 354.

- estimation of fat in, by Adam's method, 348 .

- _ - _ - centrifugal methods, 349.

- - - - - Gerber's method, 350.

- - - - - Leffmann-Beam method, 349.

- - - - Werner-Schmid method, 349 .

- of milk-sugar in, 352.

- of proteids in, 352.

- - of specific gravity of, 351.

- - of total solids in, 351.

- fat of, 312.

- frozen, 320.

- gases in, 319.

- human, 333, 345.

- humanised, 345.

- of various animals, 333 .

- pasteurisation of, 345 .

- powder, 343.

- preservation, 344.

- products, 334.

- ripening of, 340 .

- separators, 334, 349.

- skimmed, 336.

- standards, 358.

— sterilisation of, 344.

- sugar, 318.

Millet, 240.

Millon's reagent, 210.

"Mineral alkali," 10.

Mineral, definition of, 35.

Minerals, 35.

Möckern process, 173.

Moisture, determination of, in soils, 84 .

Molasses, 284.

Monkey nut, $v$. Ground nut.

Monocalcium phosphate, 142.

Monosaccharoses, 180, 184.

Morphine, 6, 214.

Moulds, 61.

Mucin, 273, 277.

Muriate of potash, 156.

Muscle, 271.

- stroma, 271.

Musculin, 271.

Myoglobin, 271.

Myosin, 271.

Myrcene, 202.

Myristic acid, 196, 313.

Myrosin, 205.

Myrrh, 206.

N.

Neon in atmosphere, 22.

Nerol, 204.

Neufchâtel cheese, 340.

Nicotine, 213.

Nitragin, 68. 
Nitrate of lime, 140, 167.

- of soda, 132, 164.

- - comparison of, with $\left(\mathrm{NH}_{4}\right)_{2} \cdot \mathrm{SO}_{4}, 165$.

- - - consumption of, 135.

- - perchlorates in, 134, 174.

- - - valuation of, by refraction, 174.

Nitrates, deposits of, $5,132,141$.

- destruction of, by starch, 70 .

- estimation of, in soils, 93.

Nitric acid in atmosphere, 25.

- - - rainfall, 26.

- organism, 64.

Nitrification, 62.

- essential conditions for, 64 .

Nitrites, estimation of, in soil, 95 .

Nitro-bacter, 64.

Nitrobacterine, 69.

Nitrogen, 5.

- estimation of, in a manure, 173.

- - - in foods, 262.

- - - in soil, 85.

- fixation of, through symbiosis, 67.

- fixing organisms in soils, 66 .

- in atmosphere, 19.

- loss of, from manure heap, 117.

- proportion of, in food retained by animals, 309.

- putrefaction of combined, 62, 115 .

- utilisation of atmospheric, 138, 140.

Nitrogenous manures, 132, 172.

- proteid matter in plants, 232.

- substances in plants, 207.

Nitro-glycerine, 6 .

Nitrolim, nitrolime, 138.

Nitroso-coccus, 64 .

Nitroso-monas, 64 .

Nitrous organism, 64 .

Nonose, 180.

Nucleon in milk, 318.

Nucleo-proteins, 208.

Nutritive ratio $v$. Albuminoid ratio.

Nuts, 245.

\section{0.}

Oat-hay, 237, 304.

Oat.straw, 237.

Oats, 237.

- bye-products of, 285.

Oil-cakes, 281.

- - manufacture of, 198.

- - value of, as manures, 131.

Oils, drying and non-drying, 196.

- essential, 200.

- extraction of, 198.

Olefine series, 7.

Olefinic terpenes and sesquiterpenes, 202.

Oleic acid, 196, 313.

- series of acids, 196.

Oleomargarine $v$. Margarine.

Oligoclase, 35.

Olivine, 36 .
Organic acids, 8.

- - and their salts, 199.

- chemistry, meaning of, 8 .

- manures, 120.

- matter in atmosphere, 30.

Organisms, micro-, 60.

Ornithine, 209.

Orthoclase, 9, 35.

Osazones, 185.

Osmosis, theory of, 224.

Osmotic pressure, 224.

- - with regard to plants, 225.

Ossein, 269.

Osteolite, 9.

Osteoporosis, 269, 303.

Ox, clot of blood of, 126.

Oxalates of potassium and calcium, 199.

Oxalic acid, 199, 248.

Oxidation, process of, 3 .

- seat of, in body, 269.

Oxygen, 3.

- absorption of, during flowering, 233.

- - - in germination, 221.

- - - in haymaking, 254.

- action of, in denudation, 41.

- as disinfectant, 367.

- evolved from leaves, 231.

- in atmosphere, 20.

- in blood, 267.

- in expired air, 269.

- in soil-gases, 71.

- need for, in nitrification, 65.

Oxyhæmoglobin, 266.

Oxyproline, 209.

Ozone as disinfectant, 367.

- in atmosphere, 28.

\section{P.}

Palmitic acid, 196, 313.

Palm-nut cake, 283.

- meal, 283.

Pancreatic juice, 275.

Para-cresol, 276.

Paraffin series, 7 .

Paraffinic acid, 49.

Parapectic acid, 194.

Parasitism, 68.

Parchment paper, 190.

"Paris green," 370.

Parmesan cheese, 340.

Parsnip, 250.

Pasteurisation, 345.

Pea, 241.

Pea-nut cake $v$. Earth-nut cake.

Pea-nuts, ground-nuts, monkey-nuts, 241.

Pear, avocado, 192.

Pearl barley, 237.

- millet, 240.

Peat, 38.

Peat as litter, 111.

Pectase, 194.

Pectic acid, pectin, pectose, 194. 
Pectin substances, 184, 194.

Pentosan, composition of a, 191.

Pentosans in fodder, 263.

Pentoses, 180, 184.

- methyl, 185.

Pepsin, 274.

Peptones, 208.

Perchlorates, effect of, on seeds, 134.

- estimation of, 174.

Perseitol, 184, 192.

Petroleum as insecticide, 371.

Phaseolunatin, 215, 282.

Phellandrene, 202.

Phenol, 276.

- as disinfectant, 368 .

Phenols, 203.

Phenyl-alanine, 208.

- sulphuric acid, 95, 280.

Phloridzin, 195.

Phosphates, mineral, production of, 144.

- insoluble, in manures, 168.

- soluble, in manures, 167.

Phosphatic manures, 142.

- valuable ingredients of, 172.

- nitrogenous manures, 172.

Phospho-proteins, 208.

Phosphorcarnic acid, 318.

Phosphoric acid, available, in basic slag, 150.

- - - in soils, 92.

- citrate-solubility of, 91.

- - estimation of, in manures, 174.

- - - in soils, 90 .

- form of, in manures, 142.

- in drainage water, 75 .

- - in guano, 120.

- limit of, in soils, 92 .

- manurial value of, 177 .

- - proportion of, in food, retained by animals, 309.

- retention of, by soils, 54

Phosphorites, 9, 143.

Phosphorus, 9.

- function of, in plants, 206.

Phytochlorin, 217.

Phytorhodin, 217.

Phytosterol, 199.

Phytyl chlorophyllide, 217.

Pialyn $v$. Steapsin.

Picoline carboxylic acid, 49.

Pig, excrement of, 108.

- - - amount of, 113.

- standard rations for, 302.

Pigeon dung, 121.

Pinene, 201.

Pixine, 316.

Plant, 219.

- food, availability of, 91.

- - improvement of, in soil, 103.

- removed by average crops, 260.

- poisons, 374.

Plants, action of light on, 227.

- constituents of, 179 .

- diminished growth of, in towns, 29.
Plants, flowers and seeds of, 233.

- formation of formaldehyde in, 231.

- leaves of, 227.

- leguminous, nodular swellings of, 68 .

- main parts of, 222.

- position of oil in, 200.

- roots of, 222.

- stems of, 227.

- turgescence of cells of, 225 .

Plasmolysis, 226.

— by spraying, 363

Plumule, 221.

Poisons, contact, 371.

- food, 370.

- plant, 374.

Polycarpaa spirostylis, 362.

Polyhalite, 154.

Polypeptides, 208.

Polysaccharoses, 183, 188.

- hydrolysis of, 186.

Pop corn, 238.

Potash, amount of, in drainage waters, 75.

- compounds, retention of, by soils, $10,75,169$.

- determination of, in soils, 89.

- felspar, 9, 35.

- limit of, in soils, 92.

- loss of, through skin, 109.

- manures, 153.

- production of, 154.

- - valuable ingredients of, 173.

- manurial value of, 177.

- muriate of, 156.

- permanganate of, 367 .

- proportion of, in food retained by animals, 309.

- sulphate of, 156.

Potassium, 9.

- chloride, 156.

- estimation of, in manures, 175.

- function of, in plants, 206.

- nitrate, 141.

- oxalates, 199.

- sulphide as fungicide, 370 .

Potato, sweet, 216, 250.

Potatoes, 248.

Preservation of milk, 344 .

Producer gas, 136.

Products, miscellaneous, used in agriculture, 359.

Proline, 209.

- oxy-, 209

Protamines, 207, 210.

Proteids, 207.

- classification of, 207.

- estimation of, $211,352$.

- formation of, in plants. 232.

- tests for, 210.

Proteoses, 208.

Protozoa and amœbae, 61.

Prunase, 215.

Prunasin, 215.

Prussic acid, 6, 214, 240, 282. 
Prussic acid, as insecticide, 371.

Psilomelane, 13.

Ptyalin, 273.

Pyrethrum. 371.

Pyrocatechin sulphuric acid, 280.

Pyrolusite, 13.

Pyroxylin $v$. Collodion.

Pyrrole, 217.

\section{Q.}

Quartz, 12, 35.

Quartzites, 38.

Quercetin, 185, 195.

Quercitrin, 185, 195.

Quinine, 6, 214.

R.

Radicle, 221.

Radiobacter, 66.

Radish, 250.

Raffinose, 183, 187, 248.

Rain, acidity of, 30,31 .

Rainfall, average, 72 .

Rain-water, analysis of, 25.

- - chlorine in, 32, 73.

Rancidity of butter-fat, 315 .

Rape-seed cake, 283.

Rations, standard, 301.

Recknagel's phenomenon, 320.

Redonda phosphate, 144 .

"Refraction," valuation of $\mathrm{NaNO}_{3}$ by, 174.

Reickert-Wollny process, 356.

Relative abundance of elements, 15 .

Rennet, 274.

Rennin, 316.

Resenes, 205.

Resins, 205.

- the gum, 206.

- hard, 205.

Respiration in animals, 268.

- in plants, 233.

Respiratory processes of animals, 5 .

- quotient, 269.

Reversible reactions, 80.

Rhamnose, rhamnitol, 184, 185.

Ribose, 180, 184.

Rice, 239.

- bye-products of, 285.

- polish, 240, 285.

Ricin, 243.

Ricinoleic acid, 196.

Rock salt, 12, 38 .

Rocks, calcareous, 38 .

- classification of, 36 .

- igneous, 37.

- metamorphic, 38.

- sedimentary, 37.

Root crops, 246.

- hairs, acids in, 200.

- nodules in leguminous plants, 68 .

- pressure, 226.
Roots, 222.

Roquefort cheese, 340 .

Rosin, 205.

Rotation of crops, 258.

- systems of, 259.

Rust, 362.

Rye, 236.

- silage, 256.

Rye-grass, 256.

S.

Saccharates, 187.

Saccharobiose, 187.

Saccharomyces cerevisia, 185.

Saccharoses, 180.

- di-, 181, 186.

- mono-, 180, 184.

- poly-, 183, 188.

Safrol, 203.

Salicin, 195.

Salicylaldehyde, 204.

Salicylic acid, 204, 346, 354.

Saliva, 273.

Salt, common, as manure, 158.

- rock, 12, 38 .

Salts, inorganic, in plants, 206.

- potash, in manures, 153, 169.

"Salufer," 366.

Sambunigrin, 195, 215.

Sand, 12, 43.

- as soil constituent, 43.

Sandarach, 206.

Sandstones, 37.

"Sanitas," 367.

Santalene, 202.

Saponification equivalent, 356.

Sarcine, 271.

Sarcolactic acid, 271.

Sawdust as litter, 112.

Scales, thermometric, 377.

Scammonium, 206.

Scheele's green, 370 .

Schlosing's method for $\mathrm{NO}_{3}$ estimation, 94, 173.

Schœnife, picromerite, 154, 156.

Scleroproteins, 208.

"Screenings," 285.

"Scrub exterminator," 361.

Sea-weed, 125.

Sedentary soils, 39.

seeds, extraction of oil from, 198, 281.

- leguminous, 241.

- miscellaneous, 242.

Selenite, 11.

Semi-permeable membranes, 223.

Serine, 208.

Serpentine, 11.

Sesame cake, 283.

Sesquiterpenes, 202.

Shales, 37.

Shäps, 285.

Sheep, analysis of blood of, 126.

- excrement of, 108. 
Sheep, standard rations for, 302.

Shoddy manure, 127.

Shorts, 285.

Silage, 255.

- composition of, 257.

- "sour," 255.

- "sweet," 255.

Silica, estimation of, in soils, 88.

- in cereals, 234.

Silicates of magnesia, 36.

Silicon, 12.

- function of, in plants, 206.

- tetrafluoride, 146.

Silos, 255.

Sinalbin, 195.

Sinapine acid sulphate, 195.

Sinigrin, 195.

Sinter, 38.

Skatole, 276.

Skimmed milk, 336.

Slates, 38.

Smut, 362.

Soap, 197.

- as insecticide, 371.

- in the bile, 277.

Sodium, 10.

- bicarbonate as milk preservative, 346.

- borate, 10.

- function of, in plants, 207.

- hydrogen sulphate, 119.

- iodate, 133.

- nitrate $v$. Nitrate of soda.

Soft cheeses, 340 .

- corn, 238.

Soil analyses, examples of, 100:

- - interpretation of results of, 97.

- definition of, 34.

- gases in a, 71 .

- "-pans," 59.

- water in a, 57, 72 .

Soils, absorption and retention by, 52 .

- bacterial activity of, measurement of, 96.

- biology of, 60 .

- black, of Russia, 48.

- "brak," 32, 59.

- changes in inorganic matter of, 51.

- - in organic matter of, 60.

- chemical analysis of, 84 .

- _ - by Dyer's method, 91.

- - - - limitations of, 90.

- classification of, 49.

- colour of, 50.

- denitrification in, 69.

- distribution of dissolved substances in, 54 .

- formation of, 38.

- _ - action of air in, 41.

- - - - bacteria in, 43.

- - - - earthworms in, 41.

_ - _ - vegetation in, 42.

- - - - water in, 39.

- improvement of, 103.

- mechanical analysis of, 83.
Soils, nitrification in, 62.

- nitrogen-fixing organisms in, 66.

- odour of, 50.

- origin of, 38.

- proximate constituents of, 43.

- reactions occurring in, 51.

- sampling of, 82.

- sedentary, 39.

- sourness of, 46.

- toxic substances in, 49, 71.

- transported, 39.

Soja-bean, 163, 241.

Solanine, solanidine, 249.

Solid matter in air, 31.

Solubilities of various salts, 379 .

Soot as manure, 129.

Sorbitol, - 184, 186, 192.

Sorbose, 180, 186.

Sorghum, 240.

"Sour" silage, 255.

Sourness of soils, 46 .

Soy-bean cake, 28:3.

spathic iron ore, 11.

Spiegeleisen, 149.

Spinel, 54.

Spirilla, 61.

Stachyose, 183, 188.

Standard rations, 301.

Starch, amylum, 183, 188.

-- action of diastase on, 189.

- equivalent, 291.

- soluble, 188.

Stassfurt deposits, 153.

- composition of, 157.

Steapsin, 275.

Stearic acid, 196, 313.

Steatite 11, 36.

Steel, 148.

Stems, function of, 227.

- rigidity of, 225.

Sterilisation of milk, 344 .

Stickstoffkalk, 138.

Stilbite, 53.

Stilton cheese, 340 .

Stomata, 227.

Straw as litter, 111.

Straws, analyses of various, 111, 294.

"Strippings," "afterings," 329.

Stroma, muscle, 271.

Strychnine, 6, 214.

Succinic acid, 199.

Sucrose $v$. Cane-sugar.

Sugar-beet, 248.

Sugar, cane-, 182, 187.

- formation of, in plants, 231.

- milk- $v$. Lactose.

Sugars, pentose, 180, 184.

- non-reducing, 182.

- reducing, 181.

Sulphate, double, of magnesium and potassium, 156.

- of potash, 156.

- of ammonia $v$. Ammonium sulphate.

Sulphur, 9. 
Sulphur, as fungicide, 370 .

- as insecticide, 371.

- dioxide as disinfectant, 367.

- - in atmosphere, 29.

- function of, in plants, 206.

Sulphuric acid, application of, to manure heap, 119.

- - determination of, in soil, 93.

Sunflower-seed, 243.

- - cake, 283.

Superphosphate, application of, to manure heap, 119.

- " basic," 148.

- "double," 146.

- methods of expressing analysis of, $147,170$.

— " reverted," 146.

Superphosphates, mineral, 144.

Surface pressure, action of, in soil, 55 .

Swedes, 247.

Sweet corn, 238.

- potato, 216, 250.

- silage, 255.

Syenite, 37.

Sylvestrene, 202.

Sylvine, 154.

Sylvinic acid, 205.

Sylvinite, 156.

Symbiosis, 68 .

T.

Tagatose, 180.

Talbot's method of dephosphorising iron, 153.

Talc, 11, 36.

Talose, 180, 186.

Tanners' refuse as litter, 112.

Tannic acid, 199.

Tannin, 199, 200.

Tartaric acid, 199.

Tatlock's method for estimating potash, 89.

Taurine, 277.

Taurocholic acid, 277.

Tea, ash of, 14 .

- Paraguay $v$. Maté.

Terpenes, 201.

- olefinic, 202.

Terpineol, 202, 203.

Tetracalcium phosphate, 143.

Tetrasaccharoses, 183, 188.

Theine $v$. Caffeine.

Theobromine, 121, 214.

Thomas-Gilchrist process, 149.

Thomas phosphate $v$. Basic slag.

"Thomas phosphate meal," artificial, 152.

Thermometric scales, 377 .

Thymol, 203.

Timothy grass, 253.

Tissue, connective, 272.

- fatty, 271.

Titanium, 14.
Tobacco smoke as insecticide, 371.

Toxic substances in soils, 49,71 .

Transpiration, 221, 227, 232.

Trap, 37.

Travertine, 38.

Trefoil, 251.

Trehalose, 182, 187.

Tricalcium phosphate, 142.

Trigonelline, 212.

Trimethylamine, 115.

Trisaccharoses, 183, 187.

Triticin, 189.

Trypsin, 275.

Trypsinogen, 275.

Tryptophane, 209, 210, 239.

Tufa, 38.

Turanose, 181.

Turnips, 246.

Turpentine, 205.

Tyrosine, 114, 208.

- formation of, from proteids, 276.

\section{U.}

Ulmic acid, ulmin, 47.

Ulsch's method of $\mathrm{NO}_{3}$ determination, 174.

Unit value of foods, 308.

- - of various manures, 176.

Urea, 279.

- fermentation of, 115.

Uric acid, 214, 279.

- - in guano, 121.

Urine, 279.

- manurial value of, 110.

\section{V.}

Valine, 208.

"Vegetable alkali," 10.

Vegetation as agent in soil-formation, 42.

Velvet beans, 163, 241.

Vetches, 252, 258, 293.

Vinyl sulphide, 205.

Vrola calaminaria, 14.

"Viscose," 190.

Vitellin, 208.

Vivianite, 9.

"Volatile alkali," 10.

Volemitol, 192.

W.

Water as agent in soil-formation, 39.

- estimation of, in crops, 261.

- for irrigation purposes, 32.

- hot, as fungicide, 370.

— in a soil, 57,72 .

- ratio of, to dry matter, in rations, 306.

- table, 57.

Waxes, 198.

Weathering, 34. 
"Weende" method of crop analysis, 261. Xanthine, in urine, 279.

- - - - objections to, 262.

Wensleydale cheese, 340 .

Werner-Schmid method of fat estimation, 349.

Westphal balance, 351.

Wheat, 255.

- bye-products of, 284.

- straw, 111, 294.

Whey, 339.

- colloidal casein in, 315.

White arsenic $v$. Arsenious oxide.

Wiborgh phosphate, 153.

Willesden paper, 190.

Wolff's feeding standards, 301.

Wolters' phosphate, 152.

Wood creosote as disinfectant, 368 .

Woodruff, 255.

Woollen waste as manure, 127.

Wrought iron, manufacture of, 148.

$\mathrm{X}$.

Xanthates, 367.

Xanthine, 49, 121, 214.

- in muscle, 271.
Xanthophyll, 216.

Xanthoproteic reaction, 210.

Xenon in atmosphere, 22.

Xylan, 184.

Xylose, 180, 184.

- production of, from gums, 191.

Y.

Yeast, action of, on maltose, 187.

- influence of, on hexoses, 185.

Yeasts, action of, on organic matter in soils, 61 .

Z.

Zein, 210, 239.

Zeolites, 52.

Zeolitic silicates, 53.

Zinc, 14.

- blende, 14.

- chloride as disinfectant, 368.

Zingiberene, 202.

Zymogens, 274. 



\section{INSECTICIDES, FUNGICIDES}

\section{AND WEED KILLERS}

A PRACTICAL MANUAL ON THE DISEASES OF PLANTS AND THEIR REMEDIES

FOR THE USE OF MANUFACTURING CHEMISTS, AGRICULTURISTS ARBORICULTURISTS AND HORTICULTURISTS

BY

E. BOURCART, D.Sc.

TRANSLATED FROM THE FRENCH AND REVISED AND ADAPTED TO BRITISH STANDARDS AND PRACTICE

Demy 8vo 450 Pages

With 83 Tables and 12 Illustrations

Price 12s. 6d. net (Post free, 13s. Home; 13s. 6d. Abroad)

Send for Circular, giving full list of Contents, post free on application to S C O T T, GRE E N W O O D \& S O N 8 BROADWAY, LUDGATE, LONDON, E.C. 


\title{
THE MANUFACTURE OF
}

\section{CHEMICAL MANURES}

BY

\section{J. FRITSCH}

TRANSLATED FROM THE FRENCH. WITH NUMEROUS NOTES

\author{
Demy 8vo 350 Pages \\ 69 Illustrations and 108 Tables
}

\section{PRESS OPINIONS}

"The author has placed before us a very readable dissertation on the Manufacture of Chemical Manures. ... The volume is a veritable mine of information and eminently worthy of perusal."-Irish Farming World.

"A book of vital interest to farmers."-Agricultural Gazette.

"The volume is quite unique in its way, and will be found exceedingly interesting by the earnest student of Agricultural Chemistry."-Aberdeen Free Press.

"Manure manufacturers, farmers and agricultural students alike have to thank the author for a work which places at their disposal a vast mass of scientific material, well arranged for study and reference."-Worcester Herald.

Price 10s. 6d. net (Post free, 11s. Home; 11s. 6d. Abroad)

Published by

SCOT T, GREEN W O O \& S O N

8 BROADWAY, LUDGATE, LONDON, E.C. 


\section{Etbrídged Catalogue}

\section{Special Teefnical Books.}

INDEX TO SUBJECTS.

\begin{tabular}{|c|c|c|c|c|c|}
\hline & GE & & PAGE & & \\
\hline & 10 & Mglaving ä & & ottery Clays & \\
\hline lemistry & & Oil & $\ldots 7$ & ryy & \\
\hline Use of & ... 10 & Evaporating Apparatus & ... 19 & Pottery Ma & \\
\hline & & xternal Plumbing & ... 20 & Pottery Marks ... & \\
\hline$m$ and its Sulphates & ... 8 & Fats $\ldots$ & 6,7 & Power-loom Weaving & \\
\hline onia & & Faults in Woollen Goo & ds 15 & Preserved Foods ... & \\
\hline ine Colours & ... 3 & Flax Spinning $\quad$... & ... 18 & Printers' Ready Reck & \\
\hline al Fats & & Food and Drugs & ... 22 & Printing Inks & \\
\hline rrosive Paints & $\ldots 4$ & Foundry Machinery & ... 2 & Recipes & \\
\hline Terms in & & & & Reinforced Concrete & \\
\hline al Pottery & ... 12 & il Engines & ... 19 & & \\
\hline hting ... & & & ... 19 & rame & \\
\hline erfumes & $\ldots 7$ & ing Recipes & $\ldots 13$ & ions & \\
\hline$\ldots \quad \ldots$ & & ting & ... 13 & etc. & \\
\hline g Agents, etc. & ... 17 & ng and Testi & $3 .$. & lys ... & \\
\hline ducts $\quad \ldots$ & ... 8 & Gre & ... & & \\
\hline ... & & , & & Tars & \\
\hline ... & 11,12 & acturing & & s $\quad \ldots$ & \\
\hline Brass ... & & & & & \\
\hline irn Printing & ... 16 & Staffs Potteri & ies & , etc. & \\
\hline$\cdots$ & $\ldots$ & & & ation... & \\
\hline oid & & Supply & & ders $\quad .$. & \\
\hline Ponto & $\because 22$ & er... & & & \\
\hline Books & 11,12 & er Substitut & & $\mathbf{S}$ & \\
\hline$\cdots$ & $\ldots$ & $\ldots$ & 4,5 & arnishes & \\
\hline is... & ... & & & Marble, & \\
\hline Essays ... & & ion & & Soaps & \\
\hline Reagents & & ce of ... & ... 19 & ... & \\
\hline Works ... & & teel Work & & 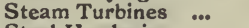 & \\
\hline ... & $\because 12$ & & & & \\
\hline Firing ... & & ing & & $\log y$ & \\
\hline covery Wo & (ia.) 1 & $\mathrm{ng}$ & & $\mathbf{S}$ & \\
\hline (Tex & & ... & & & \\
\hline for Dye & s... 1 & gments & & Lis & \\
\hline ... & $\ldots 3$ & ... & & ... & \\
\hline & ... 16 & workin & & teris & \\
\hline & $\ldots 1$ & $\ldots$ & $\ldots$ & $\cdots$ & \\
\hline s, etc. & & & & $\cdots$ & \\
\hline ratus & $\cdots$ & hic Inks ... & & ... & \\
\hline$\because \quad \cdots$ & $\ldots$ & $\begin{array}{l}\text { hy } \\
\text { s ... }\end{array}$ & 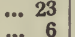 & Materials ... & \\
\hline $\begin{array}{ll}\text { ng } & \ldots \\
\text { ning } & \ldots\end{array}$ & $\begin{array}{l}\ldots 17 \\
\ldots 17\end{array}$ & $\begin{array}{ll}\text { nts } & \ldots \\
\text { s } & \ldots\end{array}$ & $\cdots 8,9$ & making & \\
\hline $\operatorname{mon}_{8}$ & $\ldots 18$ & eserving ... & $\ldots 23$ & ring & $\ldots$ \\
\hline Joists & & Soaps ... & & & \\
\hline & & Soap & & & \\
\hline dings & & ats ... & ... & ving & \\
\hline & & axes & $\cdots$ & & \\
\hline & ... & ation ... & $\ldots$ & & \\
\hline llurgy... & $\cdots$ & 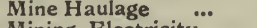 & $\ldots$ & $\mathbf{Y}>$ & \\
\hline on & $\cdots$ & & & ofing Fabric & \\
\hline ... & & hanism & ... 20 & & \\
\hline$x^{2}+2$ & ... 22 & k... & & & \\
\hline A & & our Recipes & ... & Zinc & \\
\hline A & ... 10 & & & ons & \\
\hline & & & & & \\
\hline Hat & s... 1 & hants' Manual & & W & \\
\hline rials & $\cdots$ & & & W & \\
\hline$s$ and Oils & $\begin{aligned} \ldots & 17 \\
\ldots & 7\end{aligned}$ & $\begin{array}{l}\mathrm{O} \\
\mathrm{P} \text {. }\end{array}$ & & V & \\
\hline Lamp Develo & & & & ds & \\
\hline & & al Test & & $\cdots$ & \\
\hline & & & & & \\
\hline (1) & & & & $\cdots$ & \\
\hline & & & & n & cot \\
\hline & & & & & \\
\hline $\mathrm{g} \mathrm{Ha}$ & & Plumbers' Books ... & & Zinc White Paints & \\
\hline
\end{tabular}




\title{
FULL PARTICULARS OF CONTENTS
}

\author{
Of the Books mentioned in this ABRIDGED CATALCqUE
}

will be found in the following Catalogues of

\section{CURRENT TECHNICAL BOOKS.}

\begin{abstract}
LIST I.
Artists' Colours-Bone Products-Butter and Margarine Manufacture-CaseinCements-Chemical Works (Designing and Erection)-Chemistry (Agricultural, Industrial, Practical and Theoretical)-Colour Mixing-Colour Manufacture-Compounding Oils-Decorating-Driers-Drying Oils-Drysaltery-Emery-Essential Oils - Fats (Animal, Vegetable, Edible)-Gelatines - Glues - Greases - Gums - Inks - LeadLeather - Lubricants - Oils - Oil Crushing - Paints - Paint Mauufacturing - Paint Material Testing-Perfumes-Petroleum-Pharmacy-Recipes (Paint, Oil and Colour - Resins-Sealing Waxes-Shoe Polishes - Soap Manufacture - Solvents - Spirit Varnishes-Varnishes-White Lead-Workshop Wrinkles.
\end{abstract}

\section{LIST II.}

Bleaching - Bookbinding - Carpet Yarn Printing - Colour (Matching, Mixing Theory)-Cotton Combing Machines-Dyeing (Cotton, Woollen and Silk Goods) Dyers' Materials-Dye-stuffs-Engraving-Flax, Hemp and Jute Spinning and Twisting -Gutta-Percha - Hat Manufacturing - India-rubber - Inks - Lace-making - Lithography-Needlework-Paper Making - Paper-Mill Chemist - Paper-pulp Dyeing Point Lace-Power-loom Weaving-Printing Inks-Silk Throwing-Smoke Prevention-Soaps-Spinning-Textile (Spinning, Designing, Dyeing, Weaving, Finishing -Textile Materials-Textile Fabrics-Textile Fibres-Textile Oils-Textile SoapsTimber-Water (Industrial Uses)-Water-proofing-Weaving-Writing Inks-Yarns Testing, Sizing).

\section{LIST III.}

Architectural Terms-Brassware (Bronzing, Burnishing, Dipping, Lacquering)Brickmaking-Building-Cement Work-Ceramic Industries-China-Coal-dust Firing -Colliery Books-Concrete-Condensing Apparatus-Dental Metallurgy-DrainageDrugs-Dyeing-Earthenware-Electrical Books-Enamelling-Enamels-Engineering Handbooks-Evaporating Apparatus-Flint Glass-making-Foods-Food Preserving-Fruit Preserving-Gas Engines-Gas Firing-Gearing-Glassware (Painting, Riveting)-Hops-Iron (Construction, Science)-Japanning-Lead-Meat Preserving -Mines (Haulage, Blectrical Equipment, Ventilation, Recovery Work from)-Plants (Diseases, Fungicides, Insecticides)-Plumbing Books-Pottery (Architectural, Clays, Decorating, Manufacture, Marks on) - Reinforced Concrete - Riveting (China, Barthenware, Glassware)-Sanitary Engineering-Steam Turbines-Steel (Hardening, Tempering)-Sugar-Sweetmeats-Toothed Gearing-Vegetable Preserving - Wood Dyeing-X-Ray Work.

\section{COPIES OF ANY OF THESE LISTS WILL BE SENT POST FREE ON APPLICATION.}




\section{(Paints, Colours, Pigments and Printing Inks.)}

THE CHEMISTRY OF PIGMENTS. By ERNEST J. PARRY, B.Sc. (Lond.), F.I.C., F.C.S., and J. H. Coste, F.I.C., F.C.S. Demy 8vo. Five lllustrations. 285 pp. Price 10s. 6d. net. (Post free, 10s. 10d. home; 11s. 3d. abroad.)

THE MANUFACTURE OF PAINT. A Practical Handbook for Paint Manufacturers, Merchants and Painters. By J. Cruickshank Smith, B.Sc. Demy 8vo.

[New Edition in Preparation.

DICTIONARY OF CHEMICALS AND RAW PRODUCTS USED IN THE MANUFACTURE OF PAINTS, COLOURS, VARNISHES AND ALLIED PREPARATIONS. By GEORGE H. HURST, F.C.S. Demy 8vo. 380 pp. Price 7s. 6d. net. (Post free, 8s. home; 8s. 6d. abroad.)

THE MANUFACTURE OF LAKE PIGMENTS FROM ARTIFICIAL COLOURS. By FRANCIS H. Jennison, F.I.C., F.C.S. Sixteen Coloured Plates, showing Specimens of Eighty-nine Colours, specially prepared from the Recipes given in the Book. $136 \mathrm{pp}$. Demy 8vo. Price 7s. 6d. net. (Post free, 7s. 10d. home; 8s. abroad.)

THE MANUFACTURE OF MINERAL AND LAKE PIGMENTS. Containing Directions for the Manufacture of all Artificial, Artists and Painters' Colours, Enamel, Soot and Metallic Pigments. A text-book for Manufacturers, Merchants, Artists and Painters. By Dr. JoSEp BERSCr. Translated by A. C. WRight, M.A. (Oxon.), B.Sc. (Lond.). Fortythree Illustrations. $476 \mathrm{pp}$. Demy 8vo. Price 12s. 6d. net. (Post free, 13s. home; 13s. 6d. abroad.)

RECIPES FOR THE COLOUR, PAINT, VARNISH, OIL, SOAP AND DRYSALTERY TRADES. Compiled by An Analytical Chemist. 330 pp. Second Revised and Enlarged Edition. Demy 8vo. Price 10s. 6d. net. (Post free, 11s. home ; 11s. 3d. abroad.)

OILMEN'S SUNDRIES AND HOW TO MAKE THEM.

Being a Collection of Practical Recipes for Boot Polishes, Blues, Metal Polishes, Disinfectants, etc., compiled from "Oils, Colours and Drysalteries". Crown 8vo. 130 pages. Price $2 \mathrm{~s} .6 \mathrm{~d}$. net. (Post free, 2s. 9d. home; 2s. 10d. abroad.)

OIL COLOURS AND PRINTERS' INKS. By Lows Edgar ANDÉs. Translated from the German. $215 \mathrm{pp}$. Crown 8 vo. 56 Illustrations. Price 5s. net. (Post free, 5s. 4d. home ; 5s. 6d. abroad.) 
MODERN PRINTING INKS. A Practical Handbook for Printing Ink Manufacturers and Printers. By ALPRED SEYMour. Demy 8 vo. Six Illustrations. 90 pages. Price $5 \mathrm{~s}$. net. (Post free, 5s. 4d. home ; 5s. 6d. abroad.)

\section{THREE HUNDRED SHADES AND HOW TO MIX} THEM. For Architects, Painters and Decorators. By A. Desaint, Artistic Interior Decorator of Paris. The book contains 100 folio Plates, measuring 12 in. by 7 in., each Plate containing specimens of three artistic shades. These shades are all numbered, and their composition and particulars for mixing are fully given at the beginning of the book. Each Plate is interleaved with grease-proof paper, and the volume is very artistically bound in art and linen with the Shield of the Painters' Guild impressed on the cover in gold and silver. Price 21s. net. (Post free, 21s. 6d. home; 22s. 6d. abroad.)

HOUSE DECORATING AND PAINTING. By W. NORMAN BROwn. Eighty-eight Illustrations. $150 \mathrm{pp}$. Crown 8vo. Price 3s. 6d. net. (Post free, 3s. 9d. home and abroad.)

A HISTORY OF DECORATIVE ART. By W. NORMAN Brown. Thirty-nine Illustrations. $96 \mathrm{pp}$. Crown 8vo. Price 18. net. (Post free, 18. 3d. home and abroad.)

WORKSHOP WRINKLES for Decorators, Painters, Paperhangers, and Others. By W. N. Brown. Crown 8vo. 128 pp. Second Edition. Price 2s. 6d. net. (Post free, 2s. 9d. home; 2s. 10d. abroad.)

CASEIN. By Robert Scherer. Translated from the German by СнаS. Salter. Demy 8vo. Illustrated. Second Revised English Edition. 160 pp. Price 7s. 6d. net. (Post free, 7s. 10d. home; 8s. abroad.)

SIMPLE METHODS FOR TESTING PAINTERS' MATERIALS. By A. C. Wright, M.A. (Oxon.), B.Sc. (Lond.). Crown 8 vo. 160 pp. Price 5s. net. (Post free, 5s. 3d. home; 5s. 6d. abroad.)

IRON-CORROSION, ANTI-FOULING AND ANTICORROSIVE PAINTS. Translated from the German of Louis Edgar ANDÉs. Sixty-two Illustrations. $275 \mathrm{pp}$. Demy 8vo. Price 10s. 6d. net. (Post free, 10s. 10d. home; 11s. 3d. abroad.)

THE TESTING AND VALUATION OF RAW MATERIALS USED IN PAINT AND COLOUR MANUFACTURE. By M. W. JONES, F.C.S. A Book for the Laboratories of Colour Works. 88 pp. Crown $8 v o$. Price 5s. net. (Post free, 5s. 3d. home and abroad.) 
THE MANUFACTURE AND COMPARATIVF MERITS OF WHITE LEAD AND ZINC WHITH PAINTS. By G. Petit, Civil Engineer, etc. Translated from the French. Crown $8 v 0.100 \mathrm{pp}$. Price 4s. net.

(Post free, 4s. 3d. home ; 4s. 4d. abroad.)

STUDENTS' HANDBOOK OF PAINTS, COLOURS, OILS AND VARNISHES. By JOHN FURNELL. Crown 8vo. 12 Illustrations. 96 pp. Price 2s. 6d. net. (Post free, 2 s. 9d. home and abroad.)

PREPARATION AND USES OF WHITE ZINC IPAINTS. Translated from the French of P. Fleury. Crown 8vo. 280 pages. Price 6s. net. (Post free, 6s. 4d. home; 6s. 6d. abroad.)

\section{(Varnishes and Drying Oils.)}

THE MANUFACTURE OF VARNISHES AND KINDRED INDUSTRIES. By J. GedDES McINTOSH. Second, greatly enlarged, English Edition, in three Volumes, based on and including the work of Ach. Livache.!

Volume I.-OIL CRUSHING, REFINING AND BOILING, THE MANUFACTURE OF LINOLEUM, PRINTING AND LITHOGRAPHIC INKS, AND INDIA-RUBBER SUBSTITUTES. Demy 8vo. 150 pp. 29 Illustrations. Price 7s. 6d. net. (Post free, 7s. 10d. home; 8s. abroad.)

VOLUME II.-VARNISH MATERIALS AND OILVARNISH MAKING. Demy 8vo. 70 Illustrations. 220 pp. Price 10s. 61. net. (Post free, 10s. 10d. home; 11s. 3d. abroad.)

VOLUME III.-SPIRIT VARNISHES AND SPIRIT VARNISH MATERIALS. Demy 8vo. Illustrated. 464 pp. Price 12s. 6d. net. abroad.)

DRYING OILS, BOILED OIL AND SOLID AND IIQUID DRIERS. By L. E. ANDÉs. Expressly Written for this Series of Special Technical Books, and the Publishers hold the Copyright for English and Foreign Editions. Forty-two Illustrations. $342 \mathrm{pp}$. Demy 8vo. Price 12s. 6d. net. (Post free, 13s. home; 13s. 3d. abroad.)

(Analysis of Resins, see page 9.) 


\section{(Oils, Fats, Waxes, Greases, Petroleum.)}

\section{LUBRICATING OILS, FATS AND GREASES :}

Their Origin, Preparation, Properties, Uses and Analyses. A Handbook for Oil Manufacturers, Refiners and Merchants, and the Oil and Fat Industry in General. By GeORge H. HURST, F.C.S. Third Revised and Enlarged Edition. Seventy-four Illustrations. 384 pp. Demy 8vo. Price 10s. 6d. net. (Post free, 11s. home ; $11 \mathrm{~s}$. $3 \mathrm{~d}$. abroad.)

TECHNOLOGY OF PETROLEUM : Oil Fields of the World-Their History, Geography and Geology-Annual Pro. duction and Development-Oil-well Drilling-Transport. By Henry Neuberger and Henry Noalhat. Translated from the French by J. G. McIntosh. 550 pp. 153 Illustrations. 26 Plates. Super Royal 8vo. Price 21s. net. (Post free, 21s. 9d. home; 23s. 6d. abroad.)

MINERAL WAXES: Their Preparation and Uses. By RUDOLF Gregorius. Translated from the German. Crown 8vo. $250 \mathrm{pp}$. 32 Illustrations. Price 6s. net. (Post free, 6s. 4d. home ; 6s. 6d. abroad.)

THE PRACTICAL COMPOUNDING OF OILS, TALLOW AND GREASE FOR LUBRICATION, ETC. By An Expert Oil Refiner. Second Edition. 100 pp. Demy 8vo. Price 7s. 6d. net. (Post free, 7s. 10d. home; 8s. abroad.)

\section{THE MANUFACTURE OF LUBRICANTS, SHOE} POLISHES AND LEATHER DRESSINGS. By Richard Brunner. Translated from the Sixth German Edition by Chas. Salter. 10 Illustrations. Crown 8 vo. $170 \mathrm{pp}$. Price 7s. 6d. net. (Post free, 7s. 10d. home; 8s. abroad.)

\section{THE OIL MERCHANTS' MANUAL AND OIL} TRADE READY RECKONER. Compiled by FRANK F. SHERRIFF. Second Edition Revised and Enlarged. Demy 8 vo. 214 pp. With Two Sheets of Tables. Price 7s. 6d. net. (Post free, 7s. 10d. home; 8s. 3d. abroad.)

ANIMAL FATS AND OILS: Their Practical Production, Puriflcation and Uses for a great Variety of Purposes. Their Properties, Falsification and Examination. Translated from the German of LouIs EdGAR ANDÉs. Sixty-two Illustrations. 240 pp. Second Edition, Revised and Enlarged. Demy 8vo. Price 10s. 6d. net. (Post free, 10s. 10d. home ; 11s. 3d. abroad.) 
VEGETABLE FATS AND OILS: Their Practical Preparation, Purification and Employment for Various Purposes, their Properties, Adulteration and Examination. Translated from the German of Lours EDGAR ANDÉs. Ninety-four Illustrations. 340 pp. Second Edition. Demy 8vo. Price 10s.6d. net. (Post free, 11s. home; 11s. 6d. abroad.)

EDIBLE FATS AND OILS: Their Composition, Manufacture and Analysis. By W. H. Sim mons, B.Sc. (Lond.), and C. A. Mrtchell, B.A. (Oxon.). Demy 8 vo. 150 pp. Price 7s. 6d. net. (Post free, 7s. 9d. home; 8s. abroad.)

\section{(Essential Oils and Perfumes.)}

THE CHEMISTRY OF ESSENTIAL OILS AND ARTIFICIAL PERFUMES. By ERNEST J. PARRY, B.Sc. (Lond.), F.I.C., F.C.S. Second Edition, Revised and Enlarged. 552 pp. 20 lllustrations. Demy 8vo. Price 12s. 6d. net. (Post free, 13s. home; 13s. 6d. abroad.)

\section{(Soap Manufacture.)}

SOAPS. A Practical Manual of the Manufacture of Domestic, Toilet and other Soaps. By GEORGE H. HURST, F.C.S. 2nd edition. 390 pp. 66 Illustrations. Demy 8vo. Price 12s. 6d. tuet. (Post free, 13s. home; 13s. 6d. abroad.)

TEXTILE SOAPS AND OILS. Handbook on the Preparation, Properties and Analysis of the Soaps and Oils used in Textile Manufacturing, Dyeing and Printing. By Georg B H. Hurst, F.C.S. Crown 8vo. 195 pp. Price 5s. net. (Post free, $5 \mathrm{~s}$. 4d. home; $5 \mathrm{~s}$. $6 \mathrm{~d}$. abroad.)

THE HANDBOOK OF SOAP MANUFACTURE, By Wm. H. Simmons, B.Sc. (Lond.), F.C.S. and H. A. Appleton. Demy 8vo. 160 pp. 27 Illustrations. Price 8s. 6d. net. (Post free, 8 s. 10d. home ; 9s. abroad.)

MANUAL OF TOILET SOAPMAKING, including Medicated Soaps, Stain-removing Soaps, Metal Polishing Soaps, Soap Powders and Detergents. Translated from the German of Dr. C. Deite. Demy quarto. 150 pages. 79 Illustrations. Price 12s. 6d. net. (Post free, 13s. home; 13s. 6d. abroad.)

\section{(Cosmetical Preparations.)}

COSMETICS : MANUFACTURE, EMPLOYMENT AND TESTING OF ALL COSMETIC MATERIALS AND COSMETIC SPECIALITIES. Translated from the German of Dr. THEODOR Koller. Crown 8vo. 262 pp. Price 5s. net. (Post free, 5s. 4d. home; 5s. 6d. abroad.) 


\section{(Glue, Bone Products and Manures.)}

GLUE AND GLUE TESTING. By Samuel Rideal, D.Sc. (Lond.), F.I.C. Fourteen Engravings. 144 pp. Demy 8vo. Price 10s.6d. net. (Post free, 10s. 10d. home; 11s. abroad.)

BONE PRODUCTS AND MANURES: An Account of the most recent Improvements in the Manufacture of Fat, Glue, Animal Charcoal, Size, Gelatine and Manures. By Thomas LAMBERT, Technical and Consulting Chemist. Second Revised Edition. Demy 8vo. 172 pages. 17 Illustrations. Price 7s. 6d. net. (Post free, 7s. 10d. home ; 8s. abroad.)

(See also Chemical Manures, p. 9.)

\section{(Chemicals, Waste Products, etc.)}

REISSUE OF CHEMICAL ESSAYS OF C. W. SCHEELE. First Published in English in 1786. Translated from the Academy of Sciences at Stockholm, with Additions. 300 pp. Demy 8vo. Price 5s. net. (Post free, 5s. 6d. home; 5 s. 9d. abroad.)

THE MANUFACTURE OF ALUM AND THE SULPHATES AND OTHER SALTS OF ALUMINA AND IRON. Their Uses and Applications as Mordants in Dyeing and Calico Printing, and their other Applications in the Arts Manufactures, Sanitary Engineering, Agriculture and Horticulture. Translated from the French of LUCIEN GESCHWIND. 195 Illustrations. $400 \mathrm{pp}$. Royal 8vo. Price 12s. 6d. net. (Post free, 13s. home; 13s. 6d. abroad.)

AMMONIA AND ITS COMPOUNDS: Their Manufacture and Uses. By CAMille Vincent, Professor at the Central School of Arts and Manufactures, Paris. Translated from the French by M. J. Salter. Royal 8vo. 114 pp. Thirtytwo Illustrations. Price 5s. net. (Post free, 5s. 4d. home; 5s. 6d. abroad.)

CHEMICAL WORKS: Their Design, Erection, and Equipment. By S. S. Dyson and S. S. Clarison. Royal 8 vo. $220 \mathrm{pp}$. With 9 Folding Plates and 80 Illustrations. Price $21 \mathrm{~s}$. net. (Post free, 21s. 6d. home; 22s. abroad.)

MANUAL OF CHEMICAL ANALYSIS, as applied to the Assay of Fuels, Ores, Metals, Alloys, Salts and other Mineral Products. By E. Prost, D.Sc. Translated by J. Cruickshank Smith, B.Sc. Royal 8vo. 300 pages. 44 Illustrations. Price 12s. 6d. net. (Post free, 13s. home; 13s. 6d. abroad.)

TESTING OF CHEMICAL REAGENTS FOR PURITY. Translated from the German of Dr. C Krauch. Royal 8vo. 350 pages. Price 12s. 6d. net. (Post free 13s. home ; 13s. 6d. abroad.) 
SHALE OILS AND TARS and their Products. By Dr. W. Scheithauer. Translated from the German. Demy 8vo. 190 pages. 70 Illustrations and 4 Diagrams. Price $8 \mathrm{~s}$. 6d. net. (Post free, 8s. 10d. home; 9s. abroad).

[Fust published.

INDUSTRIAL ALCOHOL. A Practical Manual on the Production and Use of Alcohol for Industrial Purposes and for Use as a Heating Agent, as an Illuminant and as a Source of Motive Power. By J. G. McInTosh, Lecturer on Manufacture and Applications of Industrial Alcohol at The Polytechnic, Regent Street, London. Demy 8vo. 1907. 250 pp. With 75 Illustrations and 25 Tables. Price 7s. 6d. net. (Post free, 7s. 9d. home; 8s. abroad.)

THE UTILISATION OF WASTE PRODUCTS. A Treatise on the Rational Utilisation, Recovery and Treatment of Waste Products of all kinds. By Dr. THEODOR KOLLER. Translated from the Second Revised German Edition. Twenty-two Illustrations. Demy 8vo. 280 pp. Price 7s. 6d. net. (Post free, 7s. 10d. home ; 8s. 3d. abroad.)

ANALYSIS OF RESINS AND BALSAMS. Translated from the German of Dr. KARL Dieterich. Demy 8vo. 340 pp. Price 7s. 6d. net. (Post free, 7s. 10d. home; 8s. 3d. abroad.)

DISTILLATION OF RESINS, RESINATE LAKES AND PIGMENTS, CARBON PIGMENTS AND PIGMENTS FOR TYPEWRITING MACHINES, MANIFOLDERS, ETC. By Victor SchwBizer. Demy 8vo. 185 pages. 68 Illustrations. Price 7s. 6d. net. (Post free, $8 \mathrm{~s}$. home ; 8s. 3d. abroad.)

DISINFECTION AND DISINFECTANTS. By M. Christian. Translated from the German. Crown 8vo. 112 pages. 18 Illustrations. Price 5s. net. (Post free, 5s. 3d. home ; 5s. 6d. abroad.)

[Fust published.

\section{(Agricultural Chemistry and Manures.)}

MANUAL OF AGRICULTURAL CHEMISTRY. By Herbert INGLE, F.I.C., Late Lecturer on Agricultural Chemistry, the Leeds University; Lecturer in the Victoria University. Third and Revised Edition. 400 pp. 16 Illustrations. Demy 8vo. Price 7s. 6d. net. (Post free, 8s. home; 8s. 6d. abroad.)

CHEMICAL MANURES. Translated from the French of J. Fritsch. Demy 8vo. Illustrated. 340 pp. Price 10s.6d. net. (Post free, 11s. home; 11s. 6d. abroad.)

(See also Bone Products and Manures, p. 8.)

\section{(Writing Inks and Sealing Waxes.)}

INK MANUFACTURE: Including Writing, Copying, Lithographic, Marking, Stamping, and Laundry Inks. By Sigmund LeHner. Three Illustrations. Crown 8vo. 162!pp. Translated from the German of the Fifth Edition, Price 5s, net, (Post free, 5s. 3d. home ; 5s. 6d. abroad.) 
SEALING - WAXES, WAFERS AND OTHER ADHESIVES FOR THE HOUSEHOLD, OFFICE, WORKSHOP AND FACTORY. By H.C. STANDAGE. Crown 8vo. 96 pp. Price 5s. net. (Post free, 5s. 3d. home; 5s. 4 d. abroad.)

\section{(Lead Ores and Lead Compounds.)}

LEAD AND ITS COIMPOUNDS. By Thos. LAMBERT, Technical and Consulting Chemist. Demy 8vo. 226 pp. Forty Illustrations. Price 7s. 6d. net. (Post free, 7s. 10d. home; 8s. 3d. abroad.)

NOTES ON LEAD ORES: Their Distribution and Properties. By Jas. FaIRIe, F.G.S. Crown 8vo. 64 pages. Price 1s. net. (Post free, 1s. 3d. home ; 1s. 4d. abroad.)

(White Lead and Zinc White Paints, see p. 5.)

\section{(Industrial Hygiene.)}

THE RISKS AND DANGERS TO HEALTH OF VARIOUS OCCUPATIONS AND THEIR PREVENTION. By Lbonard A. ParRy, M.D., B.Sc. (Lond.). 196 pp. Demy 8vo. Price 7s. 6d. net. (Post free, 7s. 10d. home; 8s. abroad.)

\section{(Industrial Uses of Air, Steam and Water.)}

DRYING BY MEANS OF AIR AND STEAM. Explanations, Formulæ, and Tables for Use in Practice. Translated from the German of E. Hausbrand. Second Revised English Edition. Two folding Diagrams, Thirteen Tables, and Two Illustrations. Crown 8vo. $76 \mathrm{pp}$. Price 5s. net. (Post free, $5 \mathrm{~s}$. 3d. home; $5 \mathrm{~s}$. $6 \mathrm{~d}$. abroad.)

(See also "Evaporating, Condensing and Cooling Apparatus," p. 19.)

PURE AIR, OZONE AND WATER. A Practical Treatise of their Utilisation and Value in Oil, Grease, Soap, Paint, Glue and other Industries. By W. B. Cowbl. Twelve Illustrations. Crown 8vo. 85 pp. Price 5s, net. (Post free, 5s. 3d. home; 5s. 6d.abroad.)

THE INDUSTRIAL USES OF WATER. COMPOSITION-EFFECTS-TROUBLES - REMEDIES RESIDUARY WATERS-PURIFICATION-ANALYSIS. By H. DE LA Coux. Royal 8vo. Translated from the French and Revised by ARTHUR MORRIS. 364 pp. 135 Illustrations. Price 10s. 6d. net. (Post free, 11s. home; 118. 6d. abroad.)

(Sec Books on Smoke Prevention, Engineering and Metallurgy, p. 19, etc.)

For contents of these books, see List III. 


\section{1 \\ (X Rays.)}

PRACTICAL X RAY WORK. By Frank T. AdDYMaN, B.Sc. (Lond.), F.I.C., Member of the Roentgen Society of London; Radiographer to St. George's Hospital; Demonstrator of Physics and Chemistry, and Teacher of Radiography in St. George's Hospital Medical School. Demy 8vo. Twelve Plates from Photographs of X Ray Work. Fifty-two Illustrations. 200 pp. Price 10s. 6d. net. (Post free, 10s. 10d. home; 11s. 3d. abroad.)

\section{(India=Rubber and Gutta Percha.)}

INDIA-RUBBER AND GUTTA PERCHA. Second English Edition, Revised and Enlarged. Based on the French work of T. Seeligmani, G. Lamy Torrilhon and H. Falconnet by John Geddes McIntosh. Royal 8vo. 100 Illustrations. 400 pages. Price 12s. 6d. net. (Post free, 13s. home; 13s. 6d. abroad.)

\section{(Leather Trades.)}

THE LEATHER WORKER'S MANUAL. Being a Compendium of Practical Recipes and Working Formulæ for Curriers, Bootmakers, Leather Dressers, Blacking Manufacturers, Saddlers, Fancy Leather Workers. By H. C. StandaOE. Demy 8vo. 165 pp. Price 7s. 6d. net. (Post free, 7s. 10d. home; 8s. abroad.)

(See also Manufacture of Shoe Polishes, Leather Dressings, etc., p. 6.)

\section{(Pottery, Bricks, Tiles, Glass, etc.)}

MODERN BRICKMAKING. By Alfred B. Searle, Royal 8vo. 440 pages. 260 Illustrations. Price 12s. 6d. net. (Post free, 13s. home; 13s. 6d. abroad.)

THE MANUAL OF PRACTICAL POTIING. Compiled by Experts, and Edited by CHAS. F. Binss. Fourth Edition, Revised and Enlarged. 200 pp. Demy 8vo. Price 17s. 6d. net. (Post free, 17s. 10d. home; 18s. 3d. abroad.)

POTTERY DECORATING. A Description of all the Processes for Decorating Pottery and Porcelain. By R. Hainbach. Translated from the German. Crown 8vo. 250 pp. Twentytwo Illustrations. Price 7s. 6d. net. (Post free, 7s. 10d. home; 8s. abroad.)

A TREATISE ON CERAMIC INDUSTRIES. A Complete Manual for Pottery, Tile, and Brick Manufacturers. By EMILE BOURRY. A Revised Translation from the French, with some Critical Notes by Alpred B. Searle. Demy 8vo. 308 Illustrations. 460 pp. Price 12s.6d. net. (Post free, 13s. home; 13s. 6d. abroad.) 
ARChItECTURAL POTTERY. Bricks, Tiles, Pipes, Enamelled Terra-cottas, Ordinary and Incrusted Quarries, Stoneware Mosaics, Faiences and Architectural Stoneware. By LEON LEFÊVRE. Translated from the French by K. H. BIRD, M.A., and W. Moore Binss. With Five Plates. 950 Illustrations in the Text, and numerous estimates. 500 pp. Royal 8vo. Price 15s. net. (Post free, 15s. 6d. home; 16s. 6d. abroad.)

CERAMIC TECHNOLOGY: Being some Aspects of Technical Science as Applied to Pottery Manufacture. Edited by Charles F. Binns. 100 pp. Demy 8vo. Price 12s. 6d. net. (Post free, 12s. 10d. home; 13s. abroad.)

THE ART OF RIVETING GLASS, CHINA AND EARTHENWARE. By J. HoworTH. Second Edition. Paper Cover. Price 1s. net. (By post, home or abroad, 1s. 1d.)

CLAY ANALYSIS AND CLAY TESTING. By A. B. SEARLE.

[In preparation.

NOTES ON POTTERY CLAYS. The Distribution, Properties, Uses and Analyses of Ball Clays, China Clays and China Stone. By Jas. FaIRIe, F.G.S. 132 pp. Crown 8 vo. Price 3s. 6d. net. (Post free, 3s. 9d. home; 3s. 10d. abroad.)

HOW TO ANALYSE CLAY. By H. M. Ashby. Demy 8vo. 72 pp. 20 Illustrations. Price 3s. 6d. net. (Post free, 3s. 9d. home ; 3s. 10d. abroad.)

\section{A Reissue of}

THE HISTORY OF THE STAFFORDSHIRE POTTERIES; AND THE RISE AND PROGRESS OF THE MANUFACTURE OF POTTERY AND PORCELAIN. With References to Genuine Specimens, and Notices of Eminent Potters. By Simeon Shaw. (Originally published in 1829.) $265 \mathrm{pp}$. Demy 8vo. Price 5s. net. (Post free, 5s. $4 \mathrm{~d}$. home; $5 \mathrm{~s}$. $9 \mathrm{~d}$. abroad.)

\section{A Reissue of}

THE CHEMISTRY OF THE SEVERAL NATURAL AND ARTIFICIAL HETEROGENEOUS COMPOUNDS USED IN MANUFACTURING PORCELAIN, GLASS AND POTTERY. By SimeON SHaw. (Originally published in 1837.) $750 \mathrm{pp}$. Royal $8 \mathrm{vo}$. Price 10s. net. (Post free, 10s. 6d. home; 12s. abroad.)

BRITISH POTTERY MARKS. By G. WOOLLISCROFT RhEad. Demy 8vo. 310 pp. With over Twelve-hundred Illustrations of Marks. Price 7s. 6d. net. (Post free, 8s. home; 8s. 3d. abroad.)

For contents of these books, see List III. 


\section{(Glassware, Glass Staining and Painting.)}

RECIPES FOR FLINT GLASS MAKING. By a British Glass Master and Mixer. Sixty Recipes. Being Leaves from the Mixing Book of several experts in the Flint Glass Trade, containing up-to-date recipes and valuable information as to Crystal, Demi-crystal and Coloured Glass in its many varieties. It contains the recipes for cheap metal suited to pressing, blowing, etc., as well as the most costly crystal and ruby. Second Edition. Crown 8vo. Price 10s. 6d. net. (Post free, 10s. 9d. home; 10s. 10d. abroad.)

A TREATISE ON THE ART OF GLASS PAINT. ING. Prefaced with a Review of Ancient Glass. By ERnest R. Supfling. With One Coloured Plate and Thirtyseven Illustrations. Demy 8vo. 140 pp. Price 7s. 6d. net. (Post free, 7s. 10d. home; 8s. abroad.)

\section{(Paper Making, Paper Dyeing, and Testing.)}

THE DYEING OF PAPER PULP. A Practical Treatise for the use of Papermakers, Paperstainers, Students and others. By JULiUs ERfurT, Manager of a Paper Mill. Translated into English and Edited with Additions by JuLrus HÜBNER, F.C.S., Lecturer on Papermaking at the Manchester Municipal Technical School. With illustrations and 157 patterns of paper dyed in the pulp. Royal 8vo, $180 \mathrm{pp}$. Price 15s. net. (Post free, 15s. 6d. home; 16s. 6d. abroad).

THE PAPER MILL CHEMist. By Henry P. Stevens, M.A., Ph.D., F.I.C. Royal $12 \mathrm{mo} .60$ illustrations. 300 pp. Price 7s. 6d. net. (Post free, 7s. 9d. home; 7s. 10d. abroad.)

THE TREATMENT OF PAPER FOR SPECIAL PURPOSES. By L. E. ANDÉs. Translated from the German. Crown 8vo. 48 Illustrations. 250 pp. Price 6s. net. (Post free, 6s. 4d. home; 6s. 6d. abroad.)

\section{(Enamelling on Metal.)}

ENAMELS AND ENAMELLING. For Enamel Makers, Workers in Gold and Silver, and Manufacturers of Objects of Art. By Paul Randau. Second and Revised Edition. Translated from the German. With 16 Illustrations. Demy 8vo. 200 pp. Price 10s. 6d. net. (Post free, 10s. 10d. home; 11 s. abroad.)

THE ART OF ENAMELLING ON METAL. By W. Norman Brown. Second Edition, Revised. Crown 8vo. 60 pp. Price 3s. 6d. net. (Post free, 3s. 9d. home; 3s. 10d. abroad.) 


\section{(Textile and Dyeing Subjects.)}

THE FINISHING OF TEXTILE FABRICS (Woollen, Worsted, Union and other Cloths). By RoBERTS BEAUMONT, M.Sc., M.I.Mech.E., Professor of Textile Industries, the University of Leeds; Author of "Colour in Woven Design"; "Woollen and Worsted Cloth Manufacture"; "Woven Fabrics at the World's Fair" ; Vice-President of the Jury of Award at the Paris Exhibition, 1900; Inspector of Textile Institutes ; Society of Arts Silver Medallist; Honorary Medallist of the City and Guilds of London Institute. With 150 Illustrations of Fibres, Yarns and Fabrics, also Sectional and other Drawings of Finishing Machinery. Demy 8vo. 260 pp. Price 10s. 6d. net. (Post free, 10s. 10d. home; 11s. 3d. abroad.)

FIBRES USED IN TEXTILE AND ALLIED INDUSTRIES. By C. Ainsworth Mitchell, B.A. (Oxon.), F.I.C., and R. M. Prideaux, F.I.C. With 66 Illustrations specially drawn direct from the Fibres. Demy 8vo. 200 pp. Price 7s. 6d. net. (Post free, 7s. 10d. home ; 8s. abroad.)

\section{DRESSINGS AND FINISHINGS FOR TEXTILE} FABRICS AND THEIR APPLICATION. Description of all the Materials used in Dressing Textiles: Their Special Properties, the preparation of Dressings and their employment in Finishing Linen, Cotton, Woollen and Silk Fabrics. Fireproof and Waterproof Dressings, together with the principal machinery employed. Translated from the Third German Edition of FrIedrich Polleyn. Demy 8vo. 280 pp. Sixty Illustrations. Price 7s. 6d. net. (Post free, 7s. 10d. home; 8s. abroad.)

THE CHEMICAL TECHNOLOGY OF TEXTILE FIBRES: Their Origin, Structure, Preparation, Washing, Bleaching, Dyeing, Printing and Dressing. By Dr. Georo voN GeORgIEvics. Translated from the German by CHARLES SAlTER. $320 \mathrm{pp}$. Forty-seven Illustrations. Royal $8 \mathrm{vo}$. Price 10s. 6d. net. (Post free, 11s. home; 11s. 3d. abroad.)

POWER-LOOM WEAVING AND YARN NUMBERING, According to Various Systems, with Conversion Tables. Translated from the German of ANTHON GRUNER. With Twenty-six Diagrams in Colours. $150 \mathrm{pp}$. Crown 8vo. Price 7s. 6d. net. (Post free, 7s. 9d. home; 8s. abroad.)

TEXTILE RAW MATERIALS AND THEIR CONVERSION INTO YARNS. (The Study of the Raw Materials and the Technology of the Spinning Process.) By Julius Zipser. Translated from German by Charles Salter. 302 IHustrations. 500 pp. Demy 8vo. Price 10s. 6d. net. (Post free, 11s. home ; 11s. 6d. abroad.) 
GRAMMAR OF TEXTILE DESIGN. By H. NisBet; Weaving and Designing Master, Bolton Municipal Technical School. Demy 8vo. 280 pp. 490 Illustrations and Diagrams. Price 6s. net. (Post free, 6s. 4d. home; 6s. 6d. abroad.)

ART NEEDLEWORK AND DESIGN. POINT LACE. A Manual of Applied Art for Secondary Schools and Continuation Classes. By M. E. WiLkinson. Oblong quarto. With 22 Plates. Bound in Art Linen. Price 3s. 6d. net. (Post free, 3s. 10d. home; 4s. abroad.)

HOIME LACE-MAKING. A Handbook for Teachers and Pupils. By M. E. W. Milroy. Crown 8vo. 64 pp. With 3 Plates and 9 Diagrams. Price 1s. net. (Post free, 1s. 3d. home; 1s. 4 d. abroad.)

\section{THE CHEMISTRY OF HAT MANUFACTURING.}

Lectures delivered before the Hat Manufacturers' Association. By Watson Smith, F.C.S., F.I.C. Revised and Edited by Albert Shonk. Crown 8vo. 132 pp. 16 Illustrations. Price 7s. 6d. net. (Post free, 7s. 9d. home; 7s. 10d. abroad.)

\section{THE TECHNICAL TESTING OF YARNS AND} TEXTILE FABRICS. With Reference to Official Speciflcations. Translated from the German of Dr. J. Herzfrid. Second Edition. Sixty-nine Illustrations. 200 pp. Demy 8vo. Price 10s. 6d. net. (Post free, 10s. 10d. home; 11s. 2broad.)

DECORATIVE AND FANCY TEXTILE FABRICS. By R. T. LORD. For Manufacturers and Designers of Carpets, Damask, Dress and all Textile Fabrics. 200 pp. Demy $8 v 0$. 132 Designs and Illustrations. Price 7s. 6d. net. (Post free, 7s. 10d. home; 8s. abroad.)

\section{THEORY AND PRACTICE OF DAMASK WEAV-} ING. By H. Kinzer and K. Walter. Royal 8vo. Eighteen Folding Plates. Six Illustrations. Translated from the German. $110 \mathrm{pp}$. Prlce 8s. 6d. net. (Post free, 9s. home ; 9s. 6d. abroad.)

\section{FAULTS IN THE MANUFACTURE OF WOOLLEN GOODS AND THEIR PREVENTION. By} Nicolas Reiser. Translated from the Second German Edition. Crown 8vo. Sixty-three Illustrations. $170 \mathrm{pp}$. Price 5s. net. (Post free, 5s. 4d. home ; 5s. 6d. abroad.)

SPINNING AND WEAVING CALCULATIONS, especially relating to Woollens. From the German of N. RBISBR. Thirty-four Illustrations. Tables. $160 \mathrm{pp}$. Dem. 8vo. 1904. Price 10s. 6d. net. (Post free, 10s. 10d. home; 11s. abroad.) 
ANALYSIS OF WOVEN FABRICS. BY A. P. BARKER and E. Midgley. Demy 8vo. About 200 pages. [In the press.

WATERPROOFING OF FABRICS. By Dr. S. MIERzinski. Crown 8vo. 104 pp. 29 Illus. Price 5s. net. (Post free, 5 s. 3d. home; 5 s. 4 d. abroad.)

HOW TO MAKE A WOOLLEN MILL PAY. By John Mackie. Crown 8vo. 76 pp. Price 3s. 6d. net. (Post free, 3s. 9d. home; 3s. 10d. abroad.)

YARN AND WARP SIZING IN ALL ITS BRANCHES. Translated from the German of CARL KRETSChMar. Royal 8vo. 123 Illustrations. 150 pp. Price 10s. 6d. net. (Post free, 10s. 10d. home; 11s. abroad.)

(For "Textile Soaps and Oils" see p. 7.)

\section{(Dyeing, Colour Printing, Matching and Dye=stuffs.)}

THE COLOUR PRINTING OF CARPET YARNS. Manual for Colour Chemists and Textile Printers. By DAvid Paterson, F.C.S. Seventeen Illustrations. 136 pp. Demy 8vo. Price 7s. 6d. net. (Post free, 7s. 10d. home; 8s. abroad.)

THE SCIENCE OF COLOUR MIXING. A Manual intended for the use of Dyers, Calico Printers and Colour Chemists. By David Paterson, F.C.S. Forty-one Illustrations. Five Coloured Plates, and Four Plates showing Eleven Dyed Specimens of Fabrics. $132 \mathrm{pp}$. Demy $8 \mathrm{vo}$. Price $7 \mathrm{~s}$. $6 \mathrm{~d}$. net. (Post free, 7s. 10d. home; 8s. abroad.)

DYERS' MATERIALS : An Introduction to the Examination, Evaluation and Application of the most important Substances used in Dyeing, Printing, Bleaching and Finishing. By Paul HeErman, Ph.D. Translated from the German by A. C. WRIGHT, M.A. (Oxon)., B.Sc. (Lord.). Twenty-four Illustrations. Crown 8 vo. 150 pp. Price 5s. net. (Post free, 5s. 4d. home ; 5s. 6d. abroad.)

COLOUR MATCHING ON TEXTILES. A Manual ." intended for the use of Students of Colour Chemistry, Dyeing and Textile Printing. By David Paterson, F.C.S. Coloured Frontispiece. Twenty-nine Illustrations and Fourteen Specimens of Dyed Fabrics. Demy 8vo. 132 pp. Price 7s. 6d. net. (Post free, 7s. 10d. home; 8s. abroad.)

COLOUR : A HANDBOOK OF THE THEORY OF COLOUR. By George H. Hurst, F.C.S. With Ten Coloured Plates and Seventy-two Illustrations. $160 \mathrm{pp}$. Demy 8vo. Price 7s. 6d. net. (Post free, 7s. 10d. home; 8s. abroad.) 
"THE ART OF DYEING ${ }^{\text {Reissue }}$ WOOL, SILK AND COTTON. Translated from the French of M. HELLOT, M. Macquer and M. Le Pileur D'Apligny. First Published in English in 1789. Six Plates. Demy 8vo. 446 pp. Price 5s. net. (Post free, 5s. 6d. home; 6s. abroad.)

THE CHEMISTRY OF DYE-STUFFS. By Dr. GroRo VON GEORGIEvics. Translated from the Second German Edition. 412 pp. Demy 8vo. Price 10s. 6d. net. (Post free, 11s. home; 11s. 6d. abroad.)

THE DYEING OF COTTON FABRICS : A Practical Handbook for the Dyer and Student. By Franklin BeEch, Practical Colourist and Chemist. 272 pp. Forty-four Illustrations of Bleaching and Dyeing Machinery. Demy 8vo. Price 7s. 6d. net. (Post free, 7s. 10d. home; 8s. abroad.)

THE DYEING OF WOOLLEN FABRICS. By Franklin BeEch, Practical Colourist and Chemist. Thirtythree Illustrations. Demy 8 vo. 228 pp. Price 7s. 6d. net. (Post free, 7s. 10d. home; 8s. abroad.)

\section{(Silk Manufacture.)}

SILK THROWING AND WASTE SILK SPIN. NING. By Hollins Rayner. Demy 8vo. 170 pp. 117 Illus. Price 5s. net. (Post free, 5s. 4d. home; 5s. 6d. abroad.)

\section{(Bleaching and Bleaching Agents.) 5}

A PRACTICAL TREATISE ON THE BLEACHING OF LINEN AND COTTON YARN AND FABRICS. By L. TAllfer, Chemical and Mechanical Engineer. Translated from the French by John Geddes Mclntosh. Demy 8vo. 303 pp. Twenty Illus. Price 12s. 6d, net. (Post free, 13s. home; 13s. 6d. abroad.)

MODERN BLEACHING AGENTS AND DETERGENTS. By Professor Max BotTler. Translated from the German. Crown 8vo. 16 1llustrations. 160 pages. Price 5s. net. (Post free, 5s. 3d. home; 5s. 6d. abroad.)

\section{(Cotton Spinning, Cotton Waste and Cotton Combing.)}

COTTON SPINNING (First Year). By Thомas Thornley, Spinning Master, Bolton Technical School. 160 pp. 84 Illustrations. Crown 8vo. Second Impression. Price 3s. net. (Post free, 3s. 4d. home; 3s. 6d. abroad.)

COTTON SPINNING (Intermediate, or Second Year). By T. Thornley. 2nd. Impression. 180 pp. 70 Illus. Crown 8 vo. Price 5s. net. (Post free, 5s. 4d. home; 5s. 6d. abroad.)

COTTON SPINNING (Honours, or Third Year). By T. Thornley. 216 pp. 74 Illustrations. Crown 8vo. Second Edition. Price 5s. net. (Post free, 5s. 4d. home; 5s. 6d. abroad.) 
COTTON COMBING MACHINES. By Thos. ThoRNLEY, Spinning Master, Technical School, Bolton. Demy 8vo. 117 Illustrations. 300 pp. Price 7s. 6d. net. (Post free, 8s. home; 8s. 6d. abroad.)

COTTON WASTE : Its Production, Characteristics Regulation, Opening, Carding, Spinning and Weaving. Ву Тномиs ThoRnleY. Demy 8vo. 286 pages. 60 illustrations. Price 7s. $6 \mathrm{~d}$. net. (Post free, 7s. 10d. home; 8s. abroad.)

THE RING SPINNING FRAME : GUIDE FOR OVERLOOKERS AND STUDENTS. By N. BоOTH. Crown 8vo. 76 pages. Price 3s. net. (Post free, 3s. 3d. home; 3s. 6d. abroad.)

\section{(Flax, Hemp and Jute Spinning.)}

MODERN FLAX, HEMP AND JUTE SPINNING AND TWISTING. A Practical Handbook for the use of Flax, Hemp and Jute Spinners, Thread, Twine and Rope Makers. By Herbert R. CARTER, Mill Manager, Textile Expert and Engineer, Examiner in Flax Spinning to the City and Guilds of London Institute. Demy 8vo. 1907. With 92 Illustrations. 200 pp. Price 7s. 6d. net. (Post free, 7s. 9d. home; 8s. abroad.)

\section{(Collieries and Mines.)}

RECOVERY WORK AFTER PIT FIRES. By RoBERT LAMPRECHT, Mining Engineer and Manager. Translated from the German. Illustrated by Six large Plates, containing Seventysix Illustrations. $175 \mathrm{pp}$. Demy 8vo. Price 10s. 6d. net. (Post free, 10s. 10d. home; 11s. abroad.)

VENTILATION IN MINES. By ROBERT WABNER, Mining Engineer. Translated from the German. Royal 8vo. Thirty Plates and Twenty-two Illustrations. $240 \mathrm{pp}$. Price 10s. 6d. net. (Post free, 11s. home; $11 \mathrm{~s}$. 3d. abroad.)

HAULAGE AND WINDING APPLIANCES USED IN MINES. By CARL Volk. Translated from the German. Royal 8vo. With Six Plates and 148 Illustrations. 150 pp. Price 8s. 6d. net. (Post free, 9s. home; 9s. 3d. abroad.)

THE ELECTRICAL EQUIPMENT OF COLLIERIES. By W. Galloway Duncan, Electrical and Mechanical Engineer, Member of the Institution of Mining Engineers, Head of the Government School of Engineering, Dacca, India; and DAviD Penman, Certificated Colliery Manager, Lecturer in Mining to Fife County Committee. Demy 8vo. 310 pp. 155 Illus. and Diagrams. Price 10s. 6d. net. (Post free, 11s. home; 11s. 3d. abroad.)

\section{(Dental Metallurgy.)}

DENTAL METALLURGY: MANUAL FOR STU. DENTS AND DENTISTS. By A. B. GRIFFITHS, $\mathrm{Ph} . \mathrm{D}$. Demy 8 vo. Thirty-six Illustrations. $200 \mathrm{pp}$. Price 7s. 6d. net. (Post free, 7s. 10d. home; 8s. abroad.) 


\section{(Engineering, Smoke Prevention and Metallurgy.)}

THE PREVENTION OF SIMOKE. Combined with the Economical Combustion of Fuel. By W. C. Popplewell, M.Sc., A.M. Inst., C.E., Consulting Engineer. Forty-six Illustrations. 190 pp. Demy 8vo. Price 7s. 6d. net. (Post free, 7s. 10d. home; 8s. 3d. abroad.)

GAS AND COAL DUST FIRING. A Critical Review of the Various Appliances Patented in Germany for this purpose since 1885. By Albert Pש̈tsch. $130 \mathrm{pp}$. Demy 8vo. Translated from the German. With 103 Illustrations. Price 5s. net. (Post free, 5s. 4d. home; 5s. 6d. abroad.)

THE HARDENING AND TEMPERING OF STEEL IN THEORY AND PRACTICE. By FRIDOLIN REISER. Translated from the German of the Third Edition. Crown 8vo. 120 pp. Price 5s. net. (Post free, 5s. 3d. home; 5s. 4d. abroad.)

SIDEROLOGY: THE SCIENCE OF IRON (The Constitution of Iron Alloys and Slags). Translated from German of HANNS FreiHerR v. Jư PTNER. $350 \mathrm{pp}$. Demy 8vo. Eleven Plates and Ten Illustrations. Price 10s. 6d. net. (Post free, $11 \mathrm{~s}$. home; $11 \mathrm{~s}$. $6 \mathrm{~d}$. abroad.)

EVAPORATING, CONDENSING AND COOLING APPARATUS. Explanations, Formulæ and Tables for Use in Practice. By E. Hausbrand, Engineer. Translated by A. C. Wright, M.A. (Oxon.), B.Sc., (Lond.). With Twentyone Illustrations and Seventy-six Tables. $400 \mathrm{pp}$. Demy 8 vo. Price 10s. 6d. net. (Post free, 11s. home; 11s. 6d, abroad.)

\section{(The "Broadway" Series of Engineering Handbooks.)}

One Uniform Size: Narrow Crown 8vo. (Pocket Size.)

VOLUME I.-ELEMENTARY PRINCIPLES OF REINFORCED CONCRETE CONSTRUCTION. By Ewart S. ANDREws, B.Sc. Eng. (Lond.). 200 pages. With 57 Illustrations. Numerous Tables and Worked Examples. Price 3s. net. (Post free, 3s. 3d. home; 3s. 6d. abroad.)

Volume II.-GAS AND OIL ENGINES. By A. KIRSCHKE. Translated and Revised from the German, and adapted to British practice. 160 pages. 55 Illustrations. Price 3s. net. (Post free, 3s. 3d. home; 3s. 6d. abroad.)

Volume III. - IRON AND STEEL CONSTRUCTIONAL WORK. By K. Schindler. Translated and Revised from the German, and adapted to British practice. 140 pages. 115 Illustrations. Price 3s. 6d. net. (Post free, 3s. 9d. home; 4s. abroad.)

Volumb IV.-TOOTHED GEARING. By G. T. White, B.Sc. (Lond.). 220 pages. 136 Illustrations. Price 3s, 6d. net. (Post free, 3s. 9d. home ; 4s. abroad.) 
Volume V.-STEAM TURBINES: Their Theory and Construction. By H. WiLda. Translated from the German; Revised and adapted to British practice. 200 pages. 104 Illustrations. Price 3s. 6d. net. (Post free, 3s. 9d. home; 4s. abroad.)

Volume VI.-CRANES AND HOISTS. Their Construction and Calculation. By H. WILDA. Translated from the German; revised and adapted to British practice. 168 pages. 399 Illustrations. Price 3s. 6d. net. (Post free, 3s. 9d. home; 4s. abroad.)

Volume VII.-FOUNDRY MACHINERY. By E. TREIBER. Translated from the German; revised and adapted to British practice. 148 pages. 51 Illustrations. Price 3s. 6d. net. (Post free, 3s. 9d. home; 4s. abroad.) [7ust published.

Volume VIII -MOTOR CAR MECHANISM. By W. E. Dомметт, A.M.I.A.E.E. 200 pages. 102 Illustrations. Price 3s. 6d. net. (Post free, 3s. 9d. home; 4s. abroad.)

Volume IX.- ELEMENTARY PRINCIPLES OF ILLUMINATION AND ARTIFICIAL LIGHTING. By A. BLok, B.Sc., A.M.I.E.E. Fully illustrated. [In the press. [IN PREPARATION.]

THE CALCULUS FOR ENGINEERS. By E. S. ANDREws, B.Sc. Eng. (Lond.), and H. Bryon HBywood, D.Sc.

HYDRAULICS. By E. H. Sprague, A.M.I.C.E.

LAND SURVEYING. By M. 'T. ORMSBY, M.I.C.E.I.

PORTLAND CEMENT. Its Properties and Manufacture. By P. C. H. West, F.C.S.

DESIGN OF MACHINE TOOLS. By G. W. Burley. LATHES. By G. W. Burley.

REINFORCED CONCRETE IN PRACTICE. By Alban H. Scott, M.S.A., M.C.I.

BRIDGE FOUNDATIONS. By W. BuRnside, M.I.C.E. WORKSHOP MANAGEMENT. BY J. BATEY.

CALCULATIONS FOR A STEEL FRAME BUILD. ING. By W. C. Cocking, M C.I.

GEAR GUTTING. By G. T. White, B.Sc. (Lond.).

MODERN GAS WORKS PRACTICE. By Alwyne MEADE, A.M.I.E.E.

STEAM BOILERS AND COMBUSTION. By J. BATEY,

\section{(Sanitary Plumbing, Electric Wiring, Metal Work, etc.)}

EXTERNAL PLUMBING WORK. A Treatise on Lead Work for Roofs. By JoHN W. HART, R.P.C. 180 Illustrations. 272 pp. Demy 8vo. Second Edition Revised. Price 7s. 6d. net. (Post free, 7s. 10d. home; 8s. abroad.) 
HINTS TO PLUMBERS ON JOINT WIPING, PIPE BENDING AND LEAD BURNING. Third Edition, Revised and Corrected, By JoHN W. HART, R.P.C. 184 Illustrations. $313 \mathrm{pp}$. Demy 8vo. Price 7s. 6d. net. (Post free, 8s. home; 8s. fid. abroad.)

SANITARY PLUMBING AND DRAINAGE. By John W. Hart. Demy 8vo. With 208 Illustrations. 250 pp. 1904. Price 7s. 6d. net. (Post free, 7s. 10d. home; 8s. abroad.)

FLECTRIC WIRING AND FITTING. By SydNey P. WALKER, R.N., M.I.E.E., M.I.Min.E., A.M.Inst.C.E., etc., etc. Crown 8vo. 150 pp. With Illustrations and Tables. Price 5s. net. (Post free, 5s. 3d. home; 5s. 6d. abroad.)

THE PRINCIPLES AND PRACTICE OF DIPPING, BURNISHING, LACQUERING AND BRONZING BRASS WARE. By W. Norman Brown. 48 pp. Crown 8 vo. Price 3s. net. (Post free, 3s. 3d. home and abroad.)

THE DEVELOPMENT OF THE INCANDESCENT ELECTRIC LAMP. By G. Basil BarhaM, A.M.I.E.E. Demy 8vo. 200 pages. 2 Plates, 25 Illustrations and 10 Tables. Price 5s. net. (Post free, 5s. 4d. home; 5s. 6d. abroad.)

WIRING CALCULATIONS FOR ELECTRIC LIGHT AND POWER INSTALLATIONS. A Practical Handbook containing Wiring Tables, Rules, and Formulæ for the Use of Architects, Engineers, Mining Engineers, and Electricians, Wiring Contractors and Wiremen, etc. By G. W. Lummis Paterson. Crown 8vo. 96 pages. 35 Tables. Price 5s. net. (Post free, 5s. 3d. home; 5s. 6d. abroad.)

A HANDBOOK ON JAPANNING. For Ironware, Tinware, and Wood, etc. By WILliam Norman BRown. Second Edition. 70 pages. 13 Illustrations. Crown 8vo. Price 3s. 6d. net. (Post free, 3s. 9d. home: 4s. abroad.)

THE PRINCIPLES OF HOT WATER SUPPLY. By JoHn W. HART, R.P.C. With 129 Illustrations. 177 pp. Demy 8vo. Price 7s. 6d. net. (Post free, 7s. 10d. home; 8s. abroad.)

\section{(Brewing and Botanical.)}

HOPS IN THEIR BOTANICAL, AGRICULTURAL AND TECHNICAL ASPECT, AND AS AN ARTICLE OF COMMERCE. By EmManuel Gross, Professor at the Higher Agricultural College, Tetschen-Liebwerd. Translated from the German. 78 Illus. 340pp. Demy 8vo. Price 10s. 6d. net. (Post free, 11s. home ; 11s. 6d. abroad.)

INSECTICIDES, FUNGICIDES AND WEED.

KILLERS. By E. Bourcart, D.Sc. Translated from the French. Revised and Adapted to British Standards and Practice. Demy 8 vo. 450 pages, 83 Tables, and 12 Illustrations. Price 12s. 6d. net. (Post free, 13s. home; 13s. 6d. abroad.)

(For Agricultural Chemistry, see p. 9.) 


\section{(Wood Products, Timber and Wood Waste.)}

WOOD PRODUCTS: DISTILLATES AND EXTRACTS. By P. Dumesny, Chemical Engineer, Expert before the Lyons Commercial Tribunal, Member of the International Association of Leather Chemists; and J. NOYER. Translated from the French by Donald GRANT. Royal 8vo. 320 pp. 103 Illustrations and Numerous Tables. Price 10s. 6d. net. (Post free, 11s. home; 11s. 6d. abroad.)

TIMBER: A Comprehensive Study of Wood in all its Aspects (Commercial and Botanical), showing the different Applications and Uses of Timber in Various Trades, etc. Trans. lated from the French of PAUL CHARPBnTIER. Royal 8vo. 437 pp. 178 Illustrations. Price 12s. 6d. net.- (Post free, 13s. home; 14 s. abroad.)

THE UTILISATION OF WOOD WASTE. Translated from the German of ERnst HubBard. Crown 8vo. $192 \mathrm{pp}$. 50 Illus. Price 5s. net. (Post free, 5s. 4d. home; 5s. 6d. abroad.) (See also Utilisation of Waste Products, $p$. 9.)

\section{(Building and Architecture.)}

ORNAMENTAL CEMENT WORK. By OLIVER Wheatley. Demy 8vo. 83 Illustrations. 128 pp. Price 5 s. net. (Post free, 5s. 4d. home ; 5s. 6d. abroad.)

THE PREVENTION OF DAMPNESS IN BUILDINGS; with Remarks on the Causes, Nature and Effects of Saline, Efflorescences and Dry-rot, for Architects, Builders, Overseers, Plasterers, Painters and House Owners. By Adolp Wilhelm Keim. Translated from the German of the second revised Edition by M. J. SALTER, F.I.C., F.C.S. Eight Coloured Plates and Thirteen Illustrations. Crown 8vo. 115 pp. Price 5s. net. (Post free, 5s. 3d. home; 5s. 4d. abroad.)

HANDBOOK OF TECHNICAL TERMS USED IN ARCHITECTURE AND BUILDING, AND THEIR ALLIED TRADES AND SUBJECTS. By AUGUStine C. Passmore. Demy 8vo. 380 pp. Price 7s. 6d. net. (Post free, 8s. home; 8s. 6d. abroad.)

\section{(Foods, Drugs and Sweetmeats.)}

FOOD AND DRUGS. By E. J. PARRY, B.Sc., F.I.C., F.C.S.

Volume I. The Analysis of Food and Drugs (Chemical and Microscopical). Royal 8vo. 724 pp. Price 21s. net. (Post free, 21s. 6d. home ; 22s. 6d. British Colonies; 23s. 3d. other Foreign Countries.)

Volume II. The Sale of Food and Drugs Acts, 1875-1907. Royal 8vo. 184 pp. Price 7s. 6d. net. (Post free, 7s. 10d. home; 8s. abroad.) 
THE MANUFACTURE OF PRESERVED FOODS AND SWEETMEATS. By A. Hausner. With Twenty-eight Illustrations. Translated from the German of the third enlarged Edition. Second English Edition. Crown 8vo. 225 pp. Price 7s. 6d. net. (Post free, 7s. 9d. home; 7s. 10d. abroad.)

RECIPES FOR THE PRESERVING OF FRUIT, VEGETABLES AND MEAT. By E. WAGNER. Translated from the German. Crown 8vo. 125 pp. With 14 Illustrations. Price 5s. net. (Post free, 5s. 3d. home; 5s. 4 d. abroad.)

\section{(Dyeing Fancy Goods.)}

THE ART OF DYEING AND STAINING MARBLE, ARTIFICIAL STONE, BONE, HORN, IVORY AND WOOD, AND OF IMITATING ALL SORTS OF WOOD. A Practical Handbook for the Use of Joiners, Turners, Manufacturers of Fancy Goods, Stick and Umbrella Makers, Comb Makers, etc. Translated from the German of D. H. Soxhlet, Technical Chemist. Crown 8 vo. 168 pp. Frice 5s. net. (Post free, 5s. 3d. home; 5s. 4d. abroad.)

\section{(Celluloid.)}

CELLULOID : Its Raw Material, Manufacture, Properties and Uses. A Handbook for Manufacturers of Celluloid and Celluloid Articles, and all Industries using Celluloid; also for Dentists and Teeth Specialists. By Dr. Fr. Böckmann, Technical Chemist. Translated from the Third Revised German Edition. Crown 8vo. 120 pp. With 49 Illustrations. Price $5 s$. net. (Post free, 5s. 3d. home; 5s. 4d. abroad.)

\section{(Lithography, Printing and Engraving.)}

ART OF LITHOGRAPHY. By G. T. RHODES.

PRINTERS' AND STATIONERS' READY RECKONER AND COMPENDIUM. Compiled by Victor Graham. Crown 8vo. 112 pp. 1904. Price 3s. 6d. net. (Post free, 3s. 9d. home ; 3s. 10d. abroad.)

FNGRAVING FOR ILLUSTRATION. HISTORICAL AND PRACTICAL NOTES. By J. KIRKBRIDB. $72 \mathrm{pp}$. Two Plates and 6 Illustrations. Crown 8vo. Price 2s. 6d. net. (Post free, 2s. 9d. home ; 2s. 10d. abroad.)

(For Printing Inks, see p. 4.)

\section{(Bookbinding.)}

PRACTICAL BOOKBINDING. By PAUL AdAM. Translated from the German. Crown 8vo. 180 pp. 127 Illustrations. Price 5s. net. (Post free, 5s. 4d. home; 5s. 6d. abroad. 


\section{(Sugar Refining.)}

THE TECHNOLOGY OF SUGAR: Practical Treatise on the Modern Methods of Manufacture of Sugar from the Sugar Cane and Sugar Beet. By John Geddes MicIntosh. Second: Revised and Enlarged Edition. Demy 8vo. Fully Illustrated. 436 pp. Seventy-six Tables. '1906. Price 10s. 6d. net. (Post free, $11 \mathrm{~s}$. home ; $11 \mathrm{~s}$. 6d. abroad.)

(Sec "Evaporating, Condensing, etc., Apparatus," p. xq.)

\section{(Emery.)}

EMERY AND THE EMERY INDUSTRY. Translated from the German of A. HaEnig. Crown 8vo. 45 Illus. 104 pp. Price 5s. net. (Post free, 5s. 3d. home; 5s.6d. abroad.)

\section{(Libraries and Bibliography.)}

CLASSIFIED GUIDE TO TECHNICAL AND COMMERCIAL BOOKS. Compiled by EDGaR GREeNwood. Demy 8vo. 224 pp. 1904. Being a Subject-list of the Principal British and American Books in Print; giving Title, Author, Size, Date, Publisher and Price. Price 5s. net. (Post free, $5 \mathrm{~s}$. $4 \mathrm{~d}$. home; $5 \mathrm{~s} .6 \mathrm{~d}$. abroad.)

HANDBOOK TO THE TECHNICAL AND ART SCHOOLS AND COLLEGES OF THE UNITED KINGDOIM. Containing particulars of nearly 1,000 Technical, Commercial and Art Schools throughout the United Kingdom. With full particulars of the courses of instruction, names of principals, secretaries, etc. Demy 8 vo. $150 \mathrm{pp}$. Price 3s. 6d. net. (Post free, 3s. 10d. home; 4s. abroad.)

THE LIBRARIES, MUSEUMS AND ART GALLERIES YEAR BOOK, 1910-11. Being the Third Edition of Greenwood's "British Library Year Book". Edited by Alex. J. Philip. Demy 8vo. 286 pp. Price 5s. net. (Post free, $5 \mathrm{~s} .4 \mathrm{~d}$. home ; $5 \mathrm{~s}$. $6 \mathrm{~d}$. abroad.)

\section{THE PLUMBING, HEATING AND LIGHTING} ANNUAL FOR 1911. The Trade Reference Book for Plumbers, Sanitary, Heating and Lighting Engineers, Builders' Merchants, Contractors and Architects. Including the translation of Hermann Recknagel's " Kalender für Gesundheits - Techniker," Handbook for Heating, Ventilating, and Domestic Engineers, of which Scott, Greenwood \& Son have purchased the sole right for the English Language. Quarto. Bound in cloth and gilt lettered. Price 3s. net. (Post free, 3s. 4 d. home ; 3s. 8 d. abroad.)

\section{SCOTT, GREENWOOD \& SON,}

Tecbnical JBook and Trade Fournal Dublisbers, 8 BROADWAY, LUDGATE, LONDON, E.C.

Telegraphlc Address, "Printeries, Cent.-London".

October, 1913. 
$\frac{u r t}{\text { usto we }}$ 
UNIVERSITY OF CALIFORNIA LIBRARY

THIS BOOK IS DUE ON THE LAST DATE STAMPED BELOW

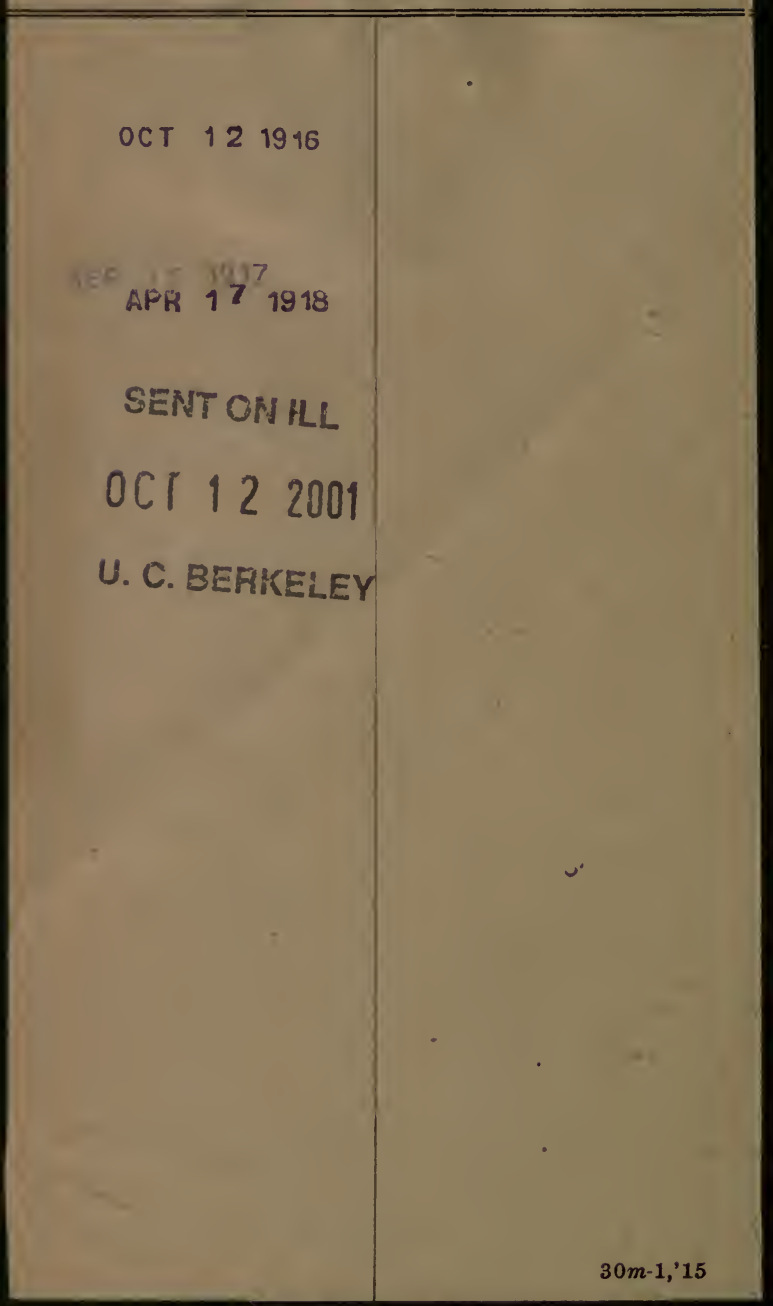


287982

$$
\begin{aligned}
& S 585 \\
& 15 \\
& 1913
\end{aligned}
$$

UNIVERSITY OF CALIFORNIA LIBRARY 
(E)

(2)

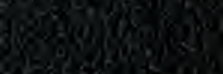

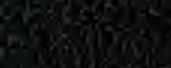

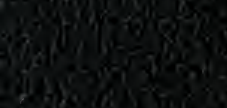

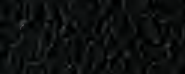

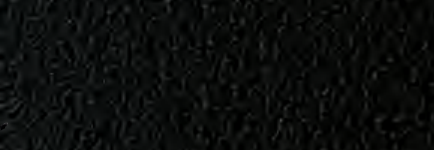

\section{6.}

